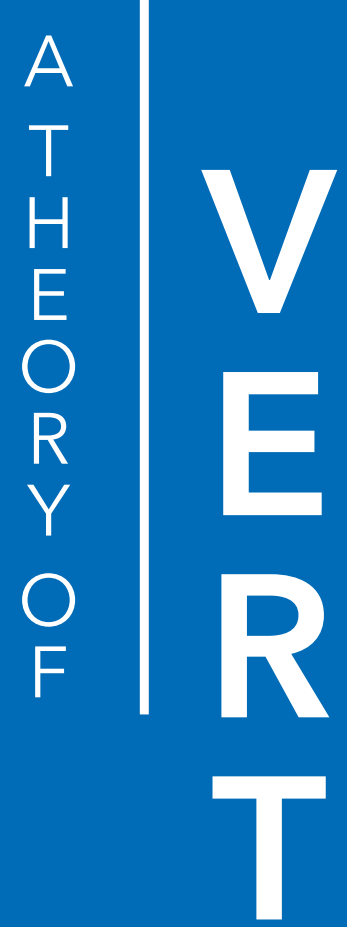

ARCHITECTURE
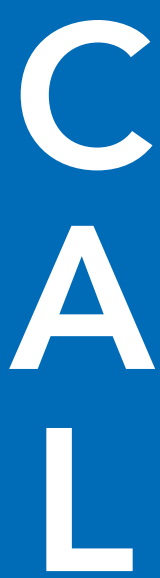

ALEX CASKEY 


\title{
A THEORY OF VERTICAL ARCHITECTURE
}

\author{
ALEXANDER CASKEY \\ BScE, University of New Brunswick, 2016 \\ BEDS, Dalhousie University, 2018
}

A thesis presented to Ryerson University in partial fulfillment of the requirements for the degree of

Master of Architecture

Program of Architectural Science

Toronto, Ontario, Canada, 2020

(C)Alexander Caskey, 2020 


\section{AUTHOR'S DECLARATION}

I hereby declare that I am the sole author of this thesis. This is a true copy of the thesis, including any required final revisions, as accepted by my examiners.

I authorize Ryerson University to lend this thesis to other institutions or individuals for the purpose of scholarly research.

I further authorize Ryerson University to reproduce this thesis by photocopying or by other means, in total or in part, at the request of other institutions or individuals for the purpose of scholarly research.

I understand that my thesis may be made electronically available to the public 


\section{ACKNOWLEDGE- MENTS}

This thesis would not have been possible without the help of others.

I would like to thank my supervisor Jurij Leshchyshyn, for his sophisticated insights, continued support, and encouragement of my enthusiasm.

Similarly, I would like to thank my advisor Carlo Parente for his valuable feedback and commentary throughout the process.

I would also like to thank the guys in the workshop, my supportive parents, my brother Christopher, my girlfriend Shaili, and Dr. Eric Thomas. 


\section{ABSTRACT}

A Theory of Vertical Architecture Alexander Caskey

Master of Architecture

Department of Architectural Science

Ryerson University, 2020

The default approach to building cities vertically is through the construction of towers. Such "common towers" multiply the "value" of a plot of ground by repeatedly stacking the most profitable types of private units vertically. These independent extrusions of land produce spaces that are disconnected from one another and the city below. The widespread proliferation of this default approach is rapidly filling the vertical territory of the world's cities with privatized stacks of ordinary spaces.

A critical investigation of "Common Towers" and the conditions that have led to their proliferation exposes opportunities that their presence conceals. There is both architectural and urbanistic potential in the vertical territory above a city that cannot be realized through the "common tower." This thesis explores the potential of the seamless vertical extension of the unconditionally public realm as a means of driving the three-dimensional organization of spaces within the volume of a city. 


\section{EXECUTIVE SUMMARY}

The following document represents research from a Master of Architecture thesis completed within the Department of Architectural Science at Ryerson University. This thesis had two main objectives. The first was to develop a theory to understand the existing and previously proposed forms of large scale vertical architecture such as towers. The second was to use that theory to demonstrate the unrealized potential of vertical architecture.

The three divisions of this thesis document represent the development of A Theory of Vertical Architecture:

Part One represents the development of a critical position on the urban design implications of existing forms and proposed forms of vertical architecture. Observation and analysis of major cities led to the development of a critical position on towers. This critical position was supported and refined by studying the work of Stephen Graham, Ken Yeang, Rem Koolhaas, Carrol Willis, Thomas Van Leeuwen, and Jane Jacobs, among others. The articulation of this position led to the development of two specific terms:

Common Towers is a term used to describe all forms of towers that are meant to multiply the 
value of the ground plane and do so by stacking private space within a self-contained, independent volume. These are towers that are only capable of supporting profitable private functions within their height and that only engage with the public realm at the lower floors near the ground plane, if at all. This term refers to towers of all common programmatic uses such as offices, residential, hotel, and "mixed" use towers. The common tower is a typological classification meant to encompass an entire family of well-established classifications, such as point towers, podium towers, and slabs.

The Default Approach to Verticality refers to the urban design practice of defaulting to common towers as the only way of inhabiting vertical territory in a city. The term emerged through an investigation of the agglomeration of factors including current building regulations, land ownership laws, zoning, financing, and private interests, that have made common towers the only practical and permissible form of vertical architecture in most cities. (Section 1.3)

The thesis postulates that there is both architectural and urbanistic potential in settling vertical territory, that can only be realized through an investigation of vertical architecture beyond the common tower and the default approach. The main research objective was to explore vertical architectures' potential for allowing a city to inhabit its own vertical real-estate.

The investigation of vertical architecture beyond the default approach began with a critical analysis and categorization of alternative approaches derived from historic visionary urbanism proposals. The proposals discussed in Section 1.4 include work by Howard, Soleri, Corbett, Corbusier, the Metabolists and others. The critical analysis of six alternative approaches led to the expansion of the research objective. The 
main research objective became to explore vertical architectures' potential for allowing a city to inhabit its own vertical real-estate in a way that:

1. Embraces the intensity of densely populated urban environments instead of trying to escape them (Urban Retreat, p. 31)

2. Benefits from clustering a dense population in vertical environments without the city being a singular structure (Mass Centralization, p.37)

3. Stretches, folds and extends the ground plane instead of separating urban functions onto multiple discrete, discontinuous planes (Multiple Ground Urbanism, p.41)

4. Supports diverse program and urban activities in a way that stimulates their overlap instead of their separation (Towers in the Park, p.46)

5. Integrates with infrastructure that supports healthy sustainable urban environments instead of superhighways that promote sprawl and car dependency (Inhabited Infrastructure, p.53)

6. Allows for the city to adapt to evolving societal needs without the need for movable space pods or adherence to an urban scale framework structure (Open-Ended Urban Framework, p.59)

Part Two builds from the critical position established in Part One to form a theoretical framework for understanding how a city could be successfully extended into its own vertical real estate. The complex nature of cities necessitated an abstraction of their physical form. The three-part reduction developed in Section 2.1 and refined in Sections 
2.3-4 allows for urban forms to be reduced to fundamental components that include:

1. Public Flow System: parts of the city concerned with the circulation and flow of people goods and utilities

a. Surface Elements: the continuous, unconditional, external surface of the public realm that enables the movement of people and things (eg. streets, paths, bridges, stairs, etc.)

b. Utility Elements: the distribution and collection network (eg. water supply, sewers, gas lines, electricity, telephone, internet cables, etc.)

c. Dynamic Elements: the transportation of people and the distribution and collection networks for materials and goods (eg. public transit, cars, emergency vehicles, garbage trucks, etc.)

2. Voids: The unbuilt volumes of the city

3. Adapted Spaces / Real Estate: all indoor and outdoor spaces and surfaces meant for localized activities

a. Urbanistically Independent Spaces: spaces suitable for functions occupancies and uses that can function and may even thrive without direct adjacency to the public realm (eg. residential, office space, storage, vertical farming, etc.)

b. Urbanistically Dependent Spaces: spaces suitable for functions occupancies and uses that are dependent on accessibility and visibility by the general public via the surface elements of the public flow system (eg. retail, libraries, parks, gathering areas, community centers, recreational facilities, etc.)

In the default approach, the public flow system is limited to the ground plane. This means that urbanistically dependent spaces are limited to lower, 


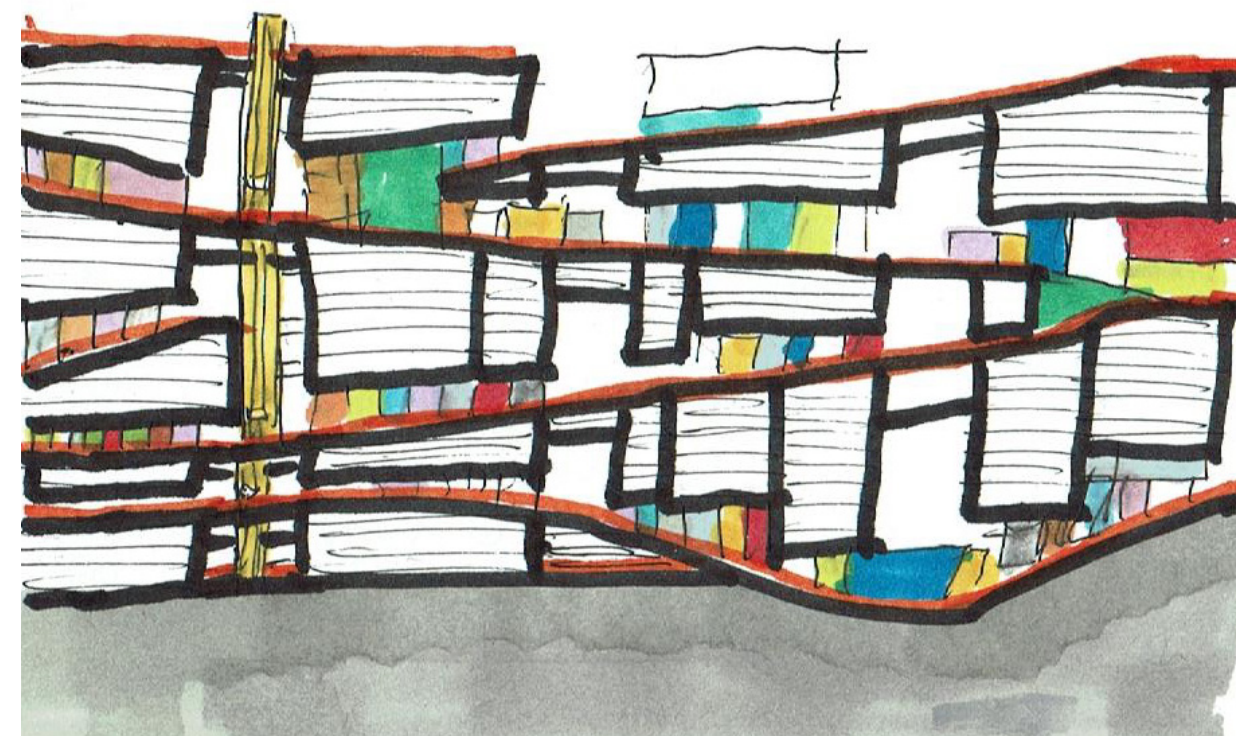

Figure i : Sectional sketch of a volumetrically organized city. The surface of the public flow system is drawn in orange, urbanistically dependent spaces are colored, urbanistically independent spaces are white, and transit is yellow.

ground related levels of the city because of their requirement for adjacency to the public flow system. With common towers, the adapted spaces in the height of the city are only suitable for urbanistically independent functions.

An alternative approach to vertical architecture was developed through extensive design research in the form of exploratory physical model-making (Sections 2.1-2). This process exposed architectural and urbanistic conditions and allowed for the study of constraints, challenges, and possibilities.

What emerged from this research was an alternative approach to developing vertical architecture in which the components of a city, including the public flow system, adapted space, and voids, could be organized as a complex network within a three-dimensional city 
volume. With this Volumetric Approach, the vertical extension of the surface of the public flow system was explored as a means of enabling vertical architecture to support urbanistically dependent spaces above the ground plane. Careful attention was given to the vertical extension of the unconditional and continuous nature of the public realm. In Section 2.5, Jeff Speck's principles for the design for Walkable Cities were adapted for a city organized in three dimensions. Principles for the design of Vertically Walkable Cities were developed as a strategy for fostering community, supporting a diversity of programs, promoting the overlap of functions and activities, and enabling intensity of urban life, all within the height of a city.

Part Three is an investigation of how a volumetric approach focused on walkability could serve the needs of a specific city. The goals and needs of the city-state of Singapore were identified through a research trip that explored the culture and built environment and through extensive background research into the history of the city's development (Section3.1). This research showed that the island's land constraints and population growth from the 1960 s onward forced the city to grow vertically. With this vertical growth, Singapore defaulted to a common tower urbanism, where the living, working, shopping and gathering spaces of the city that once overlapped, were instead neatly stacked and separated from one another. Recent pursuits of more humane vertical living conditions in the city, however, have fostered unique innovations to common tower development. Semi-public external gathering spaces have been used to break up volumes, link towers together, and stimulate neighbourly interaction.

The research in Section 3.2 explored how the unique factors that contributed to these "un-common" tower 
developments could similarly support a volumetric approach to extending the city. These factors include Singapore's consistent climate, publicly housed population, long term land leasing practices, and unified, consistent governmental structure.

The Marina South region is planned as a large scale addition to downtown Singapore. Singapore's Urban Redevelopment Authority's (URA) stated goals for the site is the creation of" dynamic urban neighbourhoods" with a wide variety of integrated land uses active streets, and public places with active programming, to provide "diversity of experiences" 1. The current lot divisions, plot ratios, and street network, established in preliminary plans for Marina South, have already ensured future development will default to common towers. An alternative scheme for the planned Marina South region illustrates how, instead of defaulting to common towers, this large-scale extension to the city could be planned volumetrically (Section3.3). It shows how controls, for the extension of the surfaces and spaces of the public realm into the height of the city, have the potential to foster a three-dimensional walkable network of neighbourhoods that is better suited to URA's goals for the site. This scheme was complemented by a more fine-grained investigation in Section 3.4 of how the regional shophouse typology could be reinterpreted, adapted, and layered as an interesting active edging to vertically walkable streets. Further investigation in Section 3.5 illustrates the potential architectural and urbanistic qualities of "dynamic urban neighbourhoods" situated in a volumetrically planned Marina South.

At the completion of this thesis, research has

Urban Redevelopment Authority. "Our Downtown." Urban Redevelopment Authority. Accessed November 28, 2019. https://www.ura. gov.sg/Corporate/Planning/Master-Plan/Regional-Highlights/Central-Area/Downtown. 
produced a multitude of unresolved issues surrounding the logistics of a volumetric approach to planning the vertical growth of a city. Future research opportunities include:

- An in-depth urban scale study of the design, organization, and placement of spaces within the volume of a city based on functional requirements such as proximity to public traffic flow and localized density, as well as daylighting, airflow, views, and access to services

- The development of a method for managing a city in three dimensions including establishing the public right of way, phasing development, surveying space, as well as assigning and transferring ownership

- Development of structural design strategies that would be capable of allowing piecemeal style development within a volumetrically planned area

- An investigation of a multi-modal threedimensional transportation network within the volume of a city

- Optimizing an approach to the threedimensional distribution and collection of materials, goods, and services through the city

- Further exploration of the potential for architectural space-making and walkability focused urban design in a volumetrically planned urban environment

In conclusion, the opportunities for future research are a testament to the core objective of this thesis, which was to expose and explore the unrealized potential of vertical architecture. 


\title{
TABLE OF CONTENTS
}

\author{
Abstract \\ Executive Summary \\ List of Figures

\section{PART 1}

1.1. The Common Tower 1

1.2. Research Statement 7

1.3. The Default Approach To Verticality 11

1.4. Visionary Urbanism 29

PART 2

2.1. Figure Ground(s) 73

2.2. A Volumetric Approach 91

2.3. Adapted Spaces 99

2.4. Public Flow System 109

2.5. Vertically Walkable Cities 123

2.6. Vertical Transportation 145

\section{PART 3}

3.1. Singapore

3.2. Uncommon Conditions

163

3.3. The Marina South Volume

3.4. Singapore Shophouses

198

3.5. "Dynamic Urban Neighborhoods"

\section{END NOTES}

Glossary

247

Bibliography 


\section{LIST OF FIGURES}

Figure i : Sectional sketch of a volumetrically organized city. The surface of the public flow system is drawn in orange, urbanistically dependent spaces are colored, urbanistically independent spaces are white, and transit is yellow. ix

\section{PART 1}

Figure 1.1.1: Vertical Growth in Chicago 3

Frank, Zack "Chicago Skyline" n.d. Digital Photograph. Adobe Stock. https://stock.adobe.com/ca/ images/chicago-skyline/92025015?prev_url=detail

Figure 1.1.2: "Stacks on Stacks on Stacks" of private space. Residential towers in Hong Kong. 4

Chan, Joseph. "Hong Kong" Jan 13, 2018. Digital Photography. Unsplash Stock Images. https:// unsplash.com/photos/gOMIZPq8CNAdenys

Figure 1.3.1-4 : Entry plates from the 1922 Chicago Tribune Competition. Top left: John Mead Howells and Raymond M. Hood, Top Right: Eliel Saarinen, Bottom Left: Walter Gropius and Adolf Meyer, Bottom Right: Helmle \& Corbett

Willis, Carol. "The Chicago Tribune Competition." The Skyscrapper Museum. Accessed November 29, 2019. https://www.skyscraper.org/EXHIBITIONS/PAPER_SPIRES/chitrib01.php.

Figure 1.3.5: The technological factors that enabled practical settlement of vertical space including the elevator, internal structure, utility pumps, electricity, telephone, and HVAC.

Figure 1.3.6: Vertical Repetition \& Replication of spatial solutions resulting in mass uniformity but design and construction efficiency 16

Figure 1.3.7: Finance \& Risk: Their proven ability to produce profits is why common towers have proliferated 20

Figure 1.3.8: Land and Ownership and Air Rights encourage the extrusion of a single program and force a single ownership 22 Figure 1.3.9: Zoning extruded the "rational" 2D organization of land into the 3rd Dimension 23

Figure 1.3.10:Fire Safety and the need for evacuation to the ground plane have made the common tower the only permissible solution 25

Figure 1.3.11: Mobility enabled the tower to act independently 27

Figure 1.4.1: Six categories of Visionary Urbanism approaches to vertical inhabitation of the future city from the past century. 30

Figure 1.4.2: Arthuro Soria y Mata: Linear City Plan, $1882 \quad 32$ Arthuro Soria y Mata: Linear City http://urbanismo-1.blogspot.com/2008/02/ciudad-lineal. html

Figure 1.4.3: Ebenezer Howard: Garden City Diagram, 189832 Ebenezer Howard's Garden City Diagram https://scodpub.wordpress.com/2011/03/01/gardencities-byebenezer-howard/

Figure 1.4.4: Tony Garnier: Cité Industrielle Plan, 1904 
tony-garnierune-cite-industrielle-1917.html

Figure 1.4.5: The American Suburb 35

Tuszynski, Micheal. "5508 Morning Light Dr, Herriman, UT 84096, USA, United States." Unsplash, April 13, 2019. https://unsplash.com/photos/2osRMIJLdbU.

Figure 1.4.6: King Champ Gillette: The Human Drift, 189436 King Champ Gillette, The Human Drift, 1894, https://beltmag.com/ utopia-niagara-falls-gillettemusk/

Figure 1.4.7: Paolo Soleri: Arcology ,1969 36

Paolo Soleri: Arcology, 1969 https:// curiator.com/art/paolo-soleri/hexahedron-arcology

Figure 1.4.8: Burj Kalifah. The concept of the mixed use supertall could be viewed as a restrained application of Mass Centralization 39

SOM. "Gallery of Burj Khalifa / SOM - 48." Arch Daily, October 23, 2017. https://www.archdaily. $\mathrm{com} / 882100 /$ burj-khalifa-som/59eb88c2b22e38dd0500014e-burj-khalifa-som-diagram.

Figure 1.4.9: Antonio Sant'Elia: Cité Nuova,1914 40 Antonio Sant'Elia: Cité Nuova,1914 https://www.guggenheim.org/artscurriculum/topic/ architecture

Figure 1.4.10: Harvey Wiley Corbett : City of the Future, 191340 Corbett :City of the Future, 1913 https://www.arretsurimages. net/articles/la-nostalgie-du-futurdhier

Figure 1.4.11: Grade separated pedestrian networks in Hong Kong 46

Yoos, Jeniffer, and Vincent James. "The Multilevel Metropolis." Places Journal, May 18, 2016. https://doi.org/10.22269/160518

Figure 1.4.12: Sky Bridges as amenity space connecting two private residential towers at Sky Habitat, Singapore 47 Caskey, Alex, "Sky Habitat', Singapore, Fall 2019

Figure 1.4.13: Raymond Hood, City of Needles, 1924

Raymond Hood, City of Needles, 1924 https://www.jstor.org/stable/990128?seq=1\#page_scan_ tab_contents

Figure 1.4.14: Hugh Ferris, Metropolis of Tomorrow, 1929 Hugh Ferris, The Metropolis of Tomorrow, 1929, http://www.johncoulthart.com/ feuilleton/2013/10/03/themetropolis-of-tomorrow-by-hughferriss/

Figure1.4.15: Corbusier: Plan Voisin, 192249

Corbusier: Plan Voisin, 1922 https://www.researchgate.net/figure/Le-Corbusiers-Radiant-City-thecity-oftomorrow-1924-5-The-unrealizedutopian-project_fig5_300146541

Figure 1.4.16: Ordos Kangbashi, New city in China designed based on value engineered towers in the park principles

Shepard, Wade. "Why Hundreds Of Completely New Cities Are Being Built Around The World." Forbes. Accessed April 13, 2020. https://www.forbes.com/sites/wadeshepard/2017/12/12/whyhundreds-of-completely-new-cities-are-being-built-around-the-world/.

Figure 1.4.17: Raymond Hood Bridge Homes, 192554

Raymond Hood Bridge Homes, 1925 https://scroll.in/article/888101/from-domed-towns-tounderground buildings-how-planners-and-artistsenvisioned-cities-of-the-future

Figure 1.14.18: Le Corbusier: Viaduct City, 193254

Corbusier Algeirs Inhabited highway infrastructure, 1931 https://www.bidoun.org/articles/lecorbusier-salgerian-fantasy

Figure 1.14.19: Kenzo Tange; Boston Harbour Proposal, 195955 Kenzo Tange, Boston Harbour Proposal, 1959https://hyperrealcartography.tumblr.com/ post/173917568970/brutgroupkenzo-tange-development-of-theport

Figure 1.4.20: Golden Mile Complex, Singapore, 1972. The only built portion of this urban Mega-structure in Singapore failed to fully integrate with the transportation infrastructure 57 Photo: Caskey, Alex, Golden Mile Complex, Fall 2019

Architecture, Failed. "Singapore's Metabolist Megastructures: The Asian City of Tomorrow?" Failed Architecture (blog). Accessed April 13, 2020. https://failedarchitecture.com/singapores-metabolistmegastructures-the-asian-city-of-tomorrow/.

Figure 1.4.21:Kiyonori Kikutake: Marine City, 1959 60 
Kiyonori Kikutake: Marine City ,1959 ttps://njitarch382.files.wordpress.com/2012/04/mcmahonvicinio-city plan-project-page-14.pdf

Figure 1.4.22: Arata Isosaki: City in The Sky, $1962 \quad 60$

Arata Isosaki: City in The Sky, 1962 https://www.thecityreview.com/arcnow.html

Figure1.4.23 Peter Cook, Plug in City, 196260

Peter Cook: Plug in City, 1962 https://www.archdaily.com/399329/ad-classicsthe-plug-in-city-petercook-archigram/51 d71 cabe8e44ecad700002a-ad-classics-theplug-in-city-peter-cook-archigramimage

Figure 1.4.24: Nakagin Capsule Tower, Tokyo, 1972. Without a larger urban system this project lost its open-ended functionality 65

Kakidai. "Nakagin Capsule Tower, at Shinbashi Tokyo Japan, Design by Kisho Kurokawa in 1972." In Wikipedia, November 1, 2018. https://en.wikipedia.org/w/index.php?title=Metabolism_ (architecture)\&oldid=943754046.

\section{PART 2}

Figure 2.1.1: A Bent Nolli map of Mayjor Cites extends the thinking of figure-ground to a three-dimensional representation of space where it could be understood in both plan and section 74

Figure 2.1.2: The reduction of urban forms in three dimensions showing the application of, Lynch-Rodwin, Nolli, and the ThreePart reduction explained in this section. $\quad 75$

Figures 2.1.3-5: Diagram showing 3D urban reduction of various existing strategies for inhabiting vertical space $\quad 77$

Figure 2.1.6-7: Top: A rendering of Kenneth King's Vertical City Concept. Above: Photo of the Pinnacle housing Development in Singapore 78

King, Kenneth. "Conceptual Rendering of a Vertical City." Buisness Insider, 2016. https://www. businessinsider.com/vertical-cities-future-of-architecture-2016-4.

"5-Room Pinnacle @ Duxton Flat Sold for Record-Breaking \$1.12 Million, Business News - AsiaOne." Accessed November 25, 2019. v.

Figure 2.1.8: Abstract bass wood model experimenting with the implications of a 3 dimensional street grid network. 79

Figure 2.1.9: Bass wood model exploring a retrofit of Mies Van Der Rhoe's TD Center, linking into a 3 dimensional gird

Figure 2.1.10: Detail of public space created at link 81

Figures 2.1.11-13: Replication of previous diagram illustrating the semi private nature of duplicated flow systems 85

Figure 2.1.14: Sketch by ken yeah show continuous circulation through the height of a tower. 86 Liberty Science Cente. "Visions of the Future - Interviews + Art - LSC 2007," 2007. http:// helenealonso.com/portfolio-item/visions-of-the-future-architects-design-tomorrow\%e2\%80\%99sskyscrapers/.

Figure 2.1.15: Abstract bass wood model experimenting with the implications of a continuous landscape throughout it's height. 87

Figures 2.1.16-17: Top: "sublime" rendering showing landscape extending through Toronto's financial district. Bottom : Unraveled section illustrating continuity of ground plane. 89

Figure 2.2.1: Map that illustrates the historic(subtraction) vs. 
modern( object in space) approaches to urban design in Paris 92 Rowe, Colin. "The Present Urban Predicament." In As I Was Saying: Recollections and Miscellaneous Essays., Vol. 1:165-220. Cambridge: The MIT Press, 1996.

Figure 2.2.2: Bass wood subtractive model where continuous circulation \& public space voids were remove from a solid block, leaving what was remaining to act as real-estate.

93

Figure 2.2.3: Sketch showing hierarchy of subtractive model 94 Figure 2.2.4: Close up image of subtractive model showing a variety of urban conditions 95

Figure 2.2.5 (Opposite Page): Sequence photos of additive model show progression of the growth of the model.

Figure 2.3.1: Maquette model showing the existence of adapted space in vertical space without a resolution of the infrastructure needed to support it. 100

Figure 2.3.2: A diagram from the Project for Public Space showing the components of sucessfull public spaces 102

Project For Public Space. "What Makes a Great Public Space." Project For public Space, 2016. https://www.pps.org/article/you-asked-we-answered-6-examples-of-what-makes-a-great-publicspace.

Figure 2.3.3: Diagram illustrating the spectrum on how function and uses of spaces in cities depend on their adjacency to the public flow system and localized density. It should be noted that the placement of functions and uses is relatively arbitrary that in reality would could be determined by context analysis.

Figure 2.3.4: The Default Approach: Urbanisitcally Dependent Spaces limited to ground plane where they are adjacent to the public flow system. The height of the city is only suitable for Urbanistically Independent Spaces. $\quad 105$

Figure 2.3.5: Diagram of the adjacency requirements for urbanistically independent and dependent spaces in relation to the public flow system. (Structure and utilities not shown) 106 Figure 2.3.6: Diagram showing the continuity of the public flow system within a more complex layering of the city 107

Figure 2.4.1-3 (Opposite): (Top) Surface Elements: streets pedways, sidewalks. (Center) Utility Elements: central utilities tunnel (Bottom) Dynamic Elements: Mass Rapid Transit system 111

TMCR Group. "Singapore Deep Sewers - TMCR Group Inc TMTunnelling Ltd," 2011. http://www. tmcrgroup.com/50.html.

Azahar, Wani. "SMRT Enhances Starting Salaries and Staff Benefits | Human Resources Online," February 26, 2018. https://www. humanresourcesonline.net/smrt-enhances-starting-salaries-andstaff-benefits/.

Figure 2.4.4: In the default approach the public flow system is horizontally configured. In order to extend the public flows system into the height of the city it must be configured to do vertical work shown here as sloped planes 113

Figure 2.4.5: Method for vertical work in the Public Flow System. The sloped plane is the governing design case as it requires the most length. 114

Figure 2.4.6: (Independent Infrastructure) Peter Cook, Plug in 
City, 1962

116

Plug in City, 1962 https://www.archdaily.com/399329/ad-classics-the-plug-in-city-peter-cook-archig ram/51 d71 ca6e8e44ecad700002a-ad-classics-the-plug-in-city-peter-cook-archigram-image

Figure 2.4.7: (Bridging Adapted Spaces) Harvey Wiley Corbert: Future City, 1910

Delineator Unknown. : Willis, Carol. "The Skyscraper Museum: Future City: New York Modern." The Skyscrapper Museum, 2007. https://www.skyscraper.org/EXHIBITIONS/FUTURE_CITY/NEW_ YORK_MODERN/walkthrough_1900.php

Figure 2.4.8: (Inhabited Infrastructure) Raymond Hood Bridge Homes, 1925116

Ferriss, Hugh. The Metropolis of Tomorrow. Princeton, NJ: Princeton Architectural Press, 1986 (1929).

Figure 2.4.9: The High-line in Manhattan is an example of a vertically extended self sported flow systems 117

Shutterstock.com. "New York June 152013 High Stock Photo (Edit Now) 1426078988." Accessed February 12, 2020. /image-photo/new-york-june-15-2013-high-1426078988.

Figure 2.4.10-11 (Opposite): Bridging adapted spaces. (top) Sky Habitat, Moe Safdie (bottom) The Pinnacle, Arc Studio Caskey, Alex Sky Habitat. Singapore. Fall 2019 Caskey, Alex.Pinacle @ Duxton. Singapore. Fall 2019

Figure 2.4.12: Interlace Apartment Complex, OMA, 2013. The irregularly stacked building masses are individually articulated and serve multiple functions as inhabited residential spaces, bridges, and amenity sky parks Caskey, Alex, Interlace Apartments. Singapore. Fall 2019

Figure 2.3.13: CCTV Building, Beijing, OMA, 2012. An example of of large scale inhabitable space that bridges vertical structures 119

Wikipedia Commons. "CCTV Circular Tower in Beijing by Ole Scheeren - Business Insider," 2016. https://www.businessinsider.com/cctv-circular-tower-in-beijing-by-ole-scheeren-2016-7.

Figure 2.4.14: Common configurations for supporting the extension of the flow system with inhabitable real-estate 120

Figure 2.4.15: Utilities running under surface of flow system above inhabited spaces. 121

Figure 2.5.1: Altered Google Maps imagery of Singapore's Financial district with the public flow spaces highlighted in orange Note how most of this is automobile infrastructure. 124

Figure 2.5.2: 2004 Park Tower proposal by Lewis Tsurumaki Lewis. Public Flow system in the form of automobile infrastructure extends vertically into the height of the mixed use tower. 125

LTL Architects. "Park Tower." LTL Architects, 2004. http://ltlarchitects.com/park-tower.

Figure 2.5.3: 2004 Park Tower proposal by Lewis Tsurumaki Lewis. Public Flow system in the form of automobile infrastructure extends vertically into the height of the mixed use tower. 126

LTL Architects. "Park Tower." LTL Architects, 2004. http://ltarchitects.com/park-tower.

Figure 2.5.4: Google Maps Satellite imagery showing various configurations of city blocks (Top to Bottom) Japan, Barcelona, Paris, New York City 130

Figure 2.5.5: 2D Walkable block 60m (200') 132 Figure 2.5.6.: 3D Walkable block $60 \mathrm{~m}\left(200^{\prime}\right)$ extended vertically at 1:12 slope and connected by vertical transit connection 133 
Figure 2.5.7: Storefronts configured on a sloped plane, in Notting Hill, London

Lovespace. "Storefront Guide: Pop-Up Shops in Notting Hill." Storefront, March 2, 2017. https:// www.thestorefront.com/mag/storefront-guide-pop-up-shops-in-notting-hill/.

Figure 2.5.8: Additive Volume Model depicting various way that the flow system could be configured 135

Figure 2.5.9: Progress photo of the Volume Model that integrates vertical blocks within a layers of urbanistically dependent and independent spaces to form vertical districts. 136 Figure 2.5.10: Sectional scans of volume model showing colored hardwoods and sloping flow system embedded within urbanisticaly independent spaces 137

Figure 2.5.11: SkyVille@ Dawson, 2007,WOHA, Sky streets periodically break up volume of towers ever 12 stories. Caskey, Alex, Skyville@ Dawson, Singapore, Fall 2019

Figure 2.5.12: SkyVille@ Dawson, 2007,WOHA, Sky street amenity space, 139

Caskey, Alex, Skyville @ Dawson, Singapore, Fall 2019

Figure 2.5.13: SkyVille@ Dawson, 2007,WOHA 139 Caskey, Alex, Skyville @ Dawson, Singapore, Fall 2019

Figure 2.5.14: Common types of adapted spaces that form a neighborhood 140

Figure 2.5.15: The configuration and layering of neighborhood components around vertically walkable blocks. $\quad 140$

Figure 2.5.16: At a larger scale 3D Walkable blocks and neighborhoods can be connected together by "main streets"s and vertical transit (Yellow) to form a three dimensional network. This network could be bound together by the strategic placement of anchors(Blue \& Green) like parks, civic buildings, and "skymarks" 143

Figure 2.6.1: Peter Cook, Plug in City, 1962146

Plug in City, 1962 https://www.archdaily.com/399329/ad-classics-the-plug-in-city-peter-cook-archig $\mathrm{ram} / 51 \mathrm{~d} 71 \mathrm{cabe} 8 \mathrm{e} 44 \mathrm{ecad} 700002 \mathrm{a}$-ad-classics-the-plug-in-city-peter-cook-archigram-image

Figure 2.6.2: Elevator: external elevator at housing development in Singapore 149

Figure 2.6.3: Diagonal Elevator: Gateway Arch tram-elevator 149 WikiArquitectura. " Gateway Arch - Data, Photos \& Plans." Accessed February 13, 2020. https:// en.wikiarquitectura.com/building/gateway-arch/.

Figure 2.6.4: Multi Directional Elevator System 149

TyssenKrup, "Multi Elevator System Render." New Atlas, June 27, 2017. https://newatlas.com/ cableless-vertical-horizontal-elevator-multi/50218/.

Figure 2.6.5: Tram/ Street Car/ Cable Car/ Funicular 150

Shutterstock. "7 Things the TTC Could Learn from One of the World's Best Transit Systems | News." The Hive, May 2017. https://dailyhive.com/toronto/ttc-learn-berlin-transit-system.

Figure 2.6.6: Buses: $\quad 150$

Brown, Lee "Halifax Transit Had a Problem Arriving on Time This Summer: Report - Halifax |

Globalnews.Ca." Accessed February 13, 2020. https://globalnews.ca/news/3962840/halifax-transiton-time/.

Figure 2.6.7: Gondola: Gondola station at 15th floor of tower in Singapore $\quad 150$

Caskey, Alex " Harbour Front Gondola Station, Singapore, Fall 2019

150

Figure 2.6.8: Rideshare/ Taxi: for individual and small groups 151

xix 
Renault Unveils Driverless Uber-Style Transport System. Accessed February 13, 2020. https://www. youtube.com/watch?v=jbaP_zecEo0.

Figure 2.6.9: Drones: Taxi services and public transit services 151 Vijayentiran, Viknesh. "Ehang Could Become First Flying Taxi Company to Go Public." Motor Authority. Accessed February 13, 2020. https://www.motorauthority.com/news/1125840_ehangcould-become-first-flying-taxi-company-to-go-public.

Figure 2.6.10: Model depicting vertical public transit core and surface level street car type transit system on a fragment of a street above the ground plane 152

Figure 2.6.11: Personal Vehicles: Development in Chongqing that features a rooftop street on 5 floor. 154

South China Morning Post"Road on a Roof the Latest Addition to China's City of Odd Architecture article/2099356/road-roof-latest-addition-chinas-city-odd-architecture.

Figure 2.6.12: Alternative Personal Vehicle 154

NISSAN MOTOR Co Ltd. "NISSAN | ZERO EMISSION | The Holistic Approach | NISSAN New Mobility CONCEPT." Accessed February 13, 2020. https://www.nissan-global.com/EN/ZEROEMISSION/ APPROACH/NEWMOBILITYCONCEPT/.

Figure 2.6.13: Active Transportation 154

"Active Transprtation for America | Rails-to-Trails Conservancy." Accessed February 13, 2020. https:// www.railstotrails.org/policy/active-transportation-for-america/.

Figure 2.6.15: Automated Delivery System: Sidewalk labs 156 Sidewalk labs, Image from article by Rieland, Randy. "Five Questions You Should Have About Google's Plan to Reinvent Cities." Smithsonian Magazine. Accessed February 13, 2020. https:// www.smithsonianmag.com/innovation/five-questions-you-should-have-about-googles-planreinvent-cities-180967368/

Figure 2.6.16: Delivery, collection and Service Vehicles

Autoblog. "Renault Twizy Delivery Concept Revealed on Twitter." Accessed February 13, 2020. https://www.autoblog.com/2015/01/16/renault-twizy-delivery-concept-revealed-on-twitter/.

Figure 2.6.17:Emergency Service Vehicles 156

Uys, Emily. "Student Invents Ambulance Drone for Speedy Medical Assistance." Design Indaba, October 2016. https://www. designindaba.com/articles/creative-work/student-invents-ambulancedrone-speedy-medical-assistance.

Figure 2.6.14(Above \& Right):Design of street above inhabited space for ASC 623 Principles of Detailing. Project involved taking into consideration surface drainage, structural loads imposed by vehicles, appropriate surface assemblies, and isolating the inhabited space below from noise and vibration. 158

\section{PART 3}

Figure 3.1.1: Google Earth Imagery Showing the location of Singapore in relation to Malaysia and Indonesia 164

Figure 3.1.2: Google Earth Imagery showing the size of Singapore's Landmass. 165

Figure 3.1.3: Ethnic Demographics of Singapore 166

Figure 3.1.4: Mean monthly temperature variation $\left({ }^{\circ} \mathrm{C}\right)(1981$ 2010) 167

Government of Singapore. "Climate of Singapore |." Meteroligical Services Singapore, 2019. http:// www.weather.gov.sg/climate-climate-of-singapore/.

Figure 3.1.5: 1971 Singapore Concept Plan 172

Urban Redevelopment Authority. "Past Concept Plans." Urban Redevelopment Authority, 2019 https://www.ura.gov.sg/Corporate/Planning/Concept-Plan/Past-Concept-Plans.

Figure 3.1.6: Population growth in Singapore by year

Figure 3.1.7-9 (Next Spread LEFT): Diagram showing the growth of Singapore's landmass, growth of the MRT system and the 
expansion of urbanization in 1973, 2002, 2018

Figure 3.1.10-12 (Next Spread RIGHT): Satellite imagery showing the growth of Singapore's landmass and the urbanization in 1973, $2002,2018 \quad 175$

USGS. "Singapore | Earthshots: Satellite Images of Environmental Change." Accessed November 20, 2019. https://earthshots.usgs.gov/earthshots/Singapore\#ad-image-0-0.

Figure 3.1.13: Map representing the growth of Singapore's, urbanization, transit system, and strategic land reclamation projects 178

Figure 3.1.14: Cars in Singapore cost on average 3-5 times what they would cost in other developed countries 181

Caskey, Alex, "Mayjor Road with Pedestrian Overpass", Singapore Fall 2019

Figure 3.1.15: $80 \%$ of Singapore lives in public housing. Caskey, Alex "Public Housing", Singapore, Fall 2019

Figure 3.2.1: Without a hinterland to expand into and a shortage of sand for more land reclamation, Singapore will be forced to grow increasingly vertical 184

Figure 3.2.2: Plan diagram showing the internal hall circulation of common towers (left) vs. uncommon external circulation (right) 185

Figure 3.2.3-7 (Left): Top to Bottom: External circulation in a post way public housing unit, sky bridges in Moe Safdie's Sky Habitat, Sky garden in foster and partner's South Bach, 187 Caskey Alex, Singapore 2019

Figure 3.2.6-7 (Left): Top to Bottom: Sky garden in WOHA 's Oasia Hotel, Multilevel public space in Marina One. 189 Caskey Alex, Singapore 2019

Figure 3.2.8: Diagram showing how the 1: 1 ground replacement policy of the LUSH program for new development leads to "uncommon" tower features like sky gardens, and sky bridges. 190

Figure 3.2.9: Diagram showing how in Singapore's HBD flats the unit are individually owned but the circulation remains government infrastructure, similar to the street. 192

Figure 3.2.10: Diagram showing how in Singapore, sunlight comes from the North between March and September, while from September to March, it comes from the South 195

Figure 3.3.1: Map of proposed Marina Bay design Project site in downtown Singapore 198

Figure 3.3.2: Diagram showing 3 major complexes surrounding site $\quad 199$

Figure 3.3.3: Cross section drawings showing three major complexes surrounding the site and underground infrastructure 199

Figure 3.3.4: Marina Bay Finance Centre Complex (Common Tower style Development)202

Zarion. "Marina Bay Financial Centre viewed from Marina Bay Sands." In Wikipedia, 2015. https:// en.wikipedia.org/w/index.php?title=Marina_Bay_Financial_Centre\&oldid=924649840.

Figure 3.3.5: Marina Bay Sands Complex (Singapore Icon, 1 acre 
sky park) 202

Caskey,Alex, "Marina Bay Sands", Singapore, Fall 2019

Figure 3.3.6: Marina one Complex (Uncommon multi floor public space and upper sky gardens) 203

Igenhoven Architects. "Marina One - The Skyscraper Center." CTBUH. Accessed November 28,

2019. http://www.skyscrapercenter.com/building/marina-one/16878.

Figure 3.3.7: Internal view of multi-floor public space at Marina one Complex 203

Caskey,Alex, "Marina One", Singapore, Fall 2019

Figure 3.3.8: Urban Redevelopment Authority Zoning Map of proposed site showing "white" unde termined rmined mixed use lots (White), Green spaces (Green), and reserved land for future development (Yellow). 205

"URA SPACE." Accessed November 28, 2019. https://www.ura.gov.sg/maps/?service=MP.

Figure 3.3.9: Image of model showing planned massing on the Marina Bay South site at URA office. The model leaves the south western area open for future development. 206

Little Day Out. "Singapore City Gallery: Glimpse In Singapore's Urban Future." Little Day Out (blog), April 1, 2017. https://www.littledayout.com/2017/04/01/singapore-city-gallery-urban-future-ura/.

Figure 3.3.10: Image of model showing planned massing on the Marina Bay South site at URA office. 207

Little Day Out. "Singapore City Gallery: Glimpse In Singapore's Urban Future." Little Day Out (blog), April 1, 2017. https://www.littledayout.com/2017/04/01/singapore-city-gallery-urban-future-ura/.

Figure 3.3.11: Conceptual render of the site from the North East of released by the URA showing future common tower typed developments 207

Mixed Development at Marina View (Upcoming Launch). "Mixed Development at Marina View ( Upcoming Launch)." Accessed November 29, 2019. https://marinaviewcondo.net/marina-viewsite-954.

Figure 3.3.12-13: The beginning of a 1:2500 model that was intended to explore the proposed site as undefined volumes instead of towers. Depicted here is an acrylic volume, next to a massing model of the Marina Bay Sands Complex. The model was not completed because of Covid-19 related interruptions. 210

Figure 3.3.14: Marina South site with future common tower development massing 211

Figure 3.3.15: Marina South site as a volume $\quad 212$ Figure 3.3.16: Marina South site as a series of volumes broken up by controls that allow ocean breezes to continue to cool the city 212

Figure 3.3.17: Controls for main streets along major axes though the site 213

Figure 3.3.18: Controls for public transit along surfaces, and vertical cores, some of which context into existing MRT stations 213

Figure 3.3.19: Controls for a three dimensional network of walkable blocks and localized neighborhoods 214

Figure 3.3.20: Controls for anchors like parks, schools, libraries, cultural centres, recreation facilities, "Skymarks" and other spaces 214 
Figure 3.3.21: Activation of existing anchors like the sky park of Marina Bay Sands 215

Figure 3.3.22: Future development shaped by established controls and designed to support necessary infrastructure

Figure 3.4.1: Singapore Shop Houses 220 Caskey, Alex "Shop Houses", Singapore, 2017

Figure 3.4.2: Elaborate Facades of Traditional Shophouses ZDL. "Singapore Traditional Shophouses." Shutterstock.com, June 3, 2017. /image-photo/ singaporejun-3-2017singapore-traditional-shophouses-652831135

Figure 3.4.3: Evolution of Singapore Shophouse Styles

Fan, Man Si. "Sense of Identity through Preservation of Singapore's Built and Natural Heritage ASIAN CITIES RESEARCH." University of Hong Kong, December 21, 2015. https://fac.arch.hku. hk/asian-cities-research/sense-of-identity-through-preservation-of-singapores-built-and-naturalheritage/.

Figure 3.4.4: View of Singapore shophouses from above in Northern part of Tanjong Pagar. 221

Google Earth Imagery

Figure 3.4.5: Typical section of contemporary Singapore street in a remaining shophouse district that shows the distinctive " 5 foot way" 221

Figure 3.4.6: Axonometric representation of a typical shophouse district. Streets lined with shops made for an interesting, walkable live-work environment. 222

Figure 3.4.7: Singapore replaced shophouse districts with residential towers, hawker centers, and malls which physically divided living and working functions into separate destinations 223

Figure 3.4.8: Adaptation of shophouse typology to a vertically walkable city. 225

Figure 3.4.9: Street (public flow system) with shophouses on both sides. Shophouses and flow system are supported by real estate below, shophouses support real estate above.

226

Figure 3.4.10: Street (public flow system) with shophouses on one side and void on the other. Shophouses and flow system are supported by real estate below, shophouses support real estate above. 226

Figure 3.4.11: 1: 200 Floating shophouse street model from above showing various intersection conditions

Figure 3.4.12: 1:200 raised shophouse street model. Shophouses are layered with inhabitable space both above and below 228 Figure 3.4.13: 1:200 raised shophouse street model showing both vertical and surface level transportation. Note the design of the edge condition where a lower observation path is separated from the street surface with a continuous planter. This is intended to take advantage of the unique conditions of a raised street by allowing the street surface to have a view out over the city that is unimpeded by a railing. 229

Figure 3.4.14-16 (opposite): 1:200 raised shophouse street model (various angles depicting street life) 231 
Figure 3.4.17: 1:200 raised shophouse street model. Small 'parket" at vertical transit waiting area. 231

Figure 3.4.18: Sketch of similar edge condition to that depicted in the model showing unobstructed view from street level 231

Figure 3.4.19: 1: 500 model exploring how the adapted shophouse typology may contributed to creating vertically walkable city blocks 232

Figure 3.4.20: 1: 500 model exploring how the adapted shophouse typology may be configured along vertically walkable city blocks layered within a larger volume 233

Figure 3.5.1: 1: 500 model exploring how walkable city blocks may be integrated within a volume. 236

Figure 3.5.2: Photo of internal void of 1:500 model. 237

Figure 3.5.3: 1: 500 roof condition. Large roof surfaces are organized with park spaces and small adapted spaces with expressive roofs. 238

Figure 3.5.4: Section through-volume of city showing variety of architectural spaces, urban conditions, programs, and designs. 240

Figure 3.5.5: Enlarged section showing shophouse street above office space, and below apartments. 242

Figure 3.5.6: Enlarged section showing shophouse street above condos and below university 242

Figure 3.5.7: Enlarged section showing shophouse street above apartments and below condos 243

Figure 3.5.8: Vignette illustrating spatial and aesthetic characteristics of vertically organized shophouse district

Figure 3.5.9: Vignette illustrating spatial and aesthetic characteristics of vertically organized shophouse district 
A

R

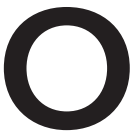

N

E 


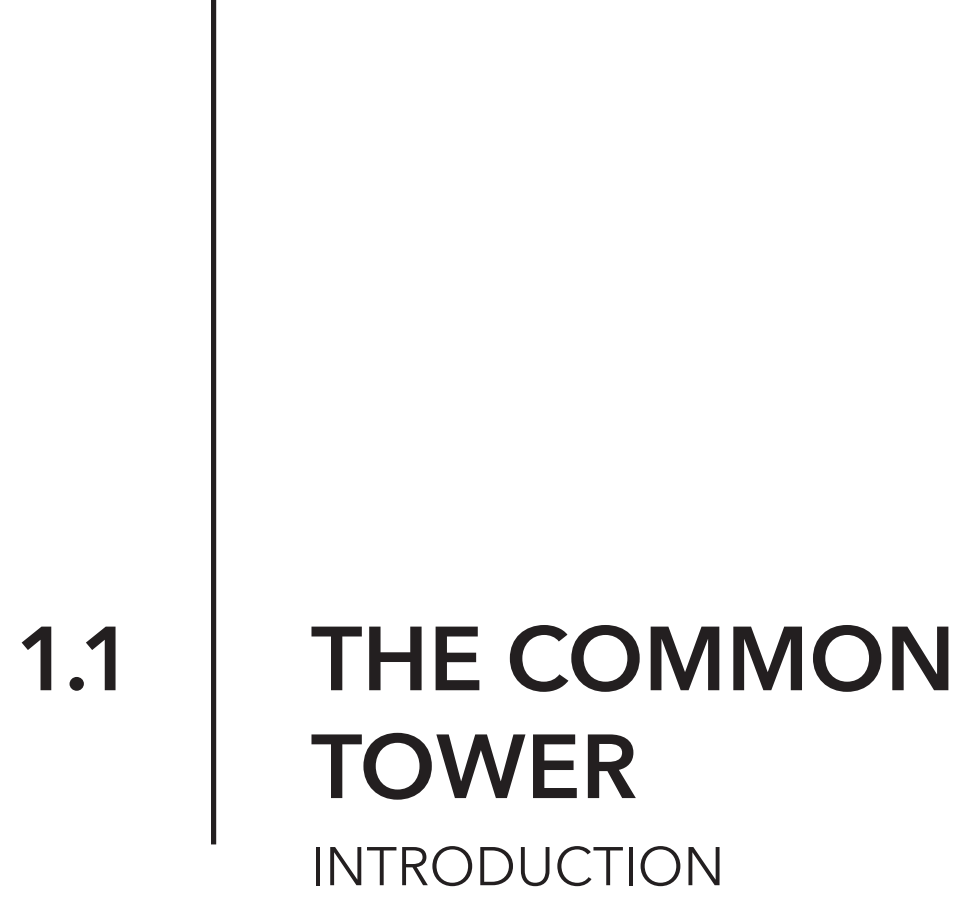

What is the worst way to settle new territory? Sam Anderson, the author of Boom Town, argues that it might be the way in which Oklahoma City was founded ${ }^{1}$. The story of the founding of Oklahoma City is a story of perhaps the most unconventional, chaotic, formation of a city in history. This "free-for-all," known as the Land Rush, involved the settlement of 2 million acres of former indigenous lands by European settlers². On April 22, 1889, over 50,000 people, lined up at the border of the so-called "unassigned lands"3. At precisely 12 -noon, state officials shot pistols into the air, setting loose the 50,000 people, to find and stake out their own piece of private land ${ }^{4}$. By nightfall, almost every scrap of desirable land had been divided up and claimed ${ }^{5}$.

\footnotetext{
1 Anderson, Sam. Boom Town: The Fantastical Saga of Oklahoma City, Its Chaotic Founding, Its Apocalyptic Weather, Its Purloined Basketball Team, and the Dream of Becoming a World-Class Metropolis. First edition. New York: Crown, 2018.

2 Anderson, Sam. "The City Born in a Day." Intelligencer, August 17, 2018. http://nymag.com/intelligencer/2018/08/how-oklahoma-city-was-bornin-a-day.html.

3 Reps, John W. "Oklahoma Land Rush of 1889." Cornell University. Accessed April 19, 2019. http://urbanplanning.library.cornell.edu/DOCS/ landrush.htm.

4 ibid

5 Anderson, Sam. "The City Born in a Day." Intelligencer, August 17, 2018. http://nymag.com/intelligencer/2018/08/how-oklahoma-city-was-bornin-a-day.html.
} 
In the days to come, the residents would come to realize the significant planning oversights in their newly founded city of Oklahoma City. Back to

back to back plots of private lands left little or no room for streets, civic space, social amenities, and infrastructure ${ }^{6}$. Eventually, a civic committee was formed and given the enormous task of going back, lot by lot, to reclaim the real-estate for this urban and social infrastructure necessary for the city to function ${ }^{7}$. Embeded in the story of Oklahoma City is a lesson on urban design, but a lesson that has once again been forgotten.

In 1854, during the New York World's Fair Exhibition in Crystal Palace, Elisha Ottis famously cut the cables to the elevator cab he was standing on to demonstrate his newly designed safety brake ${ }^{8}$. Over the following 165 years, the development and refinement of the elevator would bring effortless access to the upper floors of buildings and making vertical real-estate increasingly desirable? . At the beginning of the 20th century, the elevator, along with other emerging technologies such as electricity, the telephone, and the steel frame, would set loose companies, institutions, and private developers to stake out their own private airspace and build into the sky10. This "Vertical Land Rush" began in Chicago (Figure 1.1.1) and New York, but quickly spread to cities around the world. Similar to Oklahoma City, the settlement of new vertical territory was left solely

6 lbid.

7 "Founding of Oklahoma City | City of OKC." Accessed April 19, 2019. https://www.okc.gov/government/archives-records/oklahoma-city-history/founding-of-oklahoma-city.

8 Ascher, Kate, and Rob Vroman. The Heights: Anatomy of a Skyscraper. P. 92 of 207 New York, NY: Penguin Books, 2013.

9 ibid

10 Dupré, Judith. Skyscrapers. P.54-55 New York: Black Dog \& Leventhal : Distributed by Workman, 1996.

Graham, Stephen. "Above: Elevator/Lift: Going Up" in Vertical: The City from Satellites to Bunkers. p.135 of 392 London; New York: Verso, 2016. 


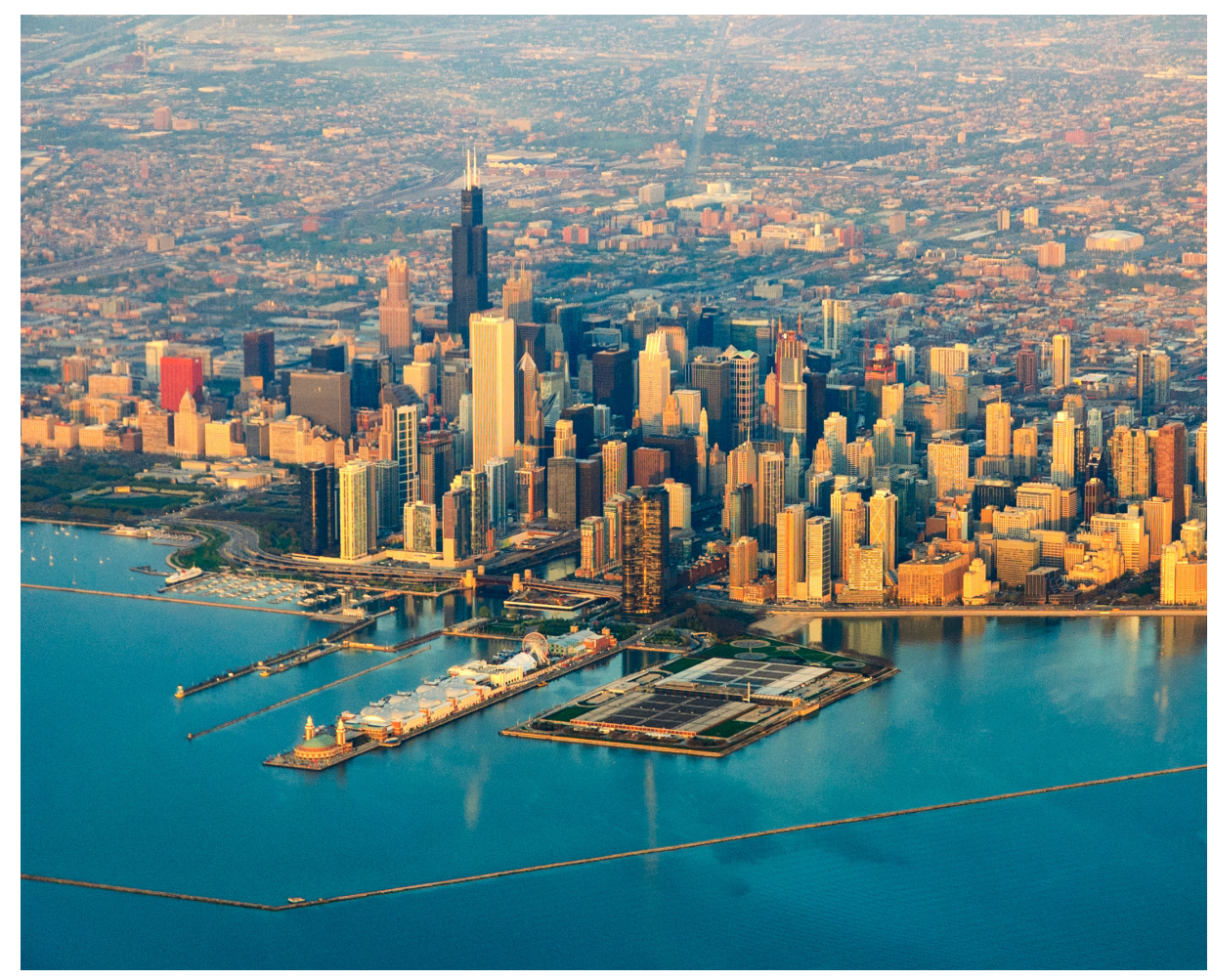

Figure 1.1.1: Vertical Growth in Chicago

Frank, Zack" "Chicago Skyline" n.d. Digital Photograph. Adobe Stock. https://stock.adobe.com/ca/ images/chicago-skyline/92025015?prev_url=detail

to private interests and did not include provisions for civic space, social amenities, and infrastructure.

In his book, A Skyward Trend of Thought, Thomas Van Leeuwen, points out that the ability to build tall was a way to demonstrate power and wealth ${ }^{11}$. Generating power and wealth, however, would prove to be the real value of building tall. Building tall meant the value of the ground plane could be replicated as many times as needed ${ }^{12}$. For those interested in turning a profit, this meant they could cash in on places where there was a high demand for land by replicating the ground plane as may times

Van Leeuwen Thomas A. Skyward Trend of Thought: The Metaphysics of the American Skyscraper. Cambridge: Mit Press, 1990.

12 This idea was derived from Koolhaas's explanation of the forces that created the skyscraper

Koolhaas, Rem. "The frontier in the sky" in Delirious New York: A Retroactive Manifesto for Manhattan. P.82-82-109 New ed. New York: Monacelli Press, 1994 


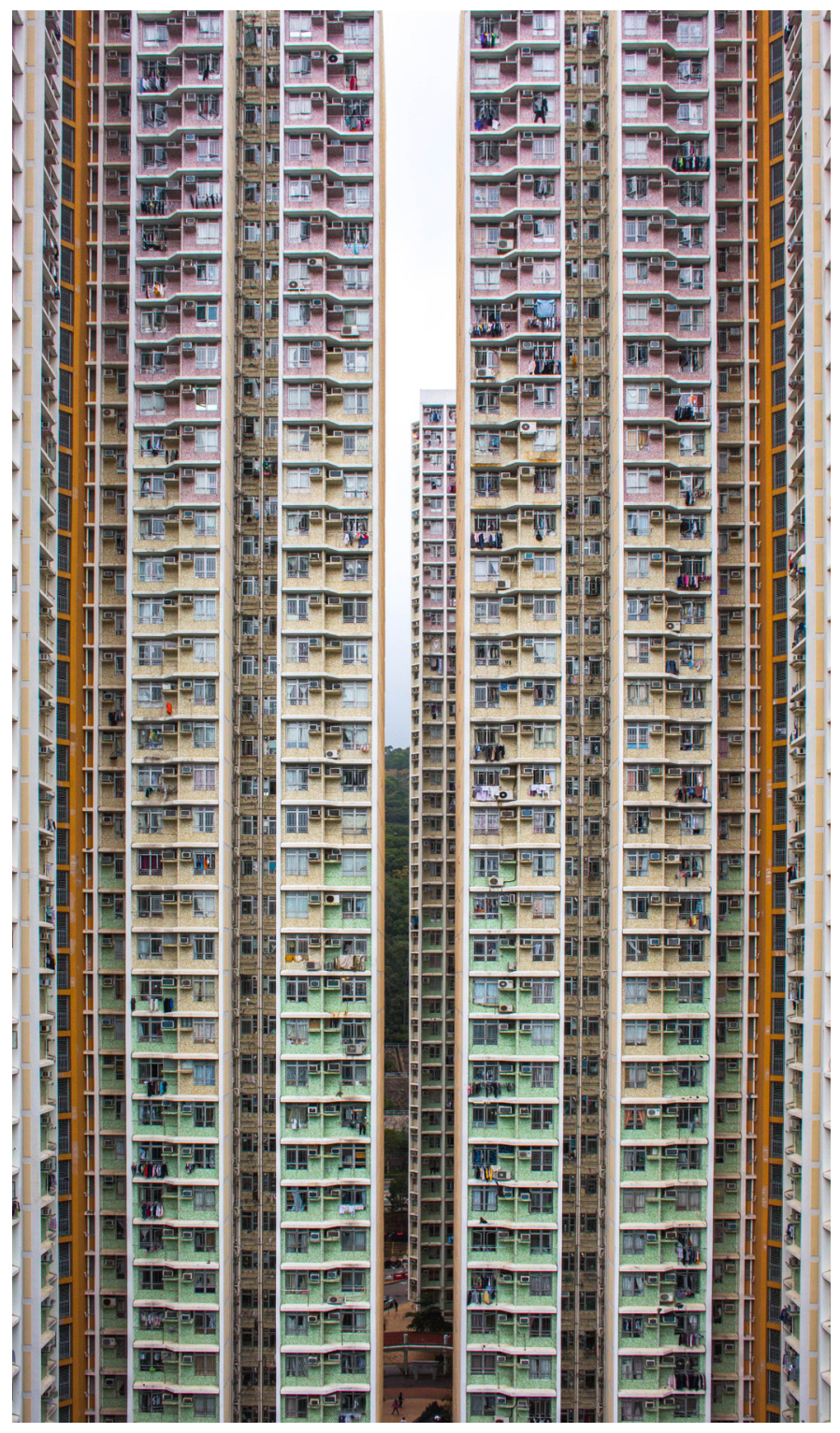

Figure 1.1.2: "Stacks on Stacks on Stacks" of private space. Residential towers in Hong Kong.

Chan, Joseph. "Hong Kong" Jan 13, 2018. Digital Photography. Unsplash Stock Images. https:// unsplash.com/photos/gOMIZPq8CNAdenys

as local regulations, or their profit margins would allow ${ }^{13}$. As Carroll Willis explains in Form Follows Finance, apart from minor regulatory interventions in the form of zoning maps, height restriction, view corridors, size restrictions, and set back laws, the architectural forms of vertical inhabitation, have been almost entirely based on what has been most profitable ${ }^{14}$. Despite over a century of innovation

\footnotetext{
13 This is the idea of economic height of a building discussed in many books on skyscrapers including:

Ascher, Kate, and Rob Vroman. "How tall should it be?" The Heights: Anatomy of a Skyscraper. P. 50 of 207 New York, NY: Penguin Books, 2013.

14 Willis, Carol. Form Follows Finance: Skyscrapers and Skylines in New York and Chica-
} 
and societal change, the fundamental characteristics of the most profitable vertical architecture have taken a singular form: The Common Tower. (See glossary)

Over the past 130 years, the common tower has grown in height, has been disguised in different fashions, and has catered its use to the most indemand occupancies. Other than this, little has changed ${ }^{15}$. The common tower is characterized by identical or nearly identical vertically stacked floor plates that repeat with the most in-demand unit types until topping out at an economic height. These spaces are serviced by one or more vertical service cores that feature elevators, fire stairs, and utility shafts. The common tower is static. The occupancy may change, the façade may be replaced, but only to be adapted for a more in demand occupancy. Common towers may be widely spaced out or just inches apart, but they always act independently from one another. Apart from its ground level or lowest floors, the common tower does not contribute to the public life of the city. There are no provisions for public space, spatial variation, civic space, or much of architectural interest in the height of the building. The common tower does not embrace the intensification of population and congestion that it brings to the city. Similar to fleeing the city for the suburbs, the common tower utilizes vertical separation of planes as a means of enabling a retreat into the sky ${ }^{16}$. The common tower is the default approach to verticality. It is the office tower, the apartment building, the public housing unit, the condo, and the "mixed-use" tower.

What has emerged from the "Vertical Land Rush" is

\footnotetext{
go. 1st ed. New York, N.Y: Princeton Architectural Press, 1995.

15 Yeang, Ken. The Skyscraper Bioclimatically Considered: A Design Primer. Chichester: Wiley-Academy, 2000.

16 Graham, Stephen. "Above: SkywalkSky Train Sky Deck: Multilev-

el Cities" in "in Vertical: The City from Satellites to Bunkers. p.238-239 of

392 London; New York: Verso, 2016.
} 
the same as emerged in Oklahoma City, stacks on stacks, on stacks, of private spaces with no provision for social infrastructure (Figure 1.1.2). As the world's cities have grown taller, they have not grown more livable. Before the skyline of every city is filled in with common towers, perhaps it is time to question if this is the only way for the city to grow vertically. The world's population is growing, and this growing population is heading for the city, so now more than ever, it is imperative to reconsider the fate of the city's vertical real estate ${ }^{17}$.

The common tower is accepted by architects and planners as the default approach to verticality, but part of the role of architecture and design is to look critically at the status quo, at the things that are deemed adequate to see what opportunities for improvement can be identified and developed. There is both architectural and urbanistic potential in the settlement of vertical territory that can only be realized by looking beyond the common tower. This thesis explores the potential for a city to be extended vertically in order to inhabit and benefit from its own vertical real-estate.

\footnotetext{
$17 \quad$ United Nations Department of Economics and Social Affairs Population Division. 2017. World Population Prospects The 2017 Revision. Key Findings and Advanced Tables, New York: United Nations. UN Migration Agency. 2017. World Migration Report 2018. Switzerland: International Orginization for Migration

United Nations Department of Economics and Social Affairs. 2018. World Urbanization Prospects: The 2018 Revision. Key Facts, New York: United Nations.

United Nation's International Organization for Migration. "World Migration Report." Switzerland: United Nations Migration Agency, 2018.
} 


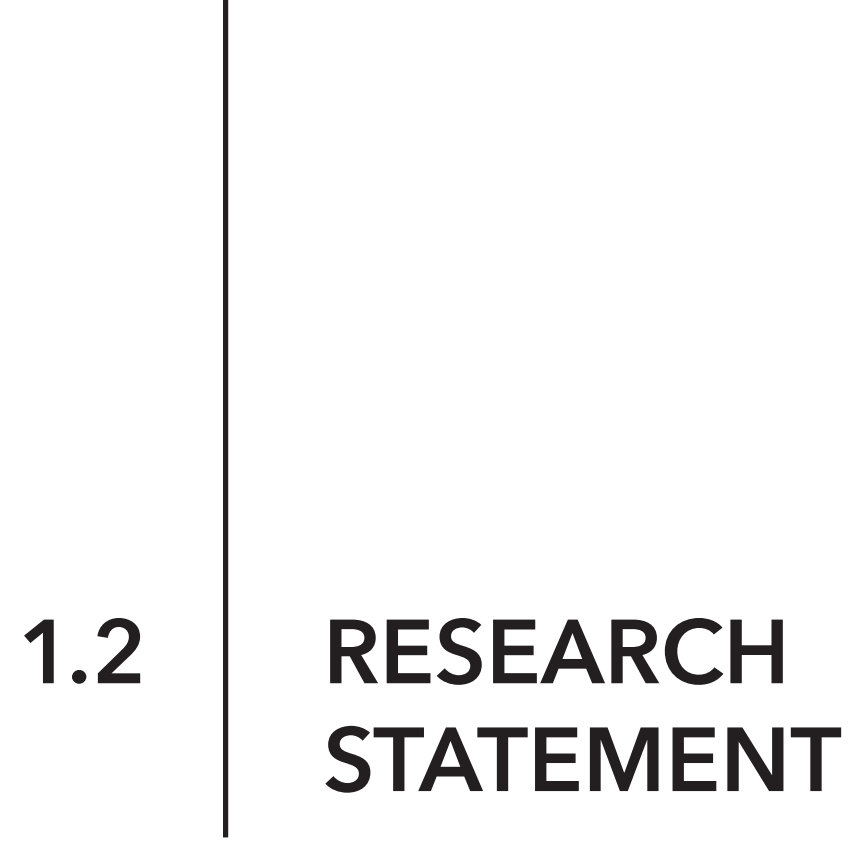

\section{Research Questions}

There is one single overarching research question for this thesis:

- How can a city be extended vertically in order to inhabit its own vertical real-estate?

This single question brings up a multitude of additional questions, including:

- What are the components of a city?

- What parts of a city should be extended vertically?

- What is required to successfully extend the diverse program and the intensity of activity in the city into its height?

\section{Research Methods}

This thesis attempts to answer these questions through the investigation of cities, not as twodimensional abstractions, typical of urban planning, but through its three-dimensional reality, a research mode commonly attributed to architecture. The research for this thesis took on numerous forms, including: 
Analysis of the Built Environment:

The critical analysis of existing forms of verticality emerged from observation, research and analysis of numerous cities, including Toronto, New York, Chicago, Hongkong, London, Frankfurt, Dubai, Bangkok, Singapore. It also included research and analysis of non-vertical cities like Paris and Washington. It was supported and refined by studying the analysis of verticality by authors such as Stephen Graham, Ken Yeang, Rem Koolhaas, Carrol Willis, and Thomas Van Leeuwen, among others.

Literature Review and Case Study Analysis:

The investigation of vertical inhabitation beyond the default approach considered alternative theories of urban forms and focused on historical, theoretical, and visionary urbanism proposals. The findings are summarized in Section 1.4

Design Research:

The development of the theoretical framework for this thesis emerged from design research. It primarily involved prototyping of abstracted urban space in a non-sitespecific manner. These were exploratory physical models constructed in response to broad initial guidelines, established to provide the opportunity for a certain degree of spontaneity throughout the modelling process. Exploratory physical model making exposed architectural and urbanistic conditions that allowed for the study of constraints, challenges, and possibilities. Diagramming, orthographic drawings, and 
digital modelling were complementary to this research methodology. Further explanation of this process and the results of this investigation are presented in Part 2 of this document.

Site-Specific Application of Theory:

Part 3 of this document is an investigation of how the theoretical framework established in Part 2 could serve the needs of a specific city. Part Three focused on the city-state of Singapore and required in-depth analysis and research into the history of the city's built environment, culture, social practices, government and other factors.

The forms of thesis research outlined above were strengthened by:

Course-Based Research:

I received special permission to enroll in PL8305 Contemporary Urban Design in Ryerson's Urban Planning Department. This elective course provided a unique, invaluable perspective on the history of the growth of urban areas, the changing academic discourse, and contemporary approaches to urban design.

Travel Research:

In August 2019, I completed a week-long solo research trip to Singapore. Initially planned for Hong Kong but adjusted last minute due to rising political conflicts, this trip provided an opportunity to study the unique forms of vertical inhabitation that occur throughout Singapore. Throughout the trip I identified, experienced, documented, and analyzed 
Singapore's many "uncommon" forms of vertical inhabitation. 


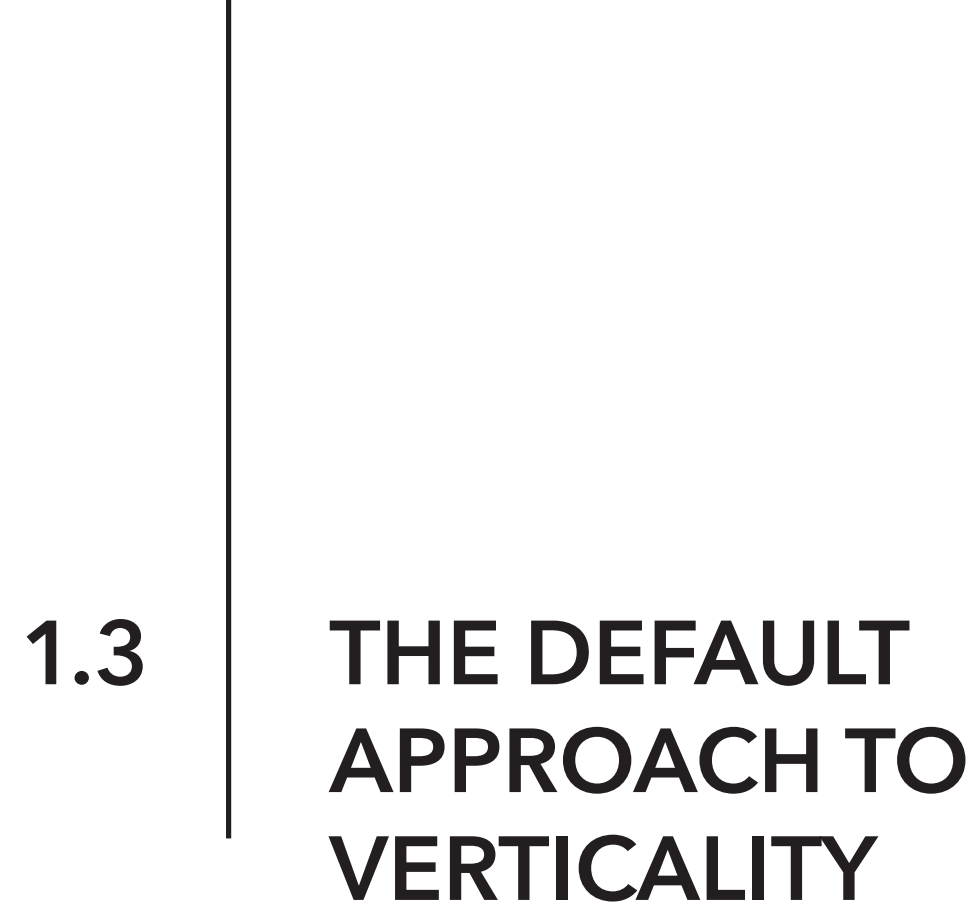

On June 10, 1922, The Chicago Tribune announced an international architectural competition seeking "the most beautiful office building in the world" as a new headquarters for "the world's greatest newspaper"1 . The competition would attract over 263 entries and feature entries from some of the world's leading architects at the time ${ }^{2}$ (Figure1.3.1-4). This widely debated competition would become a pivotal moment in the history of vertical architecture, partially as a result of the completion's captivation of public interest through massive publicity. The competition is significant because it represents one of the best-documented accounts of the profession of architecture asking the question:

What is a tower?

How tall should it be? How should its mass be distributed? What should it look like? How should it be styled? How should verticality be expressed? What role does ornament play? How should the base be treated? How should the apex be treated? It is possible to understand the significance of these questions as, at the time, towers were still emerging

The Tribune Company, and Stanley Tigerman. Tribune Tower Competition. Vol. Volume 1. p. 3. USA: Academy Editions/ Rizzoli, 1980. 2 Ibid. 

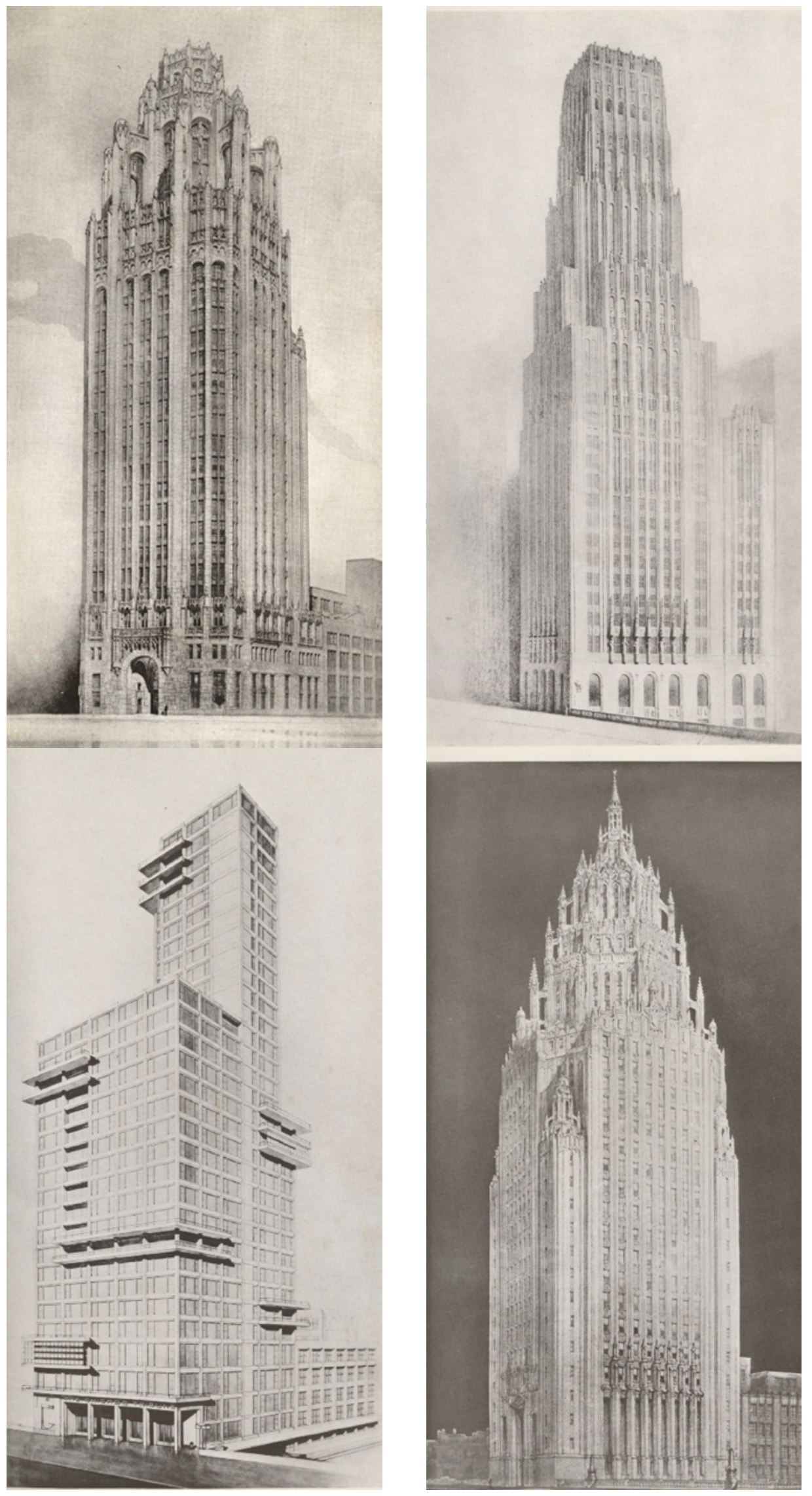
Figure 1.3.1-4 (Previous page): Entry plates from the 1922 Chicago Tribune Competition. Top left: John Mead Howells and Raymond M. Hood, Top Right: Eliel Saarinen, Bottom Left: Walter Gropius and Adolf Meyer, Bottom Right: Helmle \& Corbett Willis, Carol. "The Chicago Tribune Competition." The Skyscrapper Museum. Accessed November 29, 2019. https://www.skyscraper.org/EXHIBITIONS/PAPER_SPIRES/chitrib01.php.

as a new technology and architectural typology. The entries in the competition showed that there was no common consensus on the answers and included widely opposing ideologies ${ }^{3}$. There was, however, one commonality amongst all entries, this was their unquestioning acceptance of the tower as the default vertical typology, an agent, onto which they projected their contradicting ideas.

This default unquestioned typology is the common tower.

It has been almost 100 years since the Chicago Tribune Tower Competition, and towers are now a common occurrence in almost every major city. While towers have evolved in their appearance, and have been refined in their performance, they remain fundamentally unchanged and unrivalled as a vertical architectural typology. Today, the discourse of verticality remains primarily occupied with the same questions of height, massing, and aesthetics. Unlike during the 1920s, however, towers are no longer a celebrated novelty; they are now a well-established urban reality. For example, according to the PHORIO database, in China alone, there are 12,036 towers with ten or more inhabitable floors and an additional 933 under construction ${ }^{4}$. Around the world, urban populations are continuing to grow. As demand for real-estate increases, common towers continue to 


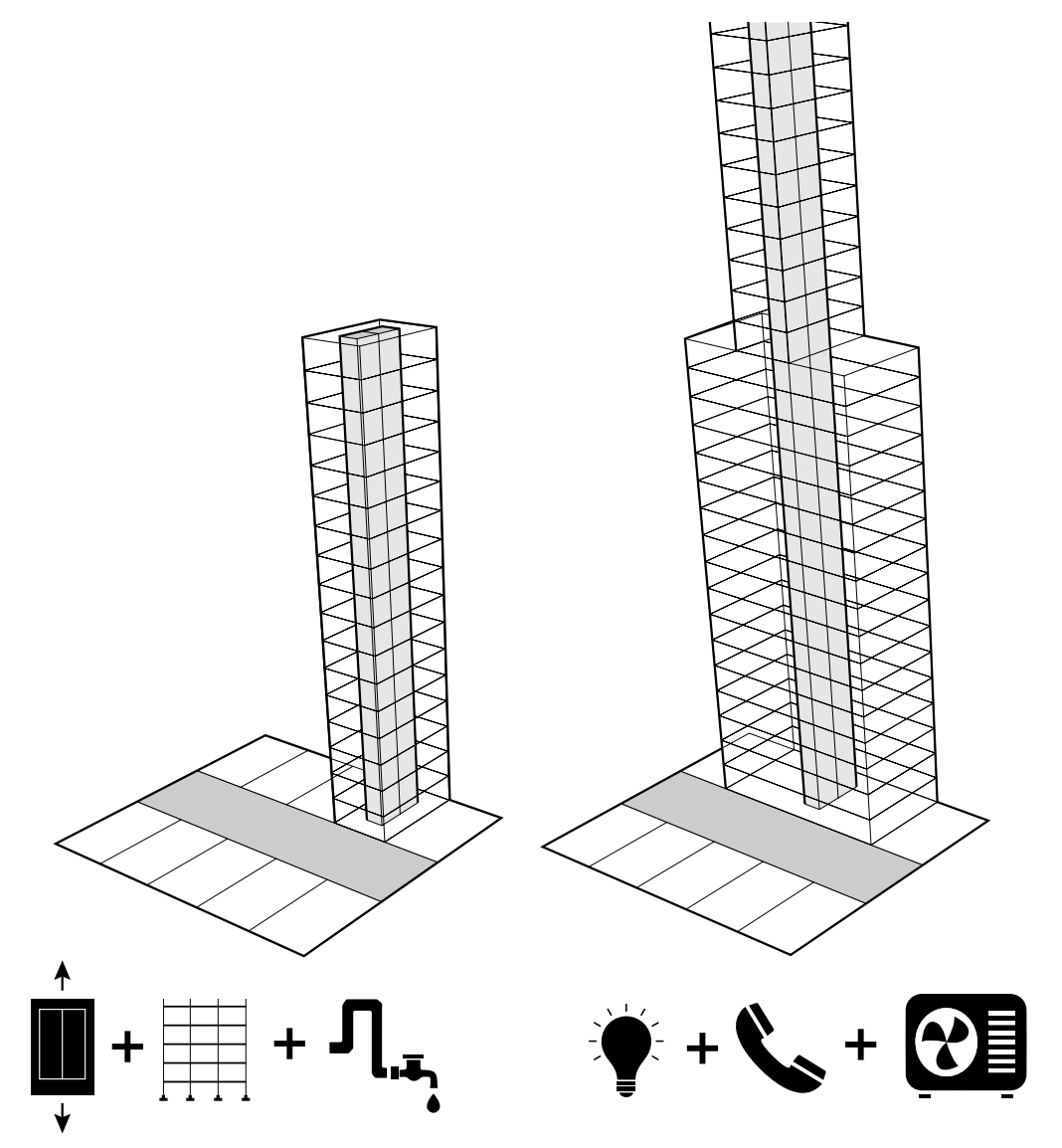

Figure 1.3.5: The technological factors that enabled practical settlement of vertical space including the elevator, internal structure, utility pumps, electricity, telephone, and HVAC. proliferate as the only practical means for enabling the settlement for new real-estate in the sky.

This thesis investigates the potential for alternative strategies for enabling the settlement of vertical real estate. Before discussing alternatives, it is worthwhile to examine the agglomeration of factors that have made the common tower both the default and the only practical typology for vertical settlement. Eight key factors, including technology, architectural decision making, government involvement, development financing, zoning, land ownership laws, fire safety, and mobility, are discussed below:

\section{The Intersection of Technological Innovations}

A series of technological innovations have come together throughout history to enable the common 
tower to be deployed as a practical means of settling vertical real-estate (Figure 1.3.5). The modern skyscraper is often considered to have originated with the Chicago Home Insurance Building built-in $1884^{5}$. This was the first example of the application of the internal skeletal frame structure used vertically'. The skeletal frame freed external walls of their loadbearing function, allowing them to become much thinner and lighter. Predating this innovation in structural engineering were two innovations that enable practical inhabitation of vertical space; these were the safety elevator, as well as plumbing and pumps supported by municipal water and waste infrastructure ${ }^{7}$. Common towers come from the internal coupling of these three technologies into a single internalized system owned and operated by the building owner.

Three additional innovations helped the common tower proliferate by removing the constraints against bigness, and thus enabling stakeholders to increase their returns. Telephone communication, and more recently the internet, enabled tower occupants to retreat further and further from the ground plane without complete isolation, which in turn enabled towers to grow to new heights ${ }^{8}$. The need for daylighting and natural ventilation in occupied spaces governed the massing of early skyscrapers, as Carroll Willis points out in her book Form Follows Finance? ${ }^{9}$. After the 1950s, however, increased

5 Ascher, Kate, and Rob Vroman. "Structure" in The Heights: Anatomy of a Skyscraper. P. 40-53. New York, NY: Penguin Books, 2013.

6 Ascher, Kate, and Rob Vroman. "Structure" in The Heights: Anatomy of a Skyscraper. P. 40-53. New York, NY: Penguin Books, 2013.

$7 \quad$ Ascher, Kate, and Rob Vroman. "Power Air, and Water" \& "Elevators"in The Heights: Anatomy of a Skyscraper. P. 92-95 \& P. 104-105. New York, NY: Penguin Books, 2013.

8 Ascher, Kate, and Rob Vroman. "Communications" in The Heights: Anatomy of a Skyscraper. P. 118-119. New York, NY: Penguin Books, 2013.

$9 \quad$ Willis, Carol. Form Follows Finance: Skyscrapers and Skylines in New York and Chicago. 1st ed. New York, N.Y: Princeton Architectural 

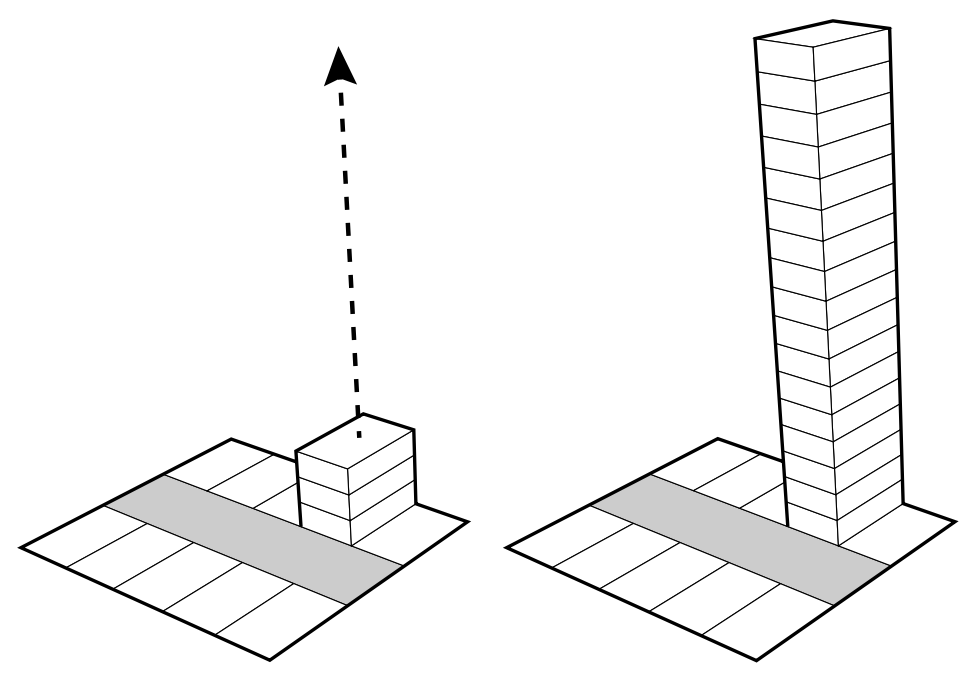

Figure 1.3.6: Vertical Repetition \& Replication of spatial solutions resulting in mass uniformity but design and construction efficiency

availably of bright florescent lighting, mechanized air conditioning, and heating enabled towers to grow in bulk ${ }^{10}$. This meant larger and deeper floorplates and more income-generating space per floor. These innovations also sealed the perimeter of tower volumes from the external climate and made it ideal for minimizing external surface area ${ }^{11}$.

\section{Design Efficiency}

Technology may have been the enabler, but the pursuit of design efficiency solidified the common tower as the default application of this technology. A defining characteristic of the common tower is its monotonous vertical repetition of spaces. As progress in structural engineering and other technologies enabled buildings to grow taller, designers continued extruding replications of the same architectural spatial solutions further and further away from the

Press, 1995.

10

Ibid.

Ascher, Kate, and Rob Vroman. "Power Air, and Water" in The Heights: Anatomy of a Skyscraper. P. 104-105. New York, NY: Penguin Books, 2013. 11 Ibid. 
ground plane (Figure 1.3.6). This repetition and replication gave common towers their characteristic of mass uniformity of space and form. In terms of structural organization, constructability, flexibility of use, the repetition and replication of floor plates was an efficient, economical solution. The repetitive nature of this design solution left few opportunities for architectural placemaking and no opportunities for public spaces within the height of a city. These considerations, however, were not of significant concern because, as described in Section 1.1, the expansion of cities was left in the hands of private interests.

\section{Public Infrastructure: Taxes}

Taxes, or the lack thereof, have been part of the reason why public infrastructure does not extend vertically. In most cities, governments have had limited economic involvement in the vertical expansion of the city. Their involvement has mainly been through a regulatory system that attempts to safeguard conditions of existing public infrastructure on the ground plane.

When towers were beginning to proliferate as an architectural typology, some recognized the density of towers would cause localized congestion of public infrastructure. Throughout the early $20^{\text {th }}$ century, Harvey Wiley Corbett continued to advocate that "the proportion of street and sidewalk facilities would need to keep pace with the vertical growth of the city $^{\prime \prime 12}$. As discussed in Section 1.4, he envisioned the city of the future, having many layers of streets and sidewalks throughout the height of the city. It is unclear whose responsibility he intended this infrastructure to be ${ }^{13 .}$ On the ground plane,

12 "Mr. Corbett's Future City." New York Times. 1929. Retrieved from http://ezproxy.lib.ryerson.ca

13 Sant'Elia, Antonio, Luciano Caramel, and Alberto Longatti. Anto- 
this infrastructure is most commonly constructed, managed, and maintained by the government, but extending these services into the height of the city would require significant capital, among other things.

Taxes are the main economic means that enable governments to provide infrastructure and services to a city. Much of the tax budget for infrastructure was likely already accounted for, as most major cities grew vertically. In North America, widespread demands for tax funding coupled with tax cuts have forced the government to resort to negotiating with the private sector for the provision of infrastructure ${ }^{14}$. As Wade Graham explains in Dreams Cities, the post-war flight to the suburbs exhausted the tax resources of major cities as highway, water electricity infrastructure had to be extended further and further to service fewer and fewer people ${ }^{15}$. During this time in the US, the federal income tax was steadily rising, but this rise eventually led to backlash ${ }^{16}$. In The Corporate Production of Downtown Space, Loukaniko and Sideris discuss the impacts of subsequent major tax cuts in the 1960s and $1980 \mathrm{~s}^{17}$. After these tax cuts, governments that had become dependent on this income for the provision of infrastructure and services were forced to embark on joint ventures, partnerships, and negotiation with private real estate nio Sant'Elia, the Complete Works. P. 228 New York: Rizzoli, 1988. Urbanefreakde. "URBAN GEOGRAPHIES: Cities / Places / Regions." URBAN GEOGRAPHIES: Cities / Places / Regions. Accessed August 11, 2019. https://urbangeographies.tumblr.com/post/127713040662/urbanfreakde-urbain-visionary-city-of-new.

$14 \quad$ Loukaitou-Sideris, Anastasia, and Tridib Banerjee. Urban Design Downtown: Poetics and Politics of Form. Berkeley: University of California Press, 1998.

15 Graham, Wade. "Chapter 4: Homesteads " in Dream Cities: Seven Urban Ideas That Shape the World. P. 147 New York: Harper Collins, 2017.

$16 \quad$ Internal Revenue Service. "Personal Exemptions and Individual Income Tax Rates: 1913-2002." Internal Revenue Service, 2002.

$17 \quad$ Loukaitou-Sideris, Anastasia, and Tridib Banerjee. "Corporate Production of Downtown Space" in Urban Design Downtown: Poetics and Politics of Form. P.73-99 Berkeley: University of California Press, 1998. 
developers ${ }^{18}$. These led to one-sided negotiations where private interest came out on top ${ }^{19}$. With limited economic involvement, city governments had little to negotiate with besides trading away the constraints of a regulatory system established to protect the interests of the general public ${ }^{20}$. Even in certain cities like Calgary, where a grade-separated pedestrian network was secured as-of-right through private developments ${ }^{21}$, the private developers responsible for its construction were able to shape the network based on their commercial interests.

Without sufficient tax income and without grounds for negotiation, governments have a limited influence on major urban developments. Without pressure from the government, the private developer has no incentive to incorporate urban infrastructure into any of the vertical growth of the city; instead, they opt for the design efficiency and proven profitability of common towers.

\section{Private Development: Finance and Risk.}

Perhaps more so than any other factor on this list, finance and risk have been most influential in the proliferation of the common tower typology. In her book, Form Follows Finance, Caroll Willis uses an analysis of the skyscrapers of New York and Chicago to build a case for how the defining architectural characteristic of skyscrapers is the pursuit of profit ${ }^{22}$. She provides a quote from Cass Gilbert, which $18 \quad$ Loukaitou-Sideris, Anastasia, and Tridib Banerjee. "Corporate Production of Downtown Space" in Urban Design Downtown: Poetics and Politics of Form. P.73-99 Berkeley: University of California Press, 1998.

19 Ibid.

$20 \quad$ lbid.

21 Yoos, Jeniffer, and Vincent James. "The Multilevel Metropolis." Places Journal, May 18, 2016. https://doi.org/10.22269/160518.

$22 \quad$ Willis, Carol. "Form Follows Finance: Skyscrapers and Skylines in New York and Chicago. 1st ed. New York, N.Y: Princeton Architectural Press, 1995. 

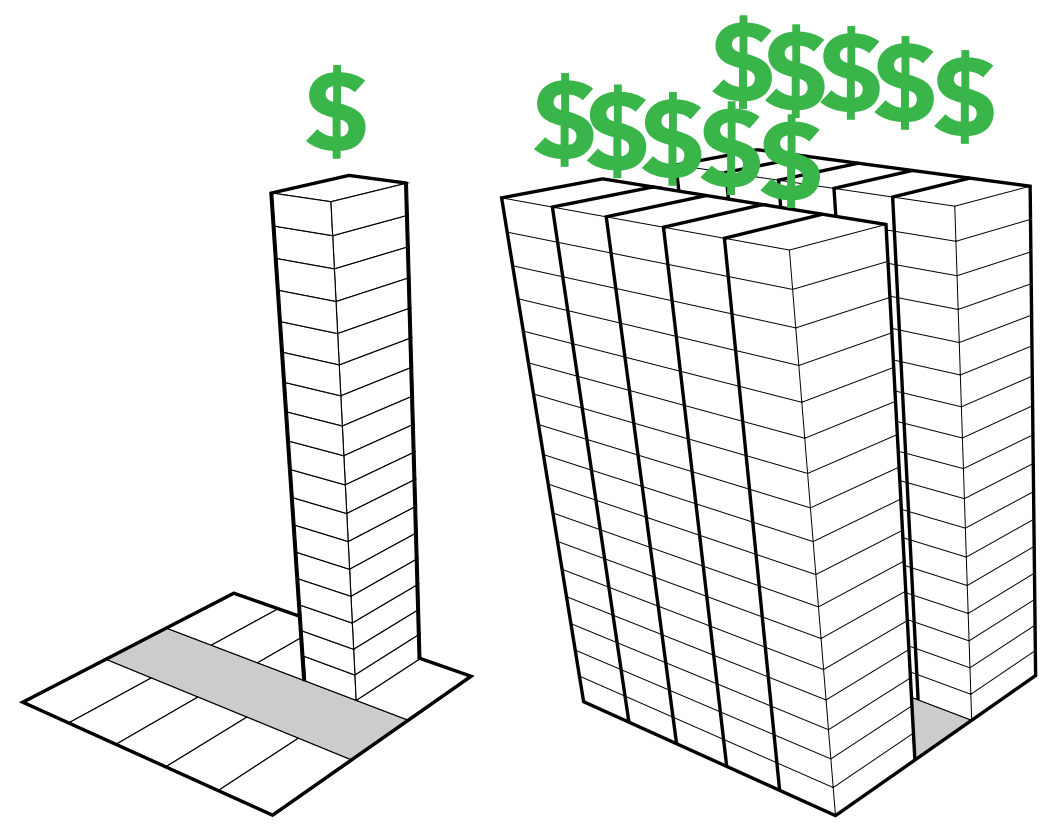

Figure 1.3.7: Finance \& Risk: Their proven ability to produce profits is why common towers have proliferated

accurately explains the proliferation of common towers around the world. He refers to the tower as:

"A machine that makes the ground pay" 23

The reason that common towers are the default approach to verticality is primarily attributed to the fact that it is a time-tested method in which to make money (Figure1.3.7). Most private developers aren't particularly interested in development for its urban design contributions; most of them are interested in finding a way to make money, that's their job. Tall buildings are large building projects, and their design and execution span over long periods. This scale of this type of project holds many uncertainties, and stakeholders typically want to minimize risk and maximize benefits ${ }^{24}$. Projects are generally evaluated 23 Cass Gilbert Quoted in Willis, Carol. "Vernaculars of Capital-
isim" Form Follows Finance: Skyscrapers and Skylines in New York and
Chicago. 1st ed. p. 19 New York, N.Y: Princeton Architectural Press, 1995.
$24 \quad$ Ruegg, Rosalie T., and Harold E. Marshall. "Methods of Econom-
ic Evaluation" in Building Economics: Theory and Practice. P.3 of 486, New
York, N.Y: Van Nostrand Reinhold, 1990.
Hillebrant, Patricia M. "Price Determination for a single Project" in Eco- 
based on economic models in order to minimize investment risk ${ }^{25}$. These models are based on the existing information from previous projects, market research, and expert opinion ${ }^{26}$. This type of economic evaluation favours quantifiable information while often omitting the more unquantifiable factors like the urban contribution and the qualities of architectural space $^{27}$. These models thus favour the replication of previously successful models like the common tower.

Common towers have proliferated thought the world because growing the city vertically has not been about the city; it has been about making money for private owners ${ }^{28}$.

\section{Land Ownership}

The structure of land ownership has played a role in the proliferation of common towers by requiring single ownership and individualized vertical infrastructure. In cities like Hong Kong and Singapore, the government retains ownership of much of the land by selling land under lease agreements instead of the full transfer of ownership ${ }^{29}$. In most cities, however, plots of land are sold off to individuals

nomic Theory And the Construction Industry.p12-185 of 233 London: The Macmillan Press, 1974.

25 Fraser, Niall M, and Elizabeth M Jewkes. "Engineering Decision Making" in Engineering Economics: Financial Decision Making for Engineers. p.1-17 of 526. Toronto: Pearson Canada, 2013.

26 ibid

$27 \quad$ Ibid.

Ruegg, Rosalie T., and Harold E. Marshall. "Methods of Economic Evaluation" in Building Economics: Theory and Practice. P.3 of 486, New York, N.Y: Van Nostrand Reinhold, 1990.

Hillebrant, Patricia M. "Price Determination for a single Project" in Economic Theory And the Construction Industry.p12-185 of 233 London: The Macmillan Press, 1974.

28 Willis, Carol. "Form Follows Finance: Skyscrapers and Skylines in New York and Chicago. 1st ed. New York, N.Y: Princeton Architectural Press, 1995.

29 Christ, Emanuel, and Christ \& Gantenbein, eds. Essays: Hong KongTypology: Hong Kong, Rome, New York, Buenos Aires. P. 16-17. Typology, ed. : Emanuel Christ]; [1. Zürich: Park Books, 2012. 


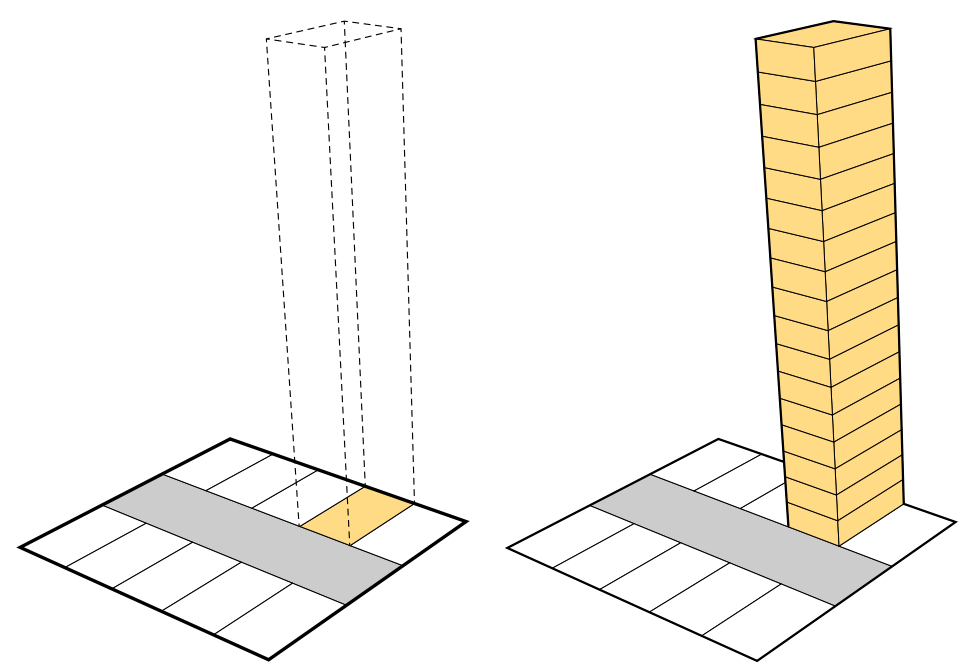

Figure 1.3.8: Land and Ownership and Air Rights encourage the extrusion of a single program and force a single ownership based on a series of understandings, one of which is that the ownership of a plot of land includes the volume of airspace above it. This means that the entire volume of vertical space belongs to a single owner (Figure 1.4.8). The only restrictions are those imposed by zoning regulations like plot ratios, height restrictions, setbacks, etc.

In the case of vertical extrusion of a lot, single land ownership encourages the replication of the same program throughout its height. The single private ownership also eliminates the potential for vertical infrastructure to serve multiple pieces of real estate. The singular owner or group of owners are forced to provide all necessary services for vertical inhabitation of real-estate on each lot. Even in the case of a condominium, where individuals own "airspace," the overall building is serviced internally and remains under single ownership typically made up of the cumulation of the condo owners themselves through a condo board ${ }^{30}$.

$30 \quad$ CMHC. "Chapter-1-Condominium-Basics." Canada Mortgage and Housing Corporation, 2019. https://www.cmhc-schl.gc.ca/en/buying/ condominium-buyers-guide/chapter-1-condominium-basics. 

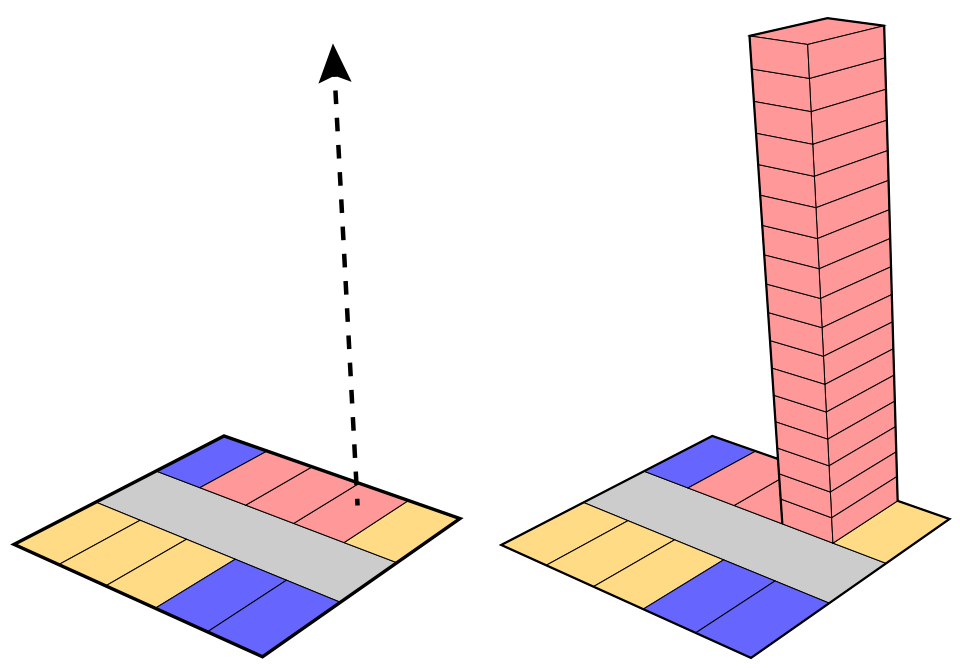

Figure 1.3.9: Zoning extruded the "rational" 2D organization of land into the 3rd Dimension

Since 1968 in New York City, the transferring of development rights has been permitted where property owners can sell off unused volumes of airspace above their buildings ${ }^{31}$. Unlike the name suggests, this transfer of air rights is not a physical transfer of volume, in which the unbuilt vertical volume above a building becomes inhabited. Instead, it takes the form of a height bonus that is applied to the top of the building planned for the purchaser's adjacent lot ${ }^{32}$. Part of this thesis involves exploring alternative approaches to air rights and land ownership that could enable forms of vertical inhabitation beyond the common tower.

\section{Zoning}

Zoning, the idea that land should be divided into zones based on certain land use, is a widespread practice that has contributed to the proliferation of the common tower typology. The practice of zoning has most commonly taken the form of two- 
dimensional zoning maps. Stephen Graham points out in his book Vertical that major cities around the world continue to intensify and grow vertically, yet, the thinking behind mapping and urban planning remains largely two dimensional ${ }^{33}$. In City Levels, Jonathan Glancy explains how the aerial perspective of cities that became increasingly available in the post-war era made the city appear as a twodimensional map, "manageable in a scientific and rational way ${ }^{\prime \prime 34}$. This led to increased use of zoning in which parcels of land were assigned single programs ${ }^{35}$. For example, in "A Contemporary City," Corbusier called for a rational division of the city into specific activity zones organized in a geometric layout that would improve traffic flow ${ }^{36}$. As cities have grown vertically, however, this rational organization of land in two dimensions has been progressively extruded higher and higher into the sky resulting in a restriction of the diversification of vertical real estate (Figure 1.3.9).

In many cities, planners have attempted to extend the use of zoning into the third dimension through the use of plot ratios, setbacks, and even more comprehensive restrictions that almost fully dictate the design of building $s^{37}$. Hugh Ferris's renders for the 1916 New York Zoning ordinance are an example of how these prescriptive types of zoning regulations impose major conditions on a design ${ }^{38}$.

\footnotetext{
33 Graham, Stephen. "Introduction" in Vertical: The City from Satellites to Bunkers. p.4-8 of 392 London ; New York: Verso, 2016.

34 Glancey, Jonathan. "The Highest Point." In City Levels, edited by Ally Ireson and Nick Barley, p.15-16. Basel ; Boston : London: Birkhäuser ; August, 2000.

35 ibid

36 Le Corbusier. "A Contemporary City." In In The City of Tomorrow and Its Planning Reprinted in "The City Reader", 2nd edition., P.336-343, 2000(1973).

37 Barnett, Jonathan. "Designing Cities Without Buildings "Urban Design as Public Policy: Practical Methods for Improving Cities. New York: Architectural Record Books/McGraw-Hill, 1974.

38 Koolhaas, Rem. Delirious New York: A Retroactive Manifesto for
} 


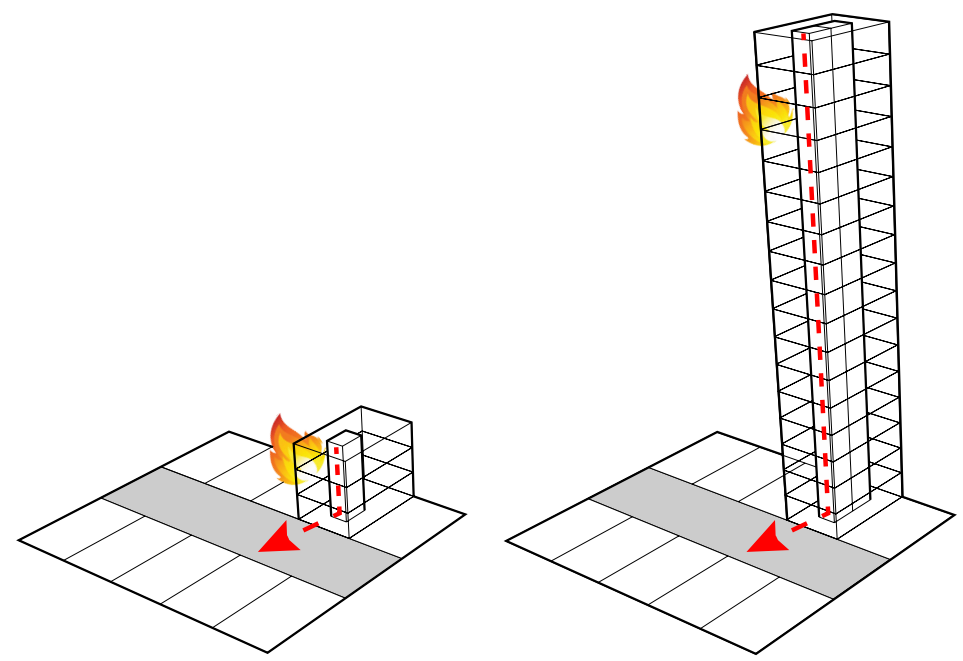

Figure 1.3.10:Fire Safety and the need for evacuation to the ground plane have made the common tower the only permissible solution

The illustrations show how the setbacks, which were calculated based on the width of the adjacent street, resulted in a defined prismatic volume ${ }^{39}$. Jonathan Barret argues that in assigning these types of volumetric constraints, planners are embedding within each lot predetermined assumptions about the orientation and organization of the building, which inherently predetermine aspects of the architectural design like daylighting, views, and uses ${ }^{40}$. This practice limits the potential of each site before design even begins. The expanding reach of regulation into the prescription of the physical form of the buildings has limited the ability for architects to developed alternative forms of vertical growth if they so desired. Instead, constraints imposed by zoning often only really enable the design of more common towers.

\section{Fire Safety \& Building Codes}

Manhattan. New ed. p. 112. New York: Monacelli Press, 1994.

39 Ibid.

40 Barnett, Jonathan. "Designing Cities Without Buildings " Urban Design as Public Policy: Practical Methods for Improving Cities. New York: Architectural Record Books/McGraw-Hill, 1974. 
Fire safety and building codes have been two of the factors that have made the common tower the only permitted method of inhabiting vertical space. Fires pose a severe risk to occupants of vertical space that is increased the further they are distanced from the ground plane. As a result, building codes enforce an extensive list of precautionary design measures for preventing the spread of fires and ensuring fire safety in tall buildings ${ }^{41}$. These include mandatory building technologies, like fire-resistant structure, sprinklers, pumps, and air pressurization systems, as well as design objectives, like compartmentalization and provisions for fire corridors and fire stairwells ${ }^{42}$.

The design requirements are all focused around the evacuation of building occupants in the case of an emergency, which until recently has mainly meant getting occupants to the ground floor ${ }^{43}$. The requirement for ground-level evacuation has restricted alternative forms of vertical growth by requiring, among other things, that vertical and horizontal circulation is internalized in fire-protected spaces (Figure 1.3.10).

As towers have become taller, the "common" approach to evacuation where everyone descends to the ground level has become more of a challenge. This has forced cities, designers, and building officials, to explore more "uncommon" forms of egress. In addition to evacuating residents to the ground, since 1990 Tokyo has advised developers to put helipads on buildings over $45 \mathrm{~m}$ tall for aerial fire

\footnotetext{
$41 \quad$ Ascher, Kate, and Rob Vroman. "High rise Fires" in The Heights: Anatomy of a Skyscraper. P. 138-139 New York, NY: Penguin Books, 2013. $42 \quad$ Ibid.

Firley, Eric, and Julie Gimbal. "High rise building regulations in seven cities worldwide" in The Urban Towers Handbook. P.198-237 Chichester: Wiley, 2011.

43 Ascher, Kate, and Rob Vroman. "Evacuation" in The Heights: Anatomy of a Skyscraper. P. 136 New York, NY: Penguin Books, 2013.
} 


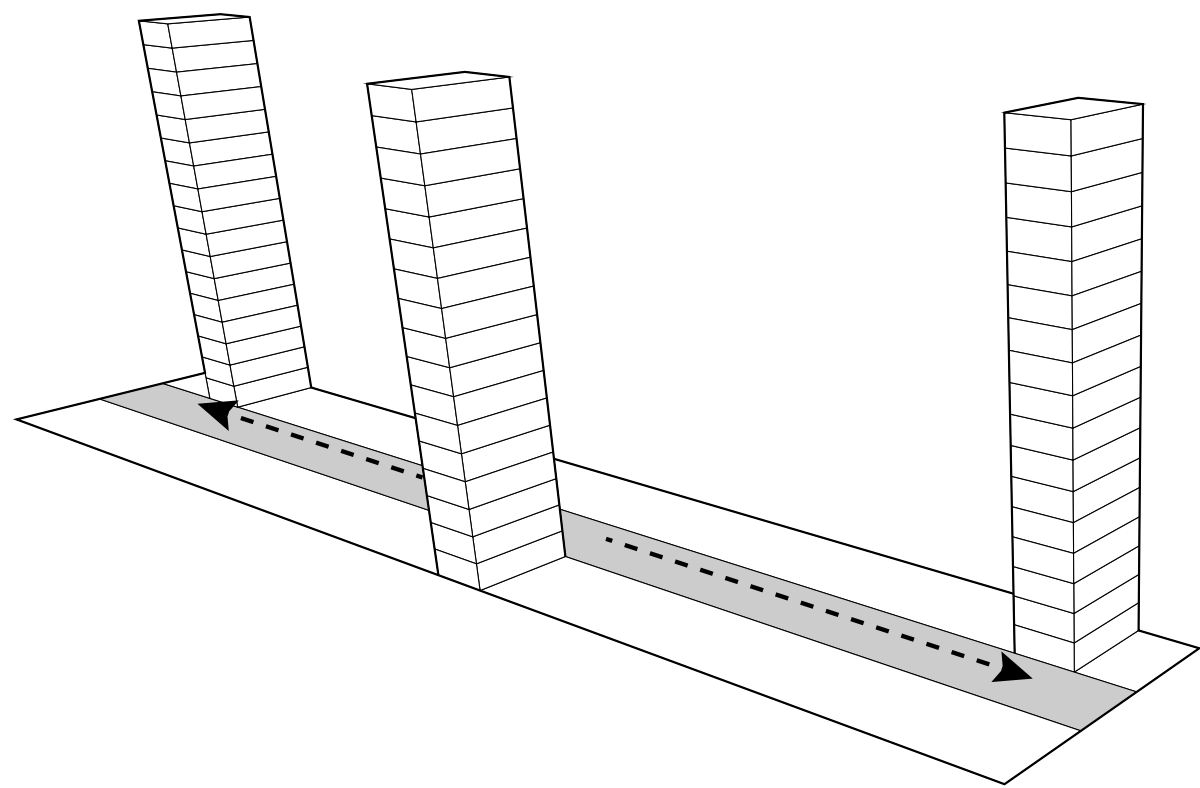

Figure 1.3.11: Mobility enabled the tower to act independently

evacuation purposes ${ }^{44}$. Another uncommon approach increasingly used throughout Asia, is the use of refuge floors located throughout the height of towers every 15-25 floors $^{45}$. In the case of an emergency, refuge floors are provided with a steady stream of clean air and emergency electricity, providing building occupants with a safe space for a prolonged period from which they can be rescued if necessary ${ }^{46}$.

There are potential fire safety benefits to alternative forms of vertical growth that would introduce egress redundancy and thus a greater degree of safety

\section{Mobility}

The increasing reach of mobility in the form of the elevator and, more importantly, the automobile have 44 Cooper, Chris. "Tokyo Has More Helipads Than Any Other City - But They're Almost Never Used - Bloomberg." Bloomberg, May 2016. https://www.bloomberg.com/news/articles/2016-05-19/why-tokyo-hasthe-most-rooftop-helipads-and-doesn-t-use-them.

45 Ascher, Kate, and Rob Vroman. "Evacuation" in The Heights: Anatomy of a Skyscraper. P. 136 New York, NY: Penguin Books, 2013. 46 Ibid. 
allowed people to overcome most of the imposed limitations of common towers. This has enabled the tower to act independently from its immediate context (Figure 1.3.11). The widespread proliferation of the tower as an isolated object is a testament to its ability to meet a societal need for cost-effective inhabitable space. The ability to descend an elevator to a car waiting in a parking garage and the ability to use that vehicle to quickly get elsewhere has meant that the relative inaccessibility of upper floors just has not been that big of a problem. In many cases, this inaccessibility of common towers has made them desirable as escapes from the city below.

The common towers dependency on the automobile as a means of overcoming its isolation from urban amenities has embedded within it its own problems. This privilege is limited to those able to drive, and only further reinforces the adverse health and environmental impacts of automobile dependency. This is further discussed in Section 2.5.

\section{Conclusion}

The eight factors discussed above have all been influential in making the common tower both the default and the only practical typology for vertical settlement. It is unlikely that any of these will change anytime soon, but it is possible to investigate the potential of the city beyond its current state. That is exactly what was done by the architects and urbanists discussed in the following section. 


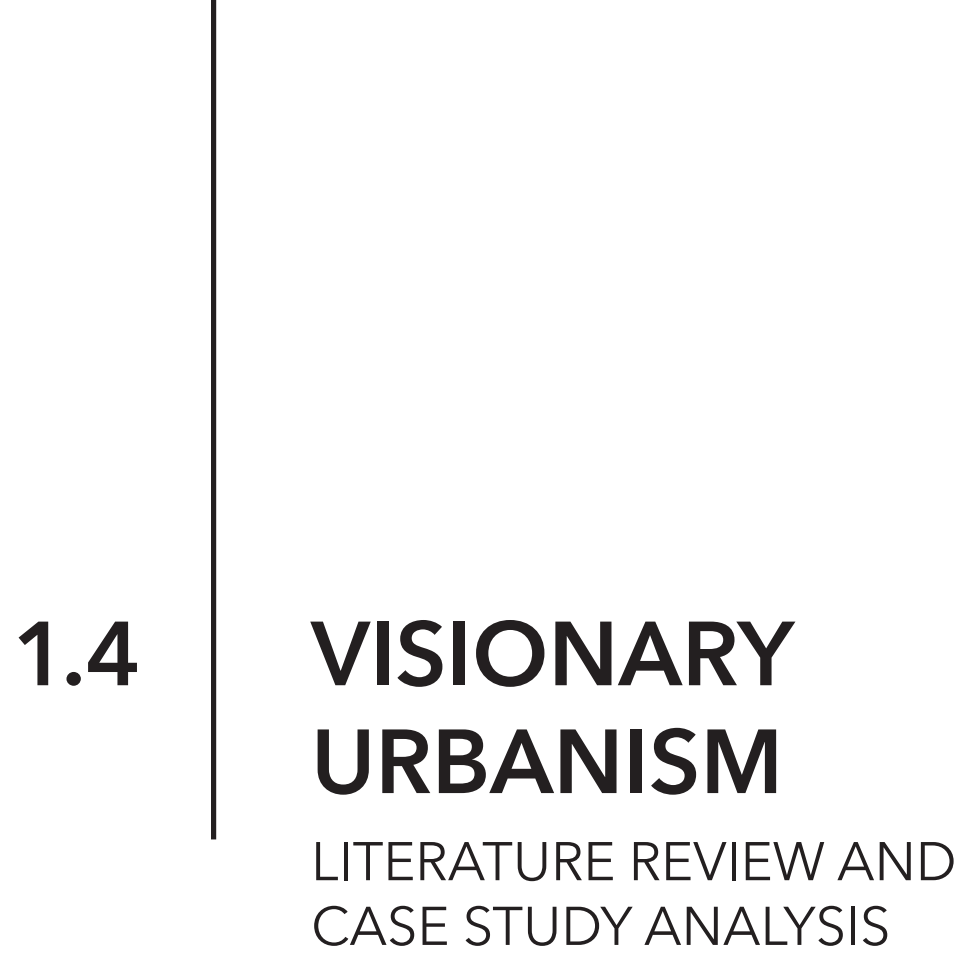

The literature review and case study analysis portion of this thesis primarily focused on historical proposals for new urban forms based on theoretical ideas, as well as the impact of these ideas on the built environment. These designs for how the future city "ought"to be are what Alex Krieger refers to as Visionary Urbanism?.

Visionary Urbanism developed by architects and urban theorists in the late $19^{\text {th }}$ and $20^{\text {th }}$ century embodied the problems facing cities at the time. Early proposals began as a response to the adverse living conditions of the industrial city, but over time became influenced by other factors like traffic congestion, demand for housing, and emerging technology ${ }^{2}$. The Visionary Urbanisms of the past are often dismissed for their utopian nature, but given further analysis, they each expose unique architectural and urbanistic conditions. The proposals included here represent six approaches to the vertical inhabitation of cities

Kreiger, Alex" Where and How Does Urban Design Happen" in Harvard Design Magazine: The Origins and Evolution of Urban Design, 1956-2006. Cambridge. Harvard University Graduate School of Design. 2006

2 Cohen, Jean-Louis. "The Ideal Community: Alternatives to the Industrial City" in The Future of Architecture, since 1889. P.241-255London ; New York: Phaidon, 2012. 


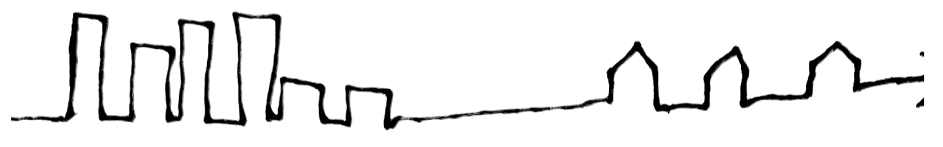

2. MASS CENTRALIZATION

3. MULTIPLE GROUNDS
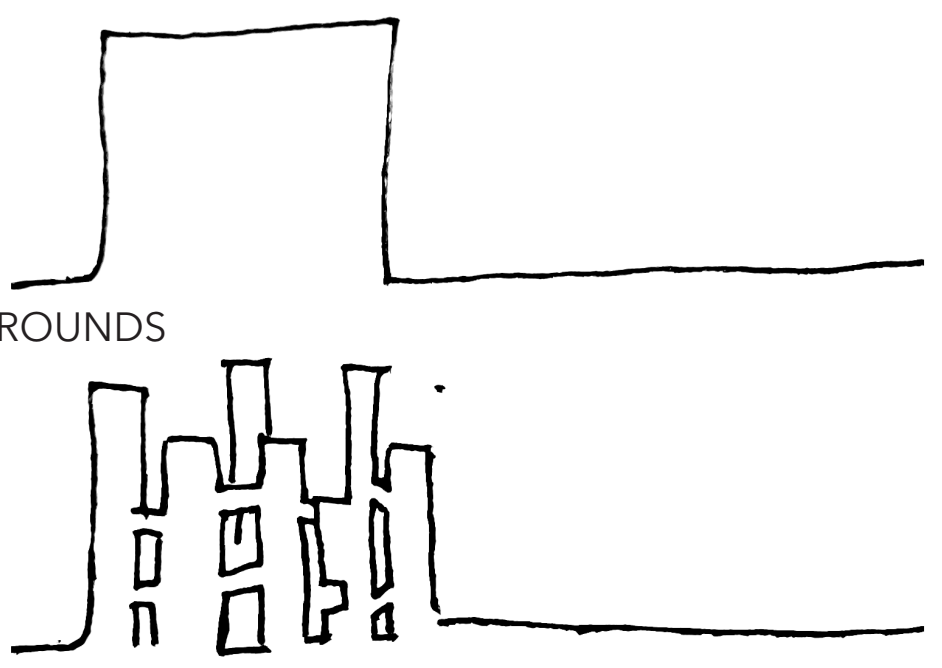

4. TOWERS IN THE PARK

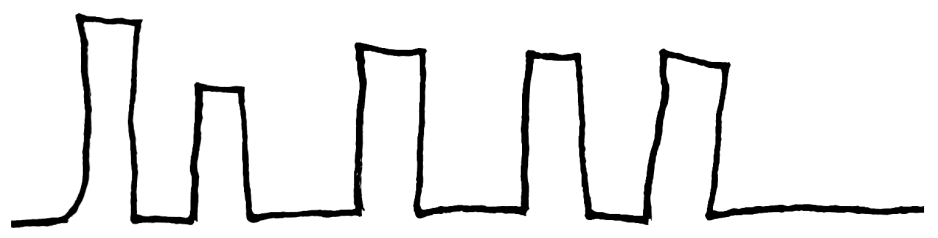

5. INHABITED INFRASTRUCTURE

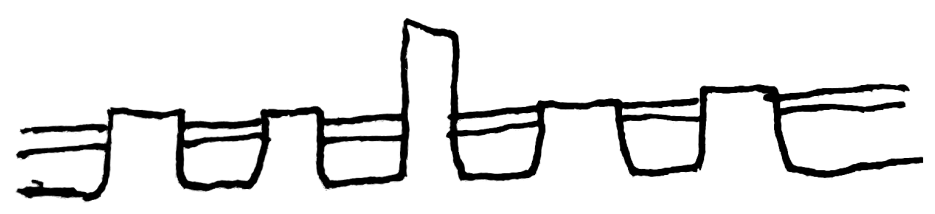

6. OPEN- ENDED URBAN FRAMEWORK

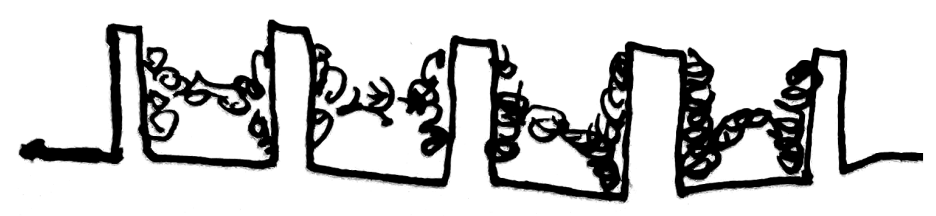

Figure 1.4.1: Six categories of Visionary Urbanism approaches to vertical inhabitation of the future city from the past century. 
(Figure 1.4.1), including:

1: Urban Retreat

2. Mass Centralization

3. Multiple Grounds

4. Towers in the Park

5. Inhabited infrastructure

6. Open-Ended Urban Framework

Summarized at the end of each category of proposals is the context within which they occurred, the urban design strategy, influence it had on the built environment, and critical analysis of the overall ideas.

Apart from the Urban Retreat category, each of the above groups of Visionary Urbanism proposals could arguably be defined as "megastructures." There are varied opinions on what classifies as a megastructure. Through varied definitions by various authors, it has come to represent a broad array of built projects and visionary proposals. The term "megastructure" has thus been avoided to allow for a more specific categorization of visionary urbanism concepts.

\section{Urban Retreat}

ARTHURO SORIA Y MATA: LINEAR CITY (MADRID, SPAIN, 1882-1892 )

Beginning in 1882, Spanish urban planner, Athuro Soria y Mata, developed plans for linear towns (Figure 1.4.2) that were intended to radiate outward from cities into a network that would extend over all of Spain. Soria y Mata proposed the development of

$3 \quad$ Curtis, William J. R. Modern Architecture since 1900. 3rd ed., [Rev., expanded, and redesigned]. P. 243 London: Phaidon, 1996. Boileau, Ivan. "La Ciudad Lineal: A Critical Study of the Linear Suburb of Madrid. 230." The Town Planning Review 30, no. 3 p. 230 (1959): 230-38. 


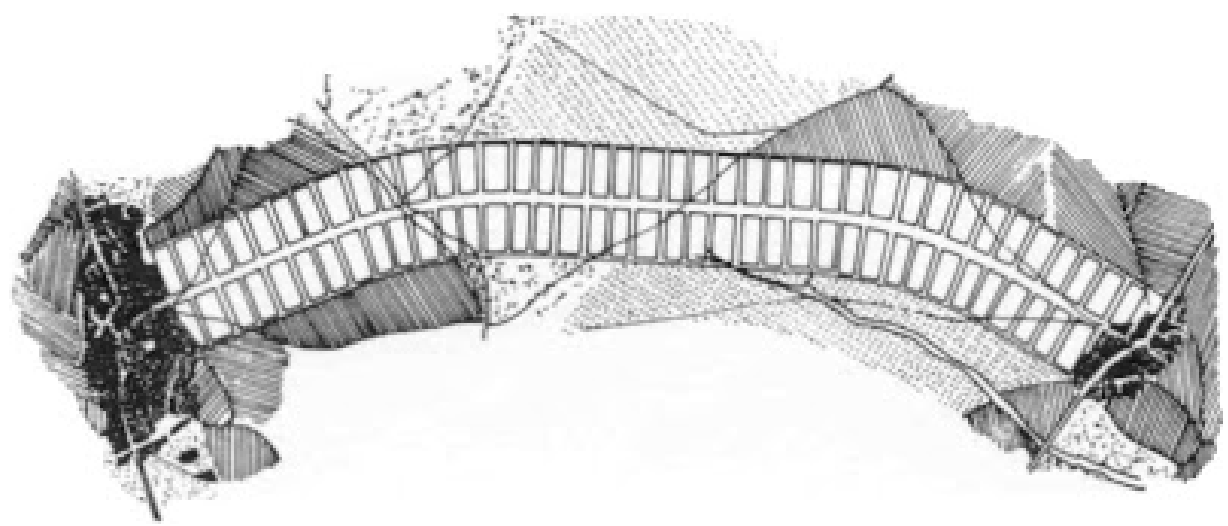

Figure 1.4.2: Arthuro Soria y Mata: Linear City Plan, 1882

Arthuro Soria y Mata: Linear City http://urbanismo-1.blogspot.com/2008/02/ciudad-lineal.html

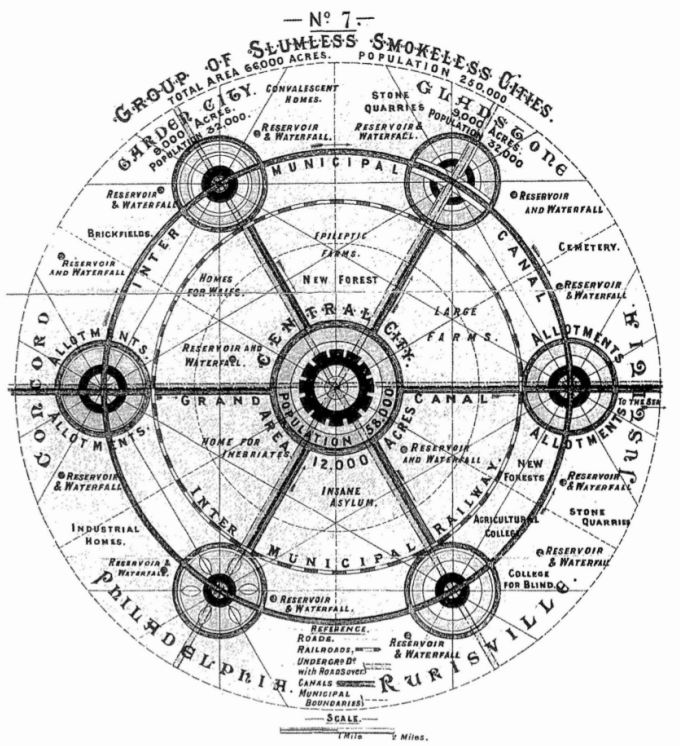

Figure 1.4.3: Ebenezer Howard: Garden City Diagram, 1898

Ebenezer Howard's Garden City Diagram https://scodpub.wordpress.com/2011/03/01/gardencities-byebenezer-howard/

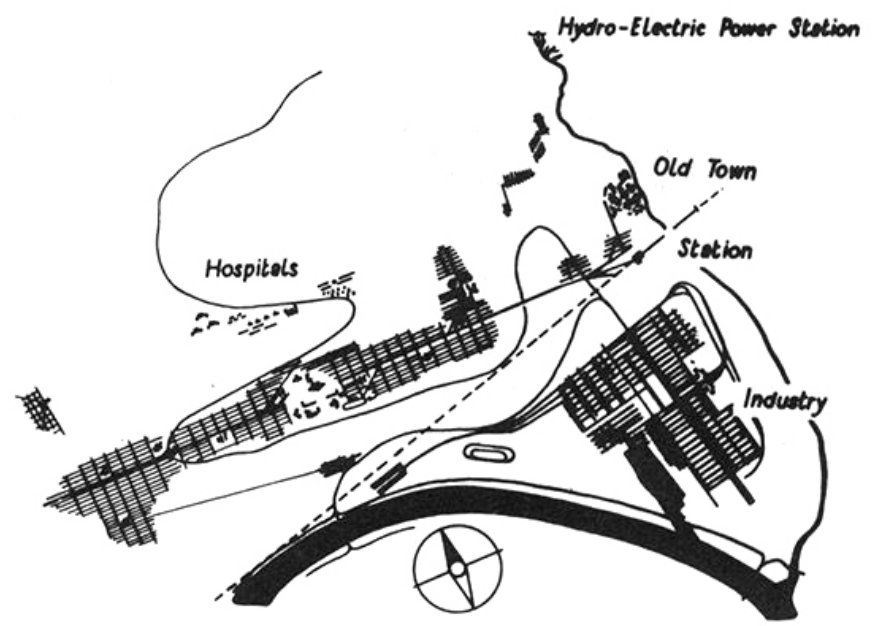

Figure 1.4.4: Tony Garnier: Cité Industrielle Plan, 1904

Tony Garnier: Cité Industrielle Plan,1904 http://architectureandurbanism.blogspot.com/2010/11/ tony-garnierune-cite-industrielle-1917.html 
land along a broad central spine that would have a road and railway/ tramway at the centre and would carry water, gas, and electrical services below ${ }^{4}$. In his plans, Soria y Mata intended for the land directly adjacent to the main spine to be occupied by widely spaced single-family detached houses ${ }^{5}$. The development was intended to be concentrated along the adjacent plots leaving the remaining land for agricultural production'.

\section{EBENEZER HOWARD: GARDEN CITY (LONDON, ENGLAND, 1898)}

In 1998 British planner Ebenezer Howard published The Garden Cities of Tomorrow in which he developed plans for a live-work "city" scattered amongst the countryside (Figure 1.4.3) separated from the city by green belts ${ }^{8}$. This "Garden City" was intended to offer all the benefits of the industrial city in a rural setting, which included jobs with high wages, attractions, and what Howard referred to as "society". To ensure the Garden City would never evolve into an industrial city, he set regulations that capped the population of each garden city at 30,000 inhabitants ${ }^{10}$. In his Garden City plan, Howard subdivided and parcelled land by function planning out specific" preserves" for industry, housing, commerce, agriculture, cultural centers, etc" ${ }^{11}$.

TONY GARNIER: CITÉ INDUSTRIELLE (FRANCE, 1904)

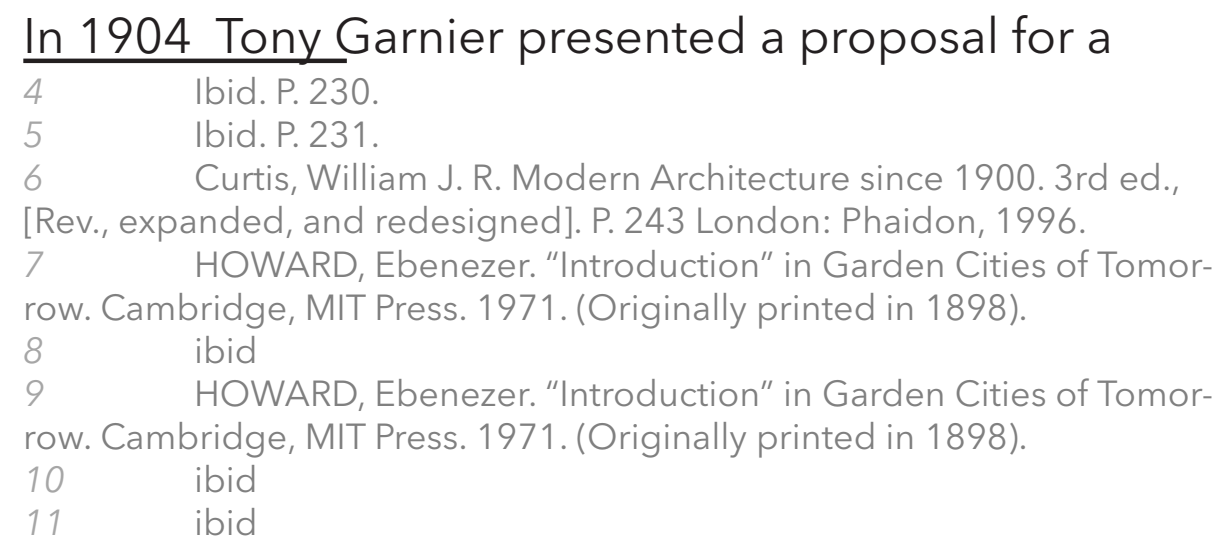


35,000 person city on an idealized site organized around the idea of separating the functions of the city ${ }^{12}$ (Figure 1.4.4). His ideas were developed between 1901 and 1917 when finally published ${ }^{13}$. In this city plan, he attempted to coordinate all social, productive, and transportation functions ${ }^{14}$. Housing consisted of family villas on tree-lined suburbanstyle streets as well as some rectangular flat-roofed apartments ${ }^{15}$. The Industrial part of the city focused around metalogical plants ${ }^{16}$. Key to the project was the attempt to create hygienic living quarters by creating a clear separation of the residential and industrial halves of the city using a green corridor that was bridged via railway ${ }^{17}$.

\section{SUMMARY}

The Urban Retreat Urbanism proposals presented in this section were reactionary to the living conditions of the industrial cities at the turn of the century. These proposals were intended to offer an escape from the growing intensification and unhygienic conditions of the industrial city through a retreat into the countryside. They proposed horizontally spread low-density living alternatives that largely favoured the single-family home. In order to ensure these areas would not evolve into industrial cities themselves, proposals were accompanied by rules and regulations intended to prevent future densification.

\footnotetext{
Graham, Wade. Dream Cities: Seven Urban Ideas That Shape the World,p. 85 Harper Collins Publishers, 2017.

Curtis, William J. R. Modern Architecture since 1900. 3rd ed., [Rev., expanded, and redesigned]. P.243-244London: Phaidon, 1996.

13 . Curtis, William J. R. Modern Architecture since 1900. 3rd ed., [Rev., expanded, and redesigned]. P.243-244London: Phaidon, 1996.

14 ibid

15 ibid

16 Cité de L'architecture et du Patrimoine. "Une Cite Industrielle:

Tony Garnier- Projet Urbanistique, 1899-1917," September 2017, 7.

17 .Curtis, William J. R. Modern Architecture since 1900. 3rd ed.,

[Rev., expanded, and redesigned]. P.243-244London: Phaidon, 1996.

Cité de L'architecture et du Patrimoine. "Une Cite Industrielle: Tony Garnier- Projet Urbanistique, 1899-1917," September 2017, 7.
} 


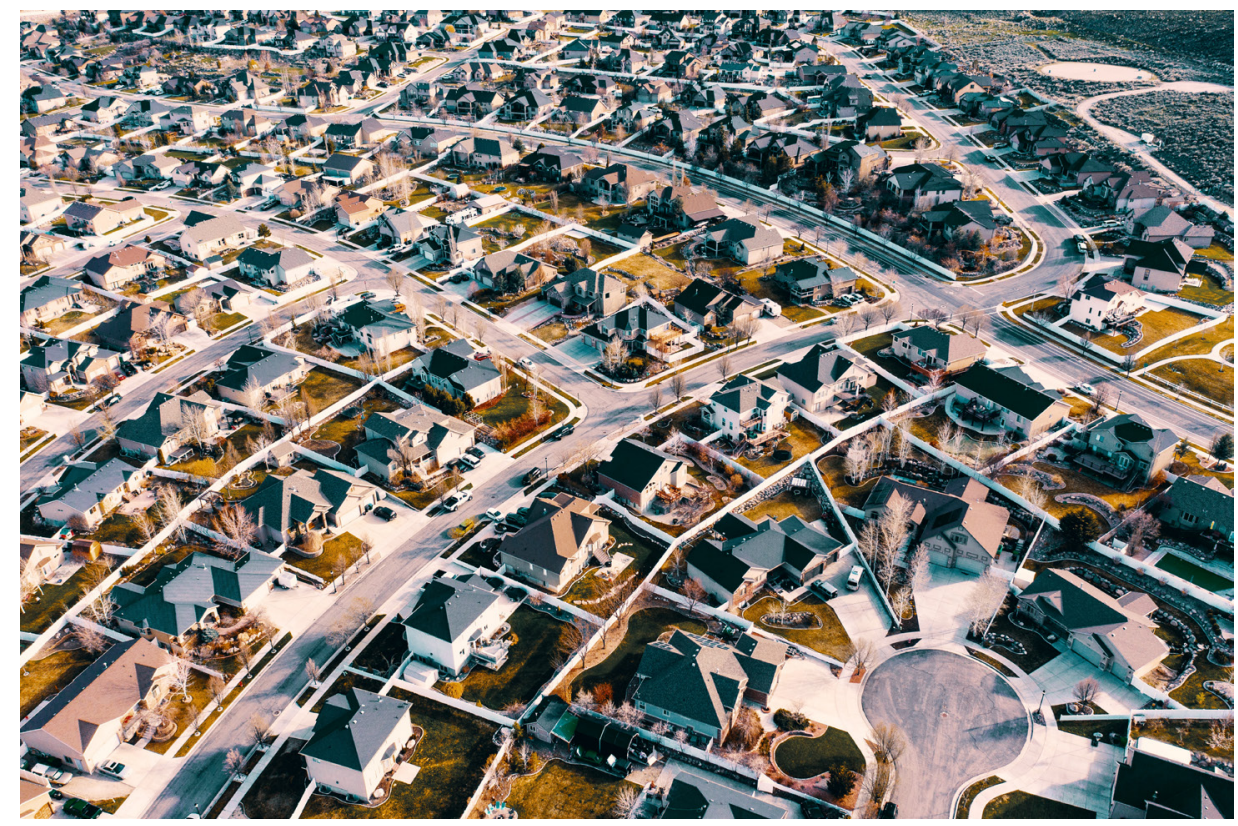

Figure 1.4.5: The American Suburb

Tuszynski, Micheal. "5508 Moming LightDr, Hemiman, UT84096, USA, United States." Unsplash,April 13, 2019. https:// unsplash.com/photos/2osRMIJLdbU.

While not the initial intention, these proposals evolved into suburban-style development (Figure 1.4.5) which today, has consumed much of the land around most urban areas, especially in North America. Its appeal has stemmed from the perceived separateness, individuality, and freedom offered by the suburban lifestyle ${ }^{18}$. These characteristics inspired Frank Lloyd Wright's own Visionary Urbanism proposal Broadacre City in 1932, which helped promote the suburban lifestyle as the American ideal ${ }^{19}$.

The retreat from the city into a low-density suburban sprawl requires an ever-increasing consumption of land, infrastructure, and fuel resources ${ }^{20}$. As a result, suburban sprawl is becoming increasingly unsustainable. Suburban sprawl is also socially

\footnotetext{
18 Bingham-Hall, Patrick. Garden City Mega City: Rethinking Cities for the Age of Global Warming. P.47 Singapore: Pesaro Publishing, 2016. 19 Graham, Wade. "Homesteads" in Dream Cities: Seven Urban Ideas That Shape the World,p. 115-151 Harper Collins Publishers, 2017. Bingham-Hall, Patrick. Garden City Mega City: Rethinking Cities for the Age of Global Warming. P.47 Singapore: Pesaro Publishing, 2016. 20 Bingham-Hall, Patrick. Garden City Mega City: Rethinking Cities for the Age of Global Warming. P.47 Singapore: Pesaro Publishing, 2016.
} 


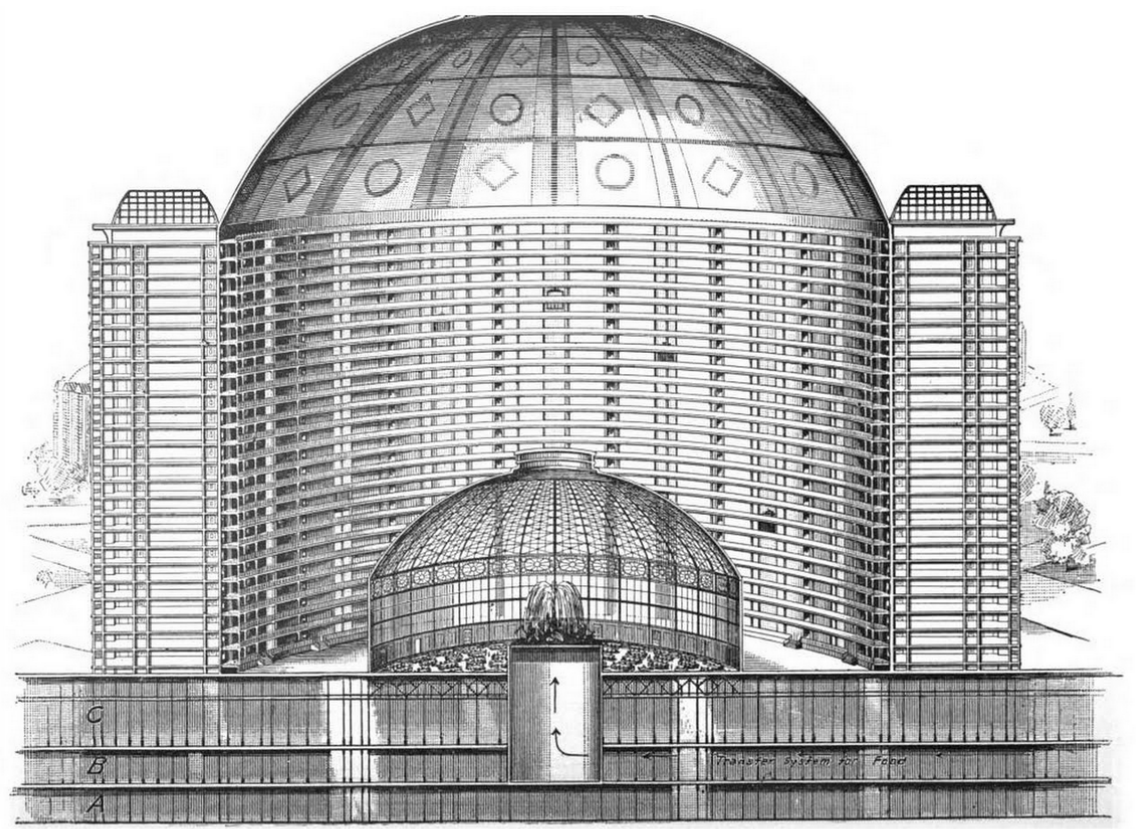

PLATE $V I$.

Figure 1.4.6: King Champ Gillette: The Human Drift, 1894

King Champ Gillette, The Human Drift, 1894, https://beltmag.com/ utopia-niagara-falls-gillette-

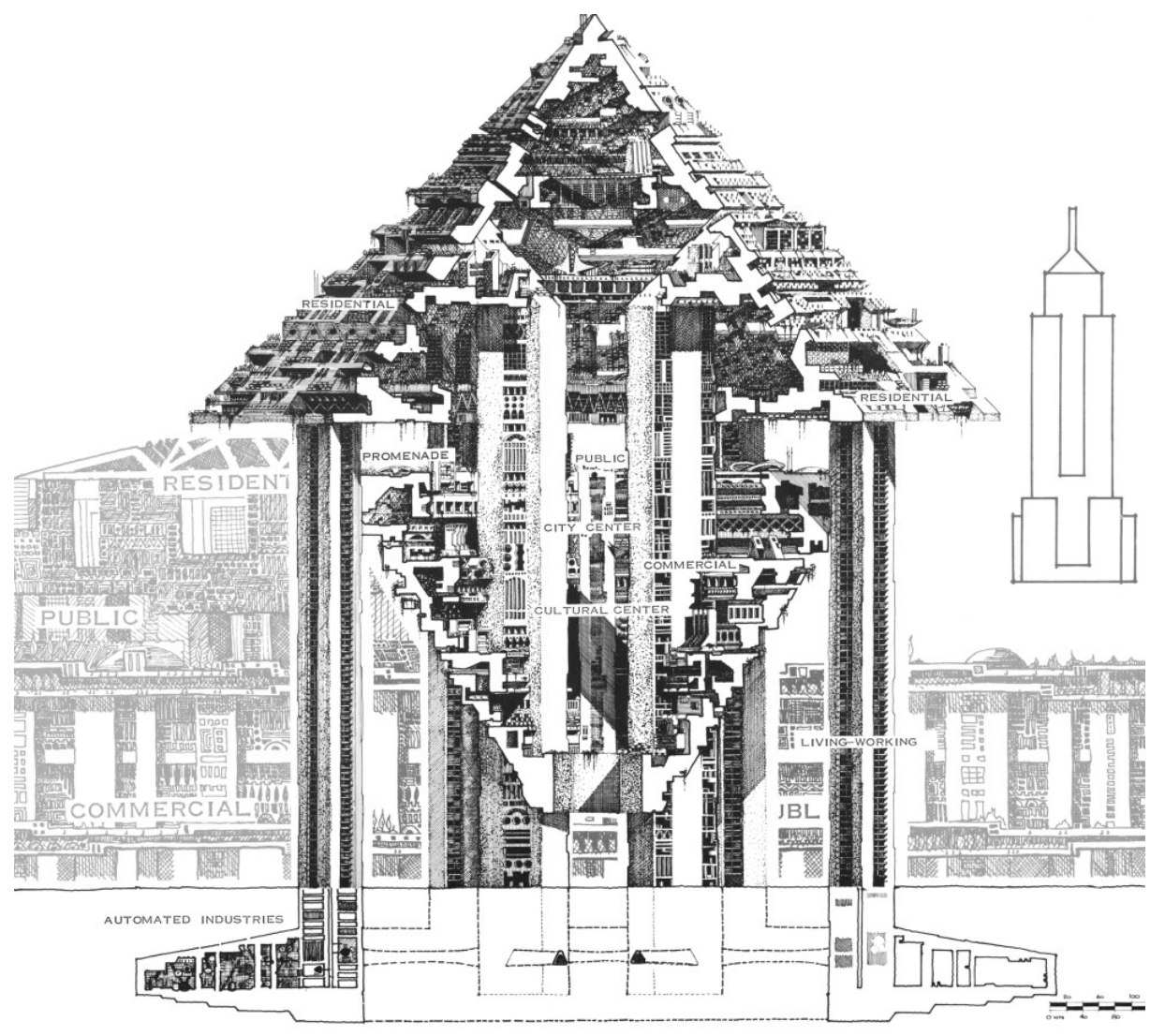

Figure 1.4.7: Paolo Soleri: Arcology ,1969

Paolo Soleri: Arcology,1969 https:// curiator.com/art/paolo-soleri/hexahedron-arcology 
isolating and intentionally lacks urbanity as living, working, shopping, exercising, gathering, and other aspects of life are typically carefully separated destinations. In addition, the increasingly selfsufficient nature of suburbs has been detrimental to cities as it undermines their economic structure, which can eventually lead to their demise ${ }^{21}$.

\section{Mass Centralization}

KING CHAMP GILLETTE: THE HUMAN DRIFT (GREAT LAKES REGION, USA, 1894)

In 1894, American inventor King Champ Gillette published a book The Human Drift in which he proposed a mass reformation of society into a centralized megacity, located along the Niagara River and powered by Niagara Falls ${ }^{22}$. Gillette intended for the city to house 60 million of the 70 million people living in America at the time ${ }^{23}$. People were to be housed in 24,000 gear-shaped, kitchen-less apartment buildings $600 \mathrm{ft}$ in diameter organized around a central $450 \mathrm{ft}$ atrium dining hall where they were to eat all their meals ${ }^{24}$ (Figure1.4.6). The city was intended to sit on three layers of artificially replicated ground plane through which transportation and the distribution of goods, utilities, and food were to occur ${ }^{25}$. Gillette's proposal epitomizes an extreme faith in the power of standardization and mass production, which was not uncommon in America at the end of the $19^{\text {th }}$ century.

\section{PAOLO SOLERI: ARCOLOGY (ARIZONA, USA, 1969)}

21 Jacobs, Jane. The Death and Life of Great American Cities. p.21. Vintage Books ed. New York: Vintage Books, 1992.

22 Gillette, King Champ. "Metropolis." In The Human Drift, p. 87-89.

Boston: New Era Publishing Company, 1894. Reprint Delmar, New York:

Scholars Facsimiles \& reprints Inc. 1976) http://urbanplanning.library. cornell.edu/DOCS/gillette.htm. (88-112)

23 Ibid. p. 89.

24 Ibid. p.89-90.

$25 \quad$ Ibid.p.93 
In 1969 American architect Paolo Soleri, who had been an apprentice of Frank Lloyd Wright in Taliesin, published the book Arcology: The City in the Image of Man, where he presents his ideas for 30 self-sufficient live-work city complexes ${ }^{26}$ (Figure 1.4.7). Focused on an extreme intensified use of the land, each "Arcology" was set in a different context, including floating at sea, burrowed into the ground, centralized on farmland, in a cold northern region, along a cliff, and even in space. Each urban complex features the typical components of a city: residential, commercial, cultural centres, city centers, public parks, promenades, and airports, parcelled and separated by function, and organized and overlapping in a three-dimensional volume. In his designs, Soleri makes a conscious attempt to eliminate the need for significant horizontal transportation ${ }^{27}$. Soleri's proposal is reflective of an extreme adaptation of the ideas of the environmentalist movement that was occurring in America in the1960's.

\section{SUMMARY}

Both Mass Centralization proposals illustrated in this section are extreme examples of future city concepts reflective of the innovation and political movements that were occurring at the time. The goal was to centralize the population into single structures or groups of structures while freeing up the surrounding land for agriculture and nature reserves. They proposed a radical restructuring of all facets of society. The singular designers employ a rigidly designed built environment that imposed their own ideological, social structure.

Mass Centralization proposals have had little

26 Soleri, Paolo. Arcology: The City in the Image of Man. 1. MIT

Press paperback ed. MIT . Cambridge, Mass.: MIT Pr, 1973.. Ibid.

27 Soleri, Paolo. Arcology: The City in the Image of Man. 1. P. 15

MIT Press paperback ed. MIT . Cambridge, Mass.: MIT Pr, 1973.. 


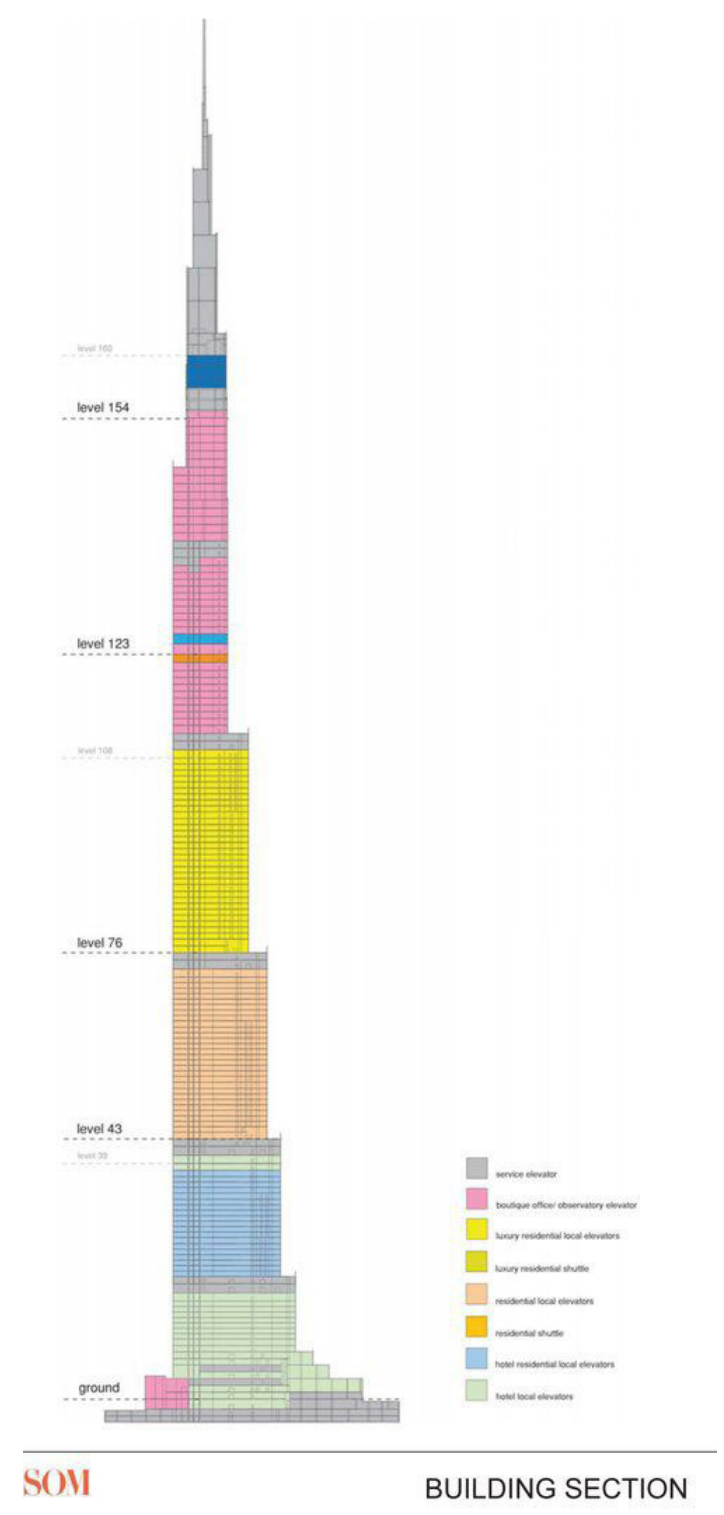

Figure 1.4.8: Burj Kalifah. The concept of the mixed use supertall could be viewed as a restrained application of Mass Centralization SOM. "Gallery of Burj Khalifa / SOM - 48." Arch Daily, October 23, 2017. https://www.archdaily. com/882100/burj-khalifa-som/59eb88c2b22e38dd0500014e-burj-khalifa-som-diagram.

influence on the built environment. The extreme nature of the proposals, the resources, and organization required, and the disruption of social systems has ensured that mass centralization has remained fictional. These proposals also lacked a plan for a transition from existing cities to the mass centralization of urban populations. 


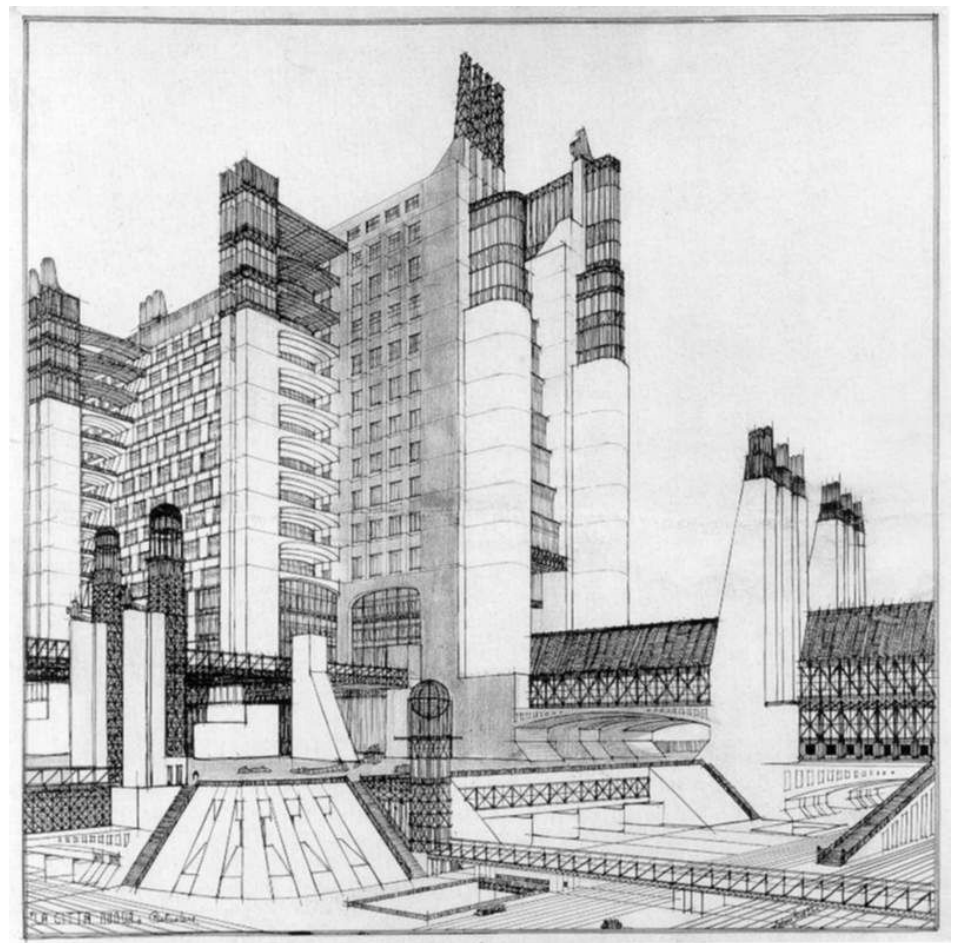

Figure 1.4.9: Antonio Sant'Elia: Cité Nuova,1914

Antonio Sant'Elia: Cité Nuova,1914 https://www.guggenheim.org/artscurriculum/topic/

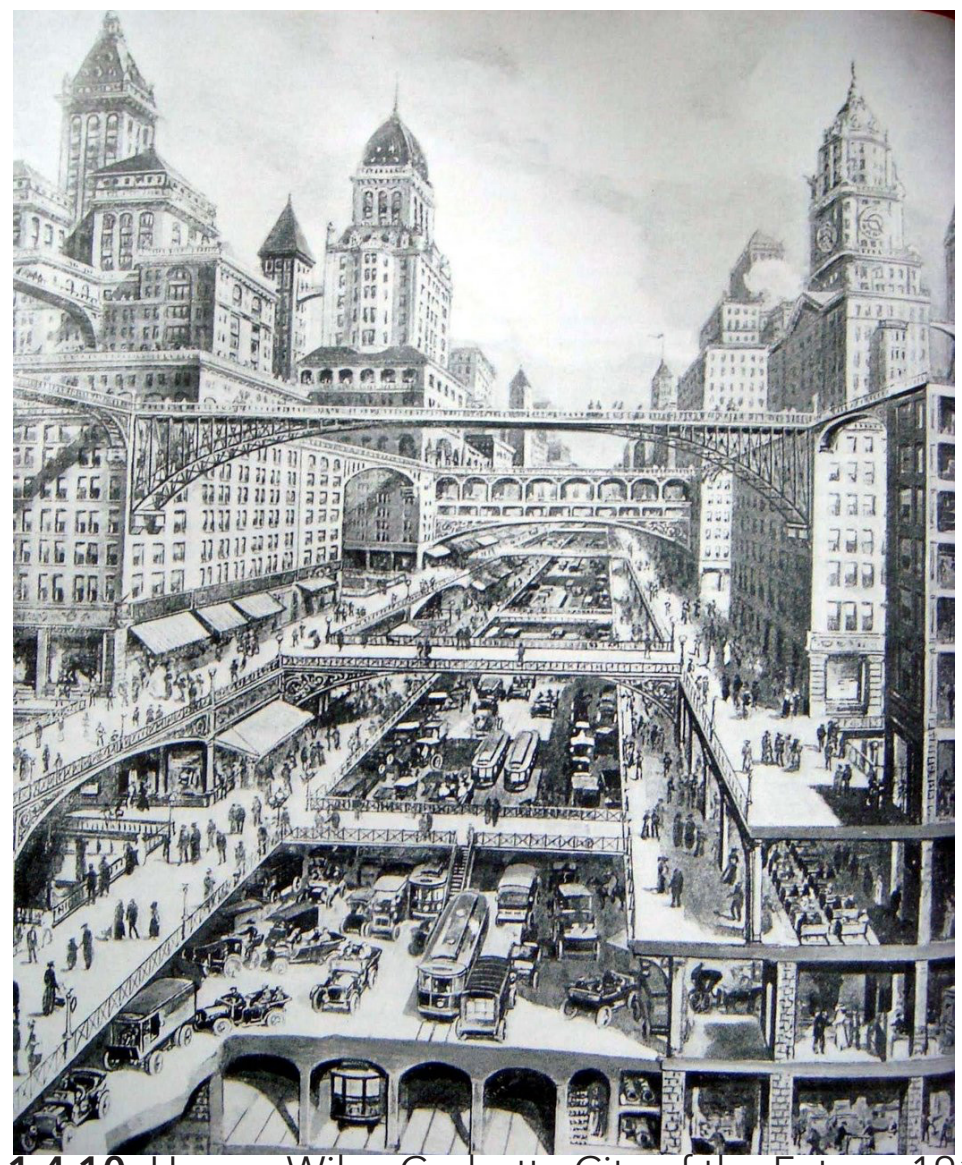

Figure 1.4.10: Harvey Wiley Corbett : City of the Future, 1913

Corbett :City of the Future, 1913 https://www.arretsurimages.net/articles/la-nostalgie-du-futur- 
The recent emergence of numerous proposals for amenity-filled supertall towers, however, could be viewed as a more restrained application of this thinking. Mixed-use supertalls like the Burj Khalifa (Figure1.4.8), along with more extreme proposals, are designed with enough living, working, shopping, and amenities spaces to make the tower operate as its own city ${ }^{28}$.

\section{Multiple Grounds}

\section{ANTONIO SANT'ELIA: CITÉ NUOVA (MILAN, ITALY, 1914)}

In 1914 Italian architect Antonio Sant'Elia published Citta Nuova as well as the Manifesto of Futurist Architecture ${ }^{29}$. In these publications, he urged for a new approach to the design of the city that called into question the replication of existing urban forms in favour of an approach that would take full advantage of all the advances going on in science, engineering, and technology ${ }^{30}$. In the manifesto, Santa Elia proclaimed, "the street will no longer lie dormant at ground level but will plunge many stories down into the earth embracing the metropolitan traffic and will be linked up for necessary interconnections by metal gangways and swift-moving pavements. ${ }^{{ }^{31}}$. His concept is depicted 28 Ascher, Kate, and Rob Vroman. "The Future: How Will We live" in The Heights: Anatomy of a Skyscraper. P. 184 New York, NY: Penguin Books, 2013.

29 am, Stephen. Vertical: The City from Satellites to Bunkers.p. 220-

221 London; New York: Verso, 2016.

Heccrujes. "Manifesto of Futurist Architecture." EVOLUTIONARY URBANISM (blog), February 28, 2017. https://evolutionaryurbanism. com/2017/02/28/manifesto-of-futurist-architecture/.

30 Graham, Stephen. Vertical: The City from Satellites to Bunkers.p. 220-221 London; New York: Verso, 2016.

Heccrujes. "Manifesto of Futurist Architecture." EVOLUTIONARY URBANISM (blog), February 28, 2017. https://evolutionaryurbanism. com/2017/02/28/manifesto-of-futurist-architecture/.

31 Sant'Elia, Antonio. "Manifesto of Futurist Architecture." Milan, July 11, 1914. https://www.abc.net.au/cm/lb/4285602/data/manifesto-of-futurist-architecture-data.pdf. 
through a series of low angle perspectival renderings that feature monumental buildings set within a larger envisioned metropolis ${ }^{32}$ (Figure 1.4. 9). The buildings are tall concrete, glass, and iron structures, interlinked throughout their height by metal walkways and high-speed escalators that all hover over a sea of high-speed transportation ${ }^{33}$. Other drawings show similar buildings bisected by layers of trains, roads, pedestrian bridges, and platforms ${ }^{34}$.

Sant'Elia's drawings are provocative in how they suggest a new urban organization, yet open to interpretation as they never depict the larger metropolis. His work primarily focused on the infrastructure inspired aesthetic treatment of these proposed urban forms ${ }^{35}$.

\section{HARVEY WILEY CORBETT: CITY OF THE FUTURE (NEW YORK CITY, USA, 1910-1928)}

In 1910, The New York Tribune published a rendering of a conceptual New York City of the future (Figure1.4.10) featuring layers of traffic, multiple layers of pedestrian paths intersected and bridged between stone-clad skyscrapers climbing high into the sky ${ }^{36}$. This rendering was based on and

\footnotetext{
32 Sant'Elia, Antonio, Luciano Caramel, and Alberto Longatti. Antonio Sant'Elia, the Complete Works. New York: Rizzoli, 1988.

33 Graham, Stephen. Vertical: The City from Satellites to Bunkers.p. 220-221 London; New York: Verso, 2016.

$34 \quad$ Ibid. P.264-270

35 Sant'Elia, Antonio, Luciano Caramel, and Alberto Longatti. Antonio Sant'Elia, the Complete Works. P. 22 New York: Rizzoli, 1988.

36 Two similar artists drawings of a New York by with dramatic layered circulation predate that of Corbett. In 1908 Harry Pettit's drawing for Moses King's King's Views of New York Guidebook featured an extremely dense New York skyscrapers bisected by pedestrian bridges on multiple levels, elaborate outdoor rooftop spaces, all under a sky of airships. Also in 1908 William Robison Leigh Drew "Visionary City" for the cosmopolitan magazine article by Hudson Maxim. It featured an even more vertically exaggerated New York (so much so that the ground is no longer visible) bisected at various levels by bridges with trains, cars and pedestrians and also featuring elaborate outdoor spaces throughout the heights of the buildings. In 1911 Moses King would publish a third drawing on the sub-
} 
accompanied by an article by American architect Harvey Wiley Corbett in which he proposed an approach to the urban design of the future city. Corbett insisted on the urgency for planning the city for the increased people and traffic in the future ${ }^{37}$ and argued that the proportion of street and sidewalk facilities would need to keep pace with the vertical growth of the city ${ }^{38}$. He was concerned with the congestion in Manhattan and developed a proposal intended to increase the travel speed of traffic through the city ${ }^{39}$. Corbett advocated for the vertical separation of the functions of the city, especially the various modes of transportation, which he separated into four layers. The bottom layer would feature electric trains, the second fast motor traffic and parking, the third slow motor traffic and the lower level of shops. The fourth layer would be open to pedestrians and the sky above ${ }^{40}$. Above the

\footnotetext{
ject by Richard Rummell featuring the same basic subject mater as Harry Pettit's 1908 drawing.

Koolhaas, Rem. Delirious New York: A Retroactive Manifesto for Manhattan. P.84New ed. New York: Monacelli Press, 1994.

Willis, Carol. "The Skyscraper Museum: Future City: New York Modern." The Skyscrapper Museum, 2007. https://www.skyscraper.org/EXHIBITIONS/FUTURE_CITY/NEW_YORK_MODERN/walkthrough_1900.php. Wood, Antony, and Daniel Safarik. "Skybridges: A History and a View to the Near Future." Council on Tall Building and Urban Habitat 8, no. 1 (March 1, 2019): 1-18. https://doi.org/10.21022/IJHRB.2019.8.1.1. Sant'Elia, Antonio, Luciano Caramel, and Alberto Longatti. Antonio Sant'Elia, the Complete Works. p.28 New York: Rizzoli, 1988.

Urbanefreakde. "URBAN GEOGRAPHIES: Cities / Places / Regions." URBAN GEOGRAPHIES: Cities / Places / Regions. Accessed August 11, 2019. https://urbangeographies.tumb|r.com/post/127713040662/urbanfreakde-urbain-visionary-city-of-new.

$37 \quad$ N.A. "The Wonder City You May Live to See: Harvey Wiley Corbett." Popular Science Monthly, August 1925. Retireved from Jariego, Paco. "The Wonder City You May Live to See." Mind the Post (blog), August 19, 2015. https://pacojariego.me/2015/08/19/the-wonder-city-you-maylive-to-see/.

38 "Mr. Corbett's Future City." New York Times. 1929. Retrieved from http://ezproxy.lib.ryerson.ca

39 Oxford University Press. "Corbett, Harvey Wiley | Grove Art." Grove Art Online, 2003. https://www.oxfordartonline.com/view/10.1093/ gao/9781884446054.001.0001/oao-9781884446054-e-7000019422. $40 \quad$ Ibid.
} 
pedestrian level, tall buildings would extend into the sky with space for restaurants, offices, schools, living quarters and elevated parks topped off by rooftop aircraft landing fields ${ }^{41}$. The elevated parks make use of a continuous ten-story setback that would have been imposed by new zoning laws after $1916^{42}$.

Corbett's concepts for a future city would appear in numerous articles and publications throughout the next two decades ${ }^{43}$. Corbett's work was never presented as a complete city design but rather as an urban design approach.

\section{SUMMARY}

The Multiple Ground Urbanism proposals shown here were occurring at a time in which the vertical growth of cities was in its infancy. The unprecedented heights of skyscrapers that suddenly appeared in Chicago and New York would have seemed unimaginable just a few decades earlier. The rapid growth of skyscrapers offered an optimistic outlook on how vertical growth in cities would evolve in decades to come ${ }^{44}$.

$41 \quad$ N.A. "The Wonder City You May Live to See: Harvey Wiley Corbett." Popular Science Monthly, August 1925. Retireved from Jariego, Paco. "The Wonder City You May Live to See." Mind the Post (blog), August 19, 2015. https://pacojariego.me/2015/08/19/the-wonder-city-you-maylive-to-see/.

$42 \quad$ Ibid.

Koolhaas, Rem. Delirious New York: A Retroactive Manifesto for Manhattan. P.112 New ed. New York: Monacelli Press, 1994.

43 According to Jean Louis Cohen the rendering inspired the work of Santa'Elia

Cohen, Jean-Louis. "The Chalenge of the Metropolis": in The Future of Architecture, since 1889. P. 077 London; New York: Phaidon, 2012. Sant'Elia, Antonio, Luciano Caramel, and Alberto Longatti. Antonio Sant'Elia, the Complete Works. P.28. New York: Rizzoli, 1988 N.A. "The Wonder City You May Live to See: Harvey Wiley Corbett." Popular Science Monthly, August 1925. Retireved from Jariego, Paco. "The Wonder City You May Live to See." Mind the Post (blog), August 19, 2015. https://pacojariego.me/2015/08/19/the-wonder-city-you-may-live-toseel.

$44 \quad$ N.A. "The Wonder City You May Live to See: Harvey Wiley Corbett." Popular Science Monthly, August 1925. Retireved from Jariego, 
These proposals attempted to multiply the ground plane of the city into a network of vertically stacked interconnected planes. They emphasize improving the flow of people and goods through the city through a separation of city functions onto distinctive layers. One strength of these proposals was that they did not attempt to provide a full solution or design the entire city. Instead, suggestive drawings and perspectives of certain instances exposed the architectural and urbanistic potential of a vertically layered city.

Only some aspects of Multiple Ground Urbanism have influenced the built environment. Apart from Hong Kong, most cities have not adopted widespread multimodal circulation networks throughout their height. What was adopted in a handful of cities in the post-WWII era was the vertical separation of the city functions and the implementation of secondary grade-separated pedestrian systems ${ }^{45}$.

The widespread adoption of the vertical separation of city functions served only to remove the overlap of private spaces, and the urban street life ${ }^{46}$. Private spaces were able to retreat into towers high above the public realm. Even in Hong Kong, which has an extensive, layered circulation network (Figure1.4.11) public circulation, does not significantly extend into the height of the city. Like elsewhere, the upper volume of the city remains occupied only by private spaces $^{47}$.

Paco. "The Wonder City You May Live to See." Mind the Post (blog), August 19, 2015. https://pacojariego.me/2015/08/19/the-wonder-city-you-maylive-to-see/.

45 Yoos, Jeniffer, and Vincent James. "The Multilevel Metropolis."

Places Journal, May 18, 2016. https://doi.org/10.22269/160518.

46 Yoos, Jeniffer, and Vincent James. "The Multilevel Metropolis."

Places Journal, May 18, 2016. https://doi.org/10.22269/160518

$47 \quad$ Frampton, Adam, Clara Wong, and Jonathan Solomon. Cities without Ground: A Hong Kong Guidebook. Rafael, Calif.: Oro editions, 2012. 


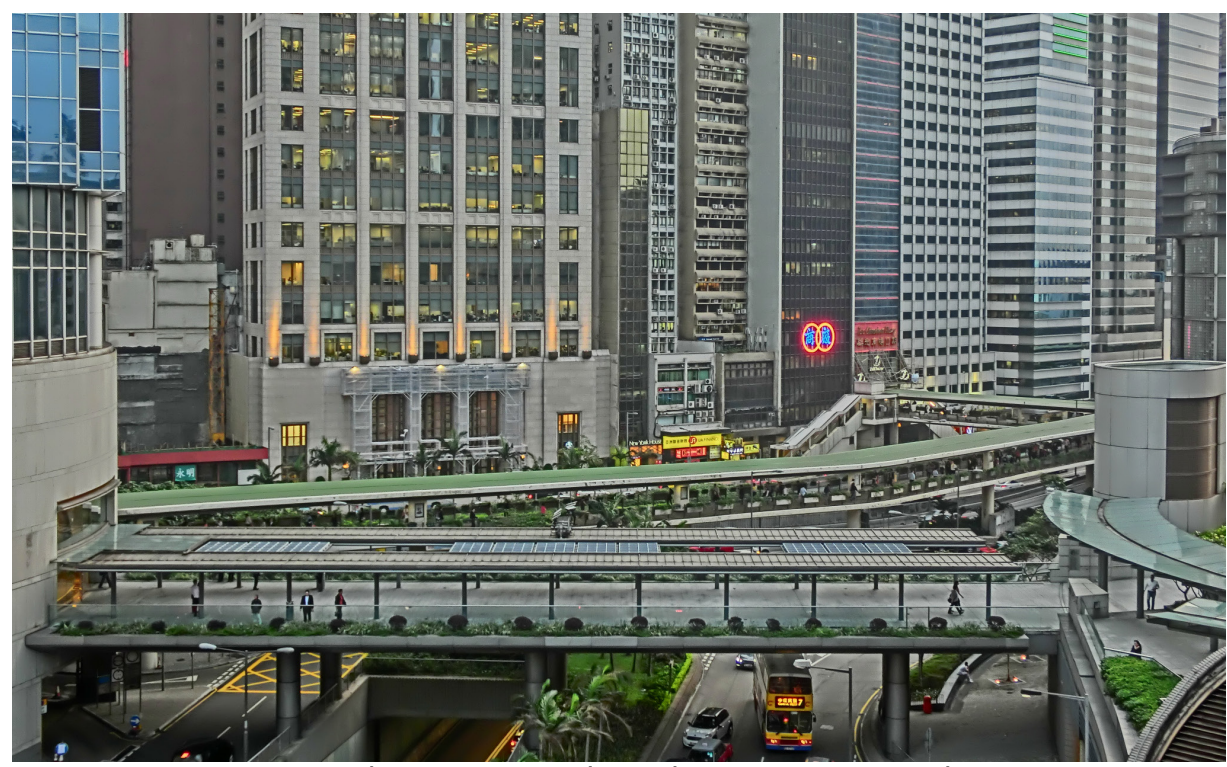

Figure 1.4.11: Grade separated pedestrian networks in Hong Kong

Yoos, Jeniffer, and Vincent James. "The Multilevel Metropolis." Places Journal, May 18, 2016. https://doi.org/10.22269/160518.

The grade-separated pedestrian systems adopted in North American cities like Toronto, Montreal, Calgary, St. Paul, and Minneapolis adopted a climatecontrolled network modelled after shopping malls ${ }^{48}$. Unlike city streets, these urban scaled networks were designed to be commercially profitable instead of comprehensive and easily navigable. In many of these cities, these commercially organized pedestrian paths undermine the street economy by offering a privileged alternative. Overlaying a second network in such close vertical proximity to the street forced them to compete for traffic flow. In most cases, the urban population of North American cities is insufficient to support both planes simultaneously.

Where pedestrian paths have managed to extend into the height of cities, they have done so only in the form of private amenity space (Figure1.4.12). There is an emerging trend for private towers to be linked together high above the ground by sky bridges and 48 Yoos, Jeniffer, and Vincent James. "The Multilevel Metropolis." Places Journal, May 18, 2016. https://doi.org/10.22269/160518. Graham, Stephen. "Skywalk, Sky Train/ Sky Deck" in Vertical: The City from Satellites to Bunkers. London; New York: Verso, 2016. 


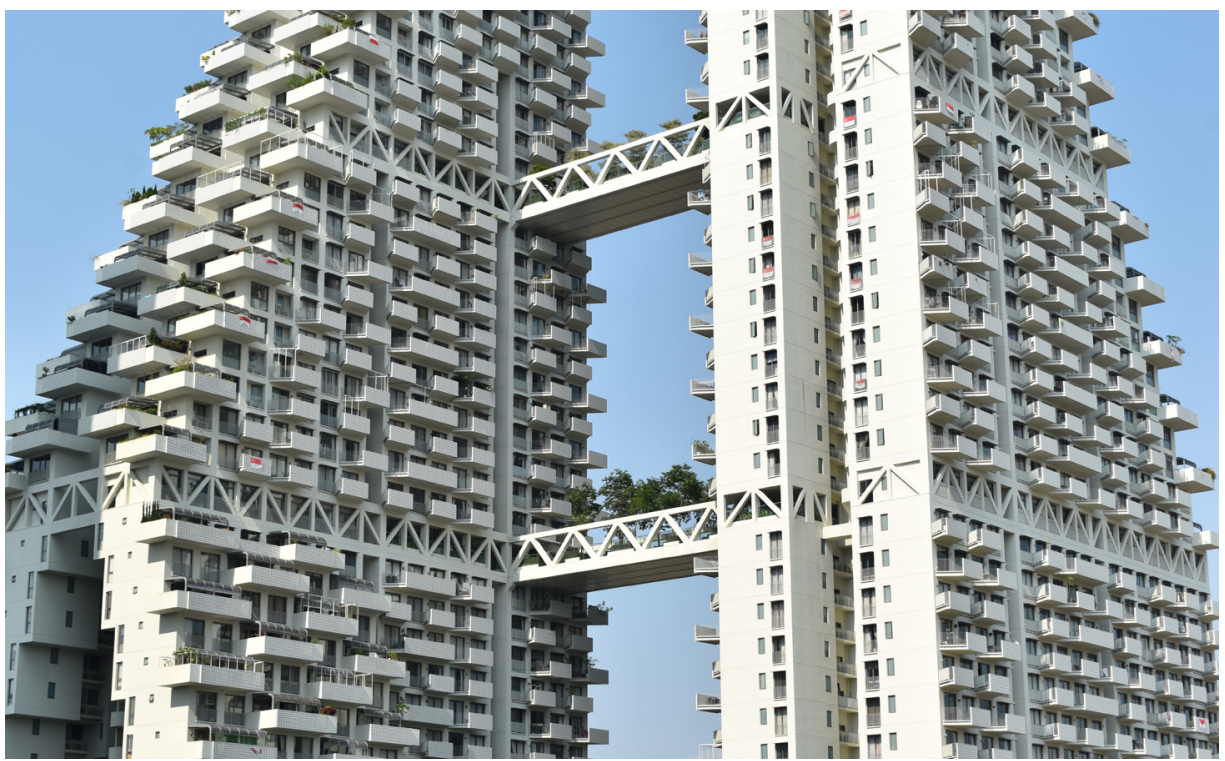

Figure 1.4.12: Sky Bridges as amenity space connecting two private residential towers at Sky Habitat, Singapore Caskey, Alex, "Sky Habitat', Singapore, Fall 2019

sky streets. Some of these spaces are even marketed as vertical public spaces, but they are only semipublic at best. As will be discussed in Section 2, fragmented and divorced from networks of public circulation, these "sky streets" are only public for the occupants of the towers with which they are linked ${ }^{49}$.

\section{Towers in the Park}

\section{RAYMOND HOOD: CITY OF NEEDLES (NEW YORK CITY, USA, 1924)}

In 1924 the New York Times published an article titled City of Needles by American architect Raymond Hood, where he presented his vision for an idealized metropolis (Figure1.4.13) in which the city is reduced to two components, towers, and the space in between ${ }^{50}$. His proposal featured supertall

\footnotetext{
49 Graham, Stephen. "Skywalk, Sky Train/ Sky Deck" in Vertical: The City from Satellites to Bunkers. P. 241. London; New York: Verso, 2016. $50 \quad$ Willis, Carrol. "The Skyscraper Museum: Future City: New York Modern: Raymond Hood." The Skyscraper Museum, October 2007. https://www.skyscraper.org/EXHIBITIONS/FUTURE_CITY/NEW_YORK_ MODERN/walkthrough_hood.php.
} 


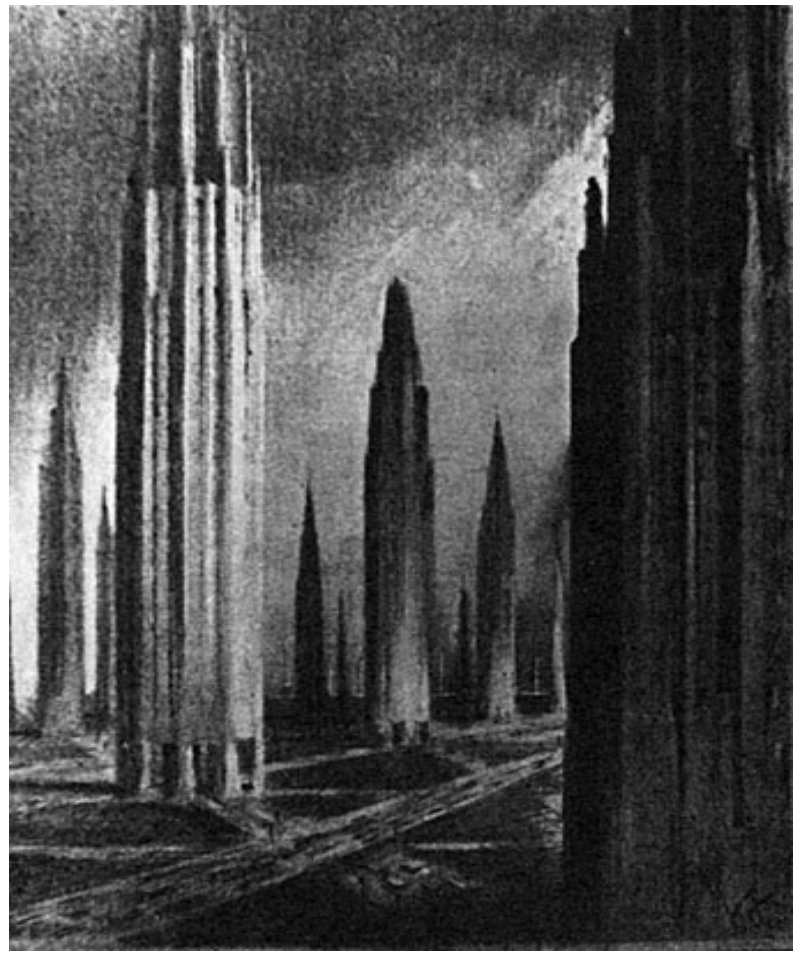

Figure 1.4.13: Raymond Hood, City of Needles, 1924 Raymond Hood, City of Needles, 1924 https://www.jstor.org/stable/990128?seq=1\#page_scan_ tab_contents

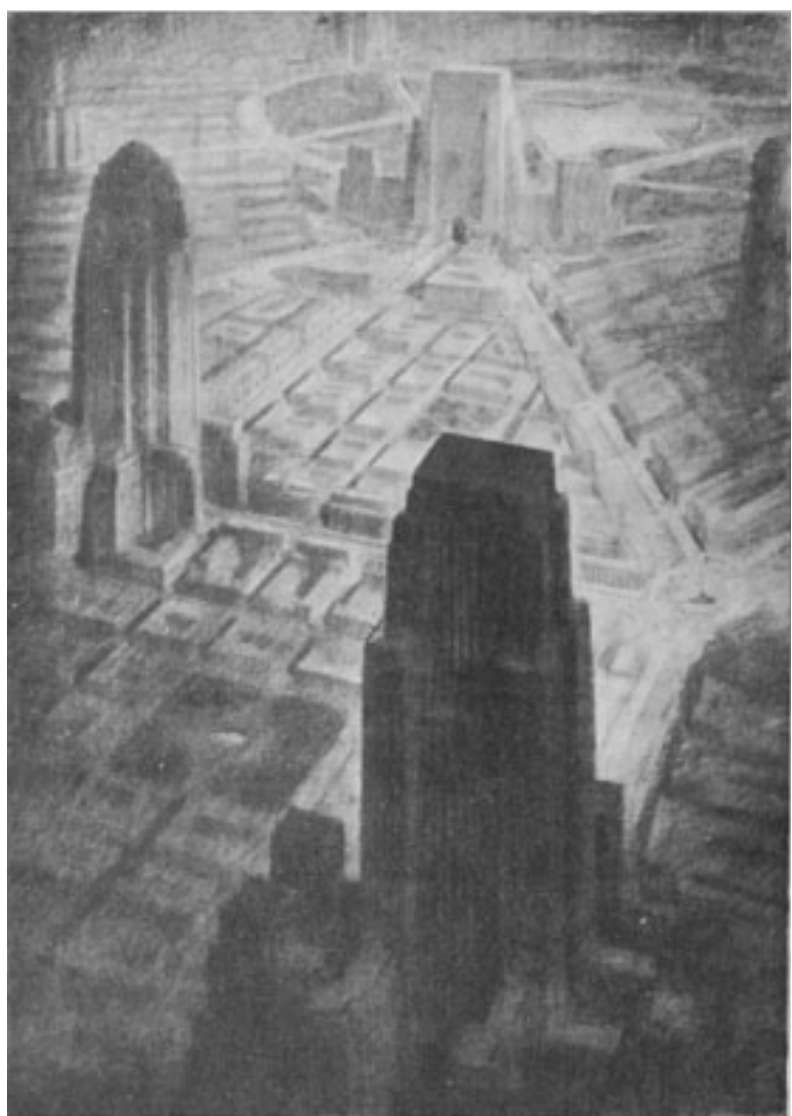

Figure 1.4.14: Hugh Ferris, Metropolis of Tomorrow, 1929 Hugh Ferris, The Metropolis of Tomorrow, 1929, http://www.johncoulthart.com/ 


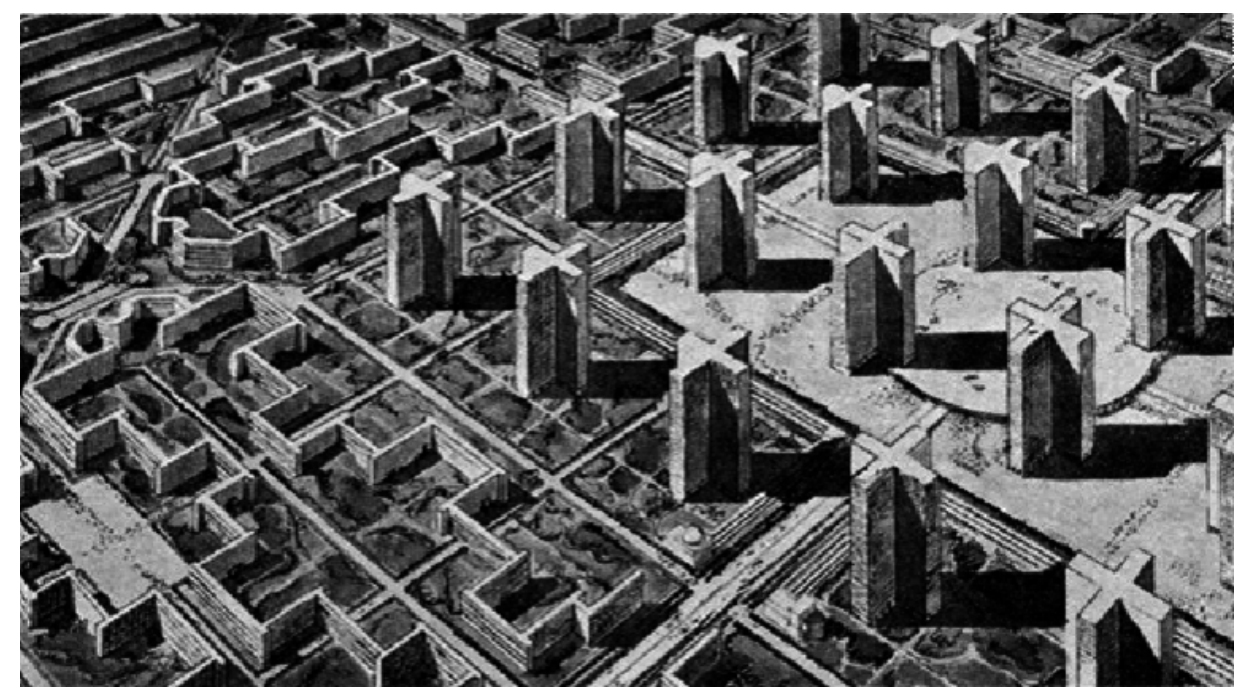

Figure1.4.15: Corbusier: Plan Voisin, 1922

Corbusier: Plan Voisin, 1922 https://www.researchgate.net/figure/Le-Corbusiers-Radiant-City-thecity-oftomorrow-1924-5-The-unrealizedutopian-project_fig5_300146541

needle-like towers spaced far from one another ${ }^{51}$. The ground in between was left for parks, parking and superhighways ${ }^{52}$. Hood would continue to promote and refine his proposal throughout the rest of the 1920 s even developing an implementable set of regulations for a needle city version of New York ${ }^{53}$. Hood proposed developers be incentivized with larger building heights for increase site setbacks, a rule that would eventually be incorporated into NYC's 1961 Zoning Laws ${ }^{54}$.

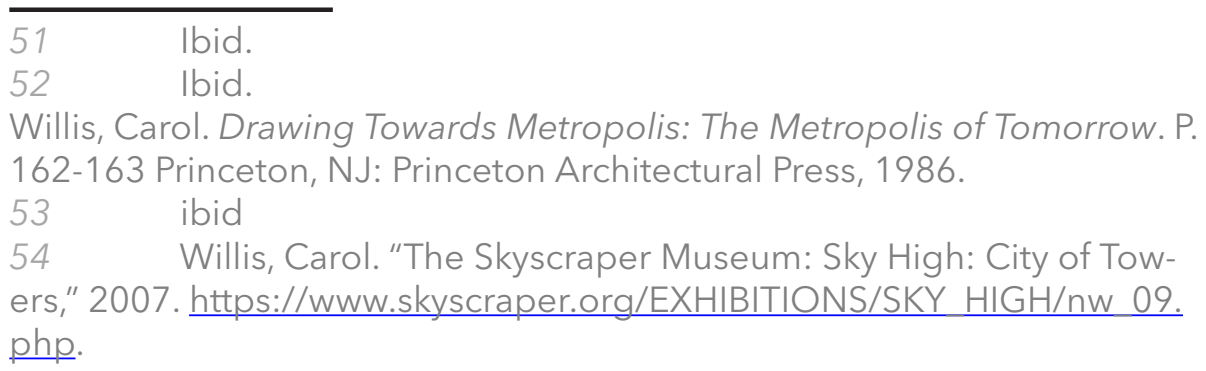


HUGH FERRIS: METROPOLIS OF TOMORROW (NEW YORK CITY, USA, 1929)

In 1929 a well-known delineator Hugh Ferris, who typically brought to life the visions of other architects, published the Metropolis of Tomorrow, where he presented an analysis of recently completed projects, emerging trends, and his own visionary urbanism concept ${ }^{55}$ (Figure1.4.14). Unlike in his accounts of the tightly clustered towers of New York City, Ferris's imaginary city featured many very tall towers with broad bases spread far apart from one another. Between towers, the city remained relatively dense with green-roofed low-rise buildings occasionally interrupted by a network of superhighways. The city itself was organized based on three primary functions, the arts, business, and the sciences, which were divided up along a series of orthogonal grids that radiated out from a central civic park/exhibition's grounds ${ }^{56}$.

\section{LE CORBUSIER: PLAN VOISIN / RADIANT CITY (PARIS,} FRANCE, 1922)

The most influential proposal of this category was presented in Europe prior to the work of both Ferris and Hood. In 1922 Corbusier exhibited his ideas for La Plan Voisin (Figure1.4.15), the city for three million inhabitants, a city plan scheme which he would attempt to "graft onto the city of Paris ${ }^{57}$. In his proposal, Corbusier separated the functions of the city into concentric zones. At the center of his proposed city stood 24 glass-clad, cruciformplanned towers spaced far apart from one another

$55 \quad$ Ibid.p.154

56 Ferriss, Hugh. "An imaginary Metropolis" in The Metropolis of

Tomorrow. P. 108-142. Princeton, NJ: Princeton Architectural Press, 1986 (1929). 
$(400 \mathrm{~m})$ to maximize light, air, views, and to protect the city from aerial attacks ${ }^{58}$. These were to contain offices, for the administration of the city, and for business ${ }^{59}$. Immediately outside the city centre, there were apartment buildings, 12 stories high, in the form of long walls orthogonally snaking on their plots of land ${ }^{60}$. Outside of these apartments were additional low-rise housing complexes grouped around inner courtyards. Beyond this outer belt was a larger protected greenbelt several miles thick and beyond this were the industrial zones of the city ${ }^{61}$. The buildings would cover just $5 \%$ of the land area in the business district and $12 \%$ in the residential district of the land, leaving the rest to parks ${ }^{62}$. In addition, Corbusier lifted the roads, utilities, and buildings onto "pilotis" as a way of leaving the "entire ground surface of the city to the pedestrian" ${ }^{63}$.

In Paris, Corbusier's scheme was not well received, so

58 Le Corbusier. The radiant city: elements of a doctrine of urbanism to be used as the basis of our machine-made civilization. P. 60-61 London: Faber, 1967

Ibid. P. 131

Blake, Peter. The Master Builders: Le Corbusier, Mies van Der Rohe, Frank Lloyd Wright. P.33-36The Norton Library. New York: Norton, 1996.

$59 \quad$ Ibid. P.33-36

60 Blake, Peter. The Master Builders: Le Corbusier, Mies van Der Rohe, Frank Lloyd Wright. P.33-36The Norton Library. New York: Norton, 1996.

61 Cohen, Jean-Louis. "Chapter Return to Order in Paris" in The

Future of Architecture, since 1889. P. 125-127 London ; New York: Phaidon, 2012.

Blake, Peter. The Master Builders: Le Corbusier, Mies van Der Rohe, Frank Lloyd Wright. P.33-36The Norton Library. New York: Norton, 1996.

62 Le Corbusier. The radiant city: elements of a doctrine of ur-

banism to be used as the basis of our machine-made civilization. P. 108

London: Faber, 1967.

Graham, Wade. "Chapter 3:Slabs" in Dream Cities: Seven Urban Ideas

That Shape the World, p. 83, 892017.

63 Le Corbusier. The radiant city: elements of a doctrine of urban-

ism to be used as the basis of our machine-made civilization. P. 98-103,

119-126 London: Faber, 1967.

Wolfe, Ross. "Le Corbusier's 'Contemporary City' (1925)." The Charnel-House (blog), June 3, 2014. https://thecharnelhouse.org/2014/06/03/ le-corbusiers-contemporary-city-1925/. 
after the economic crash in 1929, he would spend the next decade promoting his ideas and moulding his radiant city vision into proposals for cities around the world ${ }^{64}$.

\section{SUMMARY}

Towers in Park Urbanism, illustrated in the proposals above, were a reaction to both the congestion of the city, and the land consumption of sprawl. At this point in time, skyscrapers were almost exclusively American, clustered close to one another in Manhattan and Chicago ${ }^{65}$. Meanwhile, urban sprawl was in its infancy, and its wasteful nature was becoming apparent ${ }^{66}$.

In these proposals, the functions of the city were neatly separated from one another both horizontally and vertically. Along the vertical axis, similar programs were stacked into towers that were spaced far apart to maximize light air and views from within. Densely stacking the city into towers freed up much of the ground wide open spaces in between for parks, recreation and most importantly, decongested highways. Along the horizontal plane, the improved flow of automobile traffic was intended to allow for the functions of the city to be spaced far apart.

Towers in the Park Urbanism was adopted as the underlying basis for many cities built throughout

\footnotetext{
$64 \quad$ Cohen, Jean-Louis. "Chapter Return to Order in Paris" in The Future of Architecture, since 1889. P. 125-127 London; New York: Phaidon, 2012.

Koolhaas, Rem. Delirious New York: A Retroactive Manifesto for Manhattan. P.259-260 New ed. New York: Monacelli Press, 1994.

Graham, Wade. "Chapter 3:Slabs" in Dream Cities: Seven Urban Ideas That Shape the World, p. 932017.

65 Ascher, Kate, and Rob Vroman. "History: The International Style" in The Heights: Anatomy of a Skyscraper. P. 16-17. New York, NY: Penguin Books, 2013.

66 Le Corbusier. The radiant city: elements of a doctrine of urbanism to be used as the basis of our machine-made civilization. P. 60-61 London: Faber, 1967
} 


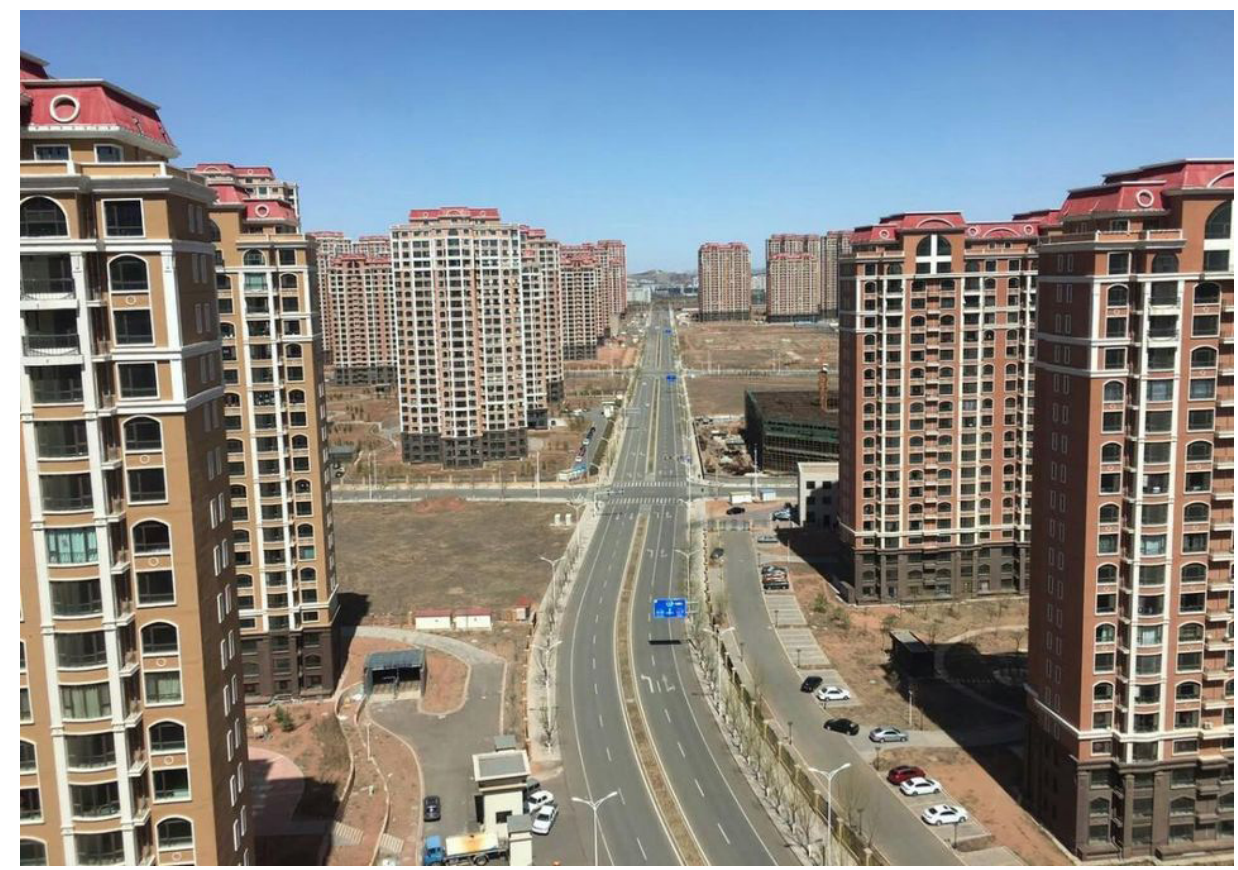

Figure 1.4.16: Ordos Kangbashi, New city in China designed based on value engineered towers in the park principles Shepard, Wade. "Why Hundreds Of Completely New Cities Are Being Built Around The World." Forbes. Accessed April 13, 2020. https://www.forbes.com/sites/wadeshepard/2017/12/12/whyhundreds-of-completely-new-cities-are-being-built-around-the-world/.

the $20^{\text {th }}$ century, especially in Europe after WWII ${ }^{67}$. In the $21^{\text {st }}$ century, it has continued its influence and has been adopted as the basis for many rapidly constructed Chinese megacities ${ }^{68}$ (Figure1.4.16).

The Towers in the Park model has become well recognized for its adverse impact on urbanity and its tendency towards social isolation. Through both horizontal and vertical separation of its components, it eliminates overlap of the public and private functions of the city ${ }^{69}$ along with the city street life, urbanity, and sense of community. The wide horizontal separation of the city's functions creates a car dependency and makes cities much less walkable. In this model, the functions of cities are removed from the urban fabric and repackaged as destinations.

\footnotetext{
$67 \quad$ Bingham-Hall, Patrick. Garden City Mega City: Rethinking Cities for the Age of Global Warming. P.49 Singapore: Pesaro Publishing, 2016.

68 Bingham-Hall, Patrick. Garden City Mega City: Rethinking Cities for the Age of Global Warming. P.49 Singapore: Pesaro Publishing, 2016. 69 Bingham-Hall, Patrick. Garden City Mega City: Rethinking Cities for the Age of Global Warming. P.73 Singapore: Pesaro Publishing, 2016.
} 


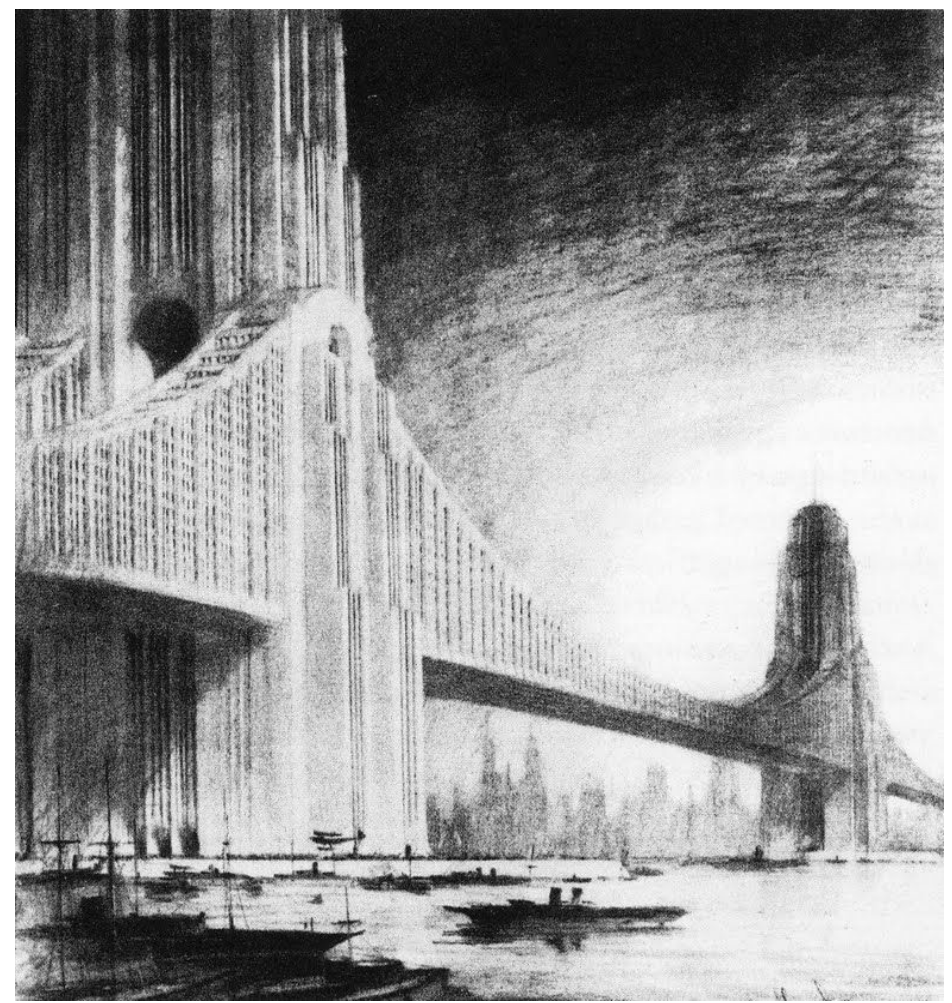

Figure 1.4.17: Raymond Hood Bridge Homes, 1925

Raymond Hood Bridge Homes, 1925 https://scroll.in/article/888101/from-domed-towns-toundergroundbuildings-how-planners-and-artistsenvisioned-cities-of-the-future

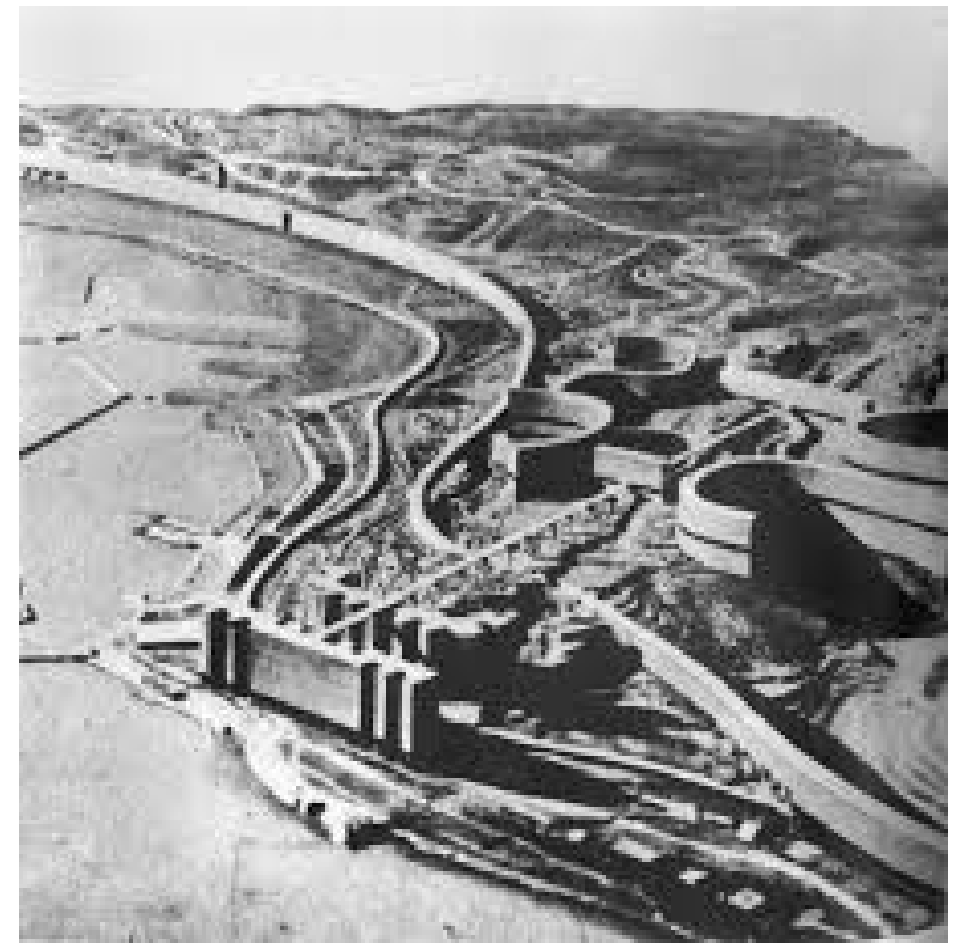

Figure 1.14.18: Le Corbusier: Viaduct City, 1932

Corbusier Algeirs Inhabited highway infrastructure, 1931 https://www.bidoun.org/articles/lecorbusier-salgerian-fantasy 


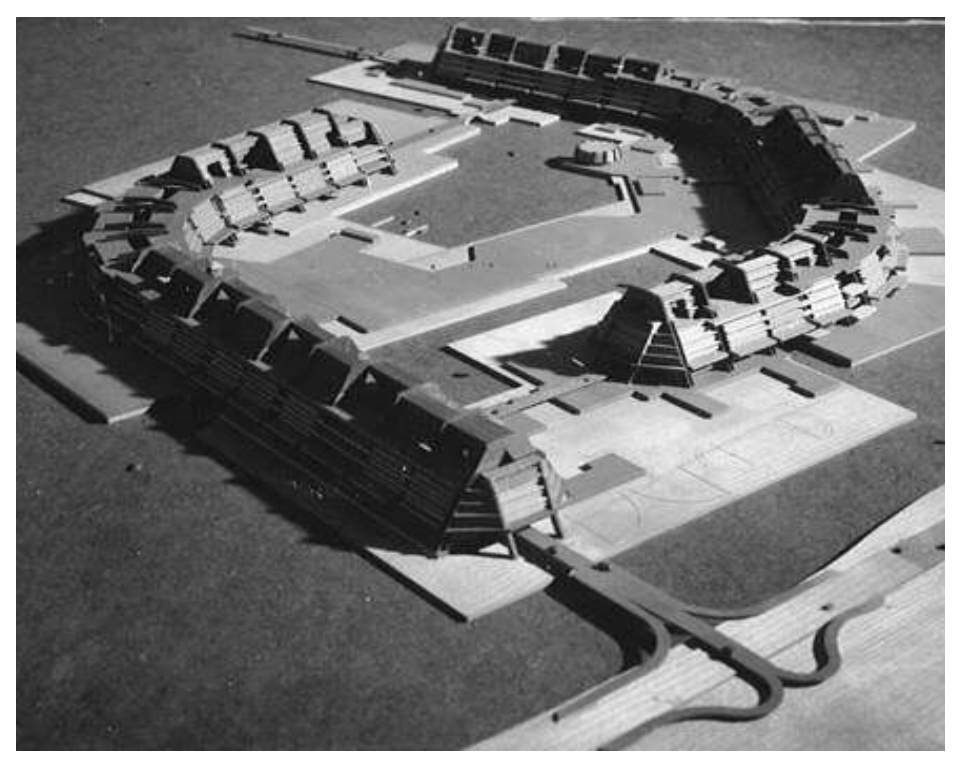

Figure 1.14.19: Kenzo Tange; Boston Harbour Proposal, 1959 Kenzo Tange, Boston Harbour Proposal, 1959https://hyperrealcartography.tumblr.com/ post/173917568970/brutgroupkenzo-tange-development-of-theport

Vertical separation of function/ program removes things like living and office spaces from the urban realm and isolates them into single-use towers. They become entirely separated from the other aspects of the city (e.g. retail, parks, libraries, cultural centres ), which remained limited to the ground plane.

\section{Inhabited Infrastructure}

\section{RAYMOND HOOD: BRIDGE HOMES (NEW YORK CITY, USA, 1925)}

In February 1925, the New York Times published an article titled Bridge Homes in which the American architect Raymond Hood presented his visions of inhabited infrastructure ${ }^{70}$. Hood's proposal featured a $10,000 \mathrm{ft}(3 \mathrm{~km})$ bridge that spanned the Hudson (Figure1.4.17), which he intended would eventually be replicated numerous times ${ }^{71}$. In addition to carrying a multi-lane expressway, the bridge was

\footnotetext{
$70 \quad$ Willis, Carol. Drawing Towards Metropolis: The Metropolis of Tomorrow. P. 162-163 Princeton, NJ: Princeton Architectural Press, 1986. $71 \quad$ Lubell, Sam, and Greg Goldin. "Skyscraper Bridges?" The Gotham Center for New York City History, August 16, 2017. https://www. gothamcenter.org/blog/skyscraper-bridges.
} 
designed to take advantage of its unique real-estate. Somewhere between 10,000 and 50,000 luxury apartments were intended to occupy the bridge pier towers and walls that extended the length of the bridge ${ }^{72}$.

\section{LE CORBUSIER: VIADUCT CITY (ALGIERS, SAO} PAULO, MONTEVIDEO, AND RIO DE JANEIRO, 1932-)

In addition to the towers in the park typology, Corbusier would also advocate for the integration of transportation infrastructure and inhabitable space, as he adapted his Radiant City concepts to other cities outside of Paris. Several Corbusier's proposals like those in Sao Paulo, Montevideo, and Rio de Janeiro would feature linear buildings extending across the cites with rooftop highways intended as a means to decongest the city and improve traffic flow $^{73}$. Perhaps most developed was his proposal for Algiers in North Africa (Figure 1.4.18), between 1932 and 1934, where a new inhabited highway was intended to run along the length of the coastal city, and a second inhabited highway would connect a mainly residential area to the central business district $^{74}$. In this project, a hierarchy for superstructure and substructure emerged that prioritized the initial highway superstructure. The secondary residential "cells" were intended to be filled out at a later date to keep pace with the demand 75 .

KENZO TANGE: BOSTON BAY PROJECT ( BOSTON, USA, 1959)

In 1959 Japanese architect Kenzo Tange began

Ibid. P. 162-163

Willis, Carrol. "The Skyscraper Museum: Future City: New York Modern: Raymond Hood." The Skyscraper Museum, October 2007. https://www. skyscraper.org/EXHIBITIONS/FUTURE CITY/NEW YORK MODERN/walkthrough hood.php.

73 Ibid. P. 222-225

$74 \quad$ Ibid. P. 226-260

$75 \quad$ Ibid. p.247 


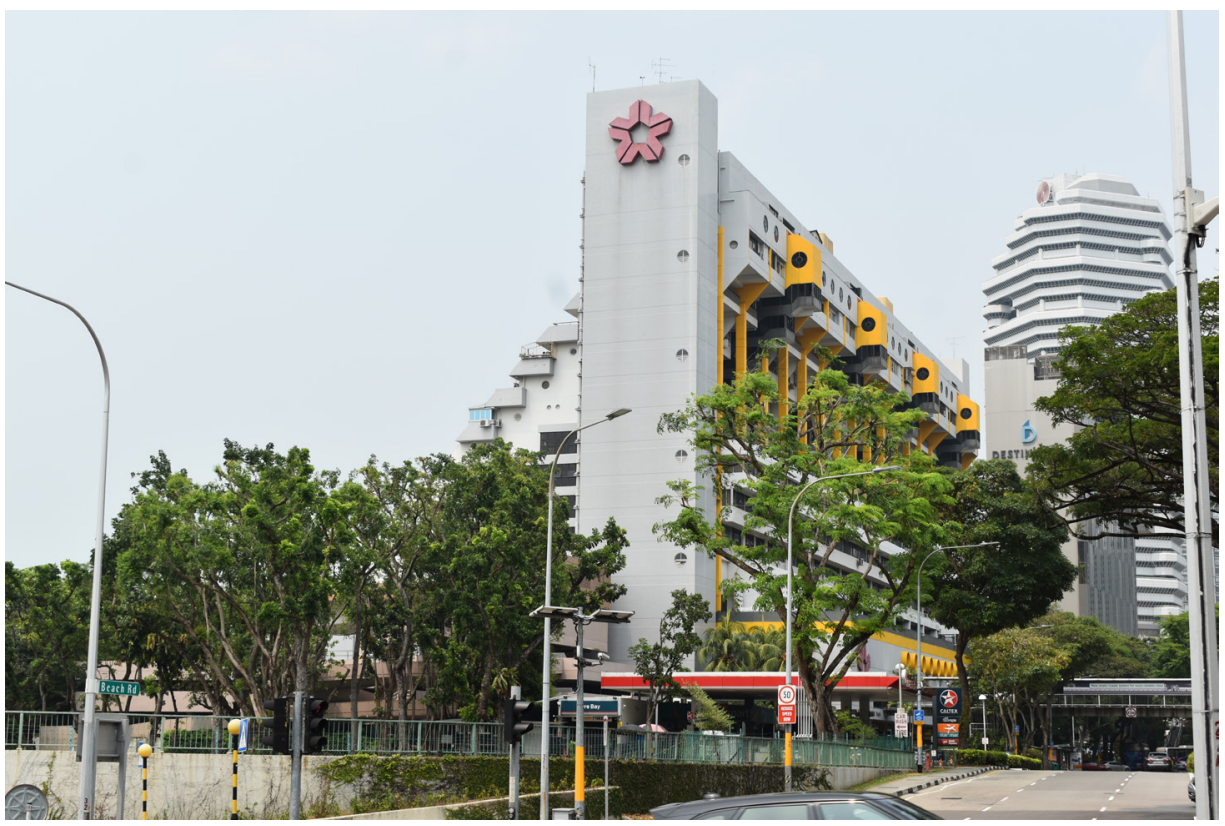

Figure 1.4.20: Golden Mile Complex, Singapore, 1972. The only built portion of this urban Mega-structure in Singapore failed to fully integrate with the transportation infrastructure Photo: Caskey, Alex, Golden Mile Complex, Fall 2019

Architecture, Failed. "Singapore's Metabolist Megastructures: The Asian City of Tomorrow?" Failed Architecture (blog). Accessed April 13, 2020. https://failedarchitecture.com/singapores-metabolistmegastructures-the-asian-city-of-tomorrow/.

teaching at MIT, where he and his students developed a plan for inhabited infrastructure intended to house 25,000 people in the Boston harbour'6 (Figure1.4.19). The proposal featured long A-frame buildings extending from the shore to man-made islands. The A-frames supported stepped inhabitable terraced space built atop of a highway ${ }^{77}$. The inhabitable space was intended to house a variety of programs, including housing, schools, shopping areas, churches, community space, and recreational facilities ${ }^{78}$. The

76 Graham, Wade. "Chapter 7: Habitats" in Dream Cities: Seven Urban Ideas That Shape the World. , p. 245-247 New York: Harper Collins, 2017.

77 Graham, Wade. "Chapter 7: Habitats" in Dream Cities: Seven Urban Ideas That Shape the World. , p. 245-247 New York: Harper Collins, 2017.

Nylias, Agnes. "On MIT Boston Harbour Project 1959 : Re Evaluation of 'Megasrtucture' Proposals by Kenzo Tange." Tokyo: Architectural Institute of Japan, October 2006.

$78 \quad$ Nylias, Agnes. "On MIT Boston Harbour Project 1959 : Re Evaluation of 'Megasrtucture' Proposals by Kenzo Tange." Tokyo: Architectural Institute of Japan, October 2006. 
The project would be put into action by the allpowerful Robert Moses of the New York Metropolitan Region. Plans for this project would eventually be put to rest due to public backlash led by Jane Jacobs regarding the displacement the project's construction would have caused ${ }^{83}$. In most cities, the built environment largely resisted inhabited infrastructure as transportation infrastructure was most commonly developed and designed independently of the rest of the built environment ${ }^{84}$.

The inhabited infrastructure proposals shown here lacked a critical analysis of the problem they were solving. In these types of projects, there is an underlying paradox that Thomas Van Leeuwen points out in The Skyward Trend of Thought ${ }^{35}$. The need to cluster the urban population together in a dense land-intensive built environment is at odds with the superhighways with which they were integrated. Instead of density and verticality, superhighways encourage horizontal sprawling to the outskirts of the city.

\section{Open-Ended Urban Framework}

KIYONORI KIKUTAKE/ THE METABOLISTS: MARINE CITY (TOKYO, JAPAN 1959)

In 1959, Kiyonori Kikutake Japanese architect and member of the Metabolist group proposed a floating city for Tokyo Bay, known as Marine City ${ }^{86}$ (Figure 1.4.21). His proposal was a cumulation of ideas from

83 Graham, Wade. "Corals" in Dream Cities: Seven Urban Ideas That Shape the World. P.154-159. Harper Perennial. 2017

84 Kreiger, Alex" Where and How Does Urban Design Happen"

in Harvard Design Magazine: The Origins and Evolution of Urban Design 1956-2006. P. 69. Cambridge. Harvard University Graduate School of Design. 2006

85 Van Leeuwen Thomas A. Skyward Trend of Thought: The Metaphysics of the American Skyscraper. Cambridge: Mit Press, 1990.

86 Graham, Wade. Dream Cities: Seven Urban Ideas That Shape the World. Chapter 7: Habitats, p. 251 New York: Harper Collins, 2017. 
Boston project would inspire Tange's proposal for the Tokyo Bay in 1960. In both the Boston Harbour and Tokyo Bay plan, an underlying theme was that the organization of infrastructure would follow a rigid set of guidelines while inhabitable space would occur in a flexible manner that may change over time ${ }^{79}$.

\section{SUMMARY}

The Inhabited Infrastructure Urbanism proposals included above were inspired by the enormous scale of highways, freeways, hydroelectric dams, bridges, and infrastructure projects going on in cities around the world at the time ${ }^{80}$.

The proposals each attempted to integrate inhabitable real estate into major transportation infrastructure projects. This approach reimagines the air rights required for large scale infrastructure projects and suggests ways in which this airspace can serve numerous functions. In these examples' horizontal continuity of the vertical spaces influenced by the transport infrastructure enable new urbanistic possibilities.

For a short time period, these and other proposals for inhabited infrastructure would influence large developments (Figure 1.4.20) and some major infrastructure works, most notably the Lower Manhattan Expressway ${ }^{81}$. Designed by Paul Rudolph in the 1950s, the plan featured inhabited frame buildings intended to span an underlying freeway ${ }^{82}$. 79 Lin, Zhongjie. Urban Structure for the Expanding Metropolis: Kenzo Tange's 1960 Plan for Tokyo, n.d.

$80 \quad$ Nylias, Agnes. "On MIT Boston Harbour Project 1959 : Re Evaluation of 'Megasrtucture' Proposals by Kenzo Tange." Tokyo: Architectural Institute of Japan, October 2006.

81 Banham, Reyner. "Dinosaurs of the Modern Movement" in Megaestructure, Urban Futures of the Recent Past. London; New York: Harper \& Row, 1976.

82 Banham, Reyner. "Dinosaurs of the Modern Movement" in Megaestructure, Urban Futures of the Recent Past. London; New York: Harper \& Row, 1976. 


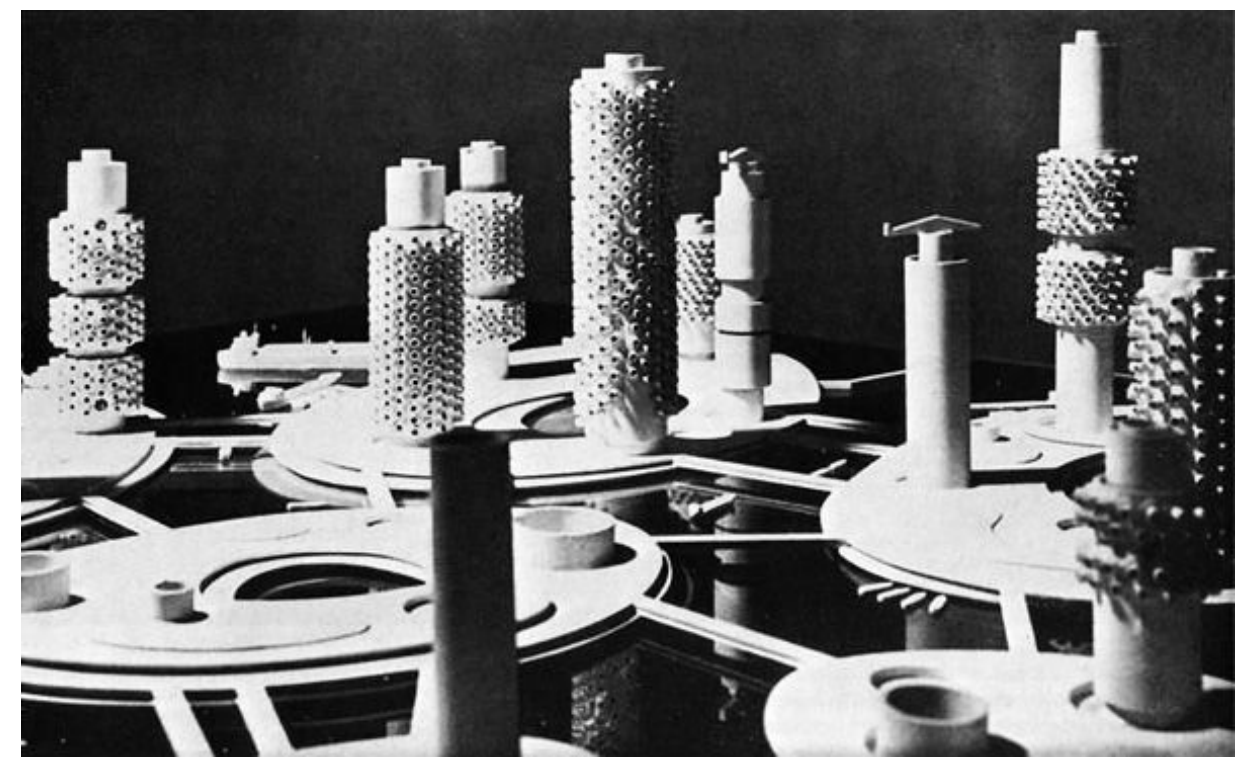

Figure 1.4.21:Kiyonori Kikutake: Marine City ,1959

Kiyonori Kikutake: Marine City, 1959 ttps://njitarch382.files.wordpress.com/2012/04/mcmahon-

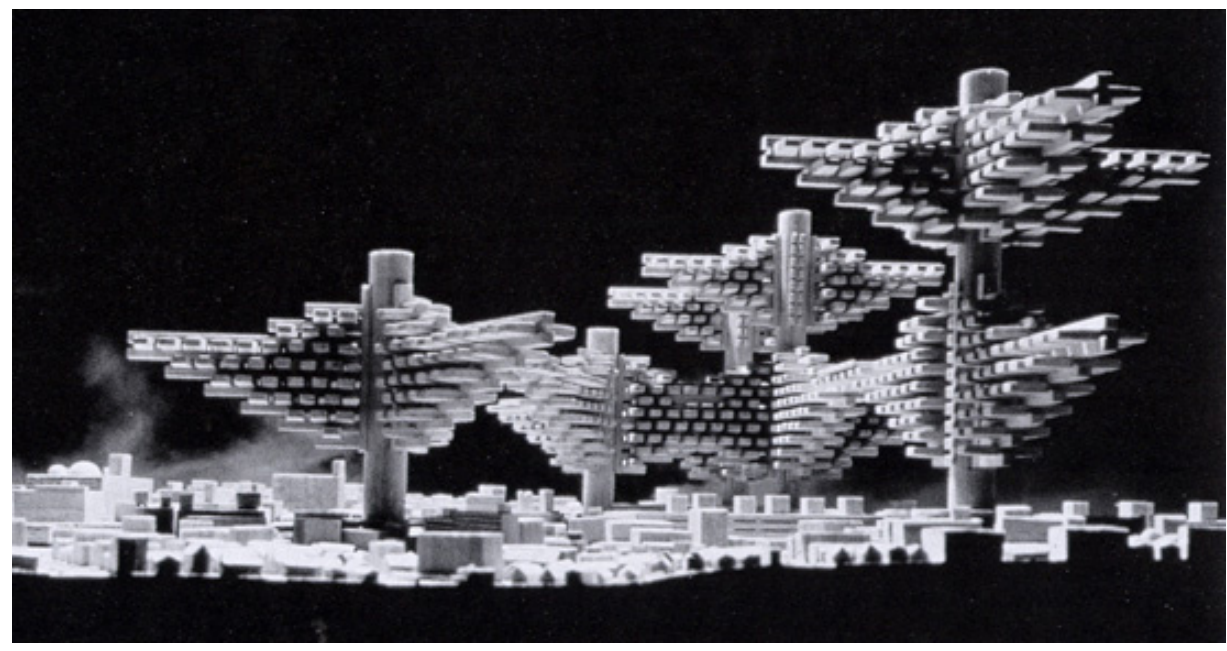

Figure 1.4.22:Arata Isosaki: City in The Sky, 1962

Arata Isosaki: City in The Sky, 1962 https://www.thecityreview.com/arcnow.html

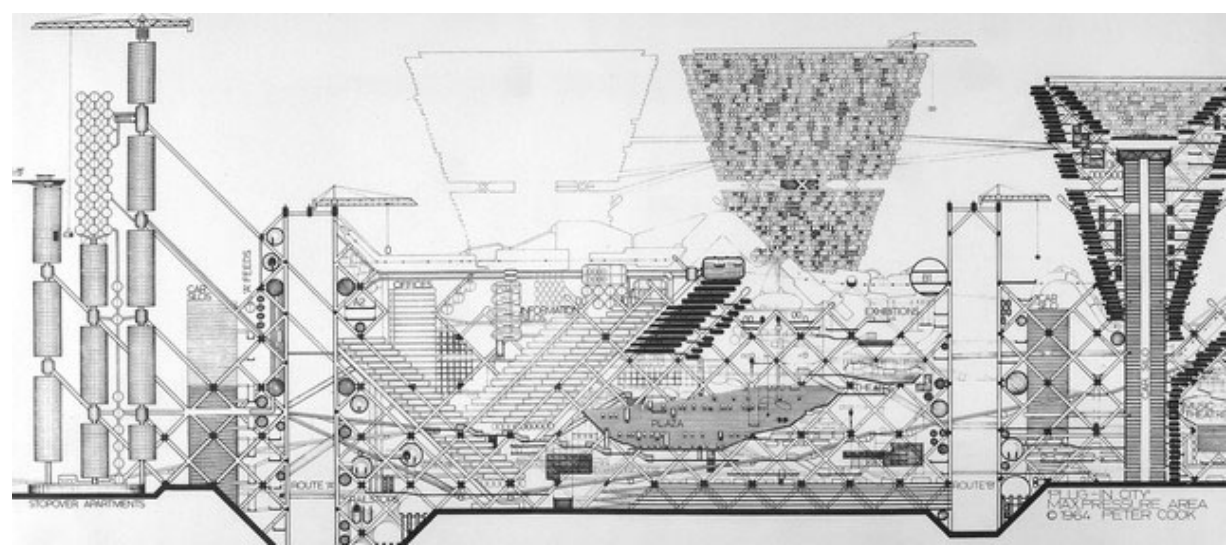

Figure1.4.23 Peter Cook, Plug in City, 1962

Peter Cook: Plug in City, 1962 https://www.archdaily.com/399329/ad-classicsthe-plug-in-city-petercook-archigram/51 d71 cabe8e44ecad700002a-ad-classics-theplug-in-city-peter-cook-archigram- 
projects he published in 1958, including Sky House, where he articulated a clear delineation of the major and minor components of the built environment ${ }^{87}$ and Tower Shaped City, where he proposed a new vertical urban organization ${ }^{8}$. The Marine City proposal featured widely spaced Tower Shaped Cities on a giant floating platform ${ }^{8}$. The towers featured large $300 \mathrm{~m}$ tall infrastructure cores, which were the major building component, and they housed all necessary services, circulation, and urban infrastructure ${ }^{90}$. The minor building components were prefabricated removable units intended to be manufactured in the core and lifted into place ${ }^{91}$. The core was intended to support up to 1250 units and to create a self-sufficient community of 5000 in each tower ${ }^{92}$. The wide spacing of the tower-shaped cities was intended to save the space on the platform for agriculture, industry, and entertainment ${ }^{23}$.

\section{ARATA ISOSAKI: CITY IN THE SKY (TOKYO, JAPAN, 1962)}

In 1962 Japanese Architect Arata Isoaki, who had worked closely with Kenzo Tange and the Metabolists, published a proposal for a new form of vertical growth to be located in the Shinjuku region of Toyko"4. The City in the Sky proposal (Figure 1.4.22) featured

87 Lin, Zhongjie. Kenzo Tange and the Metabolist Movement: Urban Utopias of Modern Japan. P. 25. New York: Routledge, 2010.

$88 \quad$ lbid.

$89 \quad$ lbid

90 Graham, Wade. Dream Cities: Seven Urban Ideas That Shape

the World. Chapter 7: Habitats, p. 251New York: Harper Collins, 2017.

91 Lin, Zhongjie. Kenzo Tange and the Metabolist Movement:

Urban Utopias of Modern Japan. P. 26. New York: Routledge, 2010.

$92 \quad$ Ibid. P. 26.

93 Lin, Zhongjie. Kenzo Tange and the Metabolist Movement:

Urban Utopias of Modern Japan. P. 26. New York: Routledge, 2010.

$94 \quad$ Graham, Wade. Dream Cities: Seven Urban Ideas That Shape

the World. Chapter 7: Habitats, p. 251New York: Harper Collins, 2017.

Gonzalez, Maria Francisca. "The City in the Air by Arata Isozaki." ArchDaily, March 8, 2019. https://www.archdaily.com/912738/the-city-in-the-air-byarata-isozaki. 
city scaled interconnected vertical forms based on the joint and core system he had developed with Kenzo Tange in 1960\%5. In the joint and core system, Isosaki took the vertical service cores of the Marine City and spaced them close enough together to be spanned by large horizontal trusses. The trusses were intended to act as enclosed multifloored living and working spaces themselves while serving as a support structure for the more transient components of the urban environment ${ }^{9 \%}$. The major structure of horizontal trusses and vertical cores provided a framework that allowed removable prefabricated capsules to inhabit the areas above and below ${ }^{97}$.

PETER COOK / ARCHIGRAM: PLUG-IN CITY (LONDON, UK, 1962)

In 1962, Peter Cook, architect and editor of Archigram magazine, published Metal Cabin Housing, which is considered an early prototype of what would eventually become Plug-in City ${ }^{98}$ (Figure 1.4.22). Cook developed and refined Plug-in City between 1962 and $1964 \%$. The central thesis of the project was focused on if "the whole urban environment could be programmed and structured for change" ${ }^{\prime \prime 100}$. The Plug-in City was a city-wide configuration of a semi-permanent superstructure and impermanent inhabitable space units. The superstructure consisted of an extensive network of transportation, structure, and services. Key to this network was its 3- dimensional framework of diagonal transport tubes serving a variety of localized and city-

\footnotetext{
95 Lin, Zhongjie. Kenzo Tange and the Metabolist Movement: Urban Utopias of Modern Japan. P. 45. New York: Routledge, 2010. 
wide transportation needs ${ }^{101}$. The superstructure was intended to have the longest service life of approximately 20-40 years ${ }^{102}$. The superstructure was fitted with cranes located on tracks and other handling machines, which would allow the "plugging in" and removal of impermanent habitable units ${ }^{103}$. These units would be designed for planned obsolescence and would be removed and replaced at the end of their useful lives ranging from 3-8 years ${ }^{104}$. Instead of separating all of the city's functions, Cook attempted to "stir" them all together ${ }^{105}$. Cook believed a vital characteristic of the city was the close proximity of many different parts and functions ${ }^{106}$.

\section{SUMMARY}

The Open-Ended Urban Framework proposals in this section emerged during an era of technooptimism ${ }^{107}$. These ideas were inspired by a combination of things such as space travel, rockets, the planned obsolescence of automobiles, and housing as a consumer product like the Dymaxion Houses proposed by Buckminster Fuller and work by Corbusier ${ }^{108}$.

101 Cook, Peter, "Plug in City" in Archigram. Rev. ed. P.41 New York: Princeton Architectural Press, 1963 (1999).

102 Peter cook was Influenced by comic book sky scrapper cities where the movement tube emerged as part of a city wide network of multilevel transportation while in reality existing skyscraper cities had a single groundplane of horizontal transportation.

Cook, Peter, and Archigram (Group), eds. "Zoom and 'real' architecture" in Archigram. Rev. ed. P. 27-29 New York: Princeton Architectural Press, 1999. Cook, Peter, "Plug in City" in Archigram. Rev. ed. P.39 New York: Princeton Architectural Press, 1963 (1999)

103 Cohen, Jean-Louis. The Future of Architecture, since 1889. P.384 London ; New York: Phaidon, 2012.

104 Cook, Peter, "Plug in City" in Archigram. Rev. ed. P.39 New

York: Princeton Architectural Press, 1963 (1999).

$105 \quad$ Ibid. p39

106 Cook, Peter, and Archigram (Group), eds. "The metropolis" in Archigram. Rev. ed. P. 24-25 New York: Princeton Architectural Press, 1999. 107 Graham, Wade. "Habitats" in Dream Cities: Seven Urban Ideas That Shape the World. P.244, 268. Harper Perennial. 2017

108 Cook, Peter, "Editorial from Archigram 3" in Archigram. Rev. ed. P. 17 New York: Princeton Architectural Press, 1963 (1999). 
These proposals challenged the notion that entire cities could be planned ${ }^{109}$ opting instead for a vision of the city as a fluid process that was flexible, mobile, and impermanent ${ }^{110}$. They recognized that the rate of change of components of a city did not all occur at the same rate and that some things like transportation infrastructure would be more permanent than things like housing units ${ }^{111}$. What makes open-ended framework projects unique, however, is the application of this thinking over the three-dimensional volume of a city. In each of these proposals, a semi-permanent infrastructural framework was intended to support impermanent spaces for things like living and working.

The scale of the proposals, and a decline in technooptimism since the mid-1970s, meant that OpenEnded Urban Frameworks would never appear in the built environment to the scale in which they were proposed ${ }^{12}$. Instead, a few projects of the time, like the Nakagin Capsule Tower, built in Tokyo in 1972 (Figure 1.4.23), borrowed the aesthetic and organization of the open-ended framework proposals ${ }^{113}$. Without a more widespread adaptation of an urban scale open-ended system, however, these types of built projects could not adhere to their intended "removable unit" functionality.

Overall, Open-Ended Urban Framework proposals 109 Lin, Zhongjie. Kenzo Tange and the Metabolist Movement: Urban Utopias of Modern Japan. P. 2 London, UNITED KINGDOM: Routledge, 2010. http://ebookcentral.proquest.com/lib/ryerson/detail. action?doclD=484779.

110 Hollein, Hans "A comment From Hans Hollein" in in Archigram. Rev. ed. P. 6. New York: Princeton Architectural Press, 1999.

Web, Mike "Boys at Heart" in Archigram. Rev. ed. P. 3-4. New York: Princeton Architectural Press, 1999.

111 Lin, Zhongjie. Kenzo Tange and the Metabolist Movement:

Urban Utopias of Modern Japan. P. 2. New York: Routledge, 2010.

112 Graham, Wade. "Habitats" in Dream Cities: Seven Urban Ideas

That Shape the World. P.268. Harper Perennial. 2017

113 Graham, Wade. "Habitats" in Dream Cities: Seven Urban Ideas That Shape the World. P.269. Harper Perennial. 2017 


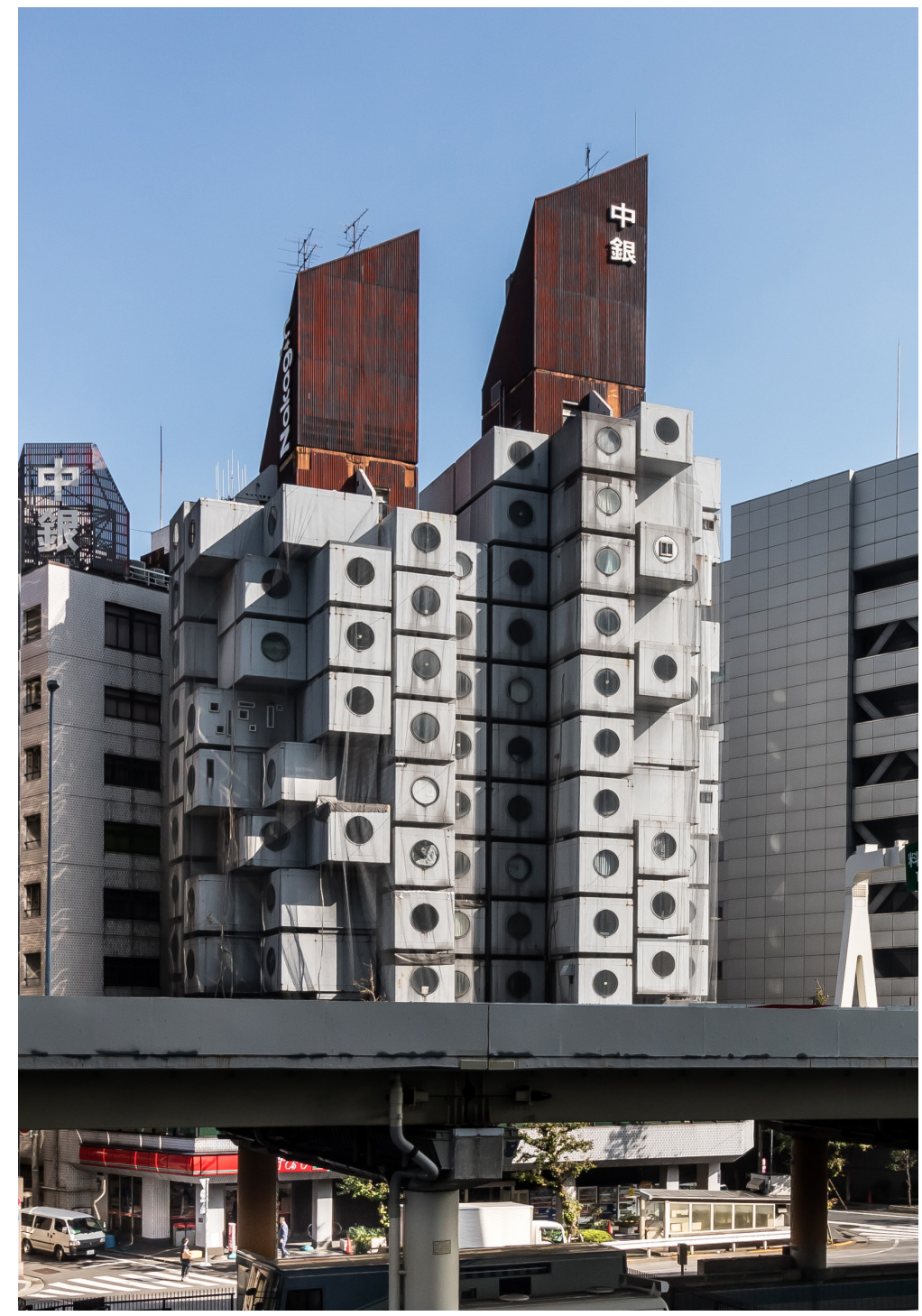

Figure 1.4.24: Nakagin Capsule Tower, Tokyo, 1972. Without a larger urban system this project lost its open-ended functionality Kakidai. "Nakagin Capsule Tower, at Shinbashi Tokyo Japan, Design by Kisho Kurokawa in 1972." In Wikipedia, November 1, 2018. https://en.wikipedia.org/w/index.php?title=Metabolism_ (architecture)\&oldid=943754046. 
tended to do two things:

First of all, they wrongly assumed the future societal need for physically moving living and working units. Sixty years after these urban framework proposals where presented, there does still not seem to be a need for physically moving living or working units. Instead, flexible units that can be renovated and modified seem to serve the ever-evolving spacial needs of society adequately ${ }^{114}$.

Second, the Open-Ended Urban Framework proposals tended to overestimate and overemphasize the "Framework"115. These projects externalize all structure and services from within private development, creating the need for enormous public support and distribution infrastructure. These systems offered limited flexibility and would have been resource-intensive. Cities tend to grow in a fragmented haphazard manner driven by private interests where adherence to systems evolve and change over time ${ }^{116}$. It was thus problematic to expect private interest to be dependent on a city investing in such largescale support infrastructure. The necessity of superstructure systems was primarily rooted in the need to physically move the more transient units. As discussed in section 2.4, without the need to physically move units, it is possible that the main structural components of a vertically organized city could remain largely within private real estate.

The more substantial impact of this movement was the emergence of a more dynamic understanding

\footnotetext{
114 Graham, Wade. "Habitats" in Dream Cities: Seven Urban Ideas That Shape the World. P.269. Harper Perennial. 2017

115 Banham, Reyner. "Fun and Flexibnbility" in Megaestructure, Urban Futures of the Recent Past. London; New York: Harper \& Row, 1976. 116 Graham, Wade. "Habitats" in Dream Cities: Seven Urban Ideas That Shape the World. P.269. Harper Perennial. 2017 Mc Cartney, Dr. Shelagh. General takeaway from the analysis of cities in PL8305 Contemporary Urban Design Course, Ryerson University 2020
} 
of the city, which has shifted the practice of urban planning away from the static, universal, fully resolved, neatly organized, master plan common during the modernist period ${ }^{11}$. The contemporary master plan has become less of a practice of design, and more of a framework of forward-thinking goals and objectives. It recognizes the complexity and interdependent nature of the urban system, demands of a specific regional context, and attempts to help govern future projects without restricting future changes ${ }^{118}$.

\section{Conclusion}

These Visionary Urbanism proposals represent the foundation of theory from which this thesis emerged.

Urban Retreat leads to urban sprawl, which is unsustainable, socially isolating, and detrimental to cities. The horizontal spread of cities can be seen as the antithesis to the Theory of Vertical Architecture.

The Mass Centralization proposals presented above were extreme in nature, yet there is value in the idea that centralizing the population in a vertical volume could conserve land resources, reduce the need for horizontal transportation and create a more urbanistically rich environment. Instead of adapting "volumetric centralization" to a single structure like in the proposals of Soleri, Gillette or contemporary supertalls like the Burj Kalifa, this thesis imagines the centralization of dense urban populations, and rich urbanity extended throughout the many structures of a city.

\footnotetext{
Busquets, Joan. Line 9: Analog Compositions: Rethinking The Master Plan and It's Scales" in Cities X Lines: A New Lens for the Urbanistic Project. Edited by Felipe Correa and Harvard University. Reprint. S.I.: Nicolodi, 2007.

118 Busquets, Joan. Line 9: Analog Compositions: Rethinking The Master Plan and It's Scales" in Cities X Lines: A New Lens for the Urbanistic Project. Edited by Felipe Correa and Harvard University. Reprint. S.I.: Nicolodi, 2007.
} 
Multiplying the ground plane of the city at various levels introduces many new architectural and urbanistic opportunities. The many components of cities, both public and private spaces, could be adapted to a city that extends into its own volume. Beyond the possible configurations discussed above, however, there is a need for continuity between the multiple ground planes of the city and for localized density capable of supporting their economies.

In both Towers in the Park and Multiple Ground Urbanism, there is a tendency towards the vertical separation of the functions of the city, which stacks private spaces into isolated "common towers". Instead of separating the functions of a city, this thesis explores how urbanity, street life, community and the overlap of functions and activities can be extended throughout a city, in three dimensions.

There is great potential in the integration of infrastructure projects with the inhabited spaces of a city. It is essential, however, to think critically about what forms of urban development infrastructure like superhighways actually encourage. This thesis explores the integration of habitable spaces with infrastructure like walkable streets and public transit that support a dense, vibrant urban environment.

The Open-Ended Urban Framework proposals offer an important lesson about the dynamic and impermanent nature of cities. The response of these proposals, however, was to develop massive infrastructure frameworks that would enable this impermanence. Cities, however, tend to grow over time in a fragmented haphazard manner where adherence to systems evolve and change and are often driven by private interests ${ }^{11}$. This thesis 119 Graham, Wade. "Habitats" in Dream Cities: Seven Urban Ideas 
explores the vertical extension of cities without the requirement for a physical framework or adherence to a strict system. Similar to the work of Harvey Corbett's proposal, this thesis aims to form three dimensional urban design strategies without providing a fully designed vision for the vertical extension of cities. The intent is to allow for many interpretations and adaptations of the ideas. In the following sections, these strategies are accompanied by architectural representation and design research intended to expose the architectural and urbanistic potential of vertical architecture.

That Shape the World. P.269. Harper Perennial. 2017

Mc Cartney, Dr. Shelagh. General takeaway from the analysis of cities in PL8305 Contemporary Urban Design Course, Ryerson University 2020 
A

$\mathrm{R}$
$\mathrm{T}$

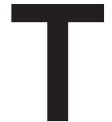

W

O 


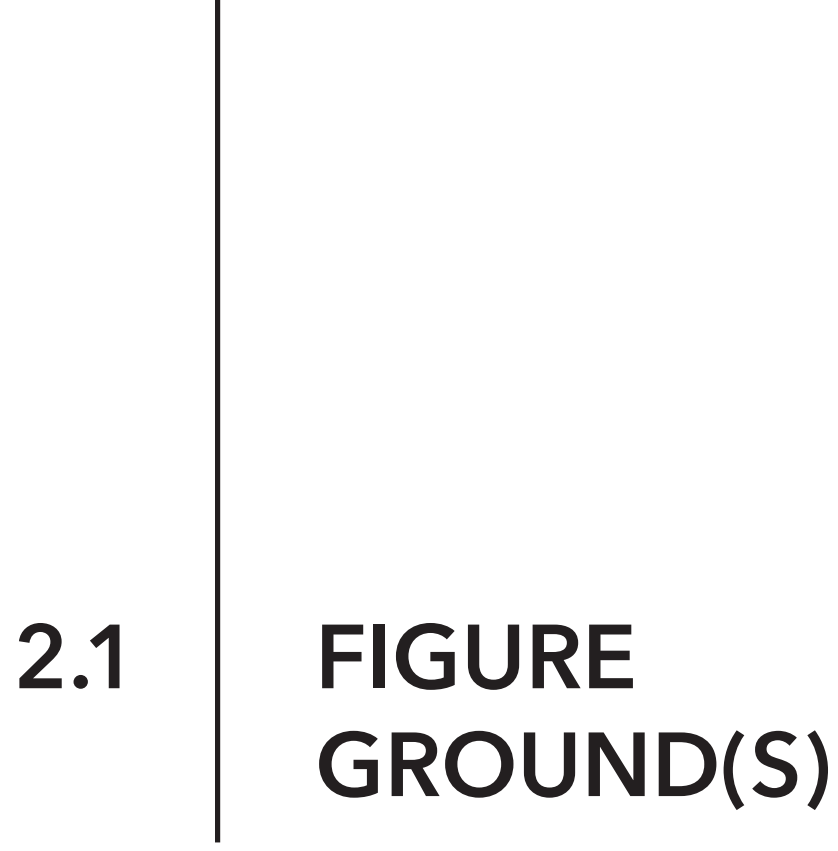

How can a city be extended vertically to inhabit its own vertical real estate?

This is the main research question of this thesis, and the chapters in part two begin to address this. This section simplifies the problem by reducing urban form to its most basic components and uses this reduction to form a three-dimensional understanding of the city. It also includes a critical analysis of current applications of multiple ground urbanism and builds an argument for why extending the city vertically needs to occur in a continuous, unconditional, and external manner.

\section{Reduction of Urban Form}

A three-dimensional understanding of the basic components of a city was deemed necessary to investigate the organization of a city within a volume.

What are the basic components that make up a city?

Answering this question required an investigation of two previously established reductions of urban form. In A Theory of Urban Form, published in 1958, Kevin Lynch and Lloyd Rodwin reduced urban form to its most basic components in an attempt to develop an 


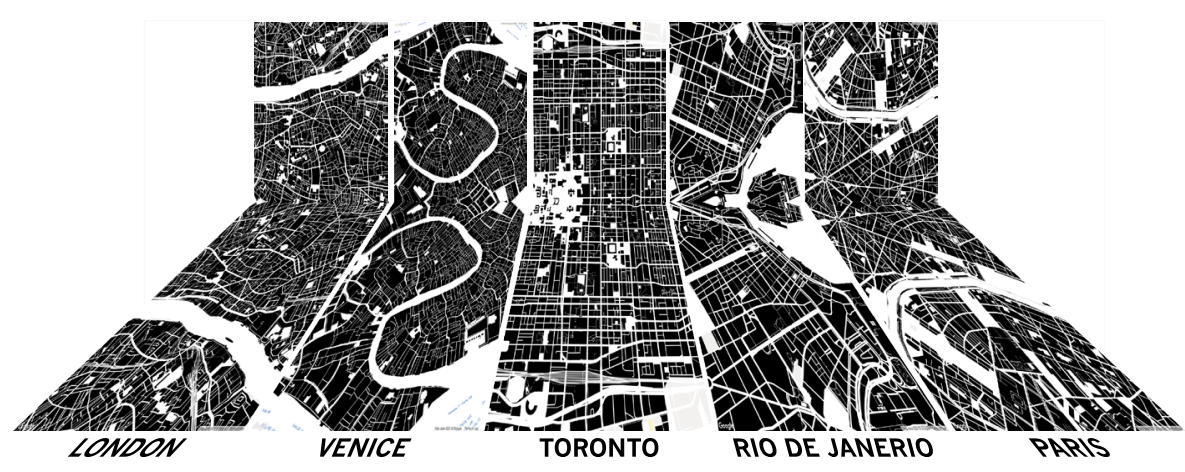

Figure 2.1.1: A Bent Nolli map of Mayjor Cites extends the thinking of figure-ground to a three-dimensional representation of space where it could be understood in both plan and section analytical model for planning the physical form of cities $^{1}$. Lynch and Rodwin argue that the physical form of all human settlements has two components:

1. Flow Systems: for the circulation and flow of people, goods and utilities

2. Adapted Spaces: for localized activities, such as living, sleeping, exchange, recreation, and production ${ }^{2}$.

The authors recognized that there are spaces like public squares, parks or other such spaces that may serve both functions simultaneously or at different times ${ }^{3}$.

The work of Lynch and Rodwin was in alignment with a more well-known reduction of urban form that first appeared on the 1748 plan of Rome by Giambattista Nolli ${ }^{4}$. What would later become known as Nolli or Figure-Ground mapping reduces the urban form to:

1. Private/Figure/Solid: Rendered as black

Lynch, Kevin, and Lloyd Rodwin. "A Theory of Urban Form." Journal of the American Institute of Planners 24, no. 4 (December 31, 1958): 201-14. https://doi.org/10.1080/01944365808978281.

\footnotetext{
2 Ibid.

$3 \quad$ Ibid.

$4 \quad$ Verstegen, lan, ed. Giambattista Nolli and Rome: Mapping the City before and after the Pianta Grande, p. 9. 2013.
} 


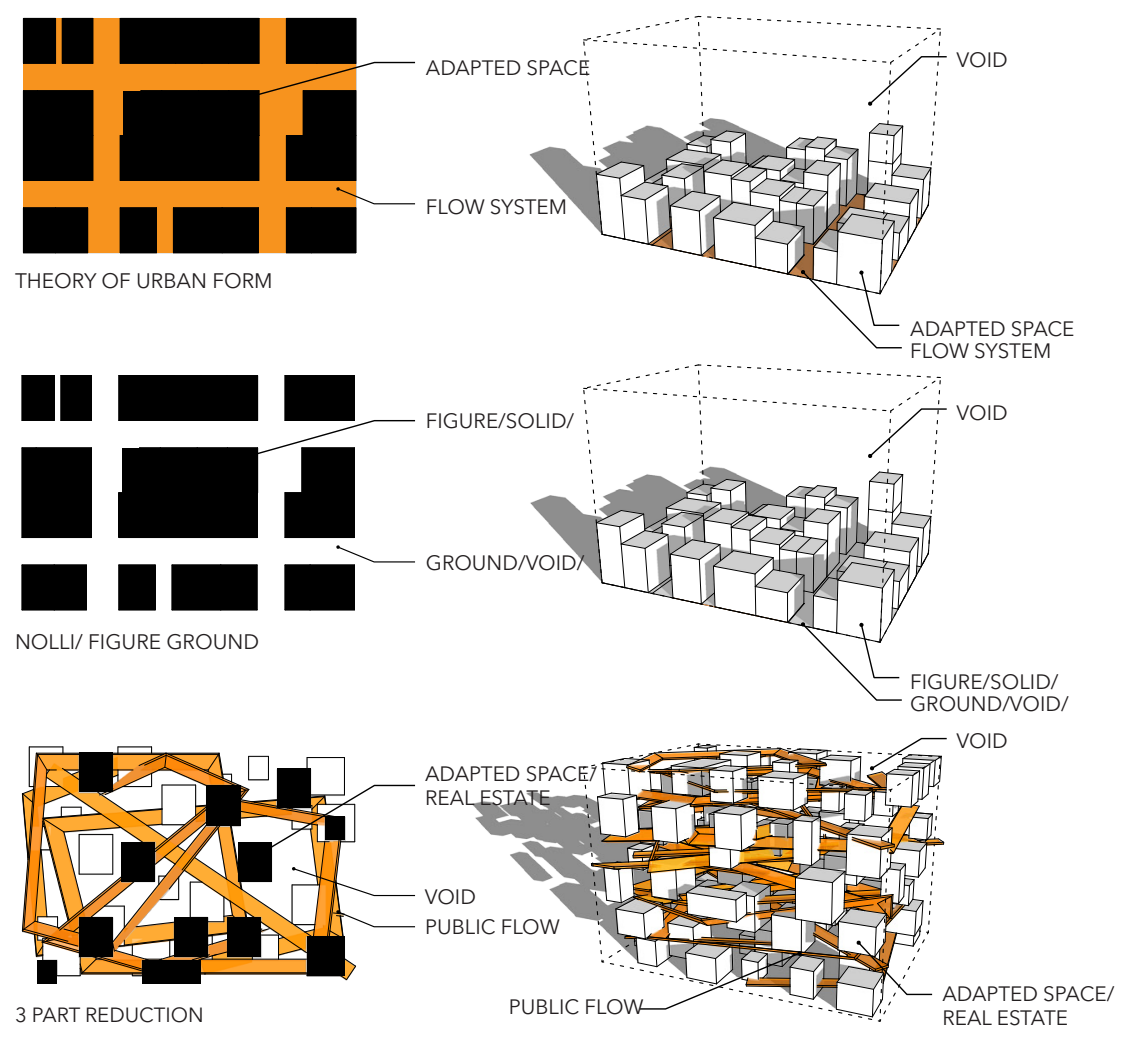

Figure 2.1.2: The reduction of urban forms in three dimensions showing the application of, Lynch-Rodwin, Nolli, and the ThreePart reduction explained in this section.

2. Public/Ground/Void: Rendered as white Both of these reductions of urban form are binary systems that were formed based on a two dimensional understanding of the city influenced by the practice of mapping.

Early design research (Figure 2.1.1) investigated the vertical extension of the city through this binary reduction of urban form. The "Bent Nolli" extends the thinking of the two-dimensional figure-ground mapping to a three-dimensional representation of space where it could be understood in both plan and section. Through its application, it became apparent, 
however, that a binary reduction of urban form is incapable of representing the city in three dimensions (Figure 2.1.2). Unlike on the ground plane, in threedimensional space, public spaces, or the public flow system, and voids are no longer the same thing. The public flow system becomes the surface, while the void becomes the unbuilt airspace above. Therefore, to reduce the city to its most basic components in three dimensions, a ternary or three-part system is required. Borrowing terminology from both Figure Ground, and Lynch-Rodwin reduction, cities can be reduced to:

1. Public Flow System

(Parts of the city concerned with the circulation and flow of people goods and utilities)

2. Voids

(The unbuilt airspace volume of the city)

3. Adapted spaces / Real Estate (all indoor and outdoor spaces and surfaces meant for localized activities)

\section{Extending the City Vertically: A Critical Analysis of Current Applications}

The three-part reduction of urban form is necessary to explore how the city can be extended vertically. It is useful to begin by thinking about the default approach to inhabiting vertical real estate, through the use of the common tower (Figure 2.1.3). This default approach is prevalent in most of today's major cities. In the default approach, the public flow system exists at the ground plane in between adapted spaces. The extension into the vertical dimension only involves the adapted spaces, while the public flow system remains at the ground level. Since the goal of this thesis is to develop a common tower urban alternative by extending the city vertically, then the research question could be reframed as: 


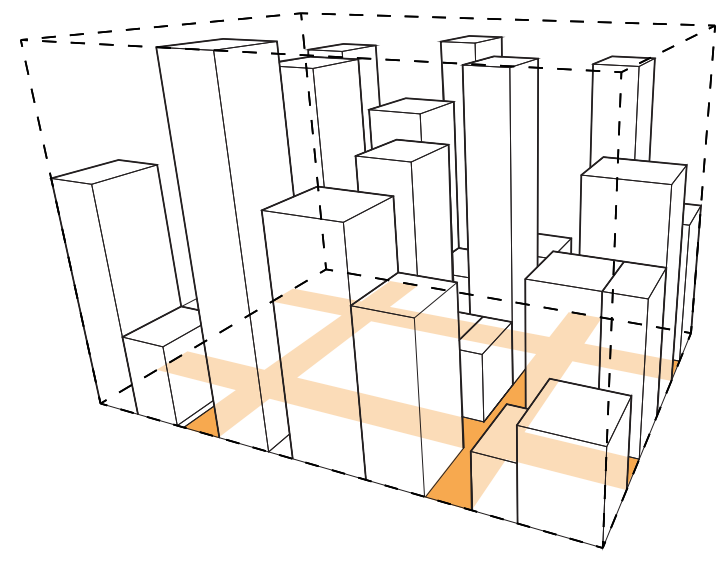

THE DEFAULT APPROACH: COMMON TOWERS

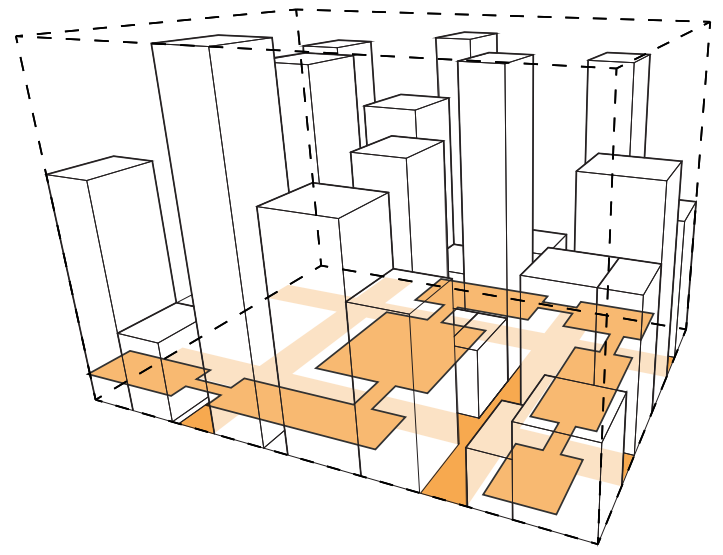

MULTIPLE GROUND URBANISM: GRADE SEPARATED PEDESTRIAN NETWORKS

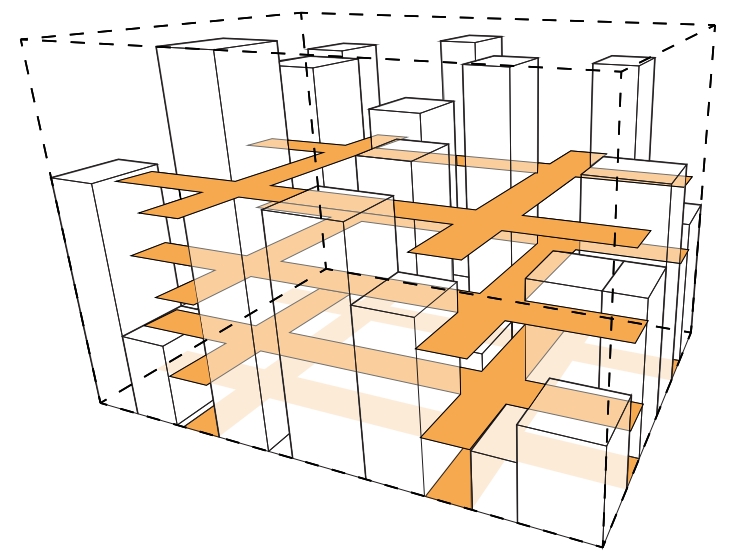

MULTIPLE GROUND URBANISM: SURFACES CONNECTED TO TOWERS AT MULTIPLE DAY-TUMS

Figures 2.1.3-5: Diagram showing 3D urban reduction of various existing strategies for inhabiting vertical space 

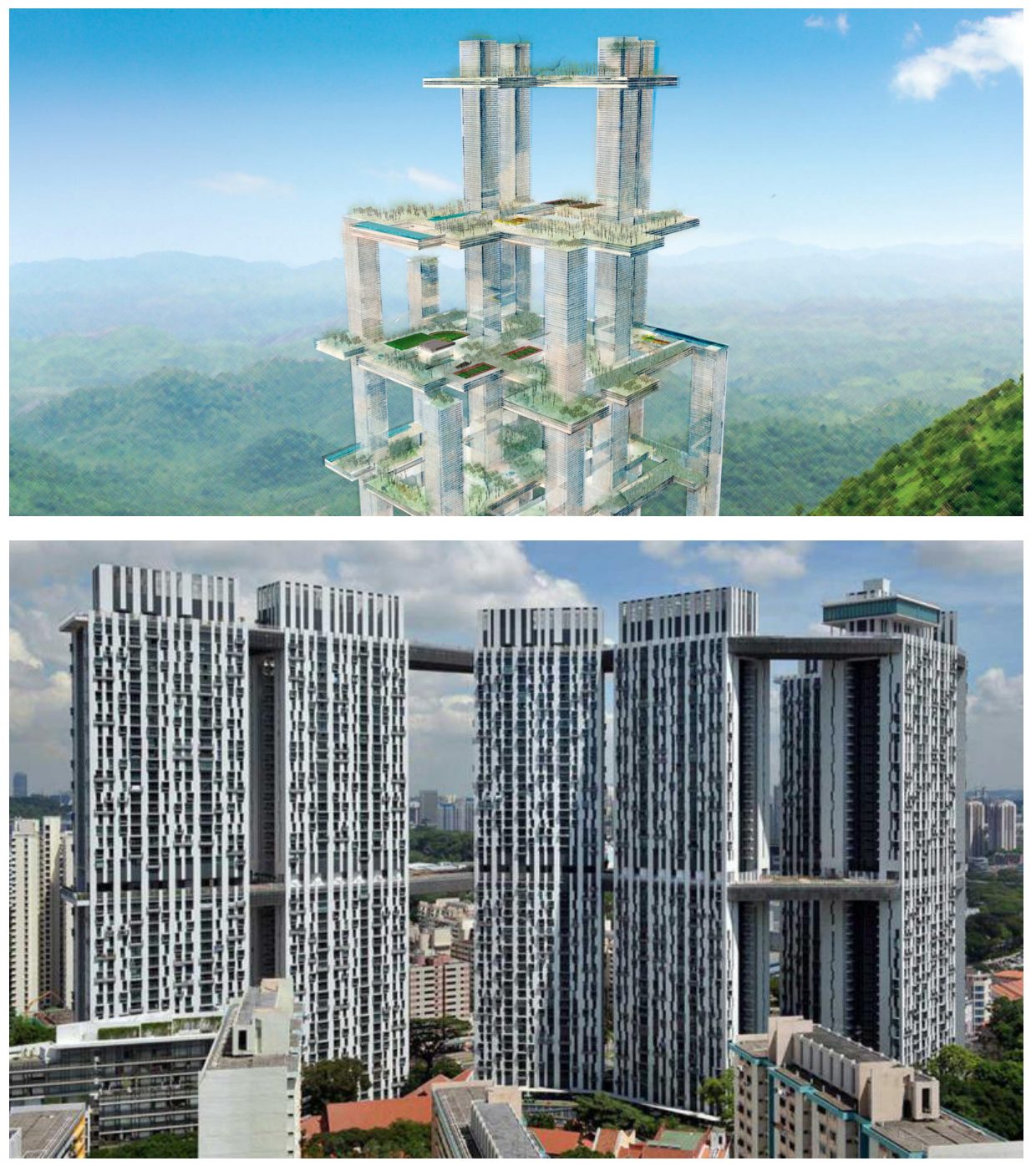

Figure 2.1.6-7: Top: A rendering of Kenneth King's Vertical City Concept. Above: Photo of the Pinnacle housing Development in Singapore

King, Kenneth. "Conceptual Rendering of a Vertical City." Buisness Insider, 2016. https://www. businessinsider.com/vertical-cities-future-of-architecture-2016-4.

"5-Room Pinnacle @ Duxton Flat Sold for Record-Breaking \$1.12 Million, Business News - AsiaOne." Accessed November 25, 2019. v.

How can a city's public flow system be extended vertically above the ground plane?

Many cities have already adopted two ways in which the public flow system can be replicated above the ground plane. Section 1.4 included an explanation of Multiple Ground Urbanism and explained how some cities around the world have partially implemented "multiple grounds." This commonly occurs through two forms: grade-separated pedestrian walkways, 


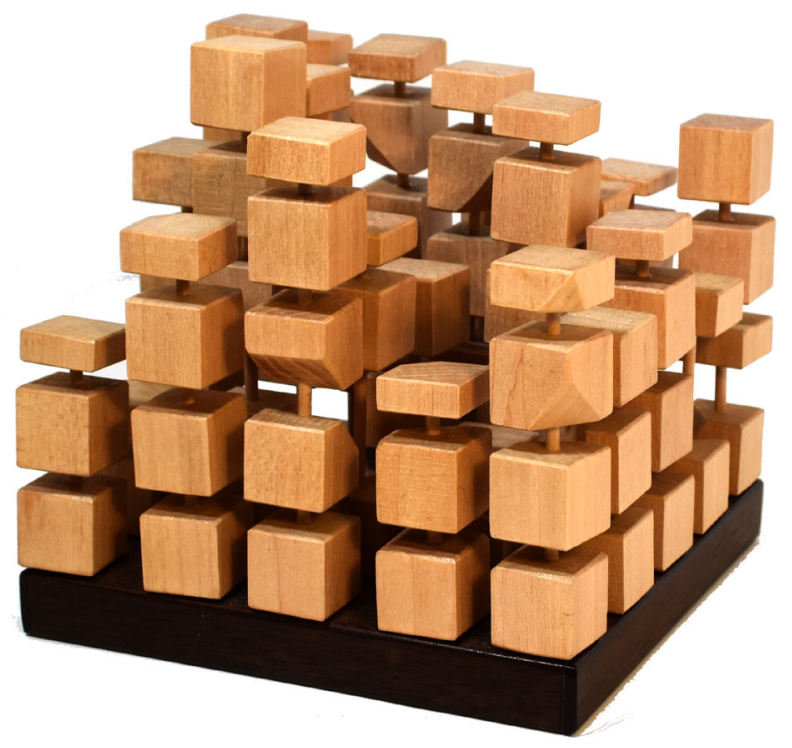

Figure 2.1.8: Abstract bass wood model experimenting with the implications of a 3 dimensional street grid network.

and the linking of towers with bridges at various levels above the ground plane.

Grade separated pedestrian walkways involve a partial duplication of the public flow system located directly above or below the existing ground plane. This is a condition that exists in cities like Hong Kong, Minneapolis, Montreal, Toronto, and Calgary. In Calgary, for example, the Plus 15 system is an extensive network of pedestrian walkways raised +15 feet above street level ${ }^{5}$. As illustrated in (Figure 2.1.4), in cities with grade-separated pedestrian walkways, both layers of the public flow system remain near

5 Graham, Stephen. Vertical: The City from Satellites to Bunkers. P. 236. London; New York: Verso, 2016. 


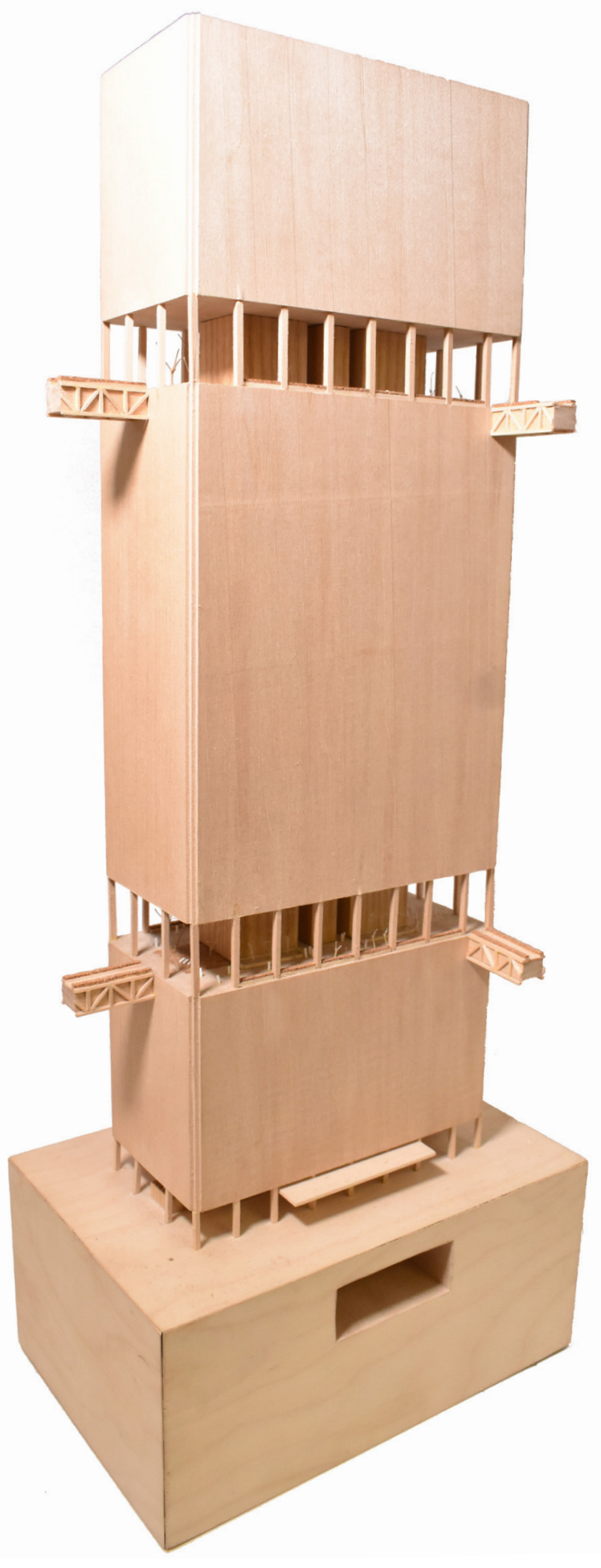

Figure 2.1.9: Bass wood model exploring a retrofit of Mies Van Der Rhoe's TD Center, linking into a 3 dimensional gird 


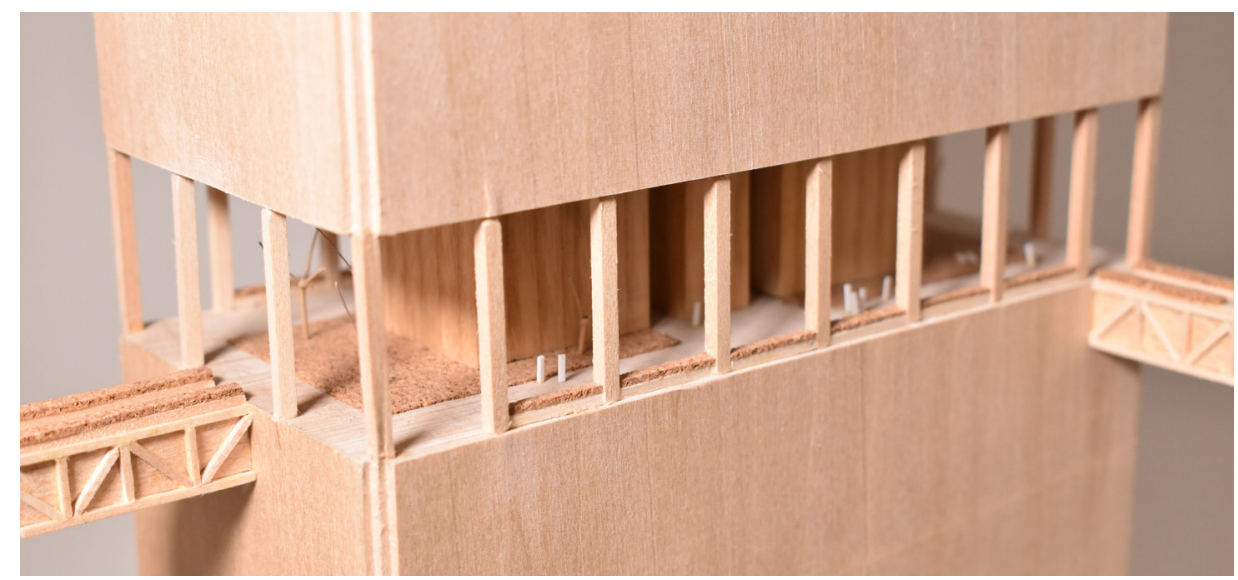

Figure 2.1.10: Detail of public space created at link

grade, while the upper volume of the city is only inhabited by adapted space in the form of common towers.

Linked towers with bridges high above the ground plane is arguably another way in which cities are duplicating the public flow system. One of the earliest examples was the 1960 National Congress Secretariat towers in Brasilia by Oscar Niemeyer that were internally bridged at floors 11 through 13 ${ }^{6}$. Other notable early examples, like the Petronas Towers in Kuala Lumpur (1997)7, were also linked by a single internal circulation connection. ${ }^{8}$ An emerging trend in luxury residential, commercial, and hotel developments, especially in Asia, is for towers to be linked together with external amenity-filled sky bridges, sky gardens, sky parks, sky streets, and sky platforms. In addition, these developments are increasingly linked at numerous intervals throughout their height. The Pinnacle housing development in

\footnotetext{
Wood, Antony, and Daniel Safarik. "Skybridges: A History and a View to the Near Future." Council on Tall Building and Urban Habitat Vol. 8, no. 1. (March 1, 2019): P. 10 of 18. https://doi.org/10.21022/ IJHRB.2019.8.1.1.

$7 \quad$ Dupré, Judith. Skyscrapers. New York: Black Dog \& Leventhal : Distributed by Workman, 1996.

$8 \quad$ Wood, Antony, and Daniel Safarik. "Skybridges: A History and a View to the Near Future." Council on Tall Building and Urban Habitat Vol. 8, no. 1. (March 1, 2019): P. 10 of 18. https://doi.org/10.21022/ IJHRB.2019.8.1.1.
} 
Singapore, for example, features extensive networks of sky streets that link seven residential towers at the $26^{\text {th }}$ and $50^{\text {th }}$ floors 9 . There are also numerous theoretical proposals for regularly linked towers at a massive scale. For example, Kenneth King and Kellog Wong's proposal for a Vertical City (Figure 2.1.6), features a series of mega towers linked by sky parks at regular intervals throughout their height ${ }^{10}$.

Early design research for this thesis investigated extending the city vertically through towers and bridges and the application of a three-dimensional grid. The abstracted block of 25 towers shown in Figure 2.1.7, presents how towers could be intersected at regular intervals with the intention that they would be connected through a network of bridges. A second model shown in Figures 2.1.9-10 explored a retrofit of Mies Van Der Rohe's TD Center in Toronto, where public spaces at the $17^{\text {th }}$ and $30^{\text {th }}$ stories were designed based on the assumption that they would connect into a three-dimensional city grid system.

Further research exposed flaws in the ability of this type of Multiple Ground Urbanism to extend a city's public flow system vertically. In all these scenarios, the public flow system is intended to be partially "duplicated" above the ground but:

Can there really be multiple grounds?

The current applications of Multiple Ground Urbanism seem to be based on the understanding of the flow system of a city as something that can be fragmented and duplicated without losing its essential qualities.

$9 \quad$ The Sky Scrapper Centre."The Pinnacle@Duxton Block 1A - The Skyscraper Center," 2019. http://www.skyscrapercenter.com/building/thepinnacle-at-duxton-block-1a/3582.

10 Schiller, Ben, and Ben Schiller. "A Vision Of The Vertical Cities Of

The Future." Fast Company, December 4, 2014. https://www.fastcompany. com/3038353/a-vision-of-the-vertical-cities-of-the-future. 
What are the essential qualities of the ground plane and flow system of a city, and can they really be fragmented and duplicated?

The theory of Landscape Urbanism provides a lens through which this question could be considered. In Programming the Urban Surface, Alex Wall explains the thinking behind the concept of Landscape Urbanism and why it should be the primary focus of urban design ${ }^{11}$. Essentially, Landscape Urbanism is the theory that the landscape of the city is what enables the organization of both objects (buildings) and the dynamic flow of urban activity $^{12}$. Here, landscape is understood not only as green area and natural spaces but as the "field that accommodates buildings, roads, utilities, open spaces, neighbourhoods, and natural habitats"13. Wall explains that landscape's enabling quality stems from its extensivity, inclusivity, as well as its "smooth and uninterrupted continuity" 14 .

In summary, according to the theory of Landscape Urbanism, the essential qualities of the ground plane (public flow systems) of cities is its ability to enable the existence and overlap of the many types of adapted spaces and activities that occur in a city. This enabling quality comes from its unbroken continuity and unconditional public access. Thus, to extend the city into its vertical real estate, then Landscape Urbanism suggests that the goal would be to extend the "flow system" vertically in a continuous and unconditional manner.

Based on the logic outlined above, both the current applications of Multiple Ground Urbanism, including

11 Wall, Alex. "Programming the Urban Surface." In Recovering Landscape, p.233-249. New York: Princeton Architectural Press, 2001. 12 Ibid. p.233.

13 Wall, Alex. "Programming the Urban Surface." In Recovering Landscape, p.233-249. New York: Princeton Architectural Press, 2001. 14 Ibid. 
grade-separated pedestrian networks and bridged private towers, cannot be considered extensions of the public flow system or "ground plane". What they are doing instead is creating fragments of semi-private connected space separate from the ground plane (Figure 2.1.11-13). While they may be intended as "public spaces" in the sky, their dependency on vertical access from within connected private buildings disengages them from the rest of the public realm. In the book Vertical, Steven Graham explains how these types of semi-private spaces mostly cater to the occupants of the elite condominiums and commercial buildings through which they pass and intend to connect ${ }^{15}$. Graham also argues that internalized, elevated "public flow networks" like Calgary's plus-15 system are not truly public as, in reality, they only cater to those that can be "commercially exploited "16. Graham's position is echoed in Junkspace by Rem Koolhaas, where Koolhaas claims: "because it costs money it is no longer free, conditioned space inevitably becomes conditional space..."17. Adapting Graham and Koolhaas's position would suggest that for a public flow system to be extended vertically in an uninterrupted, unconditional manner, it must occur entirely externally from enclosed, private, "conditioned" space.

\section{Extending the City Vertically: Continuous, Unconditional, External}

Outlined above is an argument for why extending the city vertically requires extending the public flow system in a manner that is continuous, unconditional,

\footnotetext{
15 Graham, Stephen. "Skywalk, Sky Train, Sky Deck: Multilevl Cities" in Vertical: The City from Satellites to Bunkers. P. 228. London ; New York: Verso, 2016.

16 Ibid.

17 Koolhaas, Rem. 2002. Junkspace. October. vol. 100, Obsolescence (Spring, 2002): 175- 190
} 


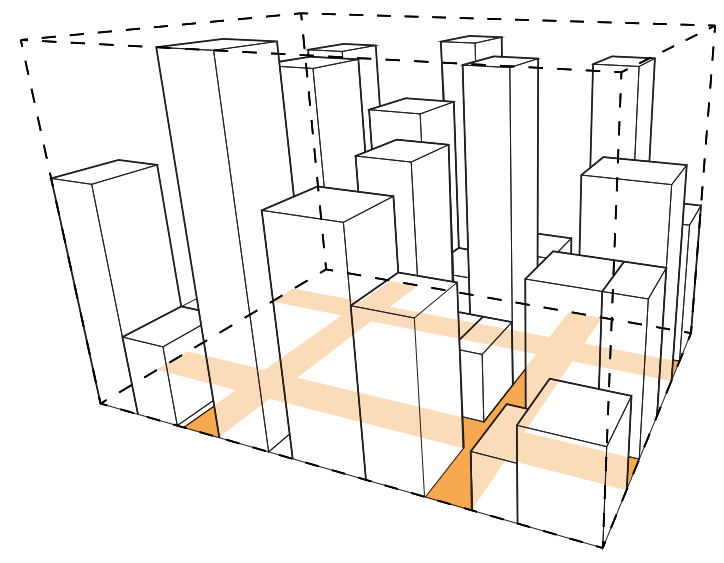

THE DEFAULT APPROACH: COMMON TOWERS

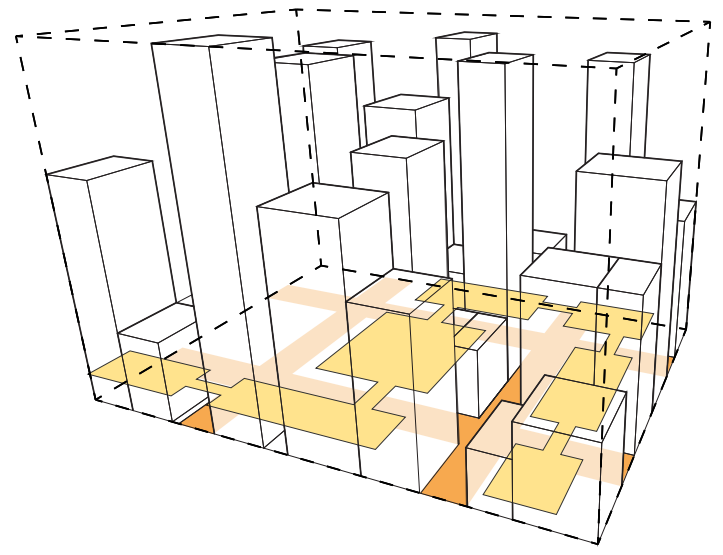

MULTIPLE GROUND URBANISM: GRADE SEPARATED PEDESTRIAN NETWORKS

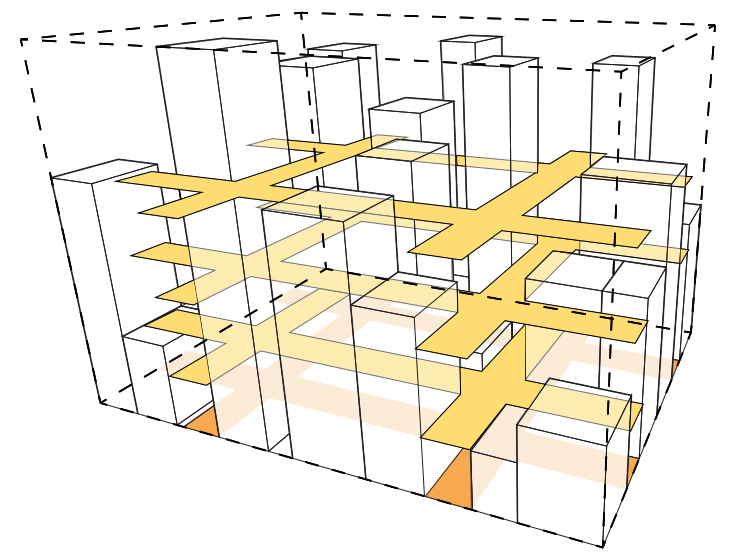

MULTIPLE GROUND URBANISM: SURFACES CONNECTED TO TOWERS AT MULTIPLE DAY-TUMS

Figures 2.1.11-13: Replication of previous diagram illustrating the semi private nature of duplicated flow systems 


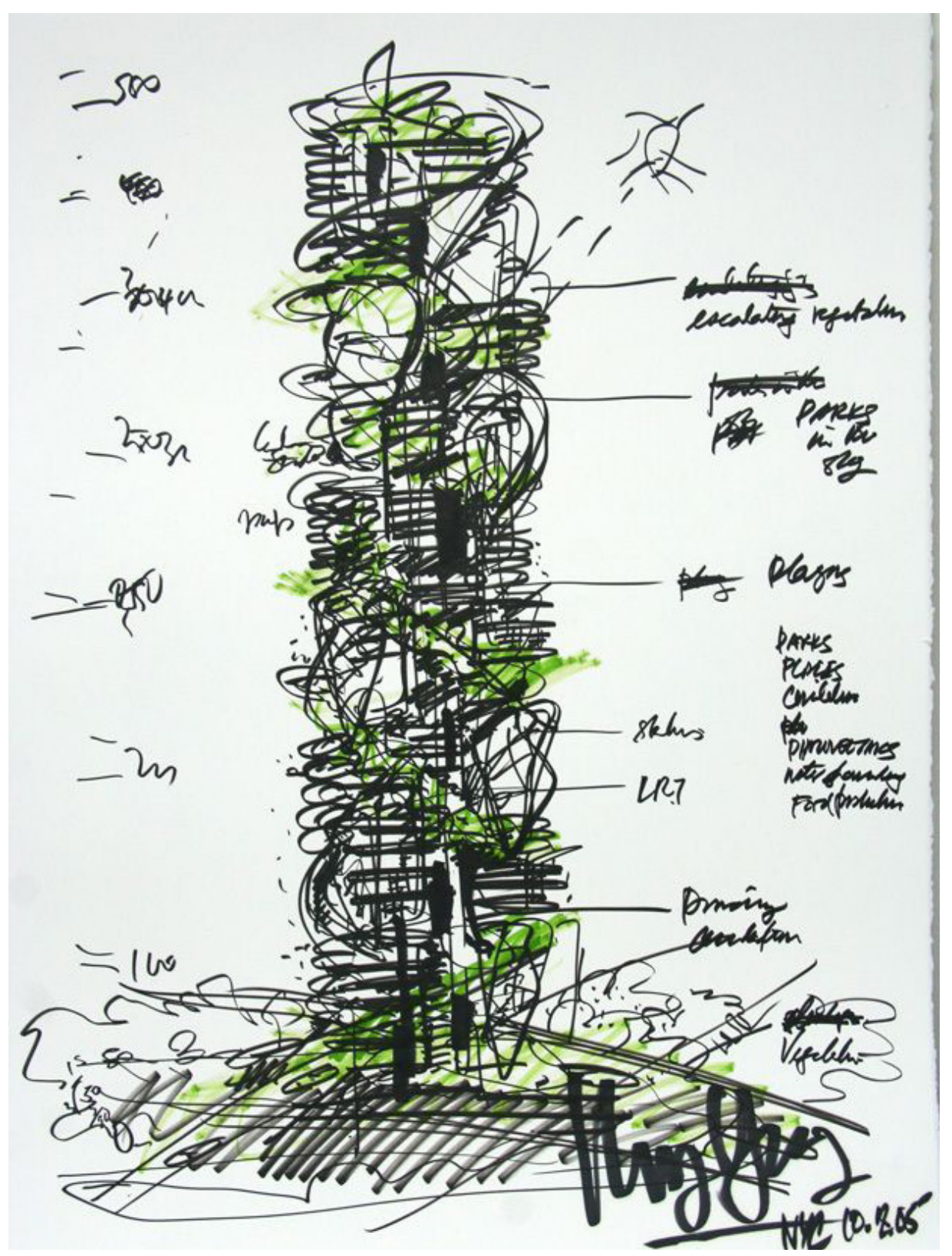

Figure 2.1.14: Sketch by ken yeah show continuous circulation through the height of a tower.

Liberty Science Cente. "Visions of the Future - Interviews + Art - LSC 2007," 2007. http:// helenealonso.com/portfolio-item/visions-of-the-future-architects-design-tomorrow\%e2\%80\%99sskyscrapers/.

and external. The work of Maylasian Architect and Author Ken Yeang has been highly influential in the formation of this thesis. Ken Yeang recognized this need for a continuous, externalized public space in his book Reinventing the Skyscraper published in 2002, as well as in a number of his earlier 


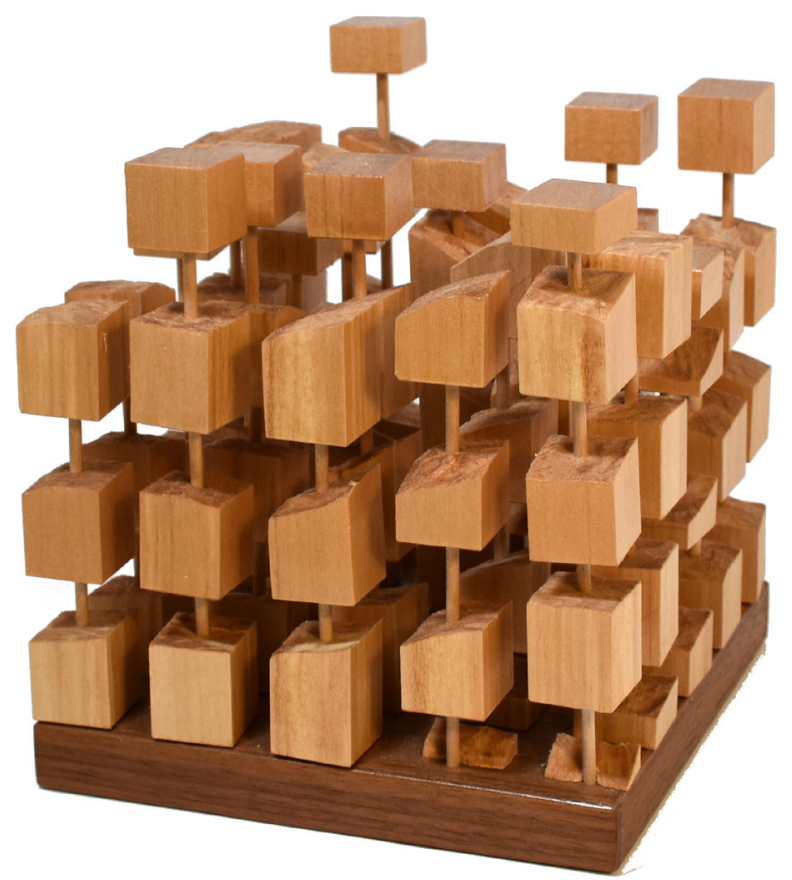

Figure 2.1.15: Abstract bass wood model experimenting with the implications of a continuous landscape throughout it's height.

publications ${ }^{18}$. Yeang often addressed this need by providing an uninterrupted spiralling ramp circulation throughout the height of his towers (Figure 2.1.14) 19. Ken Yeang's work highlights how many forms of mechanical transportation, main elevators, localized elevators, gondolas, light rail transit, could serve to supplement a central ramped public circulation 20. The supplementation of the vertical extension of the city with various modes of transportation is discussed further in Section 2.6 of this document. While the goals of Ken Yeang's work are in alignment with those of this thesis, one critique of his work 18 Yeang, Ken. "Nagoya Expo Tower" in Reinventing the Skyscraper: A Vertical Theory of Urban Design. Chichester, West Sussex, England ; Hoboken, N.J: Wiley-Academy, 2002.

19 Ibid.

20 Ibid. 
is that he consistently constrains the extensions of the city vertically within the boundary of a single tower. A shortcoming of this approach is that the continuous ramps demand a tremendous amount of infrastructure and real estate within the tower, making the proposal somewhat impractical.

Evolving design research explored the possibility of removing the responsibility of extending the public flow system in a manner that is continuous, unconditional, external, from having to occur within a single tower. Instead, the responsibility of vertically extending the public flow system was explored as a shared infrastructure. The intention was that the public flow system, the urban landscape would climb into the volume of a city through the intersection and bridging of many towers. The distribution of necessary infrastructure across many buildings was intended to minimize the dedicated real-estate within any one single structure. This strategy was again explored using an abstracted block of 25 towers (Figure 2.1.15). A double helix landscape was carved through the solids making continuous planes that could be connected by bridges. During the AR8103 Studio, this continuous landscape was imagined to extend and interconnect the closely spaced towers of Toronto's Financial District (Figures 2.1.16-17).

\section{Conclusion}

In conclusion, this section aimed to develop the theoretical framework necessary to explore how a city could be extended vertically to inhabit its own vertical real estate.

It began by breaking down the city into three basic components: the public flow system, adapted spaces, and voids. It then used a critical analysis of current urban forms and the theory of Landscape Urbanism to build a case for why vertically extending 


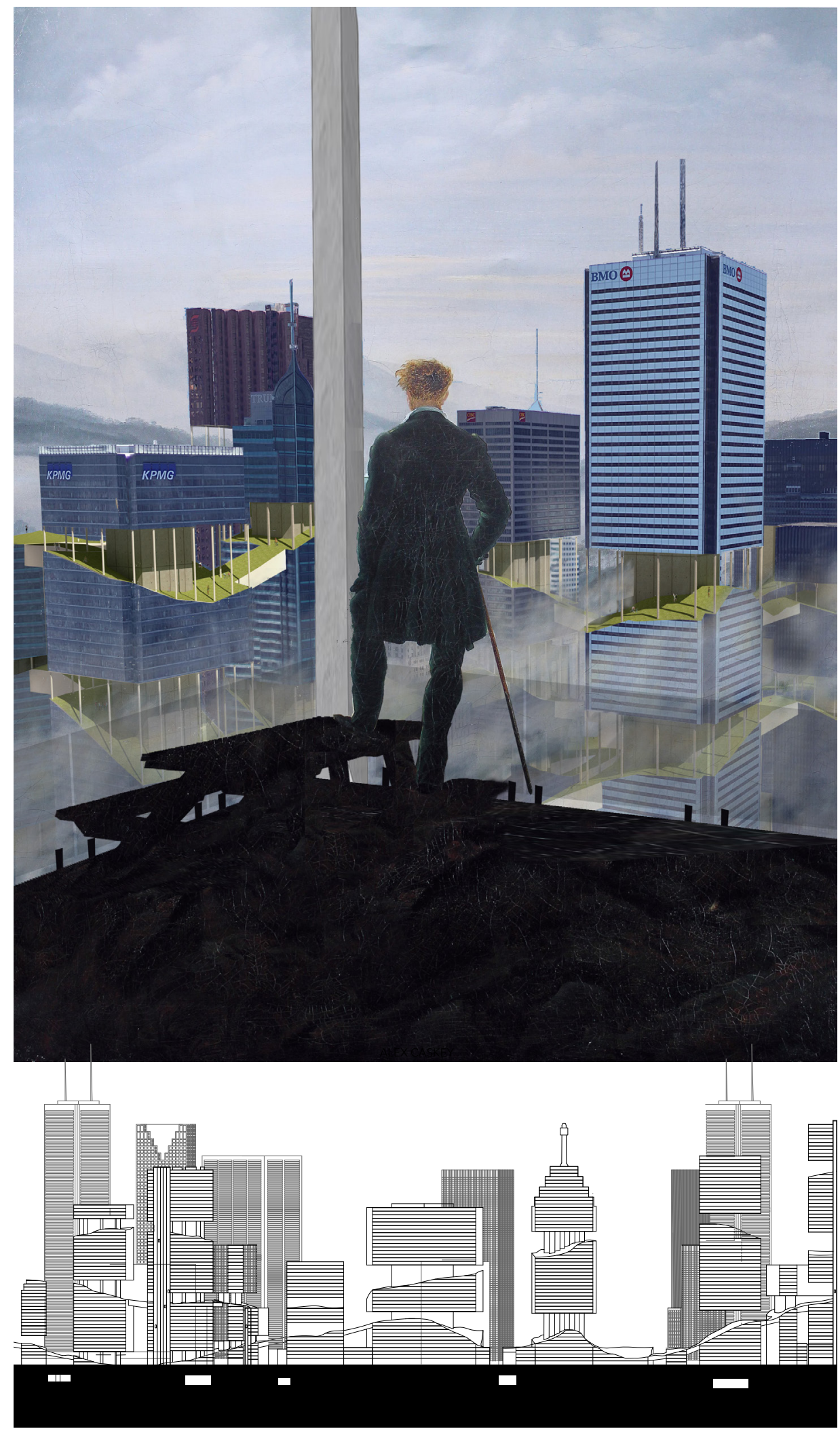

Figures 2.1.16-17: Top: "sublime" rendering showing landscape extending through Toronto's financial district. Bottom : Unraveled section illustrating continuity of ground plane. 
the city requires extending the public flow system in a continuous, unconditional, and external manner. The end of this section explained why exploring this extension of the flow system as a shared public infrastructure would minimize dedicated real estate within any one single tower. 


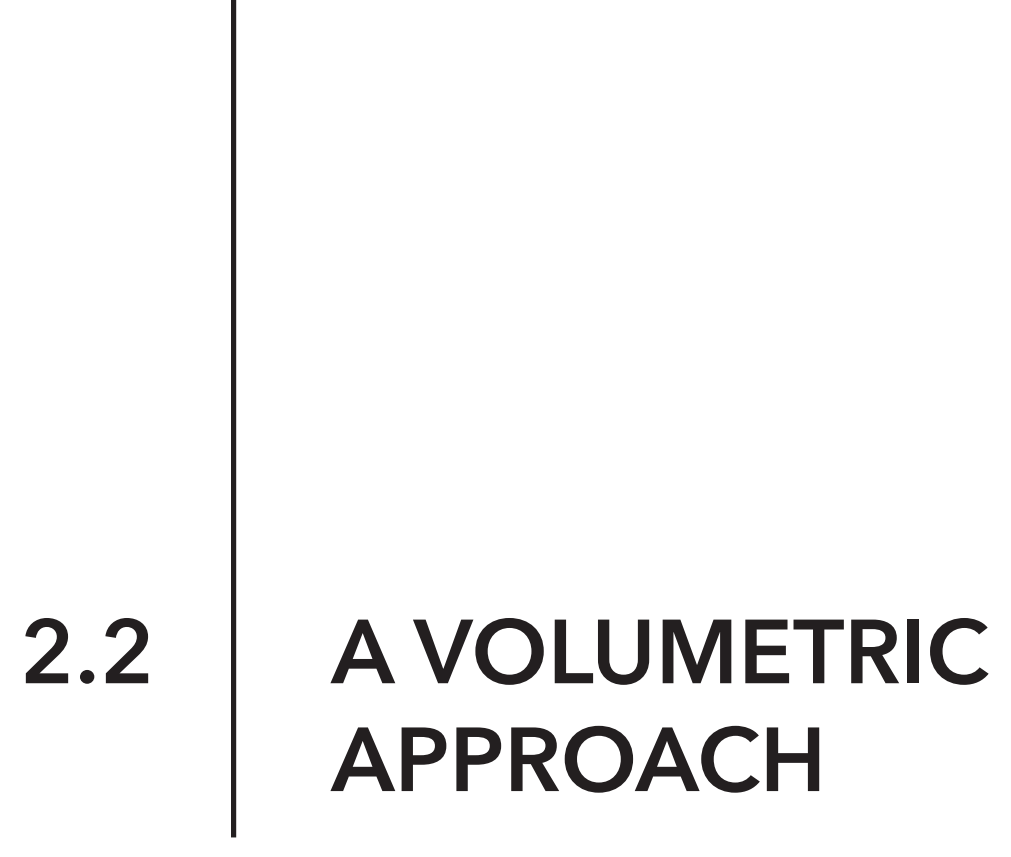

This section explains the thinking behind two exploratory design research models that led to a refinement of the ideas of this thesis. The subtractive and additive models represent a departure from the concept of towers linked by bridges that had initially been the underlying thinking in this thesis.

\section{Subtractive Model}

In his 1996 essay The Present Urban Predicament, Colin Rowe presented a critique of the modernist approach to architecture and urban design. He claimed modernism was in pursuit of a scientific method, which he felt represented the spirit of the times over the spirit of a place, fixated on objects, and avoided the use of voids ${ }^{1}$. He then proposes four "prescriptions' intended to form an alternative approach to urban design, each of which he grounded in historical precedents²:

1. Instead of treating every building as an important object: retain a uniformity of urban fabric, break from the uniformity only for

Rowe, Colin. "The Present Urban Predicament." In As I Was Saying: Recollections and Miscellaneous Essays., Vol. 1:168-169. Cambridge: The MIT Press, 1996. 


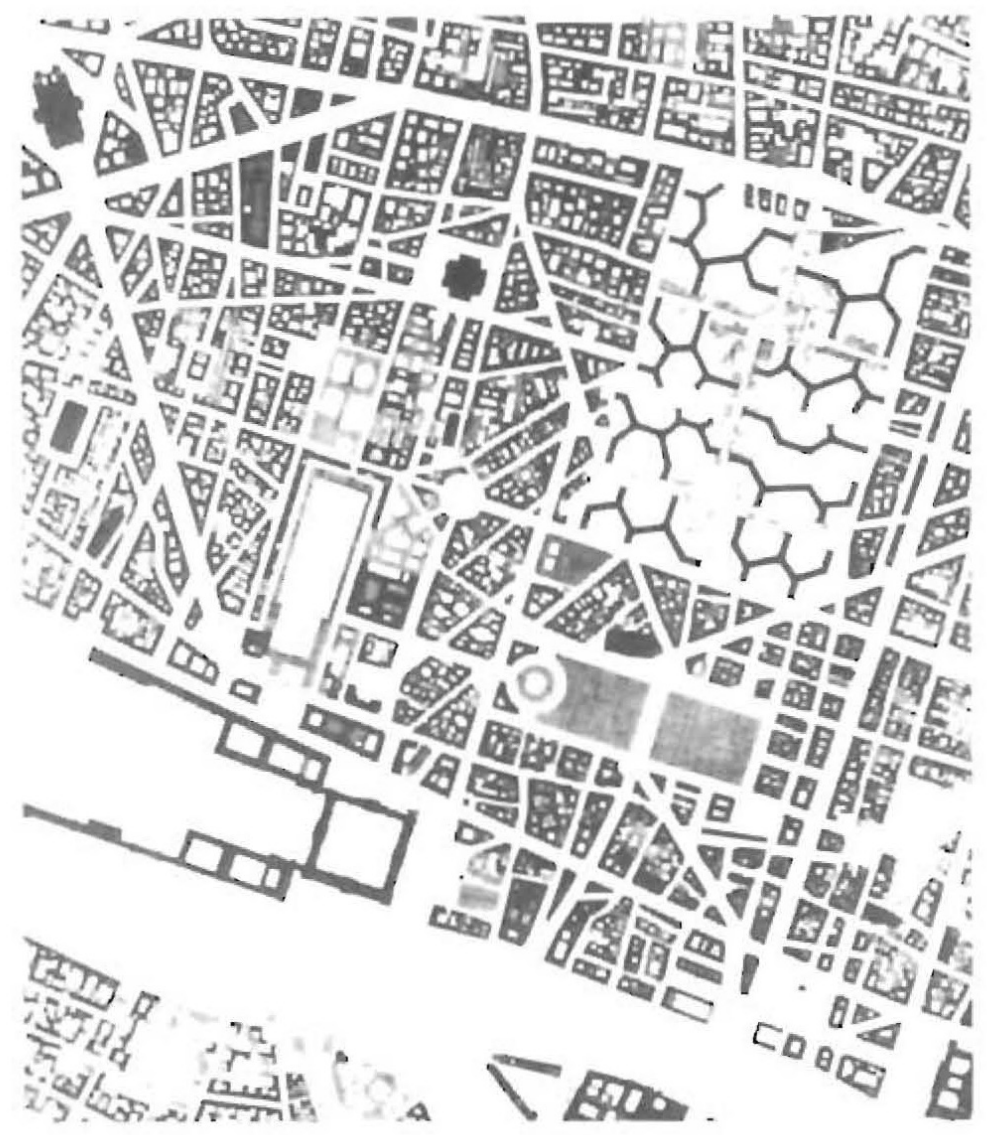

Figure 2.2.1: Map that illustrates the historic(subtraction) vs. modern (object in space) approaches to urban design in Paris Rowe, Colin. "The Present Urban Predicament." In As I Was Saying: Recollections and Miscellaneous Essays., Vol. 1:165-220. Cambridge: The MIT Press, 1996.

buildings of significance.

2. Instead of objects placed in open space: open space should be subtracted from a continuous urban fabric

3. Instead of just acting as linear objects in space: linear buildings should be used to frame internal urban spaces

4. Instead of endless greenspace: the internal voids should give rise to the reconstitution of the garden

Rowe's main argument was that urbanistically, the externalization of open space and the object buildings of modernism produced less activated spaces than the internalized spaces of historical cities 


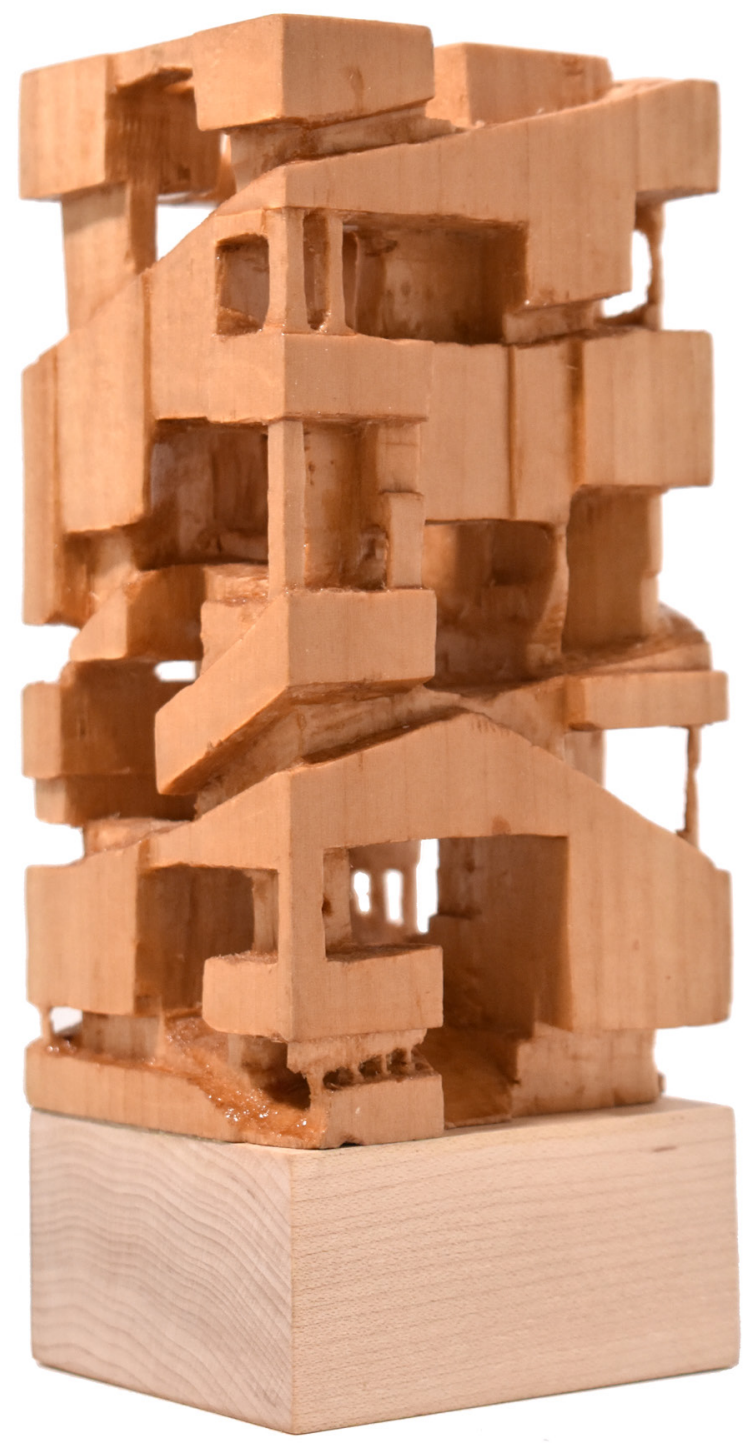

Figure 2.2.2: Bass wood subtractive model where continuous circulation \& public space voids were remove from a solid block, leaving what was remaining to act as real-estate.

(Figure 2.2.1).

While initial design research explorations had been focused on extending the flow system of a city by connecting discrete towers with bridges as a means of achieving continuity, Rowe's essay offered an 


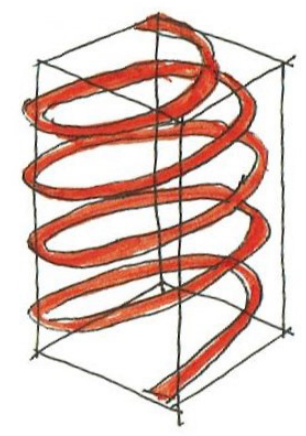

STREET

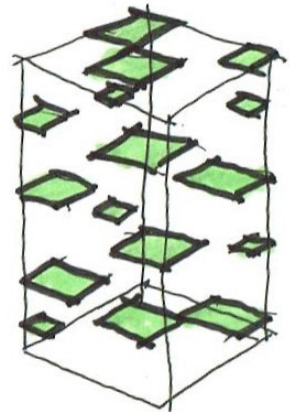

PUBLIC SPACE

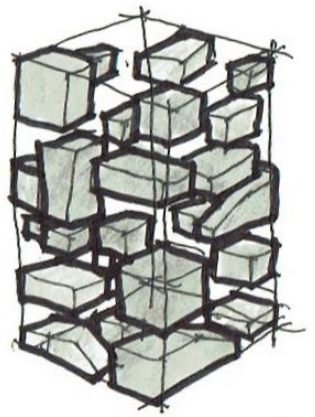

REAL ESTATE

Figure 2.2.3: Sketch showing hierarchy of subtractive model alternative perspective.

What if the idea of a tower was replaced? What if instead, the circulation and public spaces of a city were carved out of a volume, and what remained became the city's vertical real estate?

This was explored by carving out a solid block of basswood that was meant to represent a volume of a city (Figure 2.2.2). First, the continuous circulation was carved into the block, followed by the subtraction of voids public space, light, and air. The remaining volumes became the real estate of the city (Figure 2.2.3).

This model represents a significant change in thinking about how a city could inhabit its vertical space. In this scenario, real estate becomes vertically fragmented; the continuous vertical extension of the urban landscape enables the volume of realestate to exist independently from the ground plane. The fragmentation of vertical real-estate presents new opportunities for diverse programs to exist in 


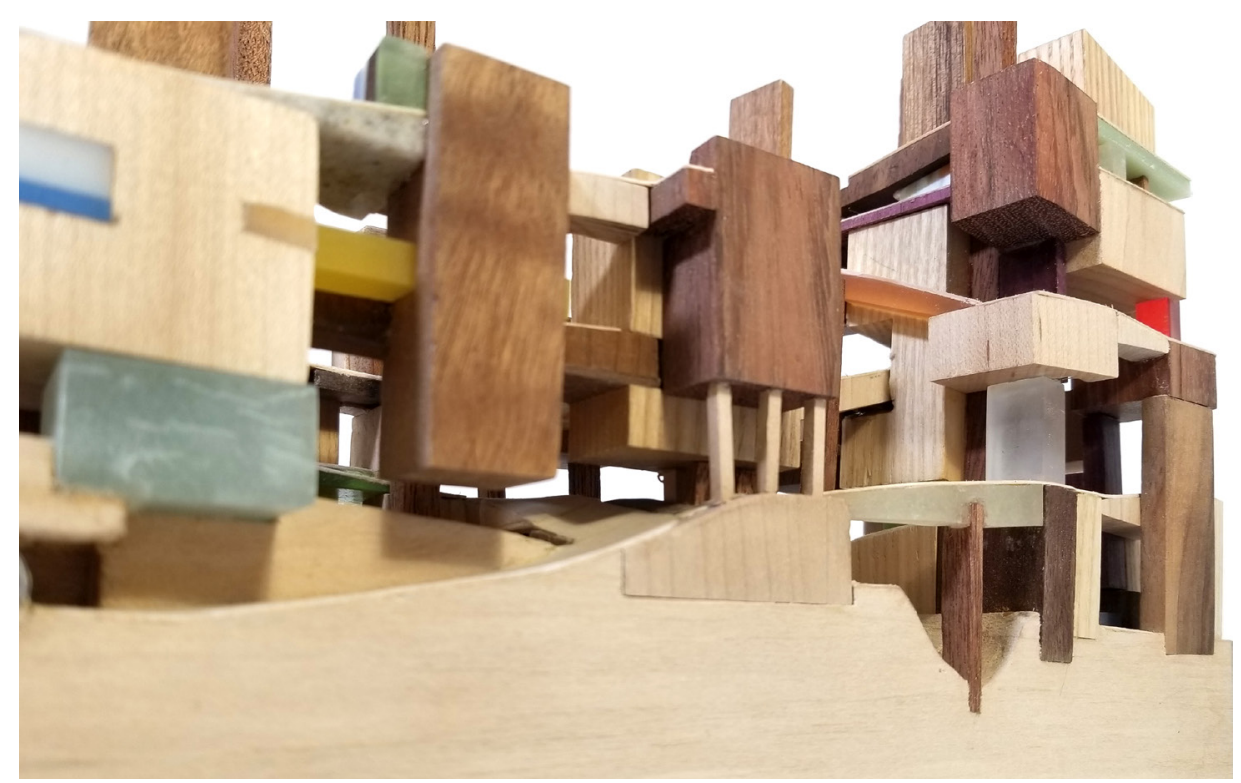

Figure 2.2.4: Close up image of subtractive model showing a variety of urban conditions

vertical spaces that were not previously supported by the common tower and the default approach to verticality.

\section{Additive Model}

While the subtractive model was extremely useful in presenting relationships and a concept of space, cities do not start out as a three-dimensional mass; they start as a void. Even in Rowe's reference to historic cities, the "solid urban fabric" is developed over time in an additive manner over multiple generations. Organizing the volume of a city required taking the ideas from the subtractive model and applying them to a volume in an additive manner.

The next model explored the extension of a city through a diagrammatic additive model (Figures 2.2.4-5). A solid block of basswood was given simple topographical characteristics, including a 1:12 slope, a river crossing, and underground tunnels. This was intended to make it suggestive of a fragment of a larger city. A plywood formwork was cut to fit around the outside to mark the extent of the "void" that 


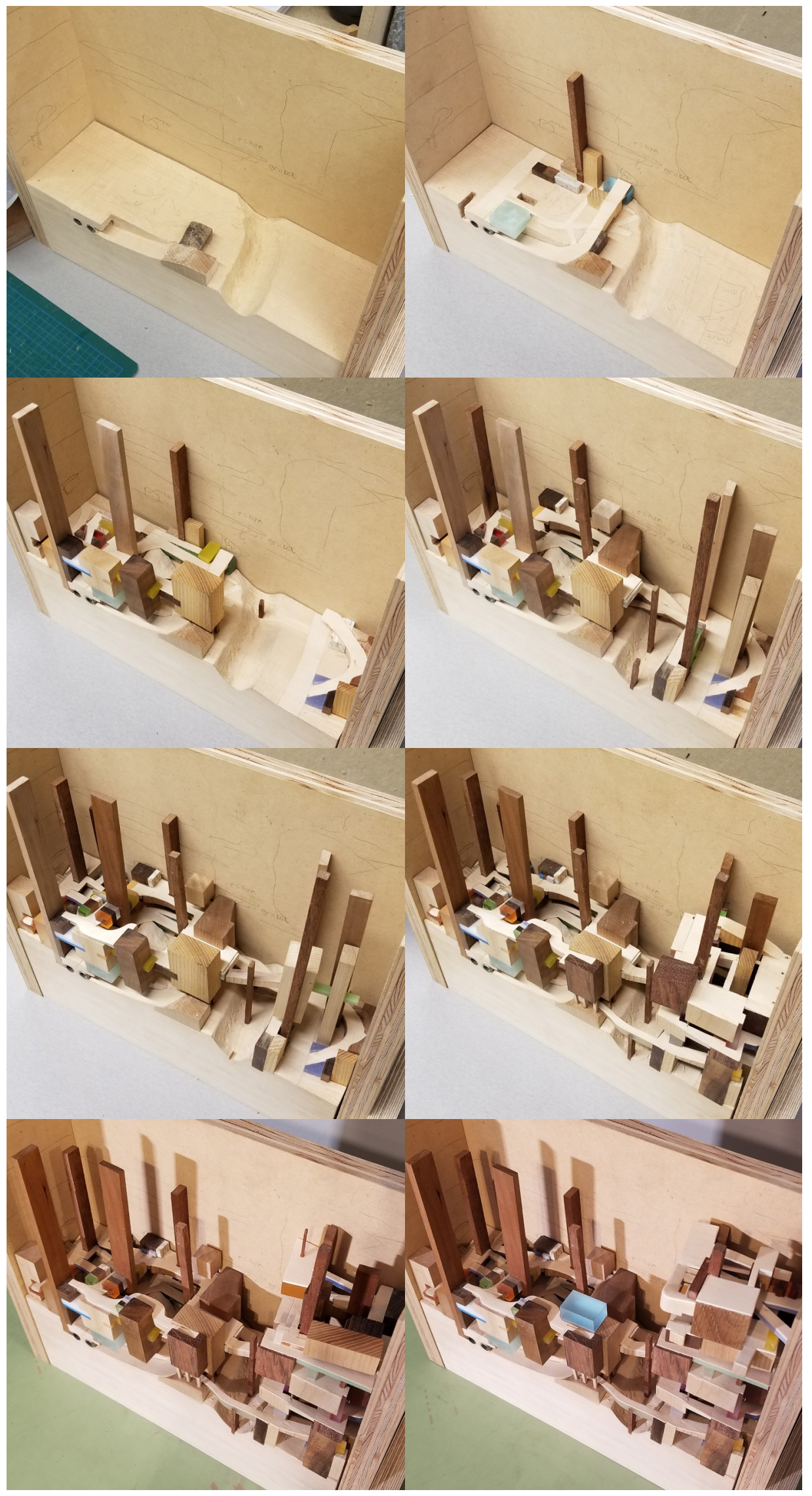


Figure 2.2.5 (Opposite Page): Sequence photos of additive model show progression of the growth of the model.

could be filled out. The diagrammatic city fragment was then extended vertically using small pieces of hardwoods and acrylic stacked from the ground plane up. The flow system of the ground plane was extended vertically from multiple points in a continuous manner. This was an attempt to introduce the characteristics of multiplicity, redundancy, and choice typical of a city's ground plane flow system.

Supplementary to the public flow system, vertical elements extend at multiple points throughout the city fragment. These are intended to be suggestive of ways in which services and vertical transportation would support and supplement the continuous public flow system. This is further discussed in Section 2.6. The variability of the material used in this model was meant to be suggestive of multiple ownership and programmatic uses made possible by the extension of the continuous public flow system. The brightly coloured acrylics are intended to suggest unique forms of adapted space that would typically be limited to the ground plane due to their dependence on adjacency to the public flow system (See Section 2.3). The considerations of practical structural configurations were not considered a priority in order to explore the potential for new formal configurations. This model is a work in progress. It has been extremely valuable as a means of presenting unique relationships and opportunities for a wide range of urban conditions that will be explained further in the next sections.

\section{Conclusion}

The design research models in this section represent a pivotal divergence from towers as the organizational structure of vertical inhabitation. 
What emerged from this research was an alternative approach to developing vertical architecture in which the components of a city, including the flow system, adapted space, and voids, could be organized as a complex network within a three-dimensional city volume. 


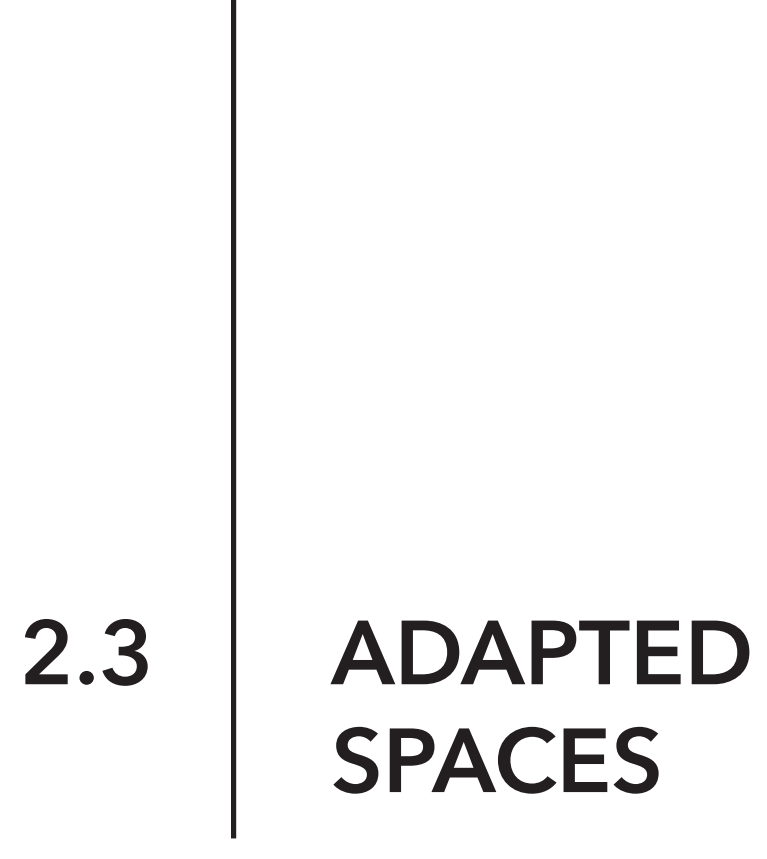

This section explores the factors necessary to enable adapted space to exists and be desirable in an aboveground context. Figure 2.3.1 shows a maquette type model that illustrates a configuration of adapted spaces in an isolated vertical context.

An analysis of existing cities showed that when it comes to desirability or suitability, not all uses, occupancies, and functions for adapted spaces have the same requirements. From this observation, it became necessary to introduce another level of reduction to the three-part urban form reduction established in Section 2.1:

1. Public Flow System

2. Voids

3. Adapted Spaces / Real Estate

a. Urbanistically Independent Spaces

b. Urbanistically Dependent Spaces

\section{Urbanistically Independent Spaces}

There are some types of adapted spaces that exist and even thrive independently from the public or urban realm. Their uses often include, but are not limited to, private occupancies like condos, apartments, offices, factories, storage facilities, vertical farming, and other uses that do not have a 


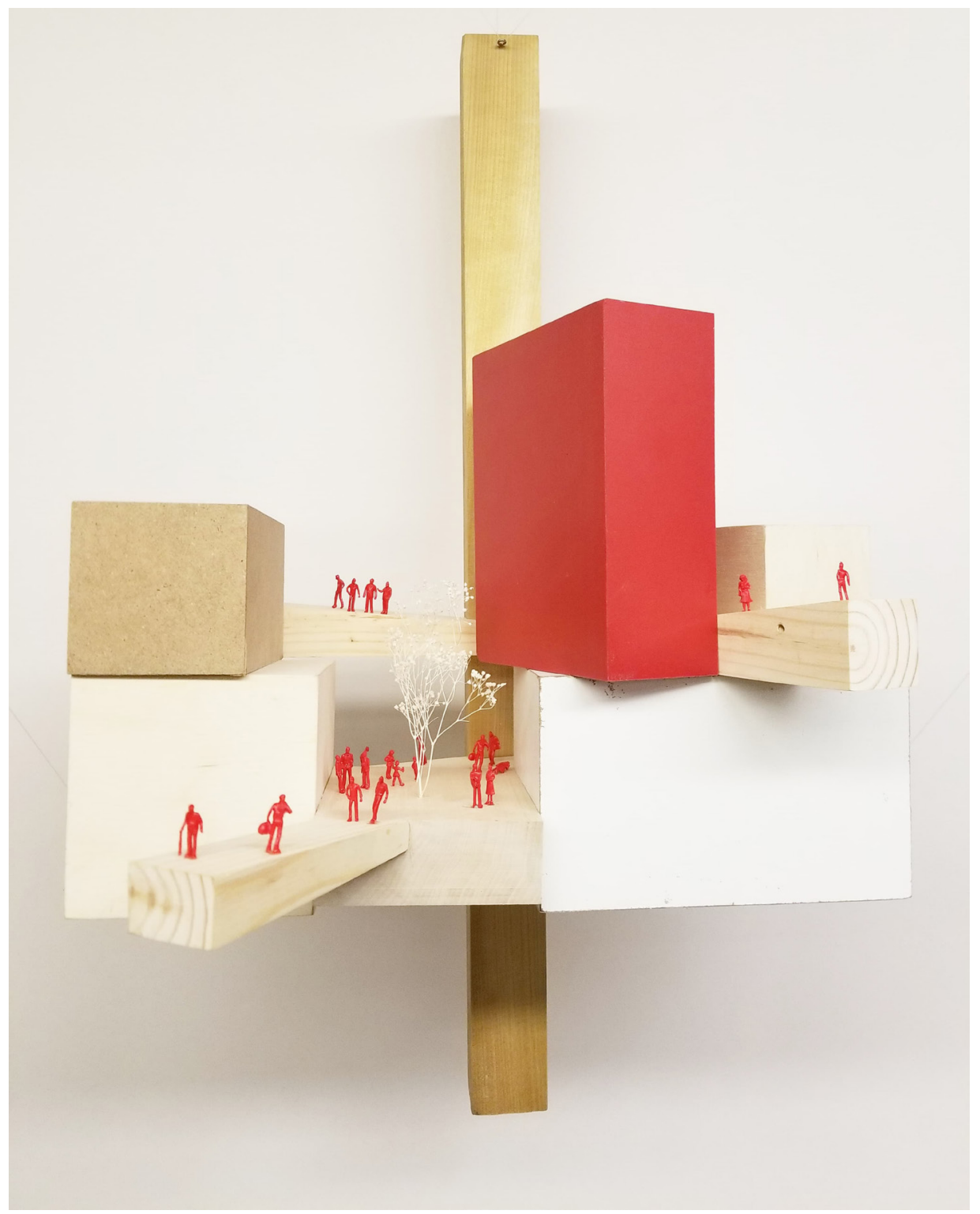

Figure 2.3.1: Maquette model showing the existence of adapted space in vertical space without a resolution of the infrastructure needed to support it.

strong dependence on adjacency to the public flow system. In these types of spaces, privacy and removal from the urban realm has minimal impact on their usefulness and may even be desirable.

The analysis of how, at a basic level, these types of spaces are currently supported at the ground plane, involves a return to the theory Landscape Urbanism introduced in Section 2.1. In Programing the Urban Surface, Alex Wall suggests that the ground plane 
enables the existence of this type of adapted space within the city ${ }^{1}$ by providing three things:

1. support structure,

2. physical access

3. connection to public utilities.

These three fundamental "enablers" could thus be regarded as all that is required for useful adapted spaces to exist. It is assumed here that other aspects of adapted space like enclosure, circulation, distribution of services and internal structure are considered to occur within the boundary of adapted space itself. It should be noted that the location, configurations and sizes of some spaces are more well suited to the specific requirements for functions, occupancy or uses. For example, the requirements for daylighting, and ventilation for office and residential spaces would differ significantly from those for storage facilities. It is possible, however, to conclude that as long as the three "enablers" (supporting structure, access, and services) are provided, adapted space could exist in a vertical context without having a physical connection to the ground plane.

\section{Urbanistically Dependent Spaces}

There are certain forms of adapted spaces whose functionality, occupancy, usefulness is dependent on its accessibility to the general public. Theses spaces rely on things like localized density and consistent traffic flow. Their uses often include, but are not limited to, commercial retail and other customer dependent businesses, as well as public amenities and services such as parks, gathering areas, community centers, educational facilities, recreational facilities, libraries, and other similar uses. For these spaces, there is increased importance on location

Wall, Alex. "Programming the Urban Surface." In Recovering Landscape, p.233-249. New York: Princeton Architectural Press, 2001. 


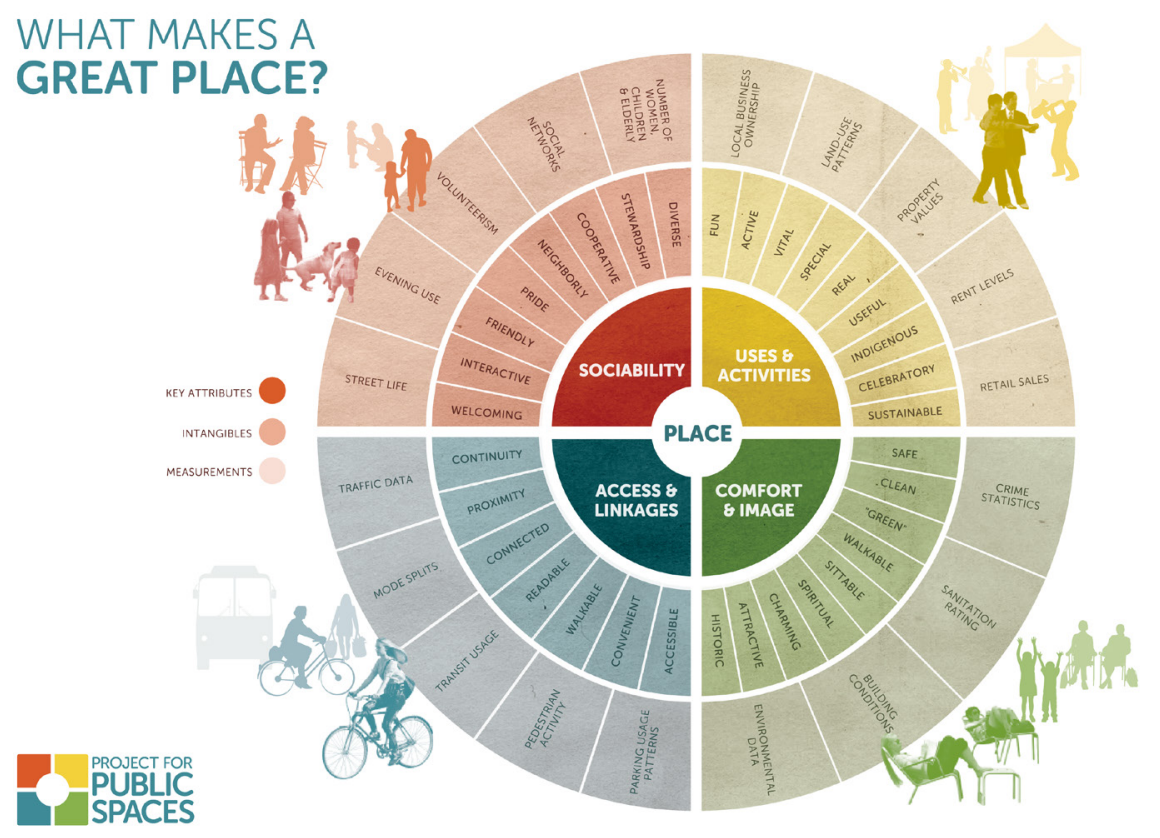

Figure 2.3.2: A diagram from the Project for Public Space showing the components of sucessfull public spaces

Project For Public Space. "What Makes a Great Public Space." Project For public Space, 2016. https://www.pps.org/article/you-asked-we-answered-6-examples-of-what-makes-a-great-publicspace.

and direct accessibility and visibility from the public flow system. The enabling qualities for urbanistically dependent spaces become:

1. support structure,

2. physical access

3. connection to public utilities

4. direct adjacency to the public flow system

5. sufficient localized density or traffic flow

Adjacency to the public flow system and density or traffic is what enables the existence and success of this second type of adapted space. It is no surprise that retail spaces in the high traffic, walkable areas, are typically the most desirable as well as the most expensive ${ }^{2}$. Figure 2.3.2 shows a diagram in which $2 \quad$ CCIM Institute. "Retail Location Strategies | CCIM Institute." Accessed April 16, 2020. https://www.ccim.com/cire-magazine/articles/ retail-location-strategies/?gmSsoPc=1.

Dependence of retail on traffic and walkability are also reflected in: Speck, Jeff. Walkable City Rules: 101 Steps to Making Better Places. Washington, 


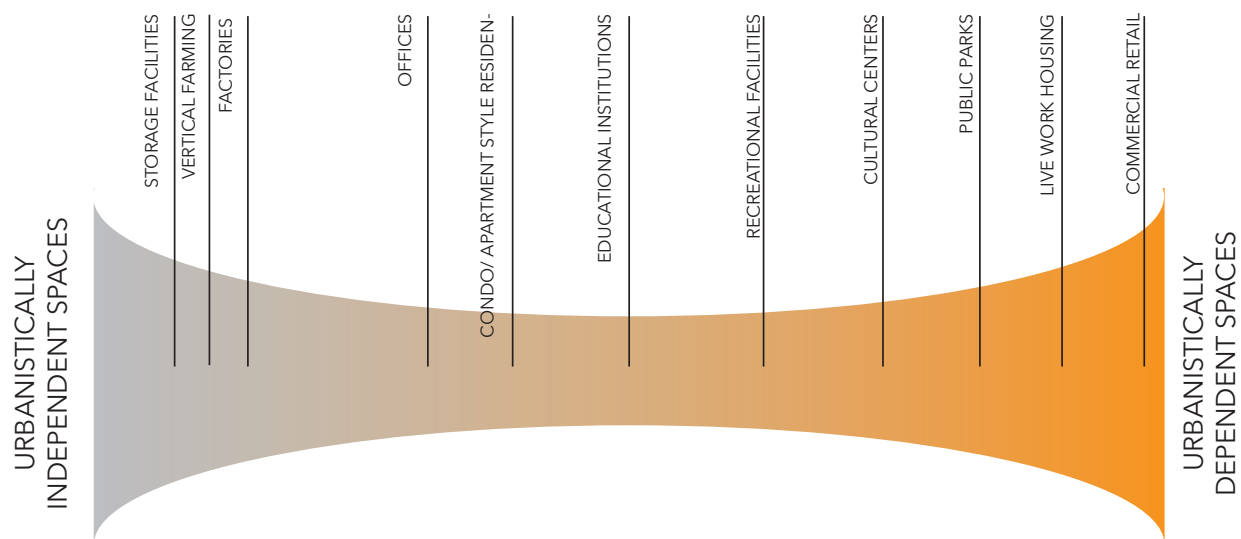

Figure 2.3.3: Diagram illustrating the spectrum on how function and uses of spaces in cities depend on their adjacency to the public flow system and localized density. It should be noted that the placement of functions and uses is relatively arbitrary that in reality would could be determined by context analysis.

the non-profit group Project for Public Spaces (PPS), lays out what they have established as the requirements for successful public spaces. The need for adjacency to the public flow system and density or traffic is reflected by the requirement for "Access and Linkages," meaning the direct and convenient accessibility of a space. It addition, the requirements for "Comfort and Image," suggest safety and comfort stem from visible accessibility and continuous flow of people in and around the space ${ }^{3}$.

\section{The Urbanistic Dependence Spectrum}

Urbanistically dependent and independent spaces should not be viewed as a rigid division of the functionality, occupancy, usefulness of spaces in a city but rather as the two polar extremes of a spectrum.

DC: Island Press, 2018.

3 Project For Public Space. "What Makes a Successful Place?" Project For Public Space, 2016. https://www.pps.org/article/grplacefeat.

These ideas of comfort and safety are also echoed in: Jacobs, Jane. "The use of neighborhood parks" in The Death and Life of Great American

Cities. Vintage Books ed. New York: Vintage Books, 1992. 
Figure 2.3.3 is a simplified illustration of this type of thinking where the right side of the spectrum indicates a dependence on direct adjacency to localized density or traffic, while the left indicates independence from these factors. The diagram features the placement of uses and functions to illustrate how this might be taken into consideration. This is meant only as an example. Based on context and intent, functions, uses, and occupancy may fall in different places within this spectrum.

\section{Extending the City Vertically: Extending Urbanisticaly Dependent Spaces}

The reason for differentiating between types of adapted spaces outlined above can be explained through an analysis of the default approach to verticality. In the default approach, the public flow system is limited to the ground plane, while the adapted spaces of common towers extend vertically. With this urban configuration, the urbanistically dependent spaces of the city, like shops and cultural centres, are limited to lower levels of the city because of their requirement for adjacency to the public flow system (Figure2.3.4). Here, the adapted spaces in the height of the city are only suitable for urbanistically independent functions.

Section 2.1 explained how the main research goal of extending the city vertically could be thought of as extending the public flow system vertically. This goal of extending the city vertically could equally be thought of as extending urbanistically dependent spaces into the height of the city. As outlined above, the requirements for these types of spaces are what necessitates the extension of the public flow system.

\section{Layering the City}

In addition to providing perspective on the 


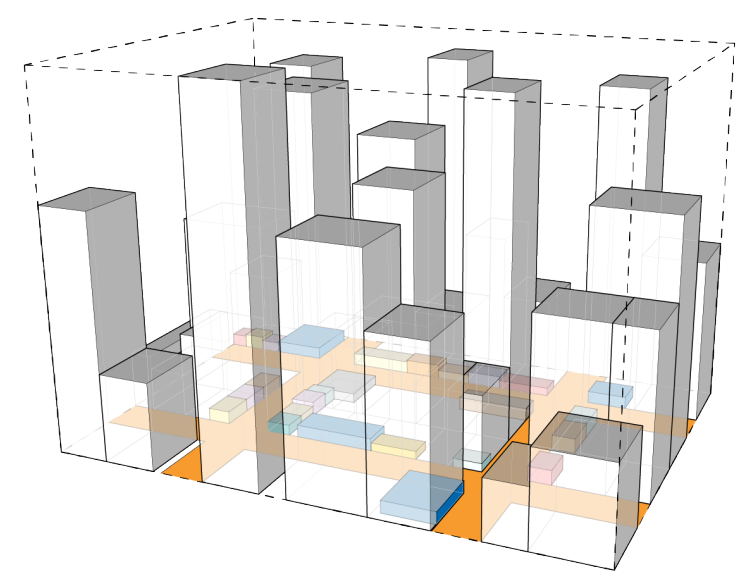

THE DEFAULT APPROACH: COMMON TOWERS

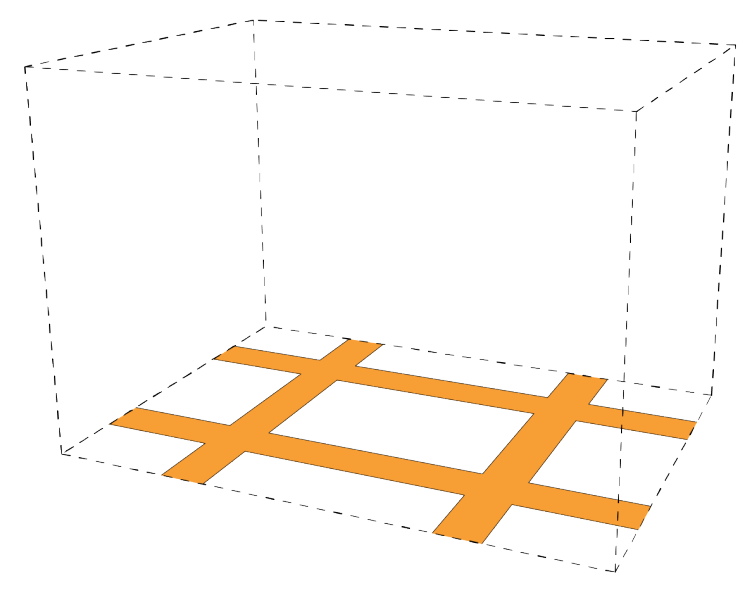

PUBLIC FLOW SYSTEM AT GRADE

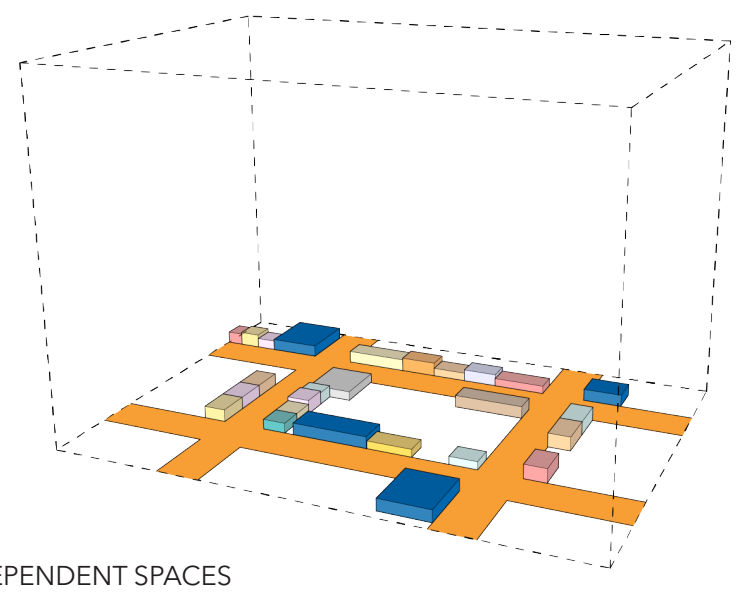

URBANISTICALY DEPENDENT SPACES

Figure 2.3.3: The Default Approach: Urbanisitcally Dependent Spaces limited to ground plane where they are adjacent to the public flow system. The height of the city is only suitable for Urbanistically Independent Spaces. 

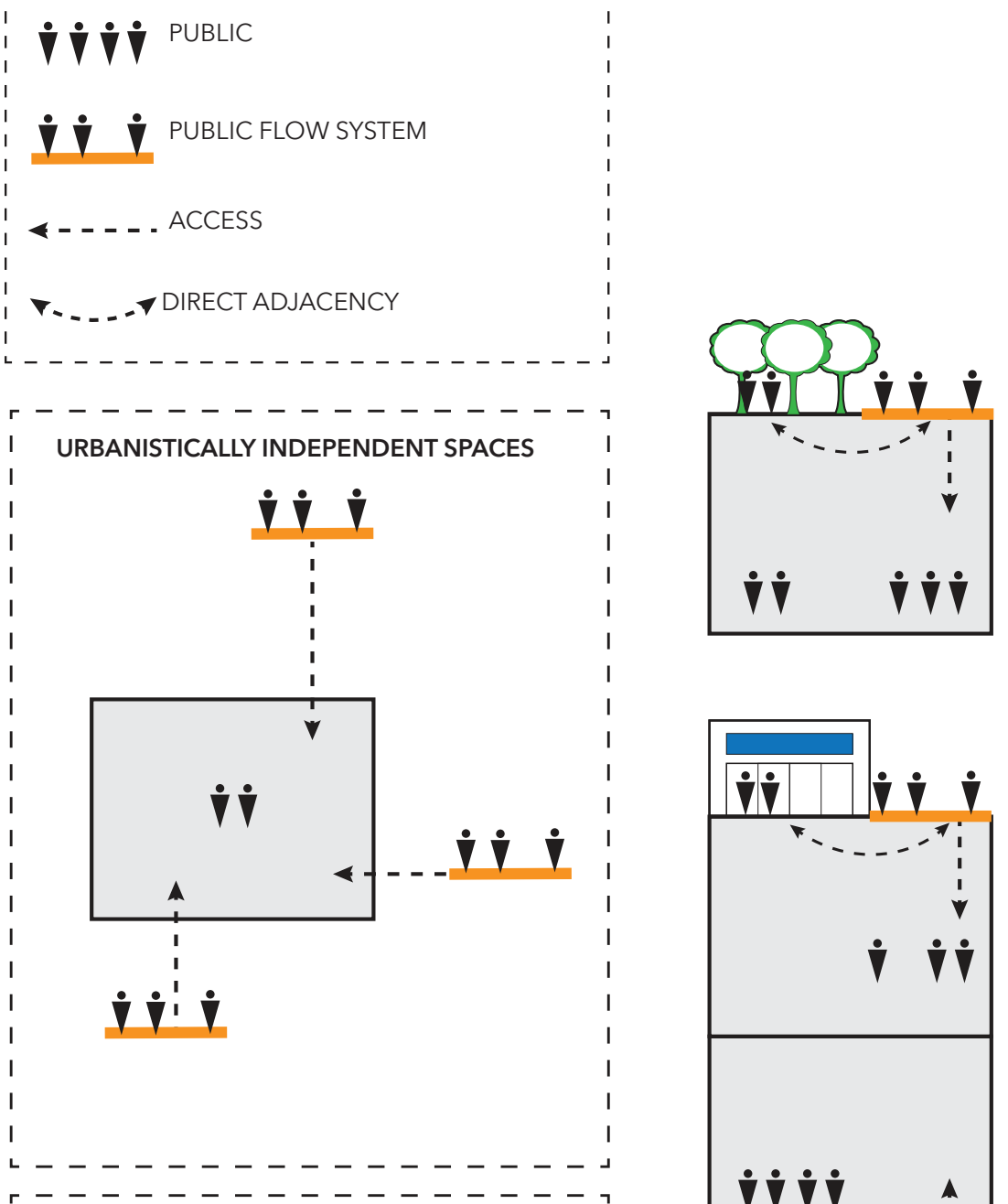

URBANISTICALLY DEPENDENT SPACES
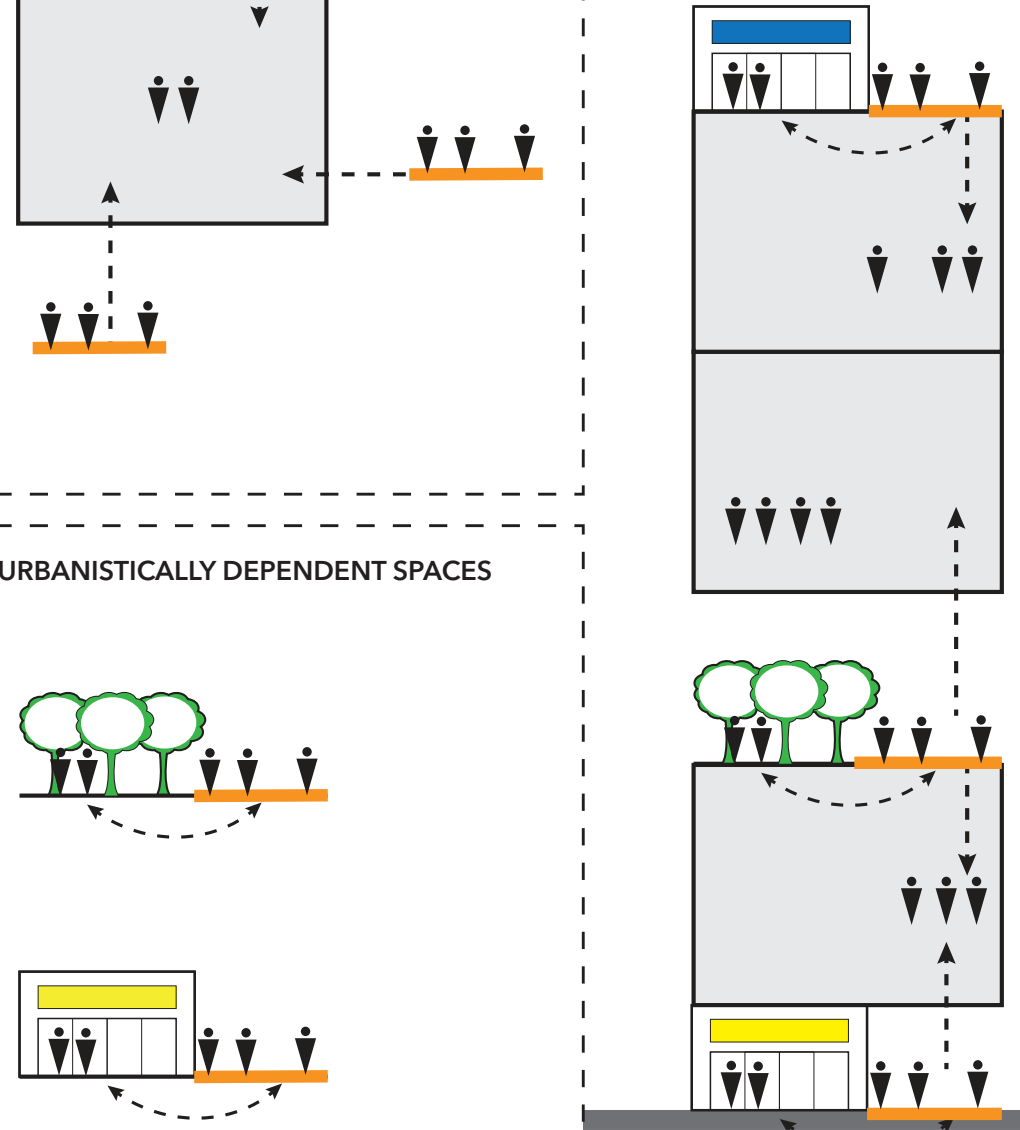

- - - - - - - - - - - -

Figure 2.3.5: Diagram of the adjacency requirements for urbanistically independent and dependent spaces in relation to the public flow system. (Structure and utilities not shown) 


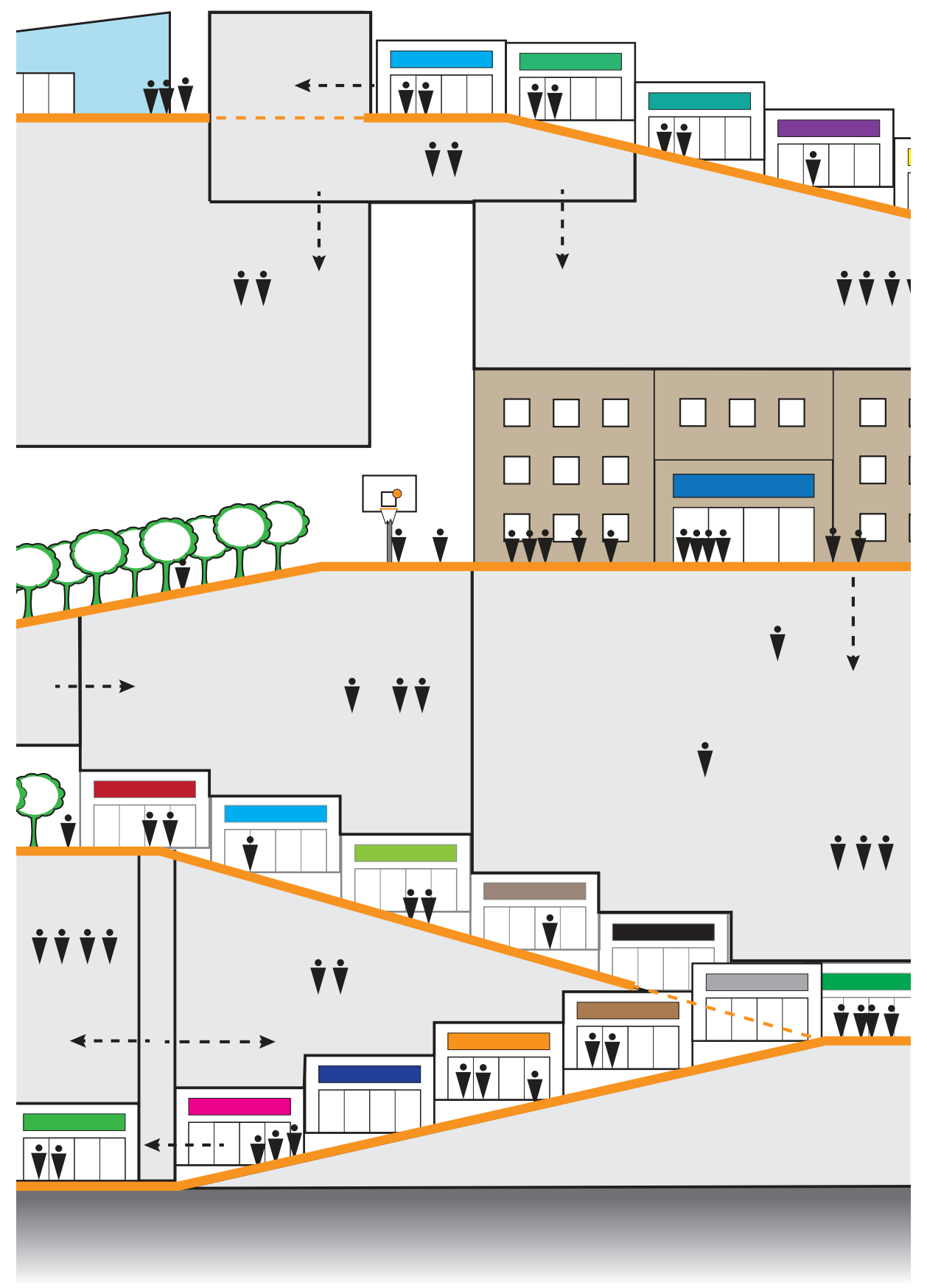

Figure 2.3.6: Diagram showing the continuity of the public flow system within a more complex layering of the city 
main research goal, the differentiation between urbanistically dependent and independent spaces suggests an attitude towards how this goal could be achieved. It outlines an urban design strategy for vertically layering the spaces of a city. If it is assumed that structural support, access, and utilities are provided, then the key difference between urbanistically independent and dependent spaces is needs for adjacency to the public flow system. Because of this difference, urbanistically independent spaces can exist successfully both above, and below, the public flow system. Within the three-dimensional volume of a city, this allows for the dense layering of the functions of the city in such a way that stimulates overlap and is mutually beneficial to both types of spaces. The diagrams of Figures 2.3.5-6 offer a visual summary of how the differentiation between urbanistically dependent and independent spaces could inform the layering of the components of a city.

\section{Conclusion}

As stated at the end of Section 1.4, one goal of this thesis was to find a way for urbanity, street life, and community to be promoted through the overlap of city functions. This section established a differentiation between requirements imposed by functionality, occupancy, and use of spaces within a city. This provided a mechanism for understanding how the current realities of the built environment shaped by the default approach reinforce the separation of spaces and activities within a city. It also provided a mechanism for understanding how increased overlap could potentially be achieved by reconfiguring and layering various types of spaces into the height of a city. 


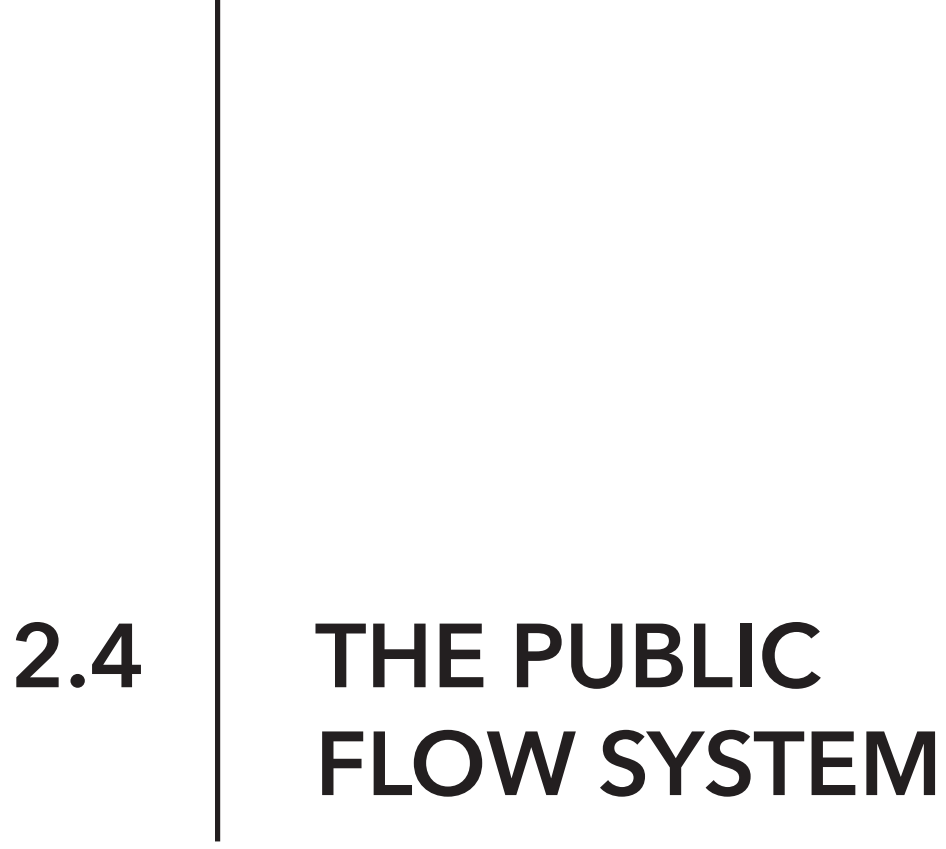

So far, in Part 2, this document has established an argument for why:

- Vertically extending the city requires extending the public flow system in a continuous, unconditional, and external manner.

- The extension of the public flow system should be investigated as a city-wide infrastructure that spans multiple structures.

- Instead of defaulting to linked towers as the organizational structure for vertical urbanism, this thesis explores the organization of a three-dimensional network of urban components within a volume.

- The differentiation between urbanistically dependent and independent spaces could inform the layering of spaces within a city volume

This section focuses on the public flow system. It explores the physical implications of extending the public flow system vertically in a continuous manner. It also establishes an argument for why, where possible, the vertical extension of the public flow system and the layering of the city should be treated as inhabited infrastructure. 


\section{Defining the Public Flow System}

As discussed in Section 2.1, the term "flow system" was borrowed from Kevin Lynch and Lloyd Rodwin's Theory of Urban Form ${ }^{1}$. In that article, they loosely define the flow system as that which is concerned with the circulation and flow of people \& goods, excluding the "flow" itself". Lynch and Rodwin argue that the flow system, along with adapted space for localized activities, is a pattern of all human settlement ${ }^{3}$. Since this thesis is focused on collective human settlement in the form of cities, the term "public" has been added to the term flow system. The aspects of the public flow system that are most common in contemporary cities include paths, streets, sidewalks, stairs, highways, bridges, pedways, transit lines, air routes, pipe networks, utility lines, escalators, elevators, among other things. In the three-part urban form reduction established in Section 2.1, the public flow system can be further reduced to:

1. Public Flow System

a. Surface Elements (Figure 2.4.1): These are the static elements, the streets, paths, bridges, and stairs that collectively form the continuous, unconditional, external surface of the public realm that enables the movement of people and things.

b. Utility Elements (Figure 2.4.2): This is the distribution and collection network that consist of services like water supply, sewers, gas lines as well as electricity, telephone, and internet cables. In typical cities, these are located above or below the level of the surface.

Lynch, Kevin, and Lloyd Rodwin. "A Theory of Urban Form." Journal of the American Institute of Planners 24, no. 4 (December 31, 1958): 201-14. https://doi.org/10.1080/01944365808978281

2 Ibid. 3 Ibid. 


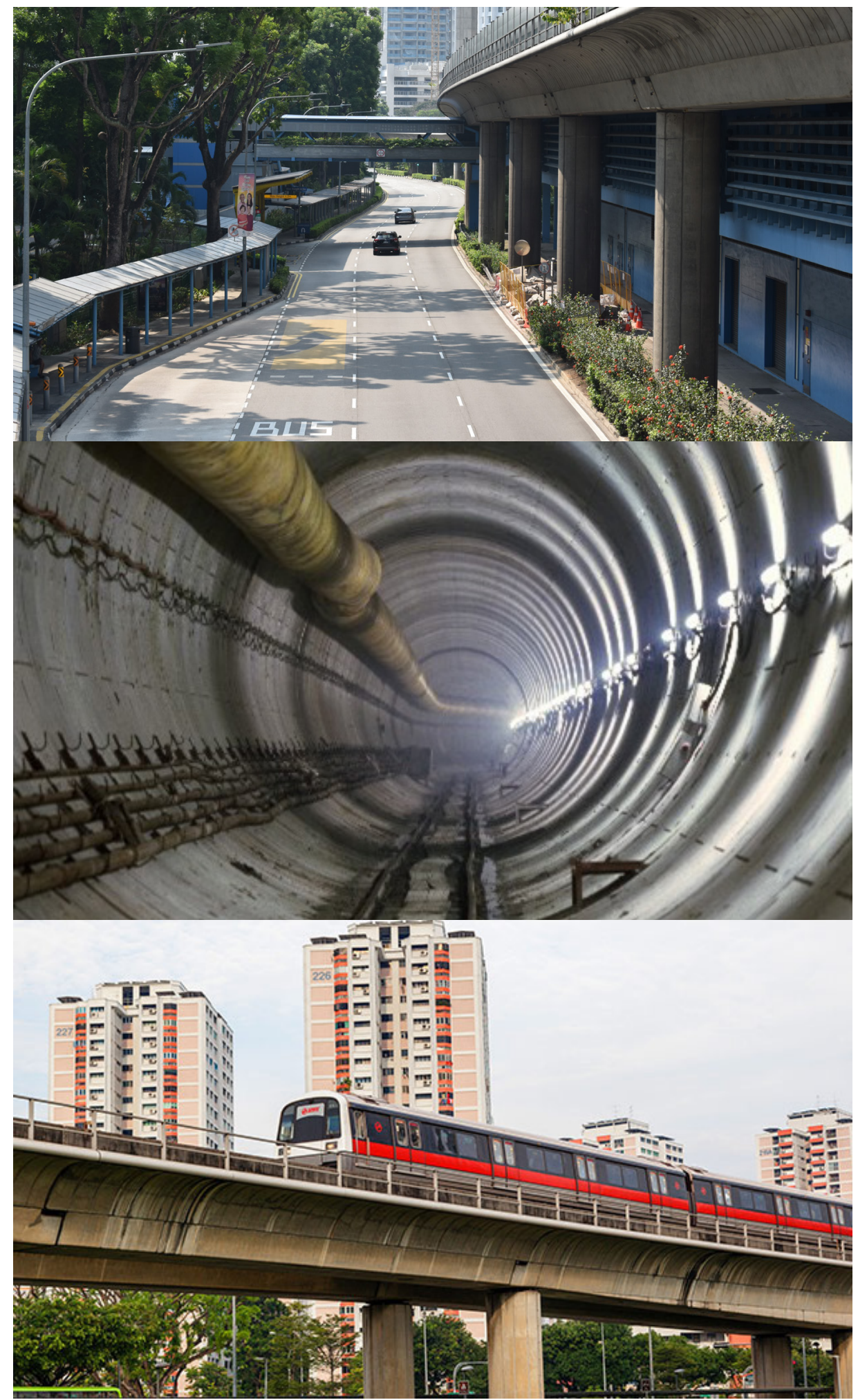

Figure 2.4.1-3 (Opposite): (Top) Surface Elements: streets pedways, sidewalks. (Center) Utility Elements: central utilities tunnel (Bottom) Dynamic Elements: Mass Rapid Transit system TMCR Group. "Singapore Deep Sewers - TMCR Group Inc TMTunnelling Ltd," 2011. http://www. tmcrgroup.com/50.html.

Azahar, Wani. "SMRT Enhances Starting Salaries and Staff Benefits | Human Resources Online," February 26, 2018. https://www.humanresourcesonline.net/smrt-enhances-starting-salaries-and- 
c. Dynamic Elements (Figure 2.4.3): These elements include the transportation of people and the distribution and collection networks for materials. These are typically located above, below, on or adjacent to surface elements. These are discussed in section 2.6.

2. Voids

3. Adapted Spaces / Real Estate

a. Urbanistically Independent Spaces

b. Urbanistically Dependent Spaces

As outlined in Section 2.3, adapted space above the ground plane relies on the vertical extension of the public flow system for both access to the surface as well as utilities. The dynamic aspects of the public flow system play more of a supportive role, which is discussed in Section 2.6.

\section{Vertical Work}

In the default approach to verticality, the public flow system is configured almost exclusively for horizontal movement. Any extension of the flow system into the height of the city typically occurs within the boundary of adapted spaces. For example, the vertical movement of people and utilities in most common towers is typically configured in a centralized distribution core. Therefore, extending the public flow system vertically into the height of a city would necessitate that the flow system be configured for both horizontal and vertical movement. This means some aspects of a cities public flow system must do vertical work(Figure 2.4.4).

Design research has primarily explored this design criterion through continuous configurations of sloped planes as the slope enables simultaneous horizontal and vertical movement. In initial explorations (Figure 2.1.13), the slope was quite steep, but later design 


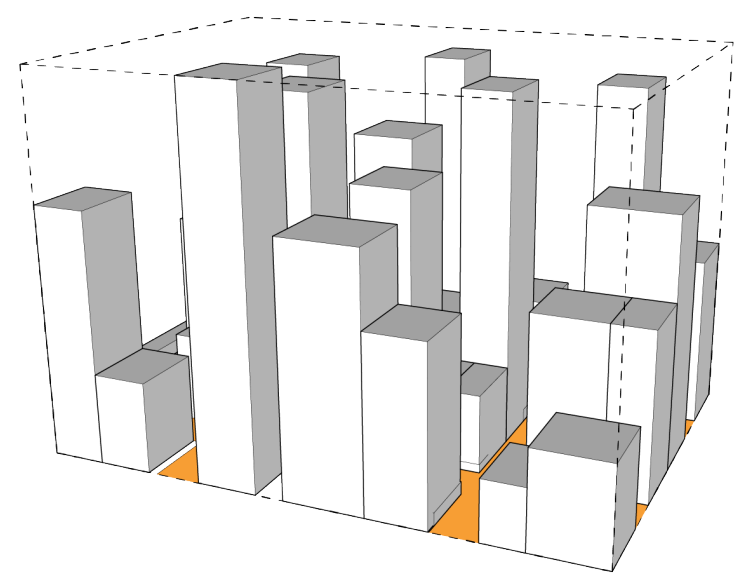

THE DEFAULT APPROACH: COMMON TOWERS

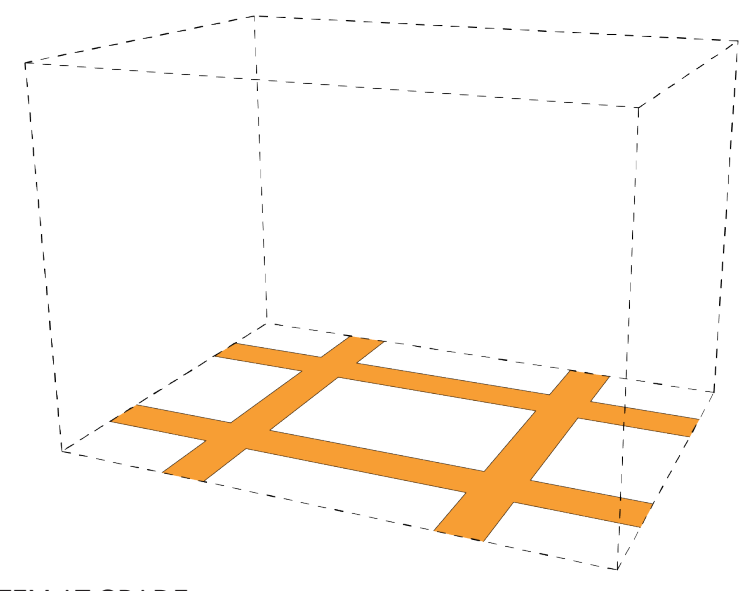

PUBLIC FLOW SYSTEM AT GRADE

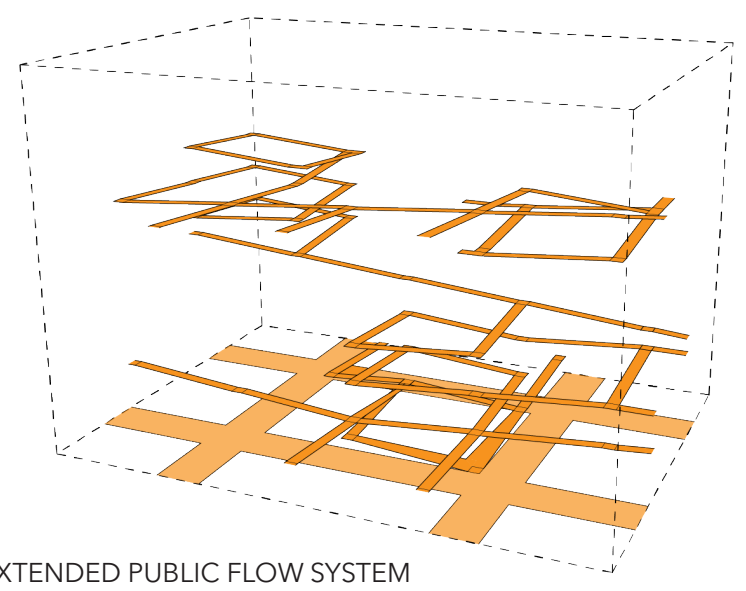

Figure 2.4.4: In the default approach the public flow system is horizontally configured. In order to extend the public flows system into the height of the city it must be configured to do vertical work shown here as sloped planes 


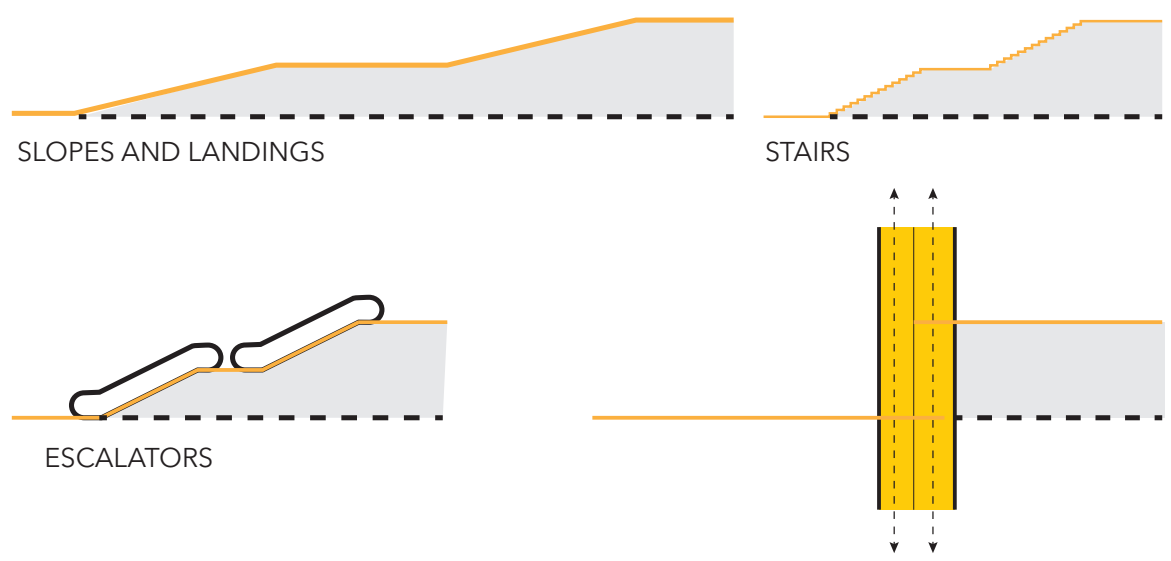

VERTICAL TRANSIT

Figure 2.4.5: Method for vertical work in the Public Flow System. The sloped plane is the governing design case as it requires the most length.

explorations adopted a more gradual slope of 1:12 $\left(4.76^{\circ}\right)$. This was selected as a means of making the flow system do vertical work while attempting to remain accessible to all $^{4}$. The vertical work achieved by a continuous sloped plane could be achieved by steeper slopes with landings, stairs, escalators, and vertical transit in more compact configurations, as indicated in Figure 2.4.5. The sloped surface, however, is both the most unconditionally continuous and has governing space requirements compared to alternatives. This is why it has been the primary method used in design research investigation.

\section{Supporting the Flow System}

On the ground plane, the public flow system is sup-

4 Fantastic Offence. "Ramp Slopes Dimensions \& Drawings Dimensions.Guide." Dimension Guide, 2020. https://www.dimensions. guide/element/ramp-slopes. 
ported by the ground itself. In order for the flow system to extend vertically, there needs to be structure supporting it. Outlined below are three possible strategies for accomplishing this. Each method stems from the Visionary Urbanism proposals presented in Section 1.4.

The first strategy would be to support the public flow system entirely independently from the real estate around it using an "independent infrastructure." This is the type of condition that occurs with the Highline in Manhattan (Figure 2.4.9), where an elevated railroad was converted to an extension of the public flow system. The Highline is built on significant structural infrastructure and sits just $9 \mathrm{~m}$ above the ground plane. Extending an independently supported flow system vertically to any great distance above the ground would require even more significant city-wide infrastructure. This support infrastructure would demand a considerable commitment of resources, and occupy a great deal of real estate. This is similar to the critique of open-ended urban framework proposals presented in Section 1.4 (Figure 2.4.6).

As a result, design research for this thesis focused on ways the extension of the public flow system could be extended by relying on structural support from adapted spaces.

The second approach would be to have the flow system supported on the structure of adapted spaces with bridges that span across voids. This method is comparable to Harvey Wiley Corbet's 1910, vision of the Future City 5 , presented in Section 1.4 (Figure

$5 \quad$ Koolhaas, Rem. Delirious New York: A Retroactive Manifesto for Manhattan. P.84New ed. New York: Monacelli Press, 1994.

Willis, Carol. "The Skyscraper Museum: Future City: New York Modern."

The Skyscrapper Museum, 2007. https://www.skyscraper.org/EXHIBITIONS/FUTURE_CITY/NEW_YORK_MODERN/walkthrough_1900.php. Wood, Antony, and Daniel Safarik. "Skybridges: A History and a View to the Near Future." Council on Tall Building and Urban Habitat 8, no. 1 


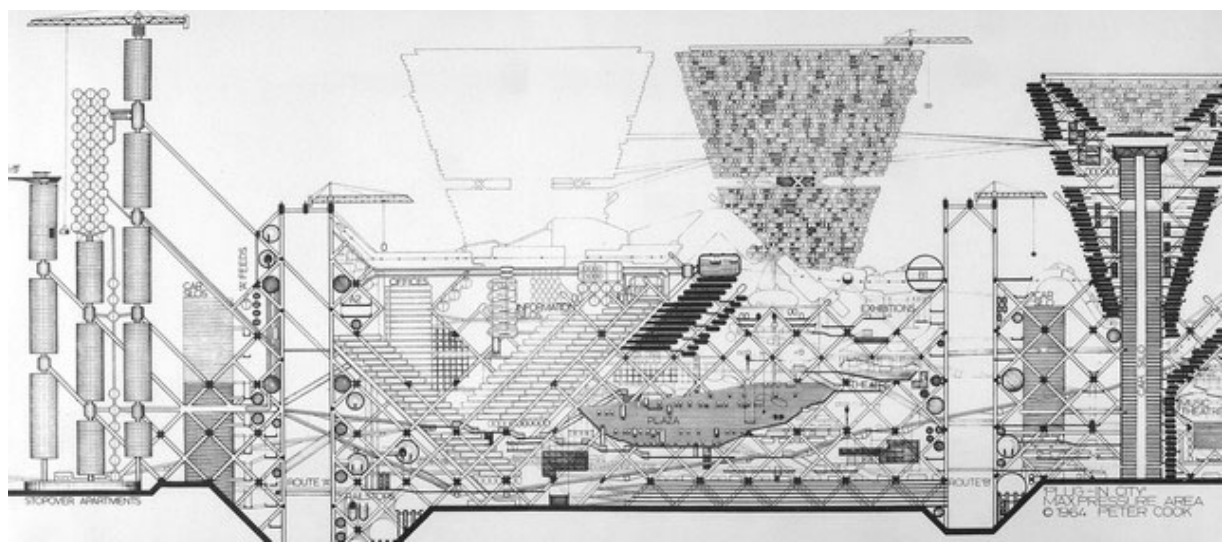

Figure 2.4.6: (Independent Infrastructure) Peter Cook, Plug in City, 1962

Plug in City, 1962 https://www.archdaily.com/399329/ad-classics-the-plug-in-city-peter-cook-archi gram/51 d71 ca6e8e44ecad700002a-ad-classics-the-plug-in-city-peter-cook-archigram-image

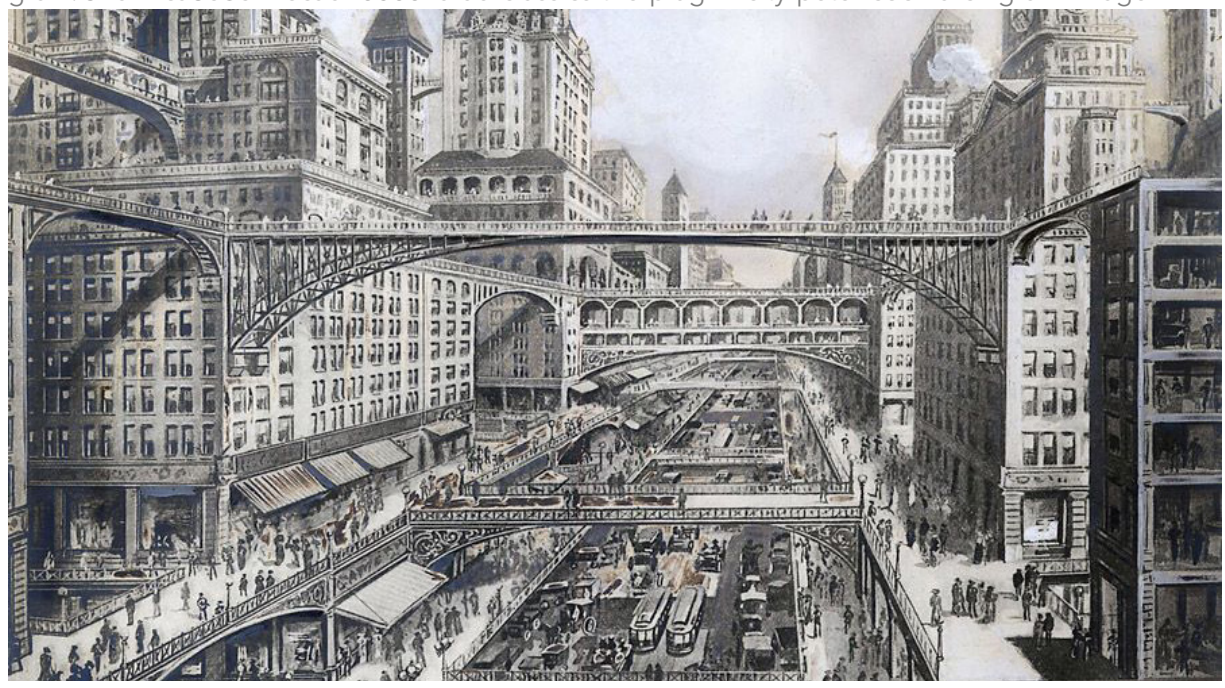

Figure 2.4.7: (Bridging Adapted Spaces) Harvey Wiley Corbert:

Future City, 1910

Delineator Unknown. : Willis, Carol. "The Skyscraper Museum: Future City: New York Modern."

The Skyscrapper Museum, 2007. https://www.skyscraper.org/EXHIBITIONS/FUTURE_CITY/NEW_ YORK_MODERN/walkthrough_1900.php

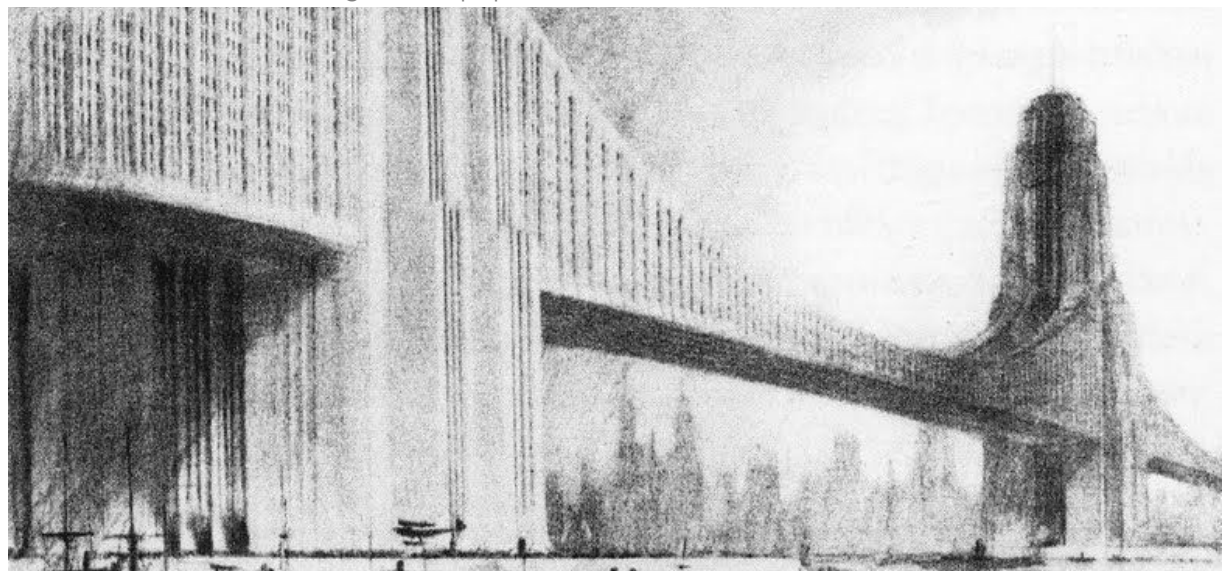

Figure 2.4.8: (Inhabited Infrastructure) Raymond Hood Bridge Homes, 1925

Ferriss, Hugh. The Metropolis of Tomorrow. Princeton, NJ: Princeton Architectural Press, 1986 (1929). 


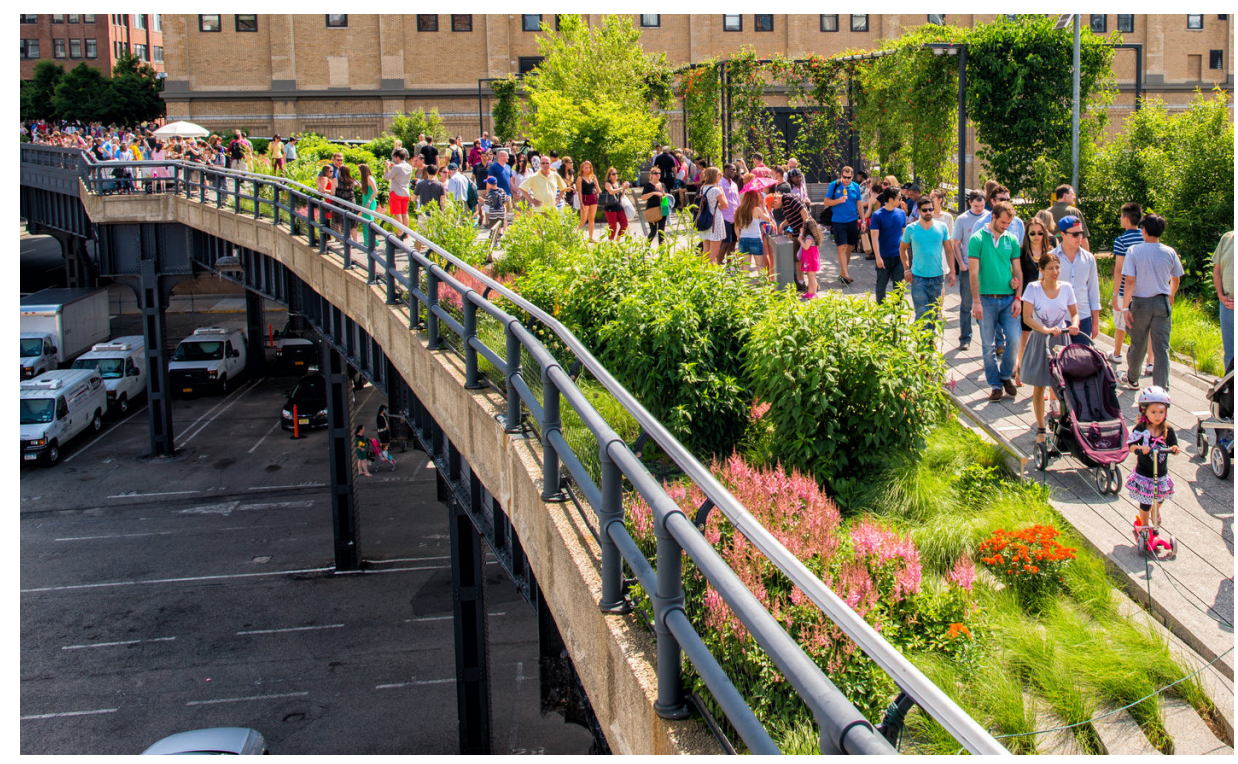

Figure 2.4.9: The High-line in Manhattan is an example of a vertically extended self sported flow systems

Shutterstock.com. "New York June 152013 High Stock Photo (Edit Now) 1426078988." Accessed February 12, 2020. /image-photo/new-york-june-15-2013-high-1426078988.

2.4.7). This is also the method in which many amenity sky bridges and sky streets are configured (Figure 2.4.10-11). As discussed in Section 2.2, bridging adapted spaces tends to adhere to linked towers as the prevalent urban configuration. Also, the bridges occupy privileged real-estate while serving only a single purpose.

Inhabited infrastructure proposals like Raymond Hood's 1925, concept for Bridge Homes (Figure 2.4.8) recognized that infrastructure like bridges could contribute to a city in numerous ways. The third approach is an adaptation of the thinking behind inhabited infrastructure, to the concept of supporting the public flow system on adapted space. Instead of spanning voids with bridges that serve a single function at the surface, the bridge is configured as both public flow

(March 1, 2019): 1-18. https://doi.org/10.21022/IJHRB.2019.8.1.1. Sant'Elia, Antonio, Luciano Caramel, and Alberto Longatti. Antonio Sant'Elia, the Complete Works. p.28 New York: Rizzoli, 1988.

Urbanefreakde. "URBAN GEOGRAPHIES: Cities / Places / Regions." URBAN GEOGRAPHIES: Cities / Places / Regions. Accessed August 11, 2019. https://urbangeographies.tumblr.com/post/127713040662/urbanfreakde-urbain-visionary-city-of-new. 

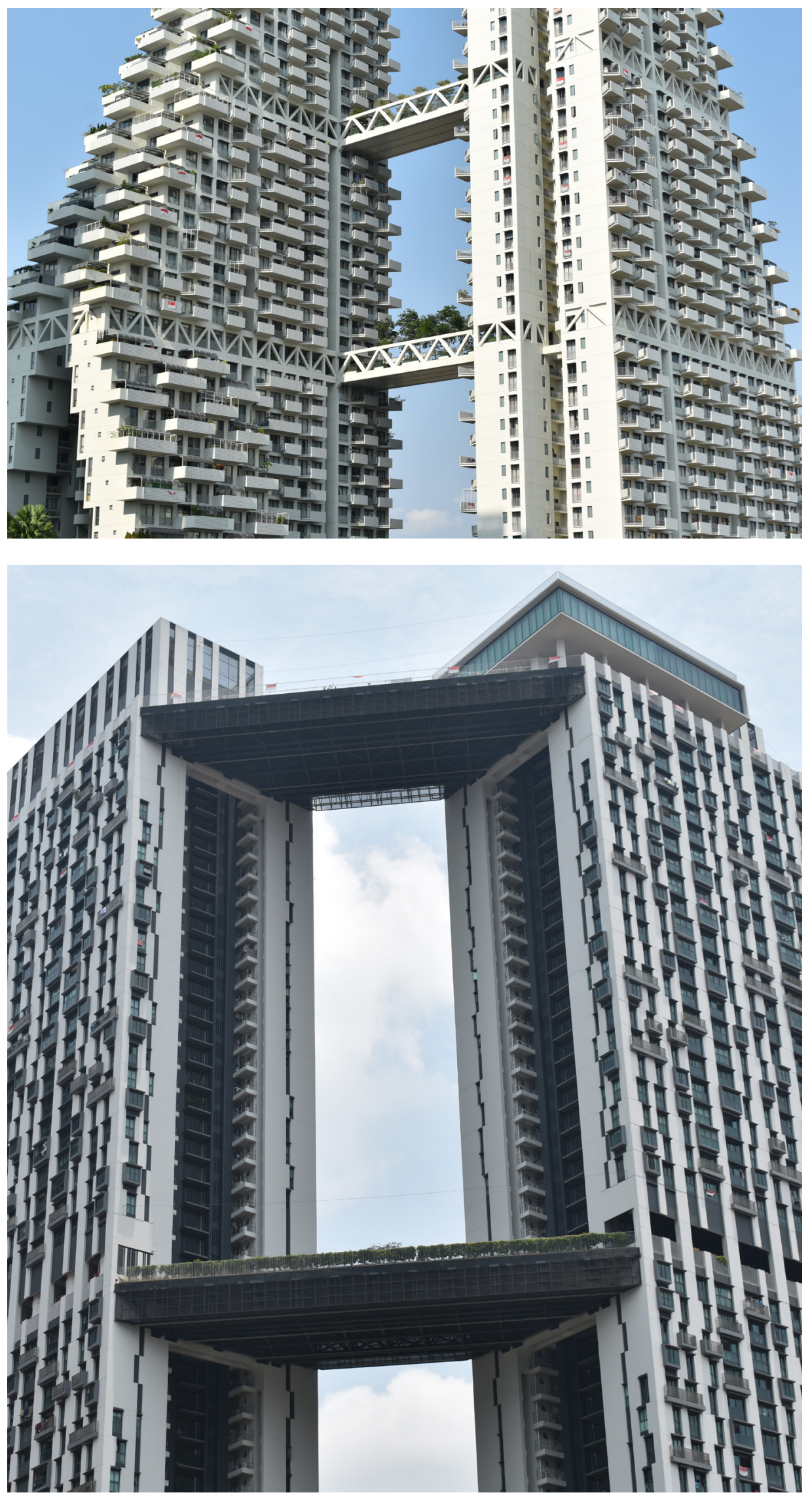
Figure 2.4.10-11 (Opposite): Bridging adapted spaces. (top) Sky Habitat, Moe Safdie (bottom) The Pinnacle, Arc Studio Caskey, Alex Sky Habitat. Singapore. Fall 2019

Caskey,Alex.Pinacle@Duxton. Singapore.Fall 2019

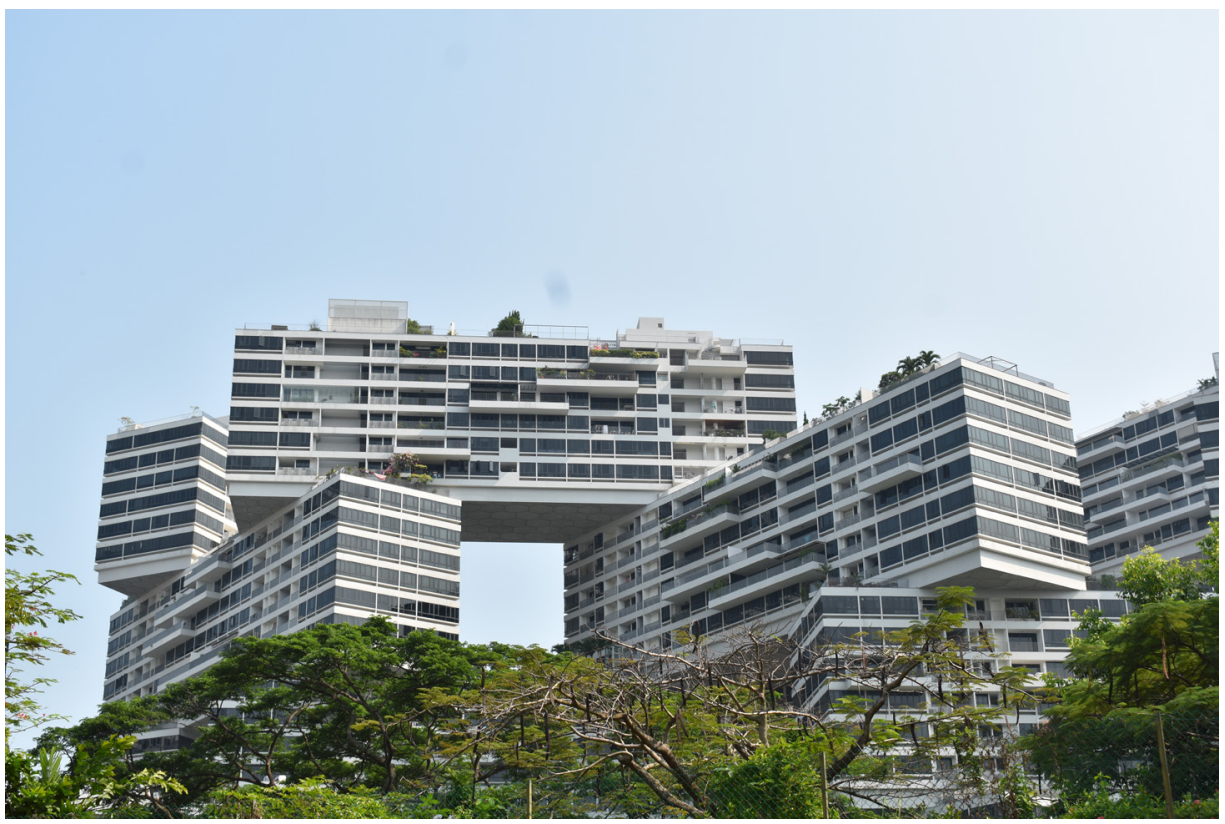

Figure 2.4.12: Interlace Apartment Complex, OMA, 2013. The irregularly stacked building masses are individually articulated and serve multiple functions as inhabited residential spaces, bridges, and amenity sky parks

Caskey, Alex, Interlace Apartments. Singapore. Fall 2019

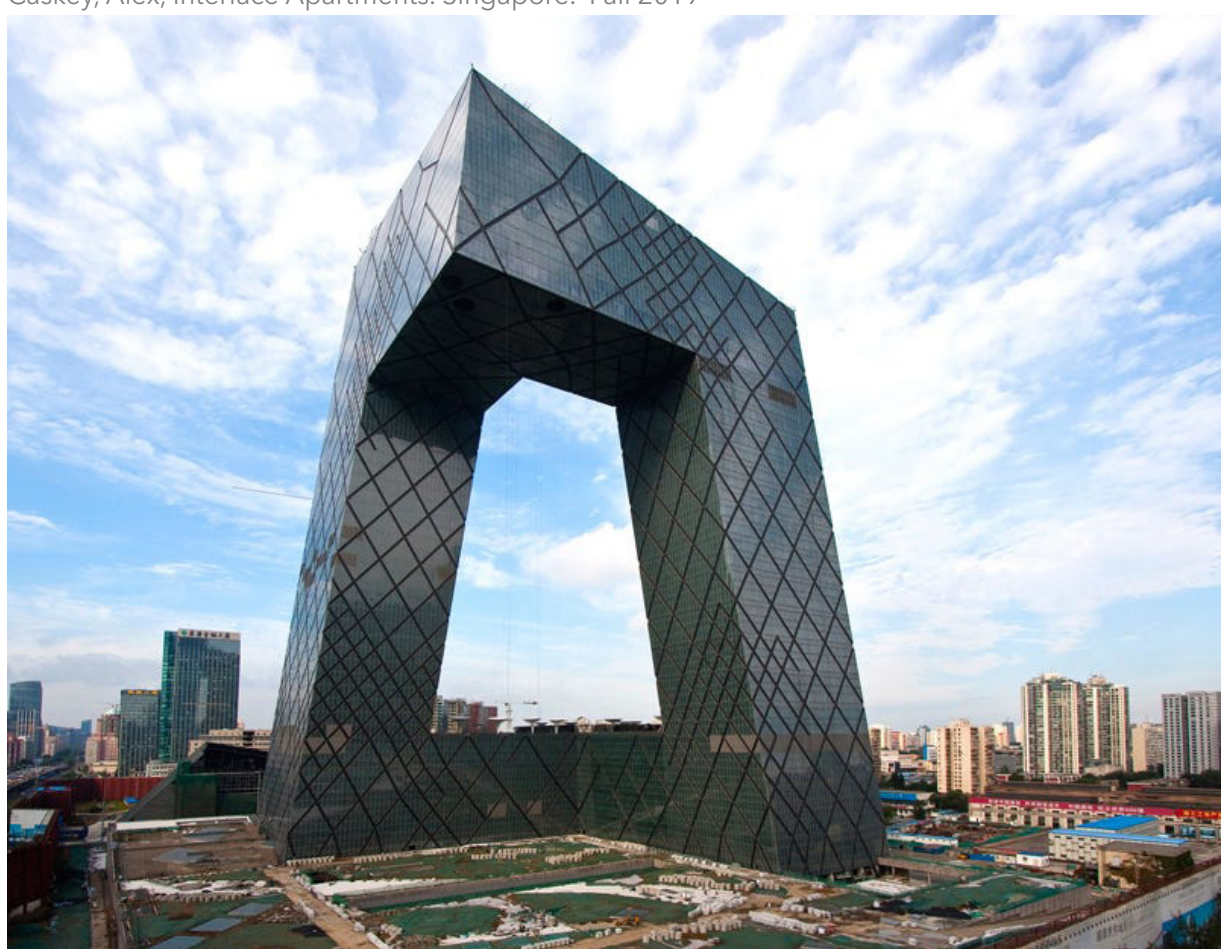

Figure 2.3.13: CCTV Building, Beijing, OMA, 2012. An example of of large scale inhabitable space that bridges vertical structures Wikipedia Commons. "CCTV Circular Tower in Beijing by Ole Scheeren - Business Insider," 2016. https://www.businessinsider.com/cctv-circular-tower-in-beijing-by-ole-scheeren-2016-7. 


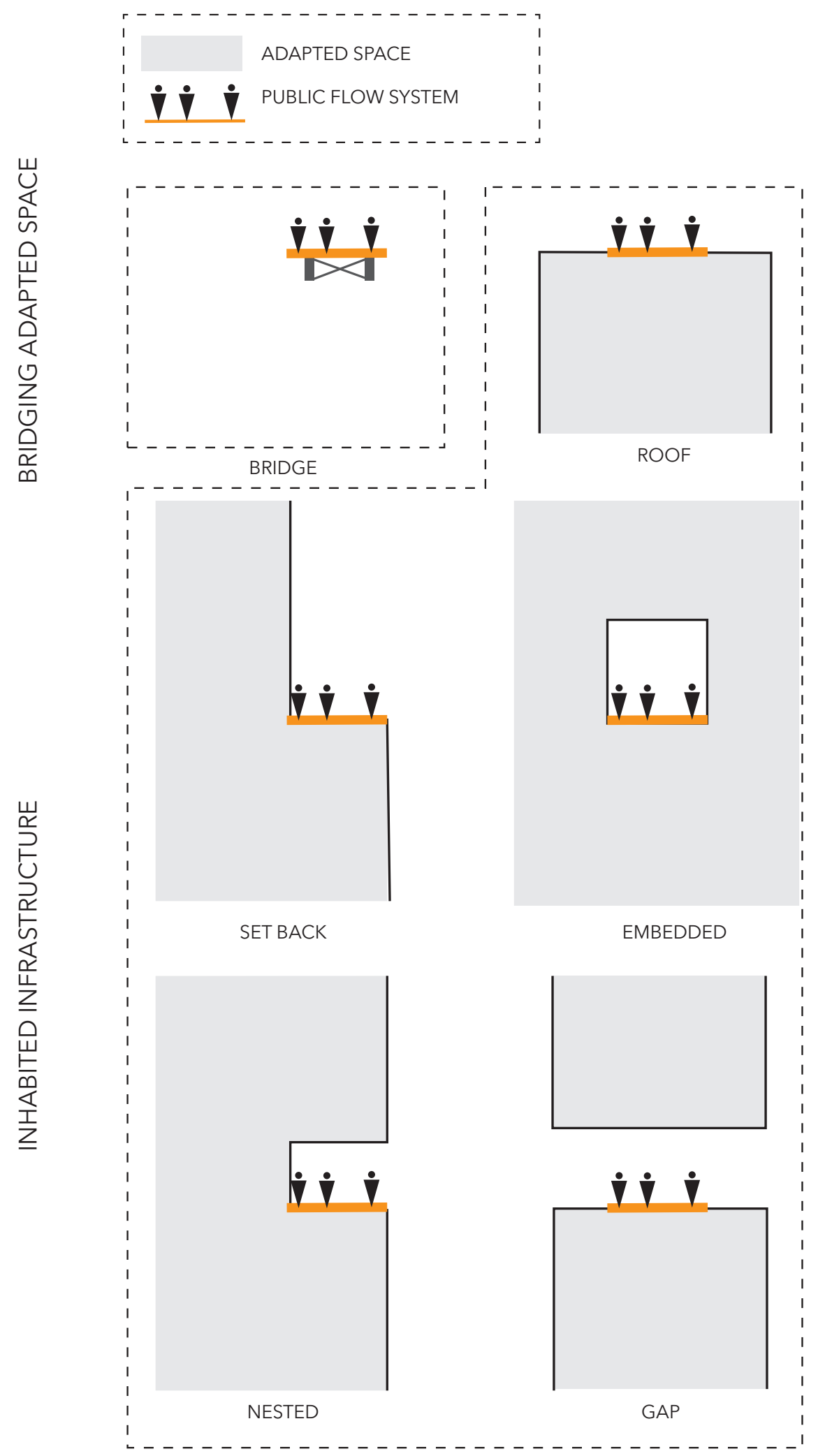

Figure 2.4.14: Common configurations for supporting the extension of the flow system with inhabitable real-estate 


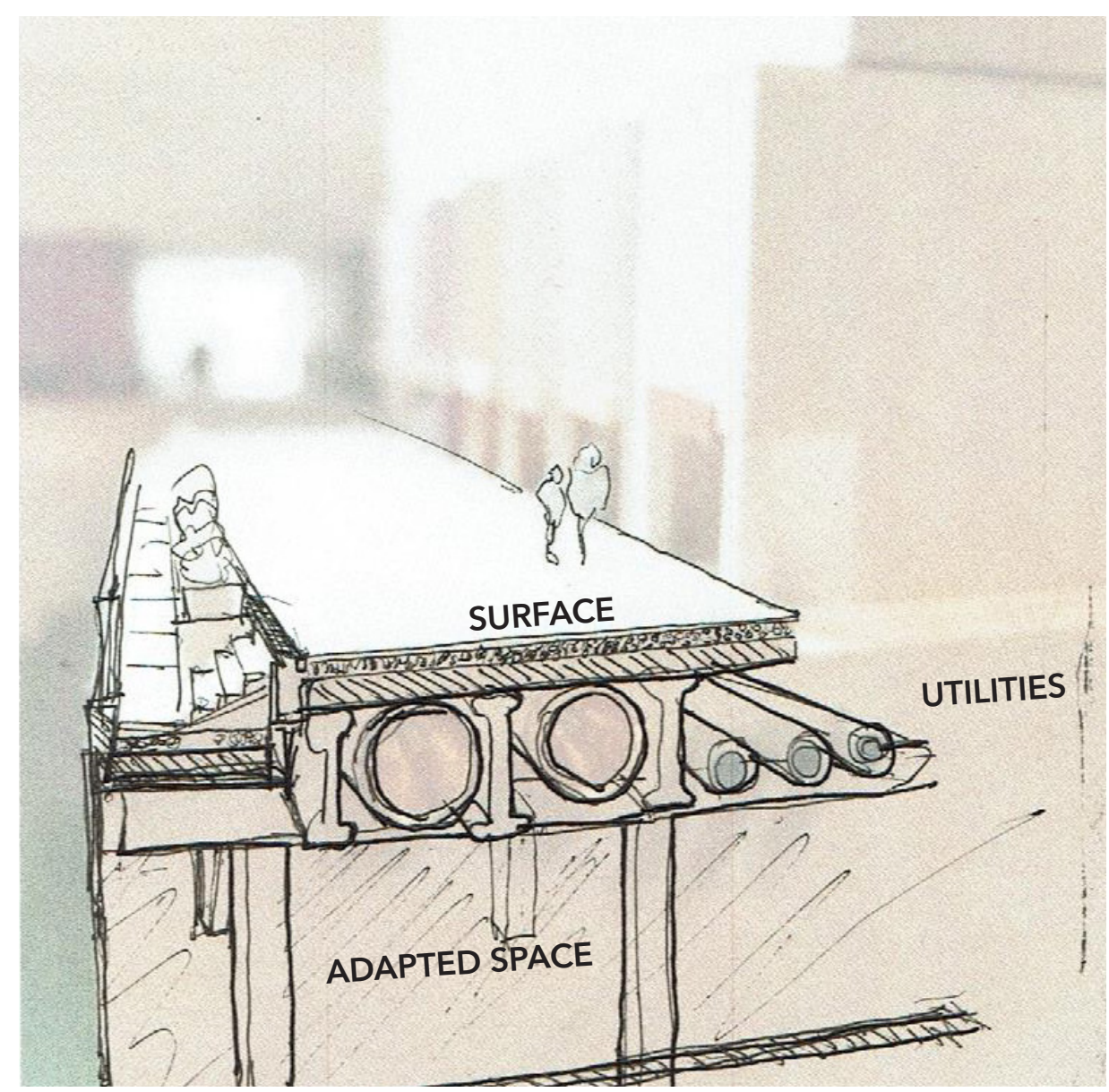

Figure 2.4.15: Utilities running under surface of flow system above inhabited spaces.

system and adapted space. Although they do not serve the public flow system, OMA has already executed numerous large-scale developments, including Interlace Apartments (Figure 2.12), and the CCTV building (Figure 2.13), that featured significant horizontal spans in the form of inhabited infrastructure.

Theoretically, a city-wide public flow system could be supported by various combinations of the three approaches explained here. Design research has tended towards bridging adapted spaces and doing so with inhabited infrastructure as much as possible. A diagram showing some of the possible configurations for supporting the extension of the flow system with adapted spaces are illustrated in Figure 2.4.14 


\section{Utilities}

Throughout design research, it has been assumed that similar to the configuration on the ground plane, the vertical extension of public utilities might follow the extension of main surface elements in a subsurface utilities crawl space (Figure 2.4.15). This configuration would neatly separate both aspects of the public flow system from the surrounding real estate. It could also enable adapted space without connection to the ground to link into public utilities wherever it meets the public flow system. Utilities could also be distributed throughout the volume of a city through many other configurations, including vertical distribution cores or more complex forms. An optimized strategy for the distribution of utilities is one of the numerous considerations for future research that has emerged from this thesis.

\section{Conclusion}

This section outlined considerations for the physical vertical extension of the public flow system into the height of a city. It differentiated between the surface, utility, and dynamic components of the public flow system. It explained why extending the public flow system vertically would require components be configured for both horizontal and vertical movement and that a continuous sloping plane is just one of numerous ways in which this can be achieved. It introduced the three methods for structurally supporting the flow system above the ground and explained why design research has focused on supporting the flow system on the structure of adapted space. It also explained the logic behind coupling the extension of the flow system's surface components with underlying utility components. 


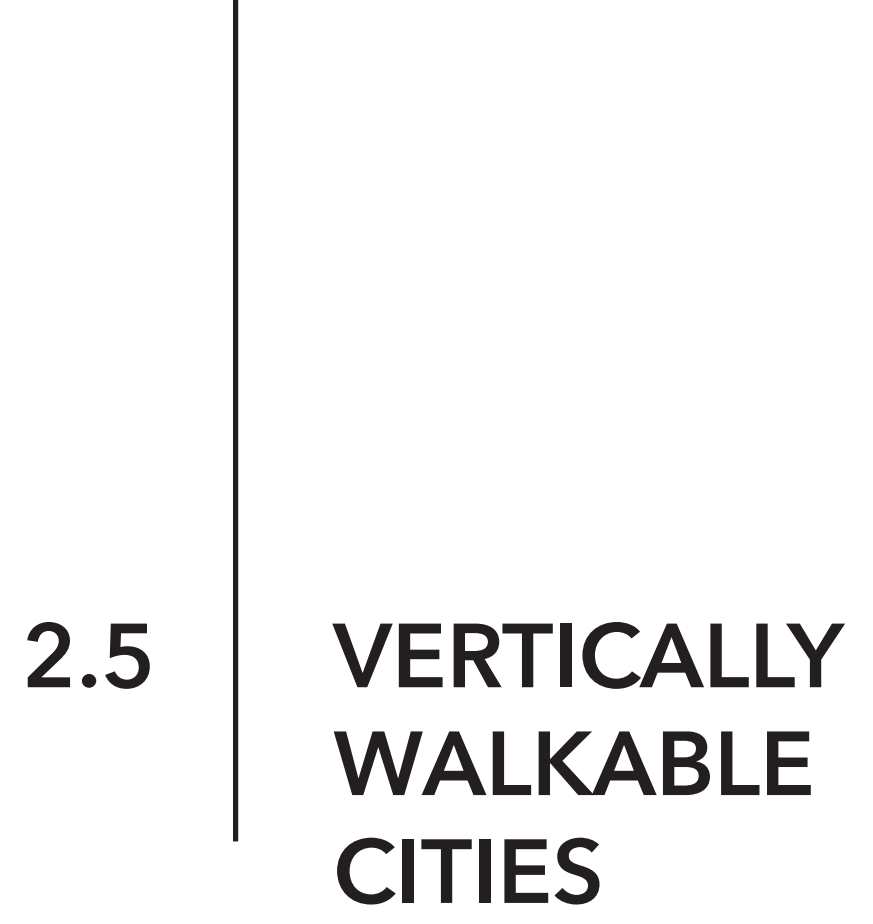

This section takes a closer look at the goal of this thesis, which is to expose the potential of verticality by exploring ways in which a city can be extended vertically. In previous sections, this goal expanded to mean extending the public flow system in a continuous, unconditional, external manner and enabling the urbanistically dependent spaces of a city such as shops, libraries, and parks to exist above the ground plane. What is lacking is an urban design strategy for how to configure the components of a city in such a manner that makes it sustainable, interesting, healthy, safe, and attractive. This section explains why the automobile-focused design of most contemporary cities does not serve as a suitable model to extend vertically, and why the principles of walkability should be a key design driver for vertically organizing a dense urban environment.

\section{Extending The City Vertically: The Automobile}

Exploring the extension of the city vertically should begin with a critical analysis of urban design strategies that have shaped existing contemporary cities. All aspects of the contemporary city may not be necessary to extend vertically. For the last half-century or more, the automobile has been a key focus in the 


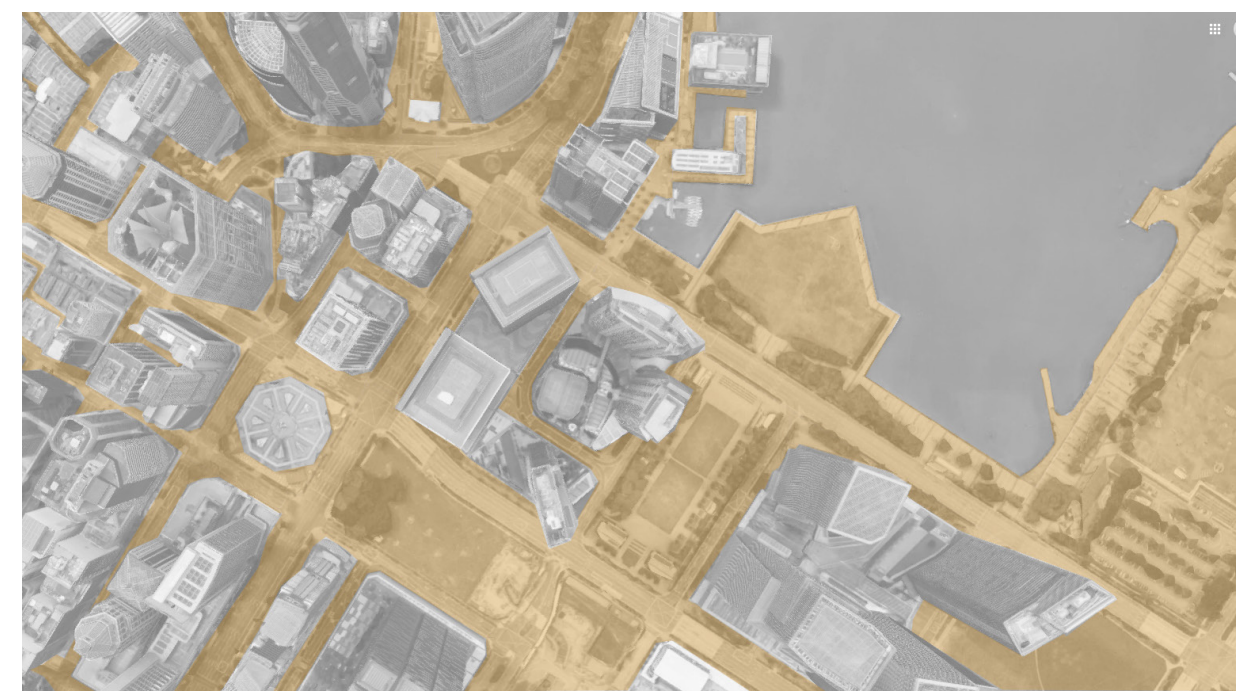

Figure 2.5.1: Altered Google Maps imagery of Singapore's Financial district with the public flow spaces highlighted in orange Note how most of this is automobile infrastructure.

design and modification of most cities. The multilane roads, traffic light-controlled intersections, roadside parking, are an integral part of the public spaces in most urban centers. As shown in Figure 2.5.1, this automobile infrastructure makes up the majority of what has been previously defined as the public flow system of the contemporary city.

Lewis Tsurumaki Lewis's 2004 Venice Biennale, Park Tower (Figure 2.5.2-3), proposal is an example of how the automobile-centric approach to urban design could be extended into the height of a city ${ }^{1}$. Throughout the height of a single tower, the automobile focused public flow system continuously ramps upwards and is intermixed with the adapted spaces of the tower. The ramping automobile infrastructure is intended to enable urbanistically dependent spaces like shops and parks to exist throughout its height.

\footnotetext{
$1 \quad$ Busquets, Joan. "Line $X:$ Speculative Procedures" in Cities $X$ Lines: A New Lens for the Urbanistic Project. P. 339. Edited by Felipe Correa and Harvard University. Reprint. S.I.: Nicolodi, 2007.

LTL Architects. "Park Tower." LTL Architects, 2004. http://ttarchitects.com/ park-tower.
} 


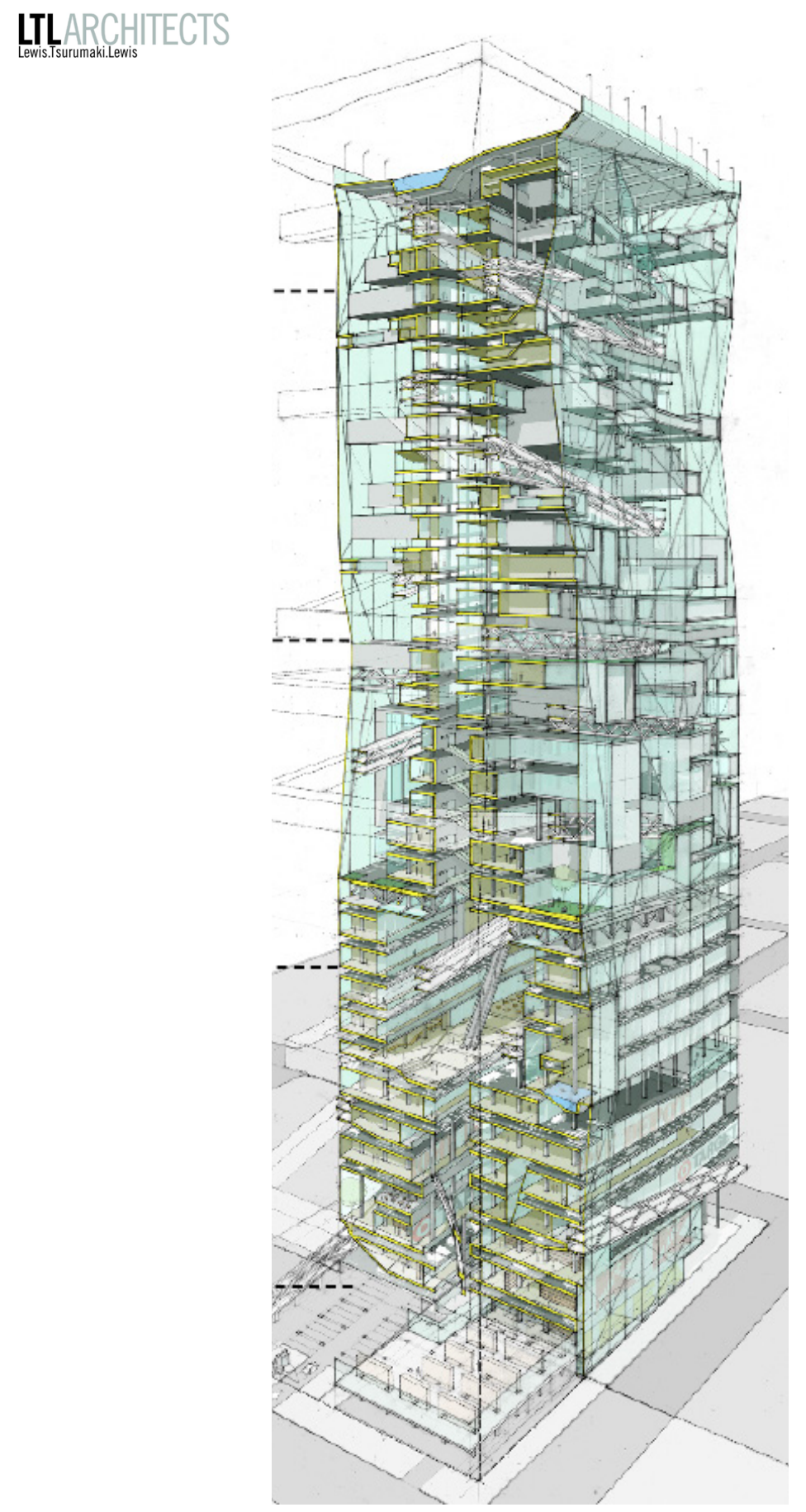

Figure 2.5.2: 2004 Park Tower proposal by Lewis Tsurumaki Lewis. Public Flow system in the form of automobile infrastructure extends vertically into the height of the mixed use tower.

LTL Architects. "Park Tower." LTL Architects, 2004. http://Itlarchitects.com/park-tower. 


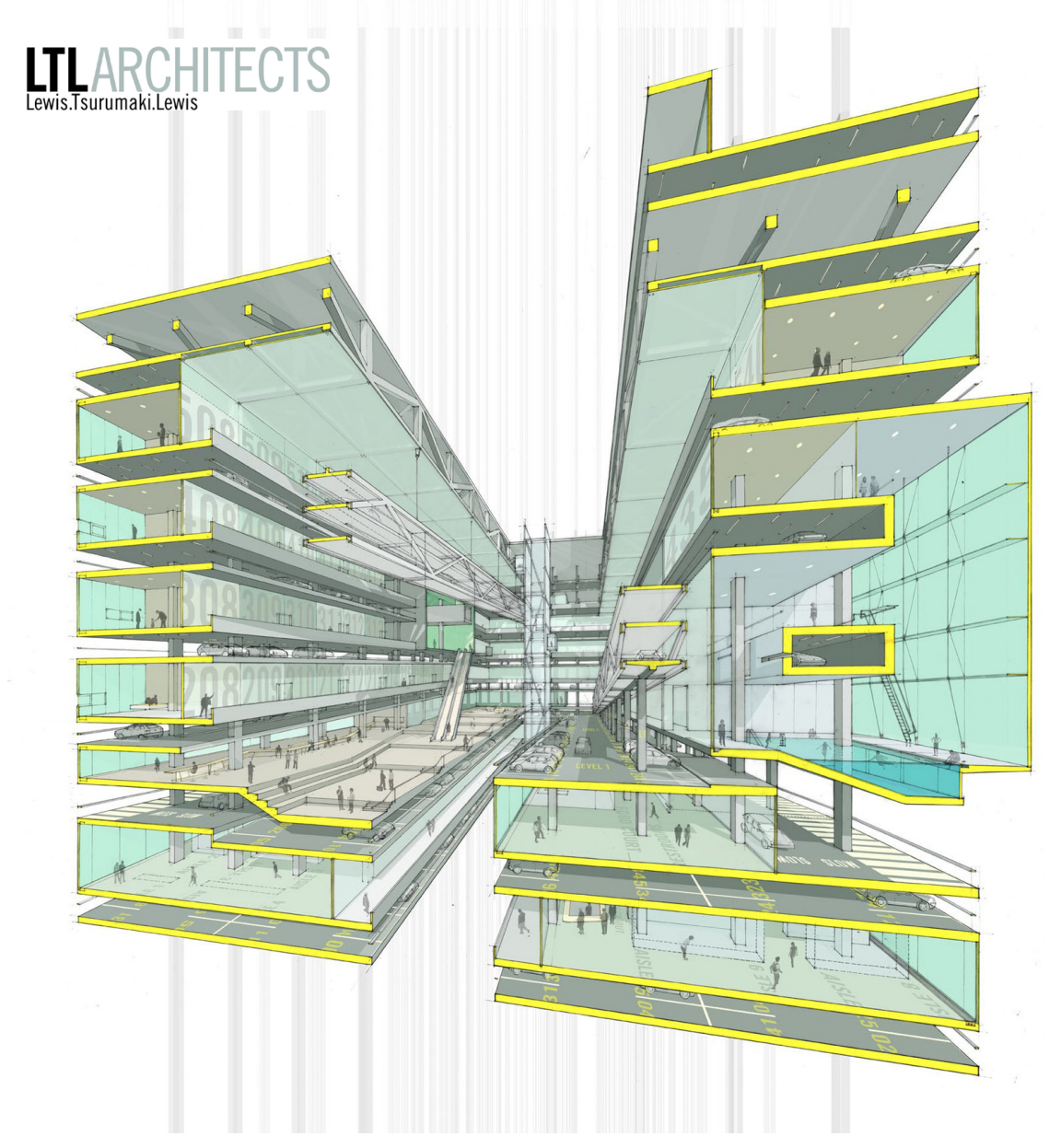

Figure 2.5.3: 2004 Park Tower proposal by Lewis Tsurumaki Lewis. Public Flow system in the form of automobile infrastructure extends vertically into the height of the mixed use tower.

LTL Architects. "Park Tower." LTL Architects, 2004. http://Itlarchitects.com/park-tower.

Contemporary cities that were designed and constructed based primarily on automobiles inadvertently created a car dependency that necessitated massive infrastructural requirements, encouraged sprawl, encouraged consumption and created a fossil fuel dependency that continues to be environmentally catastrophic ${ }^{2}$. Automobile focused design only caters to portions of the population that are economically and physically able to own and operate a vehicle, while time spent in vehicles results in decreased health, happiness and a sense 
of community ${ }^{3}$. It is also dangerous, with the World Health Organization siting road injuries as the $7^{\text {th }}$ most common cause of death worldwide ${ }^{4}$.

Park Tower illustrates how the vertical extension of some aspects of automobile infrastructure into the vertical volume might be possible, and should not necessarily be ruled out entirely. A vehicle-centric approach to verticality, however, would only further the ills of the contemporary city outlined above. Instead, there's a need for an urban design focus that benefits from clustering adapted spaces together and organizing the city vertically in a highly dense manner.

\section{Walkability}

In Walkable City Rules, Jeff Speck has reformatted the key ideas from his well-known book Walkable City into 101 actionable rules for planners, urban designers, architects, and city officials. Speck advocates for how designing walkable cities improves 5 :

Wealth: in terms of property values, reduced infrastructure spending, talent attraction, reduced health care costs Health: in terms of promoting active lifestyles, reduce health risks, less pollution

Climate Change: in terms of pollution and energy consumption

Equity: in terms of accessibility and increased mobility for the poor, minority groups, and both young and elderly populations

Community: in terms of social capital, neighbourly interaction, involvement in community affairs,

\footnotetext{
$3 \quad$ lbid

World Health Organization. "The Top 10 Causes of Death." Accessed April 17, 2020. https://www.who.int/news-room/fact-sheets/detail/ the-top-10-causes-of-death.

$5 \quad$ Speck, Jeff. "Part 1 Sell Walkability" in Walkable City Rules: 101 Steps to Making Better Places. P.1-11.Washington, DC: Island Press, 2018.
} 
Unlike automobile focused urban design strategies, these qualities are in alignment with the goal of exploring verticality as a way of making interesting, healthy, safe, and attractive cities in a compact, dense format. The principles of this book have heavily contributed to the evolution of design research. Designing for walkability has been adopted as the urban design focus for vertically organizing a dense urban environment.

\section{Extending The City Vertically: Vertically Walkable Cities}

The strategies presented in Walkable City Rules are intended as strategies for making improvements within existing urban conditions. As a result, some rules remain strongly linked to an automobile focused urban design, and adhered to a two-dimensional or flat perspective of the city.

Many of Speck's other rules, however, are actionable guidelines for a walkable city that could equally apply to a vertical context. These include

Rule 7. Push for Local Schools: integrate schools in neighbourhoods and size them accordingly instead of centralizing them

Rule 8. Push for Local Parks: integrate parks and recreation facilities within walking distance instead of centralizing them. Locate playgrounds within $400 \mathrm{~m}$ of households

Rule 9. Fix your Codes: Eliminate single-use zoning

Rule 37. Keep Blocks Small: 200ft (60m) blocks as in Portland are very walkable (1000ft max perimeter)

6 Speck, Jeff. "Various Rules" in Walkable City Rules: 101 Steps to Making Better Places. P.1-285.Washington, DC: Island Press, 2018. 
Rule 70. Do Not Fix Complexity:

unconventional intersections and spaces add both interest and safety

Rule 78. Put Street Trees Almost Everywhere: trees shape space, absorb stormwater, pollutants, and heat gain, in addition to improving property and retail value.

Rule 80 Design Sidewalks Properly: make sidewalks fully accessible, with zones for movement and transitional zones.

Rule 83. Make Firm Edges: frame publics spaces and streets with firm walls in a continuous manner

Rule 88. Make Sticky Edges: energize public spaces with a variety of active, interesting \& deep facades, at entry level

Rule 89. Limit Repetition: sameness does not create visual interest, variety is key

Rule 90. Break Up Buildings: break up big buildings into smaller buildings or at least make large buildings appear externally as smaller fragments.

Rule 96. Organize a Network of Walkability: determine where people will walk by locating anchors, use this to organize public spaces, and public dependent private real-estate.

These walkable city rules inspired a series of design research investigations that explored their application in a vertical context. The investigations are explored both in this section, as an abstract diagrammatic investigation, and in Part 3 as a contextualized design exploration specific to Singapore. Outlined below is an approach to adapting walkability-focused urban 

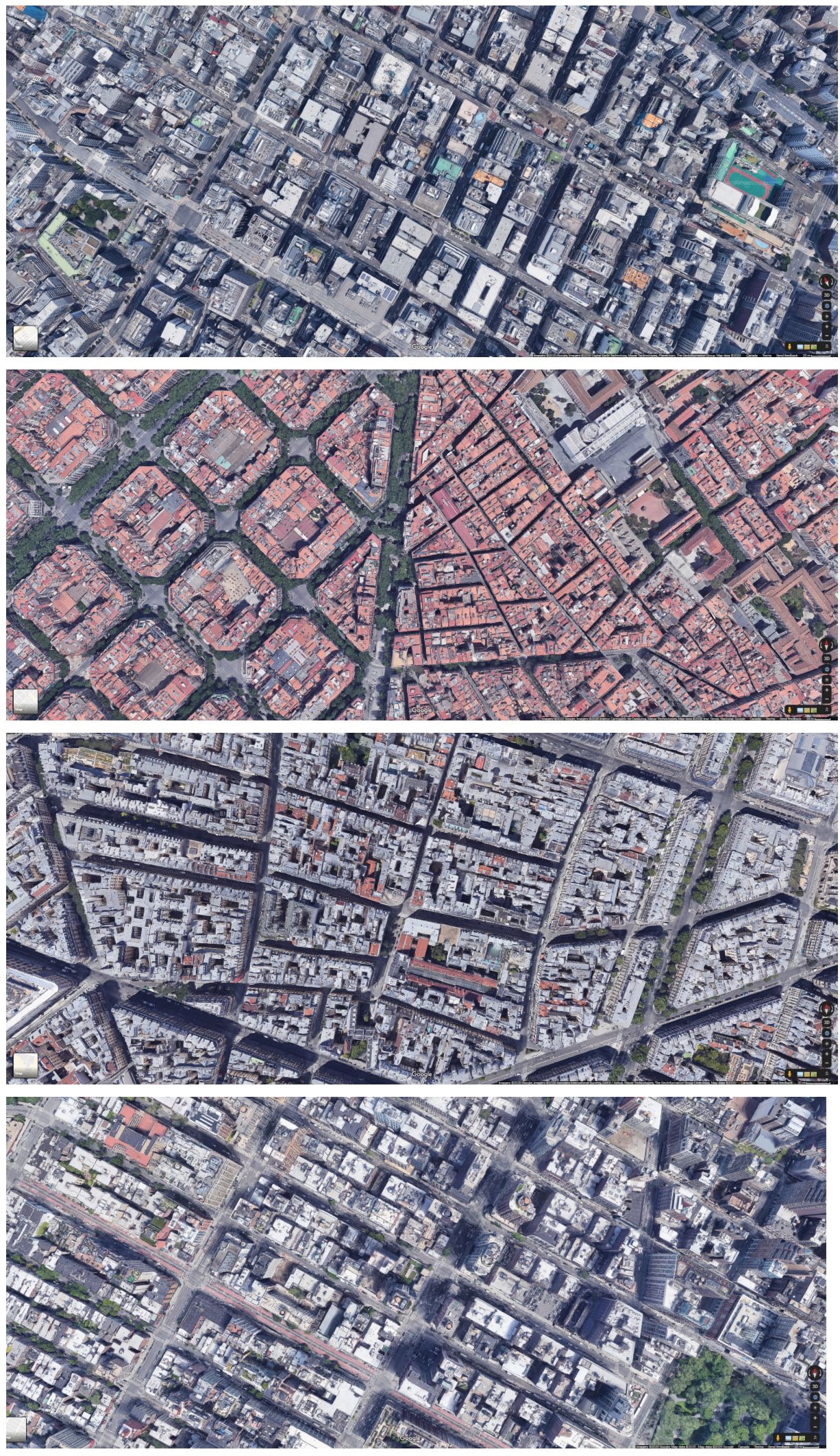

Figure 2.5.4: Google Maps Satellite imagery showing various configurations of city blocks (Top to Bottom) Japan, Barcelona, Paris, New York City 
design strategies to a city block, neighbourhood, and a three-dimensional network of walkability.

\section{Vertically Walkable Block}

The city block is a primary organizational unit of a city that appears in many shapes, sizes, and configurations in cities around the world (Figure 2.4.5). According to Speck's rules, the walkability of a street block is mainly dependent on two main factors, including:

Size: According to Speck's Rule \#37, a block should have a perimeter no more than $1000 \mathrm{ft}(300 \mathrm{~m})^{7}$.

Visual Interest: it should be firmly lined (Rule 83) with a wide variety of interesting small shops and other urbanistically dependent spaces (Rule 89,90 ) that have sticky edges (Rule 88) ${ }^{8}$.

Figure 2.4.6 is a diagrammatic representation of a block at the ground plane configured based on these two factors. A $200 \mathrm{ft}(60 \mathrm{~m})$ square block is lined with firm edges through a wide variety of buildings. It should be noted that the "sticky edge" requirement for walkable blocks is investigated further in Section 3.4 .

As outlined in Section 2.4, extending the public flow system vertically requires it be configured to do vertical work, meaning it must be sloped or do vertical work by another method. Figure 2.5.7 illustrates how the 200ft block from Figure 2.5.6 could be reconfigured for a sloping street surface. Just as is the case with urban areas on inclined topography (Figure 2.5.8), the buildings lining the

Speck, Jeff. "Rule 37 Keep Blocks Small" in Walkable City Rules: 101 Steps to Making Better Places. P.88.Washington, DC: Island Press, 2018.

$8 \quad$ Speck, Jeff. "Various Rules" in Walkable City Rules: 101 Steps to Making Better Places. P.1-285.Washington, DC: Island Press, 2018. 

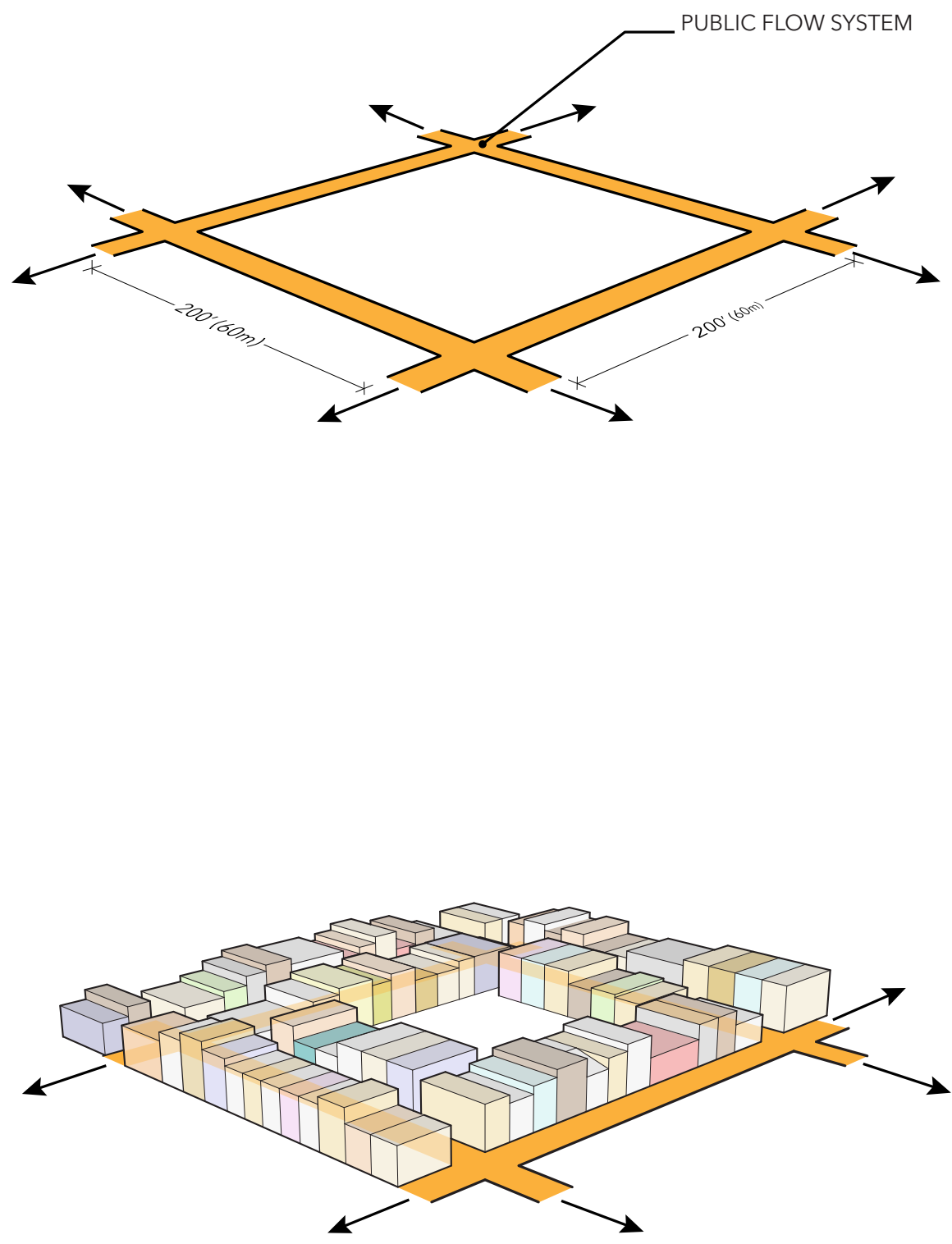

Figure 2.5.5: 2D Walkable block 60m (200') 

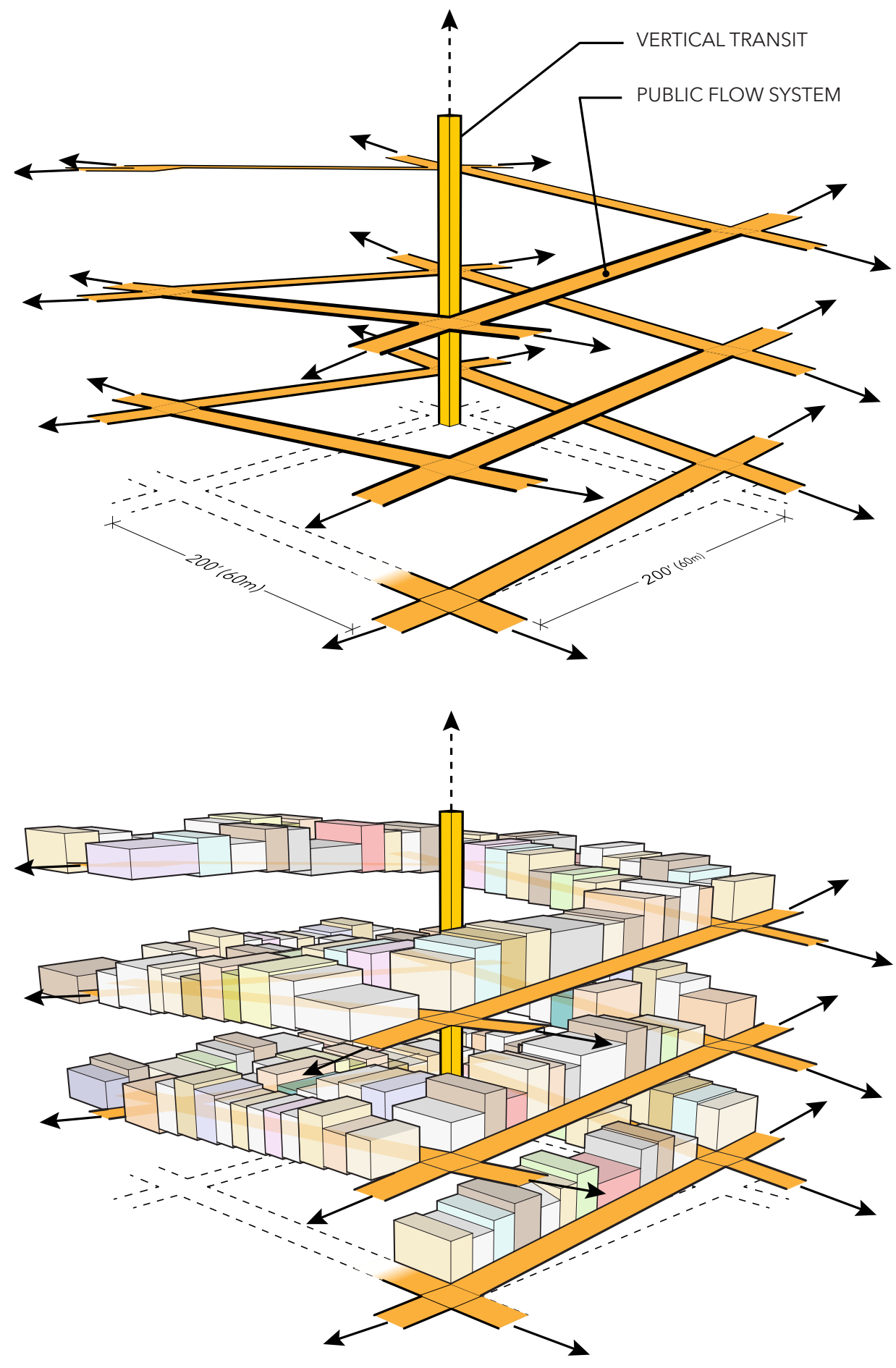

Figure 2.5.6.: 3D Walkable block $60 \mathrm{~m}\left(200^{\prime}\right)$ extended vertically at $1: 12$ slope and connected by vertical transit connection 


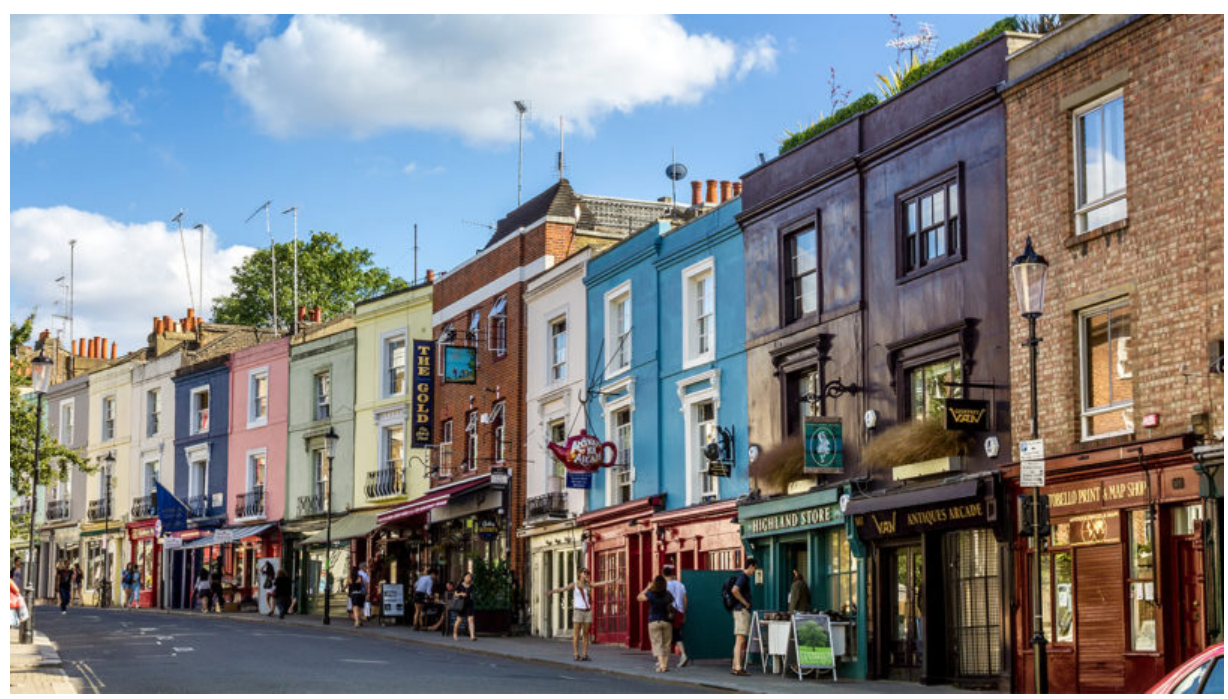

Figure 2.5.7: Storefronts configured on a sloped plane, in Notting Hill, London

Lovespace. "Storefront Guide: Pop-Up Shops in Notting Hill." Storefront, March 2, 2017. https:// www.thestorefront.com/mag/storefront-guide-pop-up-shops-in-notting-hill/.

street edge could be stepped in accordance with the slope. Since this vertical block is not restricted to the ground plane, it could be continued and repeated upward in a continuous manner, with multiple planes overlapping one another. To overcome discontinuity between planes, strategically placed vertical transit could connect blocks at various levels.

It is important to note that this $200 f t$ square block configuration is just one of many possible configurations for a vertically walkable city block. Similar conditions may also be achieved in many other ways that align with the goals of creating a vertically walkable city. See the exploratory model in Figure 2.5.9.

\section{Vertical District/ Neighborhood}

On the ground plane, multiple city blocks configured together within a larger city begin to form what is commonly thought of as a district or neighbourhood. The same thinking could be applied to the vertical configuration of city blocks. 


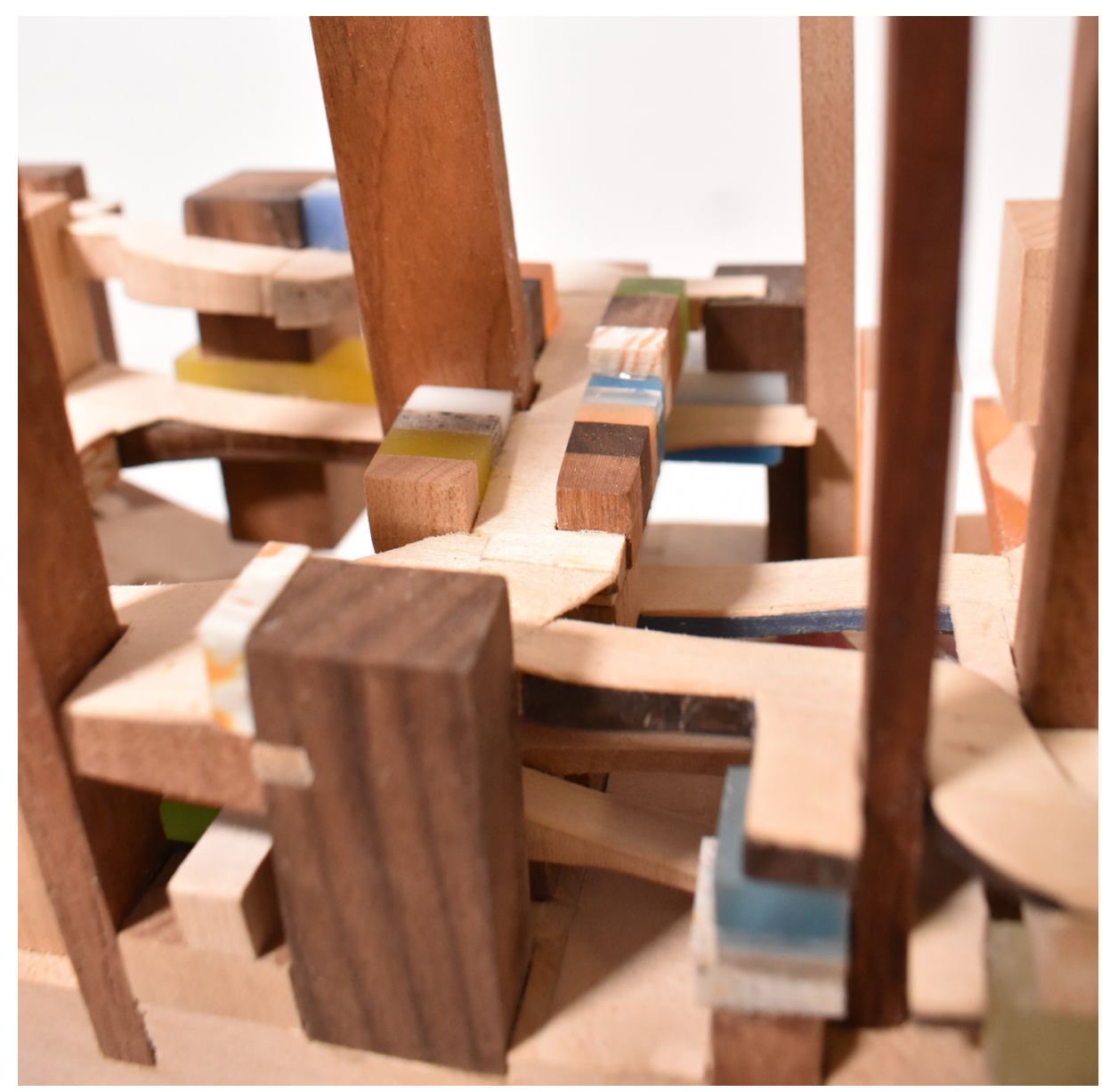

Figure 2.5.8: Additive Volume Model depicting various way that the flow system could be configured

The model depicted in Figures 2.5.10-11 explored how vertically configured city blocks, could inform the layering of urbanistically dependent and urbanistically independent spaces within the volume of a city. The 1:500 model is intended to represent a volume within a dense area of a city, where sloped walkable blocks are embedded within and supported on adapted spaces. In the model, brightcoloured hardwoods represent the urbanistically dependent spaces, which are placed adjacent to the street surface, while basswood blocks represent the urbanistically independent spaces. Together, the layering of urbanistically dependent and independent spaces in a dense, localized context form the basis for what could be thought of as a 


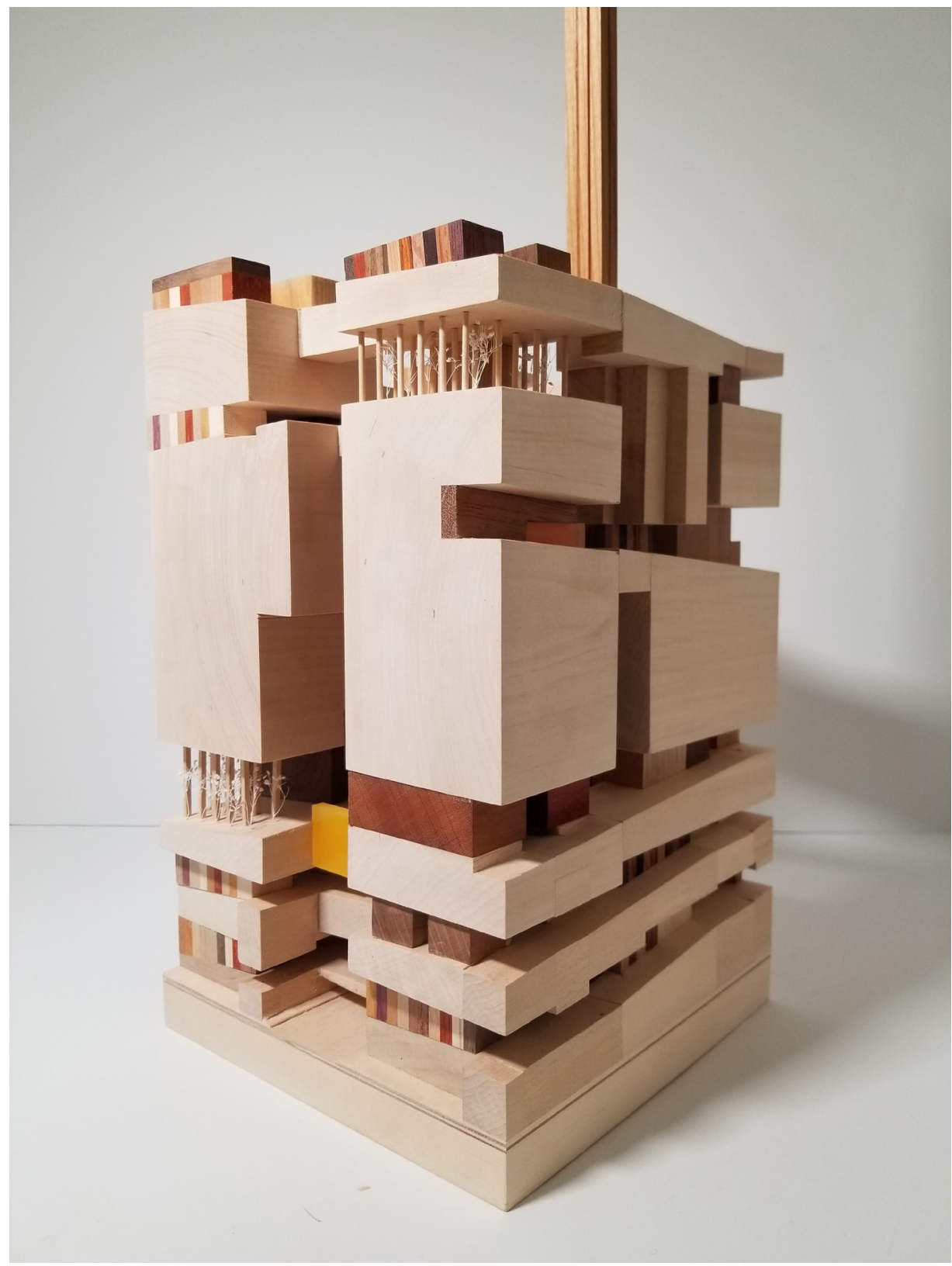

Figure 2.5.9: Progress photo of the Volume Model that integrates vertical blocks within a layers of urbanistically dependent and independent spaces to form vertical districts. vertical district or neighbourhood.

Throughout history, the urban neighbourhood has played a pivotal role in the way cities were configured ${ }^{9}$. As cities have grown vertically, however,

Busquets, Joan. Line 6: Traditional Views" Cities X Lines: A New Lens for the Urbanistic Project. Edited by Felipe Correa and Harvard University. Reprint. S.I.: Nicolodi, 2007.

Blackson, Howard. "The Five Cs of Neighborhood Planning | PlaceMakers." Placemakers, August 30, 2012. http://www. placemakers.com/2012/08/30/ 


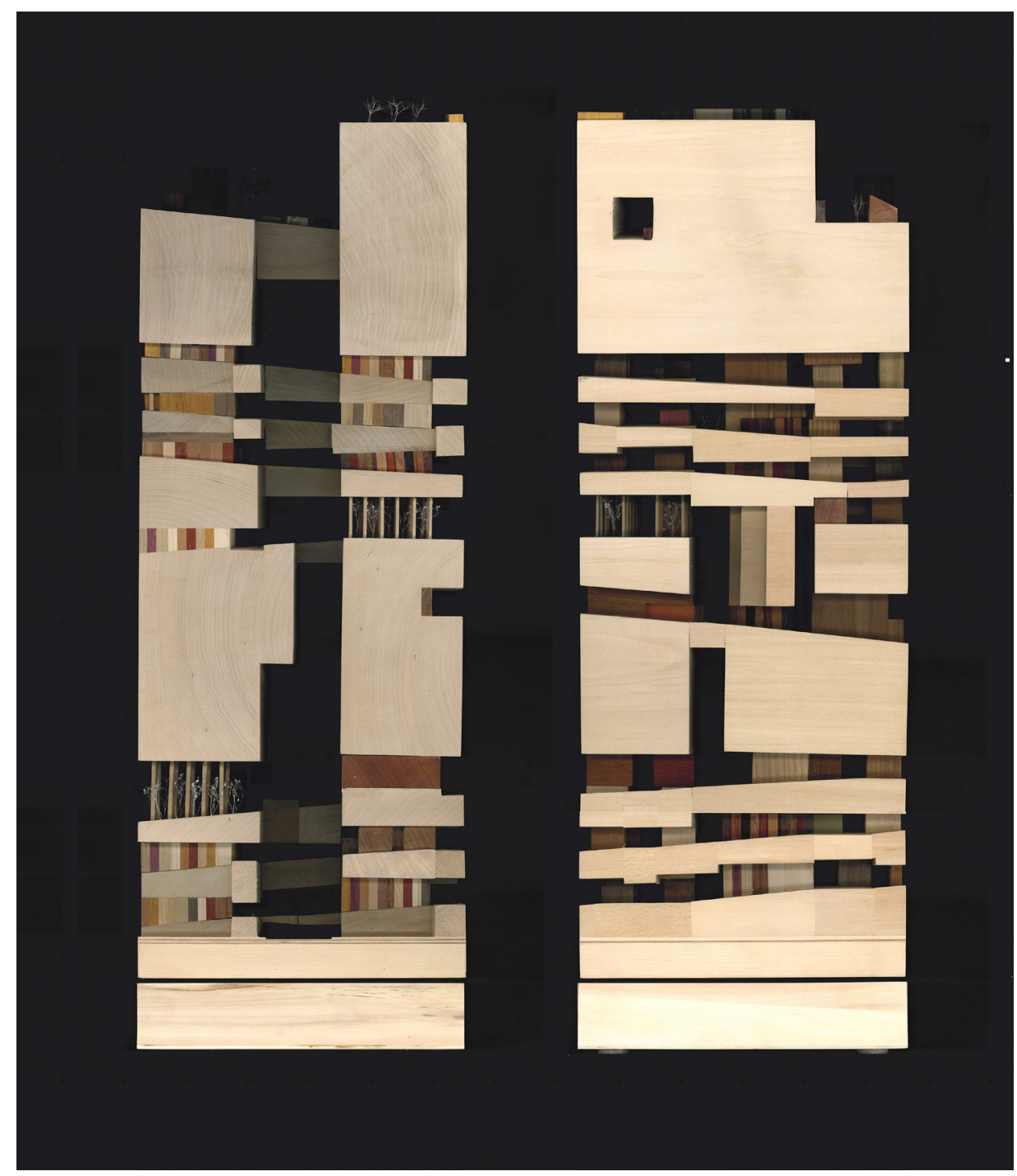

Figure 2.5.10: Sectional scans of volume model showing colored hardwoods and sloping flow system embedded within urbanisticaly independent spaces

the concept of the neighbourhood remained firmly on the ground, and in many cases, was forgotten altogether. The need for a returned focus to the neighbourhood, as a driver for urban design, was the main argument Jane Jacobs presented in the 1961 publication of The Life and Death of Great American Cities ${ }^{10}$. In the decades since this book's release, the concept of neighbourhood and community has reemerged as a focal point in architecture and urban

the-five-cs-of-neighborhood-planning/.

10 Jacobs, Jane. "Introduction" in The Death and Life of Great

American Cities. P.3-25. Vintage Books ed. New York: Vintage Books, 1992. 


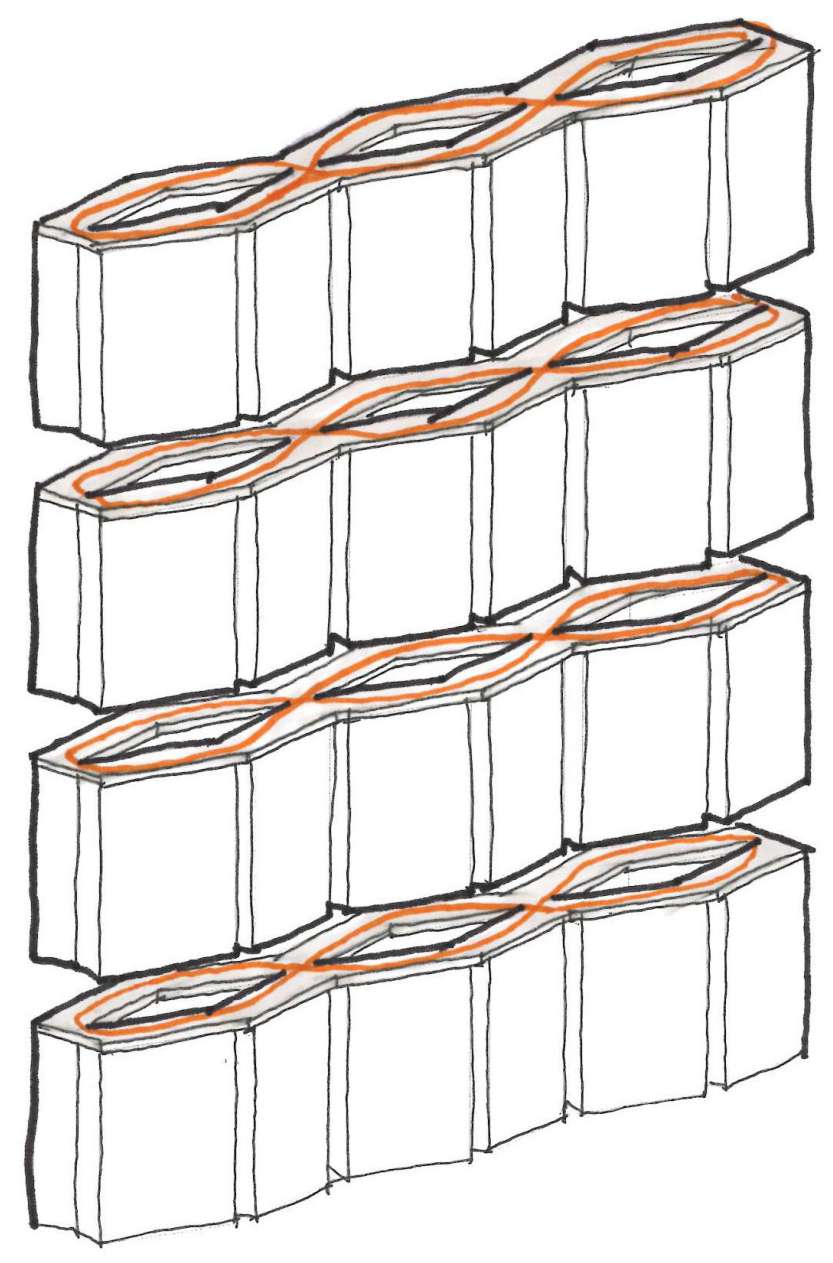

Figure 2.5.11: SkyVille@ Dawson, 2007,WOHA, Sky streets periodically break up volume of towers ever 12 stories. Caskey, Alex, Skyville @ Dawson, Singapore, Fall 2019

planning spheres, but only from a two-dimensional perspective.

Apart from mostly theoretical work, the adaptation of neighbourhood-focused design to the vertical axis of the city has only recently emerged in the tall building design world ${ }^{11}$. One of the best examples is Skyville @ Dawson, by WOHA, a public housing development where six residential towers are linked periodically with sky streets every 12 stories (Figures 2.5.12-14). WOHA claims that this configuration and

11 One early theoretical example of vertical neighborhood thinking is Cullen, Gordon. "iX Delhi Townscape". In Architectural Record p. 111-117. February 1960. 


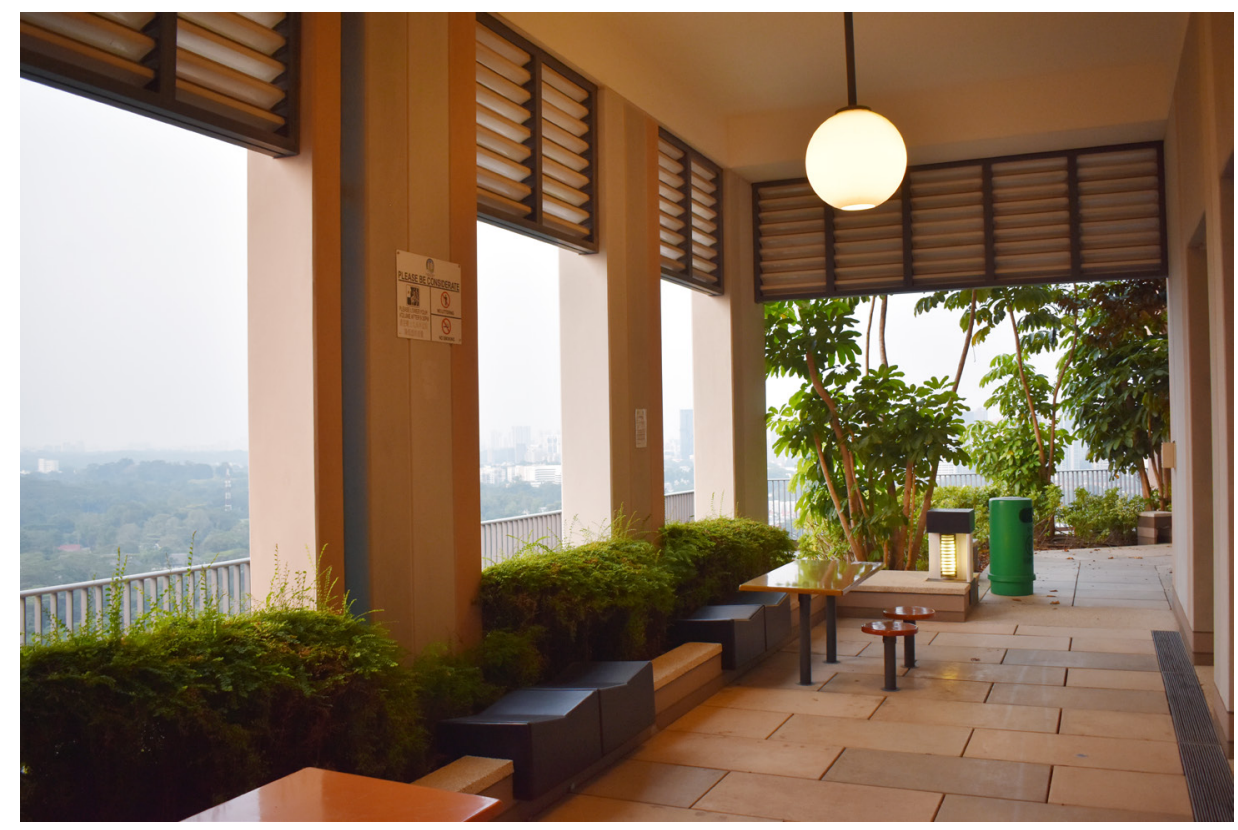

Figure 2.5.12: SkyVille@ Dawson, 2007, WOHA, Sky street amenity space,

Caskey, Alex, Skyville @ Dawson, Singapore, Fall 2019

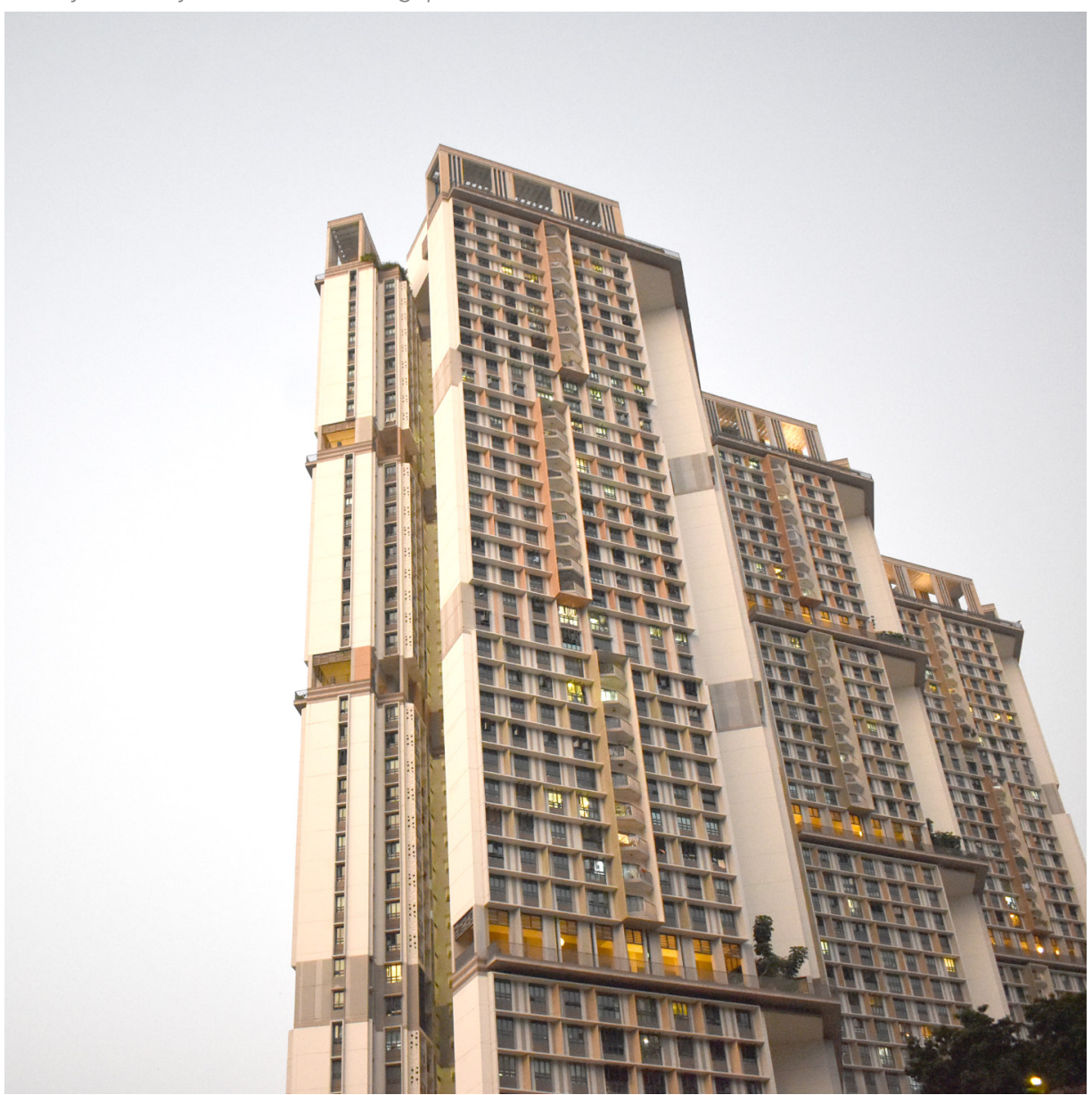

Figure 2.5.13: SkyVille@ Dawson, 2007,WOHA Caskey, Alex, Skyville@ Dawson, Singapore, Fall 2019 


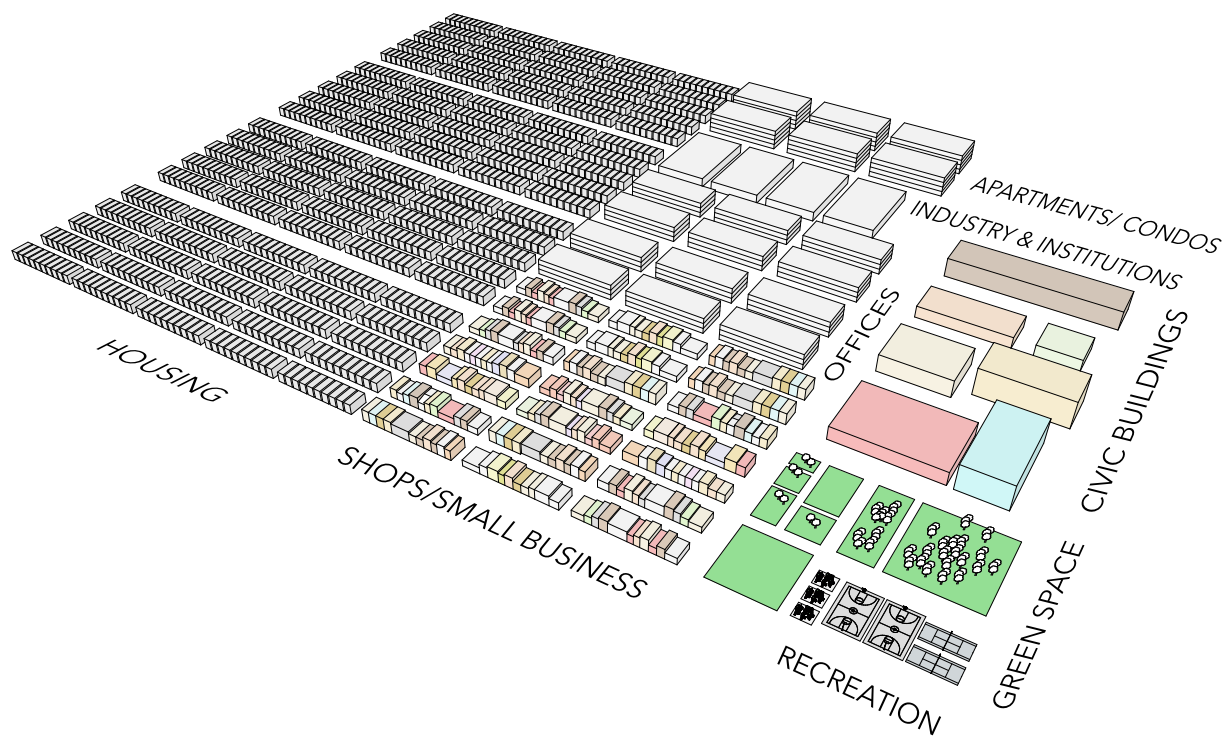

Figure 2.5.14: Common types of adapted spaces that form a neighborhood

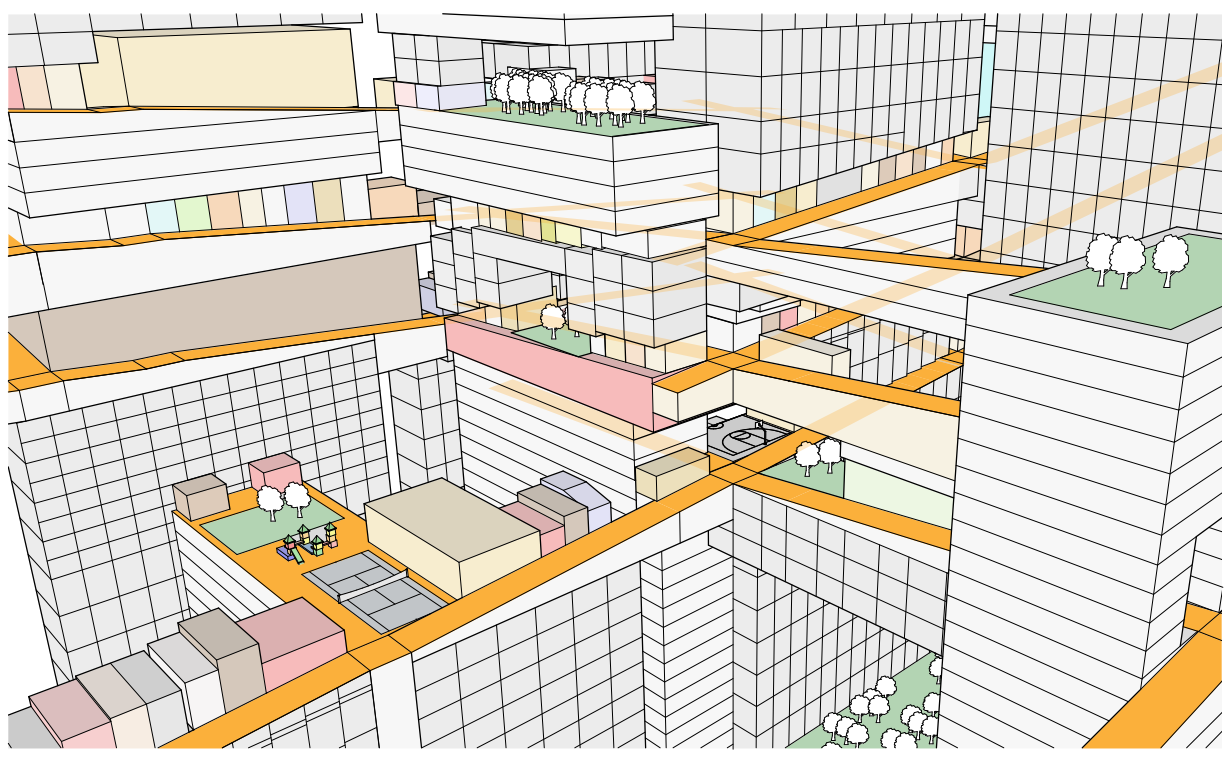

Figure 2.5.15: The configuration and layering of neighborhood components around vertically walkable blocks. 
fragmentation, of what would have likely otherwise been common towers, forms "sky villages" or what could be thought of as neighbourhoods ${ }^{12}$. In reality, these sky streets are simply large private amenity spaces, and while they certainly are more neighbourly than the common tower, they are certainly not neighbourhoods or villages. As described in Section 2.1 , the fragmentation of these sky streets from the ground plane does not support the diverse set of activities that one would expect to find in a neighbourhood.

Figure 2.5.15 is a diagrammatic representation of the diverse types of adapted spaces that might commonly be found in a functional, walkable neighbourhood where. These spaces would be sized, configured, and designed for ${ }^{13}$ :

- Housing, apartments/ condos, and hotels

- Offices, industrial spaces, and Institutions,

- Shops, and other small businesses

- Civic buildings such as libraries, schools(Rule 7), post offices, churches, community centres, and assembly halls

- Green space and Parks (Rule 8)

- Playgrounds and Recreation Facilities (Rule 8)

The neighbourhood's localized density is what would support this diversity of spaces. Figure 2.5.16 is a diagrammatic representation of a way these spaces could be vertically configured and layered. In this example, the neighbourhood spaces from Figure 2.5.15 are organized around the $200 \mathrm{ft}$ vertically

\footnotetext{
Bingham-Hall, Patrick. Skyville @ Dawson,Garden City Mega City: Rethinking Cities for the Age of Global Warming. P. 236-237Singapore: Pesaro Publishing, 2016.

13 Blackson, Howard. "The Five Cs of Neighborhood Planning | PlaceMakers." Placemakers, August 30, 2012. http://www. placemakers. com/2012/08/30/the-five-cs-of-neighborhood-planning/.

Perry, Clarence. "The Neighborhood Unit." In The Urban Design Reader, edited by Michael Larice and Elizabeth Macdonald, 54-65. The Routledge Urban Reader Series. London: Routledge, 2007.
} 
walkable blocks explored on the previous pages. The intention is that the localized density of housing and office spaces, combined with the extension of the public flow system would enable urbanistically dependent spaces to be successfully located above the ground plane. This suggests that unlike the "neighbourhood" amenity spaces at Skyville@Dawson that only support housing and gathering spaces, all of the spaces of a functional, walkable neighbourhood could exist above the ground plane.

\section{Vertical Network of Walkability}

The urban neighbourhood does not exist in a vacuum. Its community, services, and economy are local, yet at the same time rely on a much more extensive citywide network ${ }^{14}$. Similarly, the walkability of neighbourhoods stems from the walkability of the city. The need to strategically develop a network of walkability and connectivity is Jeff Speck's $96^{\text {th }}$ rule ${ }^{15}$. On the ground plane, the network is created by the physical infrastructure, the main streets and transportation systems that link walkable neighbourhoods together. The walkability of this network, however, comes from it being safe, comfortable, interesting, and useful, meaning that there are useful places to walk to ${ }^{16}$. The positioning of such anchors as grocery stores, civic buildings, and

\footnotetext{
$14 \quad$ Jacobs, Jane. "Introduction" in The Death and Life of Great American Cities. P.3-25. Vintage Books ed. New York: Vintage Books, 1992. Busquets, Joan. Line 6: Traditional Views" Cities X Lines: A New Lens for the Urbanistic Project. Edited by Felipe Correa and Harvard University. Reprint. S.I.: Nicolodi, 2007.

Blackson, Howard. "The Five Cs of Neighborhood Planning | PlaceMakers." Placemakers, August 30, 2012. http://www. placemakers.com/2012/08/30/ the-five-cs-of-neighborhood-planning/.

$15 \quad$ Speck, Jeff. "Rule 96 Identify a Network of Walkability" in Walkable City Rules: 101 Steps to Making Better Places. P.228-229.Washington, DC: Island Press, 2018.

16 Speck, Jeff. "Rule 94 Do a Walkability study" in Walkable City Rules: 101 Steps to Making Better Places. P.224-225.Washington, DC: Island Press, 2018
} 


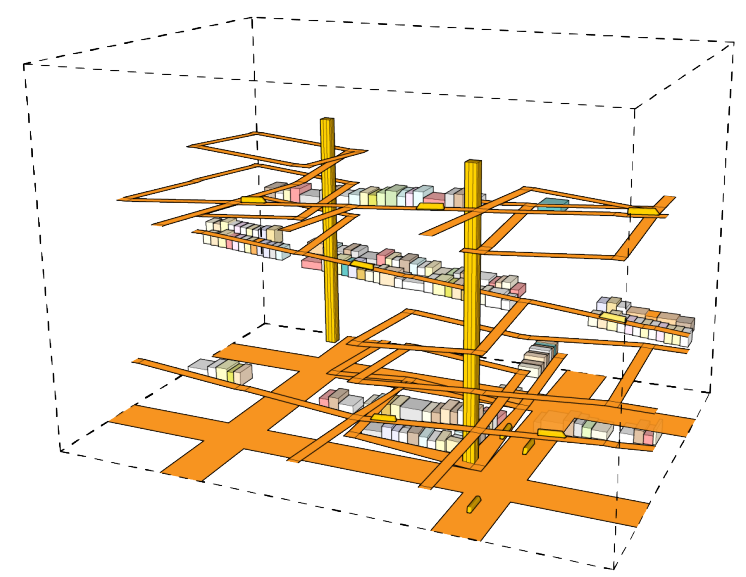

VOLUMETRIC APPROACH: MAIN STREETS AND TRANSIT

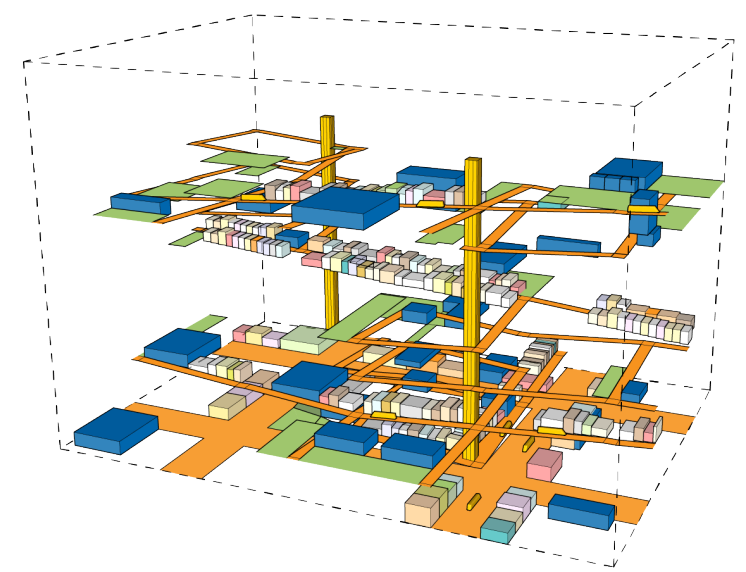

VOLUMETRIC APPROACH: STRATEGICALLY PLACE PARKS AND ANCHORS

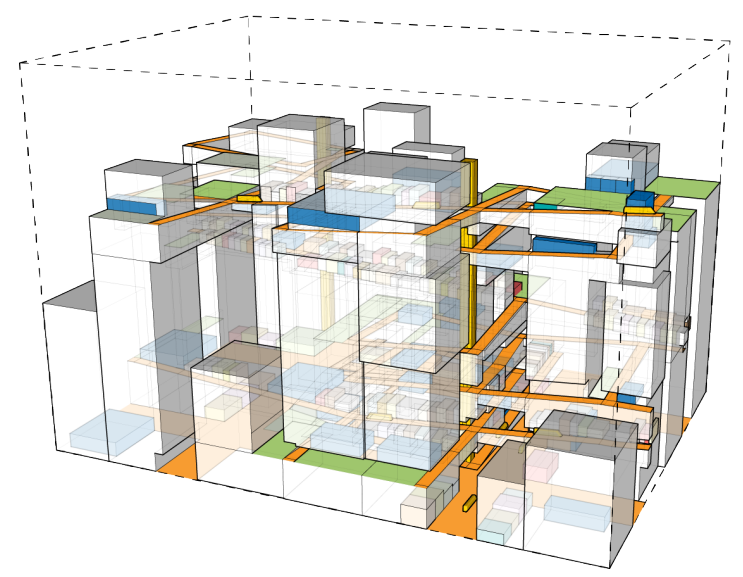

VOLUMETRIC APPROACH: FUTURE DEVELOPMENT ADAPTED TO SUPPORT PUBLIC REALM

Figure 2.5.16: At a larger scale 3D Walkable blocks and neighborhoods can be connected together by "main streets"s and vertical transit (Yellow) to form a three dimensional network. This network could be bound together by the strategic placement of anchors(Blue \& Green) like parks, civic buildings, and "skymarks" 
landmarks plays a key role in making walks useful ${ }^{17}$. The principles of creating a network of walkability could equally apply to a vertical context.

Figure 2.5.17 diagrams how vertical neighbourhoods could be configured and interconnected within the broader volume of a city. The extensions of a continuous, unconditional, an external, public flow system could be configured into a citywide network along main axes in the form of sloped "vertical main streets". The surface network of the public flow system could be supported by various modes of vertical transportation discussed in Section 2.6. Just as on the ground plane, anchors, like grocery stores, civic buildings, and "skymarks," strategically located throughout the volume of a city, could help form a useful three- dimensional network of walkability.

\section{Conclusion}

The automobile-oriented contemporary city is at odds with the centralization of large portions of the population in a dense, vertically organized environment. The adverse environmental, social, and economic impacts of a car-based society are becoming increasingly apparent. Instead of a focus on vehicles, a city that extends in a compact vertical manner should adopt urban design principles of walkability. This section explored how Jeff Speck's principles of walkability intended for a horizontally organized city, could be equally applicable to a vertical context. It discussed vertical walkability of the public flow system at three scales, the city block, the neighbourhood, and the citywide network.

$17 \quad$ Speck, Jeff. "Rule 95 Do a frontage quality assement and locate anchors " in Walkable City Rules: 101 Steps to Making Better Places. P.226227.Washington, DC: Island Press, 2018 


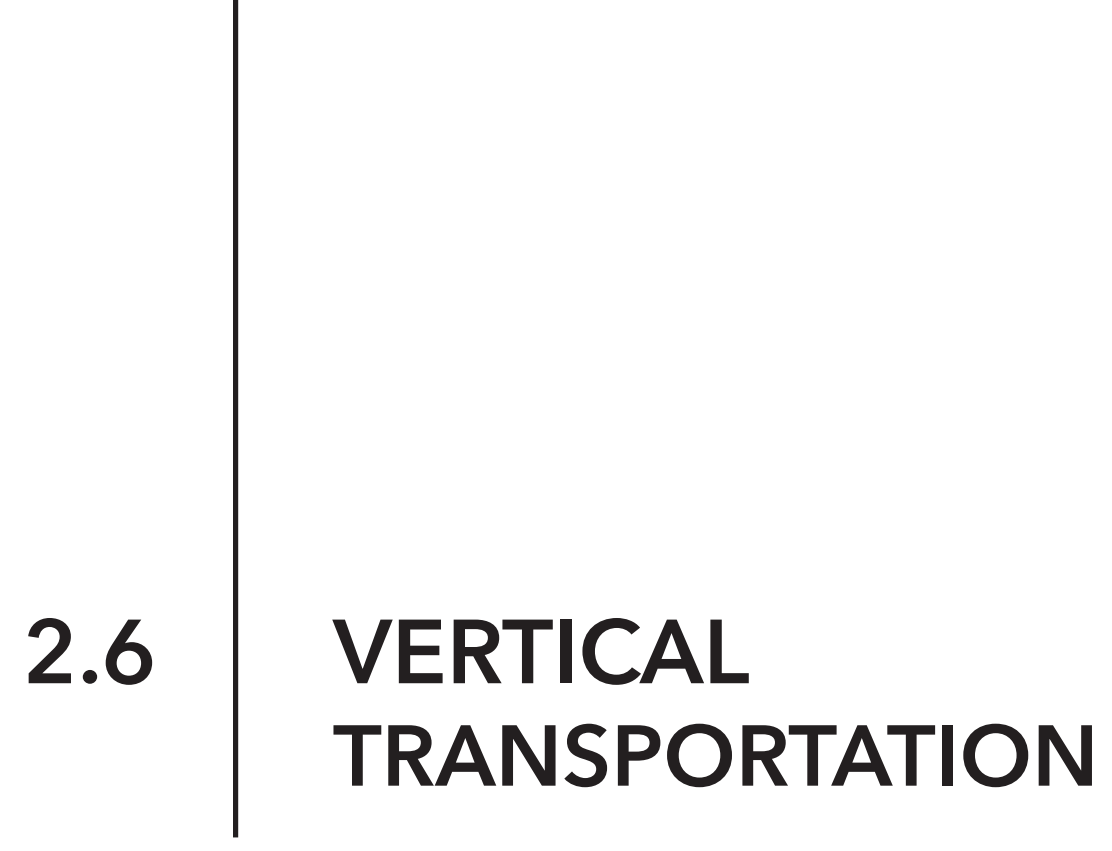

Section 2.5 established why walkability should be the primary design driver for extending a city vertically. The reality is, however, no matter how walkable a city is, some distances are just too far for most people to walk, especially if much of that city is at an incline. This section explores the vertical extension of the "dynamic" aspects of the public flow system. It outlines other modes of transportation that may be incorporated to complement and support the goals of a vertically walkable city. It also discusses how other dynamic aspects of the public flow system, like delivery and collection of goods and services, as well as emergency services, could support a city organized within a three-dimensional volume.

\section{Vertical Public Transit}

As Jeff Speck argues in Walkable City Rules:

"...because density is at the heart of urbanism, and cars obliterate density, mass transit -in some form- is key to our urban future"1

On the ground plane, walkable cities are typically complemented by various forms of public transit 


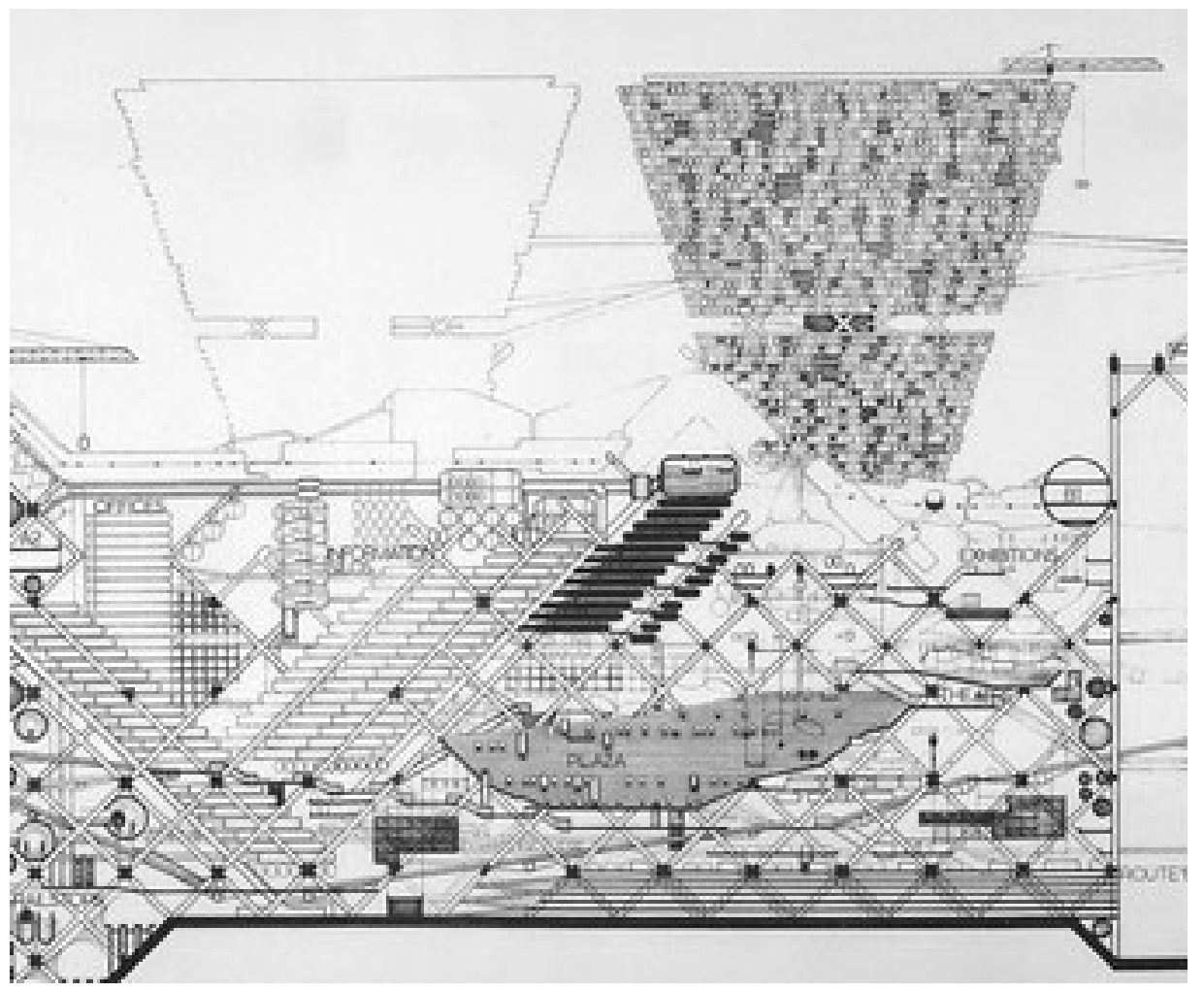

Figure 2.6.1: Peter Cook, Plug in City, 1962

Plug in City, 1962 https://www.archdaily.com/399329/ad-classics-the-plug-in-city-peter-cook-archi gram/51 d71 cabe8e44ecad700002a-ad-classics-the-plug-in-city-peter-cook-archigram-image

for trips where walking is prohibitively challenging or time-consuming. A walkable city organized throughout the volume of a city would need to do the same. In addition, the surface of a vertically extended public flow system can't achieve the same level of continuity and redundancy as it would on the ground plane. Voids would be required to allow the permeation of light and air through the volume of the city.

As a result of these two factors, there would be the need for a vertically-configured public transit system that connects the surface of the public flow system at various datums throughout the height of a city. Vertical transit alone may not suffice. Above the ground plane, there would be a need to move people both horizontally and vertically. In Peter Cook's 1962 
proposal for Plug-in City (Figure 2.6.1), he came to a similar conclusion. He addressed this condition through a citywide matrix of diagonal transit tubes ${ }^{2}$.

Such a large scale urban framework would be unsuitable for this thesis. Instead, this thesis seeks to provide less of a singular transit solution and to allow for a range of possibilities. The following is a list of existing transportation technology that could be considered as part of a vertically extended public transportation network. These include but are not limited to:

Elevators: One of the most common forms of transporting people vertically in use in all common towers is the cable elevator. Typically private, this effective method of vertical movement is based on technology dating back over 160 years that was popularized by Elisha Ottis's introduction of the safety brake in $1854^{3}$. (Figure 2.6.2)

Diagonal Elevators: Diagonal elevators can move passengers vertically and horizontally simultaneously. The elevator in the St. Louis Arch, constructed in 1960, climbs diagonally to carry passengers from the edge of the Mississippi River to the observation area at the crest of the $\operatorname{arch}^{4}$. (Figure 2.6.3)

Multi-Directional Elevators: Maglev elevators, like the Multi Elevator developed by German engineering company Tyssen Krupp, are free from cables and can move in various directions ${ }^{5}$. 
(Figure 2.6.4)

Trams/Street Cars/ Cabel Cars/Funiculars: In many cities, tram type vehicles move people along horizontal planes as an active, visible means of public transit. If properly equipped, they can move up and down inclined planes, as is the case with the cable cars in San Francisco, which travel up grades of up to $12 \%\left(1: 8 \text { or } 7^{\circ}\right)^{6}$. (Figure 2.6.5)

Busses: If there is road infrastructure, busses are a means of transit that can move unrestricted across flat and inclined planes. (Figure 2.6.6)

Gondolas: Gondolas are a commonly used means of transit when attempting to connect various peaks. In South America, gondolas have been a means of providing accessibility to upper portions of informal settlement situated along steep hills ${ }^{7}$. (Figure 2.6.7)

Rideshare/Taxi: Rideshare and taxi vehicles that pick up passengers and take them to their destination offer a large amount of flexibility. These could be either automobiles or other smaller lighter vehicles. Jeff Speck argues however that these services are not a replacement for, but a means of complementing, a shared transit system ${ }^{8}$. (Figure 2.6.8)

\footnotetext{
27,2017. https://newatlas.com/cableless-vertical-horizontal-elevator-multi/50218/.

6 Tarantola, Andrew. "How San Francisco's Cable Cars Climb Its Iconic Hills." Gizmodo. Accessed February 13, 2020. https://gizmodo.com/ how-san-franciscos-cable-cars-climb-its-iconic-hills-5889870.

Maurer, Samuel. "Hill Mapper San Francisco." Accessed February 13, 2020. http://hillmapper.com.

$7 \quad$ Graham, Stephen. "Favela: Tenuous City" in Vertical: The City from Satellites to Bunkers. P. 123. London; New York: Verso, 2016. $8 \quad$ Speck, Jeff. "Rule 25 Don't Mistake Uber for Transit" in Walkable City Rules: 101 Steps to Making Better Places. P.58-59Washington, DC: Island Press, 2018.
} 


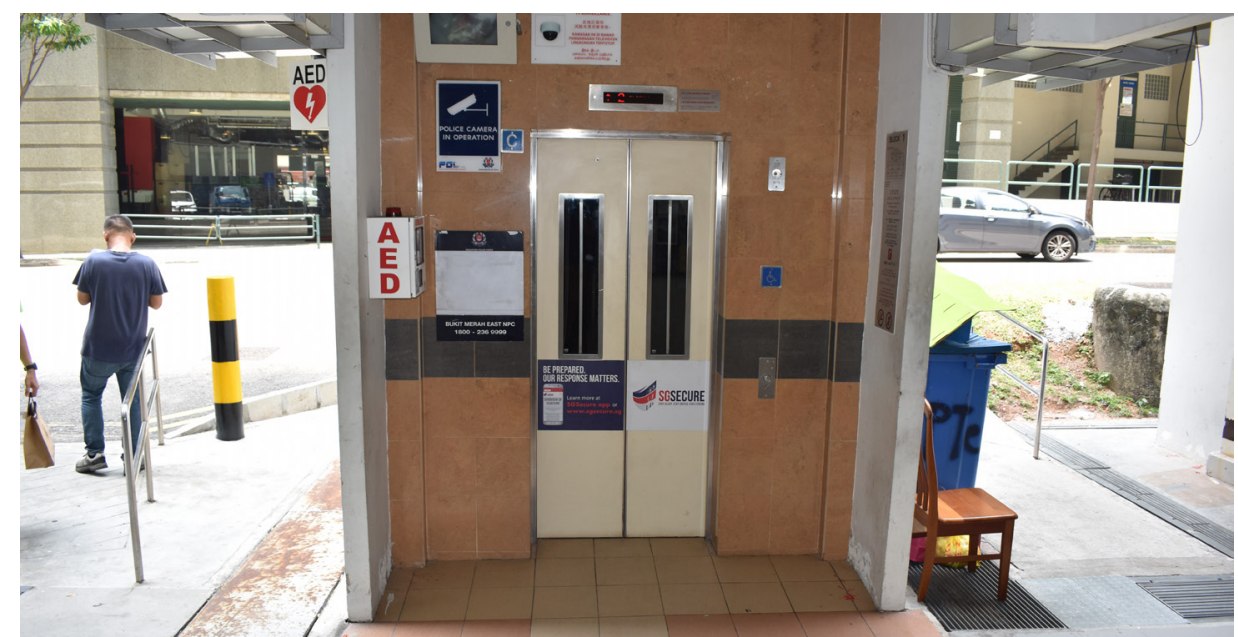

Figure 2.6.2: Elevator: external elevator at housing development in Singapore

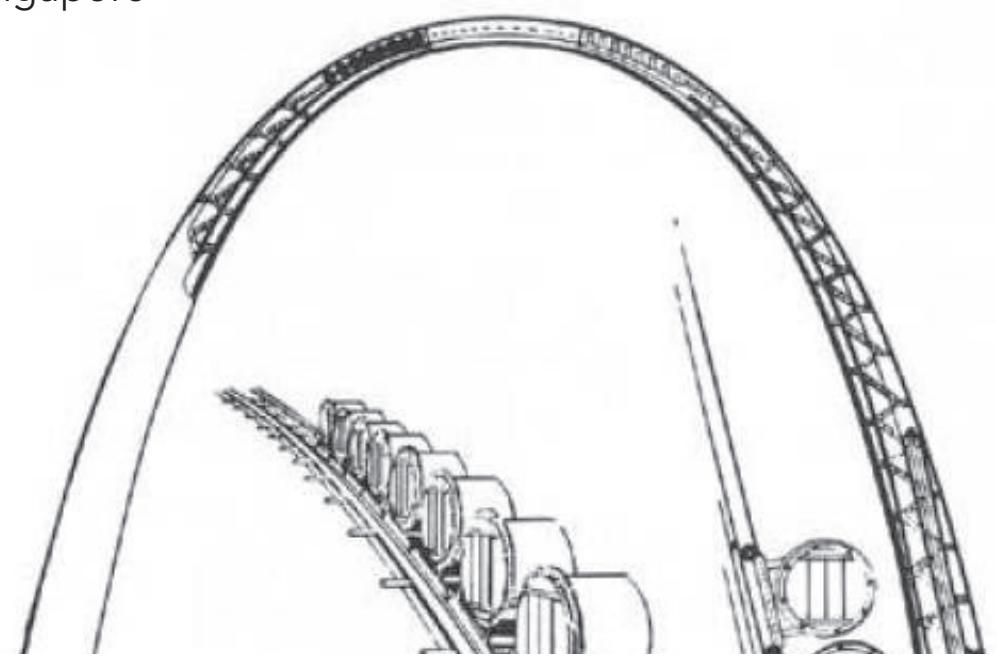

Figure 2.6.3: Diagonal Elevator: Gateway Arch tram-elevator WikiArquitectura. " Gateway Arch - Data, Photos \& Plans." Accessed February 13, 2020. https:// en.wikiarquitectura.com/building/gateway-arch/.

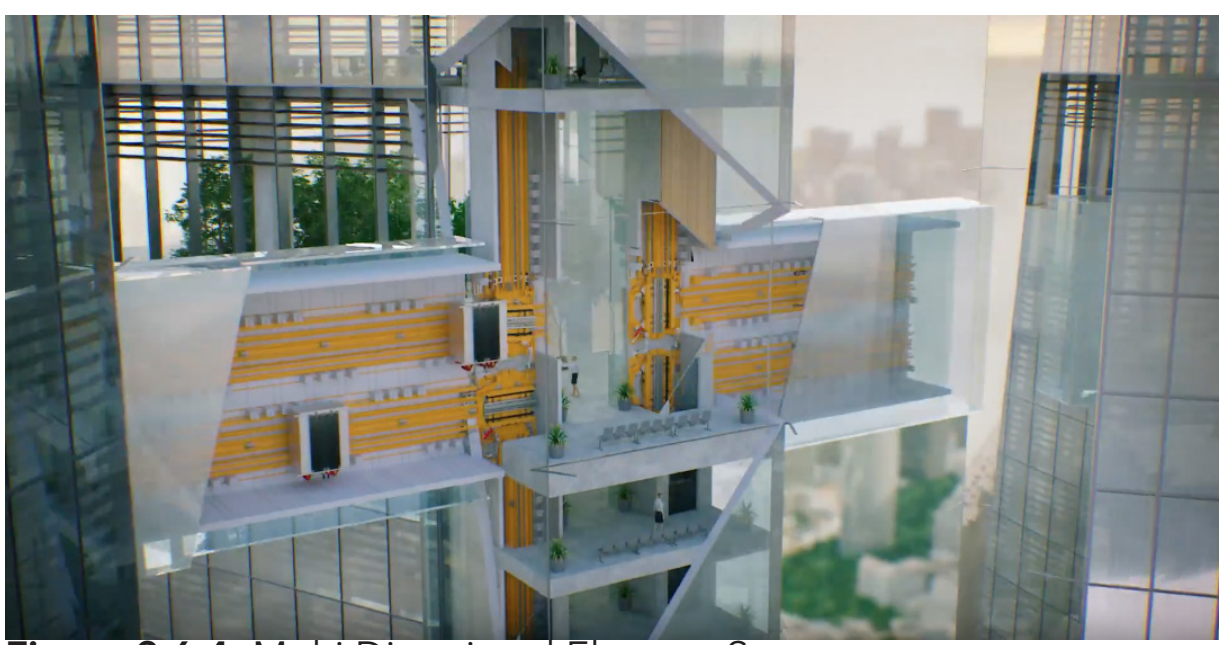

Figure 2.6.4: Multi Directional Elevator System

TyssenKrup, . "Multi Elevator System Render." New Atlas, June 27, 2017. https://newatlas.com/ cableless-vertical-horizontal-elevator-multi/50218/. 


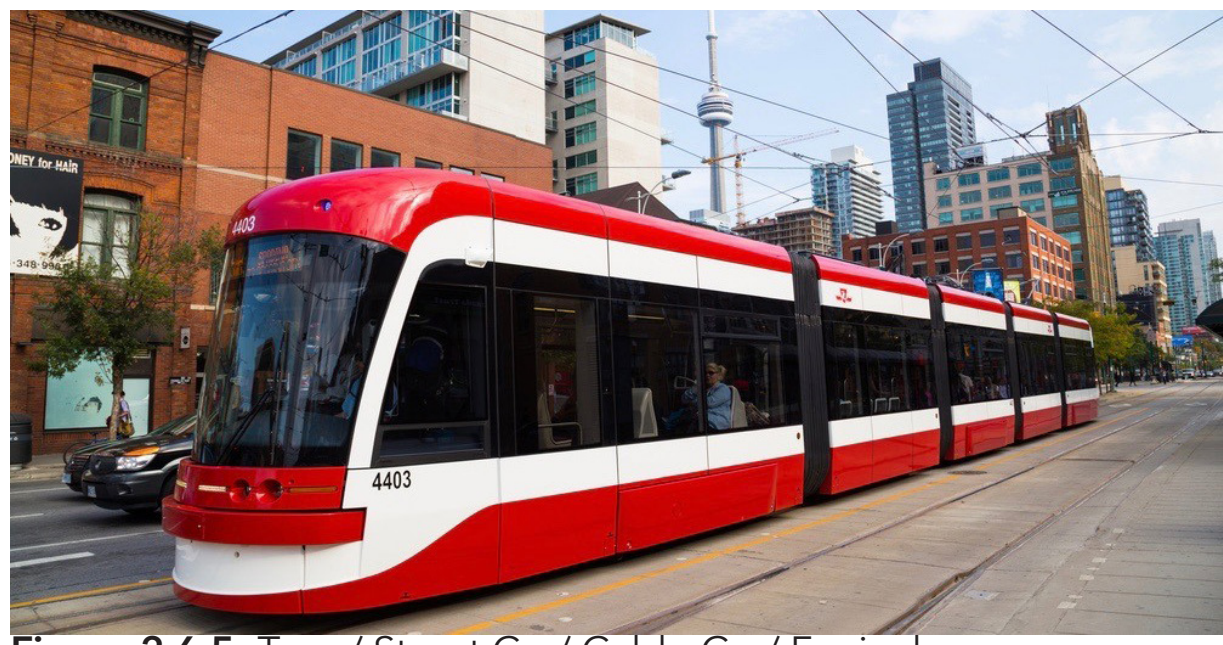

Figure 2.6.5: Tram/ Street Car/ Cable Car/ Funicular

Shutterstock. "7 Things the TTC Could Learn from One of the World's Best Transit Systems | News." The Hive, May 2017. https://dailyhive.com/toronto/ttc-learn-berlin-transit-system.

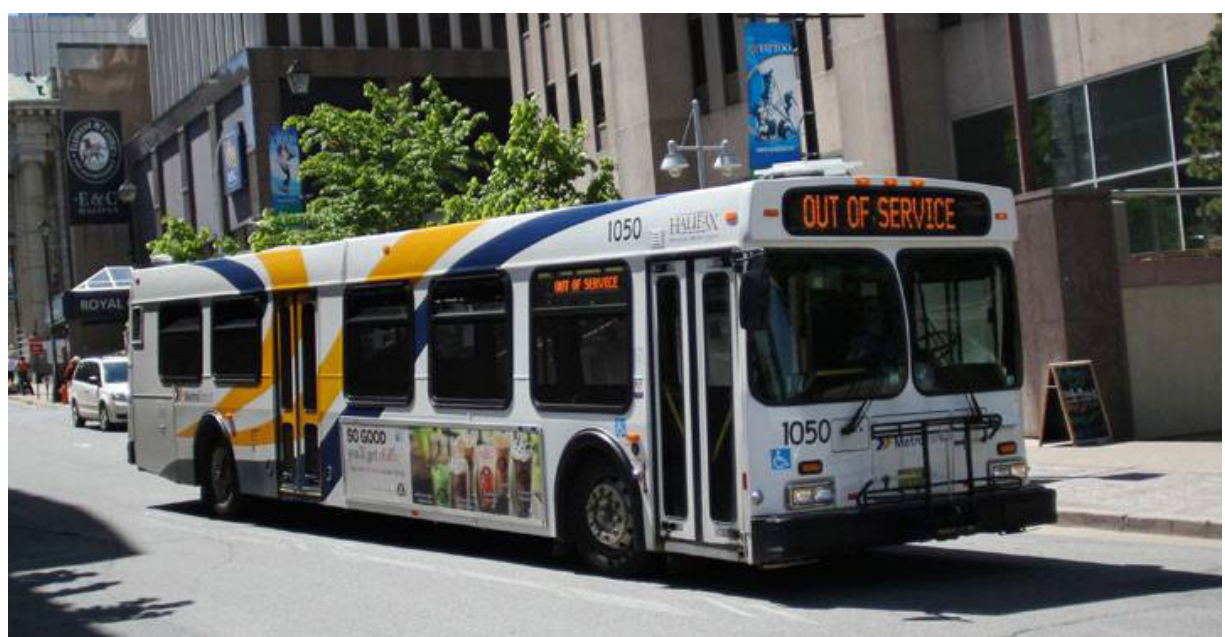

Figure 2.6.6: Buses:

Brown, Lee "Halifax Transit Had a Problem Arriving on Time This Summer: Report - Halifax |

Globalnews.Ca." Accessed February 13, 2020. https://globalnews.ca/news/3962840/halifax-transit-

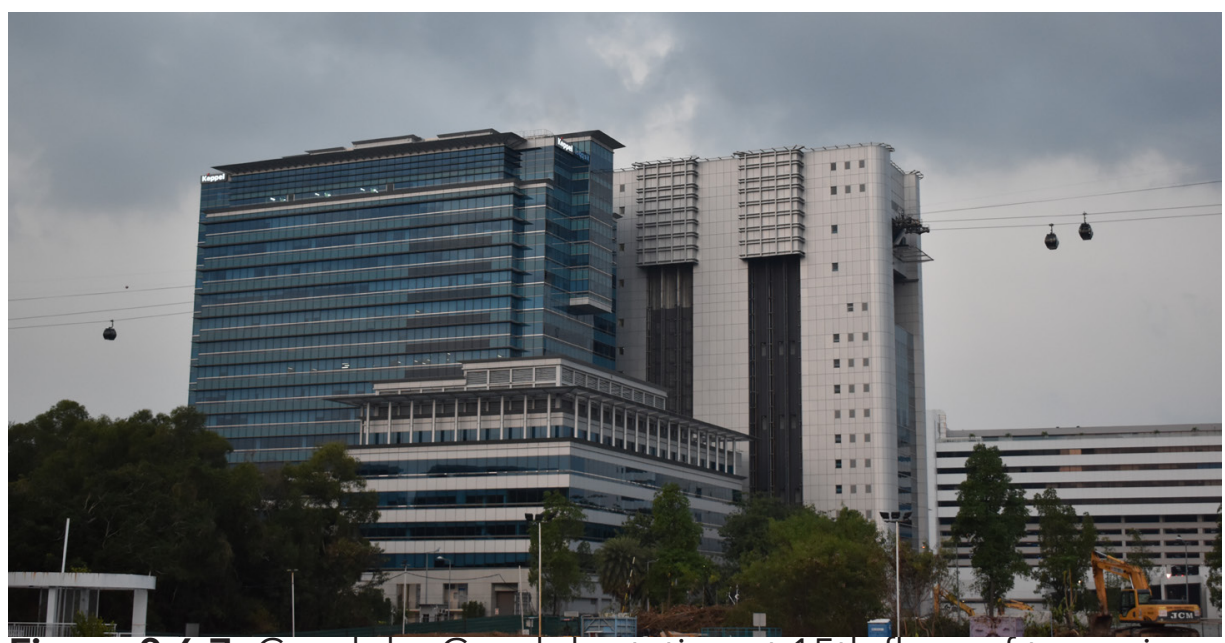

Figure 2.6.7: Gondola: Gondola station at 15th floor of tower in Singapore

Caskey, Alex " Harbour Front Gondola Station, Singapore, Fall 2019 


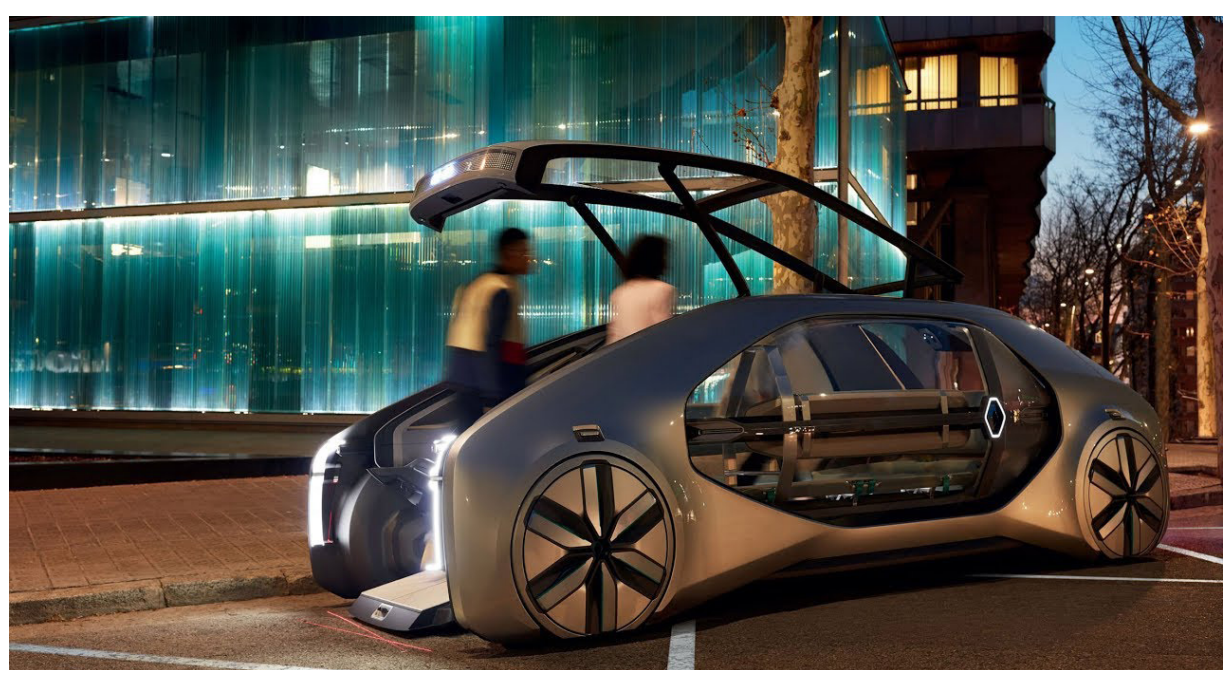

Figure 2.6.8: Rideshare/ Taxi: for individual and small groups Renault Unveils Driverless Uber-Style Transport System. Accessed February 13, 2020. https://www. youtube.com/watch?v=jbaP_zecEo0.

Figure 2.6.9: Drones: Taxi services and public transit services Vijayentiran, Viknesh. "Ehang Could Become First Flying Taxi Company to Go Public." Motor Authority. Accessed February 13, 2020. https://www.motorauthority.com/news/1125840_ehangcould-become-first-flying-taxi-company-to-go-public.

Drones: Passenger drones will likely be a reality in the future as some companies have already begun testing prototypes ${ }^{9}$. Whether they operate as a rideshare service or as a larger public transit, they could provide quick access to and from vertical spaces. The benefits of a drone type transit system would be its multi directionality and flexibility. Unlike with more rigid infrastructure like $9 \quad$ Vijayentiran, Viknesh. "Ehang Could Become First Flying Taxi Company to Go Public." Motor Authority. Accessed February 13, 2020. https://www.motorauthority.com/news/1125840_ehang-could-becomefirst-flying-taxi-company-to-go-public. 


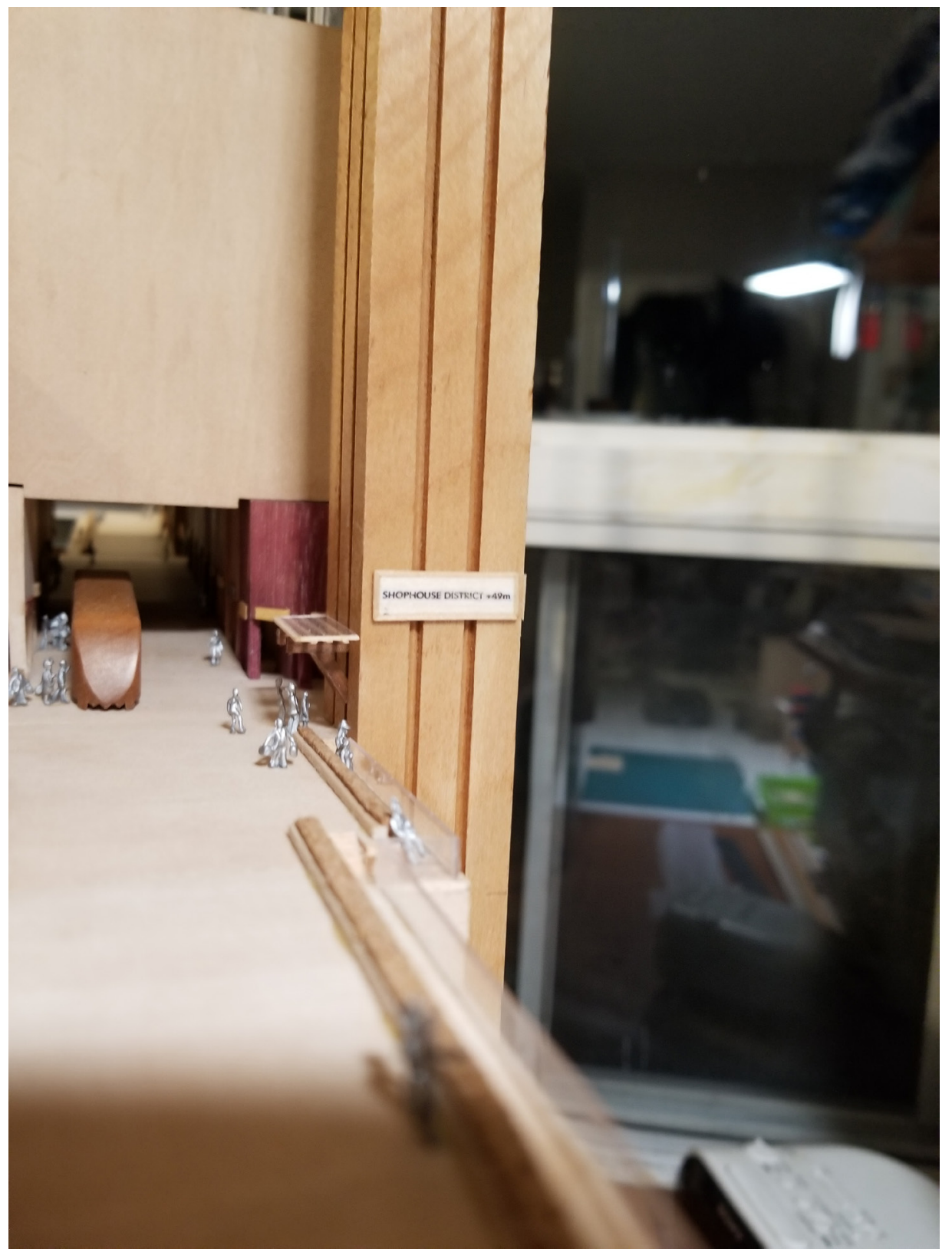

Figure 2.6.10: Model depicting vertical public transit core and surface level street car type transit system on a fragment of a street above the ground plane

an elevator, new stops could be added or moved as needed. (Figure 2.6.9)

If combined with existing ground level transportation, these technologies or other new forms of transportation could all contribute to a threedimensional public transit network. The most appropriate modes for public transit would depend 
on various conditions, including site-specific context. Throughout design research, public transit has primarily been explored as a combination of large vertical cores typical of elevator technology and horizontal tram-like transit systems that would travel along the sloped surface of the public flow system. Figure 2.6.10. shows how these two public transit modes have been articulated in a massing model. The model, discussed in Section 3.4, is a segment of a shophouse lined street intended to be situated high above the ground plane.

\section{Personal Transportation:}

There are circumstances where public transit may not adequately serve the transportation needs of people in a city. Even in a vertically walkable city, it would likely be necessary to provide infrastructure for multiple modes of personal transportation. These could include:

Personal Vehicles: As demonstrated in Lewis Tsurumaki Lewis's 2004 proposal for Park Tower (Figure 2.5.2), the thought of extending personal automobile infrastructure vertically is not completely absurd ${ }^{10}$. As mentioned, city design focused on the automobile and speed is at odds with the vertical growth of a city ${ }^{11}$. This incompatibility does not mean, however, that automobiles can not be complementary to a city designed around walkability. In some circumstances, with proper speed limits and lane sizes, walkability and personal vehicles could

$10 \quad$ Busquets, Joan. "Line X: Speculative Procedures" in Cities $X$ Lines: A New Lens for the Urbanistic Project. P. 339. Edited by Felipe Correa and Harvard University. Reprint. S.I.: Nicolodi, 2007.

LTL Architects. "Park Tower." LTL Architects, 2004. http://tlarchitects.com/ park-tower.

11 Van Leeuwen Thomas "The myth of Natural Growth" in A. Skyward Trend of Thought: The Metaphysics of the American Skyscraper. P. 86. Cambridge: Mit Press, 1990. 


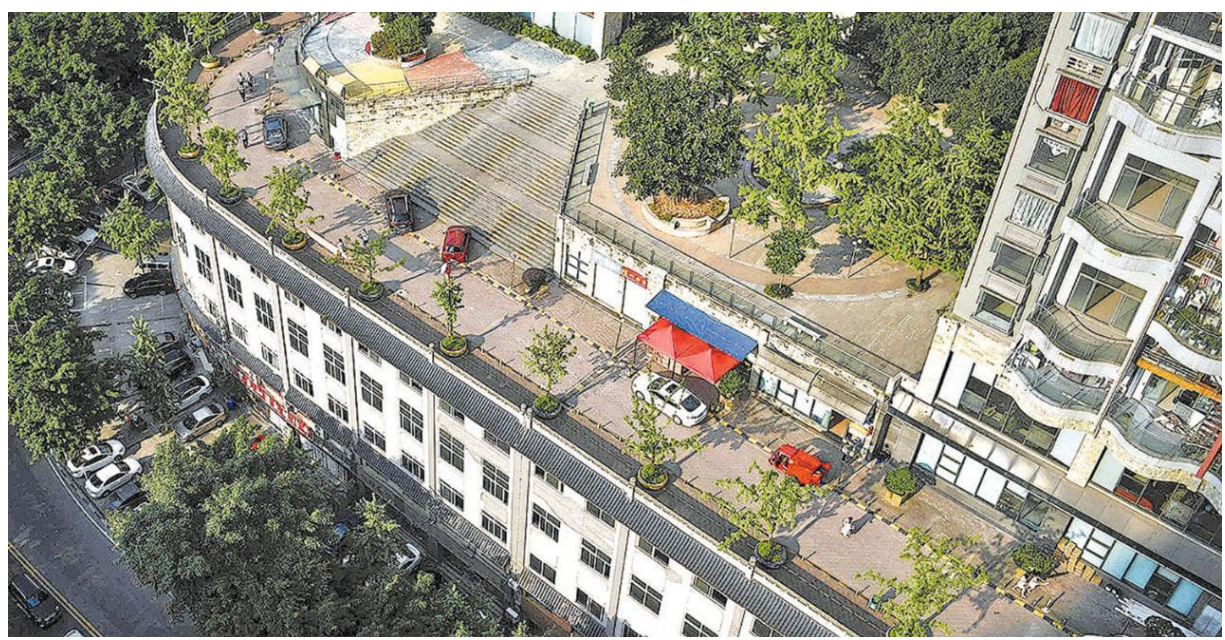

Figure 2.6.11: Personal Vehicles: Development in Chongqing that features a rooftop street on 5 floor.

South China Morning Post"Road on a Roof the Latest Addition to China's City of Odd Architecture

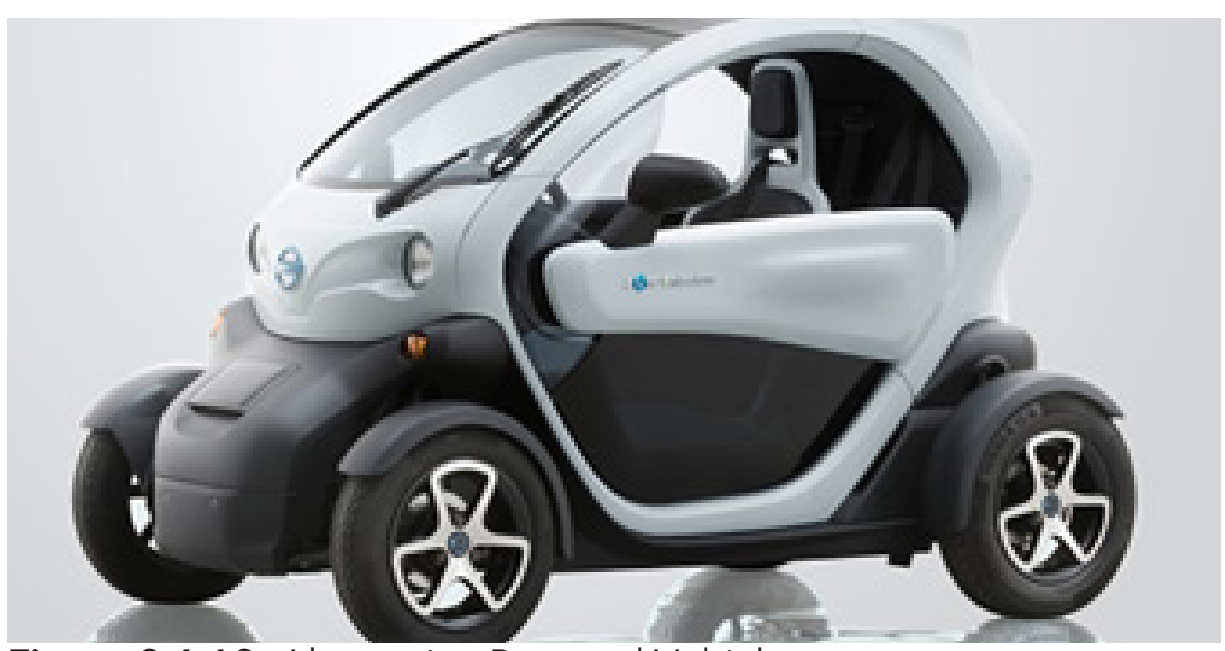

Figure 2.6.12: Alternative Personal Vehicle

NISSAN MOTOR Co Ltd. "NISSAN | ZERO EMISSION | The Holistic Approach | NISSAN New Mobility CONCEPT." Accessed February 13, 2020. https://www.nissan-global.com/EN/ZEROEMISSION/

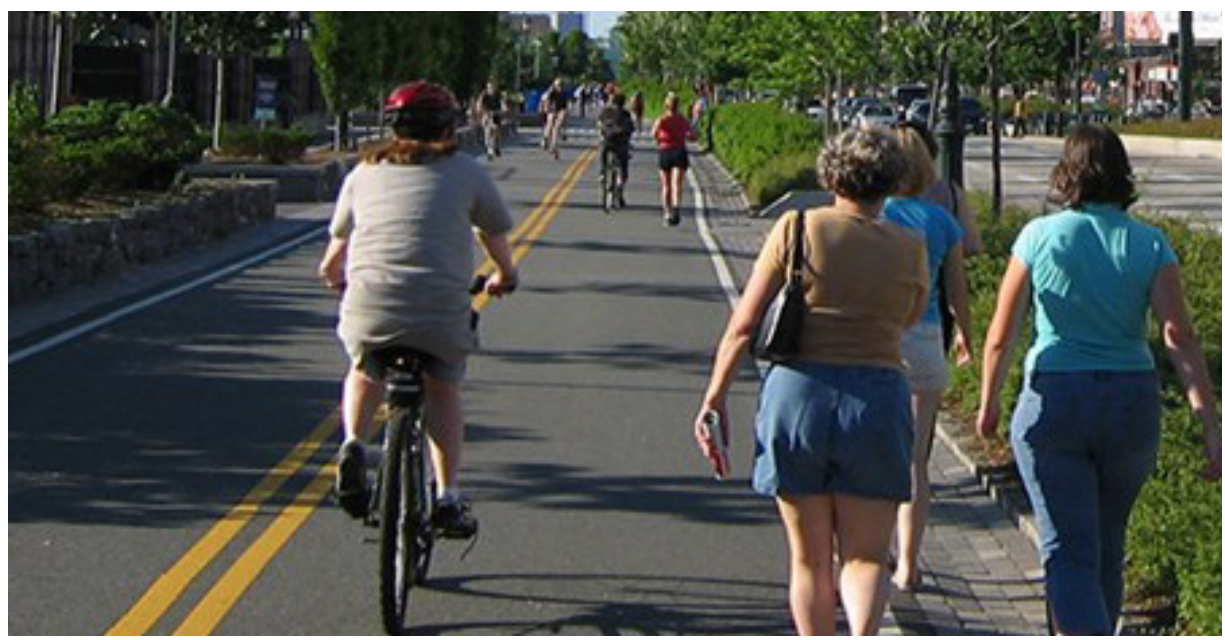

Figure 2.6.13: Active Transportation

"Active Transprtation for America | Rails-to-Trails Conservancy." Accessed February 13, 2020. https:// www.railstotrails.org/policy/active-transportation-for-america/. 
both be successfully integrated into the vertical extension of the city ${ }^{12}$. It is indeed possible.

Figure 2.6.11 depicts a building in Chongqing, China, that features a two-lane road on the $5^{\text {th }}$ story.

Alternative Vehicles: Since, as mentioned in Section 2.4, the extension of the public flow system may typically be supported by inhabitable real estate, the infrastructure required for automobiles may often be impractical. Other more compact lightweight forms of personal vehicles, like the Nissan New Mobility Concept (Figure 2.6.12), may be better suited for the vertical extension of the city ${ }^{13}$.

Active Transportation: Active modes of transportation like walking, running, bicycles, scooters, are particularly well suited for a vertically walkable city. The infrastructure required for these modes of transit is typically lightweight and well suited to be placed aboveinhabited real-estate (2.6.13).

\section{The Dynamic Support System}

In addition to moving people, an essential function of the public flow system of a city is the movement of goods and services. For a city to successfully extend vertically, things like garbage collection, goods delivery, and emergency services must be configured to extend vertically as well.

Automated Mechanical System: one approach to vertical distribution and collection on a citywide scale may be to develop a system in which this is

12 Speck, Jeff. "Various Rules" in Walkable City Rules: 101 Steps to Making Better Places. P.1-285.Washington, DC: Island Press, 2018. 13 NISSAN MOTOR Co Ltd. "NISSAN | ZERO EMISSION | The Holistic Approach | NISSAN New Mobility CONCEPT." Accessed February 13, 2020. https://www.nissan-global.com/EN/ZEROEMISSION/APPROACH/ NEWMOBILITYCONCEPT/. 


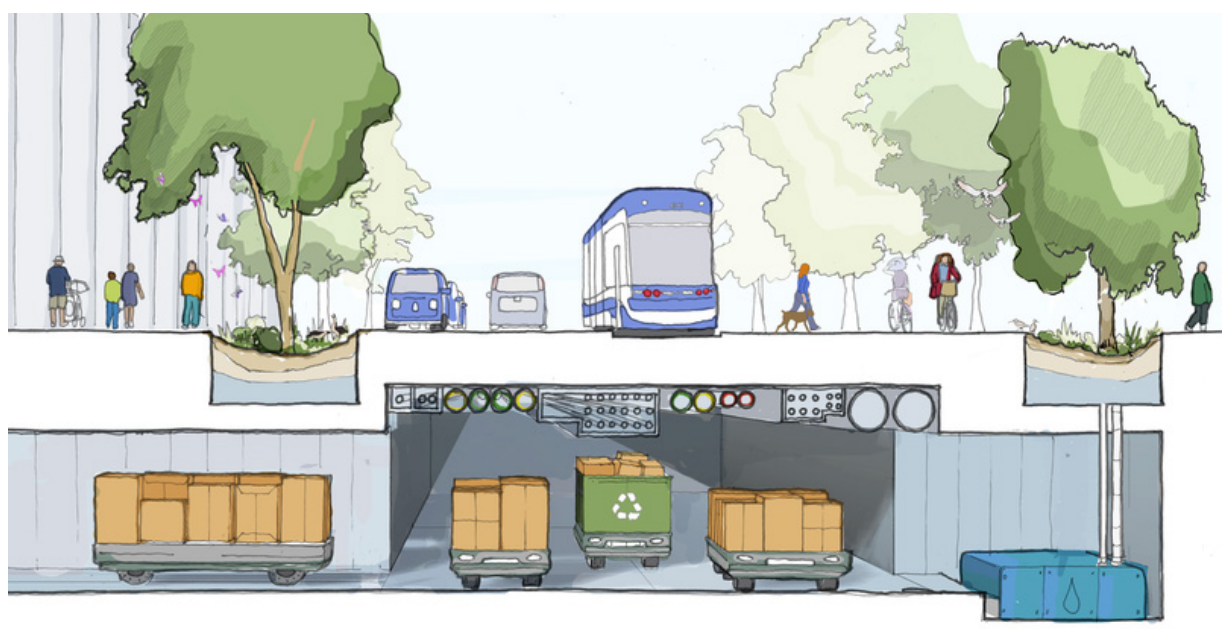

Figure 2.6.15: Automated Delivery System: Sidewalk labs

Sidewalk labs, Image from article by Rieland, Randy. "Five Questions You Should Have About Google's Plan to Reinvent Cities." Smithsonian Magazine. Accessed February 13, 2020. https:// www.smithsonianmag.com/innovation/five-questions-you-should-have-about-googles-plan-

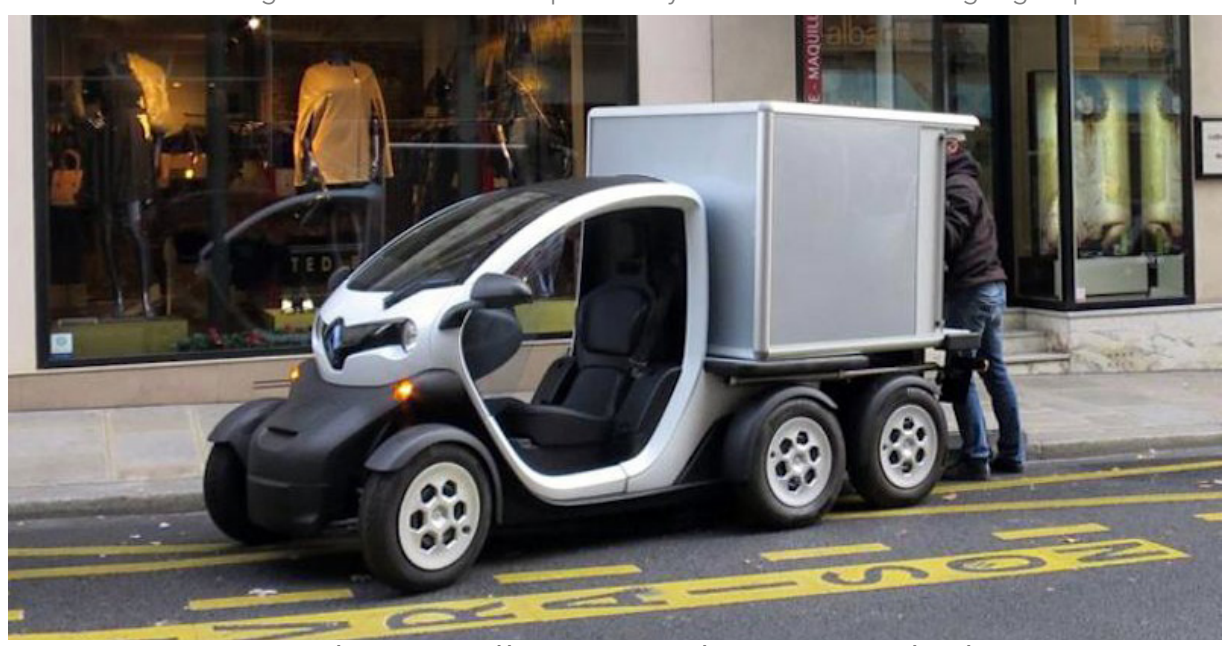

Figure 2.6.16: Delivery, collection and Service Vehicles

Autoblog. "Renault Twizy Delivery Concept Revealed on Twitter." Accessed February 13, 2020.

https://www.autoblog.com/2015/01/16/renault-twizy-delivery-concept-revealed-on-twitter/.

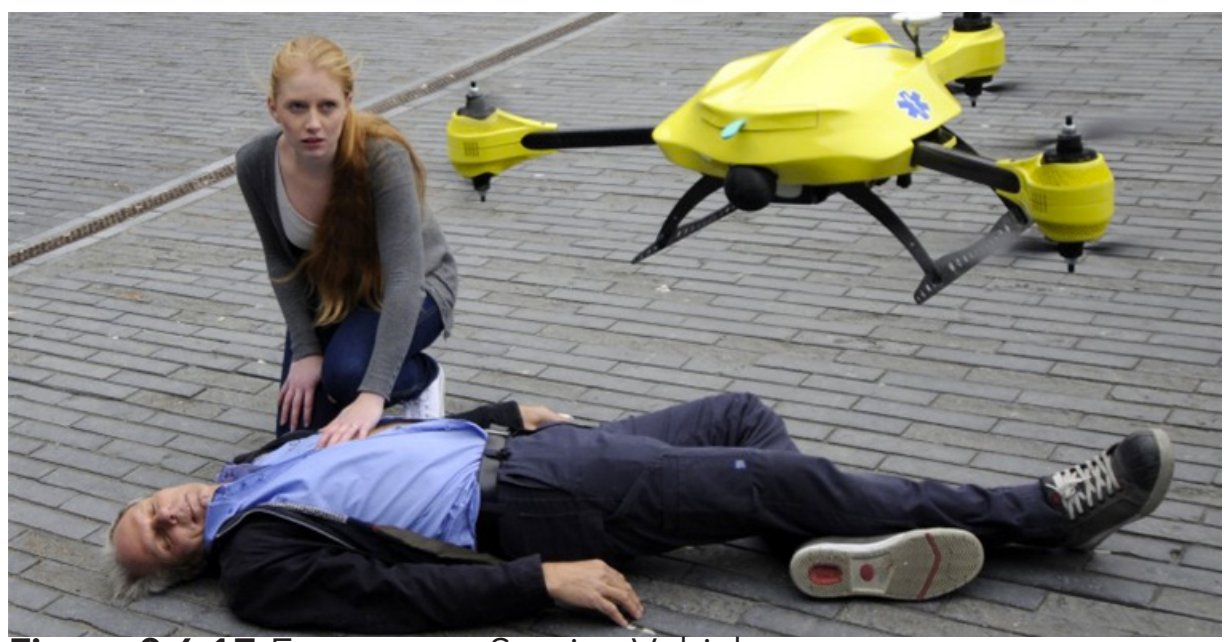

Figure 2.6.17: Emergency Service Vehicles

Uys, Emily. "Student Invents Ambulance Drone for Speedy Medical Assistance." Design Indaba, October 2016. https://www.designindaba.com/articles/creative-work/student-invents-ambulancedrone-speedy-medical-assistance. 
handled by technology. This is what Sidewalk labs were planning to do in Toronto ${ }^{14}$ (Figure 2.6.14). Automation and mechanical systems that are infrastructure intensive may not be suitable for all types of delivery and collection of goods and services.

Delivery and Service Vehicles: individual delivery and service vehicles that move throughout a city provide a flexible network that can share infrastructure with the rest of the city's public flow system. These vehicles could be automobiles, or they could take on other forms depending on requirements. (Figure 2.6.15)

Emergency Services: The extension of emergency services vertically may mean providing infrastructure for existing ground level technology like ambulances, police vehicles, and incorporating existing vertical technology like standpipes and helipads. It may also involve developing new technology like the compact ambulance drone developed by an engineering student at Delft University in the Netherlands ${ }^{15}$. (Figure 2.6.16)

For all modes of transportation, public and private, service, and emergency, the surface of the public flow system would need to be appropriately equipped based on vehicle requirements. Figure 2.6.17 depicts two detail drawings of a road surface with a subsurface utility channel situated ontop of inhabited

\footnotetext{
14 Partially as a result of the COVID-19 pandemic this project has officially shut down as of May 2020

Rieland, Randy. "Five Questions You Should Have About Google's Plan to Reinvent Cities." Smithsonian Magazine. Accessed February 13, 2020. https://www.smithsonianmag.com/innovation/five-questions-you-shouldhave-about-googles-plan-reinvent-cities-180967368/. $15 \quad$ Uys, Emily. "Student Invents Ambulance Drone for Speedy Medical Assistance." Design Indaba, October 2016. https://www. designindaba.com/articles/creative-work/student-invents-ambulance-drone-speedy-medical-assistance.
} 

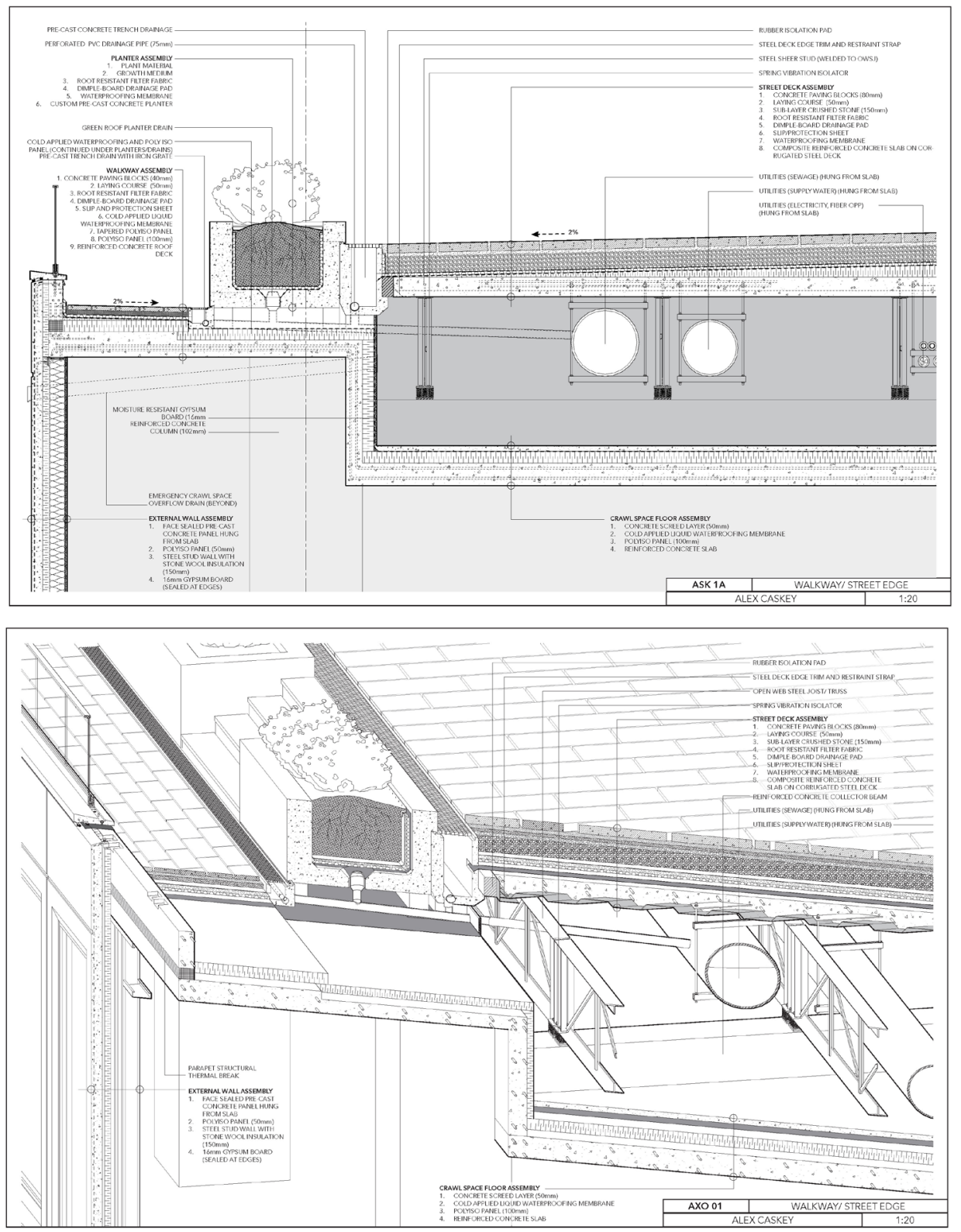

Figure 2.6.14(Above \& Right):Design of street above inhabited space for ASC 623 Principles of Detailing. Project involved taking into consideration surface drainage, structural loads imposed by vehicles, appropriate surface assemblies, and isolating the inhabited space below from noise and vibration. 

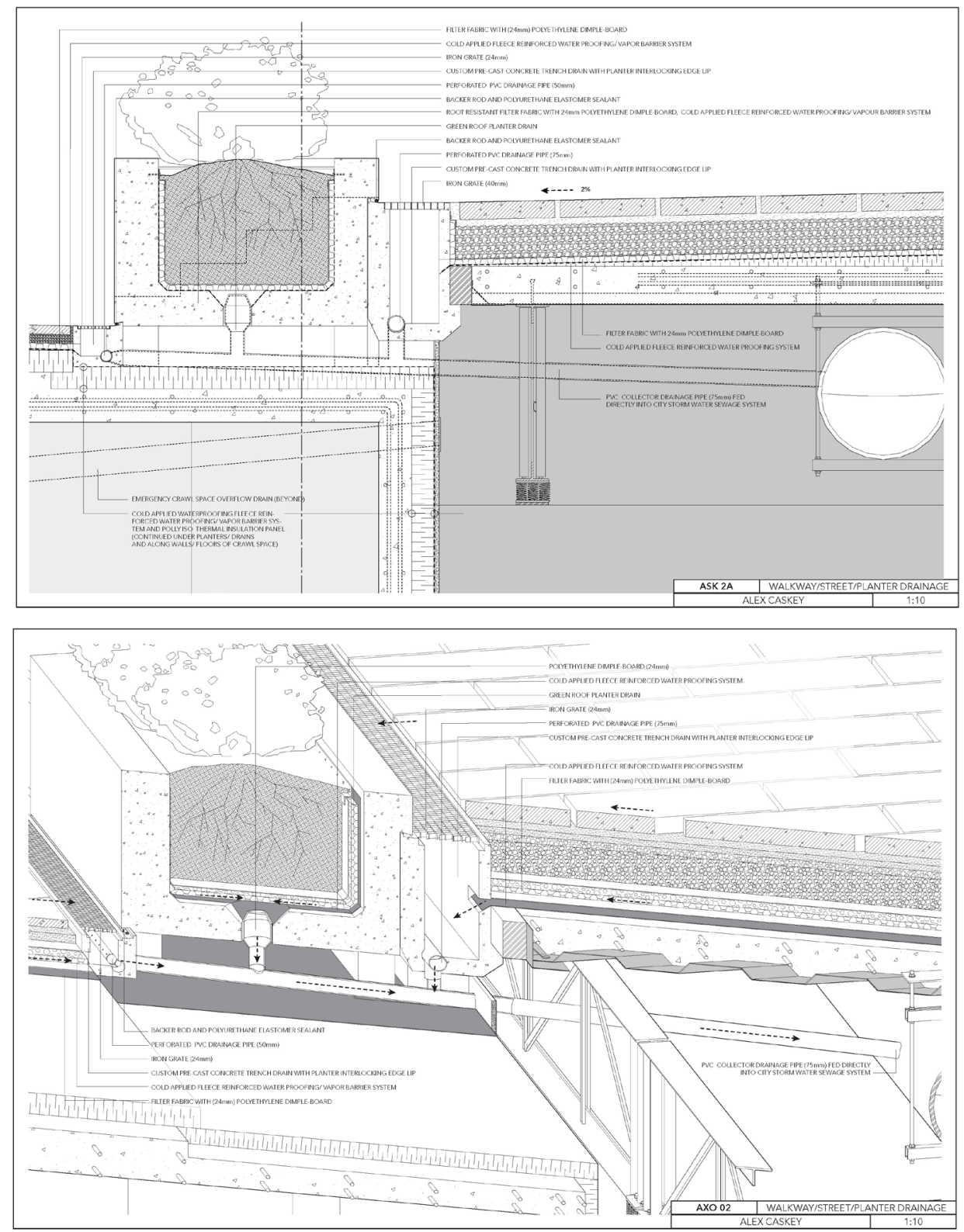

space. The project was completed as part of ASC 623 Principles of Detailing class and involved taking into consideration surface drainage, structural loads imposed by vehicles, appropriate surface assemblies, and isolating the inhabited space below from noise and vibration.

\section{Conclusion}

In conclusion, a vertically walkable city would require a dynamic transportation and distribution network for 
moving people and things throughout the volume of a city. This type of network could be made from the various existing technologies mentioned here, as well as other technologies that have yet to be invented. The most appropriate modes of transportation and distribution, however, would rely on many contextspecific factors. 
A

R

T

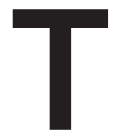

$\mathrm{H}$

R

E

E 


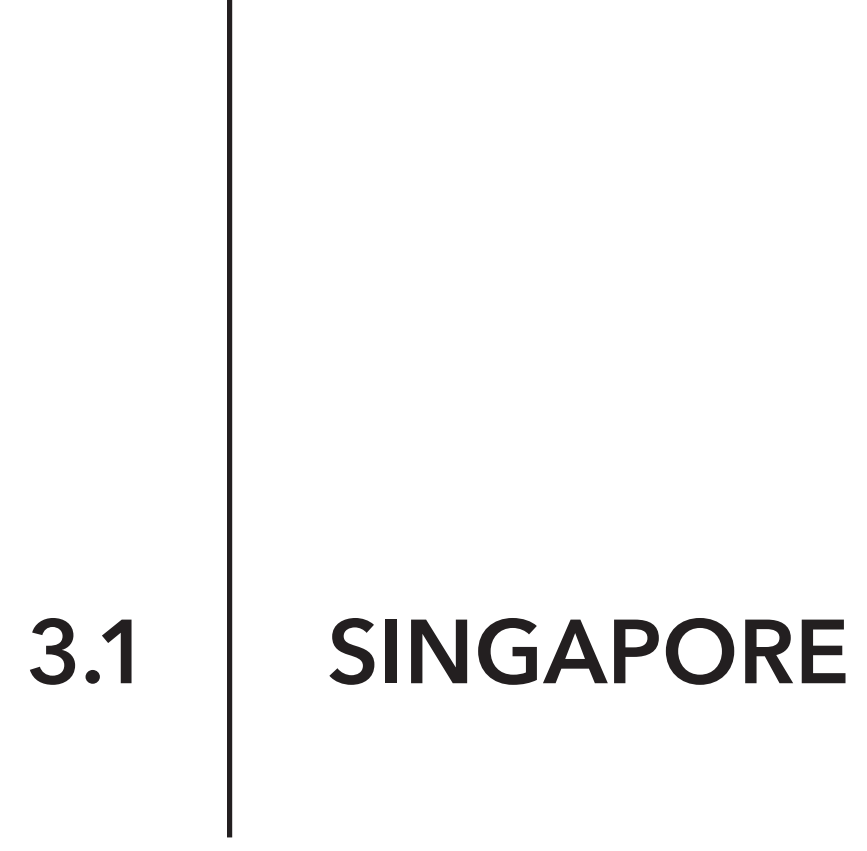

Part 3 is a context-specific investigation of the theoretical approach to the urban design of vertical space established in Part 2. This form of design research requires the ideas to adapt and change as they respond to local constraints and opportunities. Singapore was selected for this investigation as it is a city that, for many social, political, economic, and climatic reasons, is particularly appropriate for this thesis. These reasons are explained more in Section 3.2. This section focuses on background research on the city-state of Singapore and the factors that influenced its urban form.

\section{Location and Overview:}

Singapore is a series of islands located in South-East Asia at the end of the Malay Peninsula in the Singapore Strait that runs between Malaysia and Indonesia (Figure 3.1.1). The country consists of one large island and 60 smaller islands ${ }^{1}$ making up a total landmass of $725.1 \mathrm{~km}^{2}$ as of June $2019^{2}$ (Figure 3.1.2). Key to the story of Singapore is the pursuit of prosperity, the challenge of land and resource limitations, combined

Encyclopedia Britannica. "Singapore | Facts, Geography, History, \& Points of Interest." Encyclopedia Britannica. Accessed November 26, 2019. https://www.britannica.com/place/Singapore.

2 Government of Singapore. "Environment." Department of Statistics Singapore, August 27, 2019. http://www.singstat.gov.sg/find-data/ search-by-theme/society/environment/latest-data. 


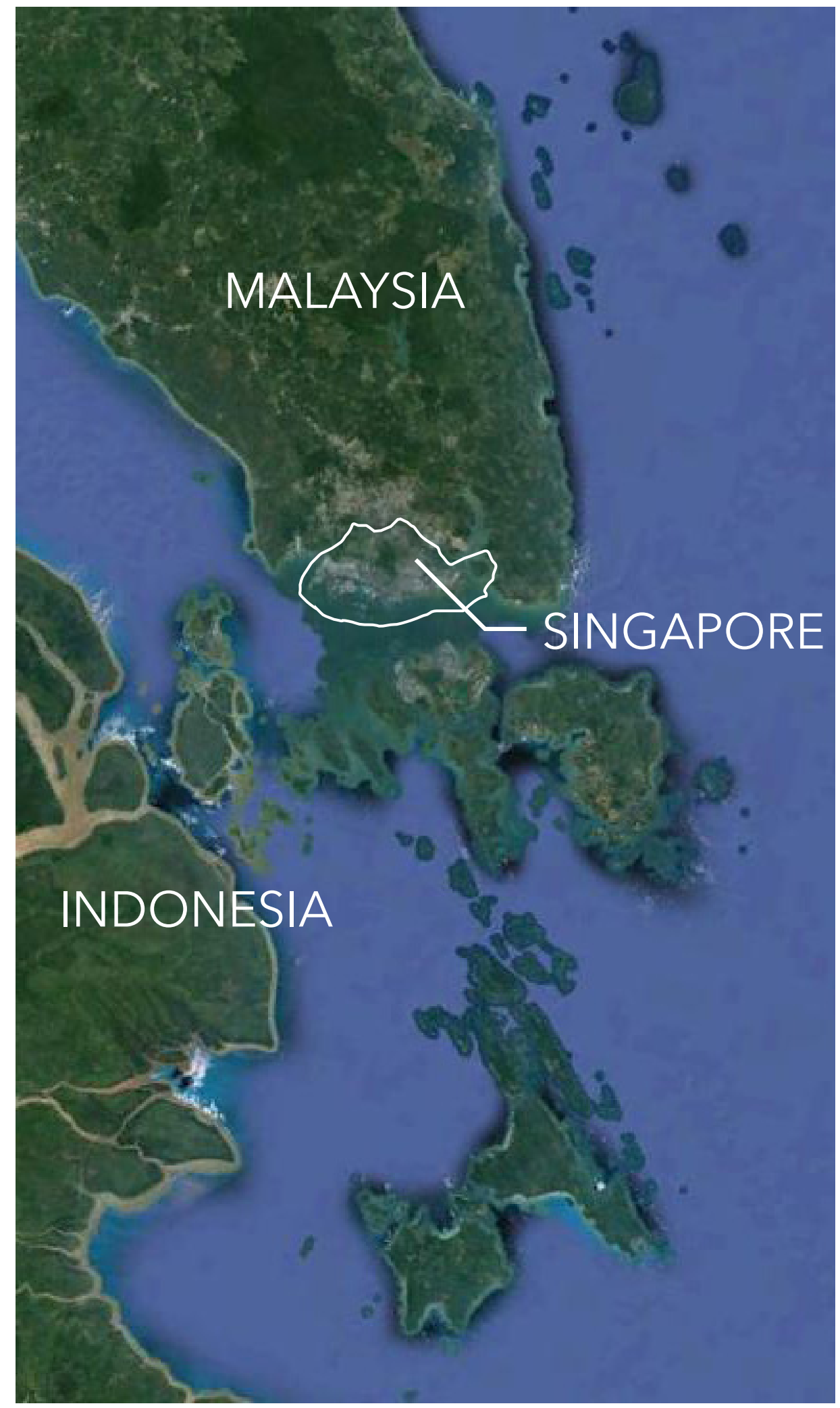

Figure 3.1.1: Google Earth Imagery Showing the location of Singapore in relation to Malaysia and Indonesia 


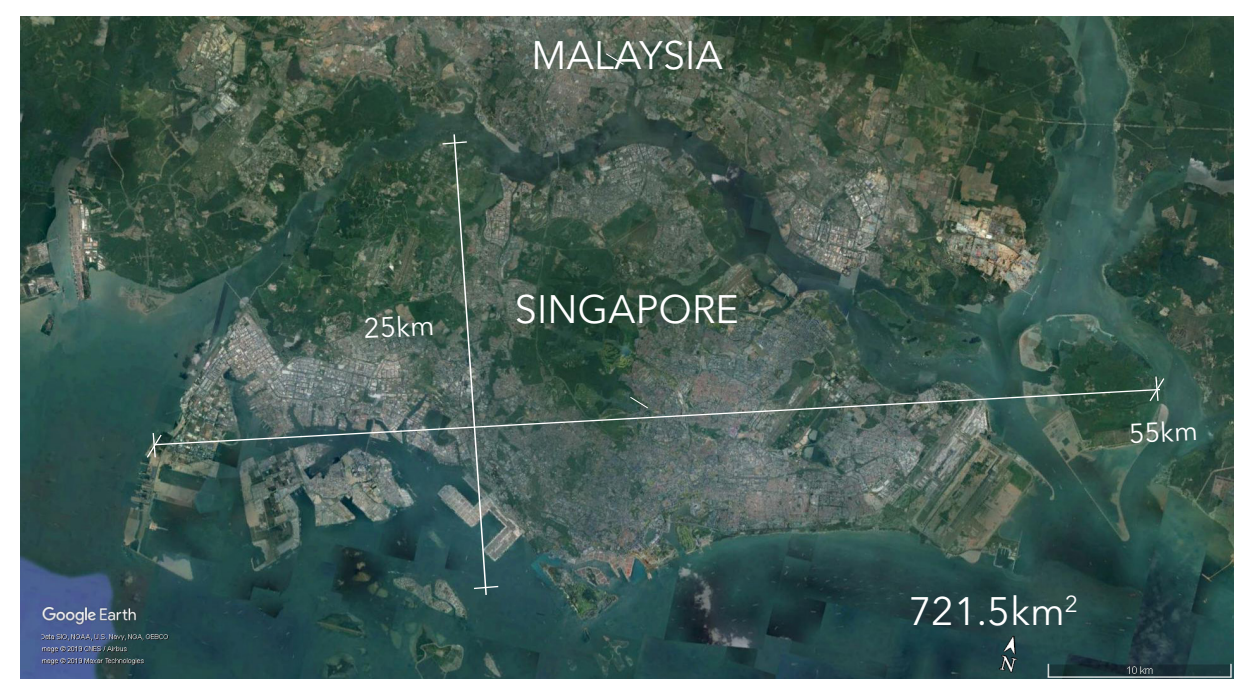

Figure 3.1.2: Google Earth Imagery showing the size of Singapore's Landmass.

with a rapidly growing population ${ }^{3}$.

\section{Population \& Density}

This relatively small landmass is home to 5.703 million people as of 2019, giving it a population density of 7866 people per $\mathrm{km}^{2}$ making it the world's third densest country ${ }^{4}$. For comparison, the city of Toronto, not including the GTA, is $630.20 \mathrm{~km}^{2}$ and its population as of 2016 was 2.731 million giving it a density of 4334 people per $\mathrm{km}^{2}$ a little over half as dense ${ }^{5}$.

\section{Demographics:}

As of 2018, Singapore's population was made up of 4

\footnotetext{
Wong, Tai-Chee, Belinda K. P. Yuen, and Charles Goldblum, eds. Spatial Planning for a Sustainable Singapore. New York: Springer, 2008. $4 \quad$ Government of Singapore. "Population and Population Structure - Latest Data." Department of Statistics Singapore, 2019. http:// www.singstat.gov.sg/find-data/search-by-theme/population/population-and-population-structure/latest-data.

World Population Review. "Countries By Density 2019," 2019. http://worldpopulationreview.com/countries/countries-by-density/.

5 Government of Canada, Statistics Canada. "Census Profile, 2016 Census - Toronto, City [Census Subdivision], Ontario and Ontario [Province]," February 8, 2017. https://www12.statcan.gc.ca/census-recensement/2016/dp-pd/prof/details/page.cfm?Lang=E\&Geo1=CSD\&Code $1=3520005 \&$ Geo2=PR\&Code $2=35 \&$ Data $=$ Count $\&$ Search Type=Begins \&SearchPR=01\&B1=All.
} 


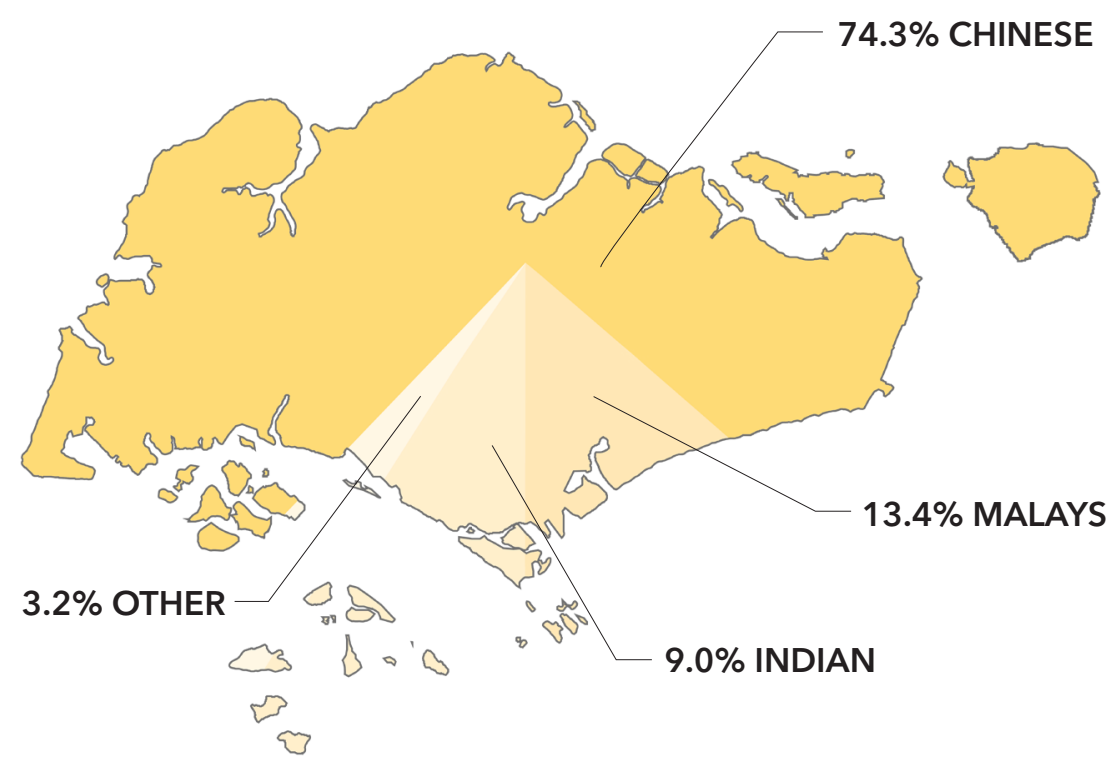

Figure 3.1.3: Ethnic Demographics of Singapore

main ethnic groups ${ }^{6}$. The population is $74.3 \%$ Chinese, 13.6\% Malay, 9.0\% Indian, and 3.2\% other ${ }^{7}$ (Figure 3.1.3). The multicultural city-state has four official languages Mandarin, Malaysian, Tamil, and English, which is considered the language of business ${ }^{8}$.

\section{Economy:}

Singapore has a highly developed and diverse free market-economy and has developed a strong reputation for its economic stability?. Singapore's economy is highly dependent on manufacturing and exports of electronic goods, petroleum products, chemicals, and pharmaceuticals ${ }^{10}$. In addition, the economy is dependent on transportation, business,

\footnotetext{
6 Singapore Department of Statistics. "Population Trends 2018." Department of Statistics, Ministry of Trade \& Industry, Republic of Singapore, 2018. https://www.singstat.gov.sg/-/media/files/publications/population/population2018.pdf.

$7 \quad$ lbid.

8 Encyclopedia Britannica. "Singapore| Facts, Geography, History, \& Points of Interest." Encyclopedia Britannica. Accessed November 26, 2019. https://www.britannica.com/place/Singapore 9 Central Intelligence Agency. "East Asia/Southeast Asia :: Singapore." Central Intelligence Agency: World Fact Book. Accessed November 26, 2019. https://www.cia.gov/library/publications/the-world-factbook/ geos/sn.html. $10 \quad$ Ibid.
} 


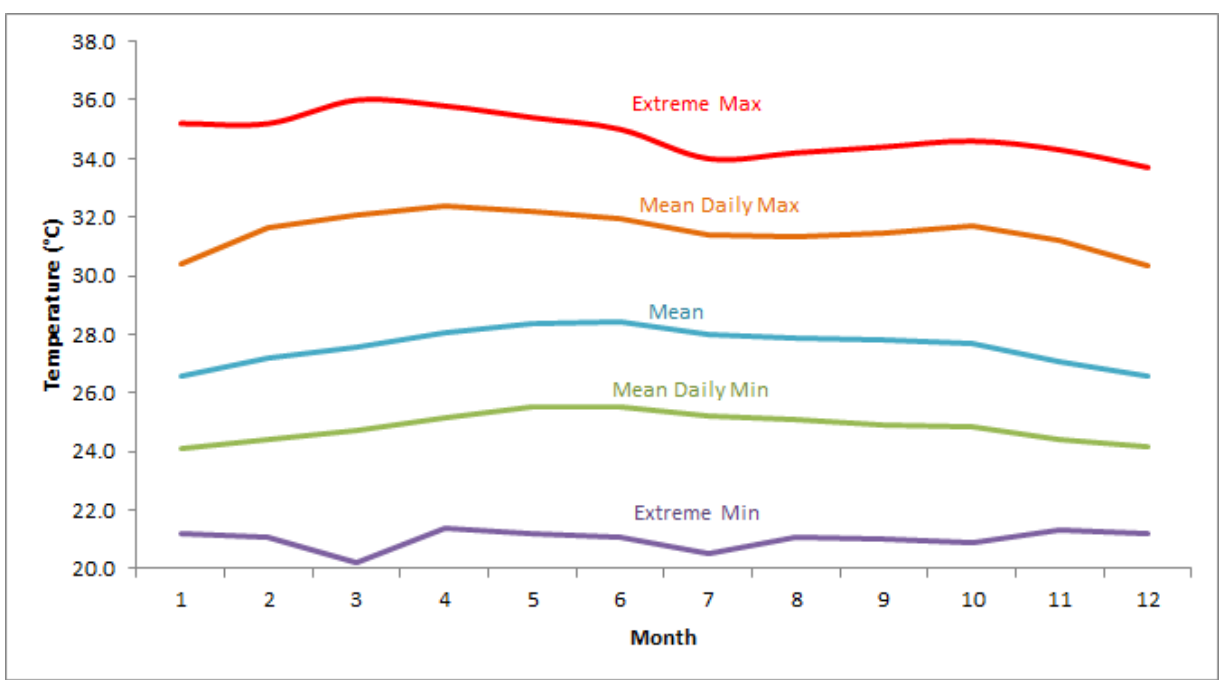

Figure 3.1.4: Mean monthly temperature variation $\left({ }^{\circ} \mathrm{C}\right)(1981$ 2010)

Government of Singapore. "Climate of Singapore |." Meteroligical Services Singapore, 2019. http:// www.weather.gov.sg/climate-climate-of-singapore/.

financial services, foreign exchange, and increasingly tourism and the casino and gambling markets ${ }^{11}$.

\section{Climate:}

Singapore is located $1.22^{\circ}$ North of the equator ${ }^{12}$. As a result, the country has a very stable year-round climate ${ }^{13}$. The country has a tropical climate with high rainfall, high temperature and high humidity year-round, with low month to month variation ${ }^{14}$ (Figure 3.1.4). Section 3.2 explains why these unique climate characteristics make Singapore very compatible with the ideas in this thesis.

\section{Ancient History:}

Early accounts of settlement in Singapore exist at

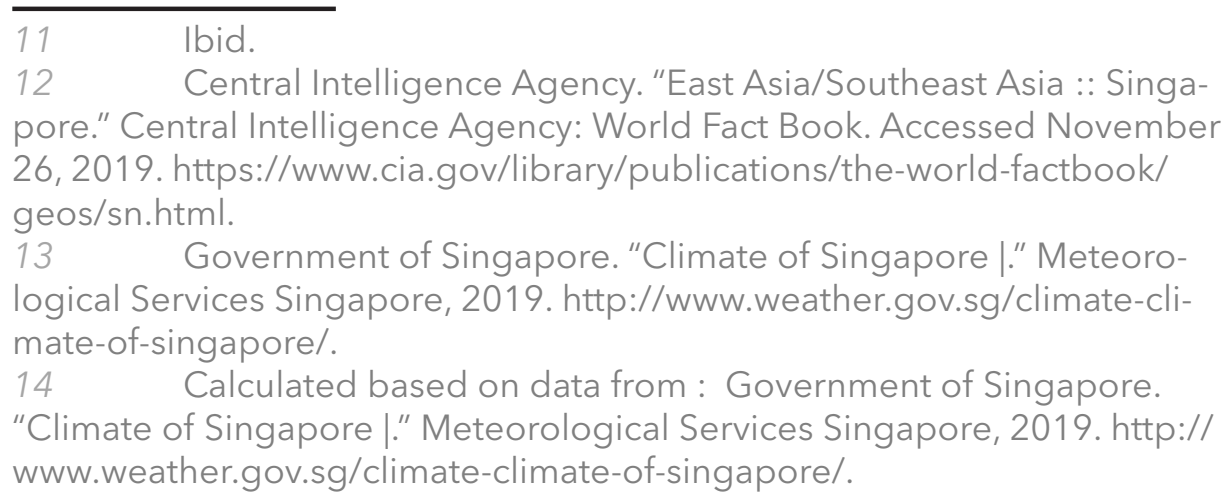


least as far back as the $14^{\text {th }}$ century when it served as a trading post for the Srivijaya Empire ${ }^{15}$. Its ownership changed hands multiple times over the next centuries, and after a fire caused by the Portuguese in the $17^{\text {th }}$ century destroyed most of the settlement, the city fell into obscurity ${ }^{16}$.

\section{British Colony:}

Colonization of the area by the British began in 1819 when Sir Stamford Raffles of the English East India Company recognized the island's potential to serve as a new port ${ }^{17}$. At the time, the island was home to approximately 1000 people ${ }^{18}$. In the years following, the city grew in an informal manner until it was decided that some form of structure and organization of the city was necessary ${ }^{19}$. In 1822 Raffles implemented the Jackson Plan, which divided the city on a regular street grid and separated the city into four major ethnic residential communities consisting of Europeans, Chinese, Indians, and Malay/Arabs ${ }^{20}$. Between 182415 Central Intelligence Agency. "East Asia/Southeast Asia :: Singapore." Central Intelligence Agency: World Fact Book. Accessed November 26, 2019. https://www.cia.gov/library/publications/the-world-factbook/ geos/sn.html.

Encyclopedia Britannica. "Singapore | Facts, Geography, History, \& Points of Interest." Encyclopedia Britannica. Accessed November 26, 2019.

https://www.britannica.com/place/Singapore.

$\begin{array}{ll}16 & \text { ibid } \\ 17 & \text { Encyclopedia Britannica. "Singapore | Facts, Geography, Histo- }\end{array}$ ry, \& Points of Interest." Encyclopedia Britannica. Accessed November 26, 2019. https://www.britannica.com/place/Singapore.

18 National Heritage Board. "The Malays," February 23, 2011. https://web.archive.org/web/20110223000344/http://yesterday.sg/ discover-more/communities-festivals/communities/the-malays/.

19 Firley, Eric, and Julie Gimbal. "High rise building regulations in seven cities worldwide: Singapore" in The Urban Towers Handbook. P.234237 Chichester: Wiley, 2011.

Government of Singapore. "History of Urban Planning in Singapore | Infopedia," 2016. https://eresources.nlb.gov.sg/infopedia/articles/ SIP_1564_2009-09-08.html.

20 Singapore Torism Board. "About Singapore: A Long, Long Time Ago," 2019. https://www.visitsingapore.com/travel-guide-tips/about-singaporel.

Government of Singapore. "History of Urban Planning in Singapore | Infopedia," 2016. https://eresources.nlb.gov.sg/infopedia/articles/ 
1826, Singapore, along with Malacca and Penang, became officially part of the Straits Settlements of the British Empire ${ }^{21}$. The city continued to grow rapidly as a port city until a decline in growth in 1842 brought on by the British development of a rival port on the island of Hong Kong ${ }^{22}$. It was not utill after 1869 that Singapore would again see growth with the completion of the Suez Canal in Egypt. Singapore's position along new major trading routes brought the city a massive increase in traffic and economic prosperity ${ }^{23}$. This brought about large waves of immigration from China as well as immigrants of Malay and Indian descent ${ }^{24}$.

\section{WWII}

Singapore remained a thriving British settlement until the Second World War when, in 1942, the British were forced to surrender to the Japanese, and the city fell to Japanese occupation until the end of the war in $1945^{25}$. During this time, the city's development stagnated, and parts of the city were destroyed when Allied airforces bombed Singapore between 1944 and $1945^{26}$.

\section{Post-War:}

After the war, Singapore once again came under British rule. Throughout the city, there was a lack of "sanitary" housing, as over 1/3 of the population was living in informal makeshift settlements ${ }^{27}$. The city began undertaking slum clearance and resettlement in a housing reconstruction program coordinated by the Housing Committee that was established in $1947^{28}$. The responsibility of housing would be taken over by the better-known Housing and Development Board

SIP_1564_2009-09-08.html.

$27 \quad$ Zareen, B. "Singapore's Public Housing : From Slums to High-

Rise." 99.co, August 2, 2016. https://www.99.co/blog/singapore/hous-

ing-yesteryear-singapore/.

28 Firley, Eric, and Julie Gimbal. "High rise building regulations in seven cities worldwide: Singapore" in The Urban Towers Handbook. P.234237 Chichester: Wiley, 2011. 
(HBD) when it was later established in $1960^{29}$.

After the war, there was growing skepticism of the British governmental structure. This led to Singapore, in 1959, becoming an internally self-governed "crown colony" where Britain retained control over defences and foreign policy ${ }^{30}$. Lee Kuan Yew of the People's Action Party became the first elected Prime Minister ${ }^{31}$.

During this time, the development of the city and government became increasingly centralized. In 1959 the Planning Department within the Prime Minister's office took on the role of the central planning authority, where they were given the power to control the development of land throughout Singapore ${ }^{32}$. Back in 1951, the Singapore Improvement Trust had been tasked with surveying the city and developing a master plan to guide the growth of the city ${ }^{33}$. The master plan, approved in 1958, was a rational, comprehensive, wellresolved plan for the city typical of post-war master planning in other major cities. It divided up the city according to land use, reserve spaces for infrastructure and open space, and assigned a maximum plot ratio for each site ${ }^{34}$. In 1959 the newly formed Planning Department set about implementing the 1958 Master Plan. It was, however, not long before they realized the strategies embedded within the plan had already become obsolete in their ability to address the rapid social and economic changes that were taking place ${ }^{35}$.

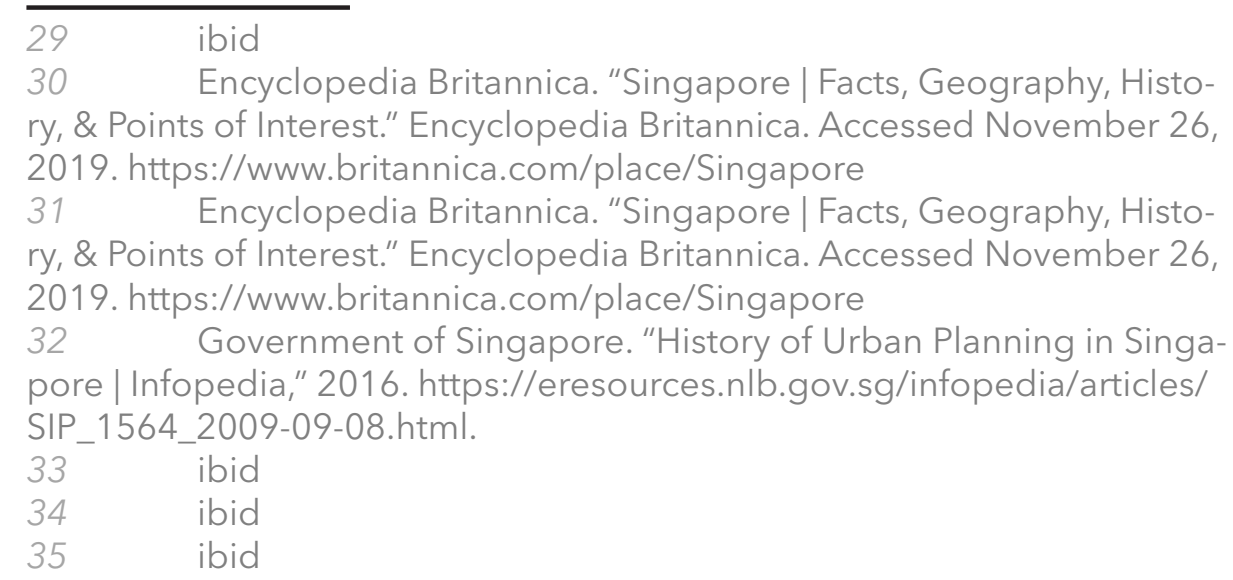


This led to Singapore seeking advice from the United Nations. The UN recommended that in order to relieve congestion, the population be decentralized and redistributed throughout the entire main island via the development of a system of motorways and public transit networks ${ }^{36}$.

\section{Malaysia:}

In 1963 Singapore broke away from British rule when it joined the newly formed Federation of Malaysia ${ }^{37}$. This arrangement, however, was short-lived as political friction caused by the conflicting ideologies of the state of Singapore and the federal government led to Singapore seceding from Malaysia in $1965^{38}$.

\section{Sovereign State of Singapore:}

1965 marked the beginning of independence for the country of Singapore ${ }^{39}$. Meeting ever-growing housing needs remained a key objective of the government. The Housing and Development Board was rapidly producing new housing blocks ${ }^{40}$. High rise developments in the form of common towers were widely constructed as a means of maximizing the use of land ${ }^{41}$. All of this development was guided by the 1971 Singapore Concept Plan (Figure 3.1.5), a long term plan drafted in consultation with United Nations experts ${ }^{42}$. Less prescriptive than the 1958 master plan, the Concept Plan was focused on a clear understanding

36 Firley, Eric, and Julie Gimbal. "High rise building regulations in seven cities worldwide: Singapore" in The Urban Towers Handbook. P.234237 Chichester: Wiley, 2011.
37 ibid
38 ibid
39 ibid
$40 \quad F i r l e y$, Eric, and Julie Gimbal. "High rise building regulations in seven cities worldwide: Singapore" in The Urban Towers Handbook. P.234- 237 Chichester: Wiley, 2011.
41 ibid
42 Wong, Tai-Chee, Belinda K. P. Yuen, and Charles Goldblum, eds. Spatial Planning for a Sustainable Singapore. P. 7. New York: Springer, 2008. 


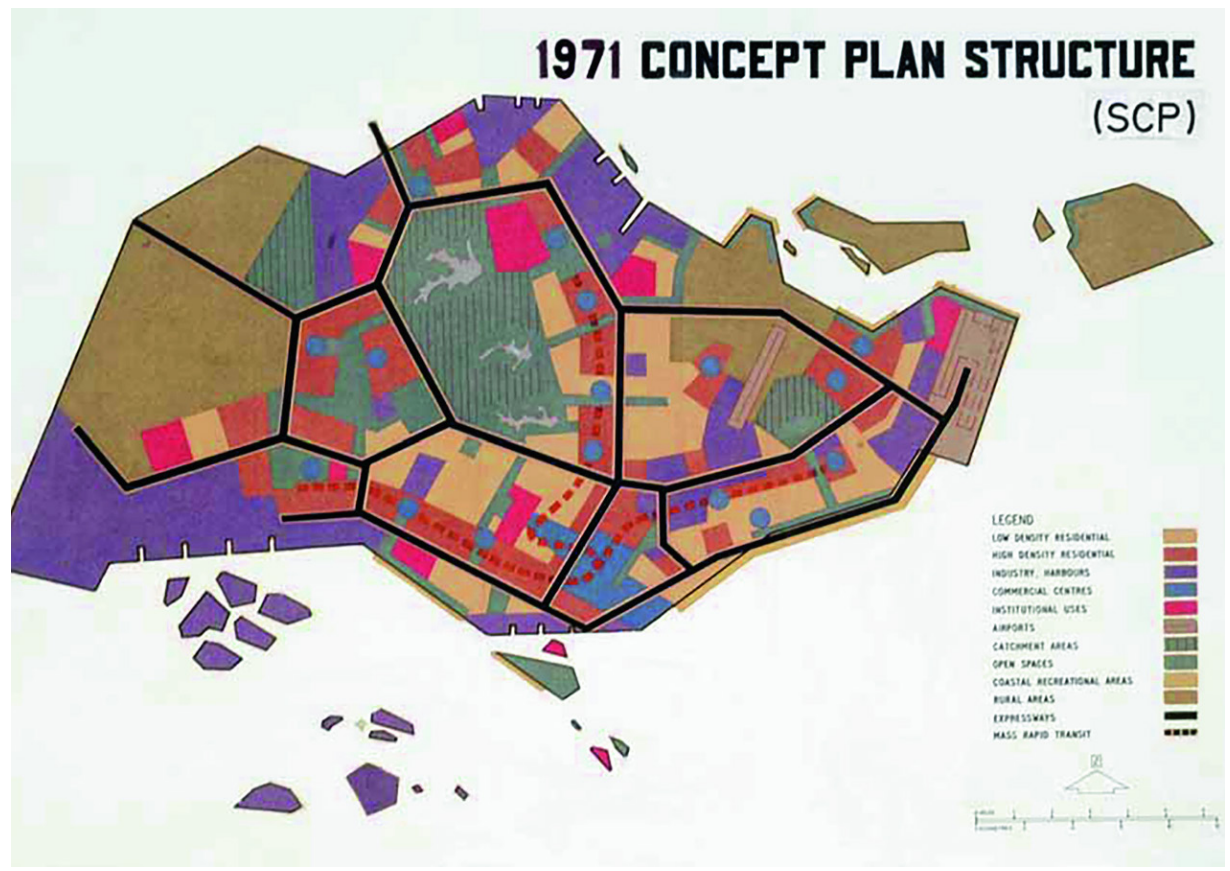

Figure 3.1.5: 1971 Singapore Concept Plan

Urban Redevelopment Authority. "Past Concept Plans." Urban Redevelopment Authority, 2019 https://www.ura.gov.sg/Corporate/Planning/Concept-Plan/Past-Concept-Plans.

of the government's goals of improving the nation's economic prosperity and raising the overall standard of living ${ }^{43}$. This meant diversifying the country's means of economic production, through industrialization, improving infrastructure, and building a modern financial district to attract foreign investment ${ }^{44}$. The concept plan and the government's goals have been continuously revised throughout the past fifty years. By the 1991 Concept Plan revision, the majority of the population had been adequately housed ${ }^{45}$. The goals of the city shifted to improving quality and a self rebranding of the city as "a City in a Garden"46. It also carried on the goal of decentralization dividing the city into 55 Planning areas organized into five regions. Emphasis was given to the development of mixed-use neighbourhoods with localized access to shopping \begin{tabular}{l}
\hline 434 ibid \\
445 ibid \\
45 Government of Singapore. "History of Urban Planning in Singa- \\
pore | Infopedia," 2016. https://eresources.nlb.gov.sg/infopedia/articles/ \\
SIP_1564_2009-09-08.html \\
$46 \quad$ ibid
\end{tabular} 
centers, healthcare, and employment opportunities ${ }^{47}$.

The 2001 Concept plan revision shifted the focus of goals again into making Singapore a "thriving worldclass city," while the 2011 revisions saw an increased focus on long term Sustainability ${ }^{48}$.

\section{Growth: In, Out, Up, Down}

The Concept Plans have illustrated the evolving goals for the city of Singapore, but the issue of land and resource scarcity has remained a key focal point throughout the city's development ${ }^{49}$. Since the 1950s, Singapore's population has grown steadily. In 1950, Singapore had a population of approximately 1 million. By the 1970s, the country's population had doubled, and now in 2019, the population has grown to 5.7 Million $^{50}$ (Figure 3.1.6.) The growth of the population of Singapore has been reflected in the rate of urbanization. For most of its early history, Singapore remained tightly packed into the South-East corner of the island ${ }^{51}$. After receiving the suggestion from the UN on redistributing the population throughout the island in the 1960s, the urban area has rapidly expanded horizontally into a metropolis that has consumed most $47 \quad$ Firley, Eric, and Julie Gimbal. "High rise building regulations in seven cities worldwide: Singapore" in The Urban Towers Handbook. P.234237 Chichester: Wiley, 2011.

Marshall, Colin. "Story of Cities \#27: Singapore - the Most Meticulously Planned City in the World." The Guardian, April 21, 2016, sec. Cities. https://www.theguardian.com/cities/2016/apr/21/story-cities-singaporecarefully-planned-lee-kuan-yew.

$48 \quad$. Government of Singapore. "History of Urban Planning in

Singapore | Infopedia," 2016. https://eresources.nlb.gov.sg/infopedia/articles/SIP_1564_2009-09-08.html

49 Wong, Tai-Chee, Belinda K. P. Yuen, and Charles Goldblum, eds. Spatial Planning for a Sustainable Singapore. P. 7. New York: Springer, 2008.

$50 \quad$ Government of Singapore. "Population and Population Structure - Latest Data." Department of Statistics Singapore, 2019. http:// www.singstat.gov.sg/find-data/search-by-theme/population/population-and-population-structure/latest-data.

51 USGS. "Singapore | Earthshots: Satellite Images of Environmental Change." Accessed November 20, 2019. https://earthshots.usgs.gov/ earthshots/Singapore\#ad-image-0-0. 
of its landmass ${ }^{52}$. This growth is shown in the maps in Figures 3.1.7-12.

Since gaining self-governance in 1959, Singapore has embarked on major land reclamation projects adding over $25 \%$ to its landmass ${ }^{53}$. These land additions have been strategic, addressing limited land resources, and aligning with the goals of the concept plan by expanding for sectors that diversify the country's economy including industry, manufacturing, oil refining, shipping, tourism, gambling, and the Changi airport that made the city a key air traffic transfer hub for all of South East Asia (Figure 3.1.13).

A second way Singapore has dealt with land limitation has been to grow vertically. The 1960s, the construction of high-rise towers, both residential and commercial, have proliferated across the island ${ }^{54}$. Since 2017 Singapore has also been investigating ways to expand down into the earth for industrial, infrastructural, and storage facilities ${ }^{55}$. This subterranean expansion would be a means to free up space on the surface to be used as residential, commercial, and open spaces ${ }^{56}$.

$52 \quad$ Ibid.

Firley, Eric, and Julie Gimbal. "High rise building regulations in seven cities worldwide: Singapore" in The Urban Towers Handbook. P.234-237 Chichester: Wiley, 2011.

53 Government of Singapore. "Total Land Area of Singapore." Data.gov.sg, 2019. https://data.gov.sg/dataset/total-land-area-of-singapore?view_id\%3De6e37f25-01 ef-4c23-a7cb-5682ab5edb75\%26resource_id\%3Df4bbfac9-c3ed-4f71-9b9a-238517b214ef.

$54 \quad F i r l e y$, Eric, and Julie Gimbal. "High rise building regulations in seven cities worldwide: Singapore" in The Urban Towers Handbook. P.234237 Chichester: Wiley, 2011

55 AFP. "Singapore Planning a Subterranean Future as It Faces Space Constraints." The Business Times, September 3, 2019. https://www. businesstimes.com.sg/real-estate/singapore-planning-a-subterranean-future-as-it-faces-space-constraints.

Kolczak, Amy. "Singapore Aims to Be the World's Greenest City." National Geographic, February 28, 2017. https://www.nationalgeographic.com/ environment/urban-expeditions/green-buildings/green-urban-landscape-cities-Singapore/.

56 AFP. "Singapore Planning a Subterranean Future as It Faces Space Constraints." The Business Times, September 3, 2019. https://www. businesstimes.com.sg/real-estate/singapore-planning-a-subterranean-fu- 


\section{SINGAPORE'S POPULATION GROWTH}

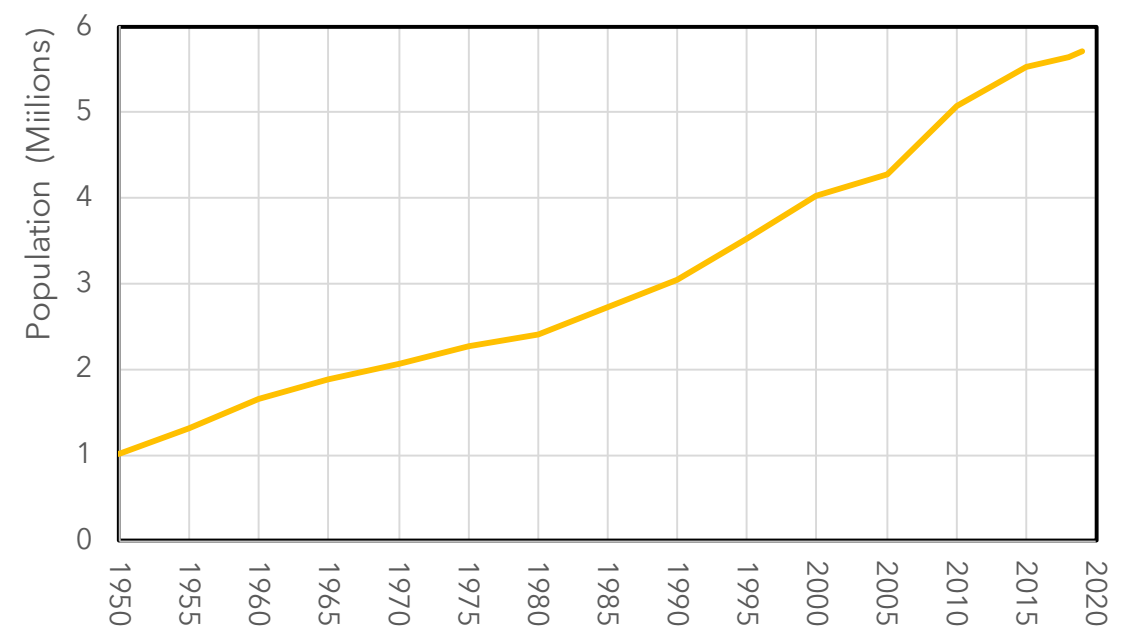

Figure 3.1.6: Population growth in Singapore by year

\section{Transportation:}

In addition to the extent of the urban expansion of Singapore, Figures 3.1.7-12 also illustrate the strong correlation between urban expansion and the growth of the city's Mass Rapid Transit System (MRT). The MRT was proposed as early as 1967 but did not become a reality for 15 years due to governmental resistance ${ }^{57}$. In 1982 plans for construction began with the first line of the MRT opening in $1987^{58}$. Since that time, Singapore has expanded the MRT into a 5-line network that services almost all of the island.

ture-as-it-faces-space-constraints.

$57 \quad$ Singapore, Remember. "A Journey into Singapore MRT's Past."

Remember Singapore (blog), July 23, 2013. https://remembersingapore.

org/2013/07/23/singapore-mrt-history/.

58 ibid

Figure 3.1.7-9 (Next Spread LEFT): Diagram showing the growth of Singapore's landmass, growth of the MRT system and the expansion of urbanization in 1973, 2002, 2018

Figure 3.1.10-12 (Next Spread RIGHT): Satellite imagery showing the growth of Singapore's landmass and the urbanization in 1973, 2002,2018

USGS. "Singapore | Earthshots: Satellite Images of Environmental Change." Accessed November 20, 2019. https://earthshots.usgs.gov/earthshots/Singapore\#ad-image-0-0. 
1973

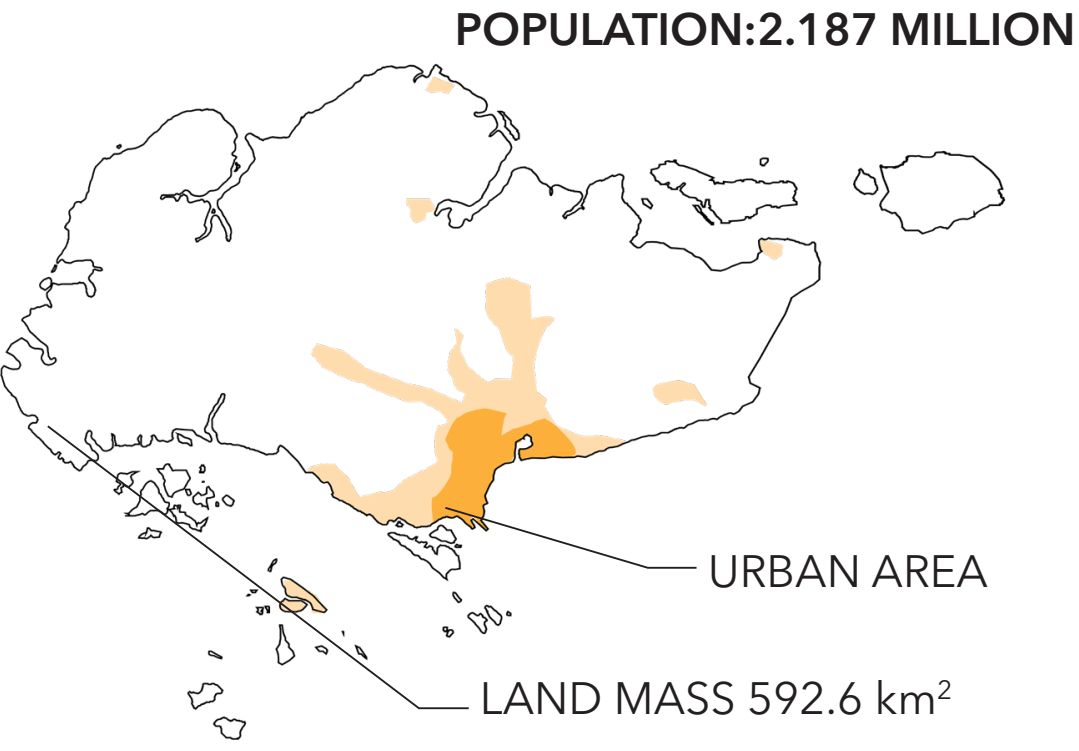

2002

POPULATION:4.123 MILLION

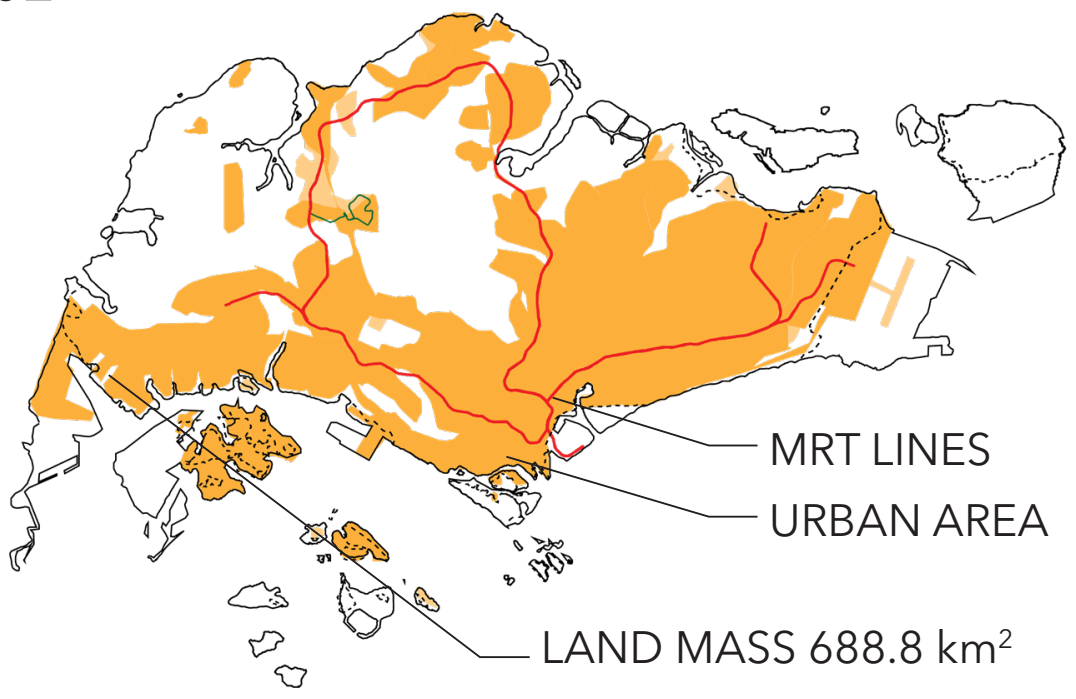

2018

POPULATION:5.638 MILLION

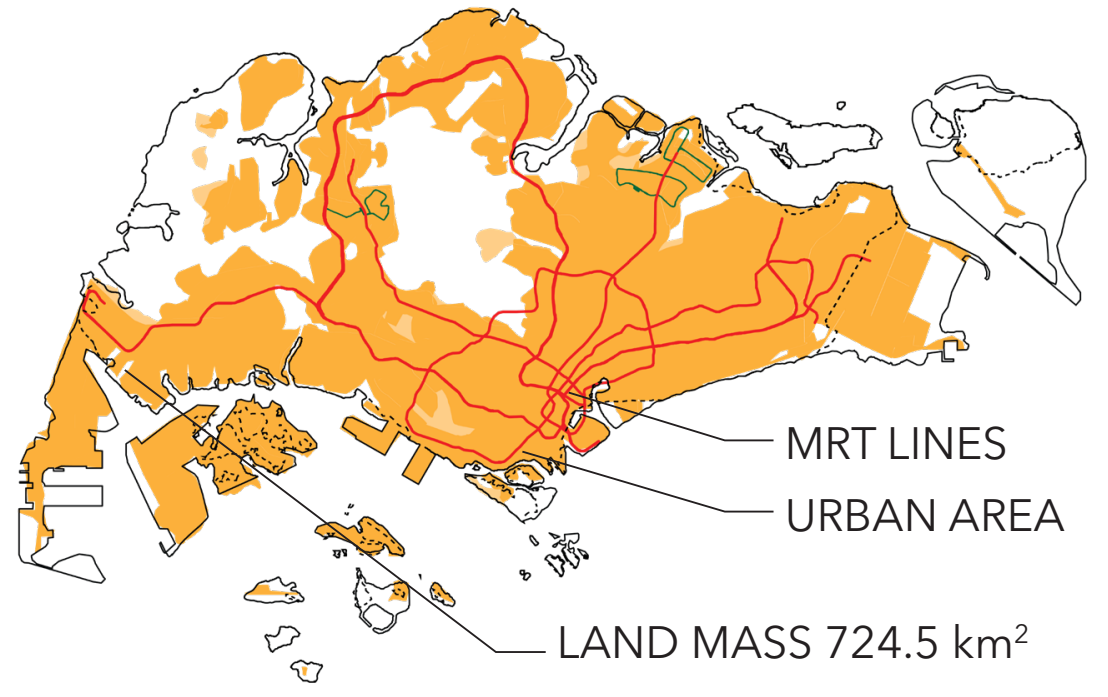




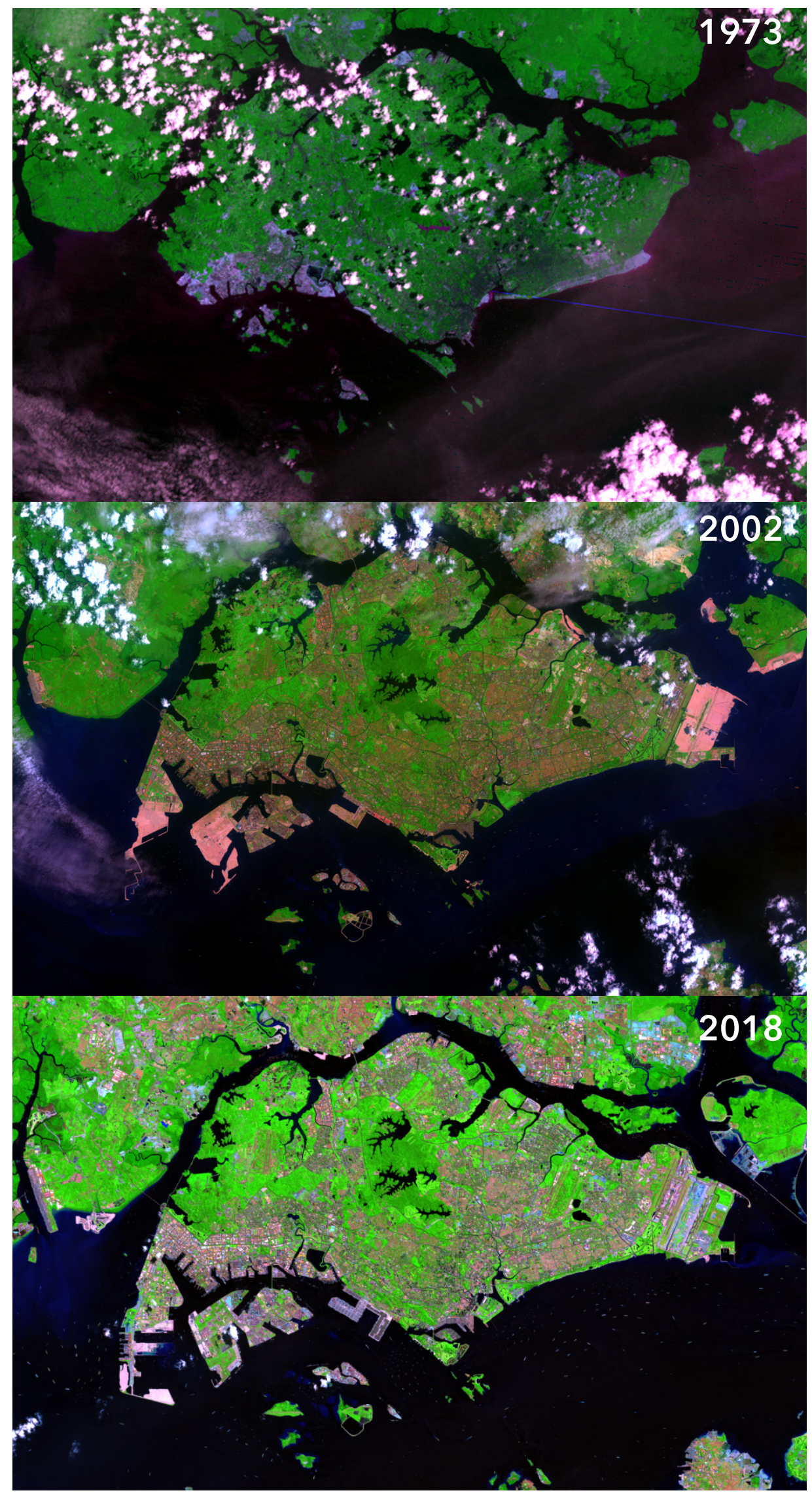




\section{SINGAPORE}

THE ILLAND CITS STAAE
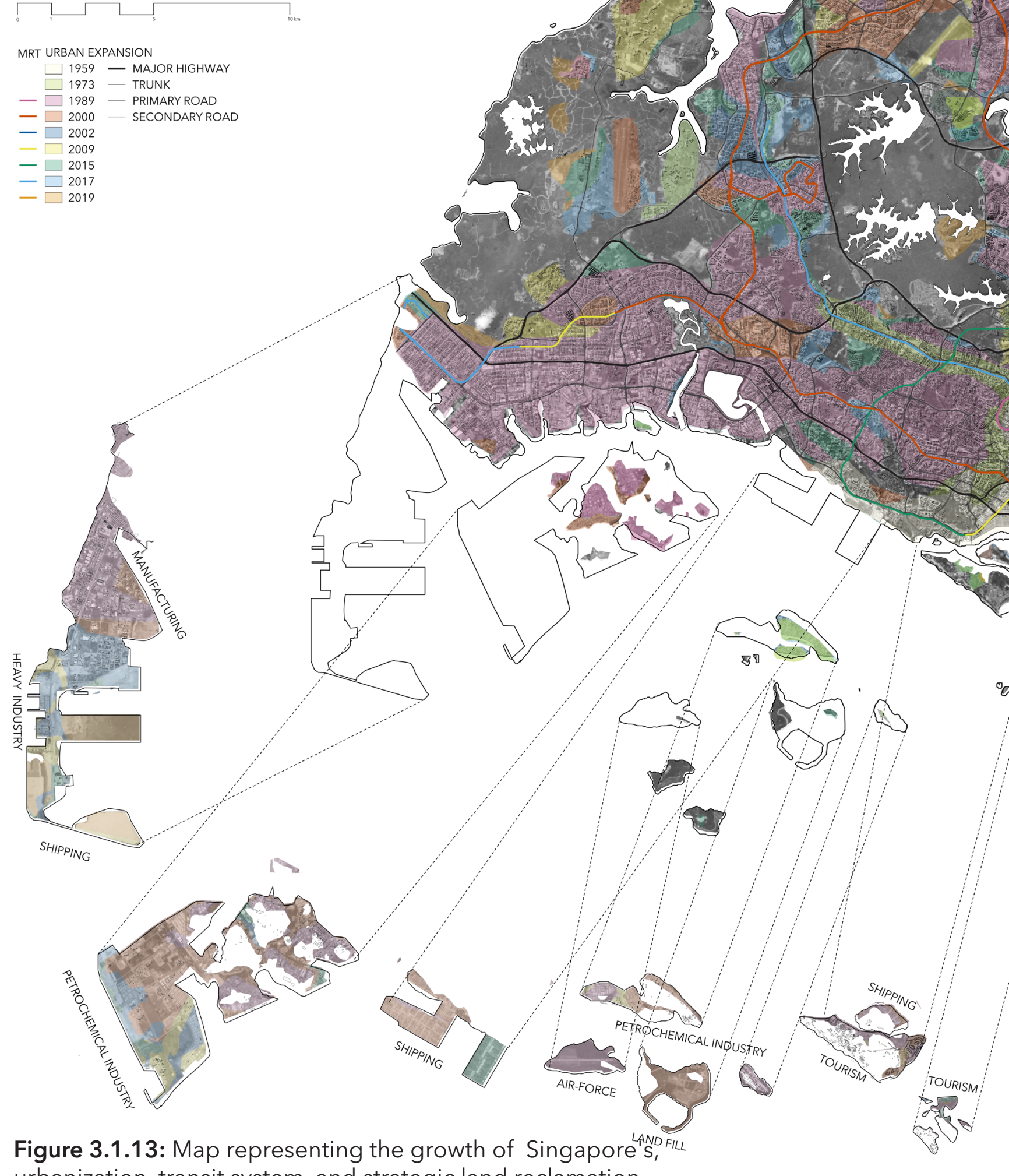

urbanization, transit system, and strategic land reclamation projects 


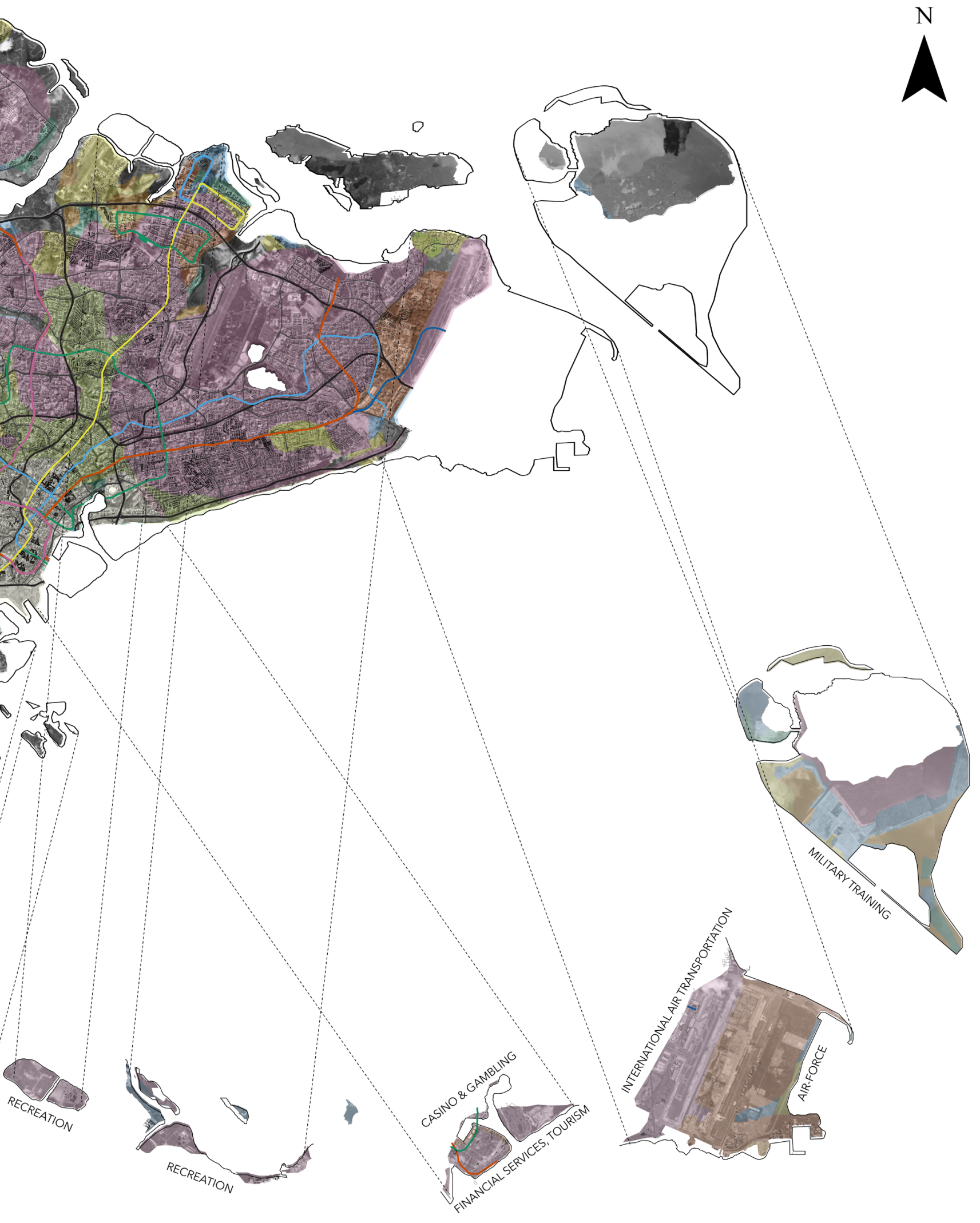


Singapore has a very high transit ridership rate, with over $65 \%$ of the public using transit for their daily commute ${ }^{59}$. Part of this can be attributed to the quality of the transit network, but it is also because the government of Singapore strongly discourages unnecessary car use. Cars in Singapore (Figure 3.1.14) are prohibitively expensive, costing, on average, three to five times what they would cost in other developed countries $^{60}$. The additional cost is a result of imposed taxes as well as the cost of a Certificate of Ownership (COE), which the government uses to regulate how many cars are on its roads ${ }^{61}$. In addition, since 1975, Singapore has been utilizing a congestion pricing system where drivers are charged for using their vehicles during peak hours in certain areas ${ }^{62}$.

\section{Housing:}

Since achieving independent governance, meeting the housing needs of the growing population of Singapore has been one of the government's main goals, a goal that they have successfully achieved. The Housing and Development Board (HBD) has provided widespread construction of housing developments for residents from a wide variety of income classes. Today, more than $80 \%$ of Singapore's population lives in some form of subsidized public housing ${ }^{63}$ (Figure 3.1.15). Of

59 Marshall, Colin. "Story of Cities \#27: Singapore - the Most Meticulously Planned City in the World." The Guardian, April 21, 2016, sec. Cities. https://www.theguardian.com/cities/2016/apr/21/story-cities-singapore-carefully-planned-lee-kuan-yew.

$60 \quad$ Ho, Timothy. "A No Nonsense Explanation On Why Cars In

Singapore Are So Expensive," November 2019. https://dollarsandsense. sg/no-nonsense-explanation-on-why-cars-in-singapore-are-so-expensive/. $61 \quad$ Ibid.

62 United States Department of Transportation - Federal Highway Administration. "Lessons Learned From International Experience in Congestion Pricing." FHWA, 2017. https://ops.fhwa.dot.gov/publications/ fhwahop08047/02summ.htm.

63 Kolczak, Amy. "Singapore Aims to Be the World's Greenest City." National Geographic, February 28, 2017. https://www.nationalgeographic.com/environment/urban-expeditions/green-buildings/green-urban-landscape-cities-Singapore/. 


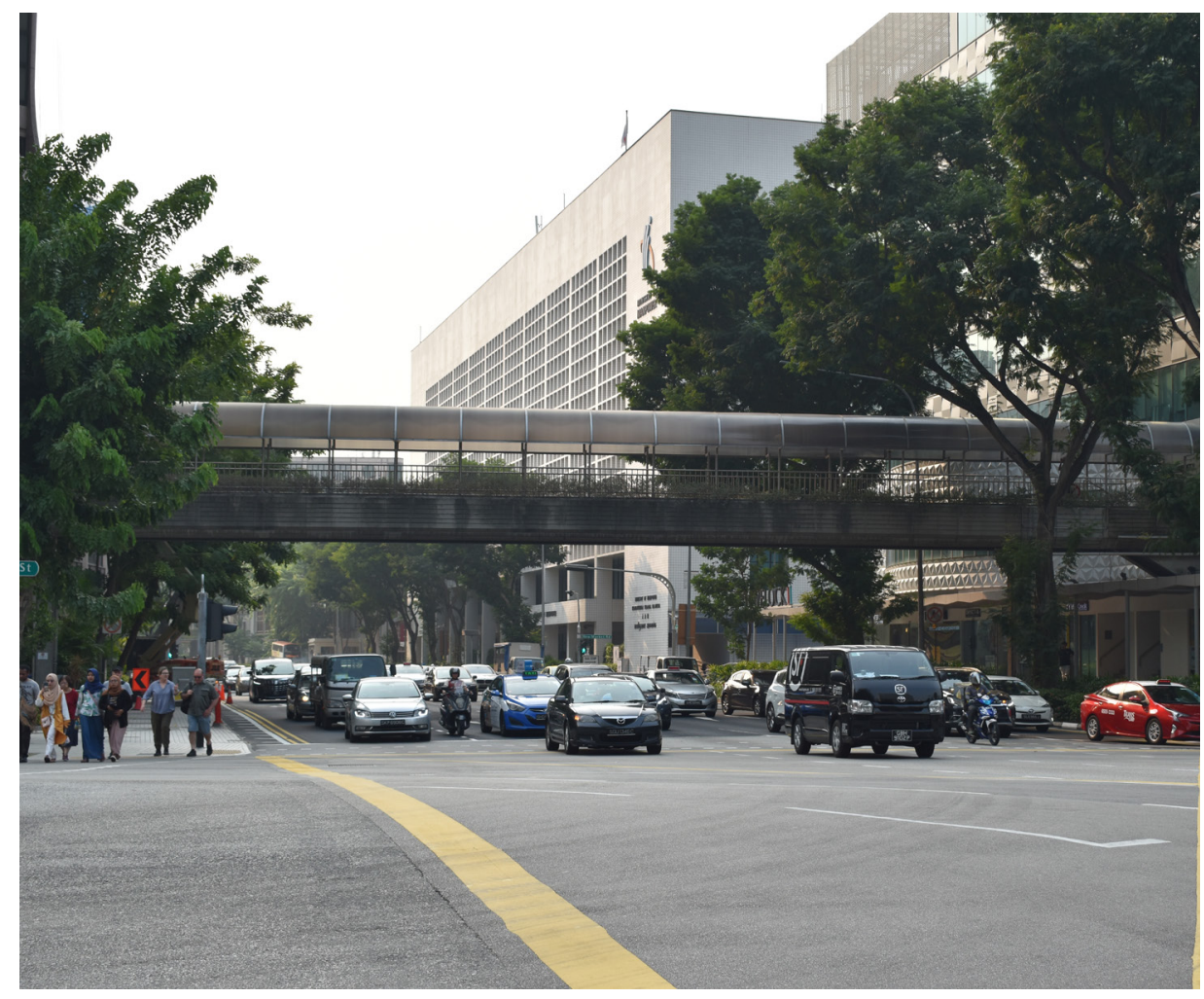

Figure 3.1.14: Cars in Singapore cost on average 3-5 times what they would cost in other developed countries

Caskey, Alex, "Mayjor Road with Pedestrian Overpass", Singapore Fall 2019

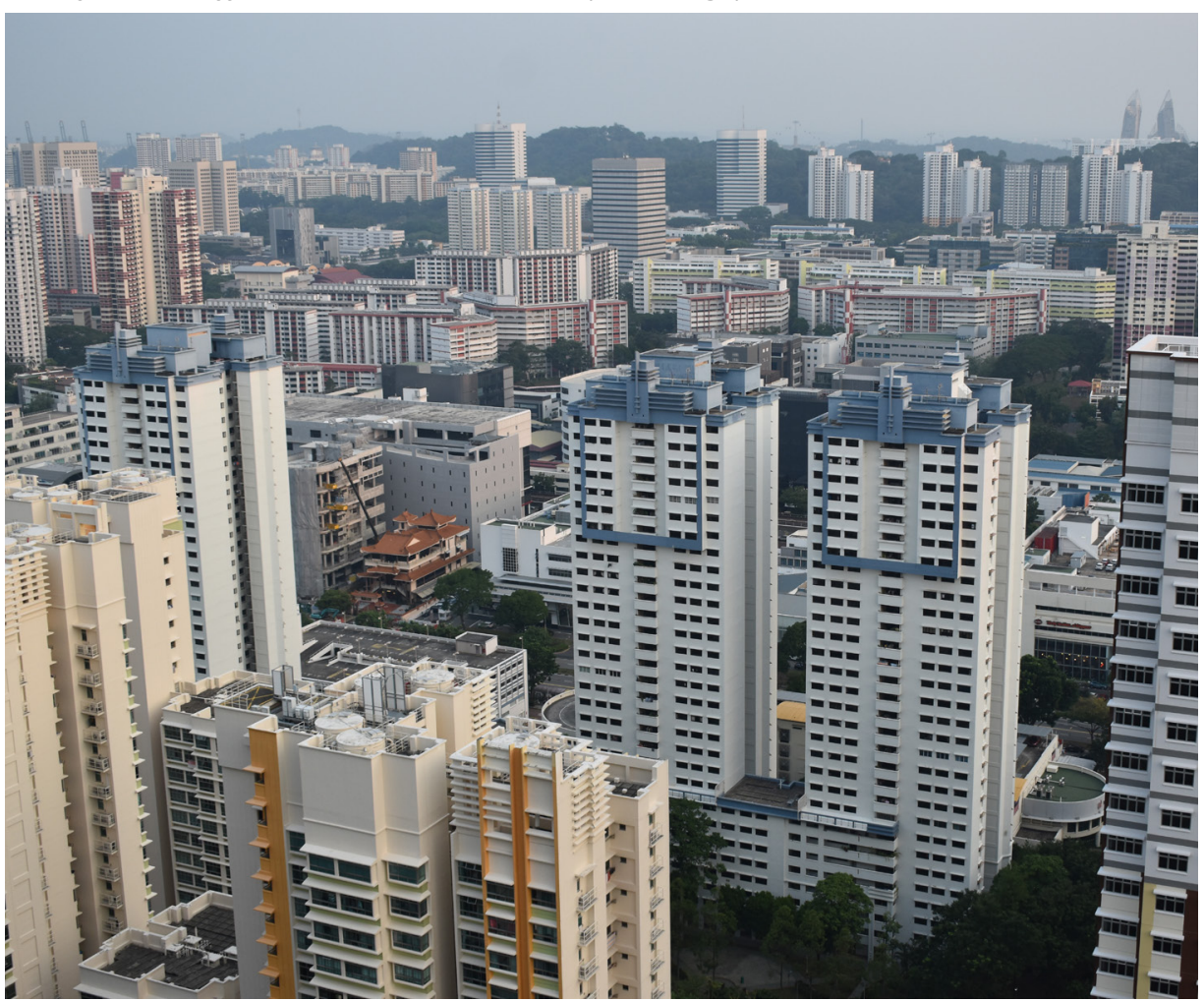

Figure 3.1.15: $80 \%$ of Singapore lives in public housing.

Caskey, Alex "Public Housing", Singapore, Fall 2019 
these residents, $95 \%$ of them are considered to "own" their own units ${ }^{64}$. In reality, ownership is provided through a 99-year lease ${ }^{65}$.

\begin{tabular}{ll}
\hline 64 & Ibid. \\
65 & ibid
\end{tabular}




\section{UN-COMMON CONDITIONS}

Section 1.3 explored the many factors that cemented the default approach of common towers as the only practical and permissible way of inhabiting vertical territory. This section discussed how the "Un-Common" geographic limitations, government structure, policies, public perception, existing typologies, climate, and other factors make Singapore well suited for an alternative approach to verticality.

\section{The Need to Grow Vertical}

The previous chapter explained the land limitations of Singapore and the government's massive land reclamation projects that added over $25 \%$ to the country's landmass since the mid $20^{\text {th }}$ century. Horizontal expansion through land reclamation in Singapore, however, is becoming increasingly challenging for two reasons. First of all, the landmass is extending out into deeper and deeper waters, meaning more sand is required to produce habitable territory. Secondly, the countries from which Singapore had previously gotten its sand (Indonesia, Cambodia, Vietnam, and Malaysia) have made sand exports illegal due to environmental concerns ${ }^{1}$. This

AFP. "Singapore Planning a Subterranean Future as It Faces Space Constraints." The Business Times, September 3, 2019. https://www. businesstimes.com.sg/real-estate/singapore-planning-a-subterranean-fu- 


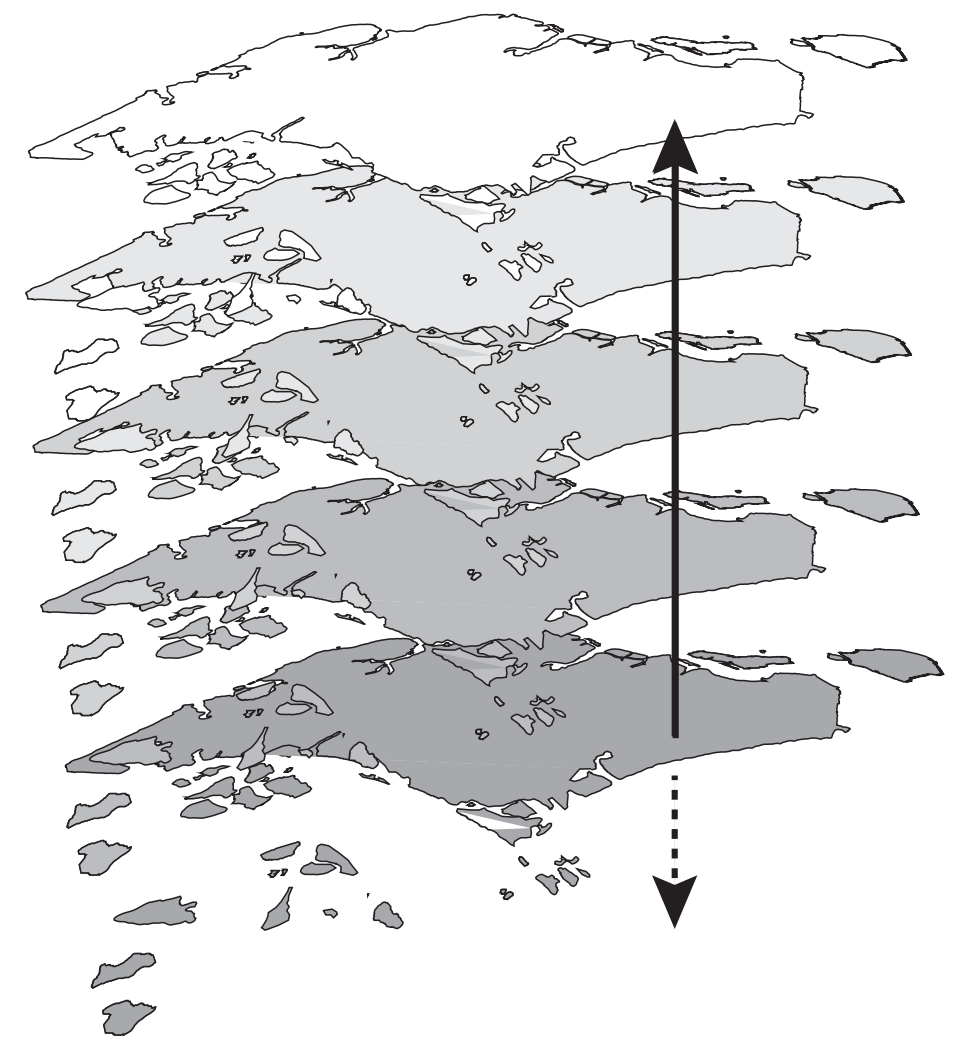

Figure 3.2.1: Without a hinterland to expand into and a shortage of sand for more land reclamation, Singapore will be forced to grow increasingly vertical

means Singapore must look further away for sand resources, which is increasingly challenging in a world where such demands for sand have led to the rise of sand mafias and sand wars ${ }^{2}$.

Vertical growth is already customary in Singapore, as the city has many tall buildings and highdensity dwellings dispersed throughout the entire metropolitan region ${ }^{3}$. As a result of the constraints

ture-as-it-faces-space-constraints.

Graham, Stephen"Below: Ground: Making Geology" in. Vertical: The City from Satellites to Bunkers. P. 298-299. London; New York: Verso, 2016.

2 Graham, Stephen"Below: Ground: Making Geology" in. Vertical:

The City from Satellites to Bunkers. P. 298-299. London ; New York: Verso, 2016.

3 Marshall, Colin. "Story of Cities \#27: Singapore - the Most Meticulously Planned City in the World." The Guardian, April 21, 2016, sec. Cities. https://www.theguardian.com/cities/2016/apr/21/story-cities-singapore-carefully-planned-lee-kuan-yew. 

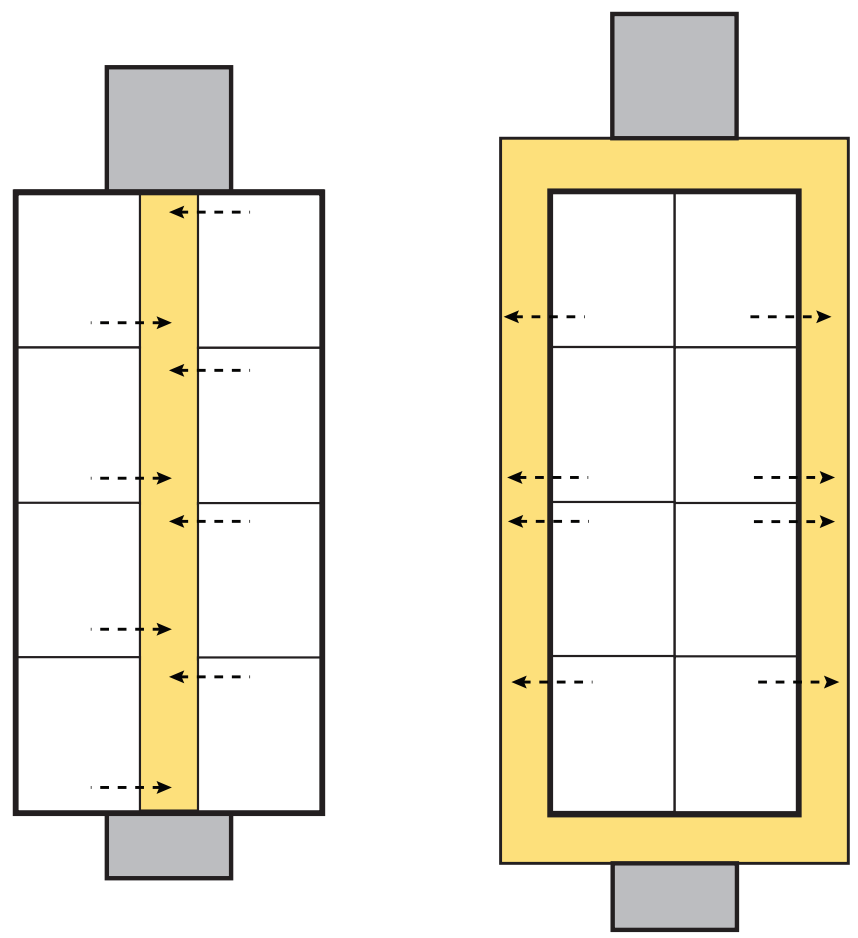

Figure 3.2.2: Plan diagram showing the internal hall circulation of common towers (left) vs. uncommon external circulation (right)

on horizontal expansion, however, it will be likely that vertical growth will become increasingly used to produce new territory in Singapore, increasing the density of the region (Figure 3.2.1).

\section{Existing Typologies}

The first part of this document explains the concept of the common tower as the default method of vertical inhabitation in cities acround the world. While the common tower has a widespread presence in Singapore, a combination of factors including climate, policy, and architectural experimentation has led to the proliferation of an "un-common" tower typology throughout the metropolitan region. These are innovative architectural responses to the limitations imposed by the common tower. Some of these uncoomon architectural typologies date back to prewar housing blocks ${ }^{4}$. What makes them 

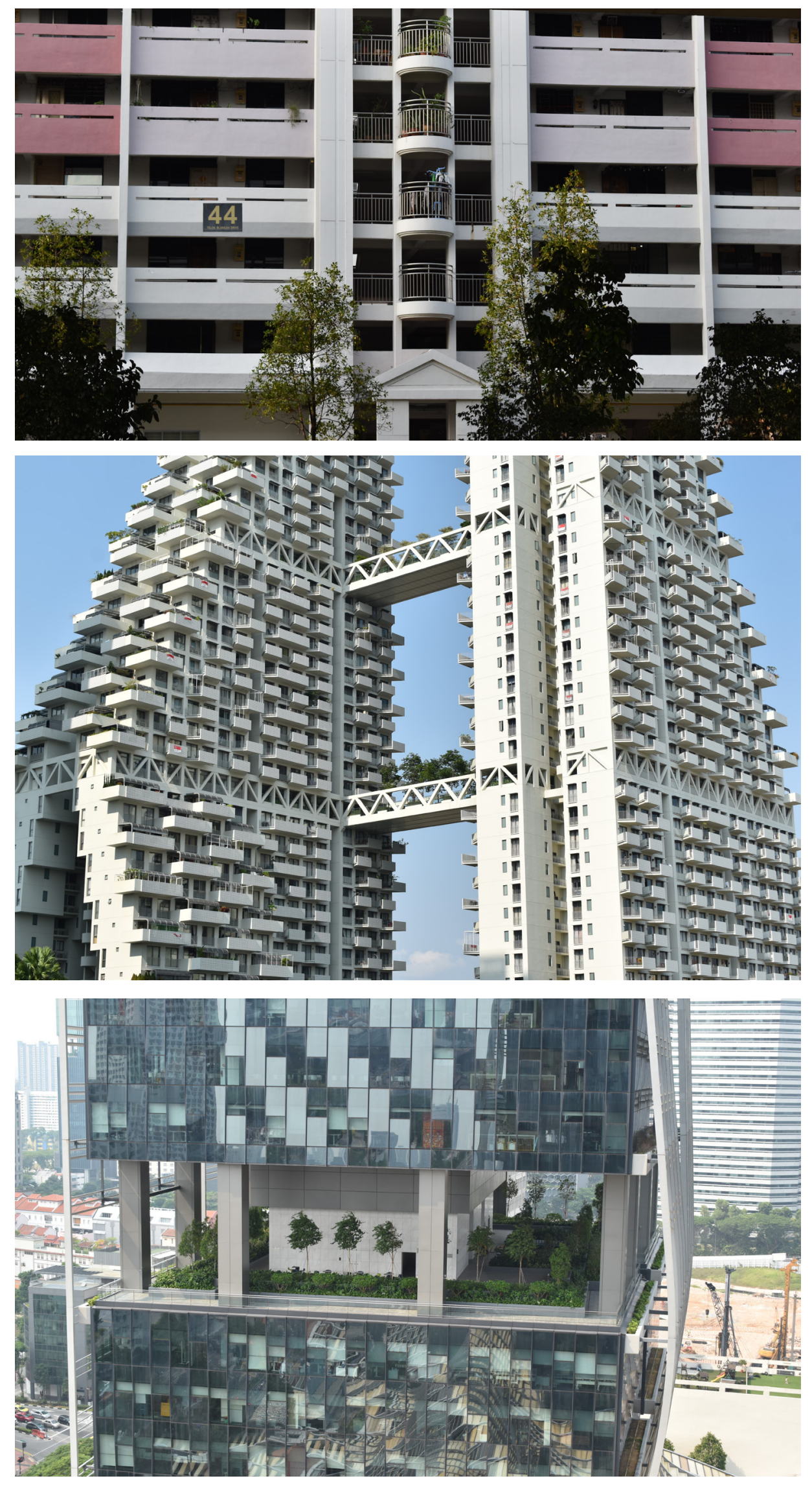
Figure 3.2.3-7 (Left): Top to Bottom: External circulation in a post way public housing unit, sky bridges in Moe Safdie's Sky Habitat, Sky garden in foster and partner's South Bach,

Caskey Alex, Singapore 2019

"uncommon" is their unique use of vertical real-estate for things such as:

- Externalized Circulation

- Sky Gardens

- Sky Parks

- Sky Streets

- Sky Bridges

- Roof Gardens

- External Elevators

- Irregular Volume Stacking

- Observation Decks

- Elevated Retail Spaces

- Multi-floor Continuous External Public Spaces

Some examples are shown in Figures 3.2.3-7. With the proliferation of these typologies throughout Singapore, the concept of extending the city vertically seems less radical here than in other cities.

\section{Public Perception of Verticality}

Singapore's population is already well accustomed to living vertically, with a large portion of its population already living in tall buildings. In addition to those housed in common tower typologies, some are fortunate enough to live in buildings with external corridors, sky bridges, and sky gardens and other such "Un-Common" features. Many of these residents have found ways to adapt to using the semi-public spaces high the air. For example, during a visit to the WHOA Skyville housing complex during an August 2019 research trip to Singapore, two young boys were witnessed racing scooters around on a sky

Rise." 99.co, August 2, 2016. https://www.99.co/blog/singapore/housing-yesteryear-singapore/. 

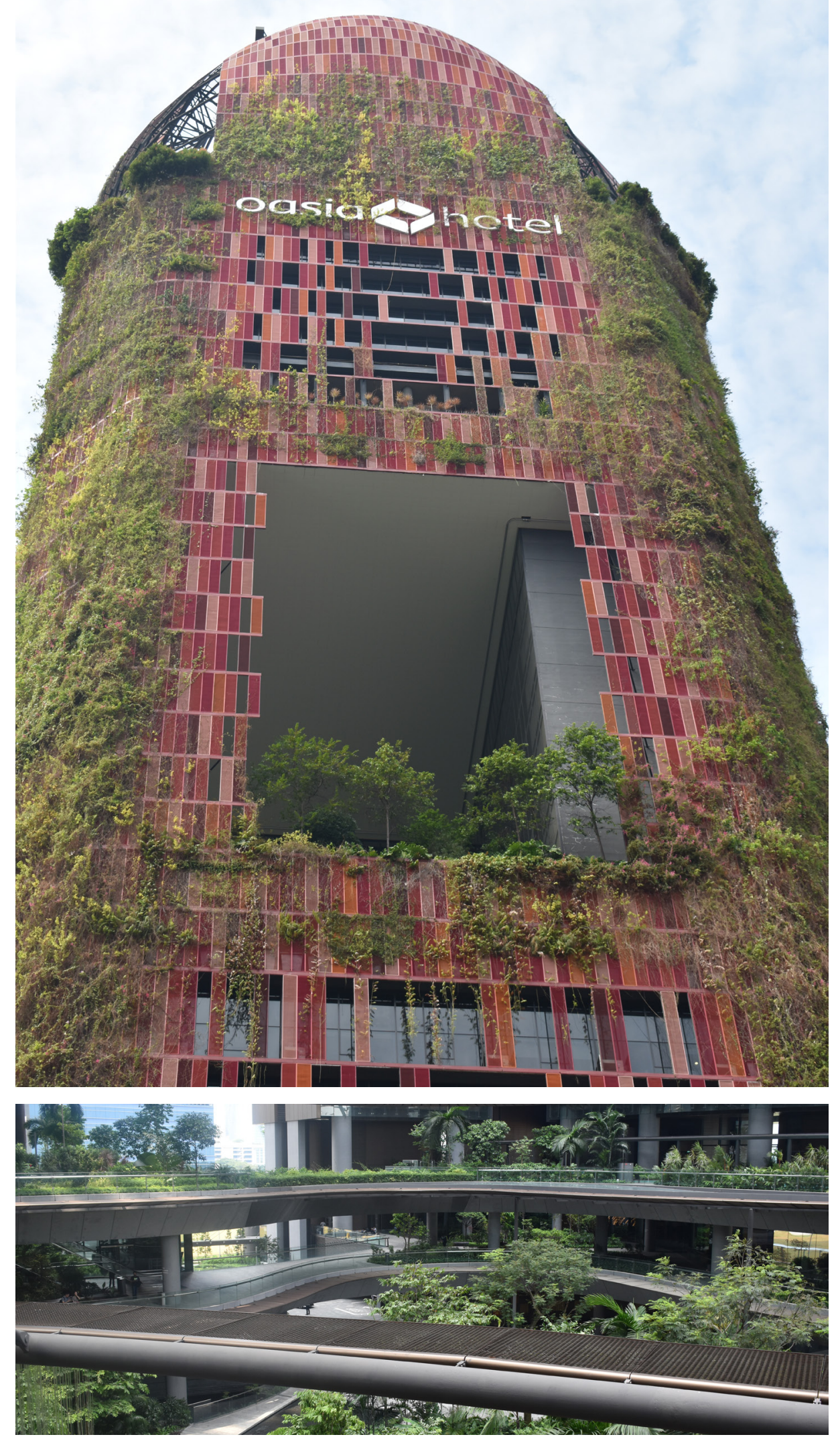
Figure 3.2.6-7 (Left): Top to Bottom: Sky garden in WOHA 's Oasia Hotel, Multilevel public space in Marina One.

Caskey Alex, Singapore 2019

street. Nearby, a young girl played hopscotch, while further along other residents were playing a game of chess. All of them were seemingly oblivious to the fact that they were on the 38th story of the building!

\section{The Pursuit of Decent Density}

Architects and Planners and the HDB in Singapore are already working to address the challenges that arise with high rise living, including an increased sense of isolation ${ }^{5}$. According to Cheong Koon Hean, the CEO of the HBD, Singapore is addressing the challenges of density by pursuing ways in which they can achieve what they refer to as "Decent Density". This is being done by integrating green spaces, gathering places, and recreational areas within new developments, as well as through urban interventions to existing parts of the city ${ }^{7}$. A good example of this it's the widespread proliferation of "three-generation playgrounds" where outdoor exercise equipment alongside play structures create community activity zones ${ }^{8}$ These $3 \mathrm{G}$ - playgrounds are also used to activate spaces in between existing towers?

In addition to interventions on the ground plane, the city has extended this thinking vertically. The Landscaping for Urban Space and High Rises (LUSH)

\footnotetext{
$5 \quad$ Kolczak, Amy. "Singapore Aims to Be the World's Greenest City." National Geographic, February 28, 2017. https://www.nationalgeographic.com/environment/urban-expeditions/green-buildings/green-urban-landscape-cities-Singapore/.

6 ibid

$7 \quad$ ibid

$8 \quad$ Kolczak, Amy. "Singapore Aims to Be the World's Greenest City." National Geographic, February 28, 2017. https://www.nationalgeographic.com/environment/urban-expeditions/green-buildings/green-urban-landscape-cities-Singapore/.

9 Caskey, Alex, General observation from research trip to Singapore, August 2019. Singapore
} 


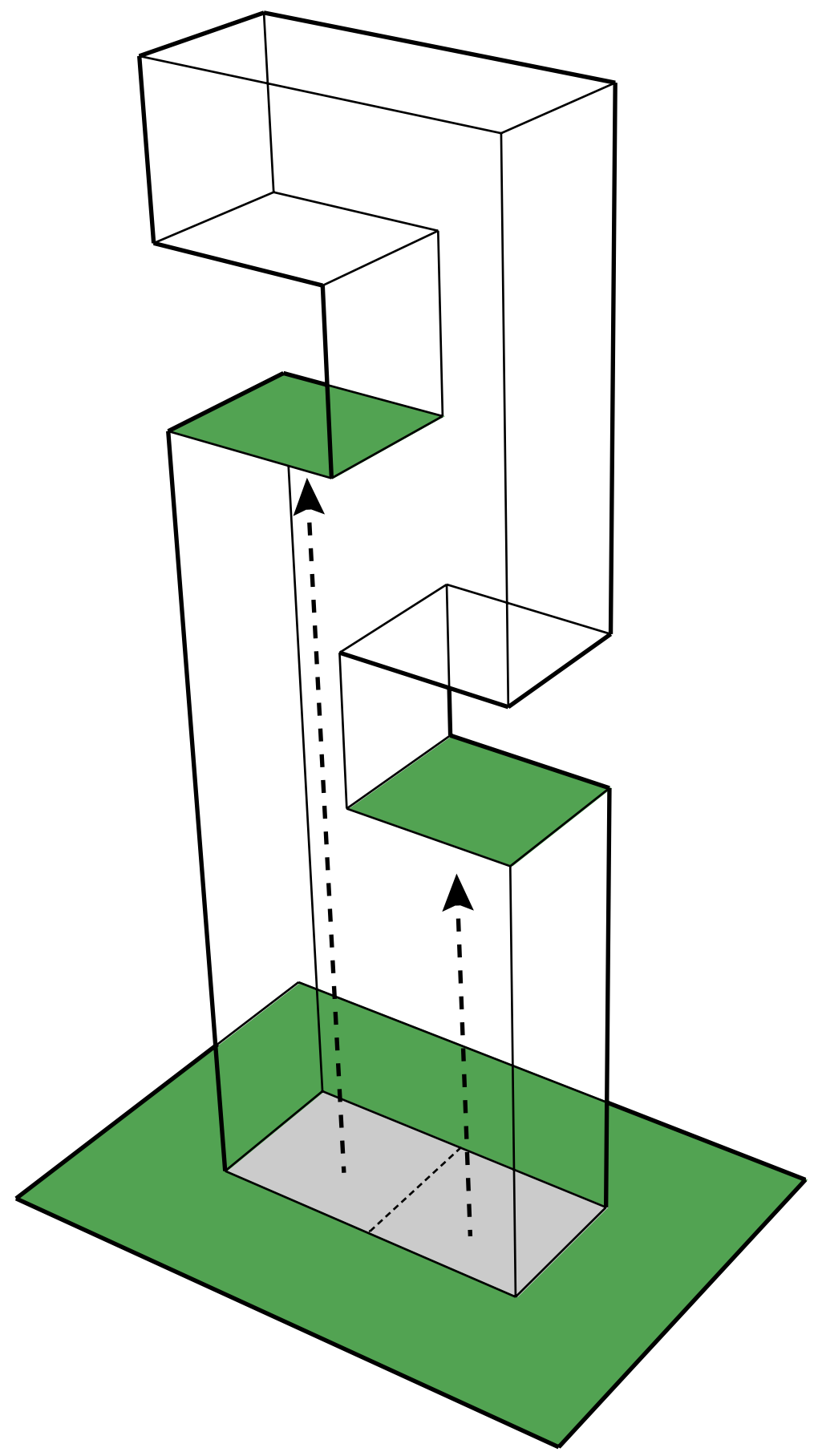

Figure 3.2.8: Diagram showing how the 1: 1 ground replacement policy of the LUSH program for new development leads to "uncommon" tower features like sky gardens, and sky bridges. 
program, first introduced in 2009 and expanded in 2014 and 2017, is a policy intended to improve the presence of green space as well as "green" infrastructure within the urban environment ${ }^{10}$. Part of this program included the implementation of a $1: 1$ greenery replacement policy (Figure 3.2.8), where any greenery displaced in the construction of a building's footprint needs to be recreated somewhere else within the height of that building ${ }^{11}$. Through the LUSH Progam, Singapore has shown the potential that policy has to modify forms of vertical growth in a city. The LUSH policy explains the uncommon typologies that have proliferated throughout the metropolis.

\section{The Governmental Structure}

Singapore's government has shown a proven ability to execute large scale urban projects. The massive land reclamation projects are a prime example of this. Singapore's ability to rapidly execute large feats of urban planning \& development has largely come from the centrality of the government ${ }^{12}$. As mentioned in the previous chapter, since 1959, city planning has been a centralized responsibility under the Planning Department of the Prime Ministers Office ${ }^{13}$. Political

\footnotetext{
$10 \quad$ Urban Redevelopment Authority. "Updates to the Landscaping for Urban Spaces and High-Rises (LUSH) Programme: LUSH 3.0." Urban Redevelopment Authority, 2017. https://www.ura.gov.sg/Corporate/ Guidelines/Circulars/dc17-06.

Kolczak, Amy. "Singapore Aims to Be the World's Greenest City." National Geographic, February 28, 2017. https://www.nationalgeographic.com/ environment/urban-expeditions/green-buildings/green-urban-landscape-cities-Singapore/.

Construction Climate Challenge. "Singapore Is Leading the Way in Green Urban Infrastructure - Volvo CCC." 2018. Accessed November 19, 2019. https://constructionclimatechallenge.com/2019/02/20/singapore-is-leading-the-way-in-green-urban-infrastructure/.

11 ibid

12 Marshall, Colin. "Story of Cities \#27: Singapore - the Most Meticulously Planned City in the World." The Guardian, April 21, 2016, sec. Cities. https://www.theguardian.com/cities/2016/apr/21/story-cities-singapore-carefully-planned-lee-kuan-yew.

13 Government of Singapore. "History of Urban Planning in Singapore | Infopedia," 2016. https://eresources.nlb.gov.sg/infopedia/articles/
} 

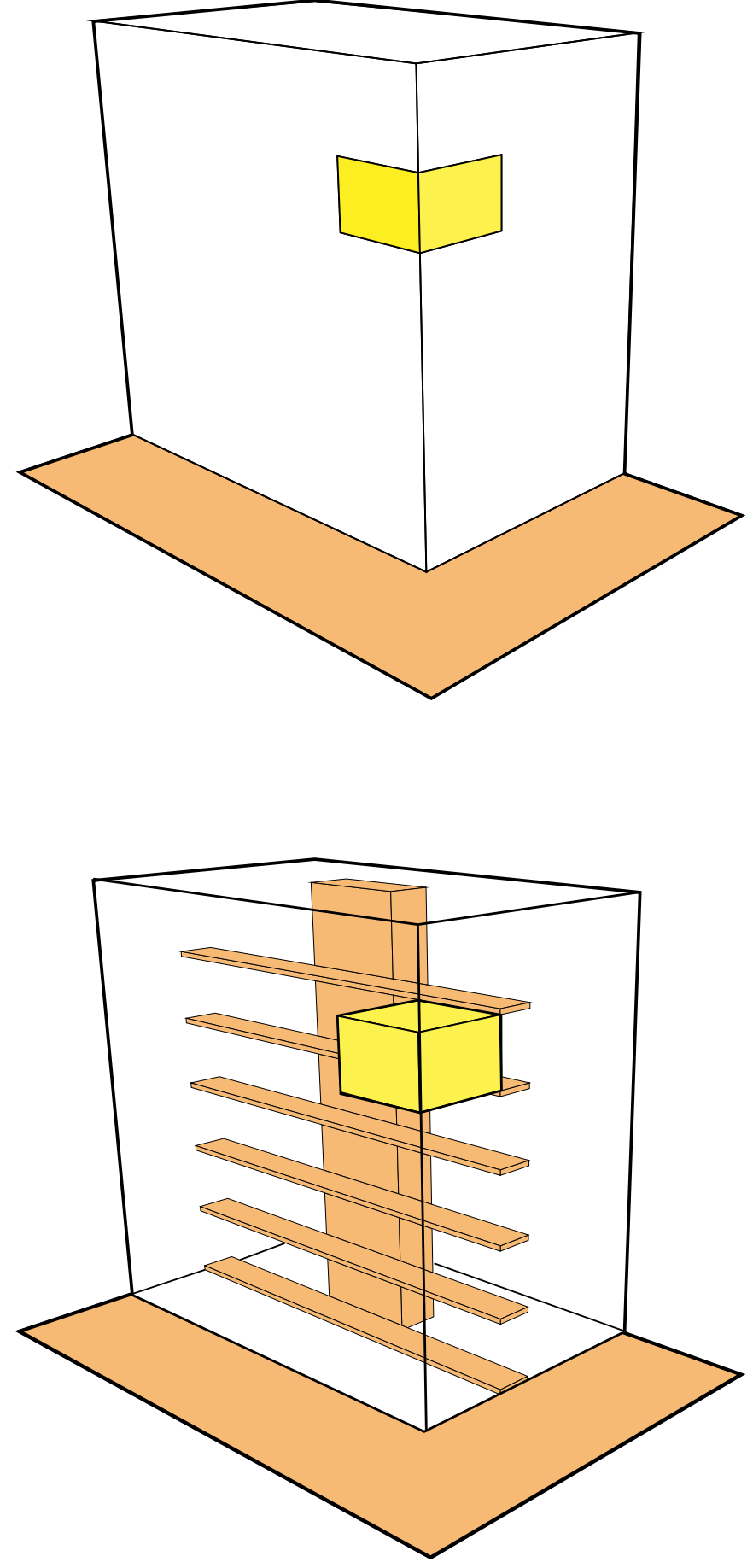

Figure 3.2.9: Diagram showing how in Singapore's HBD flats the unit are individually owned but the circulation remains government infrastructure, similar to the street. 
continuity has also played a major role in the country's ability to execute large projects ${ }^{14}$. In other countries, short term political turnover is often a challenge for projects spanning many years. In its 60 years since independence, Singapore has had only one political party in power, with three separate Prime Ministers all similar sharing ideologies ${ }^{15}$.

\section{Land "Ownership" Practices}

As discussed in Section 1.3, throughout the world's major cities, the role of land ownership has strongly contributed to the proliferation of common towers. Since a single owner or group of owners own a plot of land, the extension of a tower above it usually means that all vertical circulation and real estate fall under single ownership.

Singapore has very unique circumstances that have left the ownership and responsibility of most of the city's vertical infrastructure in the hands of the state. As previously mentioned, today more than $80 \%$ of Singapore's population lives in some form of subsidized public housing ${ }^{16}$. Of these residents, 95\% of them are considered to "own" their units ${ }^{17}$. This means that while a piece of real estate belongs to an individual or family, the government remains in control and responsible for the network of much

\section{SIP_1564_2009-09-08.html. \\ $14 \quad$ Wong, Tai-Chee, Belinda K. P. Yuen, and Charles Goldblum, eds. Spatial Planning for a Sustainable Singapore. P. 7. New York: Springer, 2008. \\ 15 Encyclopedia Britannica. "Singapore| Facts, Geography, Histo- ry, \& Points of Interest." Encyclopedia Britannica. Accessed November 26, 2019. https://www.britannica.com/place/Singapore \\ 16 Kolczak, Amy. "Singapore Aims to Be the World's Greenest City." National Geographic, February 28, 2017. https://www.nationalgeo- graphic.com/environment/urban-expeditions/green-buildings/green-ur- ban-landscape-cities-Singapore/. \\ $17 \quad$ Kolczak, Amy. "Singapore Aims to Be the World's Greenest City." National Geographic, February 28, 2017. https://www.nationalgeo- graphic.com/environment/urban-expeditions/green-buildings/green-ur- ban-landscape-cities-Singapore/.}


of the city's vertical and horizontal circulation (Figure 3.2.9).

Part 2, explained why the decoupling of private realestate from the vertical circulation system of a city, may enable it to inhabit its own vertical real-estate. In many ways, this decoupling is analogous to the current circumstances in Singapore.

\section{Climate \& Daylighting}

As mentioned in Section 3.1, Singapore's proximity to the equator means it has a very stable year-round climate with low month to month variation ${ }^{18}$. This allows for spaces like external circulation, and sky gardens to be comfortable to use throughout the year.

Singapore's proximity to the equator also creates another unique condition. In cities away from the equator, sunlight comes from a single direction throughout the year. In Singapore, sunlight comes from the North between March and September, while from September to March, it comes from the South ${ }^{19}$ (Figure 3.2.10).

\section{Conclusion}

This section explored the existing "uncommon" conditions in Singapore that vary from the "common" conditions prevalent in most other cities. As outlined in Section 1.3, such "common" conditions make

\footnotetext{
18 Calculated based on data from: Government of Singapore. "Climate of Singapore |." Meteorological Services Singapore, 2019. http:// www.weather.gov.sg/climate-climate-of-singapore/.

19 Kblog. "Singapore News Hub: Sunrise and Sunset Direction Chart For Singapore." Singapore News Hub (blog), January 13, 2010. https://singaporenewshub.blogspot.com/2010/01/sunrise-and-sunset-direction-chart-for.html.

Information verified using "SunCalc Sun Position and Sunlight Phases Calculator." Accessed November 27, 2019. http://suncalc.net/\#/1.2771,10 3.8608,11/2019.03.12/15:01.
} 


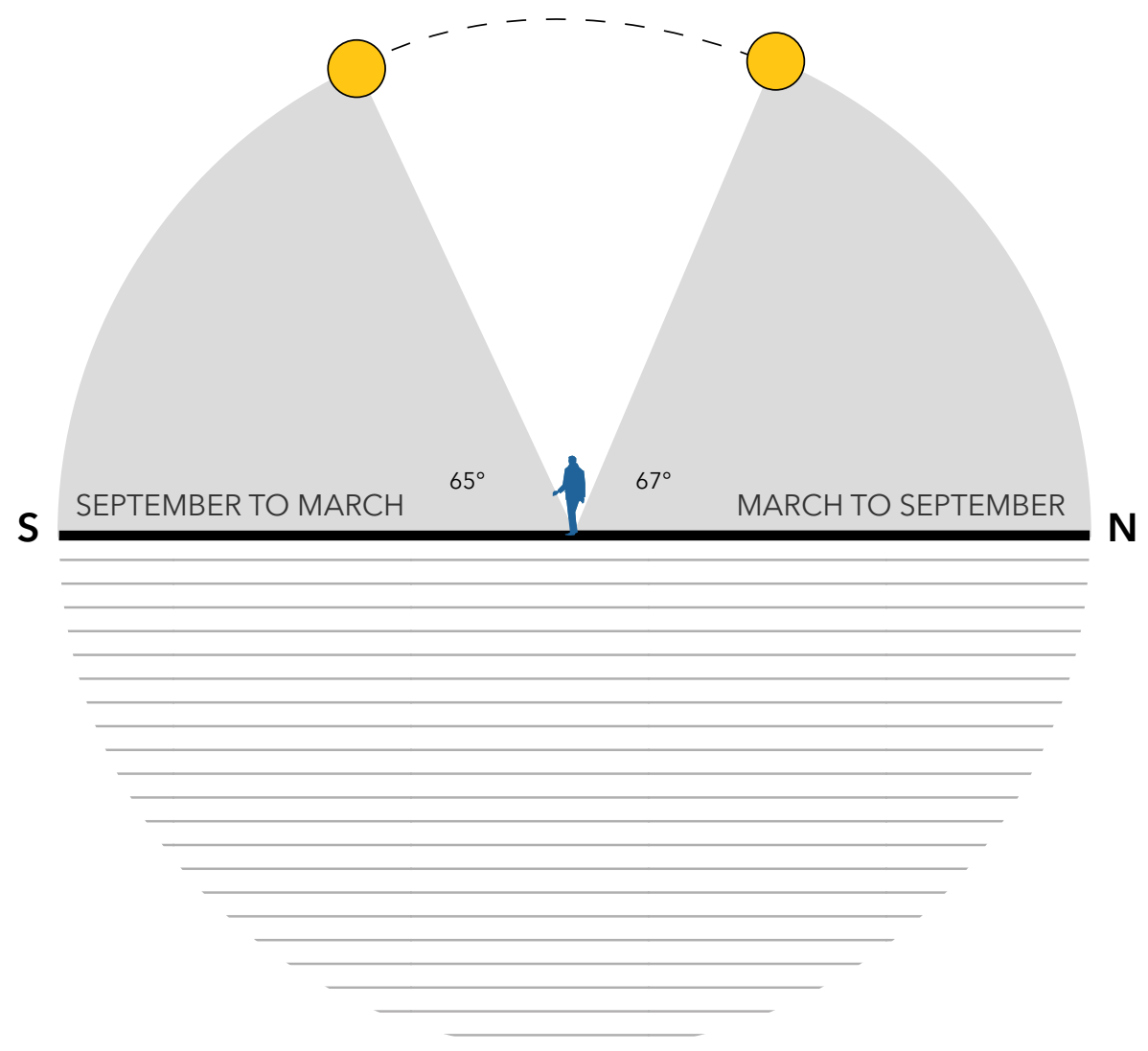

Figure 3.2.10: Diagram showing how in Singapore, sunlight comes from the North between March and September, while from September to March, it comes from the South

common towers the only practical and permissible approach to verticality. Singapore has a nationwide need for space, an existing "uncommon" tower vernacular, and widespread acceptance of vertical conditions. There are unique land ownership laws and robust governmental involvement in urban development. Also, the consistent climate of Singapore supports externalized circulation and external spaces that would be less comfortable in other climates. These conditions are why Singapore was selected for exploring how a volumetric approach to planning future development could align with the goals of the city. 


\section{THE MARINA SOUTH VOLUME}

Section 3.2 established why Singapore, as both a city and a country, is particularly well suited to an approach to verticality that goes beyond common towers. This section investigates a specific intermediate scale urban region of Singapore known as Marina South, which is a planned extension to the city. It includes a discussion of the Marina South region, the proposed future development plan, and an argument for why the established plan limits future innovative solutions. It then explores an alternative approach to thinking about the future development of the area. It investigates how a volumetric approach to development in this region may be more aligned with the city's planning goals.

\section{Context}

Marina South is a planning area adjacent to Singapore's existing Central Financial District.

The area of specific interest for this project was an approximately $1-2 \mathrm{~km}^{2}$ section of waterfront land (Figure 3.3.1-2) surrounded by the iconic Marina Bay Sands complex, the Gardens by the Bay park area, and the existing financial district. This area was artificially created as apart of Singapore's massive 


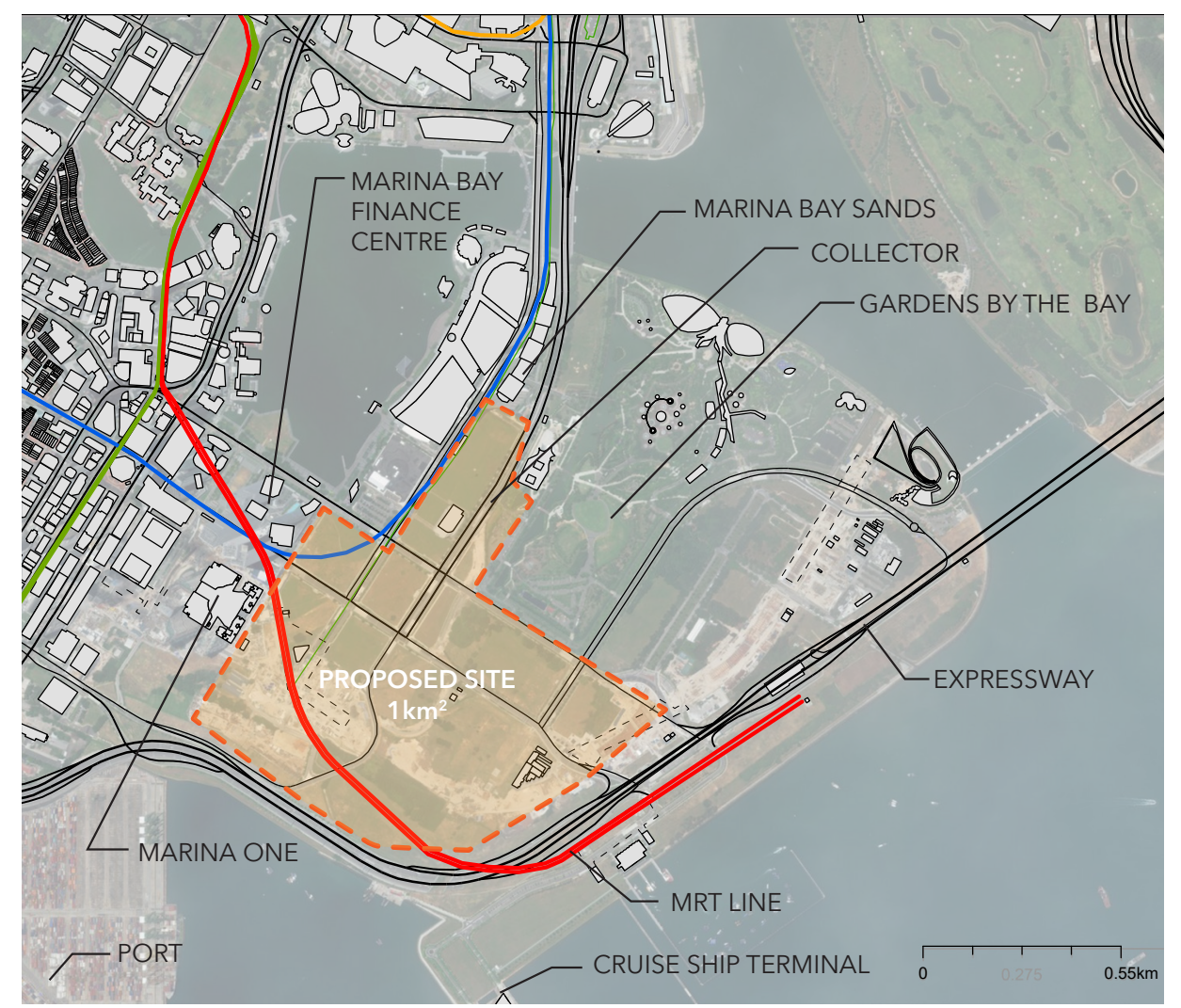

Figure 3.3.1: Map of proposed Marina Bay design Project site in downtown Singapore land reclamation projects outline in Section 3.11. In 1967, this area did not exist as part of the country's landmass.

This site was selected because it is a planned extension of the city in a central region where significant dense vertical development is expected in the future.

While the site is currently undeveloped, it is already well connected to the city's infrastructure due to plans for future large-scale development. Established infrastructure includes a subterranean utility channel, street networks, two underground MRT lines, the ten-lane Marina Coastal Expressway that runs around the perimeter, and an eight-lane collector that cuts

\footnotetext{
USGS. "Singapore | Earthshots: Satellite Images of Environmental Change." Accessed November 20, 2019. https://earthshots.usgs.gov/ earthshots/Singapore\#ad-image-0-0.
} 


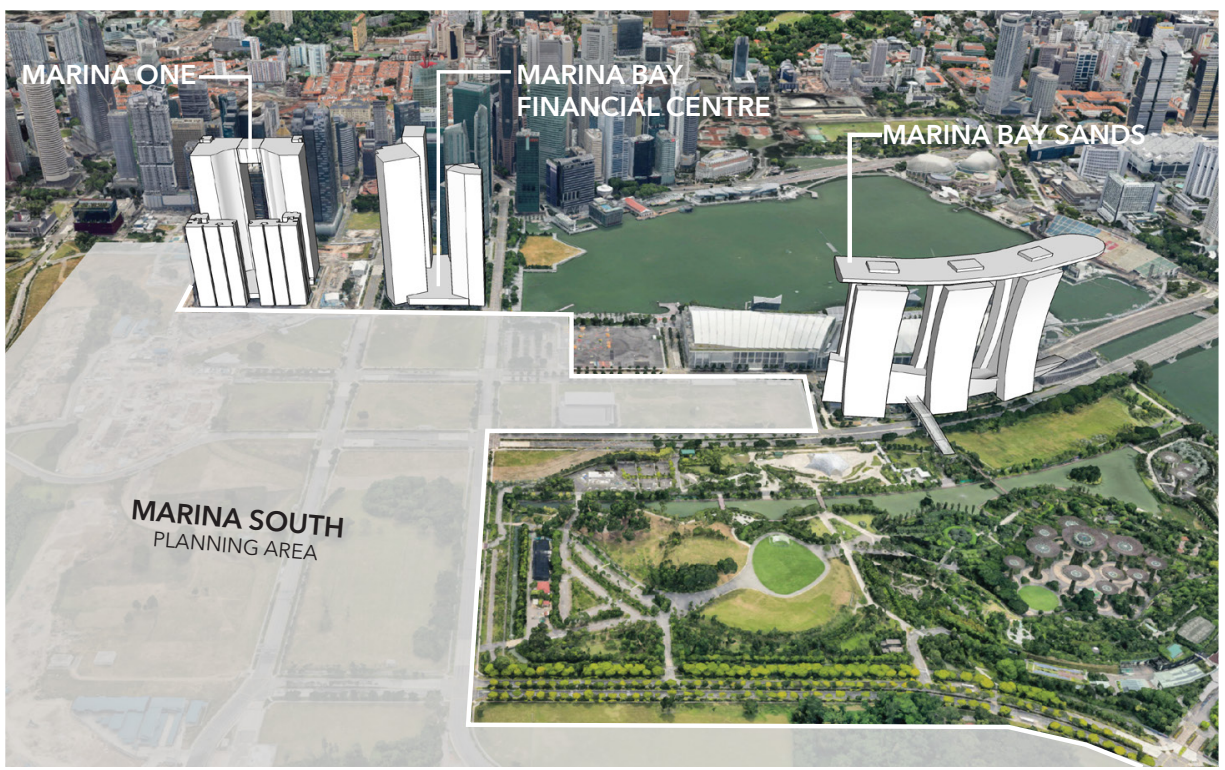

Figure 3.3.2: Diagram showing three major complexes surrounding site
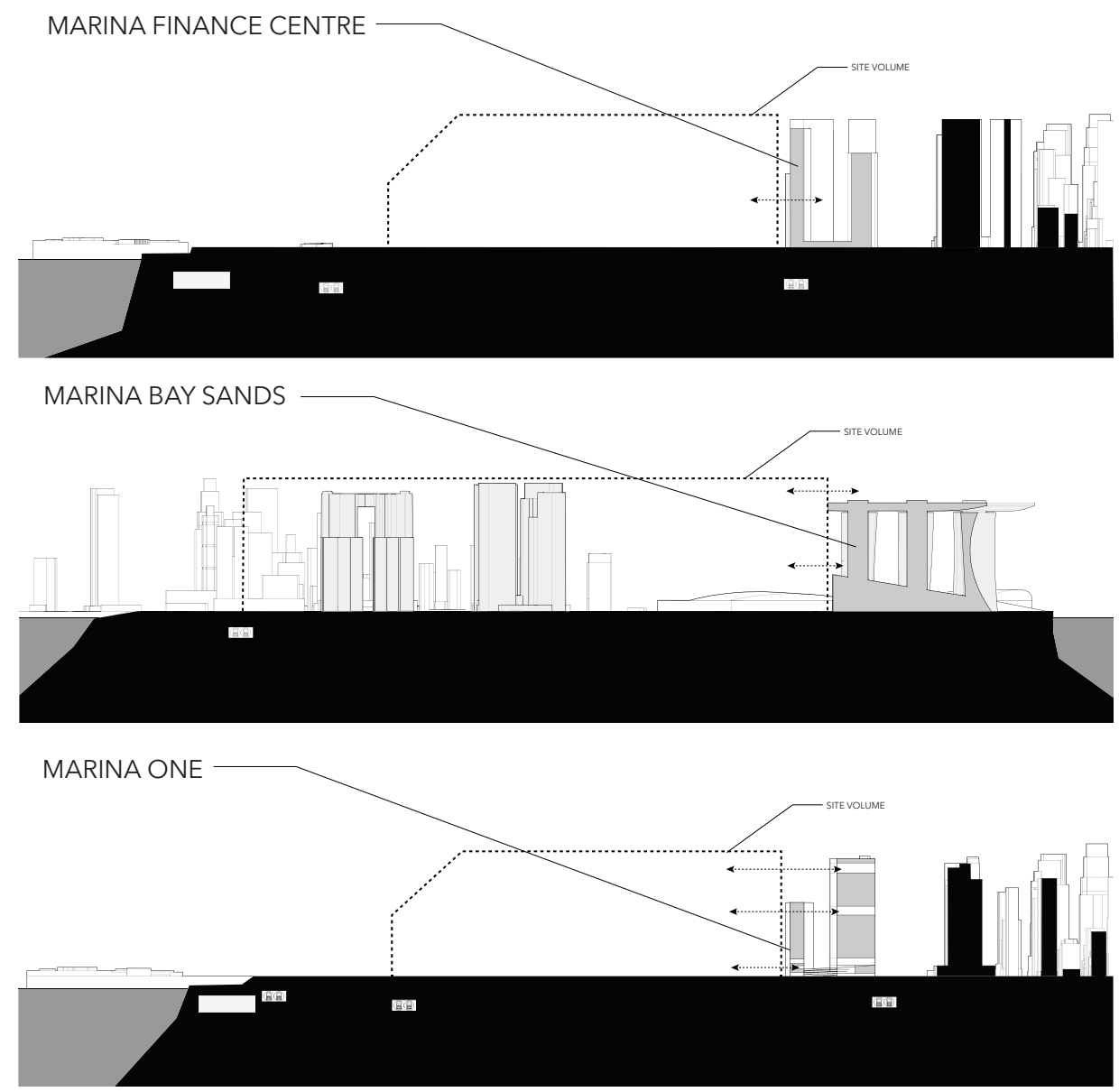

Figure 3.3.3: Cross section drawings showing three major complexes surrounding the site and underground infrastructure 
through the centre of the site.

The flat site is also abutted by three major development complexes, each with its own characteristics that together form a unique vertical context (Figures 3.3.2-3).

The Marina Bay Financial Centre Complex (Figure 3.3.4) first opened in 2013 is typical of a larger common tower styled development. It consists of three office towers and two residential towers, all tied together by a larger retail podium ${ }^{2}$. The development was planned as a major extension to the city's existing financial district ${ }^{3}$. The decision to integrate residential was the beginning of the government's initiative to develop the downtown core into a mixed-use neighbourhood rather than a purely business district ${ }^{4}$.

The Marina Bay Sands Complex (Figure 3.3.5) completed in 2010 at the cost of 8 billion dollars (CAD) was developed between a partnership with the Las Vegas Sands Corporation and the Singapore Government ${ }^{5}$. The government saw the project as an opportunity to increase the country's tourism and overall competitiveness, similar to how the Guggenheim Museum impacted the Spanish city of

\footnotetext{
$2 \quad$ Raffles Quay Asset Management. "About Us." Marina Bay Financial Centre, 2014. https://www.mbfc.com.sg/about.html.

Raffles Quay Asset Management. "Media Release: Prime Minister Lee Hsien Loong Officiates At The Grand Opening Of Marina Bay Financial Cen-Tre." Raffles Quay Asset Management, May 2013. https://www.hkland. com/data/media_releases/2013/hll_20130515.pdf

3 ibid.

$4 \quad$ Raffles Quay Asset Management. "Media Release: Prime Minister Lee Hsien Loong Officiates At The Grand Opening Of Marina Bay Financial Cen-Tre." Raffles Quay Asset Management, May 2013. https:// www.hkland.com/data/media_releases/2013/hll_20130515.pdf. Urban Redevelopment Authority. "Our Downtown." Urban Redevelopment Authority. Accessed November 28, 2019. https://www.ura.gov.sg/Corporate/Planning/Master-Plan/Regional-Highlights/Central-Area/Downtown.

$5 \quad$ Rowe, Peter G. "Reclaiming and Remaing Territories" in Emergent Architectural Territories in East Asian Cities. p. 104-113 Basel: Birkhauser, 2011.
} 
Bilbao ${ }^{6}$. While it has attracted tourism, the Marina Bay Sands complex arguably lacks a real connection to the city. It is highly visible throughout the city, yet it remains isolated on a peninsula. The defining feature that has made this complex iconic is a sky park that spans the three common hotel towers and cantilevers out $50 \mathrm{~m}$ over the edge. The park is over one hectare in area, is located $220 \mathrm{~m}$ in the air, and features pools, restaurants, and green areas, among other amenities ${ }^{7}$. This park, however, is isolated in the air and is only accessible to hotel guests and paying customers.

The Marina One Complex (Figures 3.3.6-7) is a set of 4 towers, two residential and two commercial that have a series of uncommon features. Like other "uncommon" towers in Singapore, Marina One features a series of sky garden amenity floors. These are inaccessible to the public. What is publicly accessible is a spiralling ramp located in the interior courtyard of the four towers. This spiralling ramp extends the ground plane connecting six floors of retail, restaurants, private, and public green spaces in a seamless fashion. This existing infrastructure does the hard work of lifting the public off the ground plane without creating a disconnect. The climbing public space, however, is essentially a dead-end because at the upper levels, the public has nowhere to go but back down from where they came.

\section{An Extension to Singapore: The Default Approach}

The contemporary approach to planning a region of

$6 \quad$ Ibid

A common contemporary urban design trend that Joan Busquets refers to as a "Synthetic Gesture" developed with the intent of having a similar impact to that of the Guggenheim in Bilbao

Busquets, Joan. Line 1: Synthetic Gestures Cities X Lines: A New Lens for the Urbanistic Project. Edited by Felipe Correa and Harvard University. Reprint. S.I.: Nicolodi, 2007.

$7 \quad$ Rowe, Peter G. "Reclaiming and Remaing Territories " in Emergent Architectural Territories in East Asian Cities. p. 104-113 Basel: Birkhauser, 2011. 


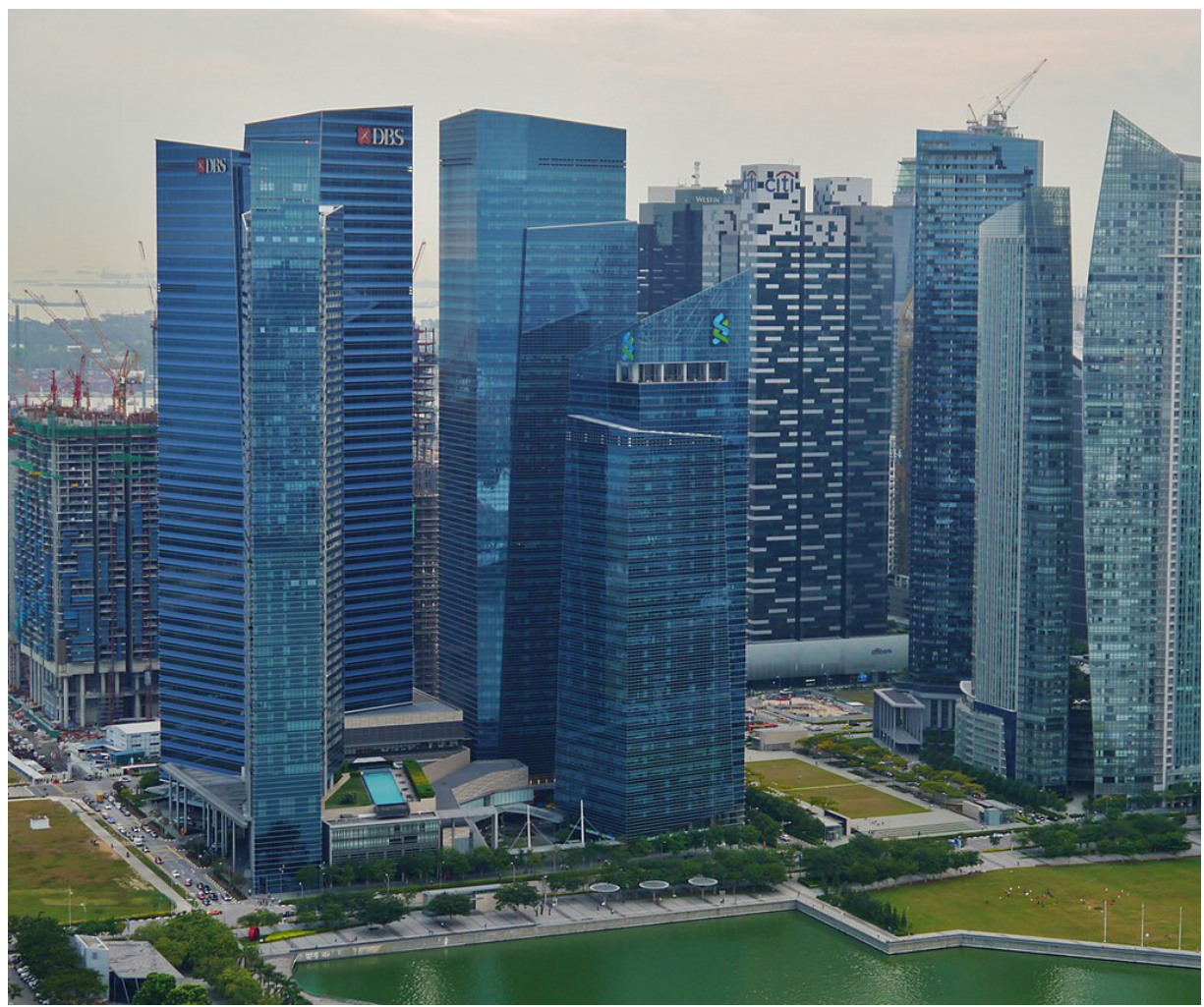

Figure 3.3.4: Marina Bay Finance Centre Complex (Common Tower style Development)

Zarion. "Marina Bay Financial Centre viewed from Marina Bay Sands." In Wikipedia, 2015. https:// en.wikipedia.org/w/index.php?title=Marina_Bay_Financial_Centre\&oldid=924649840.

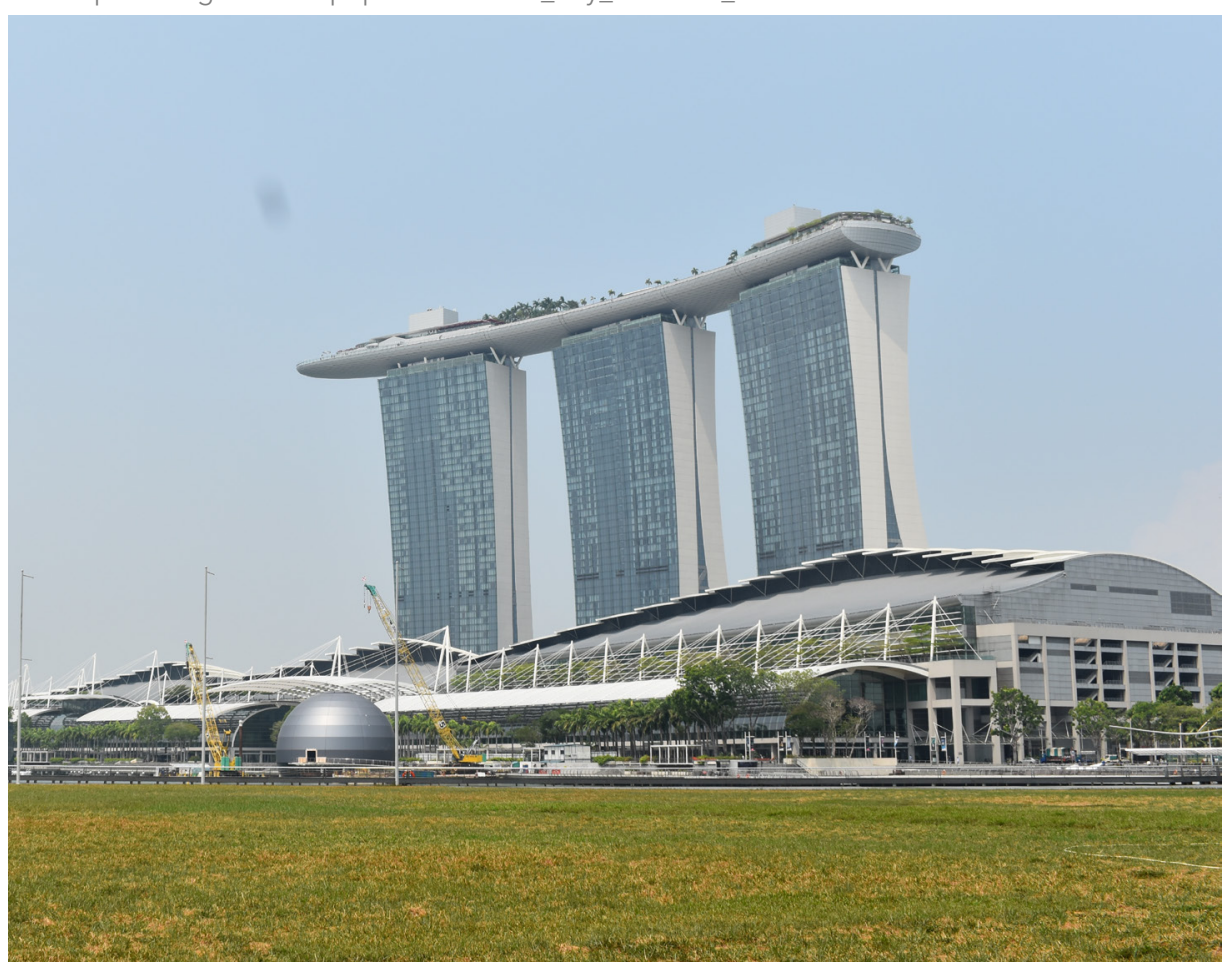

Figure 3.3.5: Marina Bay Sands Complex (Singapore Icon, 1 acre sky park)

Caskey,Alex, "Marina Bay Sands", Singapore, Fall 2019 


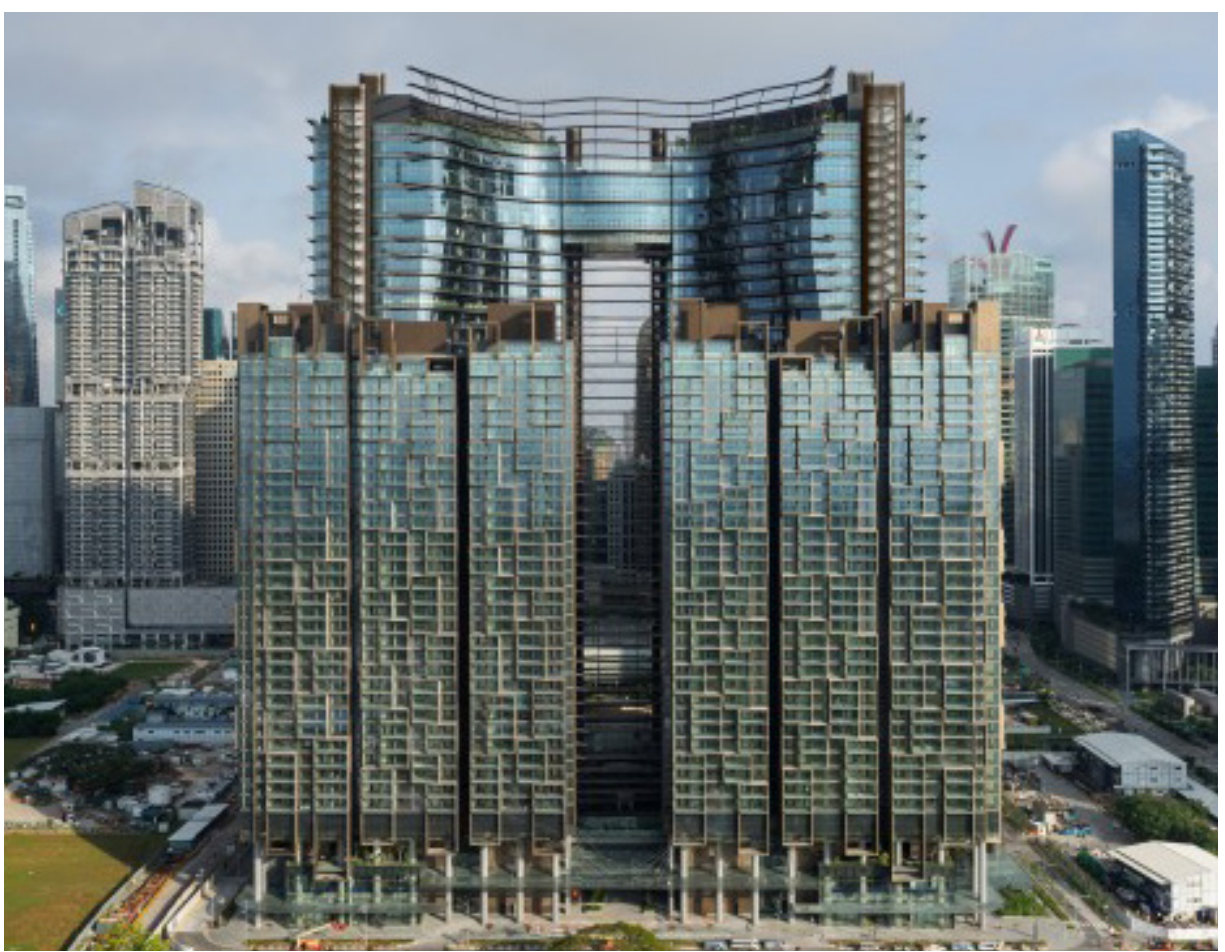

Figure 3.3.6: Marina one Complex (Uncommon multi floor public space and upper sky gardens)

Igenhoven Architects. "Marina One - The Skyscraper Center." CTBUH. Accessed November 28, 2019. http://www.skyscrapercenter.com/building/marina-one/16878.

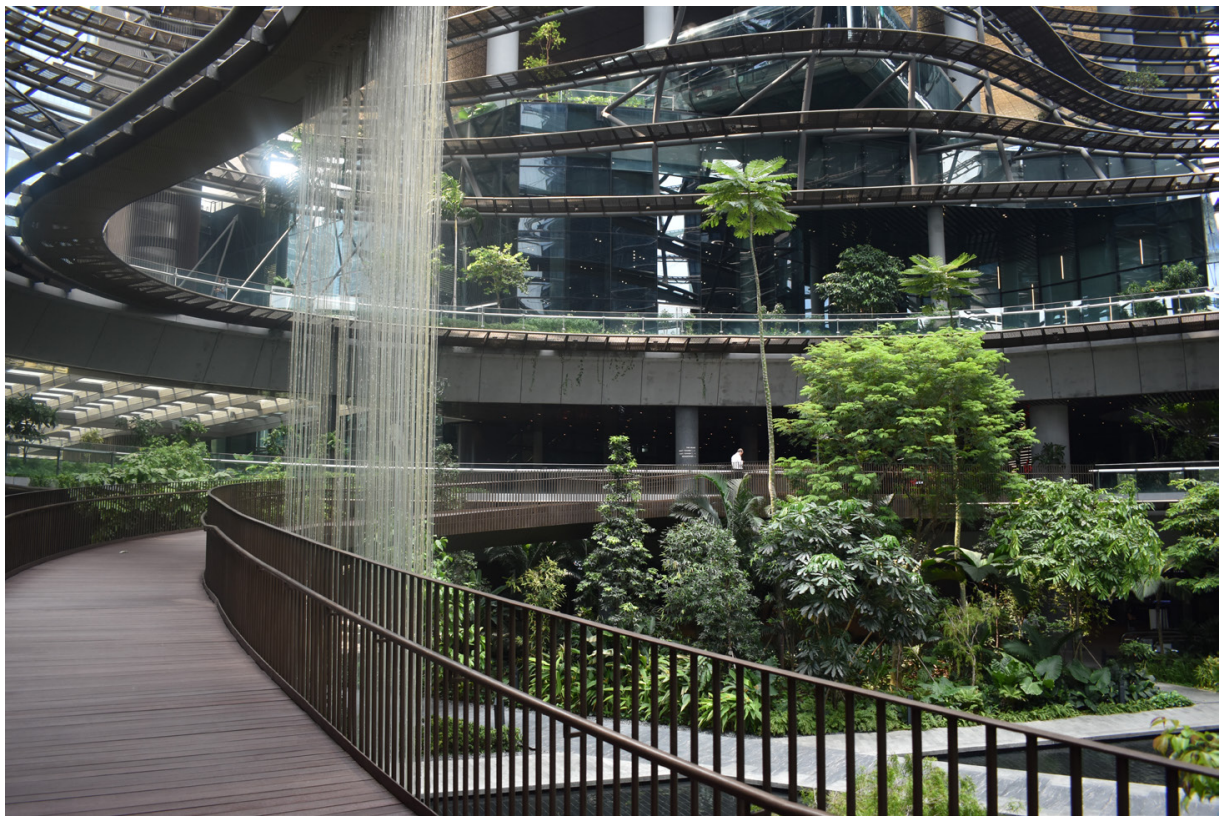

Figure 3.3.7: Internal view of multi-floor public space at Marina one Complex

Caskey,Alex, "Marina One", Singapore, Fall 2019 
this size has shifted away from the static, universal, fully resolved, neatly organized master plan models of the modernist period ${ }^{8}$. According to Joan Busquets, the contemporary approach to planning a site of this scale is to develop a framework of forward-thinking goals and objectives that helps govern future projects without restricting future changes?. Singapore is often considered to be at the leading edge when it comes to innovative urban planning strategies ${ }^{10}$. It is thus no surprise that the Urban Redevelopment Authority (URA) has attempted to plan the development of this region with clearly stated goals yet to limit the restrictions they impose on how these stated goals are achieved.

The stated goal the URA has for this site is the creation of a" dynamic urban neighbourhood" with a wide variety of integrated land uses active streets, and public places with active programming, to provide "diversity of experiences"11.

The URA has left the new development zone largely unrestricted so as not to limit the creativity of future designers. In the Master Plan Zoning Map for Marina South (Figure 3.3.8) the URA assigned a white zoning designation to the area. All new sites are zoned for undetermined mixed-use indicating that the allowable uses of the sites would be explored on a

$8 \quad$ Busquets, Joan. "Line 9" Cities X Lines: A New Lens for the Urbanistic Project.p.282-311 Edited by Felipe Correa and Harvard University. Reprint. S.I.: Nicolodi, 2007.

$9 \quad$ lbid

10 Webb, Flemmich. "Sustainable Cities: Innovative Urban

Planning in Singapore." The Guardian, October 11, 2012, sec. Guardian Sustainable Business. https://www.theguardian.com/sustainable-business/ sustainable-cities-innovative-urban-planning-singapore.

Wong, Tai-Chee, Belinda K. P. Yuen, and Charles Goldblum, eds. Spatial Planning for a Sustainable Singapore. New York: Springer, 2008.

11 Urban Redevelopment Authority. "Our Downtown." Urban Redevelopment Authority. Accessed November 28, 2019. https://www.ura. gov.sg/Corporate/Planning/Master-Plan/Regional-Highlights/Central-Area/Downtown. 


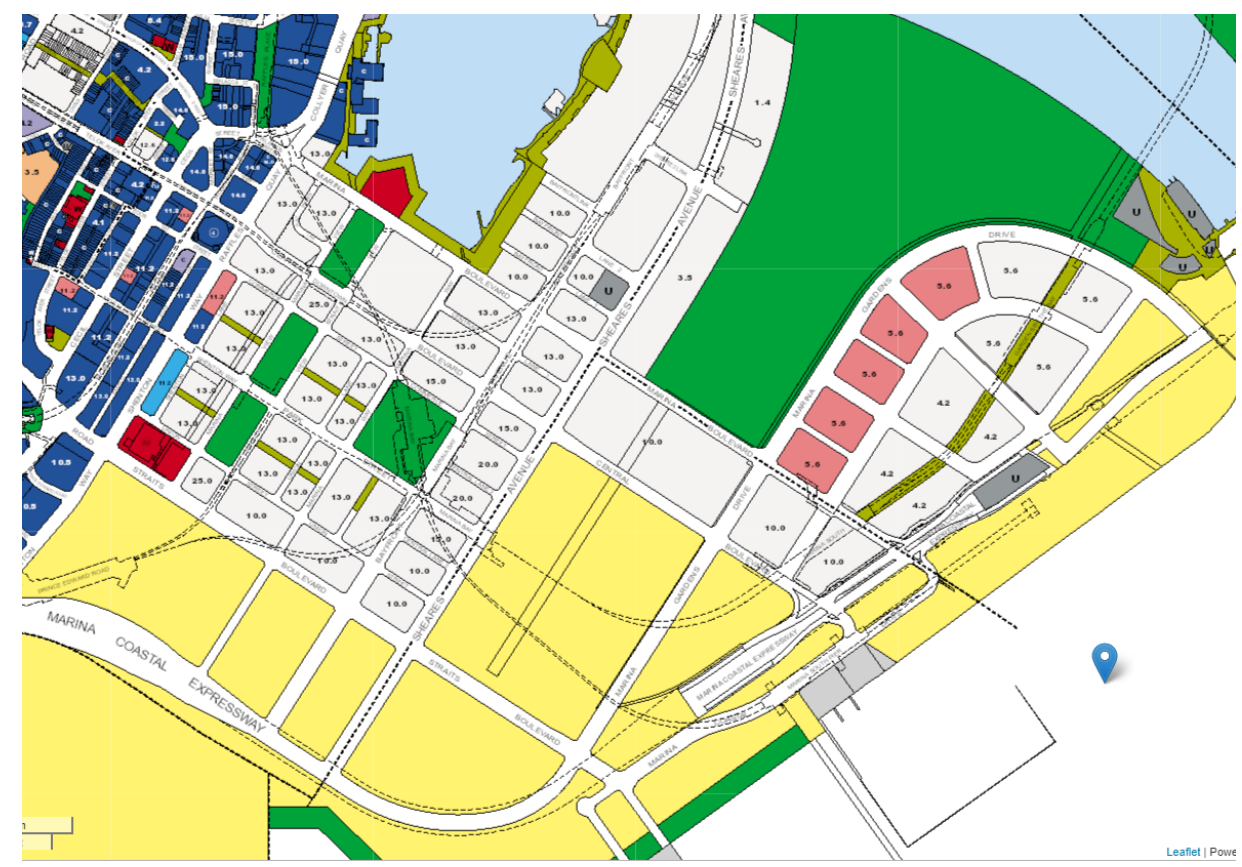

Figure 3.3.8: Urban Redevelopment Authority Zoning Map of proposed site showing "white" unde termined rmined mixed use lots (White), Green spaces (Green), and reserved land for future development (Yellow).

"URA SPACE." Accessed November 28, 2019. https://www.ura.gov.sg/maps/?service=MP.

site by site basis at a future date ${ }^{12}$.

Even though the URA has made a conscious effort to maximize future design flexibility, the current plans for Marina South still have embedded within them, preconceived notions of a final product. Section 1.3 discussed factors that contributed to the widespread proliferation of the common tower. One factor was the extension of the practice of zoning into the third dimension that gave plots of land volumetric constraints. While the Master Plan of the URA has not specified design or use of individual sites, it has imposed restrictions that necessitate future development for the Marina South region to conform to a common tower format. These include the established, street lines, lot divisions, plot ratios, and other regulations. The default approach to verticality

Ng, Benjamin, and Ching Tuan Yee. "Marina Bay: The Shape of Things to Come," 2007. https://www.csc.gov.sg/articles/marina-bay-theshape-of-things-to-come. 


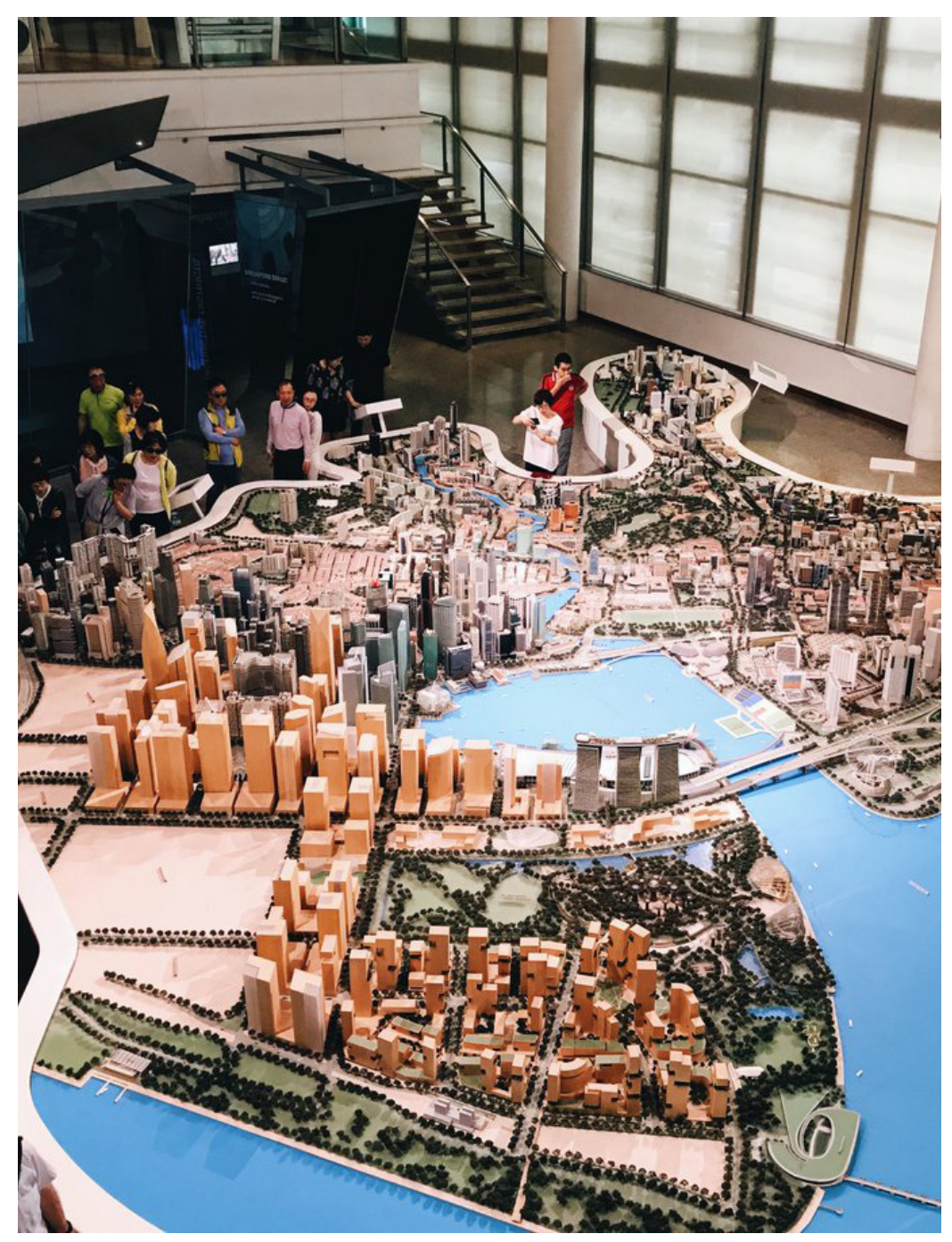

Figure 3.3.9: Image of model showing planned massing on the Marina Bay South site at URA office. The model leaves the south western area open for future development.

Little Day Out. "Singapore City Gallery: Glimpse In Singapore's Urban Future." Little Day Out (blog), April 1, 2017. https://www.littledayout.com/2017/04/01/singapore-city-gallery-urban-future-ura/.

is clearly visible in a scaled model of the entire downtown region located in the office of the Urban Redevelopment Association of Singapore (Figure 3.3.8-9 $)^{13}$. The model features each existing building

13 The URA developed the model with partial involvement of

Kenzo Tange

Xue, Charlie Q.L., and Jing Xiao. "Japanese Modernity Deviated: Its Importation and Legacy in the Southeast Asian Architecture since the 1970s." 


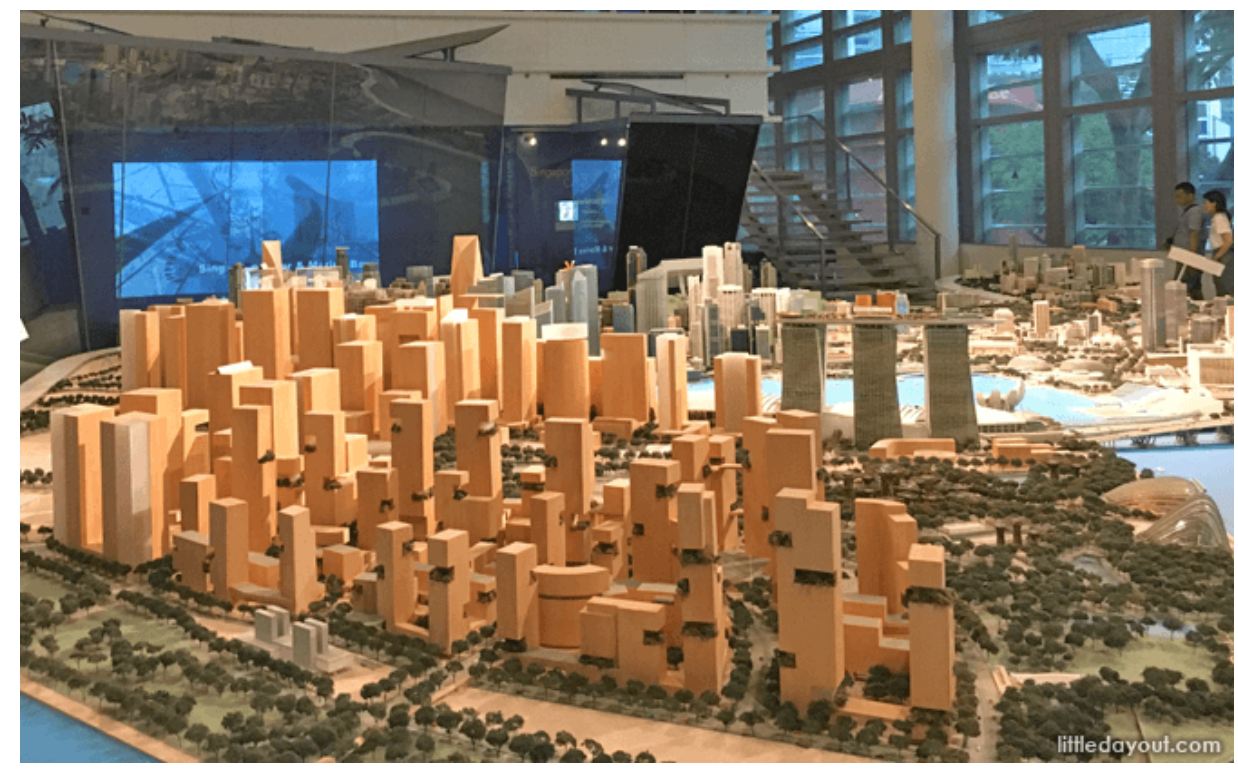

Figure 3.3.10: Image of model showing planned massing on the Marina Bay South site at URA office.

Little Day Out. "Singapore City Gallery: Glimpse In Singapore's Urban Future." Little Day Out (blog), April 1, 2017. https://www.littledayout.com/2017/04/01/singapore-city-gallery-urban-future-ura/.

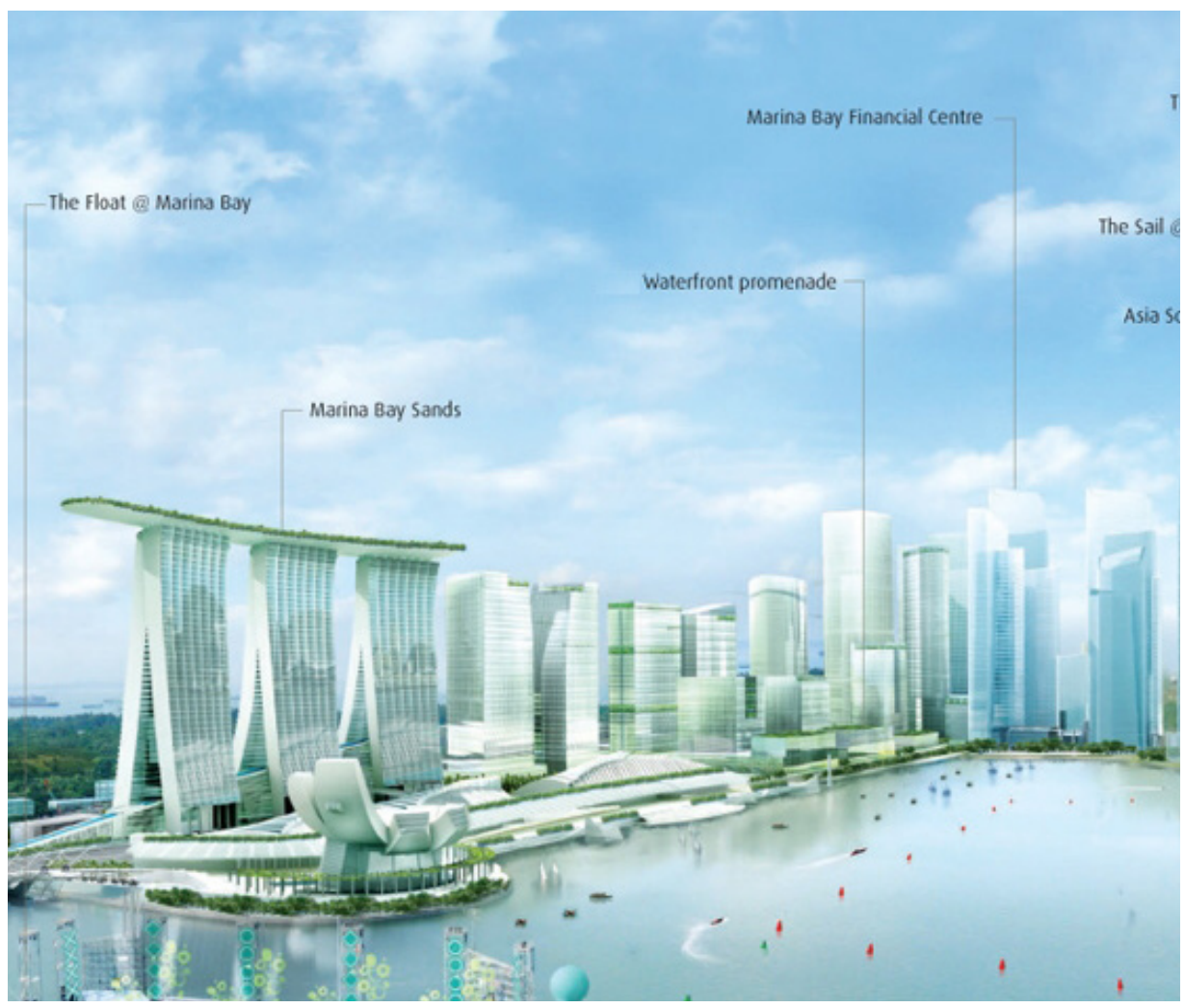

Figure 3.3.11: Conceptual render of the site from the North East of released by the URA showing future common tower typed developments

Mixed Development at Marina View (Upcoming Launch). "Mixed Development at Marina View ( Upcoming Launch)." Accessed November 29, 2019. https://marinaviewcondo.net/marina-viewsite-954. 
in great detail while block wood massing models stand-in for future developments. The Marina South site is prominently featured on the model. Its volume is filled with non-descriptive masses of towers. The models leave the southwest corner free as this area is for development further into the future. It is likely, however, that at some point, the URA will add masses of towers to this portion of the model as well. The preconceived notion of towers is further supported by conceptual renders of the area, including Figure 3.3.10 that shows the space between Marina One and the Marina Bay Sands complex being filled in with common towers.

Before anything in Marina South is ever really designed, the future architects and urban designers will be forced to work within the imposed limitations of the common tower typology. At best, their innovations will result in "uncommon" towers similar to what has been produced elsewhere in the city. As explained in Section 2.5, within their height, even the best "uncommon" towers are incapable of supporting URA's stated goal of "dynamic urban neighbourhoods" with a wide variety of integrated land uses active streets and public places with active programming and "diversity of experiences"14.

\section{An Extension to Singapore: A Volumetric Approach}

The contextualized design research portion of this thesis investigated the following two research questions:

What if instead of defaulting to common towers, the development of Marina South, the large

Habitat International 44, no. 2014 (2014): 227-36.

$14 \quad$ Urban Redevelopment Authority. "Our Downtown." Urban Redevelopment Authority. Accessed November 28, 2019. https://www.ura. gov.sg/Corporate/Planning/Master-Plan/Regional-Highlights/Central-Area/Downtown. 
scale extension to the city, was reimagined as a volume? (Figures 3.3.14-15)

Could this extension to the city foster the "decent density" the city is seeking, not just at the ground plane but throughout its entire volume? (Figures 3.3.17-22)

Compared to the default approach, a volumetric approach to vertical development that focused on the principles of walkability would be more in alignment with the URA's stated goals for Marina South. The design research challenge was to develop an alternative scheme for such a large scale development.

The goal of this volumetric scheme for Marina South was not to go as far as to actually design the future development. In Designing Cities Without Designing Buildings, Jonathan Barnett claims that contemporary large scale master planning should focus only on the elements of concern to the public while leaving the buildings to be developed at will within the established controls ${ }^{15}$. The controls then become the way to safeguard public interests without the need to over-specify design details. Controls establish territories for things such as pedestrian connectivity, circulation, public space, functionality, as well as reinforcing the character and experience of the city. Johnathan Barnnet's logic suggests that the goal of a large scale development scheme, like that for Marina South, should be focused on the control elements ${ }^{16}$.

Originally, the implications of establishing controls were intended to be investigated through exploratory physical modelmaking, as has been the main method of research utilized throughout design research.

15 BARNETT, Jonathan. (1974) "Designing Cities Without Designing Buildings" in Urban Design as Public Policy: Practical Methods for Improving Cities. New York: Architectural Record Books/McGraw-Hill, p.29-68.

16 Ibid. 

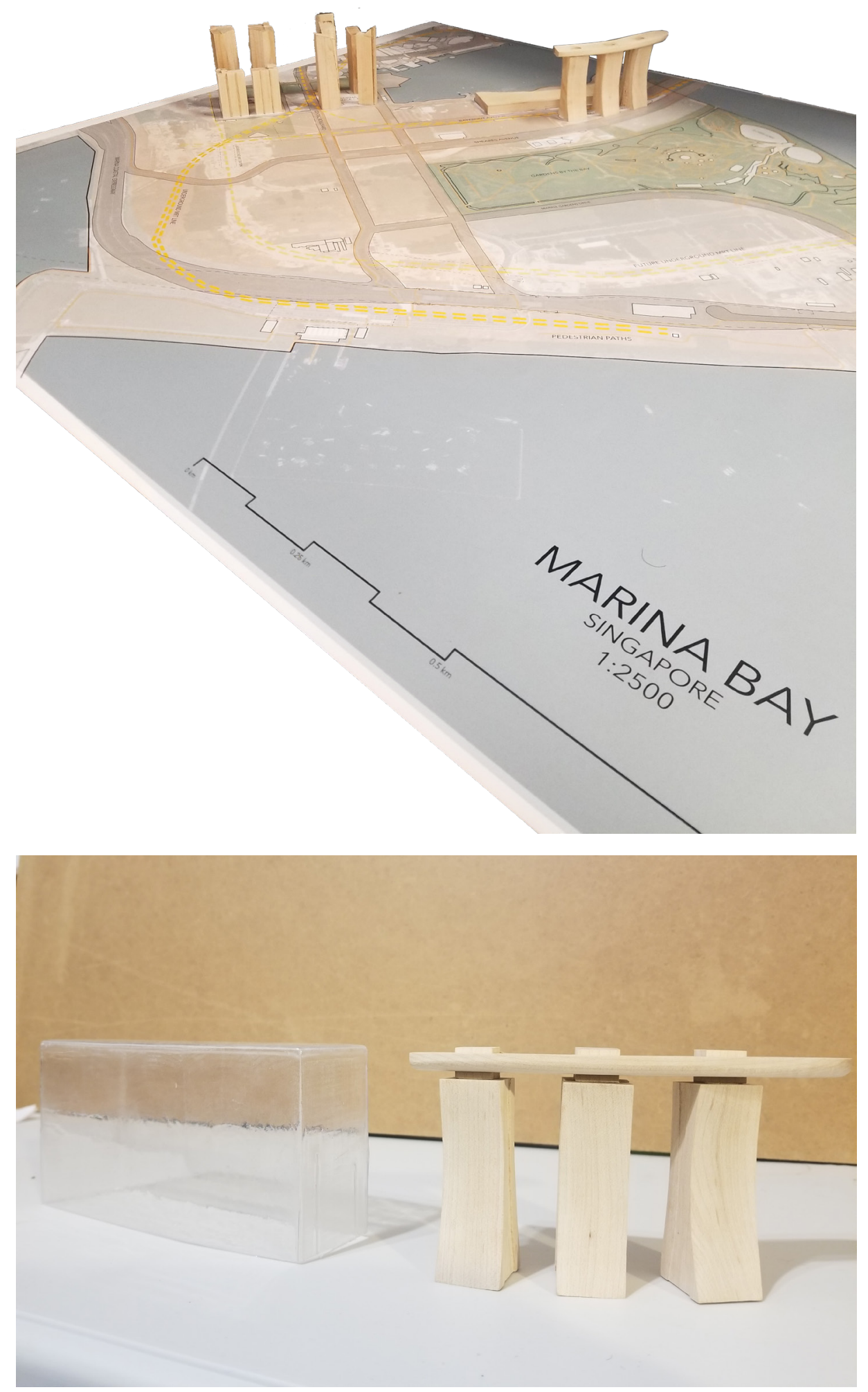

Figure 3.3.12-13: The beginning of a 1:2500 model that was intended to explore the proposed site as undefined volumes instead of towers. Depicted here is an acrylic volume, next to a massing model of the Marina Bay Sands Complex. The model was not completed because of Covid-19 related interruptions. 


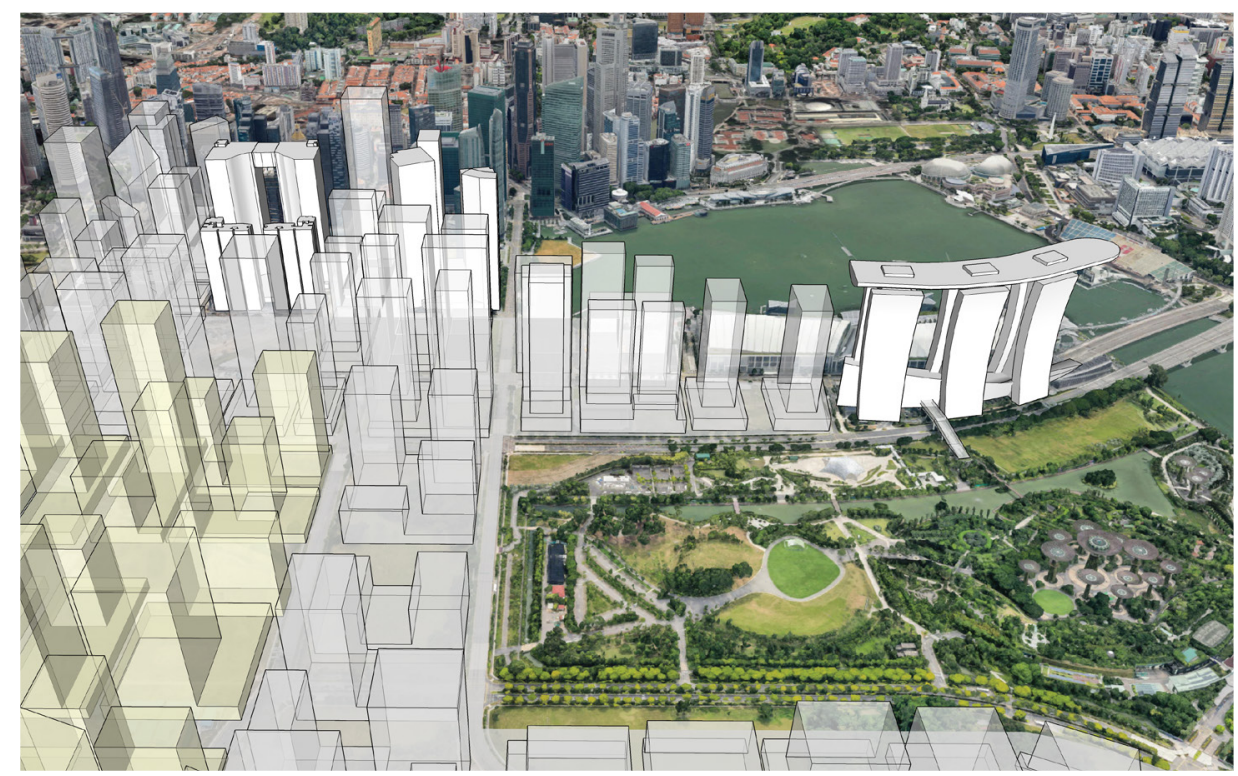

Figure 3.3.14: Marina South site with future common tower development massing

Figures 3.3.12-13 depict the beginning of a 1:2500 model that was intended to explore the potential for the site as a volume.

Due to Covid-19 complications, the physical model was never completed. Instead, the Marina South volume was explored through a digital model depicted in Figures 3.3.14-22.

The model imagery shown here diagrammatically illustrates how establishing controls within the volume of the site could shape future development. The controls include :

Wind Corridors (Figure 3.3.16): Due to its tropical climate Singapore is laid out in such a manner as to channel cooling breezes from the ocean through the city ${ }^{17}$. Volumetrically, in the financial district, this occurs along the corridors or street canyons ${ }^{18}$. It is therefore imperative that the development of the Marina South volume maintain corridors 17 Reibling, Dylan. City of the Future: Singapore. National Geographic, 2018. 4:06- 4-47 https://www.youtube.com/watch?v=xi6r3hZe5Tg

$18 \quad$ Ibid. 


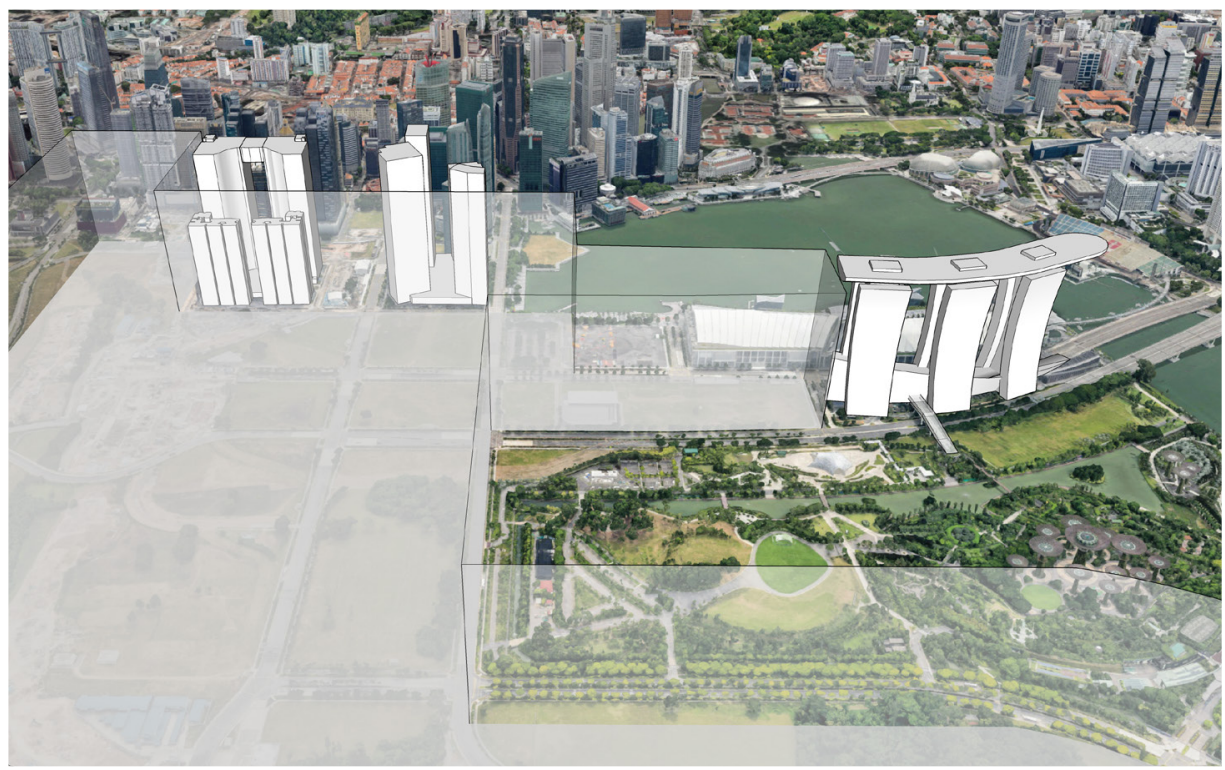

Figure 3.3.15: Marina South site as a volume

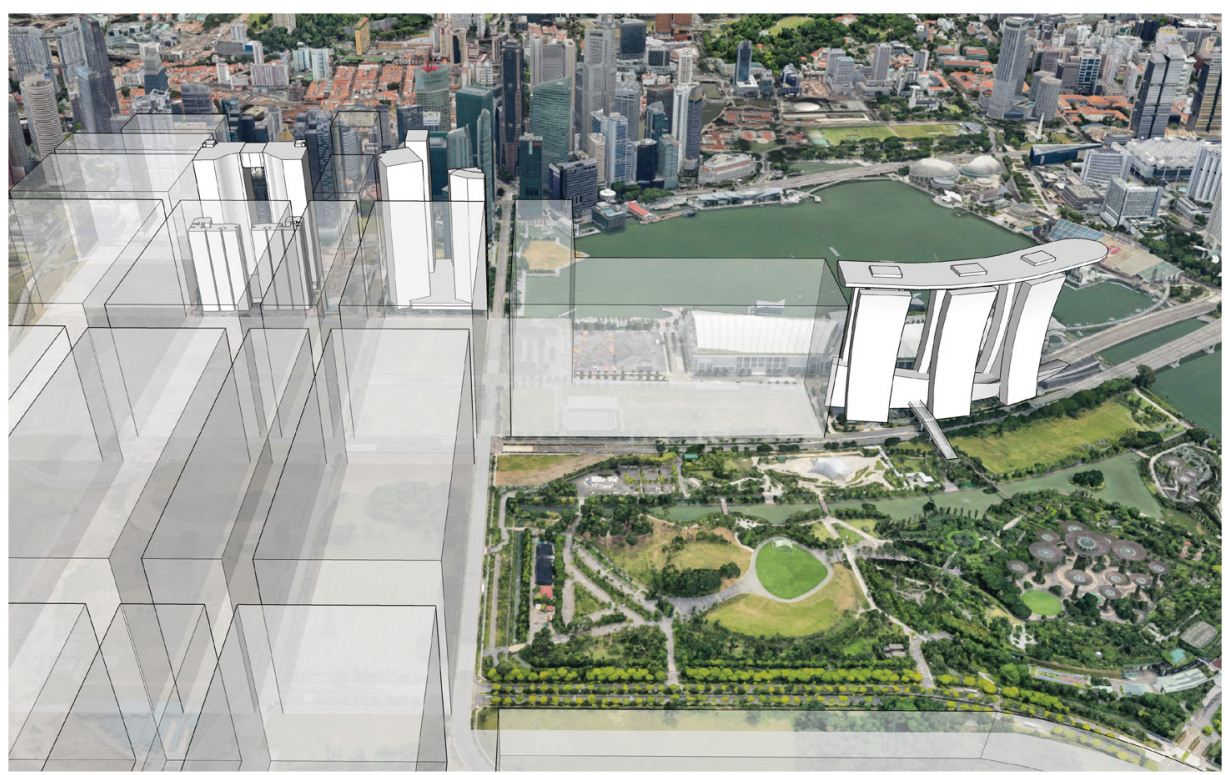

Figure 3.3.16: Marina South site as a series of volumes broken up by controls that allow ocean breezes to continue to cool the city

through which cool breezes can travel.

Main Streets (Figure 3.3.17): The site context could inform important axes through the site suitable for main streets. Along the ground plane, axes might be informed by the roads cutting through the site. In its height, axes could be informed by the three 


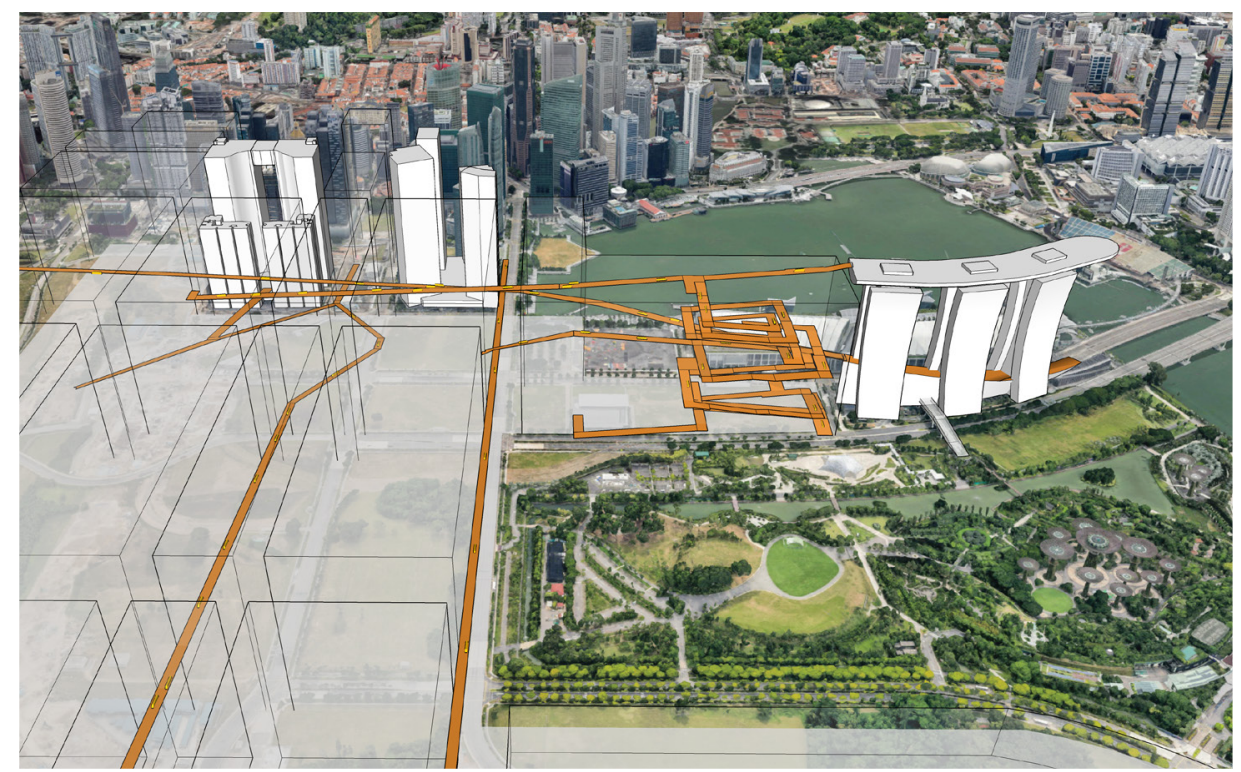

Figure 3.3.17: Controls for main streets along major axes though the site

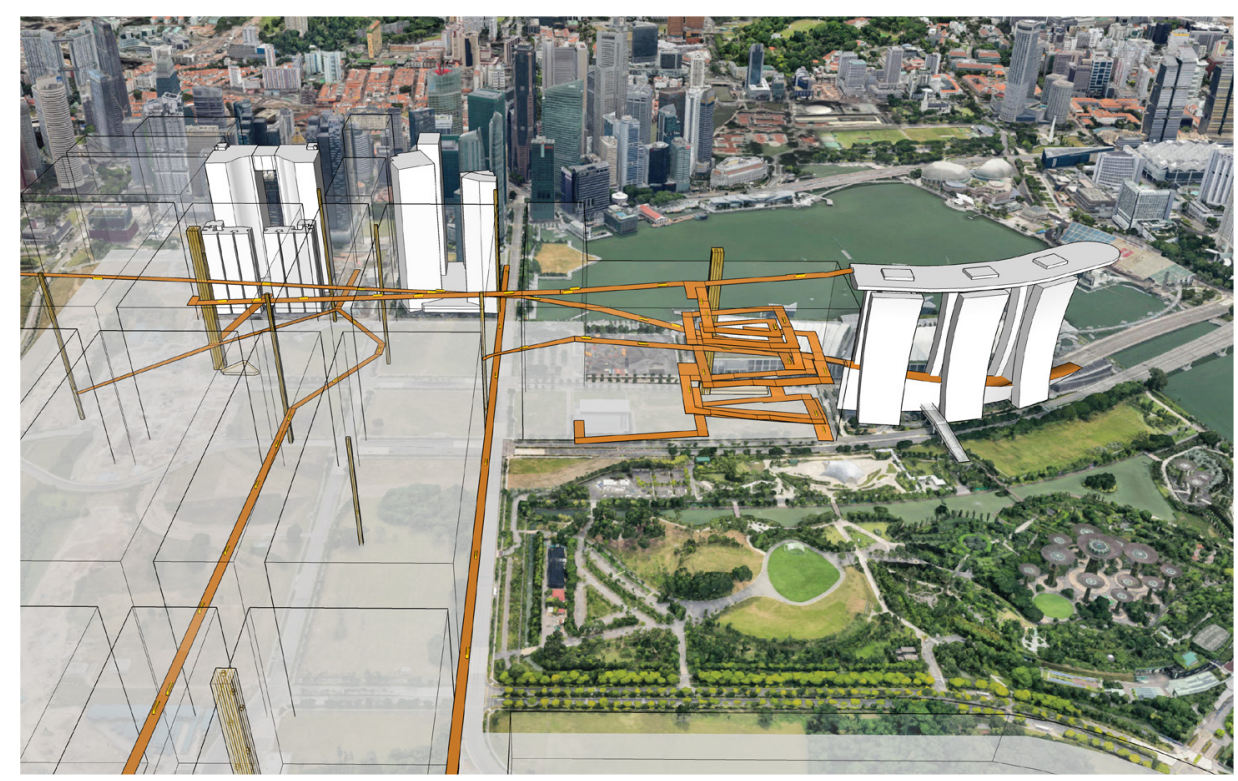

Figure 3.3.18: Controls for public transit along surfaces, and vertical cores, some of which context into existing MRT stations

surrounding complexes. The towers of the Marina Bay Sands complex are connected at the bottom by a volume that slopes down to the ground at the northeast end of the site. If the roof of this volume could be activated, it would inform a diagonal axis through the volume of the site. Similarly, the sky 


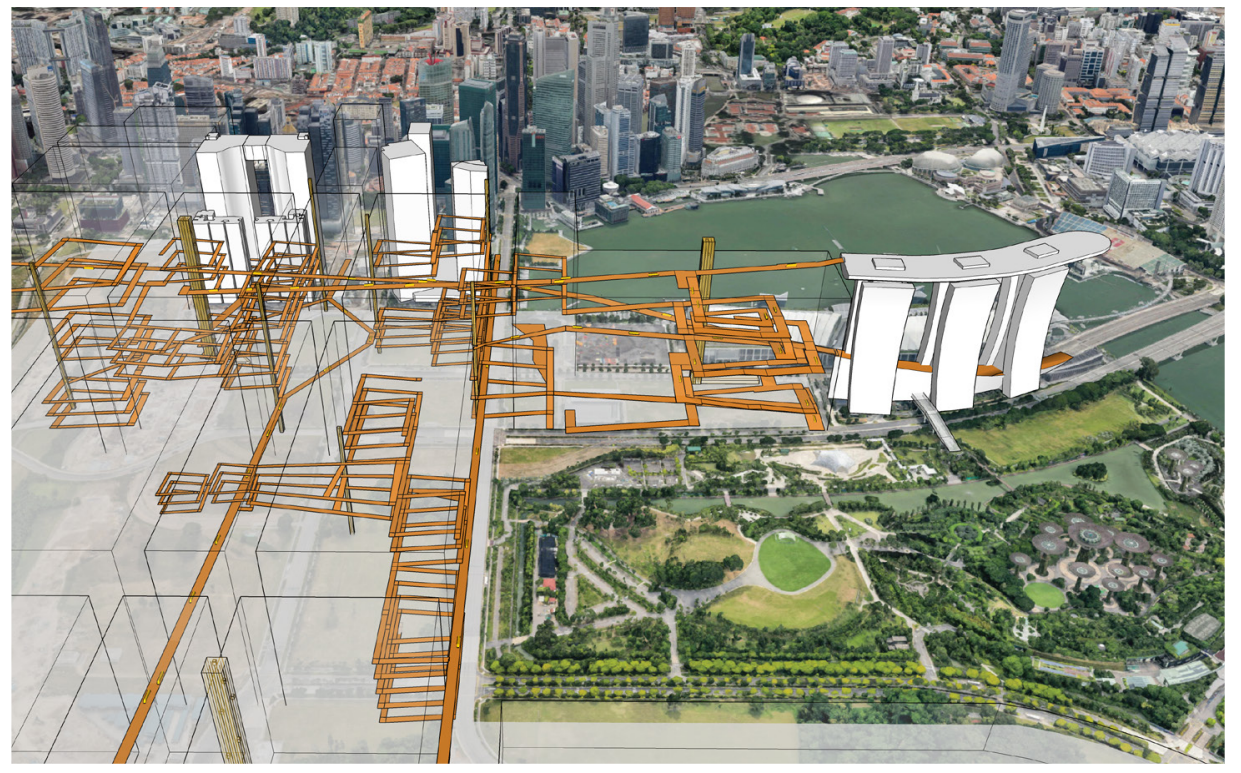

Figure 3.3.19: Controls for a three dimensional network of walkable blocks and localized neighborhoods

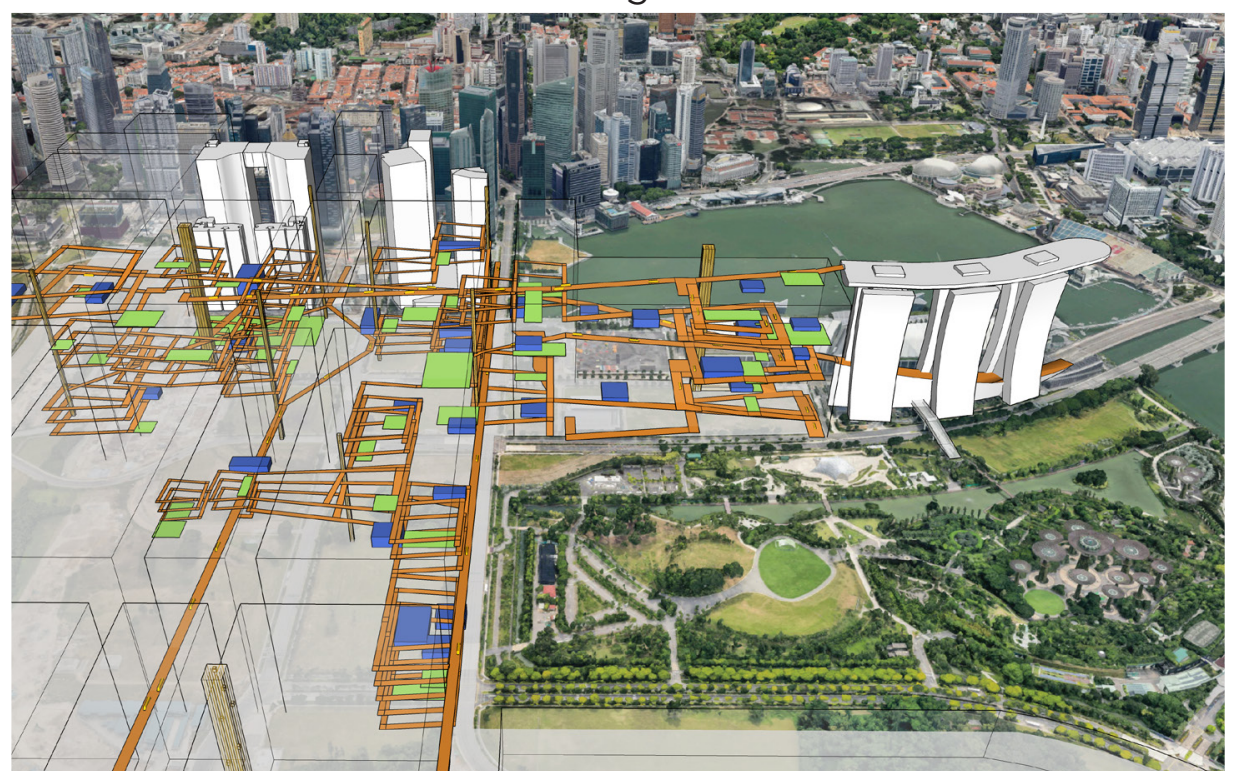

Figure 3.3.20: Controls for anchors like parks, schools, libraries, cultural centres, recreation facilities, "Skymarks" and other spaces

park of the Marina Bay Sands complex could be engaged by the extension of other major axes.

Public Transit (Figure 3.3.18): Mainstreets could be planned to be equipped with surface transit systems, while major vertical transit systems could link into existing MRT hubs. Minor forms of vertical 


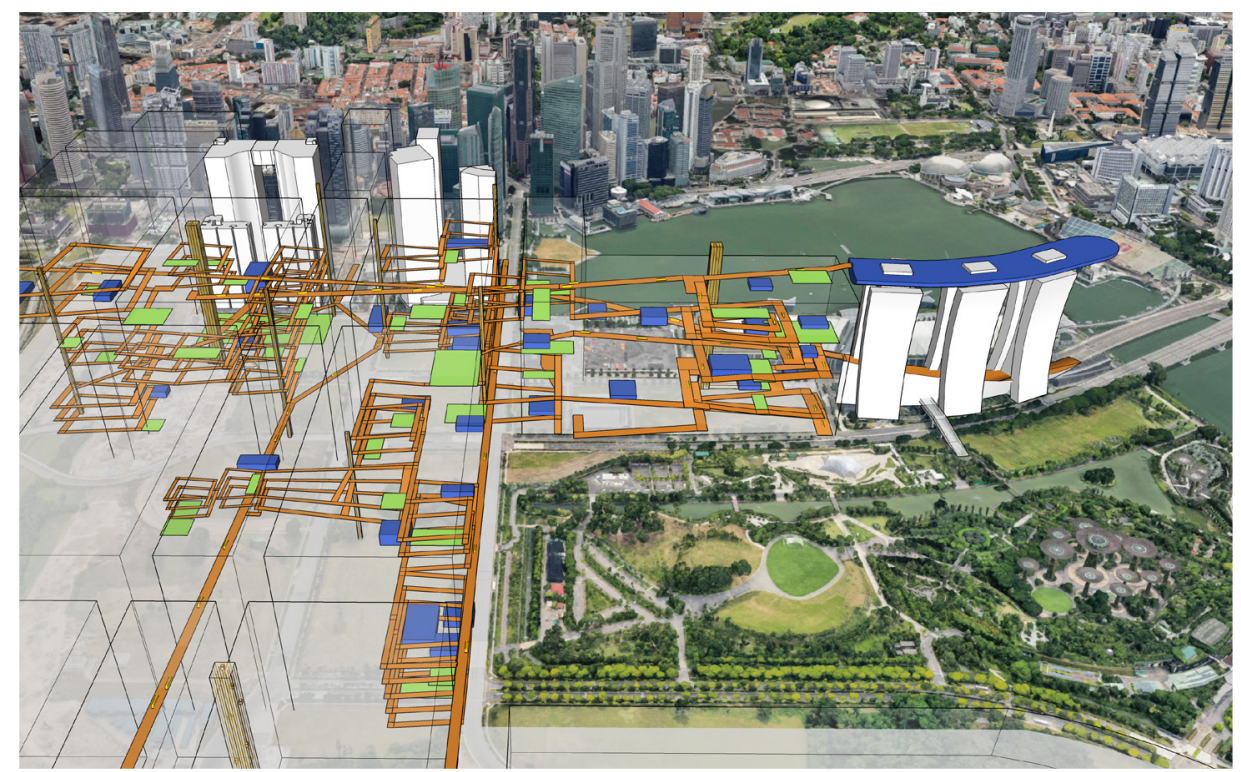

Figure 3.3.21: Activation of existing anchors like the sky park of Marina Bay Sands

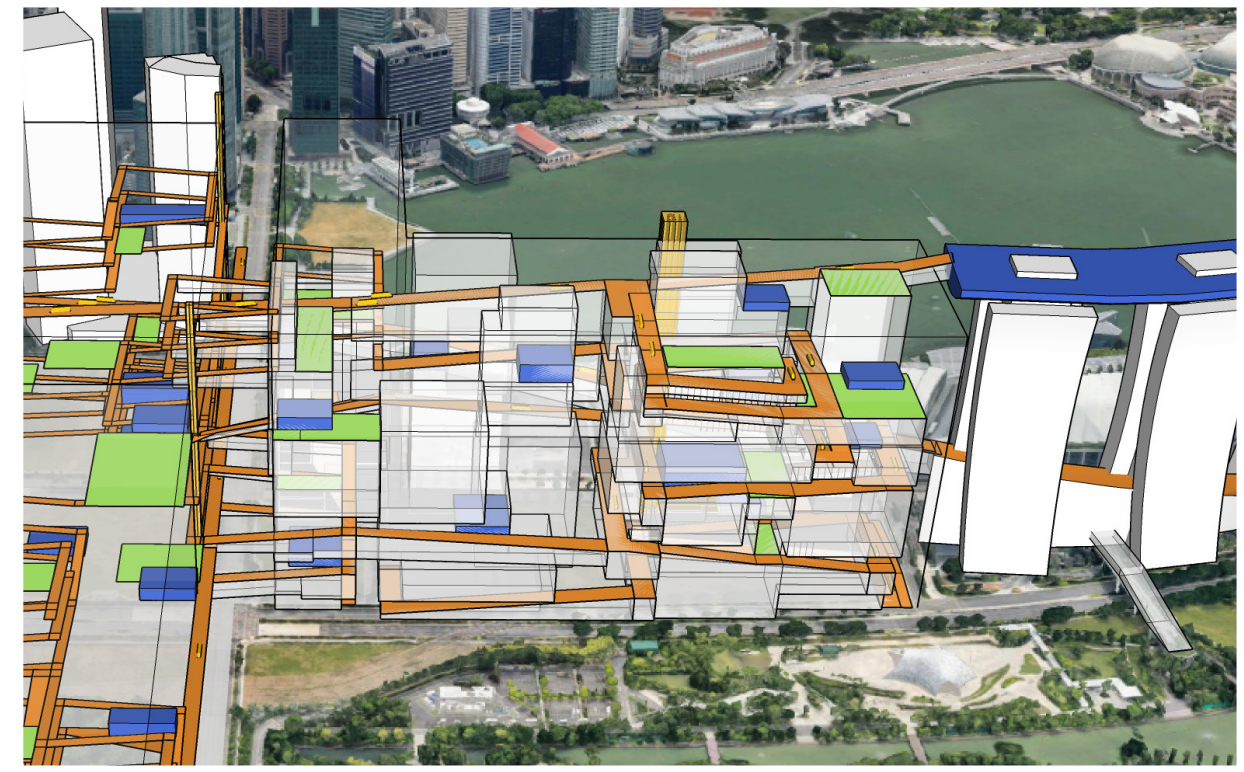

Figure 3.3.22: Future development shaped by established controls and designed to support necessary infrastructure

transit could support the system at strategic locations that link multiple datums together.

Blocks \& Neighbourhoods (Figure 3.3.19): The main axes and the transit infrastructure could link together vertically walkable blocks in a three-dimensional network. Plans for localized densities that support localized amenities could 
provide the underlying basis for vertically walkable neighbourhoods.

Anchors (Figure 3.3.20): As described in Section 2.5 , the physical connection of a volumetric network of walkable neighbourhoods would need to be bound together by plans for the strategic placement of anchors like parks, schools, libraries, cultural centres, recreation facilities, "Skymarks" and other spaces. This could be accompanied by plans for the activation of destinations within the existing vertical context, like the Marina Bay Sands sky park (Figure 3.3.21).

All of these controls could preemptively be established through the volume of the Marina South region. In this scenario, the controls that secure the extension of the public flow system that could foster a walkable network of neighbourhoods would be what would shape the future development of the site (Figure 3.3.22).

\section{Conclusion}

The Marina South region is planned as a large scale addition to downtown Singapore. The current limitations imposed within preliminary planning are not in alignment with the stated goals of the site. Instead, they unintentionally force future designers into an urban design "straight jacket" by imposing the limitations of the default approach to verticality.

This section illustrated how using controls, a volumetric approach to planning this extension of the city could be used to shape future development in a way that could better support goals for the site. Controls for the extension of the public flow system and placement of anchors could produce future developments capable of supporting an entire 
network of "dynamic urban neighbourhoods"19 throughout the entire volume of the site.

The following sections explore some of the forms of vertical architecture that a volumetrically planned Marina South region could support. Section 3.4 highlights how the desired qualities of "dynamic urban neighbourhoods ${ }^{120}$ can already be found in many of Singapore's historic shophouse regions. It then explores how the ability of these regional forms of urban design that foster a rich urbanity could be reinterpreted, adapted, and extended into the height of the city.

19 Urban Redevelopment Authority. "Our Downtown." Urban Redevelopment Authority. Accessed November 28, 2019. https://www.ura. gov.sg/Corporate/Planning/Master-Plan/Regional-Highlights/Central-Area/Downtown.

20 ibid 


\section{SINGAPORE SHOPHOUSES}

The previous section established a scheme for extending the Marina South region of Singapore into its own volume. The following two sections investigate how the urban characteristics of Singapore's historical districts could be reinterpreted and utilized as a part of this vertical extension of the city. This section explores the vertical adaptation of Singapore's livework shophouse typology.

\section{Background}

The shophouse is an architectural typology commonly constructed in Singapore from 1840 to 1960 that forms an important part of Singapore's built heritage ${ }^{1}$ (Figures 3.4.1-4). In this typology, residential areas sit atop a main-level that is traditionally used for commercial purposes. These narrow buildings are typically two to three stories tall, have common party walls, and together form continuous masses of ten to twenty-five buildings that line full city blocks ${ }^{2}$. A key characteristic of the shophouses in South East Asia that differentiates them from similar typologies found

$1 \quad$ Urban Redevelopment Authority. "The Shophouse." Urban Redevelopment Authority, 2020. https://www.ura.gov.sg/Corporate/Get-Involved/Conserve-Built-Heritage/Explore-Our-Built-Heritage/The-Shophouse.

$2 \quad$ Ibid.

Personal observation of maps imagery and drawings 


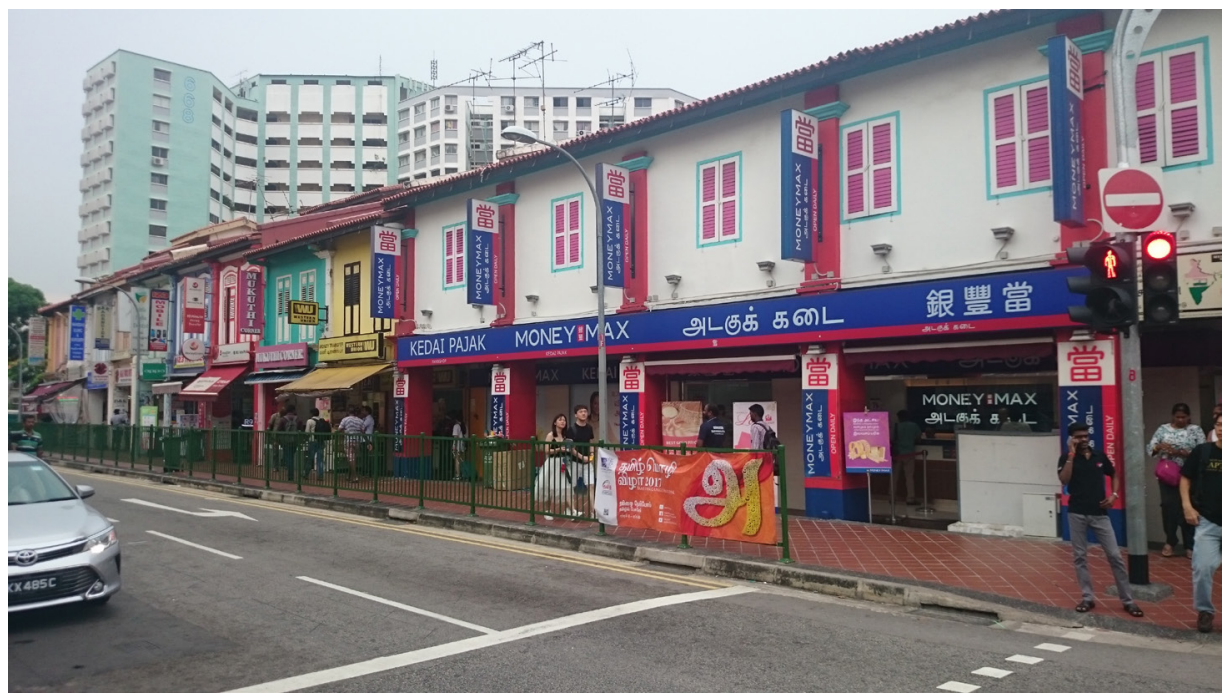

Figure 3.4.1: Singapore Shop Houses

Caskey, Alex "Shop Houses", Singapore, 2017

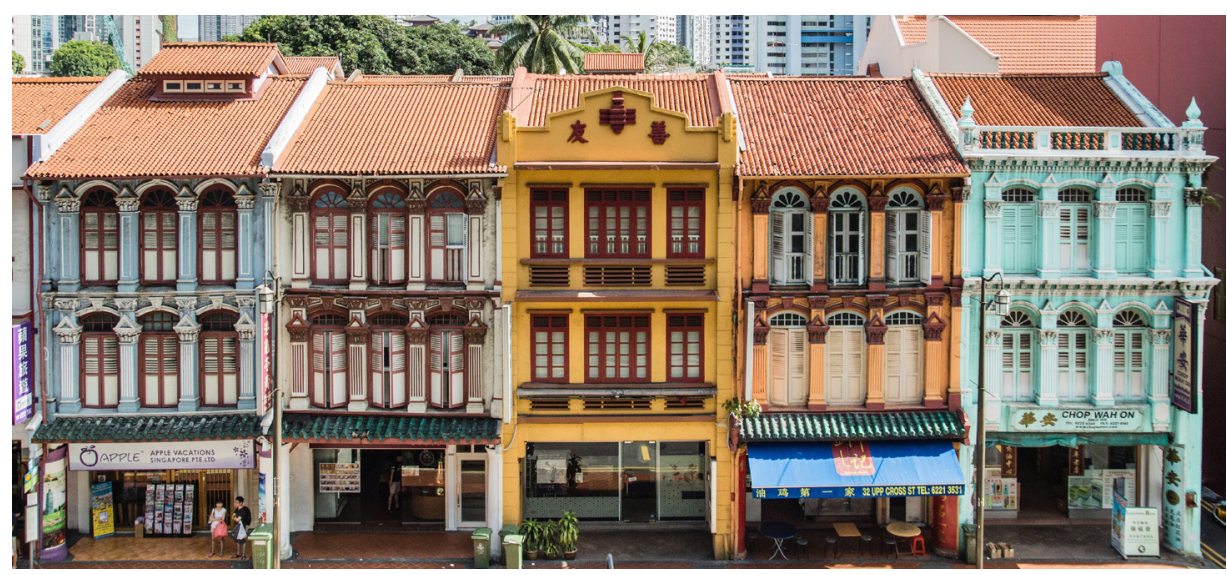

Figure 3.4.2: Elaborate Facades of Traditional Shophouses ZDL. "Singapore Traditional Shophouses." Shutterstock.com, June 3, 2017. /image-photo/ singaporejun-3-2017singapore-traditional-shophouses-652831135.

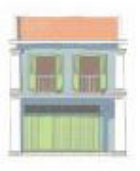

Early Shophouse style
$1840-1900$

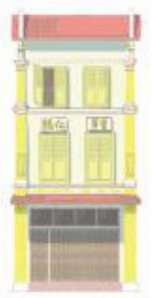

First
Transitional
Shaphose
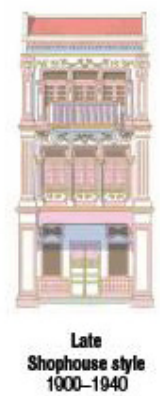

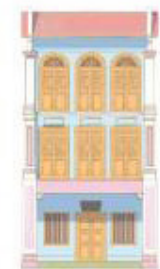

Second Transitional
Shophouse style

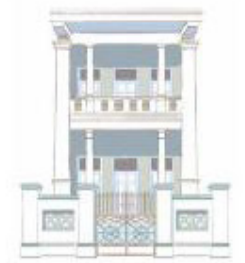

Art Deco Shophouse style

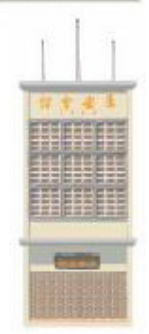

Modem Shophouse styl

Figure 3.4.3: Evolution of Singapore Shophouse Styles

Fan, Man Si. "Sense of Identity through Preservation of Singapore's Built and Natural Heritage ASIAN CITIES RESEARCH." University of Hong Kong, December 21, 2015. https://fac.arch.hku. hk/asian-cities-research/sense-of-identity-through-preservation-of-singapores-built-and-naturalheritage/. 


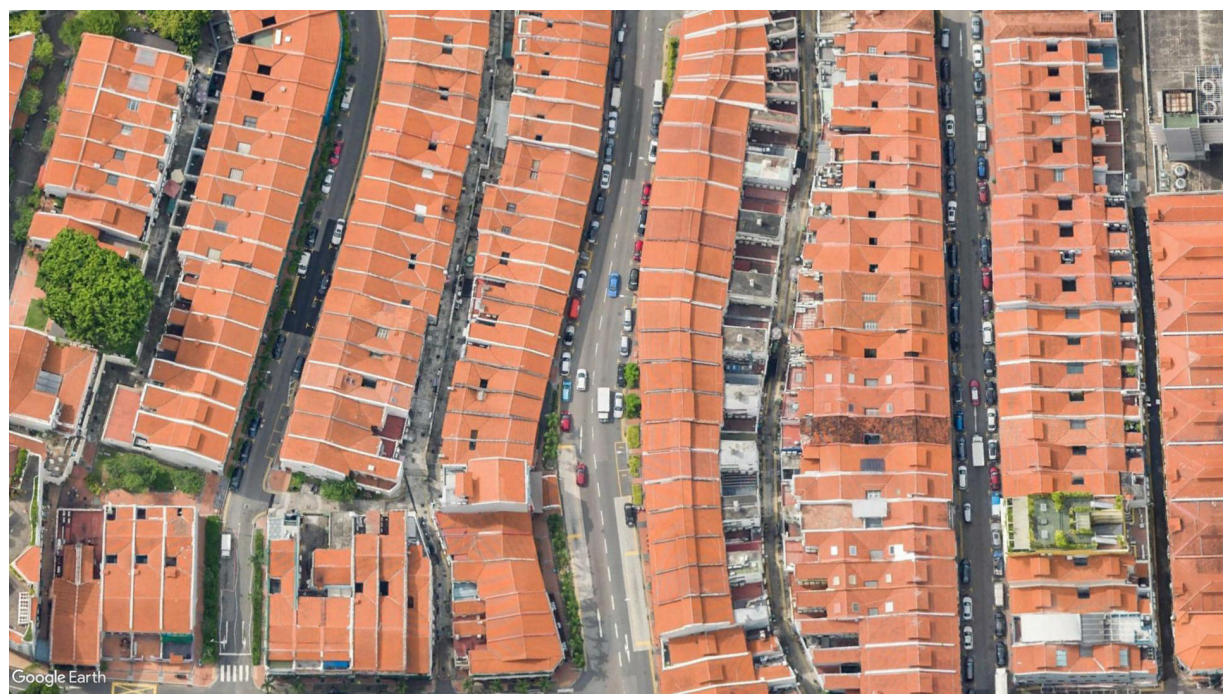

Figure 3.4.4: View of Singapore shophouses from above in Northern part of Tanjong Pagar.

Google Earth Imagery

elsewhere is the " 5 foot way" . This is a sheltered area along the commercial level of the building, set in from the façade that, together with neighbouring shophouses, forms a covered colonnade (Figure 3.4.5). For much of its history, these lively colonnades lined the streets of Singapore and moulded the city into one large commercial emporium ${ }^{4}$.

This typology has its roots in southern China in the Guangdong and Fujian provinces ${ }^{5}$. These areas were

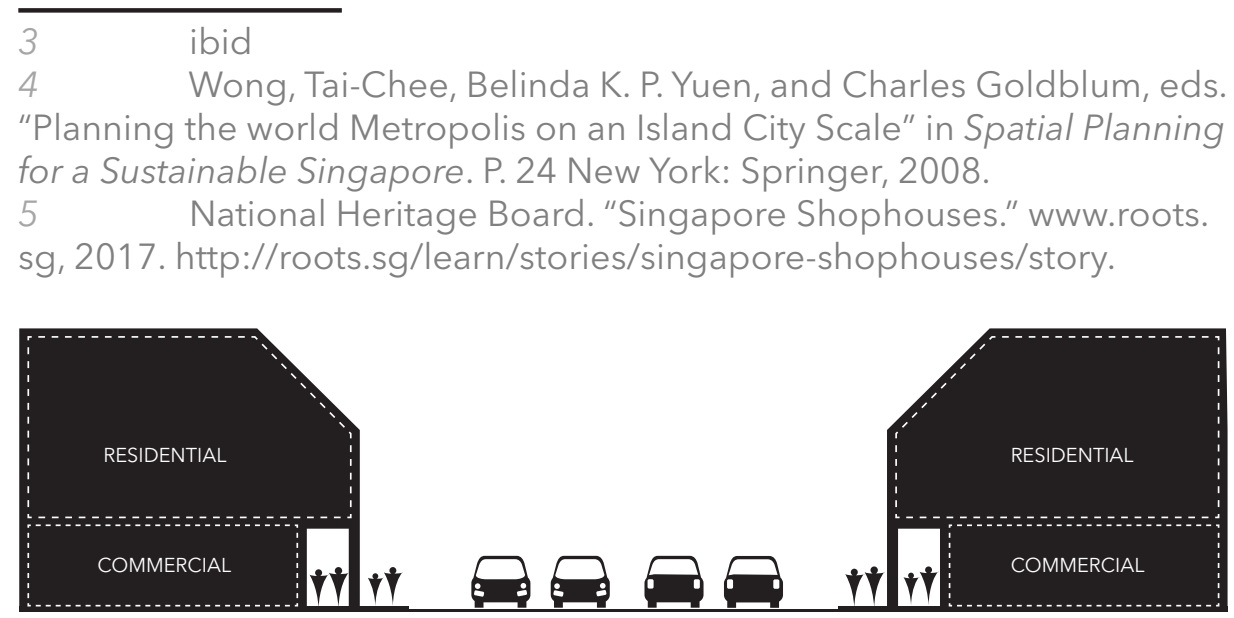

Figure 3.4.5: Typical section of contemporary Singapore street in a remaining shophouse district that shows the distinctive " 5 foot way" 


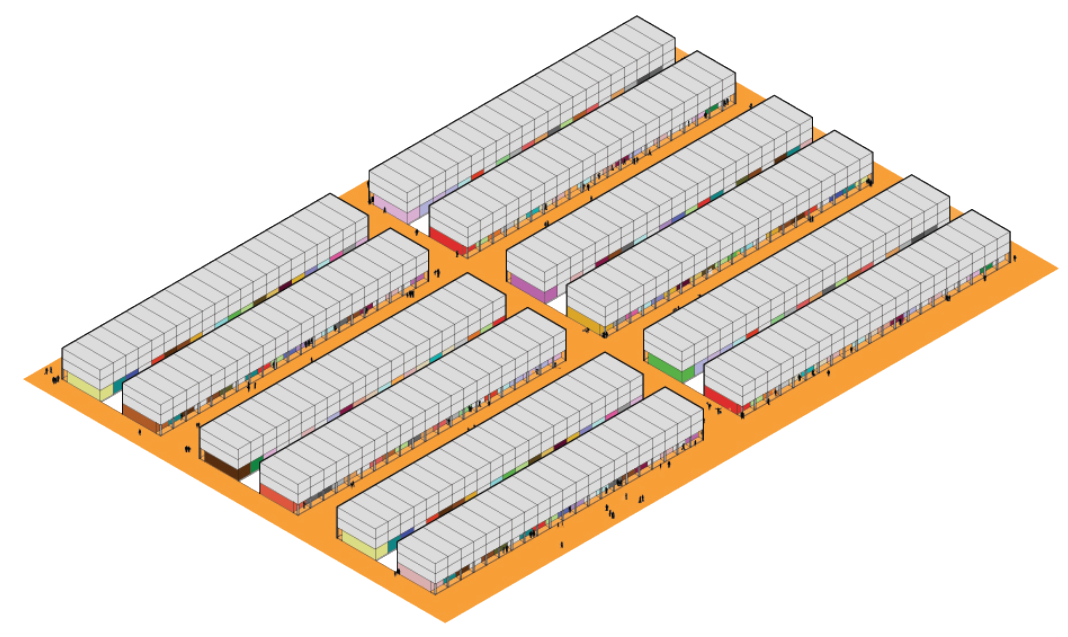

Figure 3.4.6: Axonometric representation of a typical shophouse district. Streets lined with shops made for an interesting, walkable live-work environment.

the origin of many of Singapore's early Chinese immigrants ${ }^{6}$. The widespread proliferation of shophouse complexes in Singapore can be dated to just after the implementation of the Jackson Plan by Sir Stamford Raffles in 1822 ${ }^{7}$. Shophouses from this era were mostly ornamented in a British Colonial style. The Singapore shophouse would go on to adapt many styles representative of the evolving history of Singapore. (Figure 3.4.3)

As mentioned in Section 3.1, after WWII, existing housing was incapable of supporting Singapore's growing population. Many were living in poor conditions and makeshift settlements ${ }^{8}$. There were

\footnotetext{
$6 \quad$ lbid.

$7 \quad$ Wong, Tai-Chee, Belinda K. P. Yuen, and Charles Goldblum, eds. "Planning the world Metropolis on an Island City Scale" in Spatial Planning for a Sustainable Singapore. P. 24 New York: Springer, 2008.

$8 \quad$ Zareen, B. "Singapore's Public Housing : From Slums to HighRise." 99.co, August 2, 2016. https://www.99.co/blog/singapore/housing-yesteryear-singapore/.
} 


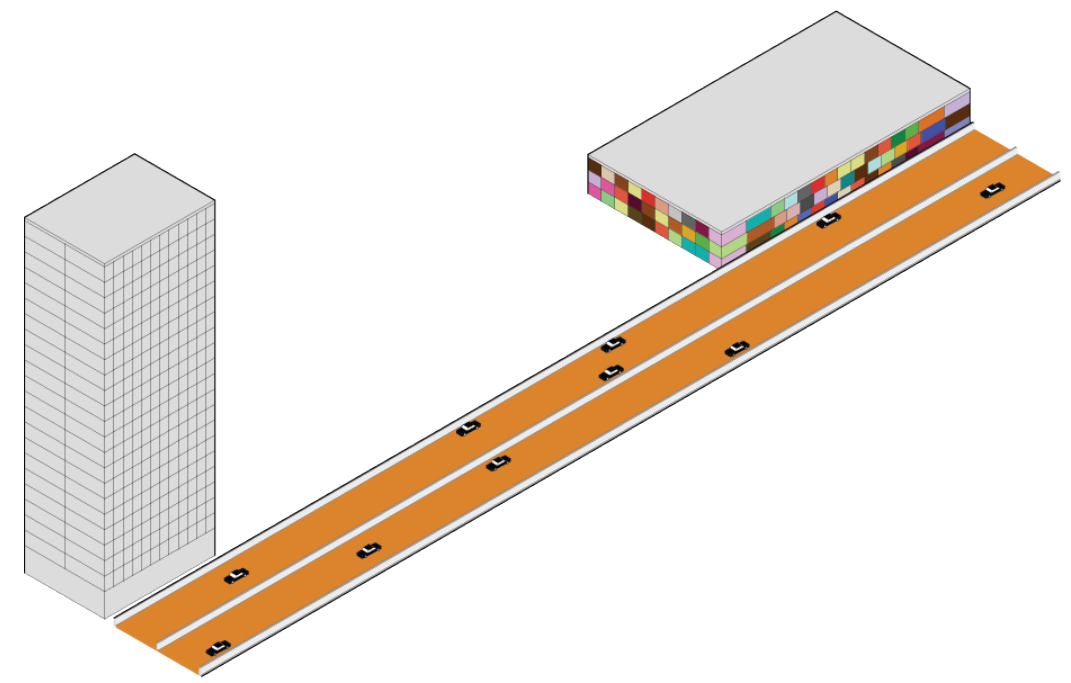

Figure 3.4.7: Singapore replaced shophouse districts with residential towers, hawker centers, and malls which physically divided living and working functions into separate destinations

very dense neighbourhoods with some areas having densities as high as 2500 people per hectare? Beginning in the early 1960s, urban renewal strategies led by the Housing and Development Board began relocating residence and conducting "slum clearance"10. This resulted in many of the shophouses being torn down ${ }^{11}$. Residents were relocated to housing blocks, and their commercial endeavours were concentrated into "Hawker Centers," malls, and other similar facilities. While these new typologies may have served a comparable function to shophouses( Figure 3.4.6), they effectively ended

\footnotetext{
Wong, Tai-Chee, Belinda K. P. Yuen, and Charles Goldblum, eds. "Sustainable City Centre Development" in Spatial Planning for a Sustainable Singapore. P. 33 New York: Springer, 2008.

10 Firley, Eric, and Julie Gimbal. "High rise building regulations in seven cities worldwide: Singapore" in The Urban Towers Handbook. P.234237 Chichester: Wiley, 2011.

11 Wong, Tai-Chee, Belinda K. P. Yuen, and Charles Goldblum, eds. Sustainable City Centre Development" in Spatial Planning for a Sustainable Singapore. P. 38 New York: Springer, 2008.
} 
the live-work style of living by physically separating the living and working environments (Figure 3.4.7) ${ }^{12}$. Commercial spaces became a destination rather than a continuous edging to the urban flow system.

Singapore is just one of many cities that abandoned its urbanity when demand for space forced the city to grow vertically. After the mid-20 th century, many cities adopted Towers in the Park urbanism. This meant organizing and separating a city's functions and putting activities like living and working into separate silos similar to the residential blocks and Hawker Centers.

The shophouse is important to this thesis because it is representative of the rich urbanity Singapore and other cities abandoned when they adopted the default approach to growing vertically. In areas of Singapore where shophouses still exist, they are energized public environments. The shophouse districts have many of the qualities that Jeff Speck claims contribute to walkable cities (see Section 2.5) including ${ }^{13}$ :

- Sticky Edges: the deep colonnades are interesting and engaging

- Firm Edges the continuity of row of shophouses frames the public space

- Variety: because of their small frontage, shophouses create visual interest through limited repetition and variety.

\section{Vertical Reinterpretation}

The main research focus of this thesis has been the vertical extension of the city. Section 2.5 explained how this was not about extending all aspects of existing cities, but the rich qualities of successful $\begin{array}{ll}12 & \text { Ibid. } \\ 13 & \text { Speck, Jeff. Walkable City Rules: } 101 \text { Steps to Making Better } \\ \text { Places. Washington, DC: Island Press, 2018. }\end{array}$ 
walkable, public spaces like Singapore's shophouse districts. This section of design research explored how the shophouse typology could be reinterpreted as a key component of a vertically walkable city.

The shophouse is an urbanistically dependent form of adapted space, and as such, it needs to be located directly adjacent to the public flow system. Figure 3.4 .8 shows how the shophouse could be reconfigured in accordance with a sloped surface of the public flow system. Shophouses would need to be staggered vertically to correspond with the 1:12 slope. This would allow the shophouses to remain level while maintaining adjacency to the public flow system. Steps or ramps would then need to be introduced between units along the colonnade.

The same diagram illustrates how at the ground plane rows of shophouses stand alone, but in a vertical context, they would also need to adapt to the layering of adapted spaces. This would require the shophouses to be supported on the structure of adapted space below and be structurally configured to allow them to support adapted space above. This would require aligning the structure in the real estate above and below with the party walls of the shophouses. Figures 3.4.9-10 are sectional diagrams that illustrate two of these conditions where

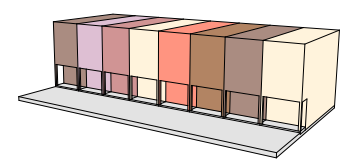

FLAT PLANE

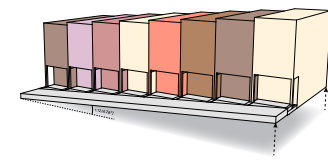

SLOPED PLANE

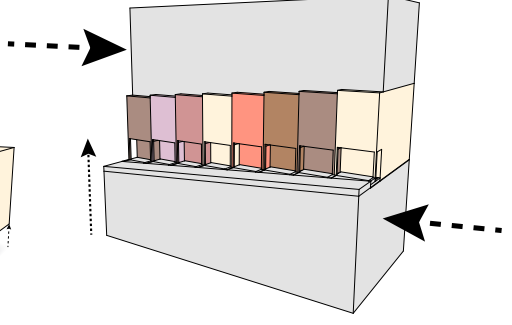

SANDWICHED WITHIN REAL ESTATE

Figure 3.4.8: Adaptation of shophouse typology to a vertically walkable city. 


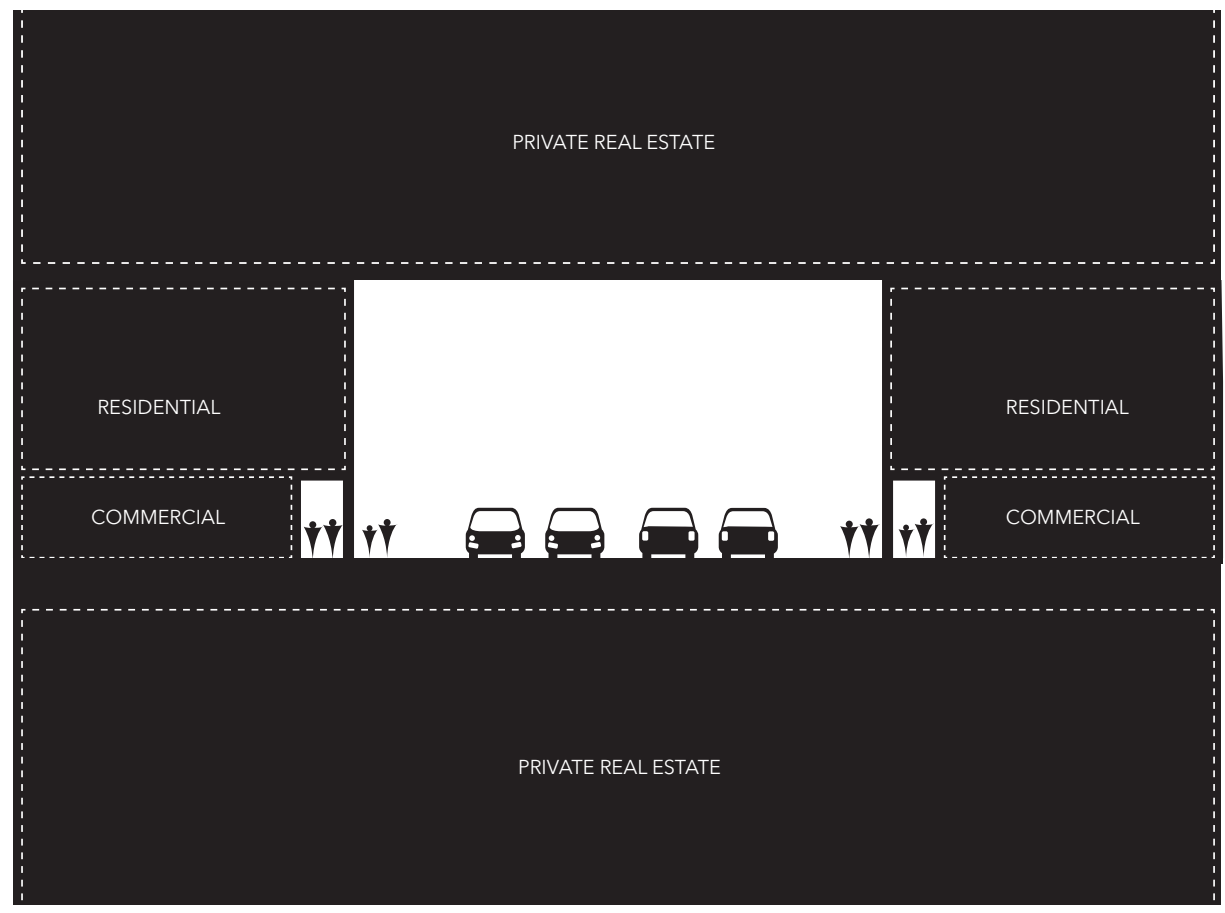

Figure 3.4.9: Street (public flow system) with shophouses on both sides. Shophouses and flow system are supported by real estate below, shophouses support real estate above.

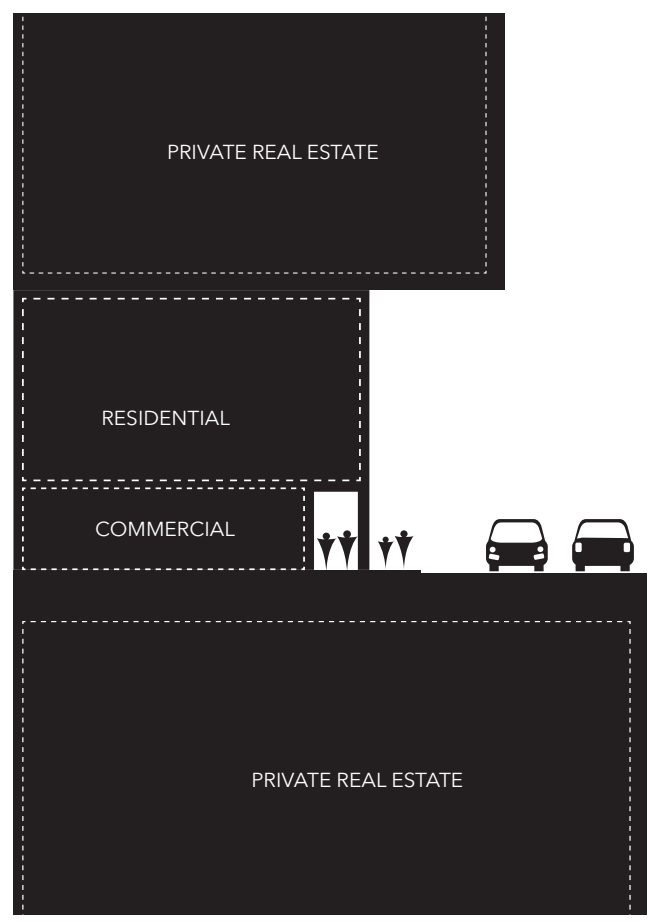

Figure 3.4.10: Street (public flow system) with shophouses on one side and void on the other. Shophouses and flow system are supported by real estate below, shophouses support real estate above. 


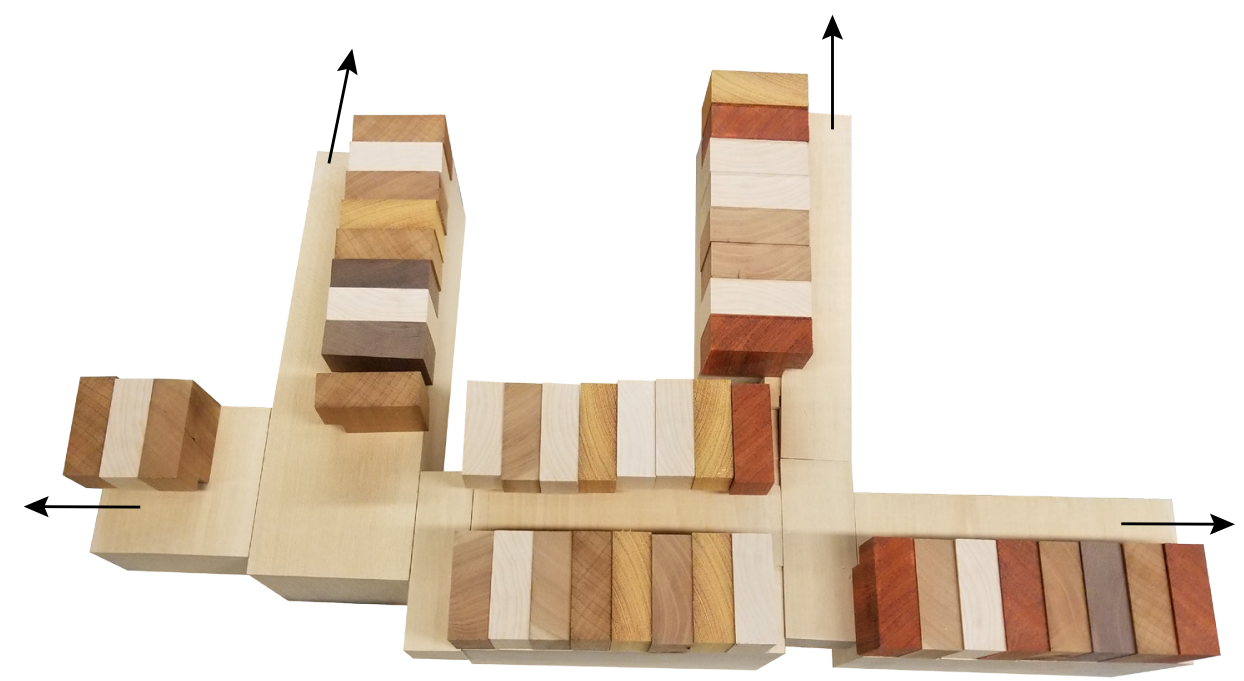

Figure 3.4.11: 1: 200 Floating shophouse street model from above showing various intersection conditions

shophouses line one or both sides of the street and are layered between adapted spaces above and below.

\section{Elevated Shophouse Street}

The 1:200 model shown in Figures 3.4.11-17 was an exploration of the urbanistic qualities of a shophouse street above the ground plane. The goal was to convincingly represent a space capable of supporting the energized public environments of traditional shophouse districts on the ground plane. The model is a series of fragmented intersecting streets lined with shophouses. Once the model was populated with small figures, the firm street edges (Rule 83) combined with the variety of shops (Rule 89), and the "sticky edge" of the 5 foot way (Rule 88), it became increasingly convincing, that this type of elevated space could serve as an engaging urban environment. 


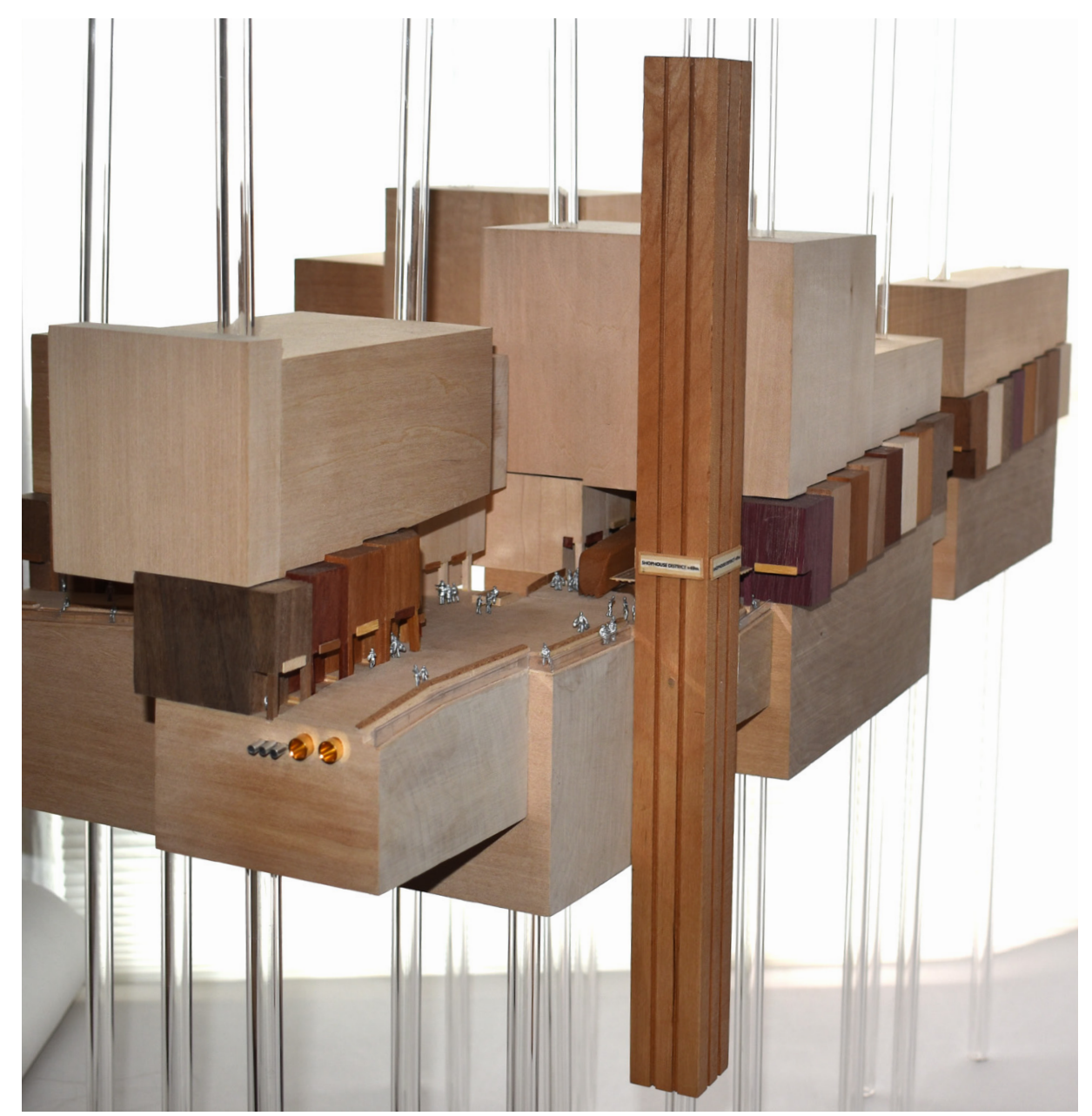

Figure 3.4.12: 1:200 raised shophouse street model. Shophouses are layered with inhabitable space both above and below

The 1:200 model was also an opportunity to explore other complementary urban design details. The street edge condition was one of these (Figure 3.4.13). Since at an elevated height, the edge of streets would offer unique vantage points, they demanded additional attention. Similar to how WOHA treated the sky-street edges at Skyville, the outer portion of the edge features a lowered pedestrian path with a railing set down from the street. This detail was intended to allow for a leisurely observational area while also allowing those on the street to have a view unimpeded by railings (Figure 3.4.18).

Another urban design detail was the inclusion of 


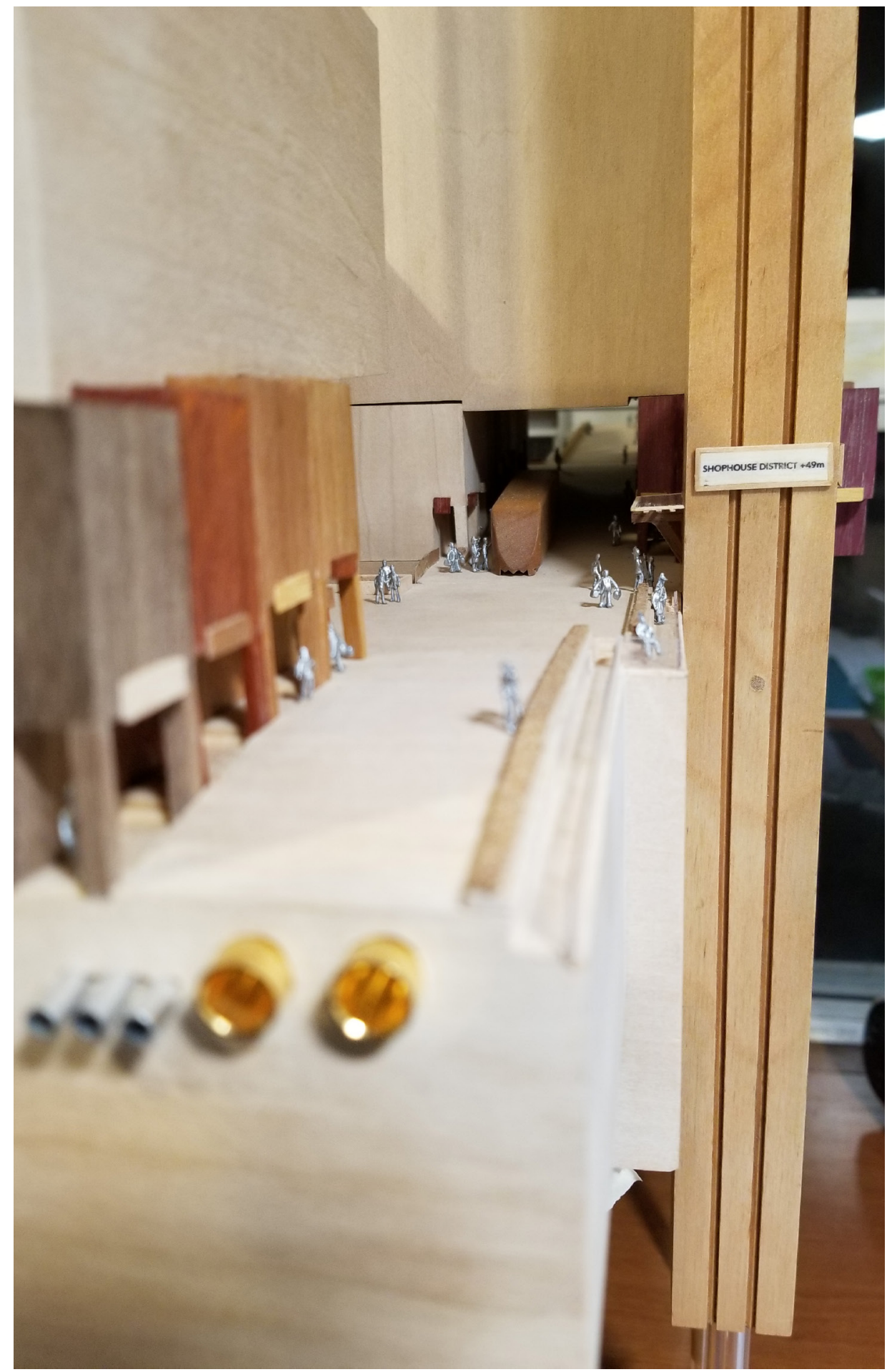

Figure 3.4.13: 1:200 raised shophouse street model showing both vertical and surface level transportation. Note the design of the edge condition where a lower observation path is separated from the street surface with a continuous planter. This is intended to take advantage of the unique conditions of a raised street by allowing the street surface to have a view out over the city that is unimpeded by a railing. 


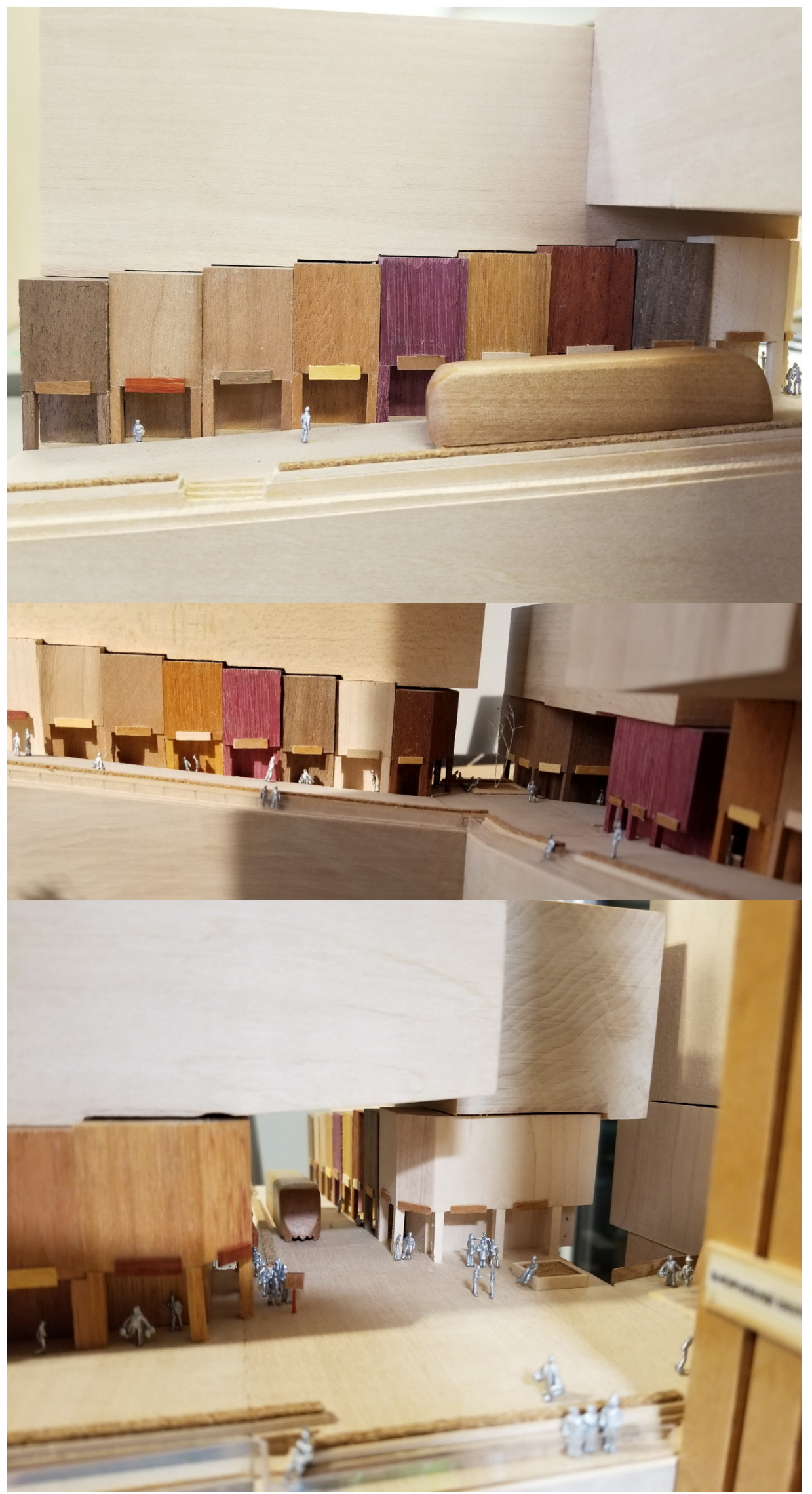


Figure 3.4.14-16 (opposite): 1:200 raised shophouse street model (various angles depicting street life)

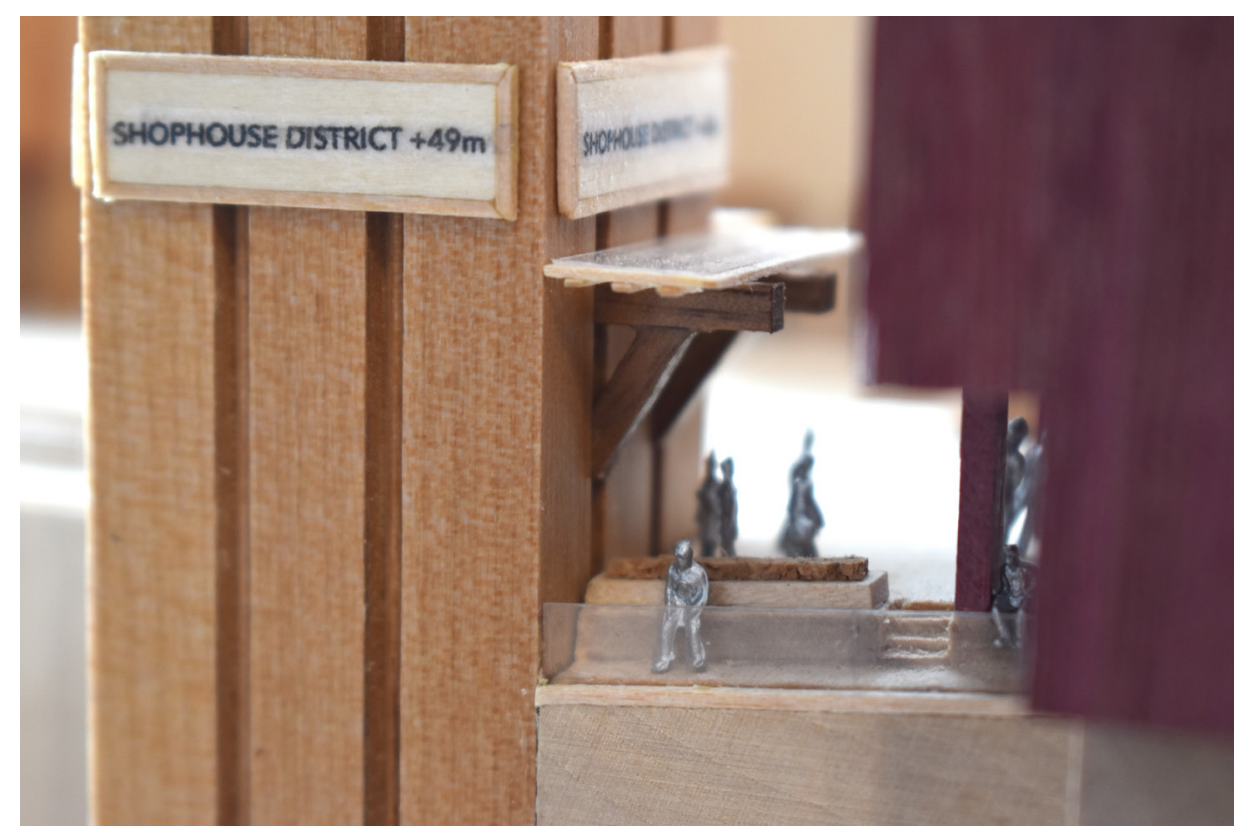

Figure 3.4.17: 1:200 raised shophouse street model. Small 'parket" at vertical transit waiting area.

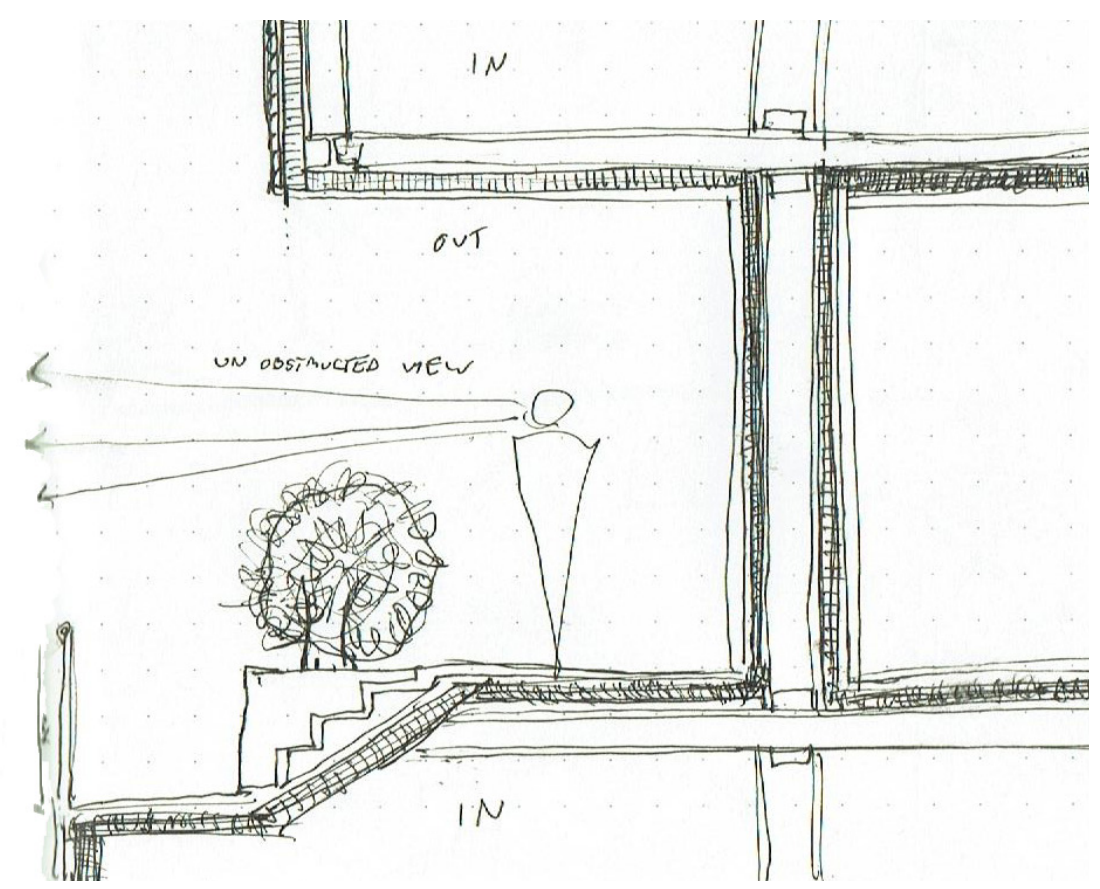

Figure 3.4.18: Sketch of similar edge condition to that depicted in the model showing unobstructed view from street level 


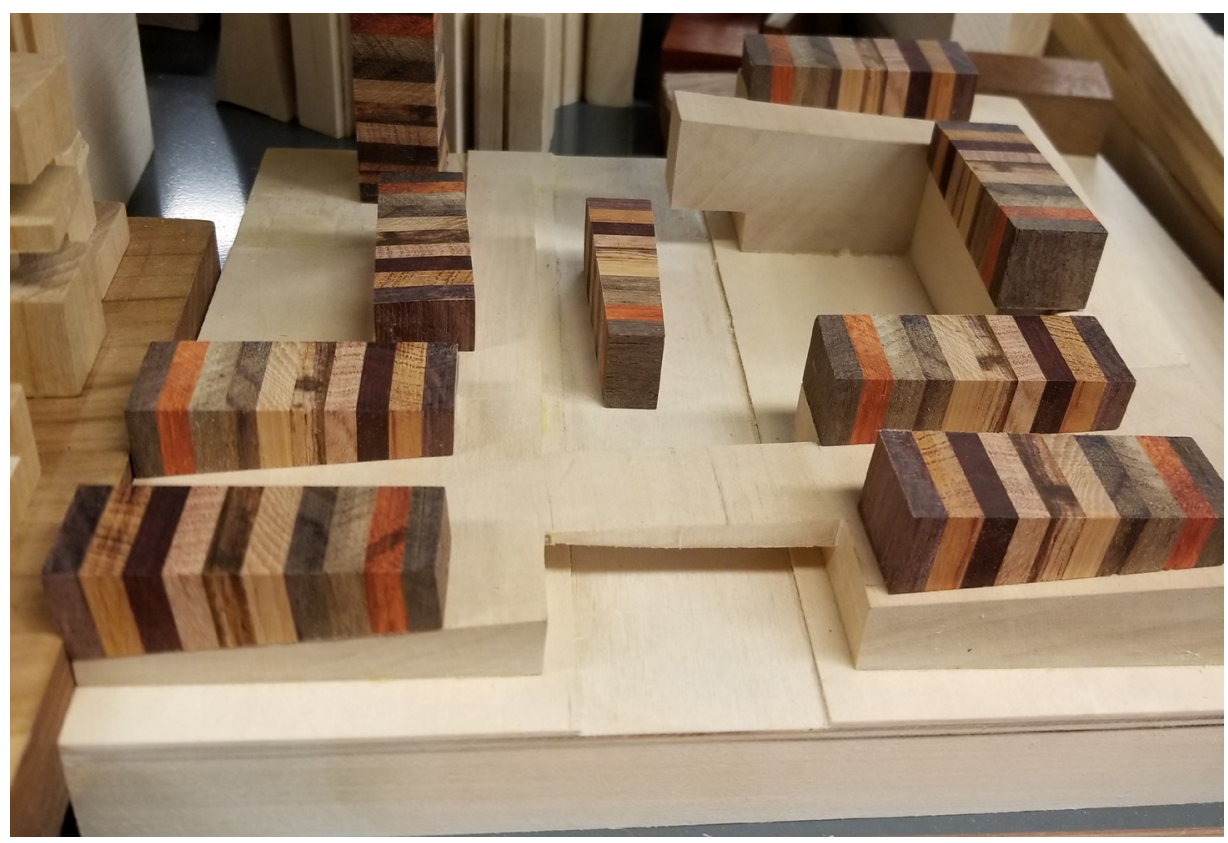

Figure 3.4.19: 1: 500 model exploring how the adapted shophouse typology may contributed to creating vertically walkable city blocks

transportation. Figure 3.4 .13 shows how both vertical and surface-level transit may complement and contribute to the public space. In the model, a vertical transit stop and a corresponding "parklet" (Figure 3.4.17) form an engaging rest area while the streetcar type vehicle suggests that this busy portion of the raised street might serve as an interchange between multiple transit modes.

\section{Walkable Blocks}

The progress photo of the 1:500 model in Figures 3.4.19-20, shows how, at a larger scale, stepped shophouses could be configured around the type of walkable city blocks. The model is intended to represent a volume of the city and is based on the same $200 \mathrm{ft}(60 \mathrm{~m})$ block configuration discussed in Section 2.5. The shophouses are represented as colourful hardwoods and are configured as a 


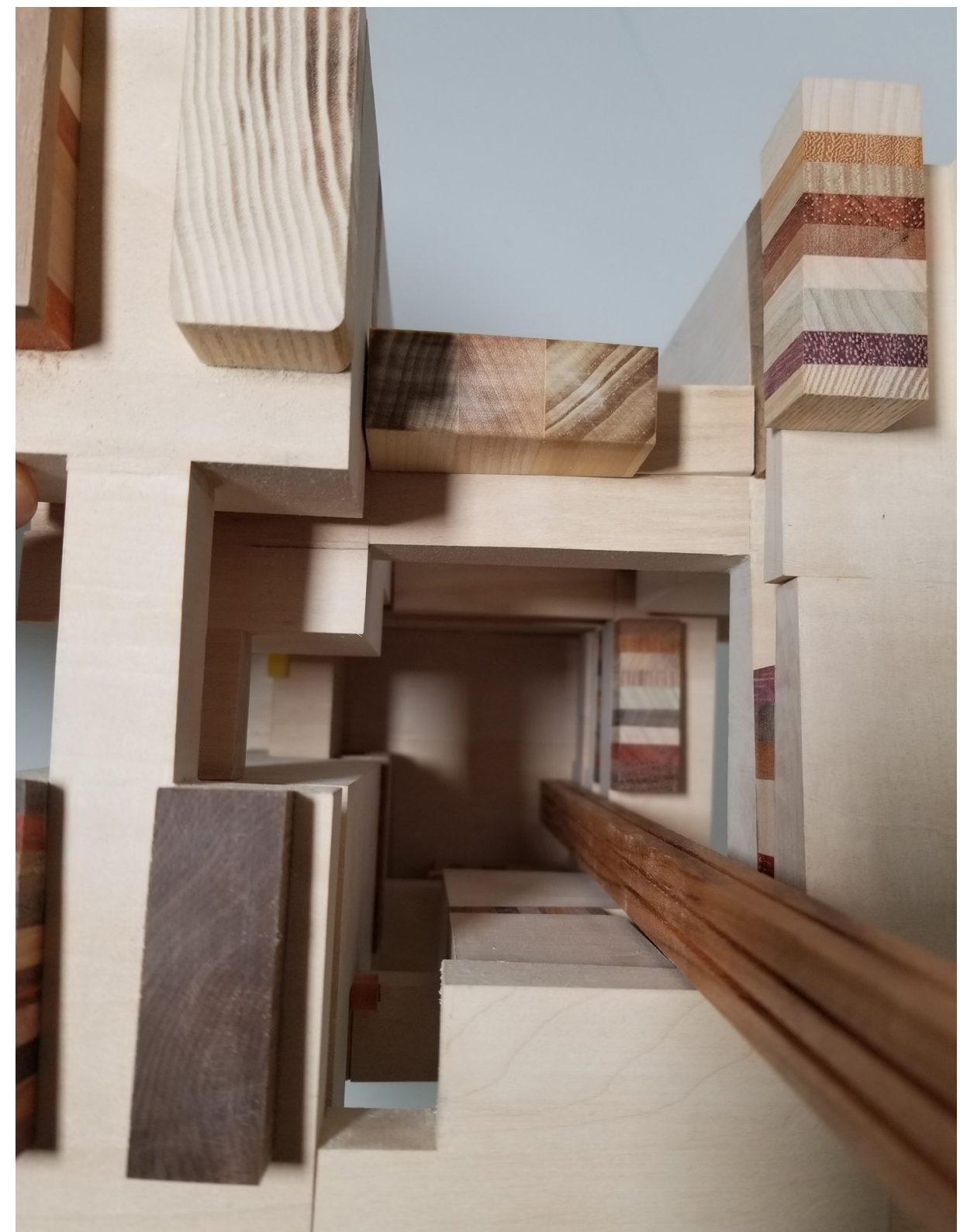

Figure 3.4.20: 1: 500 model exploring how the adapted shophouse typology may be configured along vertically walkable city blocks layered within a larger volume 
continuous edging (Rule83) that forms an integral part of the walkable block. How this layering of spaces within this model evolves to represent a walkable shophouse district is explained in Section 3.5.

\section{Conclusion}

The Singapore shophouse is an architectural typology that represents a significant part of the country's cultural history. It was largely abandoned as an urban design model when Singapore's need for space forced the city to grow vertically. This section explored how the shophouse typology could be reinterpreted and incorporated as a critical component of a vertically walkable city. It explained how, through a few adaptations, the typology could adhere to the types of sloped planes and layered spaces for the kind of vertically walkable blocks outlined in Section 2.5 Vertically Walkable Cities. 


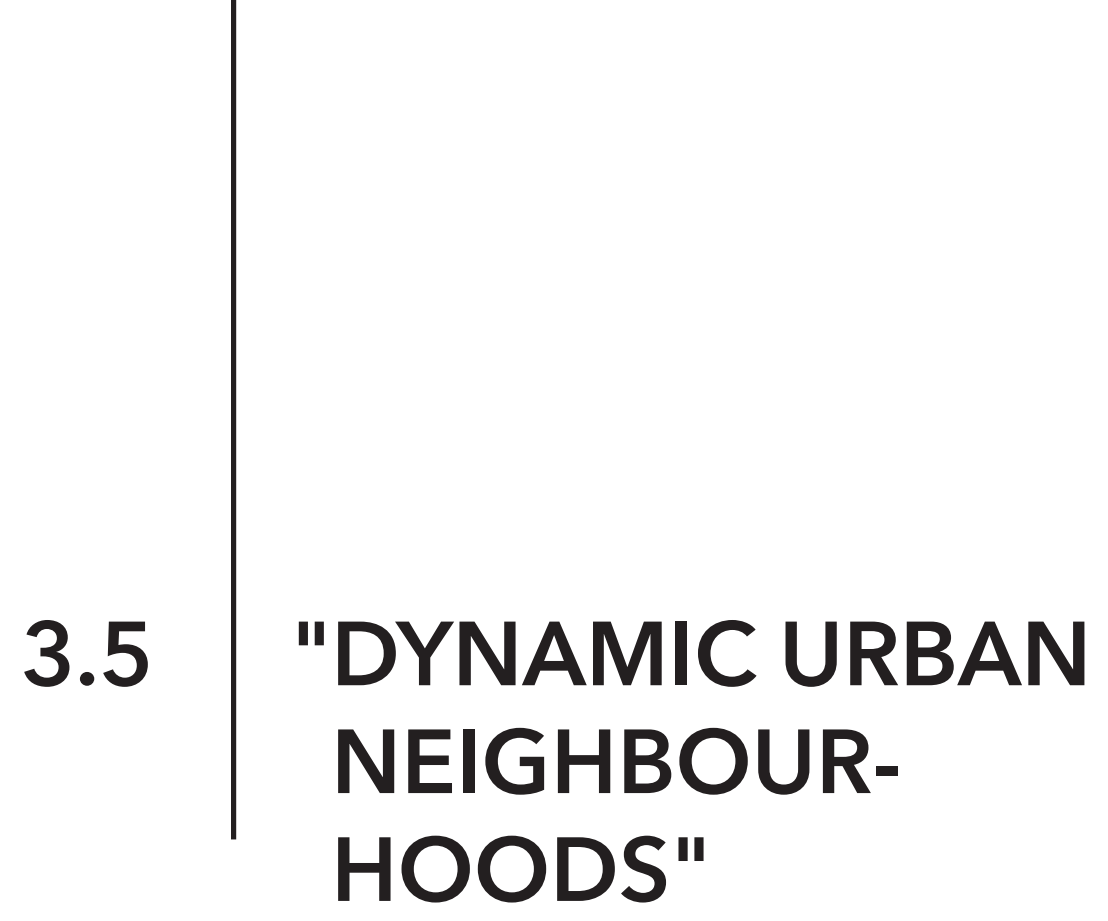

The previous section reinterpreted the Singapore shophouse typology for a vertical context through adaptations for sloped planes, layered spaces, and vertical city blocks. It illustrated how similar to its role on the ground plane, the shophouse could continue to serve as a continuous, engaging street edging that helps foster a rich urbanity.

This section jumps scales and explores how those vertical city blocks, could inform vertical districts and neighbourhoods within a volumetrically planned Marina South. Design research in this section attempts to illustrate the possibility of vertically situated "dynamic urban neighbourhoods" where, street life, opportunities, resources, culture, entertainment, and a sense of community, are established and nurtured even as the city grows vertically from the ground plane.

\section{Design Research}

Design research of vertical districts and neighbourhoods took on three forms. A wood massing model explored spatial configurations and layering of spaces and exposed unique urban conditions. A large scale sectional drawing illustrated the possibilities of spatial programming, 


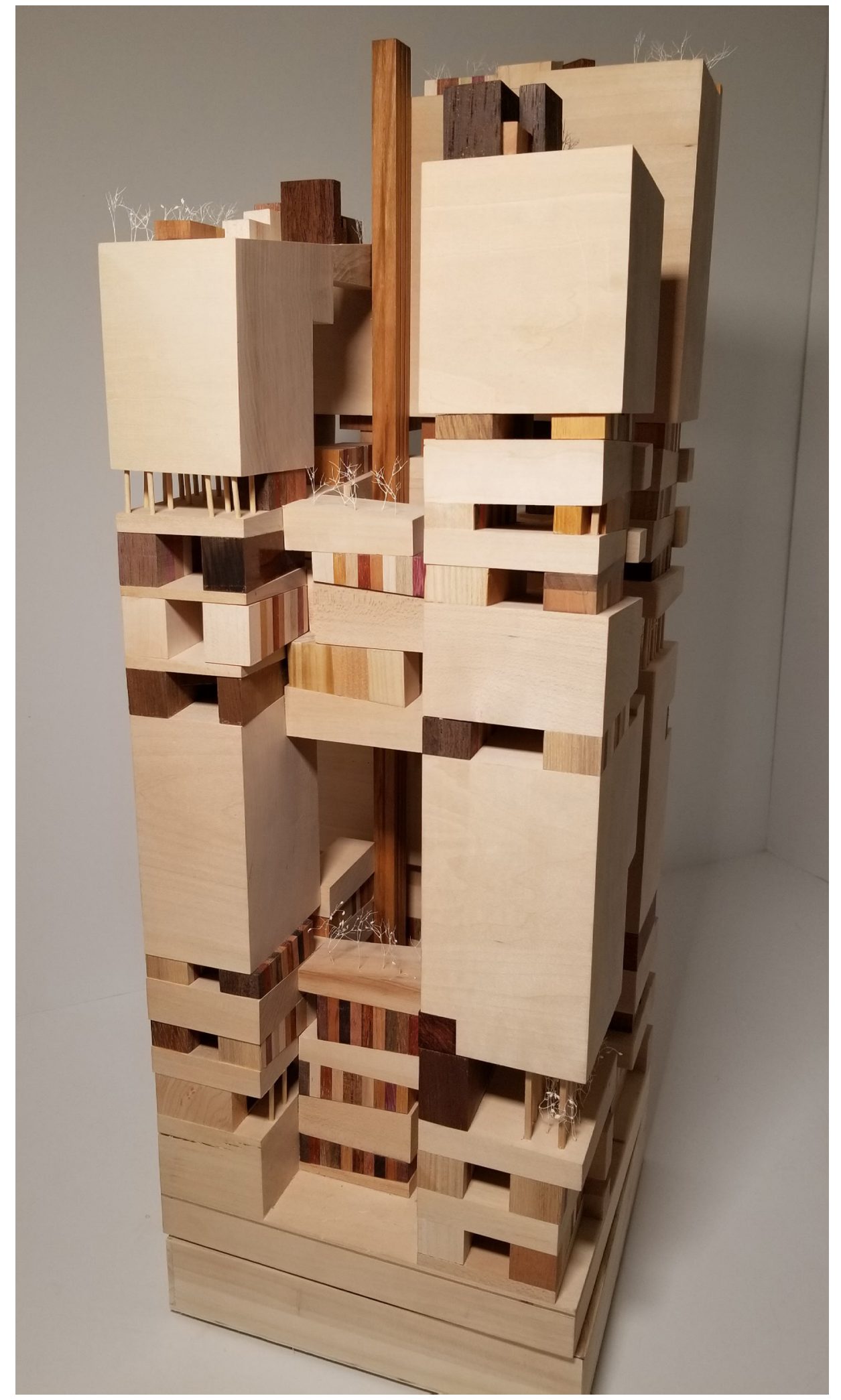

Figure 3.5.1: 1: 500 model exploring how walkable city blocks may be integrated within a volume. 


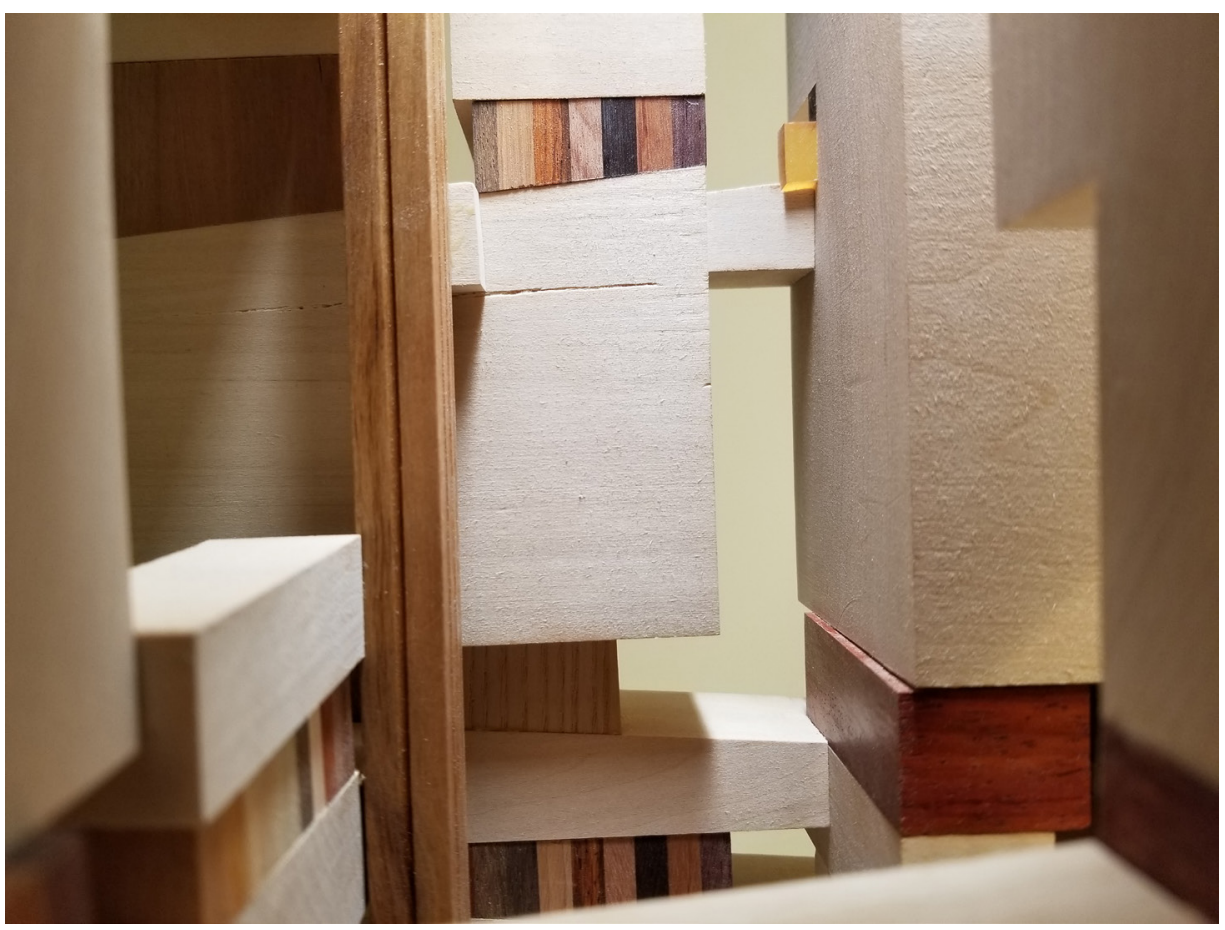

Figure 3.5.2: Photo of internal void of 1:500 model.

and perspectival vignettes suggest possible architectural and aesthetic characteristics of a vertical neighbourhood environment.

\section{Volume Model}

The 1:500 volume model presented in Figures 3.5.1-2 was a design research exploration that investigated a large volume cut from within a volumetrically planned portion of the city. Without being fixed to an exact location, the site for the exploration was representative of a $75 \mathrm{~m} \times 75 \mathrm{~m} \times 280 \mathrm{~m}$ urban volume set within a volumetrically planned Marina South region.

As mentioned in Section 3.4, this model explored how vertically configured shophouse lined blocks could be layered with urbanistically independent spaces. It also explored how other types of urbanistically dependent spaces could be integrated along the surface of the public flow system. The 


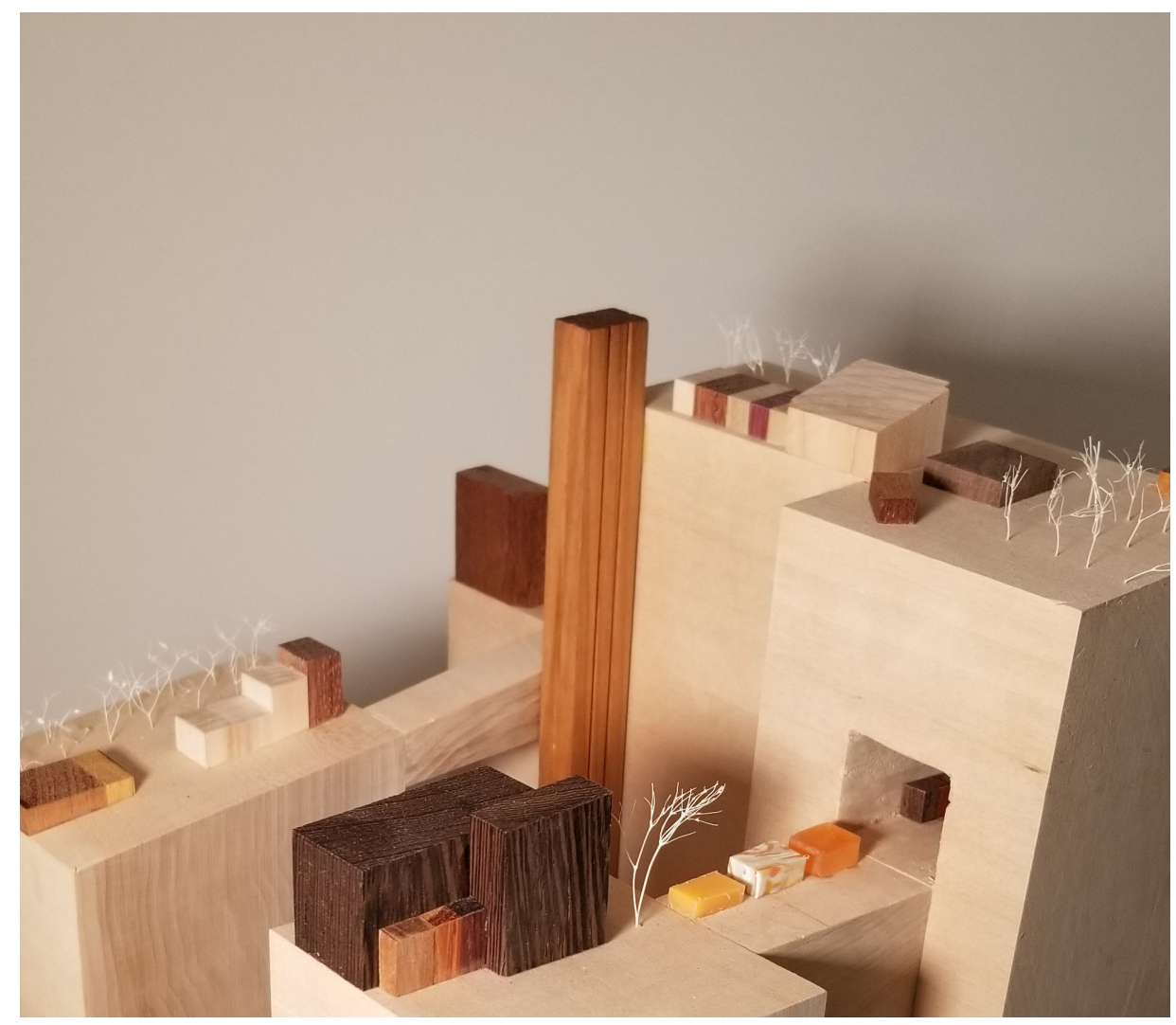

Figure 3.5.3: 1: 500 roof condition. Large roof surfaces are organized with park spaces and small adapted spaces with expressive roofs.

model was constructed of wood pieces layered vertically within a bounding rectangular prism. Basswood was used to represent various forms of urbanistically independent spaces within the volume. Colourful hardwood blocks were used to represent urbanistically dependent spaces. Small rows of similar size blocks were intended to represent shophouses while larger coloured blocks were meant to suggest civic buildings, cultural centers, education facilities, and other types of space. Urbanistically dependent spaces like parks and recreation areas were represented as surface elements within voids.

It is important to reiterate that the model represents a volume cut from within a larger city. As a result, it was assumed that where the streets, surfaces, and volumes of space met the boundary, they would 
continue beyond the volume of study. This is why the configuration of the public flow system extends continuously from the ground plane up numerous walkable blocks before being extended beyond the volume of study. At the upper levels of the volume, the flow system reemerges into the volume and climbs multiple blocks before leaving once again. This condition is representative of how two neighbourhoods could be layered above one another within a volume of the city. Within the volume of study, the upper and lower neighbourhoods are only connected to one another by a vertical transit shaft. It was assumed that within a larger volume of study, they would be connected by the overall continuity of the extended public flow system (Figure 3.3.19).

The first insight that emerged from this model was a sense of the type of architectural and urban conditions that stem from a volumetric design configured around walkable shophouse lined blocks. The model is suggestive of largely unprecedented vertical urban conditions that emerge from the diverse layers of spaces and a variety of planes (Figure 3.5.2). The "roof" condition Figure 3.5.3 was also particularly interesting. The continuity of the surface elements at this level, combined with the lack of volumes above, offers similar conditions to the ground plane.

A second insight that emerged from this model was an increased understanding and articulation of how masses of spaces could be concentrated and stacked so that the structural loads could be transferred down through the masses. The concentration of masses within the volume of the 1:500 model was meant to suggest a distinction between stacked elements and bridging elements. From this distinction, it was possible to understand how spaces could be supported through the adaptation of existing 


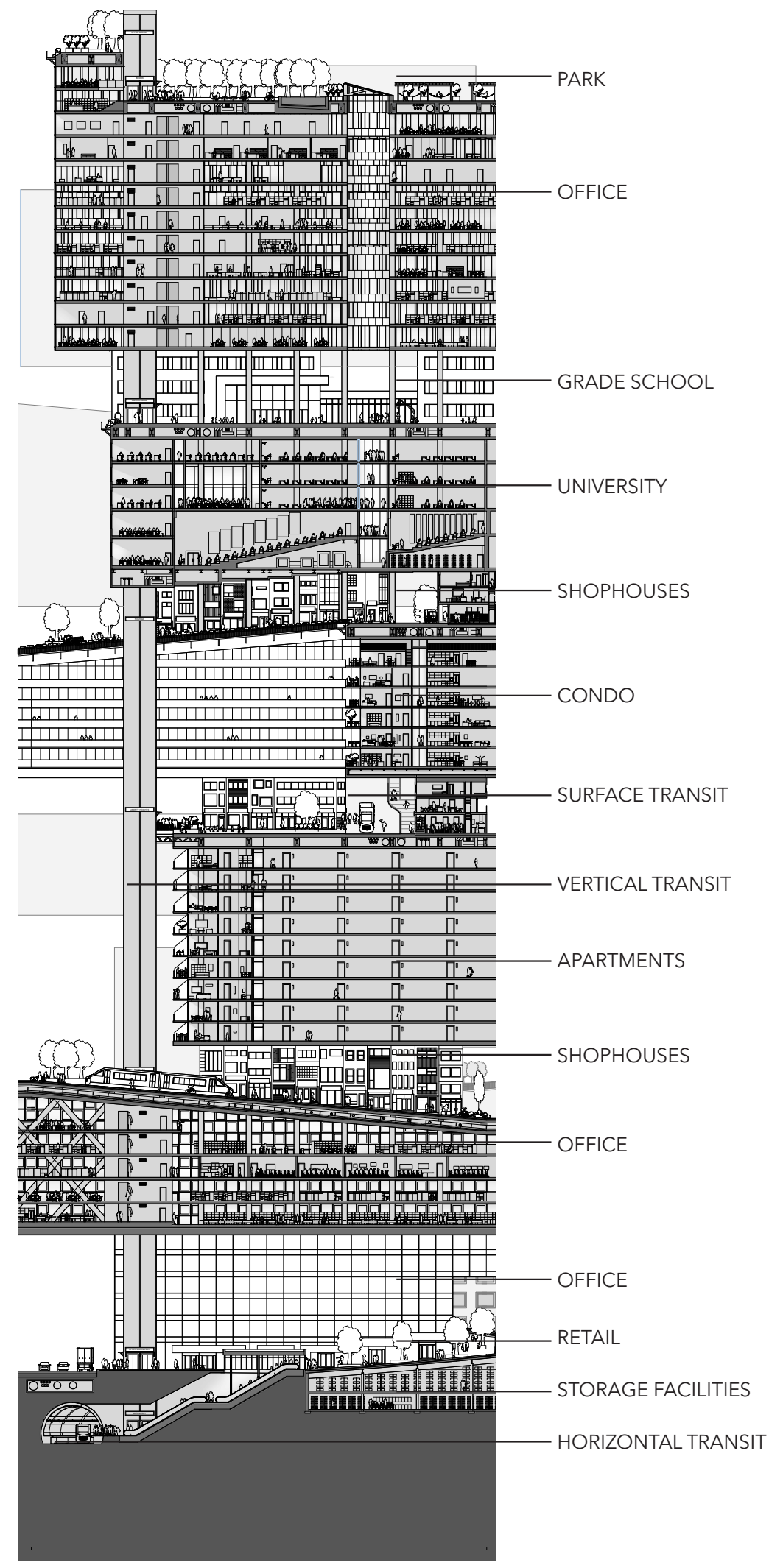

Figure 3.5.4: Section through-volume of city showing variety of architectural spaces, urban conditions, programs, and designs. 
structural strategies. These established structural strategies would include typical high rise structural systems like braced or shear wall frame systems, in addition to more complex horizontal spanning systems like that used in OMA's Interlace (Figure 2.4.12). As mentioned in Section 3.3, the goal was to explore the potential for a volumetrically planned Marina South region to support "dynamic urban neighbourhoods" throughout its entire volume. Indepth research into the structural considerations of volumetrically planned development went beyond the scope of the investigation. Structural design is one of the numerous considerations for future research that has emerged from this thesis.

\section{Section}

In Delirious New York, Rem Koolhaas strategically employs a sectional drawing and description of the Downtown Athletic Club, a tower in New York that features multiple floors of private recreation and living spaces ${ }^{1}$. In doing this, Koolhaas positions the Downtown Athletic Club as an example of the apotheosis, or apex of tower technologies' ability to foster simultaneous discrete activities within the height of the city. It should be noted, however, that even at its apotheosis, the height of the common tower was only capable of supporting urbanistically independent spaces.

The goal of the section drawing presented in Figures 3.5.4 was to investigate and demonstrate the potential for a volumetrically planned city to simultaneously foster urbanistically dependent and independent spaces within its height. The section was a design research exercise that took the vertical layering and configuration of spaces from the 1:500 model and explored how they could be programmed.

Koolhaas, Rem. Delirious New York: A Retroactive Manifesto for Manhattan. New ed. New York: Monacelli Press, 1994. 


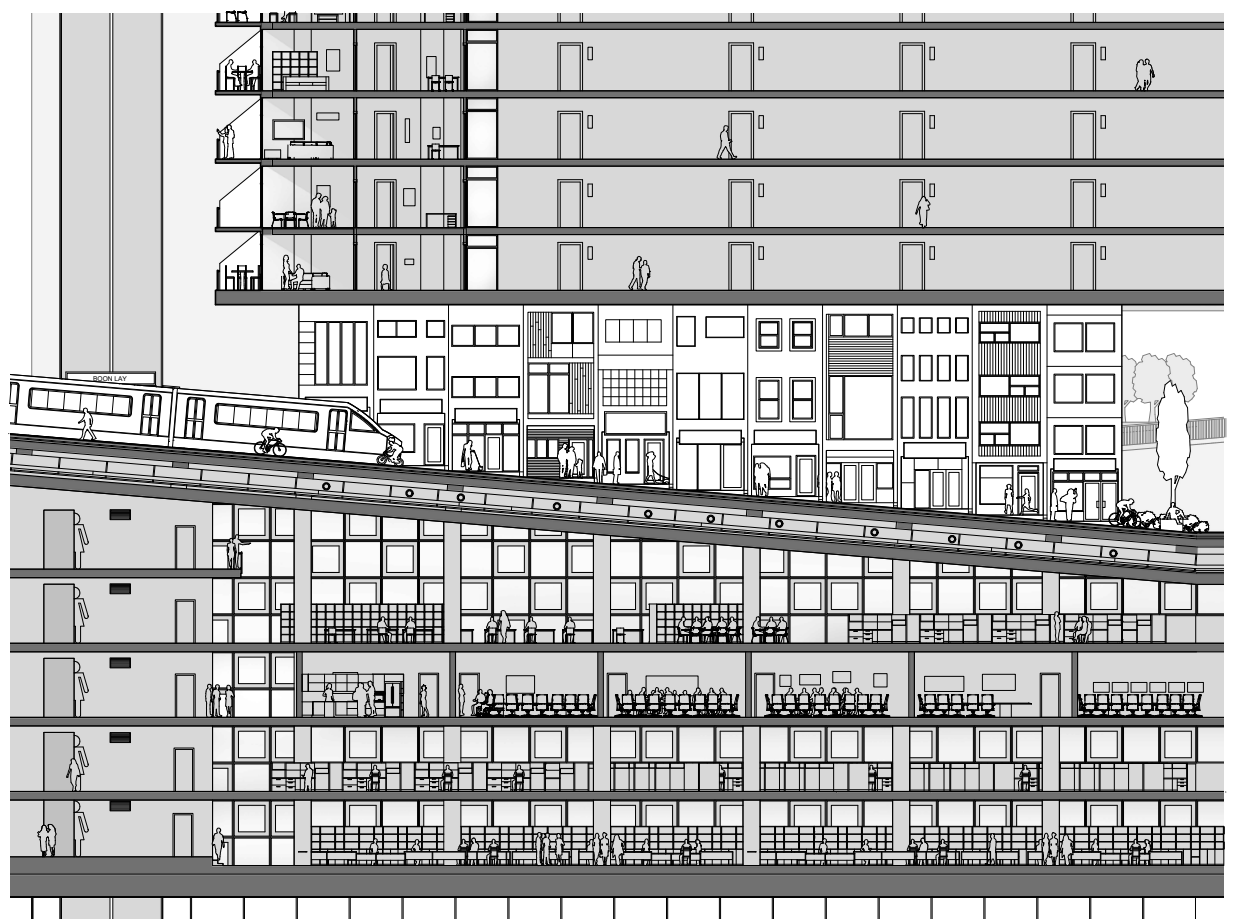

Figure 3.5.5: Enlarged section showing shophouse street above office space, and below apartments.

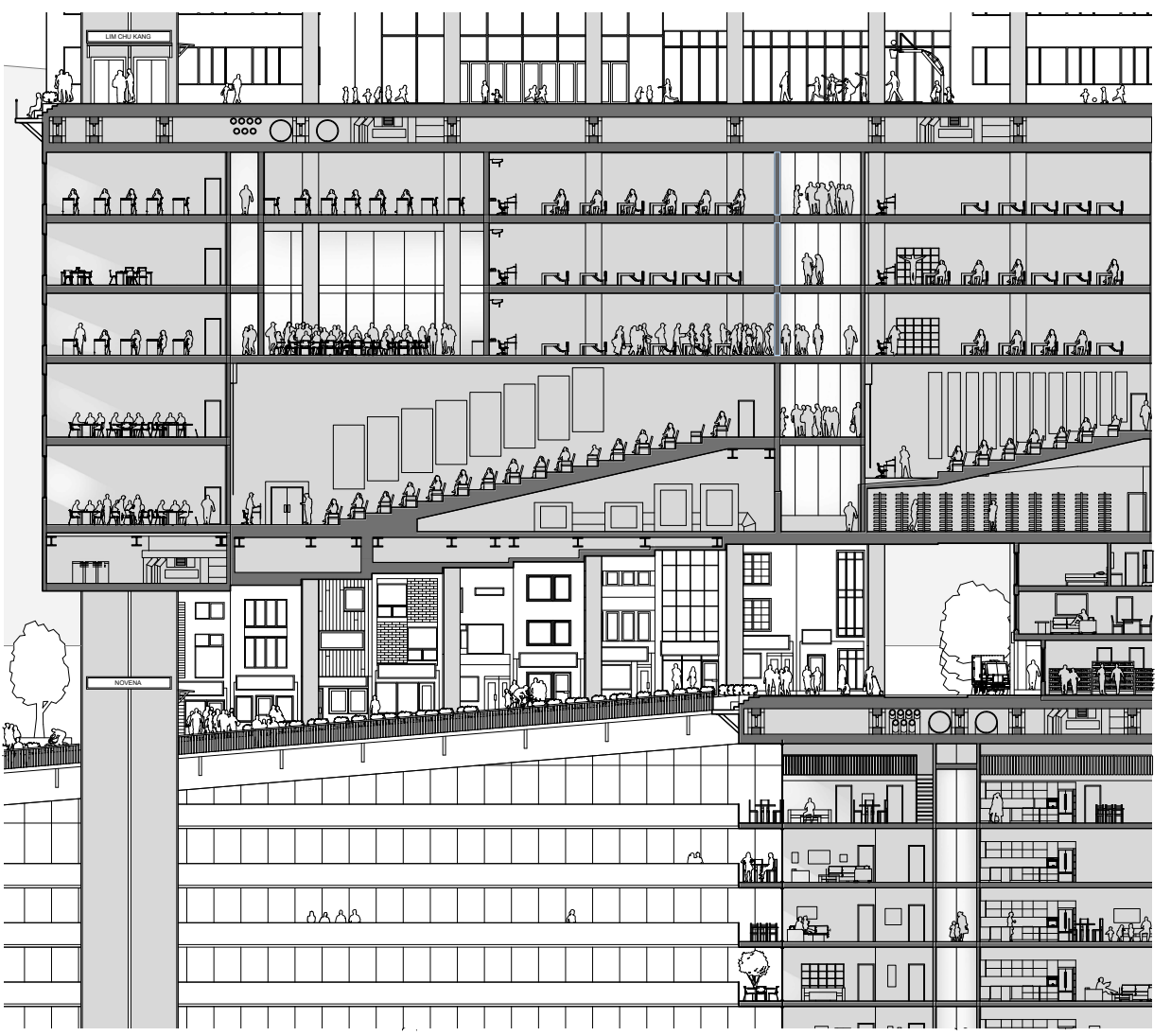

Figure 3.5.6: Enlarged section showing shophouse street above condos and below university 


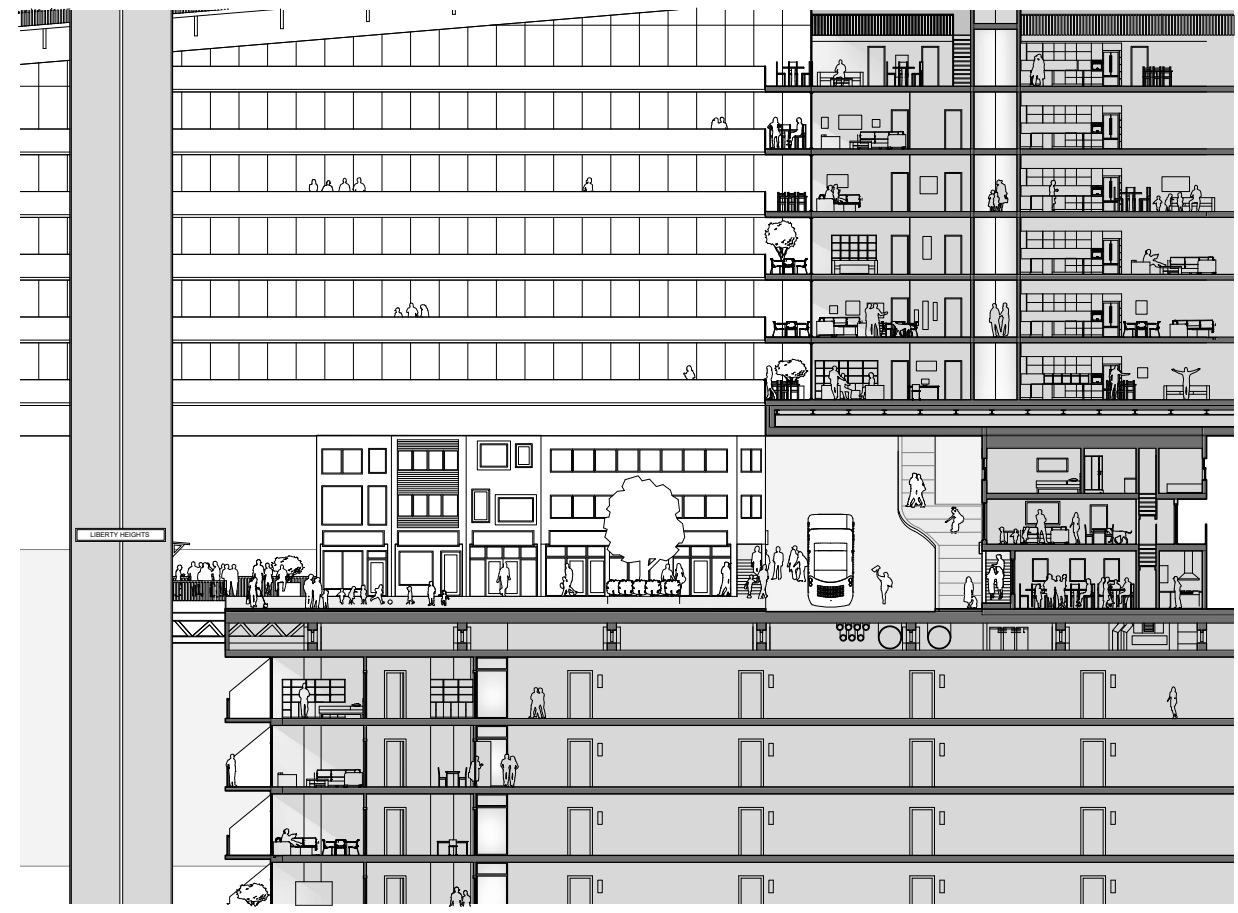

Figure 3.5.7: Enlarged section showing shophouse street above apartments and below condos

The drawing shows how along a vertical axis, a volumetrically planned development could support shophouse lined streets, public transit, office space, residential space, educational institutions, and storage facilities, among other programs. Figures 3.5.5-7 are enlargements of the section that show how the shophouse typology is incorporated as an integral part of the urban environment.

It should be noted that each mass is architecturally articulated as a separate building. This design decision emerged from the physical fragmentation of building volumes, the diversity of intended programs, as well as the desire to make the three-dimensional city visually interesting (Rule 89)2.

\section{Vignettes}

The vignettes presented in Figures 3.5.8-9 were 


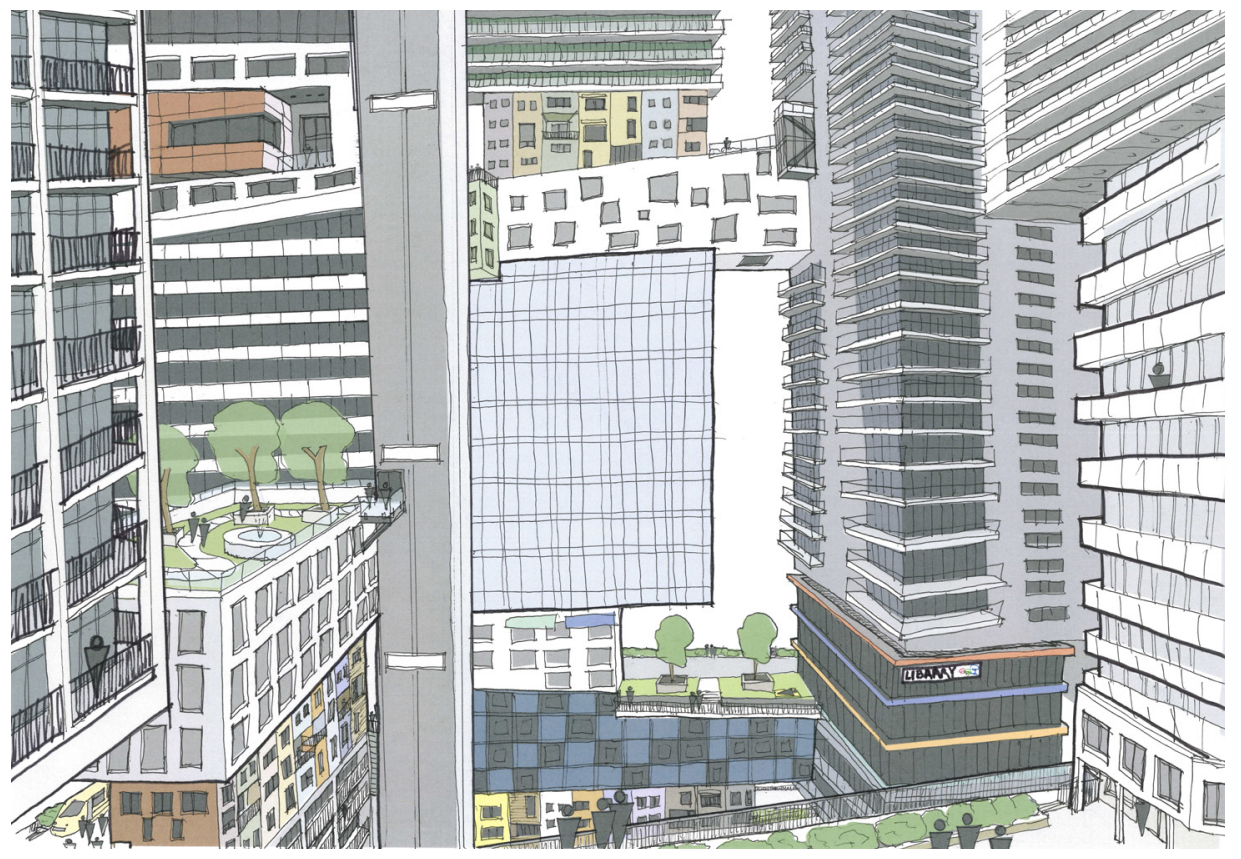

Figure 3.5.8: Vignette illustrating spatial and aesthetic characteristics of vertically organized shophouse district

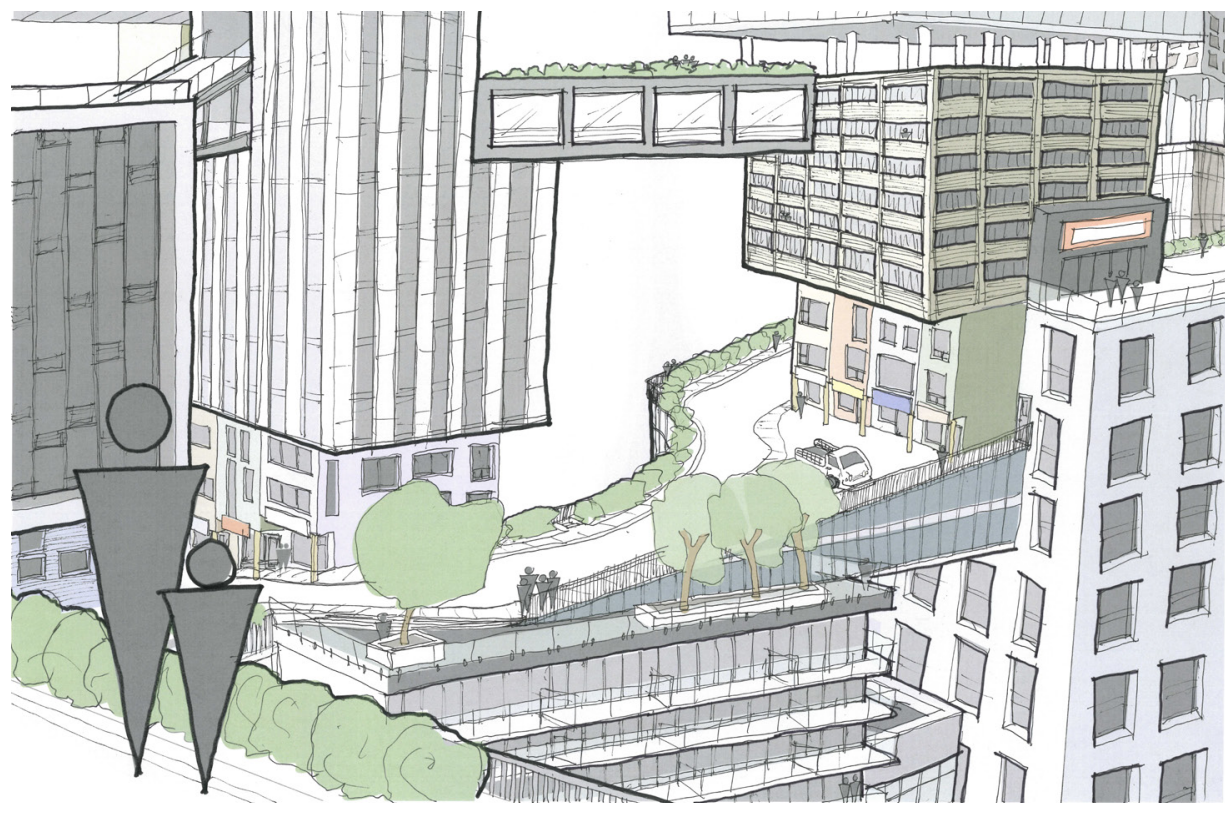

Figure 3.5.9: Vignette illustrating spatial and aesthetic characteristics of vertically organized shophouse district 
developed from model photos that were digitally altered and sketched over. Unlike massing models, the development of these vignettes required significant design decisions regarding facades, forms and aesthetic features.

The intention of these perspectives was to suggest the spatial qualities and the visual richness of a vertically organized neighbourhood. Both drawings show how, in a vertical urban environment, the edge conditions become a unique vantage point that looks out over multiple planes of public space both above and below the horizon line. Both drawings are also suggestive of how a vertical urban neighbourhood could feature overlapping urban functions capable of fostering street life and community high above the ground plane.

\section{Conclusion}

Something that emerged from studying the visionary urbanism proposals in Section 1.4 was that the stronger theoretical proposals employed selective imagery instead of fully formulated solutions. In doing so, the potential of their overall position was communicated, while many details were left to the imagination of the reader. This allowed their ideas to remain relevant as technology and stylistic preferences evolved.

The design research investigations in this section illustrated how a reinterpretation of Singapore shophouse lined streets could be incorporated as part of vertically organized neighbourhoods. It demonstrated how a volumetrically planned city could support vertically organized neighbourhoods with layers of urbanistically independent and dependent spaces. Selective imagery demonstrated some of the possible characteristics of such an unprecedented urban environment. 
These investigations represent a fraction of a volumetrically planned vertical architecture's potential to foster "dynamic urban neighbourhoods" within its height. Ideally, these selective design research investigations will inspire further research on the potential of volumetrically planned vertical architecture. 


\section{GLOSSARY}

The following definitions are explanations of how each term or phrase is intended to be interpreted in the context of this thesis.

Adapted Spaces: all indoor and outdoor spaces and surfaces meant for localized activities

Centralization: the concentration of a population into a location such as a city. This idea has taken on many forms but often is conceived with the intention of providing shared services, sharing resources, and intensifying the use of some land to de-intensify the use of other lands.

Common Towers a blanket term used to describe all types of towers that are meant to multiply the value of the ground plane and do so by stacking private space within a self-contained, independent volume. These are towers that are only capable of supporting profitable private functions within their height and that only engage with the public realm at the lower floors near the ground plane, if at all. This term refers to towers of all common programmatic uses such as offices, residential, hotel, and "mixed" use towers. The common tower is a typological classification meant to encompass an entire family of well-established classifications, such as point towers, 
podium towers, and slabs.

Dynamic Urban Neighborhoods: This term refers to the stated goal Singapore's Urban Redevelopment Authority has for the Marina South Site.

Neighbourhoods with a wide variety of integrated land uses active streets and public places with active programming to provide "diversity of experiences" ${ }^{\prime 1}$.

Inhabited Infrastructure An urban design approach derived from proposals by Rodney Hood, Corbusier, and Kenzo Tange that imagined ways inhabitable real estate could be incorporated into massive highway infrastructure projects

Mass Centralization An urban design approach derived from the proposals of King Champ Gillette and Paulo Soleri who advocated centralizing massive populations into single structures or groups of structure in order to free up surrounding land for agriculture and nature reserves

Multiple Ground Urbanism An urban design approach derived from proposals by Antonio Sant'Elia, and Harvey Wiley Corbett that envisioned networks of public spaces, of pedways, bridges, streets, highways, and trains vertically separated and stacked into the height of the city. Key to this approach is an understanding of the qualities of the public realm and ground plane as something that can be multiplied.

Open-Ended Urban Framework An urban design approach derived from proposals by Archigram and The Metabolists that envisioned large scale urban frameworks that would enable, the three-dimensional organization of mobile, impermanent spaces that

Urban Redevelopment Authority. "Our Downtown." Urban Redevelopment Authority. Accessed November 28, 2019. https://www.ura. gov.sg/Corporate/Planning/Master-Plan/Regional-Highlights/Central-Area/Downtown. 
could be changed in accordance with shifting societal needs.

\section{Open-Ended Understanding of the City A way}

of thinking about the built environment as a fluid process in which the city is not considered as a static structure that can be planned and controlled but rather something that evolves and is changed over time by the inhabitants. This idea was popularized in the 1960s and 1970s by urban theorist groups such as Archigram and the Metabolists.

Public Flow System: parts of the city concerned with the circulation and flow of people goods and utilities

Segregated Traffic: The direct separation of modes of transportation (i.e. automobiles, pedestrians, trains, streetcars, subway, flying machine, etc.) on multiple planes within vertical space. A product of multiple ground Urbanism.

The Default Approach to Verticality refers to the urban design practice of defaulting to common towers as the only way of inhabiting vertical territory in a city. The term emerged through an investigation of the agglomeration of factors including current building regulations, land ownership laws, zoning, financing, and private interests, that have made common towers the only practical and permissible form of vertical architecture in most cities.

The Volumetric Approach to Verticality is an approach to urban design that consists of securing controls for the continuous extension of the public realm into a three-dimensional city volume as a way of shaping vertical architecture that is capable of supporting diverse programming within its height

Three-Part Reduction an abstraction of urban form that reduces cities to the public flow system, voids, and adapted Spaces. 
Towers in the Park_An urban design approach derived from proposals by Hugh Ferris, Rodney hood and most significantly Corbusier, proposed the functions of the city be neatly separated and spread far apart, with private functions being stacked into towers to save space at the ground for parks, recreation spaces and most of all highways

Un-Common Towers architectural innovations that attempt to address the imposed constraints of the common tower typology. Specifically, in regards to the incorporation of public spaces or semi-public spaces within a tower's height. This typology can mostly be found in Singapore and Southeast Asia a where semi-public external gathering spaces have been used to break up volumes, link towers together, and stimulate neighbourly interaction.

Urban Retreat An urban design approach derived from proposals by Tony Garnier, Ebenezer Howard, and Soria y Mata. It originated as a response to the industrial city. This approach advocated for a retreat into nature, into low-density housing spread horizontally where living was separated from the other urban activities.

Urbanistically Dependent Spaces: spaces suitable for functions occupancies and uses that are dependent on accessibility and visibility by the general public via the surface elements of the public flow system (ex. retail, libraries, parks, gathering areas, community centers, recreational facilities, etc.)

Urbanistically Independent Spaces: spaces suitable for functions occupancies and uses that can function and may even thrive without direct adjacency to the public realm (ex. residential, office space, storage, vertical farming, etc.)

Vertical Growth: The growth of cities in the vertical direction. Vertical growth most often takes the form 
of common towers. Sometimes vertical growth occurs as a symbolic gesture to demonstrate the wealth and power of a group, city, nation, company or individual. More often, however, vertical growth occurs in response to the high demand for land located at the center of the action ${ }^{2}$.

Vertical Land Rush: A metaphor base on the 1889 Oklahoma City Land Rush meant to draw attention to the unregulated free for all nature of vertical development in cities around the world.

Vertical Real-Estate: Airspace above the ground plane that, if settled through vertical development, can be inhabited.

Vertical Settlement/ Vertical Development: inhabiting vertical real-estate by constructing tall buildings

Verticality: the built environment that extends in the direction aligned with the direction of gravity ${ }^{3}$

Vertically Walkable Cities: principles of urban design derived from the adaptation of Jeff Speck's principles for the design for Walkable Cities that is intended for a city organized in three dimensions

Visionary Urbanism a design for how the future city "ought "to be. Specifically, unrealized designs from the past.

Voids: The unbuilt volumes of the city

\footnotetext{
2 According to Van Leueen the rational for building tall comercial buildings in the city was not because there was no space nearby but rather it was because there was an underlying need for the place of business to be located at the centre of the action.

Van Leeuwen Thomas "The Centripital Force" in A. Skyward Trend of Thought: The Metaphysics of the American Skyscraper. P. 92-93Cambridge: Mit Press, 1990.

3 Educalingo. "VERTICALITY - Definition and Synonyms of Verticality in the English Dictionary." Accessed August 24, 2019. https://educalingo. com/en/dic-en/verticality.
} 


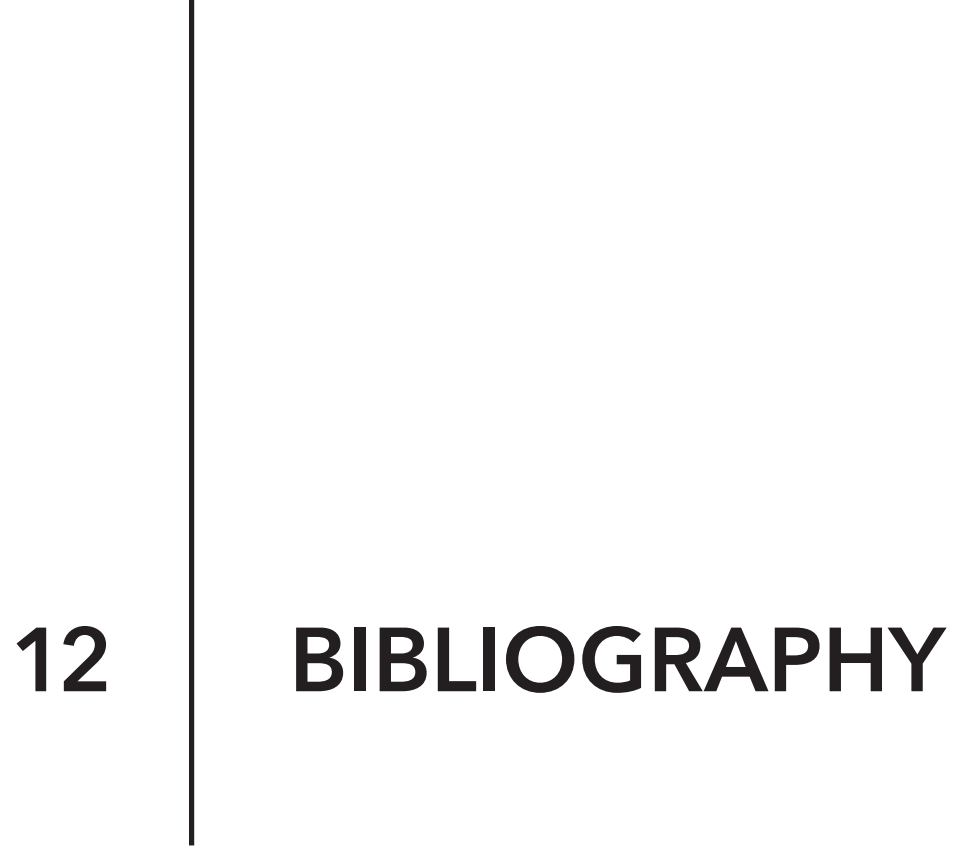

Ascher, Kate, and Rob Vroman. The Heights: Anatomy of a Skyscraper. New York, NY: Penguin Books, 2013.

Notes: a good quick reference book for technologies, dates, and people involved in tall buildings

Status: Read

Ascher, Kate. Anatomy of a City. New York: Penguin Press, 2005.

Notes: an excellent reference book that outlines the many components of a city and how they function

Status: Read

Bacon, Edmund N. Design of Cities. Rev. ed. A Penguin Book. New York: Penguin Books, 1976.

Notes: Ideas on Urban Design that influenced Ken Yeang's ideas in "Reinventing The Skyscraper: A Vertical Theory of Urban Design."

Status: Read - Partial

Banham, Reyner. Megaestructure, Urban Futures of 
the Recent Past. London; New York: Harper \& Row, 1976.

Notes: In depth discussion of the history evolution and built examples of megastructure across the globe. Surprisingly contains a lot of material on Canadian Megastructures. I would recommend familiarizing yourself with the subjectmatter before reading this book

Status: Read

Bingham-Hall, Patrick. Garden City Mega City: Rethinking Cities for the Age of Global Warming. Singapore: Pesaro Publishing, 2016.

Notes: Contemporary Megatructuralists. Presents work by the Architect firm WOHA including both completed projects and competition entries. Advocates for compact, dense cities organized vertically in a large structure.

Status: Read

Blake, Peter. The Master Builders: Le Corbusier, Mies van Der Rohe, Frank Lloyd Wright. The Norton Library. New York: Norton, 1996.

Notes: Blake Discusses these three key figure's involvement with tall buildings and the design of cities at different points in their careers

Status: Read

Boileau, Ivan. "La Ciudad Lineal: A Critical Study of the Linear Suburb of Madrid." The Town Planning Review 30, no. 3 (1959): 230-38.

Notes: Good information on Linear Suburb by Arthuro Soria y Mat

Status: Read 
Busquets, Joan. Cities $X$ Lines: A New Lens for the Urbanistic Project. Edited by Felipe Correa and Harvard University. Reprint. S.I.: Nicolodi, 2007.

Notes: Explains emerging trends in contemporary urban design. Broken into 10 parts each line features numerous examples of built work

Status: Read

Cook, Peter, and Archigram (Group), eds. Archigram. Rev. ed. New York: Princeton Architectural Press, 1999.

Notes: This is an amalgamation of all the key ideas of the Archigram magazine into one comprehensive book

Status: Read Partial

Dupré, Judith. Skyscrapers. New York: Black Dog \& Leventhal : Distributed by Workman, 1996.

Notes: a good quick reference book for technologies, dates, and people involved in tall buildings

Status: Read

Ferriss, Hugh. The Metropolis of Tomorrow. Princeton, NJ: Princeton Architectural Press, 1986.

Notes: Originally published in 1929. As one of the best know delineators (Renderer) of the early $20^{\text {th }}$ century, part one is a discussion of the many projects he was hired to bring to life. Part 2 is his observation in emerging trends where he predicts building taking up full blocks and spanning over multiple blocks, reversion to past styles, utilization of upper levels, glass towers, and reinforced concretes take over as the primary structural element. Part Three is his 
imaginary metropolis of tomorrow, where he imagines a city divided into three districts (arts, science, business) where giant towers appear as mountain peaks spaced far from one another amongst a sea of lower buildings with green roofs and multiple layers of transportation.

Status: Read

Firley, Eric, and Julie Gimbal. The Urban Towers Handbook. Chichester: Wiley, 2011.

Notes: This book unsuccessfully tries to break all towers into 12 typological categories.

The book provides a breakdown of the history of zoning, building codes, and other regulations that influenced tall buildings in New York, Hong Kong, Singapore, Paris, Frankfurt, Vienna, and London. This part of the book is a tremendous resource.

Status: Read

Frampton, Adam, Clara Wong, and Jonathan Solomon. Cities without Ground: A Hong Kong Guidebook. Rafael, Calif.: Oro editions, 2012.

Notes: interesting representation and discussion of 3-dimensional public space that spans throughout the city of Hong Kong

Status: Read

Gillette, King Camp. The Human Drift. New Era Publishing Company, 1894.

Notes: A 1894 proposal for consolidating all of American into a single city located in the Niagara Falls region. The city was to feature layers of artificial ground plan, and the population was to be housed in large towers high above the 
ground. This proposal was utopian in nature as it proposed a complete restructuring of society

Status: Read

Graham, Wade. Dream Cities: Seven Urban Ideas That Shape the World. New York: Harper Collins, 2017.

Notes: Graham gives a broad overview of the architecture and urban design ideas that have shaped the world's cities. This was an important reference as it allowed the tracing of many ideas form one to another. These include Daniel Burnham's City Beautiful, Corbusier's Radiant City, Howard's and Frank Lloyd Wrights', Garden City, Jane Jacobs' Self Organizing Cities and the Metabolist and Archigram City as Organism among others.

Status: Read

Graham, Stephen. Vertical: The City from Satellites to Bunkers. London; New York: Verso, 2016.

Notes: Graham argues against the "Flat earth" viewpoint of urbanism. While he offers a much broader perspective of the city, his views of 3-dimensional planning strongly align with the focus of my thesis. The introduction contains a great discussion on the hierarchy of verticality and how it is intrinsic to our language and social customs. The footnotes are an excellent resource for additional sources.

Status: Read

Howard, Ebenezer, and Frederic J. Osborn. Garden Cities of To-Morrow. 11. print. Cambridge, Mass: M.I.T. Pr, 2001.

Notes: An updated version of Howards 1898 
publication Garden Cities of Tomorrow an extremely influential piece of work that led to the garden city movement. Ideas presented here are further developed in Frank Lloyd Wrights Broad Acre City.

Status: Read Partial

Ireson, Ally, and Nick Barley, eds. City Levels. Basel; Boston : London: Birkhäuser ; August, 2000.

Notes: A recommended reference in Steven Graham's "Vertical" this book considers the city in cross-section. The reference focuses on the city planning scale.

Status: Read Partial

Jacobs, Jane. The Death and Life of Great American Cities. Vintage Books ed. New York: Vintage Books, 1992.

Notes: A critique of urban redevelopment and bigness that sheds light on the qualities of cities that make them functional and safe.

Status: Reading

Johnson, Scott. Performative Skyscraper: Tall Building Design Now. 1st edition. Glendale, CA: Balcony Press, 2014.

Notes: Johnson advocates for improved performance in tall buildings. Includes a discussion of the role of computer technology in shaping the design of tall buildings.

Status: Read - Partial

Koolhaas, Rem. Delirious New York: A Retroactive Manifesto for Manhattan. New ed. New York: Monacelli Press, 1994. 
Notes: Koolhaas provides a retroactive manifesto for the city of Manhattan-based on the symbiotic relationships between density and architecture. Koolhaas was both critical and fascinated by what forms of architecture could come from hyper-density or what he called "the Culture of Congestion". He points out how the skyscraper embodied and proliferated the simultaneous but independent variety of activities that take place in a city such as circulation, living, working, leisure, shopping, exercise etc. Koolhaas exposes the essence of a tower: a self-sufficient city within a city, collectively forming what he refers to as a "manmade archipelago".

Status: Read

Le Corbusier. The radiant city: elements of a doctrine of urbanism to be used as the basis of our machine-made civilization. London: Faber, 1967.

Notes: This is the publication (originally published in 1933) is where Le Corbusier presented his ideas for la Plan Voisin and Radiant City. It has been revisited and added to since the original publication. Corbusier presents ideas such as Exact air, the importance of leisure and activity spaces, unit height, project funding, the vertical garden city, artificial sites and an in-depth explanation of the radiant city master plan. The book also includes all of Corbusier's variations of the Radiant city For cites like Algiers, Buenos Aires, Rome, Soa Paulo that take on much different forms such as linear cities.

Status: Read

Lin, Zhongjie. Kenzo Tange and the Metabolist Movement: Urban Utopias of Modern Japan. London, United Kingdom: Routledge, 2010. 
Notes: This book is an in-depth explanation of the Metabolist movement

Status: Read - Partial

Lloyd Wright, Frank. The Disappearing City, [by]

Frank Lloyd Wright. 1st edition. William Far-

quar Payson, 1932. http://hdl.handle.net/2027/ mdp.39015047936219.

Notes: This is the book in which Frank Lloyd

Wright first presents his ideas for Broadacre City. This is important to study as these ideas are contrary to the basis of my thesis.

Status: Read Partial

Lloyd Wright, Frank. The Living City. Book, Whole. Horizon Press, 1958.

Notes: This is another first-person source where Frank Lloyd Wright presents his ideas for Broadacre City

Status: Read Partial

Mariani, Riccardo, ed. Tony Garnier: Une Cité Industrielle. New York: Rizzoli, 1990.

Notes: A second person account and collection of Tony Garniers work on the 1904 Cite Industrielle. This will provide another example of the visionary ideas of the future city form the turn of the century.

Status: Read second hand account

Rowe, Colin. "The Present Urban Predicament." In As I Was Saying: Recollections and Miscellaneous Essays., Vol. 1:165-220. Cambridge: The MIT Press, 1996.

Notes: a critique of the modernist approach to 
urban design that focuses on the built object. Argues historic cities where buildings were built-in continuous masses fromwhich public was subtracted foster a richer urban environment.

Status: Read

Sant'Elia, Antonio, Luciano Caramel, and Alberto Longatti. Antonio Sant'Elia, the Complete Works. New York: Rizzoli, 1988.

Notes: an indepth account of all of Sant Elia's work and his life as well as speculation into possible influences. It contains many great images of his sketches that gives comprehensive picture of his future city concepts.

Status: Read

Soleri, Paolo. Arcology: The City in the Image of Man. 1. MIT Press paperback ed. MIT 234. Cambridge, Mass.: MIT Pr, 1973.

Notes: Soleri presents 30 Arcologies which are imaginary cities conceived as a whole, focuse around the idea of an extreme intensified use of the land. Each Arcology is a giant self-sufficient live-work complex featuring all aspects of a typical city including residential, commercial, cultural centres, city centers, public parks, promenades and airports.

Status: Read

Speck, Jeff. Walkable City Rules: 101 Steps to Making Better Places. Washington, DC: Island Press, 2018.

Notes: A comprehensive guide of actional strategies for planning and designing walkable cities 
Status: Read

Sterling, Bruce, Tom Vanderbilt, Matthew Yglesias, Diana Lind, Will Self, Emily Badger, Dickson D. Despommier, and Michael Govan. The Future of the Skyscraper. Edited by Philip Nobel. SOM Thinkers. New York: Metropolis Books, 2015.

Notes: A collection of essays with many points of view on the future of tall buildings. Covers a wide array of topics, including the human phycology of living in high spaces and the perception of building movement. Also, a discussion of why the tech/ start-up companies are choosing non-tower typologies and what the effects of height limitation were on Washington D.C.

Status: Read

The Tribune Company, and Stanley Tigerman. Tribune Tower Competition. Vol. Volume 1. USA: Academy Editions/ Rizzoli, 1980.

Notes: all of the submissions for the highly influential 1922 tribune tower competition. From these drawings, it is clear that there were many conflicting ideas on what a tower should look like. Not directly discussed but visible in a select few competition submissions was an argument for towers to incorporate diverse programs throughout its height.

Status: Read

Van Leeuwen Thomas A. Skyward Trend of Thought: The Metaphysics of the American Skyscraper. Place of publication not identified: Mit Press, 1990.

Notes: Van Leewan offers an interesting perspective of the history of tall buildings. He 
argues that in many cases, the decision to build tall was not a rational decision based on demand but an assertion of power by a group, institution or individual. He argues that financial districts did not grow vertically because of land scarcity but as a result of competition.

Status: Read

Willis, Carol. Form Follows Finance: Skyscrapers and Skylines in New York and Chicago. 1st ed. New York, N.Y: Princeton Architectural Press, 1995.

Notes: Carol Willis provides an in-depth look at the economic factors of rentable space that shaped the office towers of New York and Chicago. She makes a strong argument showing that the architecture of the towers was less influenced by zoning or style than it was by finance.

Status: Read

Wong, Tai-Chee, Belinda K. P. Yuen, and Charles Goldblum, eds. Spatial Planning for a Sustainable Singapore. New York: Springer, 2008.

Notes: In-depth overview of Singapore's planning history

Status: Read

Wood, Antony. "Pavements in the Sky: The Skybridge in Tall Buildings." In Council on Tall Building and Urban Habitat, 325-32. Kula Lumpur: CTBUH, 2003.

Notes: an earlier less developed publication of ideas published in 2019. It contains the history and development as well as emerging trends and future uses of the skybridge

Status: Read 
Wood, Antony, and Daniel Safarik. "Skybridges: A History and a View to the Near Future." Council on Tall Building and Urban Habitat 8, no. 1 (March 1, 2019): 1-18.

Notes: the history and development as well as emerging trends and future uses of the skybridge

Status: Read

Yeang, Ken. The Skyscraper Bioclimatically Considered: A Design Primer. Chichester: Wiley-Academy, 2000.

Notes: The book preceding Reinventing the Skyscraper in which Ken Yeang's further develops his ideas on ecological design applied to the skyscraper

Status: Read

Yeang, Ken. Reinventing the Skyscraper: A Vertical Theory of Urban Design. Chichester, West Sussex, England; Hoboken, N.J: Wiley-Academy, 2002.

Notes: This book presents the most similar ideas to my own I have found to date. Yeang advocates for approaching tall building design with the principles of urban design, decompartmentalizing the vertical form, and diversification of vertical land uses.

Status: Read 
